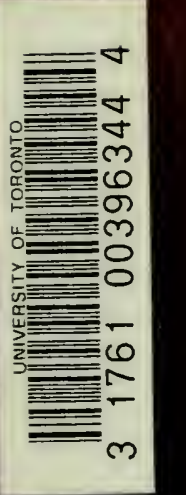

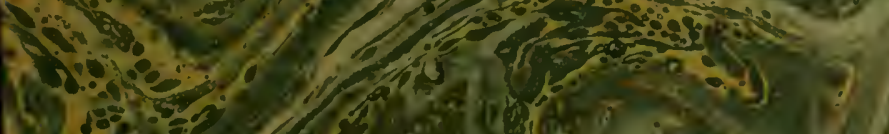

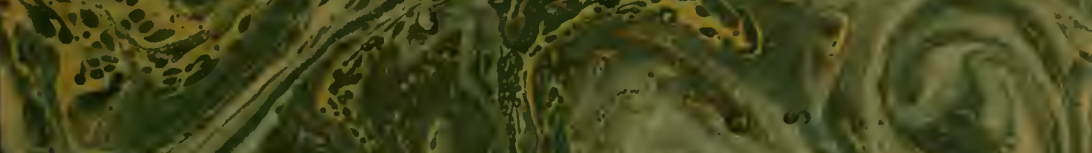

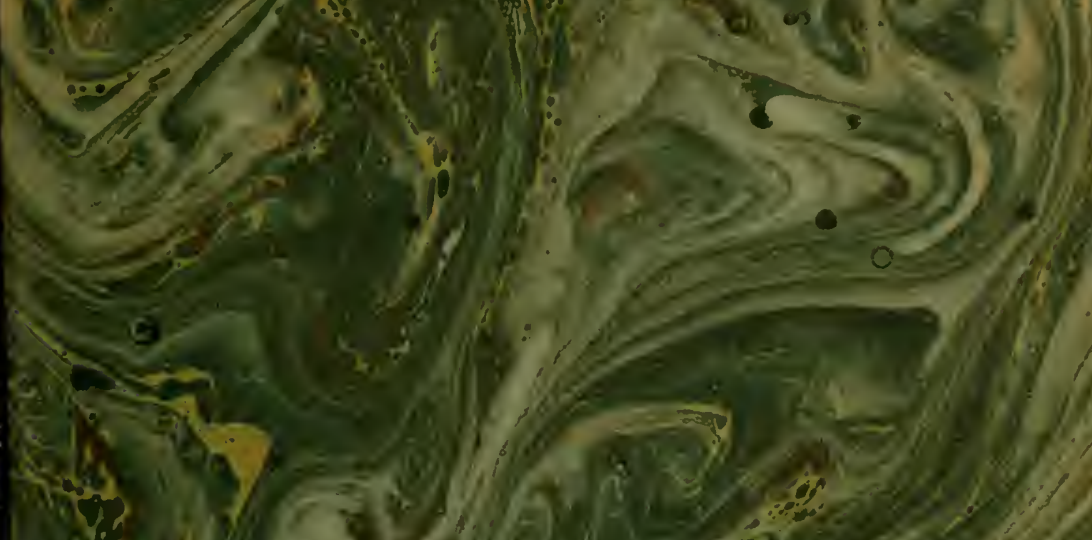

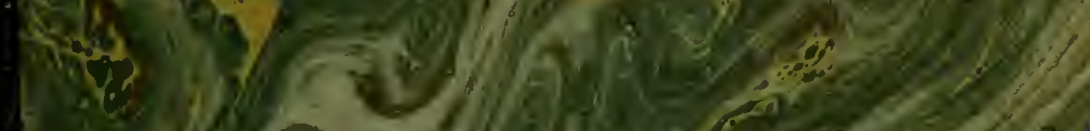

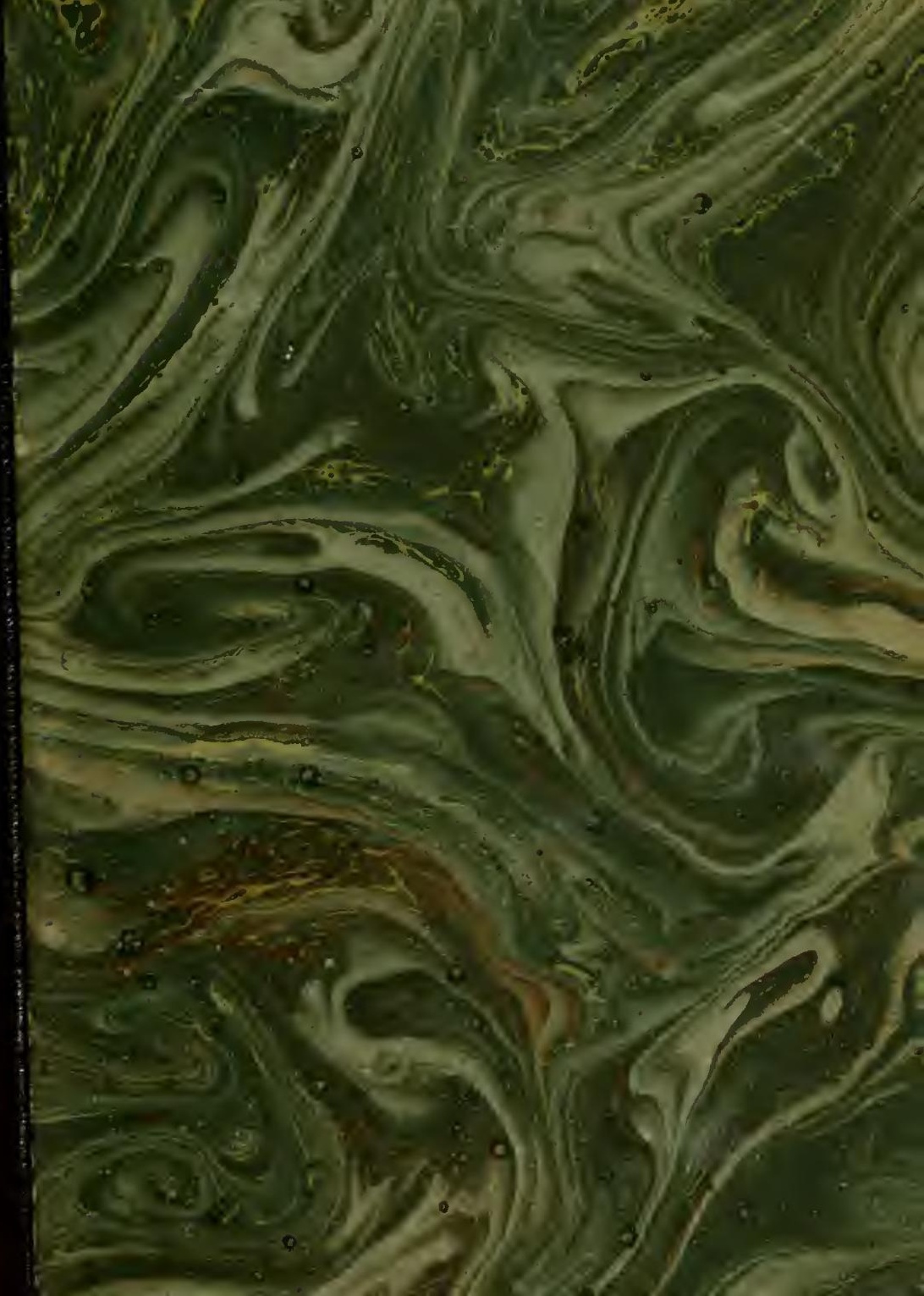




\section{$4+2$ is 7}

20 rorit 4.0.

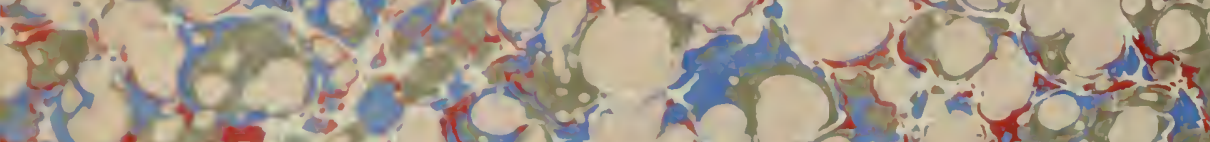

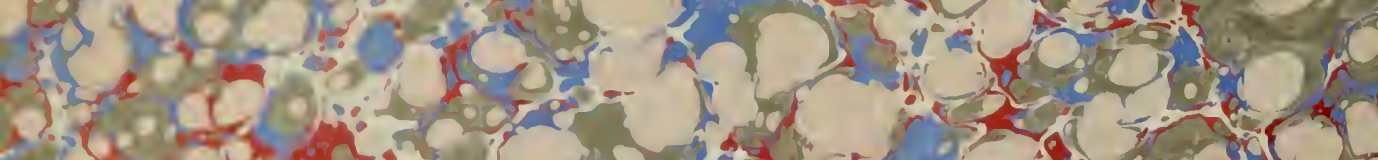
on 0 . ct 37 on

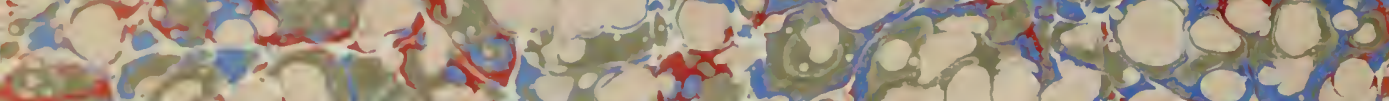
8. 0 - 15 $20018000 \mathrm{CH}$

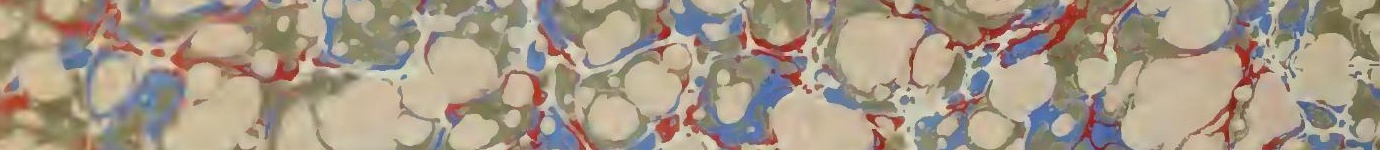

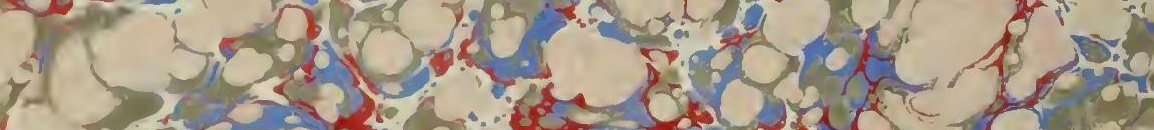
5

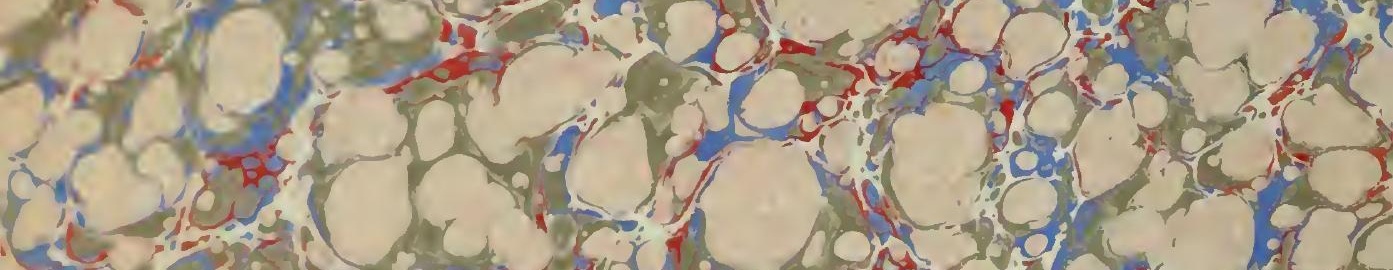

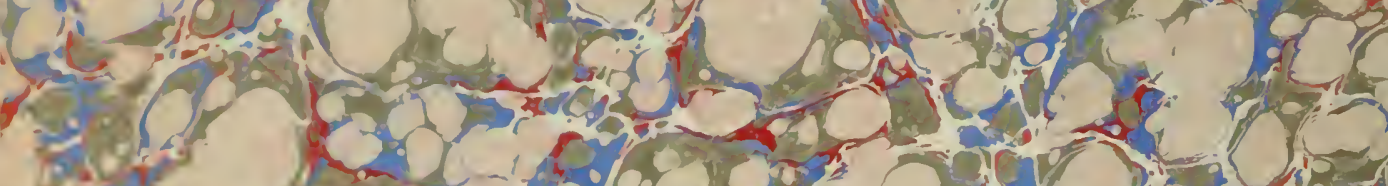

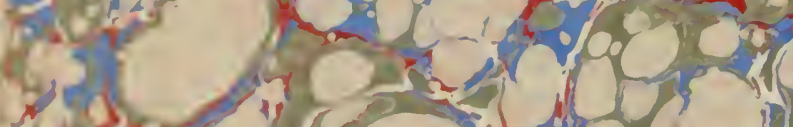

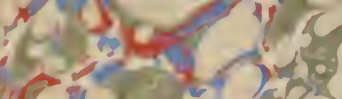

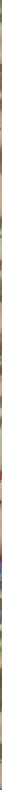









\section{GUSTAVE FAGNIEZ}

\section{L'ÉCONOMIE SOCIALE}

\section{LA FRANCE SOUS HENRI IV}

$$
13089-1610
$$

\section{PARIS}

LIBRAIRIE IICHETTE ET Cio

79, noLlevand SAIVT-GERHAIN, 79 





\section{L'ÉCONOMIE SOCIALE}

$$
\mathrm{DE}
$$

LA FRANCE SOUS HENRI IV 


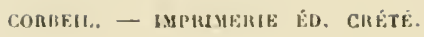




\section{GUSTAVE FAGNIE\%}

\section{L'ÉCONOMIE SOCIALE}

\section{LA FRANCE SOUS HENRI IV}

$$
1389-1610
$$

\section{PARIS}

LIBRAIRIE HACHETTE ET Ci

i9, Bovlevald SAINT-ger.uaix, 79 
HC

274

$\mathrm{F}_{3}$

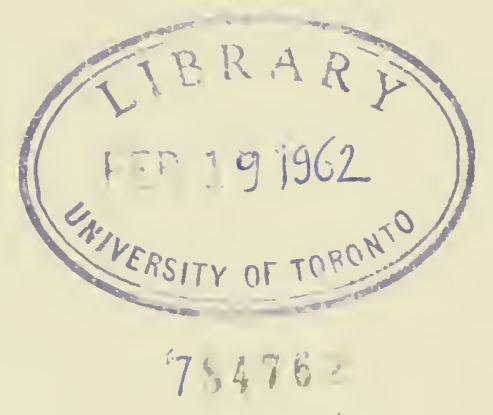


ADEMPTE ET PRESENTI 



\section{L'ÉCONOMIE SOCIALE DE: LA FRANCE}

\section{SOUS HENRI IV}

\section{AVANT PROPOS}

Si un esprit curieux des lois de l'évolution sociale voulait se rendre compte de la manière dont un peuple peul se relever de la décadence, dans quelle mesure ses propres forees y suffisent et dans quelle mesure il a besoin pour cela de son gouvernement, l'histoire lui offrirait peu de périodes aussi propres à l'éclairer que le règne de IIenri IV, partagé presque également, comme il le ful, entre une anarchie dissolvante et une féconde activité. Si celui qu'intéresserait un tel problème en cherchait la solution dans les historiens de ee prince, il constaterait que le développement économique de notre pays n'oceupe, dans les excellents ouvrages dont son époque a été l'objet, qu'une place aceessoire, qu'aucun ouvrage spécial ne lui a été consacré. Il en souhaiterait un qui, arec autant de précision que possible, déerirait la désorganisation sociale au moment où Henri IV hérita d'un droit contesté et d'une autorité en partic nominale, et pendant les années qui suivirent, déterminerait l'esprit et l'efficacité des mesures destinées à remédier ì cette désorganisation, ferait assister au progrès de la pacification, de la sécurité, du travail et de la richesse et marquerait le point où en était arrivée, dans 
le premieryuart duxru siècle, une prospérité toute récente. Ciest lä le livre que nons arons voulu écrire et, en même temps que le sujet, nous renons d'en indiquer le plan. Si, dans ce plan, la production occupe une place prépondérante, on reconnaitra arec un peu d'attention que cette place n'est pas exclusive et que, tout en n'ayant pas obtenu, conme le demande leur importance, un ou plusieurs chapilres ì part, tout en étant comme dispersées d'une façon fragmentaire dans le corps de l'ourrage, la circulation et la distribution de la richesse n'ont pas été oubliées. Les cadres consacrés de l'économie politique ne peurent êlre appliqués aux travaux historiques quautant que les documents permettent de les remplir. Or les documents les plus préeieux pour l'histoire de l'économie sociale, c'est-à-dire les documents privés, actes notariés, correspondances commerciales, livres de commerce, etc., sont précisément ceux qui, ayant été conservés arec le moins de soin. sont devenus les plus rares ou les moins aceessibles ${ }^{1}$. Le public ne nous en voudra pas, nous l'espérons, d'aroir devancé, en écrivant cet ouvrage, le moment, si jamais il doit se présenter, où des matériaux de ce gemre sortiront de l'ombre en assez grande quantité pour permettre de mieux approfondir, de mieux justifier ou même de rectifier les traits sous lesquels nous arons présenté l'érolution économique de la France à la fin du $\mathrm{xv}^{\mathrm{e}}$ et au commencement du $\mathrm{x} v^{\prime} u^{\mathrm{e}}$ siècle.

I. C'est dans celte derniére catégorie, plus encore que dans la premiere, qu'il faut ranger les winutes de notaires. L'histoire de la propriéte foncière est lá et aussi en partie celle de la propriété mobilière, et rien ne peut suppléer á ces titres qui constituent les archives de la lortune privée. Aussi faut-il vivement regretter, pour le progrès des sciences sociales et historiques, que les anciennes minutes ne soient versees que tout i fait exceptionnellement dans les dépôts publics et aussi que ceux qui ont pu les consulter dans les études aient porté trop exclusivemeut leur atlention sur les renseignements biographiques qüils contiennent. 


\section{CIIAPITRE I}

\section{L'ÉGONOMIE RURALE}

De toutes les applications de l'activité humaine, l'agriculture est celle qui se lie le plus intimement à la constitution de la société, de la propriété, de la famille. Suivant. que la société est aristocratique ou démocratique, suivant que la propriété est collective ou individuelle, suivant la part que l'organisation de la famille fait à l'autorité paternelle et aux droits des enfants, l'exploitation du sol sera extensive ou intensive, aux mains d'uneıminorité ou d'un grand nombre de propriétaires, pastorale ou agricole. En mème temps qu'elle est l'image des institutions sociales, l'agriculture est soumise aux lois régulières de la nature, toujours immuable en ses variations; elle reproduit dans ses travaux la périodicité des saisons qui les règlent; clle berce ceux qui s'y livrent au mourement monotone de ses opérations; elle donne à leur vie la permanence des habitudes, à leur esprit une quiétude qui va parfois jusqu'ì l'apathie et à la routine. De là les deux aspects sous lesquels l'économie rurale se présente à nous : elle va se dessiner à nos yeux telle que la nature et la société réunies l'ont fiite.

La multiplicité et la portée des questions soulerées par ce sujet n'en sont pas les seules difficultés. Les circonstances historiques dans lesquelles ces questions s'offrent à nous ajoulent à leur étude une difficulté de plus. Le pays que 
Ilenri $W^{\top}$ se trouva brusquement appelé à gouverner n'élait pas dans des conditions normales; était un pays malade, malade à la fois d'une maladie aiguë et de consomption. Les lois de l'économie rurale, comme de l'économie sociale en génélal, en subissaient un trouble profond. Au moment où llenri IV montait sur le tròne, il y avait onze ansqu il en était ainsi, et cela devait durer encore près de neuf ans après son avènement. Le plan du chapitrequ'on va lire a été tracé par ces circonstances exceptionnelles. II souvrira par un tableau raccourci de la situation où ces vingt ans de guerre civile et étrangère avaient réduit l'agriculture et les classes agricoles. Les mesures réparatrices adoptées par IIenri IV sont inséparables de ce tableau, elles le suivront immédiatement ou plutòt elles s'y mêleront. Eunfin nous chercherons à déterminer l'effet de ces mesures et à montrer l'état où la mort de ce prince laissa l'agriculture et les classes qui s'y consacrent.

En disant qu'à l'avènement de llenri IV la France avait été, pendant onze ans, en proie ì la guerre civile, nous aYons résumé, sous une forme abstraite, un ensemble de souffrances que ceux-là seuls pourront se représenter qui connaissent le $\mathrm{xv}^{\ominus}$ siècle, ses fureurs religieuses, son insouciance de la vie humaine, ses âpres convoitises, ses voluptés mèlées de sang où l'Italie meltait sa corruption et la féodalité renaissante sa brutalité. Nous ne pouvons pourtant laisser tout à faire ì l'imagination de nos lecteurs et nous devons placer sous leurs yeux quelques traits de la deplorable condition faite à l'agricul ture et aux cultivateurs. L'indication chronologique que nous renons de donner est, d'ailleur's, an-dessous de la réalité, car, en dehors des onze innées de gucrue intestine déclarée qu'on compte depuis le massacre de Vassy (L $L^{\text {cr }}$ mars $1: 362$ ) jusqu'à la mort de Henri III (2 aout 1:89), les habitants des eam- 
pagnes avaient été loin de jouir de la sécurité nécessaire à leurs travaux. On sait que ni les trêres ni même les traités de paix n'interrompaient pas toujours ni sur tous les points les hostilités ${ }^{1}$. Les troupes ne recevaient pas leur solde et ne se procuraient des vivres qu’ì l'aide de réquisitions. Elles frappaient les campagnes de contributions ot enlevaient le bétail ou s'emparaient de la personne des réealcitrants. Leur marche répandait la terreur dans lí population civile. Le son lointain des tambours, la poussière soulevée à l'horizon par les argoulets galopant dans la plaine, étaient pour les paysans le signal de la fuite ${ }^{2}$. C'était alors, chez tous ces paurres gens, une panique, une agitation, une cohue, dont un auteur contemporain, qui parle évidemment ici en témoin oculaire, nous a transmis la description tragi-comique : on clôturait portes et fenêtres comme si les maraudeur's pouvaient ètre arrètés par ce vain obstacle, r, chassait le bétail devant soi, on emportait ses éconor ıles, on se chargeait, on chargeait les bètes de somme des ustensiles les plus indispensables, on détachait de la cheminée les salaisons qui, dans la vie errante où l'on entrait, devaient empècher de mourir de faim, on se sauvait dans le bois le plus voisin, on s'entassait dans les églises ${ }^{3}$.

Aux états de Blois en 1388 , les trois ordres avaient proposé des moyens de remédier au fléau des troupes en marche. Le clergé et la noblesse avaient exprimé le vou que l'itinéraire, les étapes fussent fixées par un conmissaire qui les accompagnerait; le tiers état avait demanré que la population civile fût autorisée à courir sus aux pillards et que

1. Relation de Cavalli, 157i, dans la Coll. Alberi. Palma Cayet, Chronologie novennaive, Introd. 18. Lettre du roi de Navarre, 8 novembre 1580. Lettres miss., I, 326-327.

2. Agrippa d'Aubiginé, Les Tragiques: Misères, éd. Lalanne, I, 38-39.

3. Noel du Fall, Baliverneries, I, 179, éd. Assezat. Du Chatelier, L'agriculture et les classes agricoles en Bretagne, $14 i$. 
les soldats ne pussent rendre aux receleur's qui suivaient l'arméc le fruit de leur pillage '.

A cólé des troupes enròlées dans un parti et qui, tout en confondant trop sourent am is et ennemis, obeiissaient cependant à une certaine discipline, il y arait des bandes qui nélaient recomnues ni par la Ligue ni par le roi et qui sétaient formées dans le seul bul dexereer le brigandage. Ramassis de soldats licenciés, clles continmaient en temps de paix ì dévaliser et à torturer le "bonhomme " sans pouroir prétexter les nécessités de la guerre, l'intérêt d'une cause générale. Serrées de près par les prérôts des maréchaux, placées peut-ètre entre une expiation prochaine et une dernière débauche de cupidité et de cruauté, elles cherchaient un spectacle dans les souffrances de leurs victimes, liaient les paysans et les prêtres sur un bane, et leur faisaient racheter aux enchères leurs leitres de prêtrise ou la conservation d'un membre qui était mutilé si le patient ne couvrait pas ces enchères ${ }^{2}$. Elles araient mille inventions pour lui faire déclarer la eachet te où il arait enfoui ses économies : on lui serrait la tête avec une corde, on le pendait par les aisselles ou les doigts, on lui brûlait les pieds arec une pelle rougie au feu, on l'enfermait dans un four, on lui faisait prendre une immersion prolongée, on le tenaillail, on le ròtissait comme un chapon, on lui donnait les étrivières, on le salail, on le faisait jeûner, on le crucifiait, on le faisitit enfler jusquà ce qüil crevait, on hui perçait les lères, on le bernait ${ }^{3}$.

Rien ne serait plus facile que de multiplier ces scènes dhorreur qui, dans des circonstances analogues, se sont toujour's reproduites dins notre histoire. Nous aimons

1. Pıcot, llist. d's étuts génér., III, 21'.

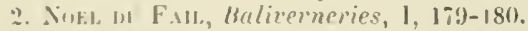

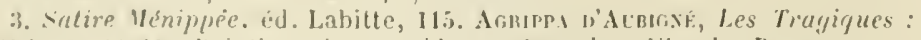
Miserpo, 41-ii. Belation des troubles... dans la ville de Rouen, p. 1.

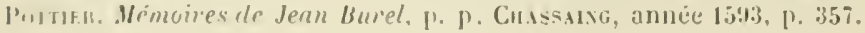


mieux emprunter à deux relations vénitiennes, l'une érrite en 1:74, l'autre en 1:382, un coup d'wil d'ensemble sur l'étal du pays : "Partout des ruines, écrit Cavalli; le bétail est, en grande partie, détruit, de sorte qu'on ne peut plus labourer et quine grande partic des champs reste en friche. Beaucoup de paysan s ont abandonné leurs maisons.... La population n'est plus, comme autrefois, probe et civile; la misère, la rue du sang, la guerre l'ont rendue rusée, grossière et sauvage ${ }^{1}$. " P'riuli nous apprend dans quelle classe se recrutaient particulièrement ceux qui vivaient de brigandage et pourquoi ils se recrutaient dans cette classe. C'était, pour la plupart, des gentilshommes paurres, comme il y en avait beancoup alors, des callets de famille qui, pricés de la plus grande partie de l'héritage paternel et n'ayant pas le moyen de s'entretenir dans l'armée régulière qui ne touchait pas sa solde, ayant d'ailleurs contracté dans la guerre civile lhabitude d'une vie aventureuse " allaient ¿ la désespérade ${ }^{2}$ " et se mettaient à vivre de rapines ${ }^{3}$.

Lorsqu'il n'ètait encore que roi de Navarre, Henri arait déjà cherché à épargner à la population, autant que le permeltaient les intérèts de sa cause et de son armée, les maux de la guerre. En 1577 il entreprit de débarrasser le plat payss de Périgord des forts et des bicoques d'où se répandait le pillage et où il trouvait une retraite . Le 130 mai 1580 , il ordonnait au commandant de Panisseau ${ }^{5}$ de faire mettre en liberté des paysans que des soldats de la garnison avaient pris pour les rançonner. Il lui rappelait que les ordonnances militaires garantissaient la liberté et la sécurité aux paysans qui ne pactisaient pas avec l'ennemí.

1. Relation de Cavalli (15:4) dans Alberi, scrie I, vol. It.

?. Expression de La Noue, dans Discour's poliliques. Discours $I \mathrm{~b}$.

:3. Relation de Priuli $(158 *)$. p. $\{1$ ?.

4. Lellies miss., I, 145 .

5. Dordogne.

6. Lellres miss. suppl., VIH, 18;. 
En 1:382 il faisait forcer et tuer les eapitaines luguenots Lal Fite, de V'aries, La Casse, et d'autres qui s'étaient asso"iés et fortiliés daus le chàtean de La Fite pour se livrer au brigandage ${ }^{1}$ En $1: 83$, il exprimait l'intention de faire dorénavant loger ses gardes dans les villes où il se trouvait et non dans les villages des environs "pour éviter la foule et plainte du peuple ${ }^{2}$ ". Le 29 aoùt $1: 58$, il recommandait ¿uI gouverneur de Montréal (Aude) d'empècher le renouvellement des courses que sa garnison avait poussées jusfu'ì Limoux $x^{3}$.

On trouve partout de pareilles préoccupations et ce n'est pals chez Henri IV qu'on s'étonnera de les trouver. La pitić n'étail pas inconnue an $\mathrm{xvl}^{\circ}$ siècle, mais ce qu'on ne connaissilit pas, ce qu'on devait ignorer jusqu' à Louvois, c'est l'art de faire vivre et mouvoir au sein de la population civile, sans de trop vives souffrances, des troupes régulières. Comment ces souffrances auraient-clles pu lui être évitées dins un temps où elle avait affaire non seulement à des troupes régulières, mais à des bandes sans areu? On peut donc affirmer que les bonnes intentions du roi de Navarre restèrent ì peu près stériles.

Les conséquences habituelles d'un pareil état de choses ne manquèrent pas de se produire : abandon de la eulture sur beaucoup de points, lépopulation des campagnes, disclles, maladies épidémiques, jacqueries nées du désespoir, du dégoùt du travail, du goùt du pillage contracté par les victimes ì l'école des bourreaux. Le "bonhomme " devenait féroce à son tour; sous les noms de Gautiers, de Croquants, de Chateanverls, des bandes peu aguerries faisaient trembler pourlant et ses éganux et ses maîtres.

Dans ce tablean si sombre la vérité pourtant oblige à

1. Lelloess miss., 1, iis.

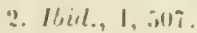

3. Iliil., li:!l. 
jeler quelques demi-teintes, quelques échircies. Quanul l'anarchie dure, les sociétés s'arrangent pour s'en accommoder, pour composer avec elle. La France surtout, si facilement inquiète quand elle est heureuse et prospère, si susceptible et si exigeante pour ses bons gouvernements, possède à l'égard des manvais ou, de ce qui est pire, ì l'égard du désordre social, surtout quand il tlatte en elle certaines passions, une patience et une fécondité de ressources qu'on ne peut s'empêcher d'admirer tout en les trouvant excessives. En ce temps-là aussi, on croyait souffrir pour de grandes causes, pour l'orthodoxie ou pour la rélorme évangélique et, en même temps qu'on en était fier, on s'ingéniait pour se dispenser de faire à l'une ou à l'autre les derniers sacrifices. Beaucoup de grands propriétaires, grâce à une prudente neutralité, en obtenant des sauvegardes, en imposant le respect par l'armement de leurs tenanciers, en concluant des ligues d'assurance mutuelle avec leurs voisins, avaient réussi à soustraire leurs domaines aux déprédations ${ }^{1}$. Les paysans eux-mêmes n'avaient pas opposé partout que l'apathie et la résignation aux maux dont ils étaient victimes. Ils avaient formé, pour se protéger, des associations secrètes qui s'étendaient parfois sur plusieurs provinces; forts de leur solidarité,

1. “... Quant ả la noblesse que j’ai réduite ả douze cents chefs de maison, il yen a huit cents lesquels ne se meuvent ni pour le bon ni pour le mauvais parli, mais les uns s'accommodent aux deux, les plus ménagers; les autres, plus casaniers que guerriers, en attendant le vent, demeurent dans leurs maisons. "Mémoire écril pour IIenri IV, par Jean de Vernyes sur l'Auvergne (1589). Annales scienlifiques, litléraires el inclustrielles de l'Auvergne, X1. "... Nul ne couroit sur les gentilshommes ni à leurs grangés et, si its ne se déclaroient de tenir ni pour un parti ni dautre, mais temporisoient, attendant quel jeu jouer... "Némoires d'Eust. Piémond, notaire royat delphinal de saint-Antoine-en-Dauphiné (1572-1608) p. p. Buuv-Durano, année 1588, p. 2:37. "... 11 n'y avoit que les grangers des gentilshommes et gens de guerre, qui étoient libres de leur betail et de leur labourage, meme la guerre ne se faisoit que aux marchaus et porres laboureur's

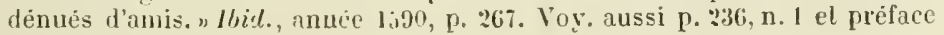
de l'éditeur, P. xxin. 
Mananis et armes, ils couraient sus aux pillards et osaient méme les attaquer dans les chiteaux qui leur servaicut de repaires. Le Daupluine, pirr exemple, eut sa Ligur de Moutélimart, sa ligne des Villains. A l'idée de se défendre vint se mèler, par une suite nalurelle. l'idée de représailles, de revendications sociales. Entre ees associations, il y en eut qui finirent par se mettre au service d'un des partis, d'autres par imiler les excis qu elles a vaient pour but de réprimer".

Parmi les traits le's plus consolants de cette triste époyue, il faut compter le labeur patient, persévérant, acharné des petits cultivateurs. Les hindes une fois éloignées, le paysan sortait furtirement des bois, rentrait dans son village envahi par les loups et les renards, saltelait, faute de bétail, à la charrue et semait à la hite ${ }^{2}$. Le calme durait-il, il remplaçait ce qui lui avait été pris, ce qu'il n'avait pu emmener ou emporter, et recommençait ì cultirer arec une ardeur nouvelle le lopin de terre héréditaire ${ }^{3}$. Parlois d'ailleurs sa pauvreté le sauvait: le sac des villes, qui était alors permis par les lois de la guerre, tentait bien plus le soldat que le pillage peu profitable des villages. Grice au désordre lu temps, la taille ne renait plus atteindre le petit cultivateur avec la même exaciitude et la même rigueur que dans les temps réguliers. Enfin toutes les provinces n'avaient pas été éprourées par la guerre civile et le brigandage. Dans sa relation de 1:3\%2, Giovanni Michicli constate que si, dans les provinces que la gruerre a désolées, surtout sur le chemin de Lyon à Paris qüil arait suivi, beaucoup dédi-

1. Voy. mème préf. p. xu, $\mathrm{xx}, \mathrm{xxu}$, et Roman, La guerve des paysansen

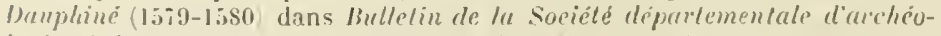
lugie el de stalistique de lu brome, XI (18ii, p. 22, 1 '9.

$\therefore$ Acrovi, Trugiques: Wiseres, I, p. $\$ 1-i 2$.

3. Carew reconnalt la supériorité dil paysan francais sur le paysan anHlinis comme sobricti el puissance de travail. A relulion of the stute of

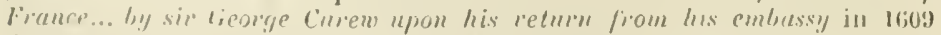
dans Buncin, An historical Vien of the negociulions letucen the courts of Englame, fivaner reml birussels... Lonton, 17it. p. 431. 
fices ont été totalement ou partiellement détruits, si les églises ont particulierement souffert - ce qui s'explique et par le fanatisme protestant et par la transformation des édifices religieux en forteresses - le sol n'a pas cessí d'être cultivé ${ }^{1}$. Les ressources naturelles de la trance, dit Priuli dans la relation de 1.082 que nous citions tout à l'heure, n'ont jamais mieux apparu que dans la guerre civile. Elle n'y a pas produit les conséquences qu'elle produit ailleurs. Pas un coin dlu pays n'est resté désert ni inculte une seule année. Les armées ont eu beau ruiner les régions qu'elles traversaient, celles qui leur succédaient ont toujours trouvé de quoi vivre. Le royaume a pu payer au roi plus de 10 millions d'écus (94381732 fr. 62) $)^{2}$ par an, sans parler de l’argent levé par les gouverneurs pour les dépenses locales, ni des sommes beaucoup plus considérables extorquées par les soldats à l'aide de mille moyens invraisemblables. La France comptait encore plus de seize millions d'habitants ${ }^{3}$.

Nous arons tenu à reproduire cet hommage désintéressé à la vitalité de notre pays. Il ne dément pas ce que nous avons dit de la mulliplicité des terres en friche, mais il permet d'affirmer que la plupart des petits cultivateurs ne se laissaient généralement pas décourager par l'inanité trop fréquente de leurs efforts, que le travail ne desespérait généralement pas de reconstituer le modeste capital foncier que la guerre civile ne se lassait guère non plus de détruire.

L'avènement de Henri IV ne procura pas à l'agriculture plus de sécurité. La guerre civile et étrangère dura, nous l'avons dit, neuf ans encore; toutefois, si le pays ne fut entièrement pacifié que par la soumission du duc de Mercœur et le traité de Vervins (mars et mai 1398 ), dès $199 . ;$

1. Alberi, IV, 288.

2. Cette évaluation et les suivantes, empruntées aux tableaux de II. $\mathrm{N}$. de Wailly, ne donnent que la valeur intrinseque.

3. Alberi, IV, 109. 
les deux liers' ou mème plus des trois quarts ${ }^{2}$ de la France reconnaissaicut l'antorité royale. Or, ì peine cette autorité ćlail-elle rétablie dans une province qu’elle s'appliquait à la purger du brigandage. Aprés la réduetion de la Normandie en 1394, les prévòts des maréchaux batlirent le pays avec de la eavalerie et pourchassèrent daus leurs retraites les voleurs qui linfestaient ${ }^{3}$. Derenu, à la suite du combat de Fontaine-Française, maître de la Bourgogne, le roi alfrunchit les campagnes des exactions et des violences que leur faisaient également subir royaux et ligueurs". Dès le mois de novembre 1990 , il avait pris des mesures pour faire observer la discipline par son armée et pour proléger contre les excès de ses soldats la population agricole, les églises et le clergé. Ln règlement militaire adopté le 3 novembre au camp d'Écouis (Eure) défendit aux chefs et aux soldats d’abandonner les quartiers à eux assignés par les maréchaux de camp et des logis et de maltraiter les habilants che\% qui ils élaient logés; il mettail en même temps sous la sauregarde royale les paysans et leur bétail, limilait à vingt-quatre heures le sac des villes prises, réservait à l'armée le blé et le vin qui s'y trouveraient. On sait qu à cette époque les armées élaient suivies d'une foule de non comballants qui contribuaient pour une large part a lindiscipline. Cette quene de pillards, de goujats, de receleurs que cliaque armée traînait après elle, fut obligée d'entrer dans les cadres. Pour prix de ces mesures protec-

I. Polrsox, Mistoire de Henri II, 11, 1 i3.

2. Ibid., 192.

3. "Sur ce que les habitants de la ville et plat pays du bailliage de Gisors ont remontrí qu'ii l'oceasion de la licence que le long cours des troubles a introduite en ce royaume et l'impunité des crimes qui se commeltent, il se trouve en tous les endroits du pays de Normandie, encore fu'il soit réduit á l'obéissance de S. Il., un si grind nombe de gens de guerre et. autres saus inlveu voleurs et brigans qu'il est impossible aux labitans dudit pays de trafiequer... "Arrêt du Conseil du 24 novembre 1594.

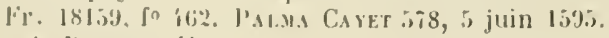

i. Pintisox, 11, 6is. 
triees, le ror exigea que les paysans ne portassent pas de vivres dans les villes rebelles ${ }^{1}$. L'élit rendu au siège de Chartres le 7 mars 1391 visait au mème lut par des mesures plus générales. Cét édit défendit, sous peine de mort, d'enrôler des troupes sans le commandement du roi, de construire ou d'occuper des forteresses et de forcer les paysans à y trarailler, de lever des contributions en argent ou en nature, de saisir le bétail et les instruments aratoires, de rançonner les paysans, les prêtres, les religieux, sauf daus le cas où ils prendraient les armes contre le roi ou fourniraient des vivres à l'ennemi, de faire payer une rançon aux prisonniers avant que les gouverneurs de provinces et les officiers supérieurs de l'armèe eussent décidé sils avaient été pris en vertu du droit de la guerre, de se saisir, sous aucun prétexte, des femmes et des enfants, de piller, de son autorité privée, les biens de l'ennemi². Le cri des populations aux abois arracluait souvent aux belligérants des trèves particulières, de province à province, de diocèse à diocèse, car, dans cette guerre née et alimentée de passions fédéralistes, chaque région, chaque chef se battait et traitait un peu pour son compte. Le premier objet de ces trêves était de rendre à la population civile la sécurité et de sauvegarder les moyens d'existence qui lui restaient encore. A Annonay, en $1 \% 74$, les sectateurs des deux religions se garantissaient réciproquement la tolérance et la sùreté; une trêre stipulait que les portes, fermées aux étrangers, s'ouvriraient au conmerce, et que la population de la campagne environnante ne serail pas troublée ${ }^{3}$. En 1592 l'échevinage d'Amiens proposait à celui d'Abbeville un projet d'accord destiné à soustraire l'agriculture et

1. Arrêtés du Roy publiés en ses camps et armées pour la sùreté des lahoureurs. Châlons, 1591.

2. Thuani IIstoria, $\mathrm{V}, 61$.

3. Memoires de Gamon. Coll. Michaud, 1 , vin, 616,618 . 
le commerce aux ravages de la guerre'. En décemlire 1:ig(i, la ville et le diocise de Narbonne faisitent une trève ared les diocèses de Saint-l'ons et de Bériers dans l’intérèt du labourage?. Dans celles entre Ilontmorency et Nemours pour le Vivarais, d'une part, le Lyommais, le Beaujolais et le Fore\%, de l'autre, dans celle entre le roi et Mayenne, les inlérits de l'agriculture sont slipulés, comme ceux du commerce. Liarticle í de la trêre signée à La Villette le 3 juillet 1393 est ainsi conçu : Les labourenrs pourront, en toute liberté, faire leurs labourages, charrois et aures accoutumés, sans qü̈ls y puissent ètre empèchés ou molestés en quelque façon que ce soit, sur peine de la vie... ". L'article lä r'egle que " tous gens de gnerre, d'une part et d'aulre, seront mis en garnison, sans quïl leur soit permis de tenir les cliamps à la foule du peuple et ruine du plat pays ". L’article 16 charge les prévûts des maréclıux de faire la police de la campagne ${ }^{3}$. Un traité particulier: applifua expressément aux rendanges des environs de Paris la liberté accordée par la trêve de La Villette aux travaux agricoles; comme la trêve de La Villette, il était le fruit de la lassitude des combattants, du désir de ménager Paris où l'opinion était de plus en plus favorable ¿ la paix et où le roi ne devail pas tarder ì entrer. Les articles 4 et 16 de celte trêre furent également reproduits dans celle qui fut conclue à Lyon le 23 septembre $1: 99.0^{5}$.

De la part de Henri IV ces stipulations étaient sincères, elles l'étaient moins de la part des chefs de la Ligue, et on peut croire, sans leur faire injure, quils en tenaient peu

1. Monuments inédits de lhisloire du tier's ètal, II, 1028, dans les Documents inédits.

2. Délibérations du conseil de la commune de Carcassonne, 20 déc. 1596. Mèm. de la Société des urls el sciences de Carcassonne, II, 1856.

3. Pilua Cayet, Chr. noven., $498-500$.

4. Traile particulier pour les vendanges des environs de Paris, 2 octribre 1593. Paris, chez lived. Morel.

5. L'sina Cinyt, Op. laud., cso. 
de compte, car le principal notif qui les retenait dans l'Union était d'exploiter le plus possible leurs gouvernements et leurs charges jusqu'au moment où ils se verraient obligés de faire leur soumission. Les paroles que les auteurs de la Satire Ménippée mettent dans la bonche du sieur de Rieux ${ }^{1}$, orateur de la noblesse aux étals généraux de 1:93, ne calomnient pas cette noblesse guisarde et peignent fidèlement, au contraire, les intérêts qui l'altachaient à la Ligue : "Cependant je courrerai la rache et le manant tant que je pourrai, et n'y aura paysan, laboureur ni marchand autour de moi à dix lieues à la ronde qui ne passe par mes mains et qui ne me paye taille ou rançon ${ }^{2}$." Si l'on compare les aveux du sieur de Rieux à ce que les registres des étals de Bretagne et les travaux d'histoire locale nous apprennent des crimes commis dans cette province, dans l'Anjou, le Poitou et ailleurs, par les Eder de Fontenelle ${ }^{3}$, les Kerhanland, les Anne de Sanzay, les La Magnane, les Langoiran, les Duplessis de Come, les La Hotte Serrant, les deux frères Saint-Offange, on voit que les auteurs de la Satire Ménippée n'ont rien exagéré. On frissonne encore dans les veillées de Bretagne en écoutant les chants populaires qui racontent les crimes et le chàtiments d'Eder de Fontenelle roué le 27 septembre 1602 et nous émeuvent sur les victimes d'une femme, Marguerite Charlès et des Rannou, ses lieutenants qui, postés à la tète d'une bande de voleurs, à Saint-llichel-en-Girève, entre Lannion et Plestin, détroussaient et assassinaient les voyageurs *

1. M. Prioux a essayé de réhabiliter ce personnage.

2. Satire Ménippée, 115.

3. Fontenelle a trouvé aussi des défenseurs. Voy. Geshin et Barthélewy, Anciens évêchés de Bretagne et Duserg.veur, dans Bulletin de la Société académique de Brest, IV, 186ł-65, p. 242.

4. Chants populaires de la Basse-Bretagne, p. p. Luzec, II. - Drourx, Essai hist. sur l'Entre-deux Mers. Ac'es de l'Academie... de Bordeaux, XXXII, 1870, p. 377. 
Il faut ajouter que ce n'est qu'en $1: 398$ qu'Eiler de Fontenelle, Duplessis de Come, Saint-Ollange firent leur soumission (encore venons-nous de roir que le premier restil incorrigible), que la pacilication de la Bretagne ne mit pas complètement fin au brigandage et ì la terreur qui y avaient régué du commencement de $1: 393$ à la fin de 1597, que le légendaire capitaine Guillery, établi arec une bande de quatre cents hommes dans la forèt de Machecoul, continua ì voler sur les grands chenins, it forcer les maisons de campagne, ì rendre le commerce impossible dans un rayon de trente ì quarante lieues et n'expia ses erimes sur la roue quen $1608^{1}$. A la même date la Bourgognne était encore frappée de contributions par d'anciens capitaines ligueurs, parcourue par des bandes d'anciens soldats de l'Union qui trouraient daus les chàteaux de Talan, de Vergy, de Noyer's un refuge assuré ${ }^{2}$. Les détrousseurs de passants et de maisons que nous renons de nommer enrent de nombreux émules et de nambreux successeurs. Leurs exploits, oì la générosité et lhéroüsme venaient parfois se mồler au hrigandage, se sont emparés de limagination populaire et ont donné à la littérature française un type dont le succìs n'est peut-être pas encore épuisé ${ }^{3}$.

1. Pifure de Lestone, Reg. journal de Hemri $1 Y$, éd. Jouaust, 4ī. Ilist. vérilique des grundes et experubles voleries et subtilitis de Guillery, p. p. 13. Fulon. 18:8, in-8. - La l'rise el défaite du capitaine Guillery, in-8, 1609. Réimprimé dans I'ar. hist. el lilléraires, 1, 289. Remroches du cripitaine Guillery, ltil., XIII. - Levot, Les fières Guillery ou deux rouliers brelons, dans Bulletin de la saciété académique de Brest, VII, 1871, p. 118. - Diaire de Jacques Merlin sur les choses les plus memorables qui se sont pressées en La Rochelle. Arch. hist. de Saintonge, V, 1878. - Discour's de la prise fu capitaine Chapeau et du capitaine la Callande, 1586. Var. hist. et lill., VII, 227.

2. Pollsox, III, 13-1f.

3. Rapprociler it ce point de vue le personnage imaginaire de Picotin l.u plaisante nouvelle apportie sur tonl ce qui se passe en la querre de

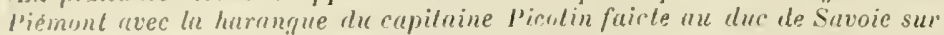
le mécontentement des solrlats fiangais, 161;. Vur. hist. et (ill., V'l), et le fuersonuage histuripur de Carrefous. Exerulion du rapitaine Carefour. lid. 
La démolition des forteresses élevées pendant la guerre arait lait l'objet d'un veu des notables assemblés à Ronen en 1.:96 ${ }^{1}$; ee vœu répondait anx intentions du roi. Il supprima spontanément les garnisons de tous les chàteaux appartenant à des particuliers ${ }^{2}$. En 1596 il licencia les gens d'armes qui foulaient le Dauphiné. Les compagnies supprrimées arant continué à virre sur le parsan par lequel elles se faisaient entretenir, à raison de $40 \mathrm{~s}$. ( $\because \mathrm{fr}$. 84) par jour et par cavalier, la population fit entendre de nouvelles plaintes. Le roi ordonna que les compagnies de pied et de cheval qui ne figuraient pas sur l'état d'effectif arrèté au mois d'aoùt seraient supprimées et évacueraient la province. Si elles continuaient à rouloir lever des contributions, . la population était autorisée à résister ${ }^{3}$. Une déclaration du 2 'février 1397 ordonna aux gouverneurs et aux lieutenants généraux et particuliers de courir sus aux gens de guerre qui tenaient la campagne sans commission royale et d'obliger ceux qui traversaient le pays en rerti d'ordres du roi, à se rendre sans délai à leur destination. Les commandants de ces corps de troupe devaient, avant d'entrer dans une province, faire connaitre au gouverneur les ordres en vertu desquels ils se déplaçaient, ainsi que le nombre et le nom de leurs hommes, et prendre l'attache de ce gourerneur pour trouver, par étape ou autrement, des logements et des vivres. Tous les mois, les gouverneurs informeraient le roi des troupes qui auraient passé dans leur gouvernement, ainsi que de la conduite qu'elles y auraient tenue Sa correspondance témoigne de sa vigueur dans la répression de l'indiscipline. En 1596, il ordonne au connétable de Montmorency d'envoyer la maréchaussée contre les bri-

1. Porrson, II, 281 .

2. Lettres du 17 janvier, 26 février 1595. Lettres miss., IV, 299, $31 \mathrm{~s}$.

3. Lettres miss., VIII, 623.

4. ISAMBEHT, $\mathbf{X V}, \mathbf{1 2 S .}$ 
gands qui infestent les grandes routes et contre les déserteur's qui en grossissent le nombre '. La mème ammée, il enjoint au duc de Montpensier de licencier ou d'envoyer à larmée sa compagnie de chevau-légers, qui, depuis six mois, pillait le pays ${ }^{2}$. En 1.597 il érrit au connétable de forcer les compagnies qui parcourent la Champagne à rejoindre l'armée et, si elles sy refusent, de les faire tailler en pièces ${ }^{3}$. En 1398 les garnisons de Normandie, ne recevant pas leur solde, se répandent dans le pays. Sur les plaintes du parlement le Rouen, le roi envoie l'argent et écrit au due de Montpensier de les faire rentrer dans les places et, en cals de résistance, de les exterminer: Le $1^{\text {er }}$ arril 15998, sadressant au connétable: "... Je rous prie, lui dil-il, non seulement de ne faire payer les compagnies qui refuseront dentrer en garnison, mais aussi de casser... et faire courre sur celles qui se débanderont pour tenir les champs... Si nous n'arons tous aucune compassion du peuple, il faudra quill succombe el que nous périssions tous avec lui; auquel propos je rous dirai que jai reçu depuis pen infinies plaintes de rotre compagnie de gens d'armes et de celle de Splandian, lesquelles on $m$ a rapporté être encore vers Argentan, faisant peu de cas d'aller en l'armée et opprimant grandement mes sujets du pays, ce que je m'assure que vous ignorez... Partant je rous prie d'y pourroir". "La mème année, il lit marcher trois régiments contre un capitaine nommé Leviston qui ravageait le Berry et il annonça l'intention, lorsque la paix qui se négociait alors arec l'Espagne serait conclue, de décharger sans tarder son peuple " de telle sorte de gens ${ }^{6} "$

1. A et 6 uar's 1596. Lelles miss., 11 , 513-31\%.

2. Lo roi au connetable, i octobre ling. Hiel., bíc.

3. 23 avril 159\%. Hid., 1V, 349.

4. Le roi au parlement de Cormandie, IF férrier 1598. Ibid., IV, 903.

i. Ithid., IN. 946.

(j. \& mai 1598. I/sid., 11, 975. 
La paix signée, ce fut le connétable " son compere " quil chargea de licencier l'armée, ce qui était une mission difficile, car on lui derait encore sa solde ${ }^{\star}$. Peu de temps après le traité de Vervins, le 4 aoùt, il léfendit le port des armes à feu ${ }^{2}$. C'était là une mesure radicale, difficile à faire exécuter et à concilier avec le droit de chasse; il y dérogea le premier par une foule de dispenses particulières ${ }^{3}$. Aussi, dans son édit général sur la chasse de 1601, il se relàcha de cette rigueur et permit aux gentilshommes l'usage de l'arquebuse sur leurs terres. Mais les passions étaient encore trop ardentes, les habitudes trop peu pacifiées pour que cette permission ne fùt pas prématurée : la noblesse en profita pour vider ses querelles particulières. la pais publique fut mise en péril, il y eut une recrudescence de rassemblements armés et de meurtres. Le roi interdit done de noureau à tout le monde l'usage de l'arquebuse et du pistolet ${ }^{4}$. Cette interdiction, toutefois, ne pourait ètre durable et, l'apaisement ayant fait des progrès. la déclaration du 3 mars 1604 rendit aux seigneurs le droit de chasser à l'arquebuse dans leurs domaines". Dès 1601 un édit, également inspiré par la préoccupation de la sùreté publique, arait réservé à l'État le monopole de la fabrication et de la rente des pièces d'artillerie, de la poudre et des munitions de guerre ${ }^{6}$.

En conservant aux gentilshommes, par son édit de 1601, le privilège exclusif de la chasse, le roi défendit de chasser dans les blés en tige et les vignes depuis le $1^{\text {er }}$ mars jusqu'après les vendanges et obligea les seigneurs de fiefs à

1. Lethes miss., IV, 100?.

2. Isambert, XY. Issmbert date cette déclaration du a arril, mais c'est sous la date du 4 août qu'elle est visée par la déclaration du 1 '́ août 1601 .

3. Editsur la chasse de I601. Isambert.

4. Déclaration du I'́ août 1603. Foxтıxox, II, 3i1.

5. Ibid., $3 \pm 2$.

6. Is aybert, $\mathbf{X}$ i, 263. 
réunir lrurs hommes tous les trois mois pour faire la chasse anx loups, anx renards, anx blaireaux et anx autres animaux nuisibles qui sétaient heaucoup multipliés pendant les guerres civiles. Du reste. le souci de l'agriculture est ee qui apparait le moins dans cet édit, comne dans celui de juillet 1607: ee qui ý domine, e'cst la pensée de conserrer le gibier et de limiter le droit de chasse au roi et aux seigneurs qui feront recomnaitre leurs titres par les aulorités compélentes.

Il ne suffisait pas le songer à la sécurité luture du cultivateur, il fallait aussi soccuper de la situation précaire et obérée où le passé le laissait. Ayanit sourent perdu dans la guerre sa récolte et son matériel d'exploitation, il avait emprunté pour le remplacer et pour vivre. Il avait dù parfois le faire à 100 pour 100 et jamais il n'avait pu le laire à noins de huit un tier's ${ }^{1}$. Endetté envers les particuliers, ayant hypothéqué ses récoltes ${ }^{2}$, enlacé par l'usurier de village qui l'amenait, de sursis en sursis, à un abandon it vil prix $x^{3}$, le cultirateur était aussi endetté envers le fisc, auruel étaient encore dues des tailles échues avant 1:89. Sous le coup de l'emprisonnement et de la saisie, il abandonnait son village et laissait =es champs en friche. A quoilui aurait servi de rentrer dans sa maison, à peu près assurée maintenant contre le pillage, pour s'en voir bientôt expulsé, pour se voir arrèter par les recor's? Des actes officiels de 1:\%: signalent la " eessation presque générale du labour ", la multiplicité " des terres demeurées désertes et

1. Vemoire de Jean Burel, p. p. Chassatsa, p. 270.

2. Voy. dans le minutier du notaire Mabric, aux archives du palais de justice à Toulouse, de nombreux emprunts dont le remboursement est assigné sur les réroltes de pastel.

3. La femme du paysan, Mlarion, prie Dieu :

lave l'usurier méchant, qui dès longlemps aguigne

Lt hume de ses yeux le closeau de leur vigne

En ses papiers journaux ne les puiste aceroclee.

Pronic, Les Pluisirs de la vie rustique (15i5). 
incultivées ${ }^{1}$ ". Pour alléger l'arriéré, le roi commença par réduire d'un tiers les intérêts des rentes au denier dix et au denier douze qui étaient échus de 13089 à 1.393 (édit du 8 juillet $159 \%)$. Les arrérages échus avant cette période ne subissaient pas de réduction, ils devaient ètre payés en $159 . ;$ et 1396 , en mème temps que les intérêts de la période quinquennale et les intérèts courants, au taux stipulé par le contrat ${ }^{2}$. En $1909 \ddot{3}$, Henri déclara insaisissables les instruments aratoires et le bétail et défendit de réquisitionner illégalement les laboureurs, leur's chevaux et leur matéricl d'exploitation ${ }^{3}$. Il rendait ainsi perpétuelle l'insaisissabilité temporaire accordée par Charles IX en Lכ̆TI: et satisfaisail au vou exprimé par le tiers aux états généraux de $1: 376$ et de $1.588^{\circ}$. Ce fut pour fournir des chevaux à l'agriculture. non moins qu'aux voyageurs et aux transpor'ts, qu'il créa des relais dans les villes et les loourgades distantes entre elles de 12,14 ou $1 \%$ lieues ${ }^{6}$. Le grand élit de $1600^{7}$, qui réforma profondément l'assiette et la perception de la taille, remit aux contribuables l'arriéré de $1: 396$ et des années antérieures. qui s'élevait à 20 millions (\$84:3860̈6 1 r. 08), fit rentrer dans la classe des taillables tous les usurpateurs de noblesse ${ }^{8}$, déjoua les fraudes employées pour échapper à l’impôt et autorisa les paroisses à racheter, au prix contant, dans les quatre ans, les communaux et les droits d'usage aliénés à vil prix pour payer les exactions qu'elles avaient eu à subir dans la guerre civile ${ }^{9}$.

1. Déclaration de mars 1595. Lettres royaux à l'échevinage d'Angers. du ler octobre de la même année, dans Mém. de la Société nationale d'agriculture, sciences et arts d'Angers, 1851, p. 178.

2. Fontanon, I, 722.

3. Déclaration du 16 mars 1595. Isanвert, XV, 98-199.

4. Ibid., XIV, 238.

5. Рісот, III, 186.

6. Édit de mars 1597 .

7. ISAMBERT, $\mathrm{XV}, 131$.

8. Pullippson (Heinich IV und J'hilipp III, II, 318) éralue á 40000 le nombre de ceux dont les noms furent rétablis sur les rôles.

9. ISAMBERT, no 139 . 
Cétait surtout sur les cultivateurs que pesilit la iaille. Ce fut à eux que profitèrent les réductions sucessives qui, de $1: 397$ à 1609, en abaissèrent le montant de 20 à 1 t' millions'.

Hemri IV n introduisit pas, au contraire, d'améliorations importantes dans l'assiette et la perception d'un autre impôt qui portait sur un des produits les plus utiles à l'agriculture et à lélève du hílail?. Nous voulons parler de la gabelle. Cet impôt, on le sait, revètait la forme d'un monopole. Ce qui aggravait ce monopole, c'est que le contribuable, au lieu de le supporter dans la proportion de sa consommation, le supportait dans la mesure déterminée par le fisc. Tous les ans des conseiller's de la cour des aides répartissaient entre les paroisses des généralités soumises à la gabelle la quantité de sel quills estimaient répondre à leurs besoins. Cette quantité leur était fournie par le fermier de la gabelle à un prix exorbitant. De 15 écus ( $141 \mathrm{fr}$. 37 ), le prix du muid sétait élevé, après 1588 , à $63(099 \mathrm{fr} \text { (60) } 3)^{3}$. Georges Carew, ambassadeur d'Angleterre on France de 1606 à 1609 , estime que le sel nécessaire à la consonmation anmuelle de sa maison coutait vingt-huit fois plus à Paris qu'en Angleterre ${ }^{4}$. Les paroisses répartissaient entre leurs habitants le sel qui l'ur avait été imposé par les conseiller's. Cette répartition, elle non plus, n'était pas, tant sen faut, en rapport arec les besoins de chacun : les uns en avaient plus qu'ils n'en pouraient consommer, les autres étaient insuffisamment pourvus, mais, le sel étant monopolisé par l'État, les premiers ne pouvaient rendre leur excédent aux seconds. Il faut ajouter, pour ne rien exa-

1. De 58458656 fr. 08 a 37755629 个r. 80 .

2. Voy. uolamment sur l'utilité du sel dans la nourriture du bétail, l'ablé Tessier, Viscours prél. de la section Agricullure de l'Encyclopédie mélh., p. 21.

3. Croptuli., Dialogue sur les canses des misères de la France, p. 233. CLA-

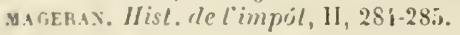

i. Dans Bucu, An hislorical View..., p. $\{38$. 
gérer, que ce système ne s'appliquait dans toute sa rigueur qu aux pays de grande gabrlle, c'est-ì-dire aux généralités de Paris, d'Orléans, de Tours, de Bourges, de Moulins, de Dijon, de Chàlons, de Soissons, d'Amiens, de Rouen et de Caen. Sully, peu partisan d'ailleurs de la gabelle ${ }^{1}$, tenait à ce qu'en cas d'augmentation, l'assiette de la crue eût lieu non par généralités mais par paroisses; l'estimation du revenu d'une généralité prêtait plus, en effet, à l'arbitraire que l'estimation de celui d'une paroisse. Il veillait aussi à ce que la répartition fùt équitable, à ce qu'elle tint compte de l'augmentation et de la diminution du revenu ${ }^{2}$. C'est, à notre connaissance, le seul indice quill se soit occupè de la gabelle. Nous devons dire cependant que, d'après M. Dareste ${ }^{3}$, il aurait réussi à diminuer le prix du sel en augmentant le produit de l'impôt. Ce produit était notablement atteint par une contrebande active et audacieuse qui s'exerçait publiquenent, sous la protection de la noblesse et même des autorités locales :

C'était beaucoup d'alléger les charges de l'agriculture. Il fallait encore l'encourager à produire en lui ouvrant des débouchés aussi étendus que possible. L'ancien régime n'arait pas compris que le meilleur moyen d'avoir le blé à bon marché est de le laisser circuler librement. Les pouvoirs locaux cherchaient toujours à le retenir dans les prorinces où il avait été récolté. Quant au gouvernement cen-

1. En 1605 il représentait au roi " qu'il n'y avait point de plus onéreuses impositions que celles qui se levaient par capitation sur le sel... "Economies. roy., éd. 1725, Amsterdam, VIIl, 65-66.

2. Sully au lieutenant de Blois. 23 octobre 1606 . Économies roy., 1X, 215.

3. Hist. de l'administration..., II, 1 (10.

4. D'autant qu'en la basse Normandie il y a plusieurs gentilshommes yui font trafic du sel publiquement et contraignent leurs sujets de prendre du sel en leurs maisons... le sieur de Montgomery, gouverneur de Pontorson qui est accusé... de donner escorte aux faux sauniers... la plus trande partie de la noblesse de Normandie en font trafic ordinaire. Arrêt du conseil du roi du 13 septembre 1599. Arch. nat. 
trill, il accordait asse\% libéralement des trailes, cost-ì-dire des permis dexportation, parce que ces traites étaient pour lui une source de revenus. Bodin blime la facilité arec laquelle nos rois permettaient lexportation de nos denrées et particulièrement du blé et, partageant sur ce point le préjugé de son temps, il y roit une des causes de l'enchérissement ${ }^{1}$. Depuis son avènement jusquen $4: 39 \%$, Ienri IV avait autorisu la libre sortie des grains. A lire le préambule des lettres patentes du 12 mars de cette année, par lesquelles il interdit lexportation, on croirait quil a changé de systèn1', car'. après avoir rendu hommage aux bienlaits de la liberté commerciale, il déclare que la France peut se passer des étranger's et se suffire à elle-même et que la continuation de la libre exportation la réduirait à la disette; mais cette interprétation ne serait pas exacte et il ny eut lì en réalité qu'une mesure de circonstance. La guerre. renait d'ètre déclarée à l'Espagne. Or l'Espagne était le marelıé le plus important de nos céréales et nous lui fournissions presque toutes celles dont elle arait besoin. C'était pour la priver de cette ressource et nous réserver toutes les nòtres au début d’une guerre et en prérision d'une disette, que le roi réroquait ou plutôt suspendait la liberté d'exportation. Aprés la paix de Vervins, il la rétahlit, au moins partiellement. Il accorda ì la Bretagne, à la Normindic, à la Champagne, au Languedoc, à la Guyenne, le droit d'exporter leur blé et leur vin, moyennant une surtaxe d'un demi-écu ( $4 \mathrm{fr}$. 7ö) par charge de blé et d'un écu (9 fr. :30) par muid de vin ${ }^{2}$. Il ne tarda pas à étendre celte liberté à tout le royaume ${ }^{3}$. Enfin, le 26 février 1601 ,

1. Discour's sur les causes de l'extréme cherlè qui est aujourl'kni en Frence, 1586, l'ur. hist. el litt., V'II, 137, 1'i, 173-17'.

2. Liete rétablis:ant cette liberté restreinte ne s'est pas conservé. Elle résulte des lettres patentes du 26 février 1601 publices par Delamare, Trailé de la police, liv. V, p. 932.

3. Lcttres de Ilenri $\mathbb{N}$ au gouverneur de Béziers du 2i janvier 1:99 
il abolit celte surtaxe et rendit l'exportation entièrement libre. Mais, sinspirant toujours plus des circonstances que de ses préférences doctrinales, il ne cessa jamais de linterdire quand la récolte fut peu abondante ${ }^{1}$.

Il eut plus d'une fois à défendre contre l'intérêt local le principe dont il avait compris la fécondité. En 1604 les autorités du Dauphiné interdirent la sortie du blé. L'écherinage de Lyon s'en plaignit. Le roi écrivit à Lesdiguières, gourerneur du Dauphiné, de réroquer celte prohibition. Il fait, ì cette occasion, une profession de foi économique tris explicite : "Voulant, comme il est juste et raisonnable, dit-il, que la liberté du commerce soil permise en toutes nos prorinces et que cellesqui ont nécessité d'une espèce de marchandises, même de celle de l'aliment et nourriture les persomnes, en soient secourues par les autres oì elles abondent darantage ". "La mème année, le parlement de Toulouse fit ce qu'on arail lait en Dauphiné. Les fermiers des traites foraines refusèrent alor's de payer le prix de leurs fermes. Les trésoriers de France en Languedoc en informèrent Sully qui se plaignit au roi ${ }^{3}$. On se fera une idée du pouroir que sarrogeaient, en pareille matière, les fonctionnaires subalternes eux-mêmes et de la fàcheuse décentralisation qui régnait dans l'administration des subsistances publiques, en lisant une let tre où le ministre raconte au roi que le juge de Saumur a défendu de transporter les blés hors duroyaume et d'en rendre dans son ressort. "Si chaque officier en faisait autant, érrivait Sully, volre peuple

(Lettres miss., Vill, $i: 6$ ) et à Gilbert de La Trémoille, marquis de Royan, du 30 janvier de la même année, p. p. Marchegay, dans Arch. hist. de Saintonge, I (1874), p. 32i.

1. ... seroit arrivé que, auparavant et durant led. temps, la stérilité de blés et vins étant advenue... les traites qui avoient accoustumé de s'eu faire parles provinces de Normandie, Champagne et Picardie ont èté délais-

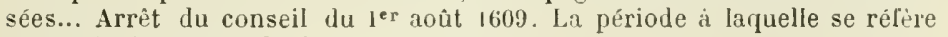
cet arrêt dura plus de deux ans et demi.

2. Lettre du 3 octobre 1604 à l'échevinage de Lyon. Lettres miss., V'1, 300.

3. Sully au roi, 13 sept. 1604. Econ. roy., VIl, 223. 
-erait bientòt sans argent et par conséquent Votre Majesté. Nous arons cassé le jugement et donné ajournement personnel aux offieiers qui l'ont domé '. "

En mème temps quil Iultait contre les préjugés et légoïsme des hommes, Ilenri I V cherchait à vaincre l'avarice le la nature. Il prenait i corur de transformer en cultures les marais qui, en Gascogne, dans l'Aunis, le P'oitou et ailleurs ${ }^{2}$. sélaient formés naturellement ou, comme ceux de la Dombes ${ }^{3}$ et de la Brenne, avaient été créés artificiellement. Mais leur desséchement ne pouvait ètre entrepris quà l'aide de procédés dont personne en France n'arait le secret et le capitaux qu une entreprise aussi nouvelle et aussi hasardeuse n'avait guère chance d'obtenir de ses sujets. Pas un Français ne se présenla pour tenter ce grand travail. Le roi accepta alors les offres d'un Hollandais de Berg-op-Zoom, Humphrey Bradley, qui, dans un pays conquis sur la mer et sans cesse menacé par elle, avait ilcrpuis l'expérience des travaux d'endiguement et de desséchement.

Déjà Bradley avait obtenu le privilège du desséchement des marais de Chaumont-en-Texin ( $1: 97$ ), puis, au mois de janvier 1:99, celui du desséchement des palus de Bordeaux * Ces entreprises particulières le désignaient pour la direction de l'entreprise générale à laquelle songeait Henri $\mathbf{I V}$. Il reçut le titre de maitre des digues et passa arec le roi, le s avril 1599, un traité en forme d'édit. Aux termes de ce traité, les marais salants, les marais et les étang's poissonneux, ceux qui, alimentant les fossés des villes et des chì-

1. Sully au roi, 27 avril $160 ;$ Ibid., IX, 286 .

2. Cela ne l'emprechait pas d'en sentır' tout le charme. Dans une lettre it la belle Corisande, du 17 juin 1586 , ceux de Marans, dans l'Aunis, lui ont fourni le sujet d'un paysage plein de frajcheur et de lumière. Cité far Itrs, llenri IV écrivain, p. 2it?.

3. Gurscr, Essai sur les causes de la dépopulation dans la Dombes el l'origine de ses étrings.

4. Droxve, llist. des dessichements des lacs el marais. 
teanx, araient une imporlance stratégípue, tous ceux, en un mot, qui élaient utiles devaient ètre conservés. Le principal bénéfice de l'entrepreneur deviait consister dans la moitić des terrains desséchés, qüils appartinssent au domaine ou à des particuliers. Ceux-ci étaient obligés de subir le desséchement, sils n’aimaient mieux l'exécuter euxmêmes, mais la moitié du terrain leur restait. Ils avaient mème le choix entre l'une et l'autre moitié. Enfin ils pouvaient ou acquérir la part de l'entrepreneur au prix fixé par lui ou le forcer à acheter leur part un einquième en sus du prix d'estimation de l'autre moitié. Les marais du domaine devaient être partagés aussi bien que ceux des particuliers. On ne pouvait laisser l'entrepreneur seul juge de l'utilité on de l'inconvénient de dessécher tels ou tels marais et il fallait écouter les observations de tous les intéressés. Le grand maitre des eamx et forèts, les maîtres particuliers et leurs lieutenants furent chargés de faire à cet égard une enquète de commodo et incommodo, de visiter tous les marais de leur ressort et d'envoyer au greffe de la Table de marbre les procès-rerbaux de leur visite et de leur enquète? En pressentant les difficultés " de ce grand ouvre.... dont néanmoins toutes les circonstances, qualités et accidents et retardements ou difficultés ne se peurent qu'à peine reconnaitre du premier coup par la nouveauté du fait ", IIenri IV ne sélait pas trompé. A la fin de 1606 , l'entreprise u'était soutenue que par les capitaux de l'entrepreneur. Celui-ci s'associa pourtant quelques compatriotes. La déclaration de janvier 1607 reconnut cette association, fit appel aux capitaux français, précisa et augmenta les droits des entreprencurs envers les propriétaires, accrut leurs a vantages et visa à faciliter leurs opérations ${ }^{2}$. Ln moisaprès, pour accélérer la solution de leurs difficultés avec les propriétaires,

1. Isanbert, $\mathrm{X} V, 212-222$.

$\therefore$ Is AMBERT, $\mathbf{X} Y, 313-3 ? 2$. 
ce qui ćlait tonjours, aree l'insuffisance des capilaux, la piere d'achoppement, le roinomma dans chaque généralité une commission chantrene d'en connaitre'. Vers la fin de son rège, Hemri IV navail pas renoncé à l'espoir de mener à lien ce vaste dessein. Lambassideur anglatis Carew nous apprend qüil sen occupail encore.

sil ne lui fut pas dommé de jourir des résultals de sal persévérance. l'urure d'utilité publiquequ il avait conçue n'en fut pas moin accomplie et l'honneur en remonte directement i lui. Hn nobserve mème pas ici ces intermptions qui se produisent dans la plupart des aurres de longue haleine et qui aminent il se deminder si l'on est en présence d'un mourement dommé yui continue on de plans et d'efforts numeanx dont il fant attribuer le mérite à d’autres qua inx iniliateurs. Toute l’̈mpulsion vint de IIenri IV et de lis Sociéti enonstilue en 1607 , et cette impulsion ne sarrèta pas. C'est donc à lui el à ellequil faut équitablement reporter en crande partic le mérite dés desséchements accomplis mème aprís sa mort, mème par des sociétés particulières sorties de la premiere: la transformation des palus de Bordeaux en cultures, le curage des fossés de la ville et le redressement de ses lalus qui furent exécutés, du vivant de Henri IV par un compatriote, un élève et un auxiliaire de brarley, Conmol Goussen; le desséchement des marais de Chaumont-en-Vexin lont Bradley céda l'entreprise au duc de Longueville, engagiste du comté; celui de l'étang de la souterraine entrepris, au lendemain de la mort de Henri $I V$, par le seigneur du lieu, Anne de Levis, duc de Ventulour, et acheré seulement au mois d'août 1620; celui des marais de sicy et du lac de Sarlieves en Aurergne. cr dernier dî à un Allemand, ottario de Strada, qui se fixa dans ce pars et y erea une fimille encore subsis- 
taute ${ }^{1}$; celui des marais de Lesche dans la Brir, exécuté en 1629 seulement mais d'après un projet concu en $1609^{2}$; les entreprises de dessćchement des marais de Tonnay-Charente ${ }^{3}$, de ceux du bas Languedoc, la seconde confiéc à llarc de Comans qui succéda à Bradley, du vivant mème de celui-ci, dans la direction générale, de ceux de Lárchant près de Yemours, pour laquelle le chapitre de Totre-Dane de Paris traita, le 2:3 juillet 1611 , arec Jéròme de Comans ; le traité d'asséchement du marais Varnier et l'autres terres immergées aux bords de la Seine. Presque tous ces travaux soulevirent les protestations ef la résistance des populations ${ }^{5}$ qui n'y royaient ni l'assainissement, ni la mise en valeur du sol, mais seulement la perte de la pèche qui les faisait virre; presque tous furent exécutés par des ouvriers flamands et hollandais qui formèrent des colonies et des villages, dont les noms de Polder's, dr Petite-Flandre, ete., attestaient l'origine ${ }^{6}$. A la mauraise volonté du grand nombre on est heureux d'opposer l'initiative de quelques grands propriétaires, tels que Claude de Montconnis qui employa toute sa fortune à dessécher et à fertiliser la vaste plaine située entre Ryant-Saze, Rochefort et les Angles, dans le canton de Villeneuve-lez-Avignon ${ }^{7}$.

Ces eaux stagnantes que Henri IV arait voulu remplacer par des terres cultivées, c'est la forèt qui en empèche la multiplication. En retenant et en absorbant les eaux

1. Conexny, Notice sur les ent:eprises de dessechements... dans la généralite d'Auvergne, 1870.

2. Dexis, Lectures sur l'agricullure en Seine-et-1larne, p. 245.

3. Arrêt du conseil du 6 mars 1610. Bibl. nat. mss. Franç., 181ii, fol. $255, \mathrm{r}^{\circ}$.

4. Dexis, Ubi supra.

5. Dans la Charente elle alla si loin rue les levées faites pour le dessichement des marais de Tonnay-Charente furent percées par la malveillance, et les parties déjả desséchées inondées. Arrèt précité du 6 mars 1610.

6. Dionse, Op. laud.: Déclaration de janvier lg0i. Isambert, XV. Malvezis, Histoire du commerce de Bordeaux, II, 390. I. Sinceri Itinerarium Galliæ, 1'1.

7. De Rirbes, Une grande dame dans son ménage, p. 32-33. 
pluviales et souterranes. elle les empêche de devenir un fléalu et les rẻduit à n’ìtre qu un bienlinit. Mallıcurensement les forêts oflrent à la cupidité de l'itat et des populations linitrophes des tentiations irrésistibles. Les prédécesseurs de Menri 11 araient abusé des déboiscments ', des aliénations, Henr IV lui-même sy était laissé entrainer. Les gruerres eiviles avaient farorisi les usurpations des riverains, les dégits du beitail . fitit tomber en désuétude les rìglements forcstiers. Les titres et les plans domanianx avaient été délruits. Les détenteurs en profitaient pour pratipuer des coupes abmsives. les populations pour sattribuer indument des droits d'usige. Lees agents de l'administration colludaient aree les adjudicataires des rentes; les arpenteurs, par exemple, fem attribuaient des lots plus étendus que ne le portaient les adjudications.

Le roi commenega par réduire le nombre des droits usagristes, des coupes extraordinaires et des ofliciers (édils de Folembra! ${ }^{3}$ et de lionen. février l.ig6 et janvier 1:397). Ilenri III, pour baltre monniaie, avait, en 1.77.). remplacéle garind maitre enquêtemr et rélornateur général des forèts par six grands maîtres qui, en $1: 386$, étaient devenusalternatils. Ces offeriers exploitienent sins scrupule des charges quïls avaient payées fort cher et mirent les forèts au pillage. Henri IV rétablit l'mite dans la direction en créant une charge de surintendant des eanx et forèts de France, et remboursa deux des maitrises créées par son prédécessenr, celles de lille-de-france et de la Normandie ${ }^{4}$. An mois de mai 1:97, il compléta par un édit en quarante articles la

1. Bravinn P’unss en déplure déja l'abus. Recepte vérilable par laquelle tous les hommes de la firance pourront apprendre à multiplier el augmenter lenr's trisors, éd. Cap, p. 86-si.

?. Machor, Crondilion furestirse de l'Orlcanais, 91, 98.

3. Lialit de Folembriy fut liwuve personnelle du roi et de Montmoreney. lug. la lelle du roi an connélable, zis février 1596.

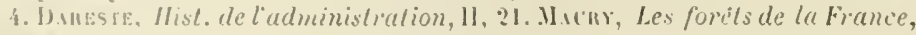
iil-i\}? 
réforme de l'administration forestière. Les mesures adoplées par le conseil consisterent ì faire dresser des procès-verbaux et des plans fixant le bornage des forèts et des rentes et à assurer la conservation de ces titres aux greffes des Tables de marbre; à obliger les verdier's, gruyers, segrayers et maîtres sergents à faire les inspections réglementailes; ì maintenir aux Tables de marbre et aux maîtrises particu lières la connaissance des affaires forestières que les intéressés portaient devant les parlements, moins compétents et déja surchargés ; à taxer les vacations des officiers (art. 2'); à établir les droits réservés au domaine dans les forêts possédées par des apanagistes, engagistes, etc. (art. 26); à assurer, dans les bois des particuliers, la conservation des baliveaux et des hautesfutaies (art. 40); à rendre plus difficile la soustraction des baliveanx et des jeunes arbres (art. 31, 33); à restreindre les droits de paisson et de glandée (art. 34); à interdire la chasse aux roturiers qui s'en arrogeaient le droit sous le courert des seigneurs dont ils dépendaient (art. 36); à obliger les sergents louvetiers qui négligeaient de détruire les loups à adresser, tous les trois mois, aux maitres particuliers et gruyers rapport des prises faites par eux ${ }^{1}$.

Bien que l'exploitation des mines soit rangée par les économistes au nombre des industries, nous nous en occuperons ici, parce qu'il sagit de produits tirés du sol et d'une richesse principalement due à la nature.

Sans rouloir fairel'histoire de l'industrie minière avant IIenri IV. nous dirons pourtant que Charles VI fut le premier de nos rois qui rerendiqua pour la royauté le droit de copropriété et de contrôle dans l'exploitation des mines. Le droit de copropriété fut fixé au dixième du produit 2.

1. Isambert, $\mathrm{NV}, 1 \mathrm{i} 1$.

2. Ordonnance du 30 mai 1413 dans le recueil de LAMÉ Fletry, De la législation minérale sous l'anc. monarchie, pièce 1. 
Lialil de Fingois lor du 17 octobre $1: 320^{\prime}$ ordonna la revision des concessions, menaģa de poursuites les débiteurs In droit de dixième et subordonna lexploitation à l'autorisition rovale, rériliée par le contròleur gánéral des mines. Sousllenril! l'exploitation, divisée jusque-lit entre plusieurs concessionnaires. ful confiée ì une société minique placée ons la direction du sirede Robervil et investie de grands

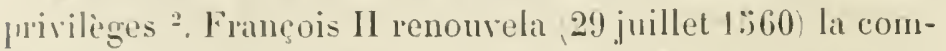
mission donnée par Ilenri II i Claule Cirippon de SaintJulien, assorié de Roberval pour la recherehe et l'exploitation des mines et lui confirma, pendant quatre ans, lahandon du dixiène. Cetle commission ne fut pas infruetueuse. Elle amena la découverte de gisements dans le Beaujolais, l'Auvergne, le Lyonnais, le Dauphiné, la P'rorence, le Languedoc, le Bourbonnais, le Poitou ${ }^{3}$, mais la guerre civile vint bientôt entraver l'exploitation. Elle n'avail pas encore éclaté quand, le 11 juillet $1: 361$. Charles IX confirma au concessionnaire son monopole et l'alloeation du dixième ". Les propriélaires le mines ayant prétendu que ce droit ne devait ètre prélevé que sur les mines qui étaient déjà en exploitation, Charles IX déclara quill sappliquait à toutes et que, à moins de clause expresse, la propriété des mines nétait pas passée aux acquéreurs ni anx détenteurs du domaine ${ }^{5}$.

Ilenri IV fil faire une enquête sur la richesse minière et sur les meilleurs moyens de l'exploiter ". Ces recherches rívélìrent l'existence de gisements dont Palma Cayet et de

1. LaмE Flechr, p. 22.

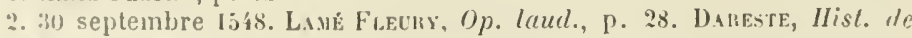
lardininistration, II, I8'.

3. LAME FLECRY, p. 4r.

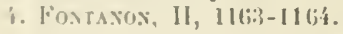

5. 26 mai 1563. Ibid., III, 45.5. Cf. Thuani Historia, II, 358, anno I.363.

1i. "... vuï le rapport fait en icelui nostred. conseil par ceux que nous furiuns ci-devant envoyés pour faire faire recherches desd. mines et des moyens de lus mettre en valeur..." (Édit de juin 1601, art. 4. Lamś Fleersi, p. ii.) 
Thou ont donné l'énumération d'une façon presque identique '. On découvrit dans les Pyrénées des mines d'or, d'argent, de talc et de cuirre, daus les montagnes du pays de Foix des mines de jayet et de pierres précieuses. On recueillit dans l'Ariège des parcelles d'or. On s'aperçit que le sol des environs de Carcassonne renfermait des mines d'argent; quil y avait dans les Cévennes et le Góvaudan des mines de plomb et d'étain, qu'on trouvait du fer en Auvergne. L'or et l'argent abondaient près du village de Saint-Martin-en-Lyonnais. La Normandie pouvait fournir de l'argent et de l'étain de très bonne qualité. La mème exploration amena la découverte de mines de plomb à Annonay, de marcassite, d'or et d'argent en Picardie et en Brie.

Encouragé par ces résultats, le roi rendit, en juin 1601 , un édit sur les mines, qui fut surtout l'curre de Sully et qui confirmait les déclarations de François ${ }^{\text {er }}$, de Henri Il, de François II et de Charles IX. II en diffère pourtant essentiellement en ce que, tandis que les prédécesseurs du roi, peu confiants dans les bénéfices de l'exploitation, avaient abandonné aux entrepreneurs le droit régalien du dixième, Ilenri reprenait ce droit, mettait l'exploitation en régie, en faisait vraiment un service public. C'est là ce qui fait la nouveauté de l'édit. J.-A. le Thou et l'ambassaleur d'Angleterre, H. Neville, lui ont attribué une portée exag̨érée en laissant entendre qüil enlevait aux propriétaires l'exploitation de leurs mines ${ }^{2}$. Les articles $17-22$ recon-

1. Chron. sept. anno 1602. - Thuani IIistoria, V', 156, anno 1603.

2. Ut ne singulares toto regno domini eruendis illis sibi injuriam fieri conquerantur, aut inde damnum sentiant, eis prospectum, cautumque ut sulfuris, nitri, ferri, chalybis, chalcanthi, carbonis cespitarii, lapidis cierulei, qui pro tegulis est, gypsi, cretie, lapidis cæmentarii et molaris fodine penes eos sint, nee a proprietariis illorum possessio avocari possit. (Thuani Historia, VI, 156, anno 1603.) I understand there are lately discovered in Poictou and Auvergne certaine mines of silver, which they hope here will prove very beneficial. The King hereupon is about a reglement generally for all the mines in France, determining to take them all into his own hands, and to content the proprietors with a certayne portion, 
nairsent expressément, au contraire, le droit des propriélitires dexploiter cux-mèmes, ils les obligent seulement ì le faire sous la surveillance du contrôleur général des mines, dans les conditions fixées par le grand maître, et à faire apposer une marque sur les produits. Lesmines énumérées par l'article 2 ne sont pas, comme linsinue de Thou, celles dont l'édit laisse, par exception, l'exploitation auxpropriétaires, mais celles sur lesquelles le roi renonçait ì son droit du dixième. (On peul seulement conclure de l'article 21, en le ripprochant d'un arrìt du conseil du 14 mai 160 't dont nous parlerons plus tard, que l'État a qualité pour se substiluer dans l'exploitation, au bout d'un certain temps, au propriétaire négligent.

Le lıut personnel créé par l’édit se composait d'un grand maitre surintendant, d'un général rélormateur en titre d'office, d'un licutenanl général conseiller du roi, d'un contróleur gincial et d'un greflier. Tous ces officiers touchaient des gages fixes et des racations. L'ambassadeur' Neville ${ }^{1}$ dit que Sully, par löntérèt passionné qüil portait à lindustric minière, semblait désigné pour la charge de grand maître surintendant. Ce fut pourlant à Roger de Silint-Liry, duc de Bellegarde, qüelle fut donnée. Celle de licutenant grónéral échut à Martin Ruzé, sieur de Beaulieu, secrétaire d'État. Pierre Beringhen, premier chambellan, fnt nommé contrôleur ${ }^{2}$. Le Parlement n'enregistra l'édit qu'à la suite de lettres de jussion répétées ${ }^{3}$. Un arrêt du conseil du 1 ' mai 1604 le confirma et le compléta en forti-

proportionable to the profit that shall arise, and so to manage all by his own officers, a matter which is like to be very olfensive. The edict I have seen as ys drawn but yt is not yet passel the Parliament. Mr. de liosny alfecls the matter much, and, if it proceed, is like to be great master or superintendant of all the mines in France. (II. Neville a Cecill, 20 aout 1599 (1. s.). Sir Ralph "Inuood's. Memorials of affairs of state. London, 1:25, 1, 93.)

1. rili supra.

2. Thumi llistoria, l,ce. cil.

3. Lellres miss., V1, Gil. 
fiant le contrôle de l'État et en s'occupant du sort des ouvriers. Le trentième du produit net fut consacré à leur assurer les secours spirituels et matériels, dontils étaient souvent privés par l'isolement des mines en pleine campagne; des aumôniers et des médecins furent attachés à l'exploitation. Si, dans le mois de la concession, l'exploitation n'était pas commencée, le grand maître pourait transférer la concession à d'autres. La suspension du travail exposait aussi les concessionnaires à la déchéance. Ils devaientfaire connaitre les noms de leurs associés, quine ponvaient céder leurs parts sans en aviser le grand maitre et le lieutenant. Ils étaient tenus de nonmer, pour diriger l'exploitation, un gérant qui était responsable envers l'État. Ils ne pouvaient enfin abandonner l'exploitation sans prévenir le grand maître ou le lieutenant particulier.

L'arrêt renouvela l'obligation de faire apposer sur tous les produits la marque du premier. Il établit, au profit des ouvrier's et des fournisseurs, un privilège sur les autres créanciers Ce privilège primait même le droit du roi. II créa un fondeur, essayeur et affineur général ; précédemment le fondeur était un agent des compagnies etles droits du roi étaient sacrifiés. Comme l'avait fait déjà l'édit d'octobre 15.2, il désintéressait les seigneurs hauts-justiciers et fonciers en leur accordant une part d'entrepreneur et attirait les étrangers experts en les affranchissant du droit d'aubaine ${ }^{1}$.

Cette lígislation, qui conciliait le droit de propriété et l'intérêt public, était bien conçue et elle aurait déreloppé la production minière, si les mines avaient été plus abondantes en France, si le rendement avait mieux récompensé les efforts et les dépenses des entrepreneurs, si les ouvriers n'avaient pas été rebutés par un travail pénible. Mais les

1. LAMÉ FLEURY, p. 8i. 
richesses de notre sous-sol étaient encore moins considérables alors qu aujourd hui, puisque le bassin houiller de nos départements du Norl ne faisait pas partic du territoire. Lambassadeur vénilien, Vendramin, constate en 1600 que la France, qui abonde en richesses maturelles de toutes sortes, manque de mines ${ }^{2}$. Ce n'est pas que les gisements. on vient de le voir, ne fussent asse\% multipliés, mais ils nétaient pats assez productifs, mème pour courrir les frais. J.-A. de Thou déclare que les entrepreneurs ne ponvaient sen tirer qu’en condamnant les ouvriers ì un régime excessirement frugal. Les ourriers français, habitués à une vie douce et aisce, ne purent se faire à ce régime, non plus ұu aux fatigues et au péril d'un pareil travail. On fit renir des Allemands, mais ils śen dégoùterent aussi dès quils commurent lexistence plus large et plus facile que leur olluait notre pays ${ }^{2}$.

Nous venous de montrer ce que fit ou tenta de faire Ilenri IV pour l'agriculture. Il fut secondé, dans cetle partie de son unvre, non seulement par Sully mais par le premier en date de nos agronones, par un homme dont linfluence a contribué au succès de certaines cultures particulières et à la propagation du goùt et de la science de l'agriculture en général.

Olivier de Serres ${ }^{3}$ appartenait à une famille protestante originaire d'Orange, où elle possédait la Tour des Serres. Yé à Villeneure-de-Berg, il était le frère ânes de Jean de Serres, pasteur et auteur de l'Inventaire de l'histoire ale F'lance, c'est-à-dire de l'un des meilleurs ourrages historiques de ce lemps. Il nous apprend lui-même: qüil

1. Al.beli, 1, série Iv, 459.

$\therefore$ Thuani llistoria, VI, 156, anno 1603.

3. Voy. sur lui, outre le travail de Gasparin, Journal d'agric. prat., $2^{\mathrm{e}}$ série, trine lll et l'úlocre de l'rançois de Neufchâteau, le livre de M. Vaschalde, Insi; 8.

i I'réface du Théltre dagric. 
passa le temps des guerres civiles ì cultiver ses terres, à se livrer à des expériences agricoles, à éludier les livres d'agriculture. Ce qu'il ne nous dit pas, c'est qu'avant de se' consacrer exclusivement à faire valoir, il arait pris une part active, quoique courte et limitée, aux guerres religieuses. Ce fut à lui que les protestants durent de reprendre Villeneuve-de-Berg, qui avait été occupée par les catholiques.

Comme agriculteur, il se distingua surtout par l'irrigation du Pradel, domaine situé en Vivarais qu'il tenait de sa femme, Marguerite d'Arcons, et par l'extension de la culture du mûrier. Mais tout ce qu'il fit, soit par ses essais, soit par ses écrits, pour la propagation du mûrier, nous le rattacherons à l'industrie des soieries et nous en parlerons plus tard. Nous ne nous occuperons pas non plus ici du traité qu'il a intitulé : La seconde richesse du múrier blane (1603), parce que ce traité a pour objet l'application industrielle de l'écorce du mùrier et est, par conséquent, étranger à l'agriculture. C'est aux connaissances agricoles dont il fit preuve dans son grand ouvrage, aux préceptes qu'il y traça, à l'influence exercée par cet ouvrage que nous devons nous attacher.

Ce qui rend le Théâtre d'agriculture très supérieur aux traités qui l'avaient précédé, c'est qu'au lieu d'être un recueil de recettes en partie fantaisistes, il est le fruit à la fois de l'étude des agronomes anciens et modernes et de l'expérience. Il est divisé en huit lieues ou livres. Dans le premier, l'auteur indique les considérations qui doivent guider pour le choix d'un terrain, la distribution de la maison, l'administration du "ménage ". Le second s'occupe de la culture des céréales et des légumes. Le troisième traite de la vigne, du vin et des autres boissons, le quatrième des pâturages et du bétail, le cinquième de la volaille, de l'élève des vers à soie, de l'emploi de l'écorce du 
murier, le sixième des jardins et vergers, le septième de leau et du bois, le lunitième de l'emploi de tout ce que fournit le domaine rustique pour l'alimentation, l'habillement. le mobilier, la lumière, le traitement des maladies des hommes et des animaux. On roit que l'ourrage est un traité d'économie domestique autunt que d'agriculture. Cost, il faut le répéter, une arurre originale en même temps que fondée sur la tradition.

II. de Gasparin y signale particulièrement, parmi les choses nomelles, le conseil de commencer les travaux de la jachère immédiatement après la moisson, celui d'ameublir le sol par le brùlement des chaumes, celui d'ourrir les travaux par un labour léger. C'est dans Olivier de Serres quion trouve la deseription la plus méthodique et la plus exacte de la jachère. C'est lui qui a le premier fint ressortir la nécessité périodique des défoncements profonds, c'est ì lui quion doit la distinction capitale des plantes épuisantes et de celles qui ne le sont pas, véritable fondement d'une bonne théorie des assolements. II s'est fait le patron et l'arocat de cultures peu répandues de son temps: le mais, le houblon, la betterave récemment importée d'Italie et dont il signale le " jus..., semblable ì syrop de sucre " sans se douter du parti que notre siècle devait tirer de cette propriété, la garance, le sainfoin, l'esparcette peu cultivée en dehors des environs de Die, le riz qu'on récoltait en petite quantité dans notre pays et que nous recevions du l'iémont et des Indes ${ }^{1}$. Il recommande le soufrage de la vigne ${ }^{2}$. Il pressent les nuages artificiels ${ }^{3}$.

Le succès du Thédtre d'agriculture fut considérable. Publié en 1600 il eut, jusqu'en $167 \%$, dix-neuf éditions :

1. P. 14i.

2. Liec Jll, chap. v.

3. Г'. $259-200$.

千. L'après .I. de l'alloux, l'ouvrage d'OI. de Serres aurait été négligé sous Louis Xll et n'aurait retrouvé la faveur du public que sous Louis XVI et 
Ce succès et l'autorité quill consacrait surrécurent à l'ancien régime. En 180\%, à une époque qui présentait arec celle où il arait fait son apparition plus d'une analogie, le gouvernement consulaire, estimant qüil pourait ranimer et propager le goùt de l'ag riculture, le faisait réimprimer ì l'Imprimerie nationale arec les commentaires des plus savants agronomes du temps. Les nombreux lecteurs quill troura au

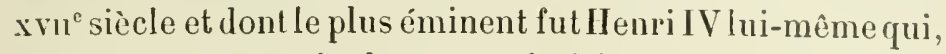
trois ou quatre mois durant, se le faisait lire pendant une demi-heure après son diner, ses einq réimpressions de 1600) i 1610 donnent le droit d'affirmer qu’il exerça sur l'agriculture une sérieuse influence. Mais il faut sen tenir à cette rérité générale; il serait téméraire de lui attribuer directement l'adoption de cultures et de méthodes nouvelles. Il faut se rappeler combien, surtout en agriculture, les ininovations sont lentes à prévaloir, et l'histoire doit résister à la tentation de donner une origine et une date précises à des découvertes, à des progrès dont la théorie et l'exemple ont sourent précédé de bien loin le triomphe.

C'est la réalité des choses, telle qu'elle ne se trouve ni dans les textes de lois ${ }^{1}$ ni dans des ouvrages le plus souvent en avance sur leur temps, qu il faut maintenant essayer de saisir et, pour le faire, pour caractériser l'état soeial et économique, l'esprit et les mœurs des classes rurales, pour déterminer les méthodes et les pratiques suivies par l'agriculfure, nous nous placerons, autant que possible, dans celte période qui, tout en se ressentant de l'anarchie qui l'avait précédée, a donné à l'aetivité du pays la sécurité dont elle a besoin.

urâce à l'abbé Rozier, l'auteur du Trailẻ d'agriculture. Notice sur Olivier de Serres dans Mémoires de la Société d'agricullure, scienceset arts d'Angers, 18 '3.3.

1. Il faut avoir toujours présent à l'esprit cet adage du xvie siècle d'une mélancolie résignée : Le laboureur n'a rien à soy et si avons nous prou de lois. 
Lil France était alors par excellence, bien plus encore qu'aujourd'hui, un pays agricole. La pacification du pays avait fait rethuer vers les campagnes la population rurale qui, pour sauvegarder ses hicns et sa vie, sétait aggloméréc dans les villes. La terre laissée en friche ou cultivéce đlune façon irrégulière, réservait aux bras qui lui étaient rendus une fécondité nouvelle. Malhenreusement elle ne pouvait guère compler que sur des bras. Comme l"industrie, comme le commerce, l'agriculture souffrait de la prílérence du capital pour certains placements mobiliers. La multiplicité et le caractère occulte des lypothèques, l'espéce dindivision qui grevalt la propriété effrayaient le rrédit'. On ne tromvait à emprunter sur biens-fonds qu’à force de cautions et à un taux usuraire ${ }^{2}$. La propriété était dejjì beaucoup plus divisée qu'on ne l'a cru pendant longtemps ${ }^{3}$.

Les grands propriétaires appartenaient aux trois classen de la société, noblesse, clergé, bourgeoisie dans une proportion qui sátccroissail au profit de cette dernière. La noblesse, remplie de cadets exclus ou à peu près de la sucression paternelle, śtait en majorité peu aisée. La paurreté des gentilshommes de Beauce était proverbiale. "Gentilhomme de Beausse, il est au lit pendaunt quion racconmole ses chausses ". Leur régime était à l'avenant de leur garderobe, et rétait un dicton qü̈ls déjeunaient de laar ‘n hempi: Ceux de Bretagne neétaient pas moins mise-

1. DAmFstr, llistoire des classes agric., 301.

2. L.iffryas, Remontrances en forme d'edil, art. xir.

3. Pour la Provence voy. De lirbas, Les familles el la societé en Franre l'our la Bretagne Du Chiteluen et Duper. Ilisl. de la réunion de la Brelarpur, II. 31!. Pour la Touraine et Ia région du Cher l'abbé CnevatuEn, Inmules de lu sociele d'agriculture, sciences, arts et b.-lellres d'Indreet-l,oire, XIXII IS60 et Memoires de la Societé archéologique de Tomaine,

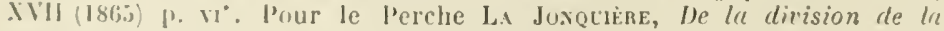
lmopriélé le'ritoriule dans le l'erche. Bulletin de la Société historique et curch. le l'(0rne, II (1883).

i. I.E lior d be Lixcr, Prot. frame. : "En menoire de quoy, encores de 
rables'. Beaucoup de revenus seignenriaux, qui autrefois étaient payés en nature, ayant étí convertis en argent, a vaient subi la dépréciation qui, depuis l'augmentation de la circulation monétaire, arait avili les espèces. Ĺne partie de la noblesse cherchait, sans scandaliser personne, des ressources dans les affaires, patronant et commanditant des entreprises industrielles ${ }^{2}$, vendant son inlluence aux traitants, s'associant ì leurs baux arec l'encouragement du pouroir qui exemptait de pareilles associations de la dérogeance ${ }^{3}$, hasardant dans les spéculations son honneur et ses capitaux. "En ce temps-là, écrit un contemporain, l'on ne parlait que de banqueroutiers à la cour". "Cette classe était partagée entre deux tendances. Les traditions, la nécessité de l'épargne, le rang et l'autorité qui leur y étaient dévolus. retenaient le plus grand nombre dans leurs terres ${ }^{5}$. Ils y rivaient des produits de leur cru, s'y complaisaient dans la jouissance de leur's droits honorifiques et utiles et ne les quiltaient que pour passer quelques mois dhiver à la ville roisine, dans l'hôtel délabré de lamille ${ }^{6}$. Le type accompli de ces gentilshommes campagnards, c'est Olivier de Serres : " IIon inclination et l'état de mes affaires, nous apprend-il

jrésent, les gentilshommes de Beauce desjeunent de baisler et s'en trouvent fort bien et n'en crachent que mieulx. "RAbet.ss, Gargantua, 1, xvi : "Et desjeuner tous les matins - Comme les escuiers de Beauce ". Copur-LART, Monologue rles perriqques.

1. Du Chitelier, L'agriculture et les classes agricoles en Bretagne.

2. "... Lacte de l'assuciation... entre le sieur de Serbaude tant pour lui que pour un seigneur notable de ses amis et aucuns ses associés... " Arrêt du conseil du 6 mars 1610 . Arch. nat. Brevet accordé par le roi, le 28 septembre 1596, au vidame de Chartres et a Saint-Germain d'Apchon pour l'exploitation d'une invention destinee á faire de l'acier. Bulletin du Comité de la langue, de l'histoire et des arts. 111 (I855-56). p. 302. S.Ivary, l'arfait négociant, I, 162. Dictionnaire du commerce, vo Société.

3. Arrêt du conseil du 10 décembre 1605 . Bibl. nat. franc., 18169 fol., 65. Articles du bail de la table de mer de Marseille arrêtés au conseil le $1 \dot{4}$ août 1608. Arch. nat. Collection des arrêts du conseil.

4. Mercure fruns., année 1609, fol. 3íl.

5. Relations de Badoer, I, 85, 8i, de Gussoni et Nani, 1, $\mathbf{5} 5 \mathbf{4}$, de Duodo. Alberi, Append., 81, 102. Théatre d'ngriculture, Jl, 774 .

6. Mémoires de J. A. de Thou, 1582. Coll. Michaud, XI, 210,341. 
lui-mème. mont retem aux thamps, en ma maison et faicl passer une bonne partie de mes meilleurs ans, durant les guerres civiles de ce royaume, cultivant ma terre par mes serviteurs, comme le temps l'a peu porter". "Le genre de vie adopté par Olivier de Serres et par d'autres propriélaires de la mème classe élait encouragé par le roi, par Sully, par lopinion. L'attrail de la conr, les perspectives de fortune qu'elle pouvait offrir et, par exemple, liune de ces pensions ${ }^{2}$, que le roi, si ménager pourtant de l'argent de la France, n’lésitait pas à multiplier sauf à les suppriner au premier acte de désoléissance, décidaient les autres à laisser leurs terres ì des fermiers et ì partir pour l'aris ou Fontainebleau sans autre équipage que deux ou trois laquais ${ }^{3}$. Mais ni le roi, ni Sully n’aimait les quémandeurs, et plus d'un de ces barons de Foneste, après aroir diverti le Lourre par ses allures provinciales, revenait césenchanté au manoir patrimonial. Ceux qui avaient su résister à la tentation de le quitter, qui, disposant d'un revenu de 2000 ì 12000 livres, avaient été assez sages pour préférer la vie large ou fastueuse qu'il leur assurait i la campagne, aux embarras qu il n'aurait pu leur éviter à la suite du roi, ceux-là exerçaient par leur patronage, par l'exemple d'une culture mieux entenduc, une influence très salutaire. Ce n'est pas que tous eussent désappris les habitudes violentes ou grossières que les guerres civiles

1. Théalre d'agriculture, Préface.

$\therefore$ Leur chilsre annuel dépassait un million d'écus (10113115 f1. 12). Relation de G. Carew (1lit19), p. 434.

3. "... those, who are anywise eminent for military or civil ableness, lie bindeth them to this obsequiousness by giving them pensions of which there are a great number and well paid) so long as they continue in their lutifulness. But upon the least disobedience they are sure to have their pensions stopt, which maketh them very eareful not to do any thing against lis will... they abandont heir country habitation and, with two or three lackeys to attend them, follow the court.. their possessions remaining in the hands of their farmers, who pay all taxes and yield their lindlords sin much the less rent... "Relation de G. Carew, 437 . 
araient déreloppées. Les meurtres, les duels qui n’étaient quelquefois que des assassiuats déguisés, les rapts, la fabrication de la fausse monnaie, le faux saunage armé, loppression capricieuse ou systématique des vilains, livrognerie venaient attester chez un certain nombre la persistance d’inslincts héréditaires endureis au feu des luttes intestines et encouragés par de grandes chances d'impunité : "Jésus! " pourra dire encore douze ans plus tard la femme d'un conseiller au Chàtelet, " que les grands seigneurs sont heureux dans les petites villes! Ils entreprennent tout sans contredit. Si le bou seigneur arait fait cela à Paris, il serait au Chàtelet il y a longtemps'. ") Les archives criminelles, les chroniques locales nous réservent sans doute la découverte de hobereaux du genre de cet Hercule d'Angilemont qui, alors que les guerres civiles n'étaient plus qu'un douloureux souvenir, continuait, de ses châteaux de Caumont et de Fronsac, à rançonner les bateaux qui passaient sur la Garonne et la Dordogne et se mettait cyniquement aut-dessus des lois ${ }^{2}$.

Le clergé était encore le plus grand propriétaire foncier du royaume. Mais, précisément à cause de sa richesse et sous prétexte de l'intérêt religieux engagé dans la guerre, nos rois l'avaient largement saigné, lui avaient souvent imposé des décimes et des dons gratuits, avaient gagé sur ses biens, déjà assignés au payement des rentes de l'hôtel de ville de Paris, des emprunts sélevant à 300 ou 400000 écus $^{3}(28498399$ fr. 48 et 3799812 fr. 64). Le

1. Caquets de laccouchée, 142. Est-il besoin de rappeler les crimes dont l'Auvergne était le théâtre cinquante ans plus tard et dont les mémoires de Fléchier sur les Grands Jours nous ont conservé le sıuvenir?

2. Tamzey de Larroque, Hercule d'Angilemont, 1890. Cf. Robrou, Essui sur la littérature et les mours dans la première moitiè du xvite siècle, p. 219 et suiv. Gacisox, Les États de Languedoc, p. 13.

3. Relation de Duodo, 111-112. Sous l'influence des passions anticléricales, l'idée de confisquer ses biens et de les remplacer par une pension égale í leur revenu s'était même produite. Ĺn capitoul de Toulouse, Terlon, 
clergé du dincise de Laon, par exemple, avait été réluit au plus ơrand dénuement; il arait été obligé d'engager ou de rember à vil prix ses propriétés et il ne mil guère moms d'un demi-siecle ì réparer ses pertes ${ }^{1}$. Les biens affectés au culte, ceux qui composaient les menses épiscopales, capilulaires, abbaliales, conventuelles araient souffert des spoliations commises par les protestants ef mème par les catholiques, ainsi que de lit gestion de mandataires insouriants ou avides?. Grice ì la mainmorte, grìce ì des réghtes et ir des traditions d’administration excellentes, était encore pourtant dans le clergé quion trouvait, en même temps que les plus grands domaines, l'administration la mieux entendue.

Autour de ces grands propriétaires et dans des liens étroils aves eux se groupait une population de tenanciers ct de mercenaires. Le régime foncier qui unissait les premier's et la seconde élait une sorte d'indivision, de enpropriété, oì l'on distingue l'une part l'ancienne directe, de l'autre des obligations et des droits contractuels. C'est par suite de la directe, c'est à titre d'ancien mainmortable que le vilain était soumis au chef cens, aux corvées, anx banalités, à la justice: c'est en qualité de fermier et de colon parliaire qüil devait la rente ou la quotité du produit stipule par le contrat.

Le serrage subsistail encore dans certaines provinces, en liourbonnais, en Nirernais, par exemple, mais, mine depuis de longs sièrles par les faits et les idées, dans l'ordre

[1resnta un projet dans ce sens aux États de Languedoc de 155:) et 1.j60.

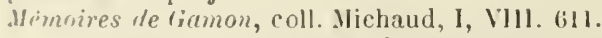

1. Linçuîte sur la situation de ce clergé en 1:96, p. p. Matton.

2. As for the clerrymann... they live not so wealthiley at this day as their prerlecessors have done. CAREW, p. 439. "... essendo la nobiltit rovinila fler le guerre passate ed il elero medesimamente per listessil causa, amincinno questo da poco in qua a ristorarsi... Baroen, 8:i. Les édits de apritılation de Troyes, de Sens, de Laon, de Chateau-'Thierry, déchargérent les ceclésinstiques des decimes arricrés. P. C.иет, 5is-5i9, 581, isi. loy. aussi les nombreux arrits accordant des remises de décimes. 
des faits par l'extension conlinue des défrichements et le hesoin croissant de bras, dans lordre des idées par la conviction de la supériorité du travail libre sur le travail servile, il n'étail plus qu'une exception. La situation aconomique du petit cultivateur n'étail pas moins avantageuse que son statut personnel. Débiteur de cens et de rentes en argent, producteur agricole, célait lui qui profitait de l'abaissement de la valeur monétaire é de l'élévation du prix des denrées. Enfin il était, ainsi qu'on va le roir, protégé contre l'éviction par des baux de longue durée.

Le fermage et le métayage ne doivent pourtant pas c̀tre rangés dans cette catégorie, car ils ne dépassnient pas neuf ans, e'est-à-dire la période au delì de laquelle les baux levenaient emphytéotiques et étaient considérés par les jurisconsultes comme entrainnant translation du domaine utile et perception des lods et ventes ${ }^{1}$. Le preneur pouvait, en donnant caution, ne payer le fermage qu'à la fin de lannée; à défaut de caution, il payait par quartier ${ }^{2}$. Olivier de Serres ${ }^{3}$ conseille de passer le bail par-devant notaires. D'après le droit canon, l'Église ne pouvait s'en dispenser, pas plus qu'clle ne pouvait loner ses terres pour plus de trois ans:

Le métayage était plus répandu rue le fermage, surtout dans le Midi et il devait conserver cette préférence jusqu'à la fin de l'ancien régime. Dans certaines provinces pour-

1. "... Nous tenous l'opinion des vieils interpretes que tout bail qui se fait à plus de neuf ans, translere la seigneurie utile... "Lorsead, De la distinction des rentes, liv. I, chap. $\mathrm{v}, \$ \mathrm{~s}$. Voy. les baux de la ferme de Villeroy de 1510 a 1609 dans I' Append. des études hist. sur l'administration de l'agriculture en France, par Ilavguis

2. Pierre de Loulle, Le Digeste du droit et pratique de France, 1619, liv. X, tit. V.

3. I, 53 .

i. "Le louage des immeubles ne se peut faire que pour neuf ans des biens séculiers et trois des ecclésiastiques. " P. DE LOCıLE, Op. laud. C'était neuf ans que les baux de biens ecclésiastiques ne devaient pas dépasser, d'après I'ordonnance de Blois (1579). IsıмвEnт, XIV-401. 
tant il faisait place an fermage. C'est ée qui arriva dans l'une des plus riches du royaume, la Normandie. La terre yaugmentail heaucoup de valeur, les cultivateurs y avaient inequis une aisance fui leur permetlait d'en offrir un prix plus élevé et de supporter les avanees de sa mise en vileur; les propriétaires purent des lors substitner an lojer en nature un lorer en alrgent. an meme temps quils metlaient a la charge des preneurs les frais de certains amendements ${ }^{1}$. Cette ingmentation ne fut pas d'ailleurs particulière à la Normandie, elle lut générale de 1600 à la lin du règne et mème au delà et correspondit à la hausse croissante des produits agricoles et des fermages².

Le bail it complant était adopté pour les vignes dans le Poitou, l'Anjou, le Maine, la Saintonge, l'Aunis, le Nivernais et le Dauphiné ${ }^{3}$. Par ce contrat le preneur sengageait à mettre ou à entretenir un vignoble en valeur et à fournir au bailleur une certaine ruantité de fruits; souvent le premier derenait, au hout de cing ou de sept ans, propriétaire de la moitié. S'il entretenait arec négligence. il pouvait ètre évincé. Dans certaines parties de cette région, la propriété était considérée conme transférée au preneur, dans d'autres elle restail au bailleur, ailleur's la question était controrersée. Ce qui est plus important pour nous que ces distinctions juridiques, c'est le stimulant que le bail is compline ne pouvait manquer de provoquer thez le preneur.

Le hordelage élait la tenure propre an Nivernais. "Plus des trois parts des héritages, nous apprend son jurisconsulte Corpuille, tant is villes quanx champs, sont tenus en

1. BrackeramE, Votes et documents concernant l'élal des campagnes de ln Ilrutr-Normandie dans les dernier's lemps du moyen äge, p. 31-32.

$\because \%$ oLl.s, Les rmiations dn recenu el du prix des terres en firance au

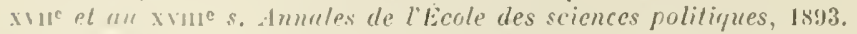

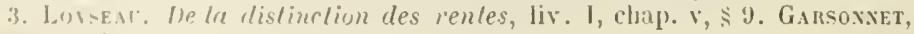
llist. ales luralions perprituelles. 
bourdelage ${ }^{1}$. " La rente due par le m'eneur était payable en argent pour les prés, les bois et les vignes, en blé pour les terres lahourables, en plume, c'est-ì-dire en rolaille, pour le bétail ${ }^{2}$. Autant le bail i complant était farorable au progrès de l'agriculture, autant le bordelage lui était contraire. Le bordelier ne pouvait sous-arrenter et était tenu de faire des améliorations sans avoir l'espoir d'en profiter ${ }^{3}$.

Le domaine congéable, appelé aussi bail à convenant et quevaize, était particulier à la Bretagne. II sauregardait mieux les intérêts du fermier et par cela même ceux de l'agriculture, car, en lui imposant la résidence, en lui interdisant de vendre, de démembrer et d'hypothéquer la tenure, il lui accordait, en cas d'éviction, le remboursement de ses impenses et de ses traraux ${ }^{4}$.

C'est encore le principe de la longue durée ou de la perpétuité qui distingue l'emphytéose, qu'on trouve un peu

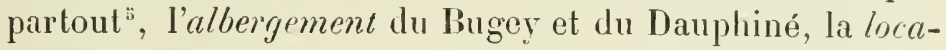
tairerie perpétuclle du Languedoc, la main-ferme du nord de la France, le bail colonger de la région rhénane. Dans un petit pays de la Picardie, le Santerre, ce principe était poussé si loin que la résistance du fermier à l'expulsion légale était, sous le nom de droit de marché et de maurais

1. Mémoire de ce qui est ì faire pour le bien du pays de Nivernais dans les OEurres de Copulue, I, 2i I.

2. Lorsead, Op. taud., S 9.

3. Garsonnet, Hist. des locations perpétuelles... Pépix Le Ilalleur, Hist. de l'empliytéose, p. 257-258.

4. Coutume de Bretagne dans Boerdot de Richebolrg, VII, 412. Garsonxet, Op. laud.

5. Coume exemple d'emphytíose, citons le bail perpétuel (pour' quatrevingts ans) de quatre cents arpents en friche sis dans la paroisse de Betz en Touraine. Il est passé par le chapitre de Saint-Martin de Tours moyennant 4 den. t., 101 boisseaux de seigle mesure de Loches de rente foncière spéciale et indivisible par arpent. Les preneur's doivent payer la dime $\dot{a}$ l'onzième, selon la coulume de tous fruits décimables. Ils s'obligent à faire les bảtiments, réparations, améliorations, plants de vigne déterminés par devis et á payer un fermage de 24 boisseaux d'avoine. Ils auront les gaspeaux et le tiers des pailles et logeront les bailleur's quand ils viendront pour leurs allaires. 9 juillet $156 \mathrm{~s}$. Arch. nat. Kk, 943 . 
"rí. onlre dans les maurs ${ }^{1}$. Cette rapide revue des conditions dlans lesquelles était exploitée la propriété rurale ne justifie-t-elle pas la conclusion suivante d'un ourrage sur lit maticre : "La location perpétuelle et le bail à longue durée élaient. écrit M. Garsonnet, le droit commun de la [1rojuriété en France avant 1789²."

Plus stable. plus permanente encore élait la condilion des paysans qui faisaient partie des rares communatés agricoles encore existantes. A lorrigine elles avaient été pour les tenaneier's un moyen de se soustraire à la mainmorte, car leurs nembres héritaient les uns des antres. Le travail, les bénéfices, les pertes y étaient partagés : l'un labourait ou touchait les boufs, l'autre conduisait le bétail au piturage. Les affaires communes étaient gérées par le maitre de la communumé; celui-ei était inscrit pour elle sur le rûle des tailles et avait qualité pour la représenter et l'engager', au moins en matière mobilière ${ }^{3}$.

Si lon ne tenait compte que de la sécurité dont elle jouissait sous l'empire de pareils contrats et du cours ascensionnel que la rérolution économique imprimait à ses bénélices. la classe des moyens et des petits cultivateurs 11 aurait pas eu à se plainlre ; mais il faut aussi aroir égard ì la façon dont sa situation était affectée par les institutions publiques et par les mœurs.

La lutte séculaire entreprise par la royautí pour rentrer en possession des attributions de la souveraincté quelle avait concédées ou laissé prendre, était fort avancée mais non terminée. Cette soureraineté restait démembrée. La population rurale inférieure était victime de ce dualisme.

1. Lefort, La condition de la propriélé dans le nord de la France, et G.u-uxit, llist. des local. perpél., p. 273-2í. - Cr. La Réforme sociale, t. IXIV, I. !II.

2. Op. lonul., ए. 3 s8.

3. Luskfi., lnsl. coulo, no 92. Dareste, 81. Gunent, La famille limousine, p. .2. 
Elle avait deux maîtres : le roi et le seigneur. Elle acruittait deux fois les charges et les prestations qui sont le prix de la protection et des avantages que toute société est censée procurer à ses membres. Elle était justiciable du roi, mais elle relevait aussi de la juridiction du seigneur; 'puand elle avait payé la taille au roi, elle avait encore à payer' la taille seigneuriale; la corrée seigneuriale ne la dispensait pas de la corvée royale. Pour la justice, par exemple. yue royons-nous? En même temps que les juridictions royales, bailliages, sénéchaussées, présidiaux, avaient attiré à elles, par l'extension des cas royaux et par prévention, la majorité des affaires, les juridictions seigneuriales s'étaient multipliées à l'infini. Chaque village, chaque hameau, chaque chàteau même avait la sienne. Ces justices champétres, ces basoches faméliques, ces procureurs, ces greffiers, ces notaires, ces arocats, ces sergents auxquels notre littérature, depuis les " chicanous du sire te Basché $^{1}$ " jusqu'à Brid'oison, a fait la place qui leur est due, il leur fallait vivre, il leur fallait faire entrer dans la eaisse du seigneur appauvri des amendes, des confiscations. Tout ce monde-là, à commencer par le juge botté, éperonné ${ }^{2}$ et en tenuc de chasse qui y préside, est ignorant et servile pour le seigneur autant quil est avide. Ses mangeries faisaient de larges brèches dans l'épargne des paysans ${ }^{3}$. Il manquait donc à ceux-ci le bienfait d'une justice indépendante, éclairée et peu coûteuse. Des agents si zélés, si intéressés respectaient-ils toujours les principes tutílaires qui n'admettaient la légitimité des tailles, des corvées, des banalités seigneuriales, que lor'squ'elles s'appuyaient

1. Rabelais, Pantagruel, $\mathrm{IV}, \mathrm{x} 1 \mathrm{I}-\mathrm{x} \mathrm{x}$.

2. Le seneschal de Rennes... tenait ses plaids botté et éperonné, la perche joignant sa chaire pour y attacher son épervier... Noec ou FAlL, II, 16.

3. Loyseat, Abus des justices de village. OEurres, 1678, in-fol. "Autant redouté qu'un procureur de seigneurie l'est des villageois. "F'retrère, Roman bourgeois, éd. Ed. Fournier, 2:6. 
sur un titre ou au moins sur la prescription ${ }^{1}$ ? Ne (herchaicnt-ils pas à perpétuer les usurpations et les abus que leurs maitres araient commis à la faveur des guerres “iviles et dont ils prétendaient bien faire des droits? Par exemple, nous avons vu que le droit de chasse était suspendu sur les terres ensemencées depuis le $l^{\text {er mars jus- }}$ qu après les vendanges. Nous ajouterons que les seigneurs ne pouraient tenir garenne ouverte ou jurée ${ }^{2}$ qu'en vertu d’une autorisation spéciale lu roi, et quà défaut de cetle autorisation les voisins pouraient exiger la destruction des lapins33. (Gui oserait affirmer pourtant que la fureur de la chasse. qui possédait la noblesse et qui sétait exercée sans frein pendant les troubles, sarrêtit toujours devant ces barrieres?

Quelle influence les conditions légales, économiques, fiscales que nous venons dïndiquer araient-elles sur les mœurs et l'esprit des classes rurales, envisagées dans leur ensemble, grands propriétaires fonciers, usufruitiers ì long: terme, simples manouvriers?

Un des conteurs les plus exquis du $\mathrm{xr}^{\mathrm{e}}$ siecle, celui qui a trouré, pour peindre les mours de la société rustique de cette époque, les couleurs les plus franches et les plus rraies, Noül du Fiil, a opposé les gentilshommes contemporains de Francois $l^{c_{r}}$, ses compagnons d'armes de Pavie, maniant la lance de onze pieds et demi, vivant sobrement, aux contemporains grêles et anémiés de Henrilll, assouplis à tous les raffinements du savoir-vivre, ayant la flatterie sur les lèvres et la trahison dans le ceur. La danse, le

1. BolcuEn 1'Arris, Code rural. D'apres la presque unanimitẻ des auteurs, le Iroit atux rurvées ne s'acquict que par titre, la possession sans titre ne suffit pas. Gicror, Traite des fiefs, p. 262.

2. Par opposition it la garenne close de murs.

3. Contune du bailliage de Meaux (1509), chap. xxvm, Boccun l'Arors,

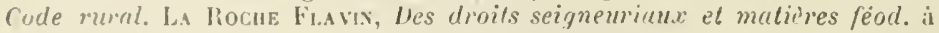
ha suite d'Améts not. din parlement de Toulouse. 1620. 
palet, la barre, la longue paume, la pelite guerre étaient les délassements de cette vigoureuse jeunesse. Les jours de fète, elle revêtail le pourpoint de satin, les chausses bouffantes de taffetas, le bonnet de relours à plume, la cape de drap ou de frise, les escarpins; les jours ordinaires elle se contentait diun costume plus simple. La résidence seigneuriale n'arait le plus sourent en ce tempslà qu'une salle d'apparat où l'on remarquait, pour toute lécoration, des cornes de cerf auxquelles élaient accrochés des chapeaux, des trompes de chasse, des laisses de chiens, puis un dressoir où était rangée toute la bibliothèque qui suffisait aux besoins intellectuels des habitants du château ${ }^{1}$, la Bible de Nicole Oresme, la Légende dorée, le Calendrier des bergers de Jean de Brie, les Quatre fils Aymon, Ogier. le Danois, Mélusine, le Roman de la Rose, enfin les râteliers pour les arcs, les arbalètes, les arquebuses, les rondelles, les épées. Les chiens y allongeaient sur la paille souvent renourelée leurs memlres harassés par la chasse. Deux chambres étaient réserrées aux étrangers. Le châtelain était sûr de trouver à cent lieues à la ronde l'hospitalité qu’il offrait lui-mème? .

Ce n'est pas au fond des provinces, ce n'est pas au sein de Ia noblesse qui virait sur ses terres que la décadence amenée dans les mours par les guerres civiles et l'influence corruptrice des Valois arait pu se faire sentir, et la simplicité dont Nö̈l du Fail, arec l'exagération naturelle au moraliste et au conteur, fait un mérite aux contemporains de François $I^{\text {er }}$, se retrourait, à peu de chose près, parmi les contemporains de Henri IV qui étaient restés fidèles au manoir patrimonial.

1. "... Comme notre nohlesse, quelques-uns réservẻe, est ignorante des honnes lettres... " Noel de FaIl, Contes d'Eutrapel, 1, $24 i$.

2. Contes et discours d'Eutrapel, chap. xxir. Sur l'ameublement et le luxe intérieur au $x^{2} 1^{e}$ siècle roy. Les Blasons domestiques (1539) clans le Recueil de .lontaiglon, VI. 
I part yuelques grands seigneurs, tels que Lesdiguières et Epernon, qui jouissaient dans leurs gouvernements d'une quasi soureraineté et s'entouraient d'un luxe prineier, la grande majorité les gentilshommes et des hénéficiers qui résidaient constamment ou une partie le l'amnée dams leurs terres, y menaient un train fort modeste. D'abord, nous latrons dit, beacoup parmi les premiers itaient paures of eeux qui araient 300 livres de rente $(1461 \mathrm{fr}$. 46) se piquaient de certaines recherehes'. Le petil nombre de ceux dont le revenu était phus élevé réservaient les prodigalités pour leurs séjours ì la ville ou à la cour. Tous ne possédaient pas une habitation aussi vaste et aussi bien entendue, des communs anssi complets que ceux dont ()livier de serres a tracé le plan et la distribution pour son ménuger modèle. Biti sur un rocher ou entouré de douves larges et profondes, flanqué de tours rondes ou (arrées qui ennoblissent l'architecture et inspirent le respect, ce chiteau idéal est précédé d'une basse-cour au milieu de laquelle se trouve une fontaine jaillissante, ou tout au moins un puits ou une citerne et qui est bordée de galeries couvertes. Sous ces galeries sourrent le cellier, le bùcher, divers magasins, l'entrée de la cave dont l'acer. doit être commode pour que les visites du chitelain ou de la chàtelaine y soient fréquentes. A u premier et an second étage sont placées la cuisine et ses dépendances, c'estit-dire le garde-manger, la boulangerie, le fournil, Ia lingerie. la buanderie, la vaissellerie, la laiterie, la fromagerie, puis une ou deux salles de réception, sept ou huit chambres approprićes aux diverses saisons et dont chacune est pourvue de garde-robes, de privés, de garde-menbles, le lingerie, de cabinets pour la conservation des titres et papiers. Sous le toit sétend pour les serviteurs une

1. "... Le "gentilhomme ayant atteint jusqu à ciuq cents livres de revenu... vislint trancher du grand... "Théalve d'agric., J, :2.. 
chambre spacieuse, d'où ils peurent surveiller la grande cour ct les écuries. A cûté sont les greniers et les fruitiers. Lne partie des combles est occupée par une terrasse et un belvédère (mirande); on n'y jouit pas seulement d'une belle vuc et de la promenade en plein air et à couvert, on s'en sert aussi pour faire sécher le linge et les fruits. Les granges, étables, écuries, bergeries, placées au couchant de l'habitation, en sont séparées par une grande cour de quinze ou vingt toises. Sur l'un des côtés de cette cour sélève la maison du métayer ou du fermier, qui peut ainsi roir entrer et sortir le bétail. On y remarque aussi un grand hangar qui sert à la fois de remise, d'abattoir et d'atelier. Près des abris destinés au bétail sont déposés les fumiers ${ }^{1}$. A peu de distance de la maison s'étend le jardin d'agrément, arec un labyrinthe au centre, le verger arec ses arbres fruitiers en quinconce, les terre-pleins pour les jeux de paume et de balle, les cibles pour l'arquebuse, l'arc et l'arbalète ${ }^{2}$, le rucher.

Toutes les résidences seigneuriales n'étaient pas pourrues les commodités et des agréments que nous venons d'énumérer. Le genre de vie de leurs propriétaires ne fásail presque aucune place à la représentation et à la vanité. Le chàtelain de Mesnil-au-Vast, le sire de Gouberville mangeait dans de la vaisselle d'étain. Olivier de Serres signale comme une dérogation à la simplicité primitive, l'habitude chez les gentilshommes possesseurs de 500 livres de rente de prendre les repas à part, dans une salle particulière, au lieu de les prendre comme jadis ì la cuisine arec les serviteurs ${ }^{3}$. Trois cheraux, six chiens courants. deux lévriers et six épagneuls, un autour ou un lanier

1. Théâtre d'agric., ler lieu, chap. v.

2. Rabelais, (jargantua, I, LY. - Gouberville, P. 295. Cf. la description d'une résidence seigneuriale donnée par l'ambassadeur rénitien Duodo dans Alberi, Append., p. 81.

3. Théátre d'agric.. I, 2?. 
pour lir volerie, voila tout ce qui composait, daus le dernicr quart du $\times{ }^{\circ} 1^{\circ}$ siècle, léquipage de chasse d’un gentilhomme campagnard'. Ce mème Couberville présidait aux travaux quill faisait exécuter, était en état de faire luimême tout ce quil commandait et greffait en personue ses arbires à fruits.

Cette compétence, rette surveillance, cette simplicité de vie, en rapprochant le propriétaire de ses tenanciers et de ses ourricrs, amenait untre eux une certaine analogie dhalitudes, une certaine familiaritó. L’aulorité du propriétaire n’en etait pas diminuée, sa sollicitude pour ses inférieurs en était accrue. Il aplanissait leurs différends et leur évitait les procis, les faisait soigner dans leurs maladies, poursuivait leur dégrèvement, quand ils avaient été trop imposés, veillait ì l'accomplissement de leurs devoirs religieux ${ }^{2}$. Il ne se permettait les roies de fait qu'à l'égard de ceux qui étaient d'un ordre tout a fait subalterne ${ }^{3}$. Les ripports des grands propriétaires et de ceux qui étaient placés sous leur dépendance paraissent aroir dé excellents dans les trois premiers quarts du $x^{2} y^{e}$ siècle".

Les guerres civiles les altérèrent assez profondément. Bouleversés dans leur's labitudes sédentaires et laborieuses, désespérés de voir avorter sans cesse leurs elforts pour les reprendre, ruinés, errants, deremus de victimes pillards et brigands ì leur tour, les paysans rapportèrent dans la vie régulière le goout du désouvrement et de la licence ${ }^{5}$, l'amertume contre les classes dirigeantes qüils

1. Les plaisirs du gentilhomme chcompestre, par P. ‥ R. [Xicolas Rapis, (iiii).

$\therefore$ " te donnai à nos serviteurs pour aller demain à confesse, parce qu"il estrit nu jubilé, 5 sols. " Golbervilte, p. 613.

3. lliil.

4. Ilirl et de linbe. Les fumilles el lu socielé en France... 1. 212, 11, 2.

5. "Puur ce un il fische beaucoup a aucuns de se remeltre i travaller en leur mesinge alries avoir gousté la licence de la guerre... et aiment mircux voler el roher que retourner en leur preniere subjection. "Dia-

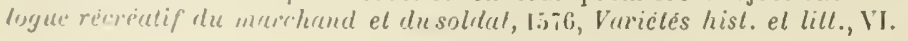


enreloppaient dans une animosité trop justifiée par une partie d'entre elles. Ce chingement n'a pas échappé, on l'a ru, aux ambassadeurs rénitiens, qui cependant n'eurent que des rapports passagers avec la population rurale. II pourait échapper encore moins à Olivier de Serres, qui vivait en contact quotidien avec elle. Olivier de Serres est sans illusion sur ceux qu'il emploie. Ce n'est pas qu’il ressente à leur égard de l'aigreur ou du dédain. Ce n'est pas un maurais maitre; il fait, par exemple, un devoir aux propriétaires de donner des soins aux serviteur's malades, mais e'est un maitre que l'expérience a rendu méfiant. II les sait peu consciencieux et intéressés, et il prend ses précautions contre leurs défauts. Il recommande de limiter autant que possible le nombre des ouvriers à l'année, sauf à embaucher, s'il le faut, des hommes de journée, de ne pas faire attendre aux mercenaires leurs salaires, mais de ue pas leur avancer des acomptes, à moins de maladie ou d'autre cause légitime, de leur devoir tonjours quelque chose, afin de les foreer à revenir, de les surveiller de près, d'affecter à leur égard une grandle fermeté, de ne pas aller toutelois jusqu'à les frapper, à moins qu'il ne s'agisse de serviteurs d'un ordre infime.

Malgré la préférence d'Olivier de Serres pour les journaliers, les ouvrier's qualifiés étaient loués à l'année, dans des assemblées ou loueries, a partir de la Saint-Jean, de la Saint-Michel, de la Saint-Martin, de la Toussaint, de Noël, de Pàques, etc., et payés partie en nature, partie en argent ${ }^{\prime}$. Le patron payait au mercenaire le vin de marché. Ces contrats n'étaient pas faits par écrit, mais devant témoins ${ }^{2}$. On en troure un assez grand nombre dans le livre de raison d'Olivier de Serres et surtout dans celui du sire de Gouberville. Au mors de janvier $10 \% 61$ (n. s.), celui-

1. Thedtre d'agric., I, 39.

2. Gocberville, passim. 
('i embituche un liboureur pour un an it raison de 8 livres 30 fr. 32) tout compris ${ }^{1}$. Au mois de juillet de la mène anmee, il loue un cherrier pour un an, moyennant 60 s. (11 l\%. 36) et une paire de souliers; il lui fait espérer davantage sil est content de lıi ${ }^{2}$. Le 23 mars 160?, Olivier de Serres engage un meunier pour 3 liv. $10 \mathrm{~s}$. (9 fr. 4't) par mois. Le 21 septembre de la même année, il loue pour un all, à partir de la Saint-Michel, mojennant $10 ̈$ livres en argent (40 fl. 4.i), vingt pans de drap, me chemise, un chapeau et la chaussure, un bouvier qui devait être en mème tumps une sorte de factotum. Le 2 mai $161 \mathrm{i}$, il arrête un patre pour un an; il lui promel dix-huit pans. de drap, un chapean, une chemise, des souliers et 6 lives en argent $(11 \mathrm{fm}, 18)^{3}$. Aux travailleurs salariés renaient se joindre les corréables. Les femmes partageaient arec les hommes les plus rudes travaux : elles sciaient les blés. battaient en grange *

Comme tout ce qui touche ì la vie rurale. les habitations des cultivateurs aisés et des simples paysans ont peu change. C'est parmi les premiers qu il faut ranger le propriétaire de la petite maison que Philibert Hegemon nous fait aperceroir dans son poème de La Colombière avec le four, l'étable, le pressoir, la grange. le colombier yui en dépendent. C'est aussi dans la demeure d'un rustique à son aise que nous introduit Nö̈l du Fail. Il nous fait traverser, pour y entrer, une cour close de haies d'églantiers et d'aubépines. Au milieu de cette cour le tas de fumier et sur les côtés les baitiments d'exploitation. A la maison est altenant un appentis oì sont rangés les charrettes, les essieux, les limons, les timons. Les nurrs et le sol de l'habitation sont en torchis, le plafond est

1. P. $633^{\mathbf{t}}$.

2. P. C.3.

3. Livre de raison d"(0l. de Serres, P. P. Vaschalde, 1856, 8.

4. GOCBFHVHLL, 2!), :!). 
en charpente apparente. La courerture est en chaume ${ }^{1}$.

Une fois entré, on était sédlit en royant briller au ritelier, dans un ordre parlait, les instruments aratoires, les outils et les harnais. La nappe était encore mise comme pour proclamer une hospitalité toujours prête. Les restes du dìer, du pain et du lard, anmonçaient que cette hospitalité était aussi frugale qu'empressée. Le mobilier se composait d'un colfre renfermant les hardes, conservées dans la marjolaine et notamment le demi-ceint de la maitresse de la maison, et au-dessus une raisselle grossière, d'un lit contigu au foyer, où l'on ne montait pas sans peine et qui fermait par des rantaux, ce qui le faisait ressembler à un buffet, d'escabeanx et de chaises de bois, mal équarries mais bien assemblées ${ }^{2}$.

Sans doute ce tableau a été tracé par un littérateur, c'està-dire par un auteur qui avait le droit d'altérer la vérité en rue de l'effet qu'il voulait produire. Il ne laudrait pas pourtant se hàter d'en attribuer certains traits à la fantaisie. Si, par exemple, I'on s'étonnait qu'un cultivateur assez riche pour posséder un cheptel aussi nombreux que le supposent les bâtiments et le matériel mentionnés par Nö̈l du Fail, se contentit d'une habitation de torchis et de chaume, d'un mobilier aussi sommaire, d'une vaisselle grossière, nous apprendrons à nos lecteurs que ce ne ful pas arant 1620 qu'à Paris même on commença à bâtir arec de la chaux, du sable et de la pierre dure, que toutes les maisons construites antérieurement dans la capitale étaient faites, comme s'exprime le document administratif qui établit ce fait curieux " de boue et de crachat ${ }^{3}$ ». Nous

1. Noel du FaIL, Baliverneries, I, chap. IV.

2. Itid.

3. "Chacun sait que toutes les anciennes maisons de Paris sont la plupart basties de boue et de crachat, que l'on a commencé á batir depuis trente ans avec chaux et sable et pierre dure. "Le vêritable advis présenté au roi et ì la reine régente le 27 juillet 1651 , par le Sr de Marsay. 
furons remiurquer que ce nélait pas seulement, en dépit de Malherbe, la cabsune du paure qui itait couverte de "himume, mais amssi. jusqu ì une époque assez tardive, les re-idences de la bourgeoisie; nous rappetlerons la vaisselle d'itain oin mangrait Gilles de fiouberville qui etait pourtant un tout autre personnage que le propriétidire de lit maison derorite par Noël du Frail.

Au-dessous de l'un et de l'autre se plaçaient les réritables paysans, dont les cliaumières peurent ètre ramenees it trois lypes principanx. Le prenter consiste dans une maison construite en gros blocs de granit et perée de petites ourertures. In rez-de-chaussice tries bis sert de cellier, de resserre, de poulaitler et the porcheric. Il 11 y a yu'me piece d'habitation, elle est contigüi à celle du rezde-chaussie mais surélerée d'un ou deux mètres et acees-ible par un escalier. Elle est plafonnée de grosses poutreset de solires, surmontéc d'un grenier et pourve linne cheminee. Le sol est en terre battue recourerte de sable granitique et d'argile. On ne sétonne pas de la prélominance du granit quand on sait que ce type appartient an .lorvin. Là où la nature ne fournil pas de matérianx aussi solides, là où manque l'art de les exploiter économiquement, le paysan cherche presque sous terre un asile contre les intempéries; ce n'est plus une maison quï habite, c'est presque une tanière. En Aurergne, dans le Velay, dans la parlic septentrionale de l'ancienne Aquitine, res habitations souterraines sont couvertes d'une sorte de ucmulus en terre et en pierres, soutenu par un pilier central et des poutres rayonnantes et asses semblable anx rhumpignons qui agrementent nos jardins modernes. Cu mème aspect écrase se retrouve dans certianes chamnièes le la Brelagne et du Bocage, dont le sol est inférieur au sol naturel et dont le toit de chaume descend prespue jusqu ii terre. C'ent un type que tout le monde comnait. On 
est pent-ètre plus familiarisé encore arec la chaumière à pans de bois hourdés en terre mèlée de paille, ì courerture de chaume et de birdeaux dont l'on rencontre des échantillons dans une partic du l'erehe et de la basse Normandie. Tandis que, dans toutes ces régions, le paysan se clôt et se terre, en Languedoc, en Guyenne, en Provence surtout, la maisonnette rustique sourre au soleil et à la lumière, se décore d’escaliers extérieurs, de balcons, dappentis pour travailler en plein air ${ }^{1}$.

Pour juger les habilations rurales de la fin du xrre siècle et du commencement du xv" ${ }^{e}$, il faut oublier les exigenees que la diffusion du bien-être a répandues dans toutes les classes. Sinon la demeure du gentilhomme campagnard n échapperait pas elle-même à la sévérité de notre délicatesse moderne, et nous plaindrions nos ancêtres d'une absence de comfort, dont l'idée leur était aussi étrangère que le mot et dont ils ne sentaient nullement la priration. Si humbles que fussent les demeures de nos paysans, si délabrées que la guerre les eǹt laissées, l'abbŕ de Marolles prétendait que leurs habitants étaient mieux logés que certains seigneurs de Pologne et de Suède et qu'il n y en avait pas parmi elles qui ne témoignàt de la préoccupation d'un certain bien-ètre ${ }^{2}$.

L'inventaire du mobilier qui les garnissait n'est pas long à faire, et ce mobilier n'était pas très diflérent de celui dont Noël du Fail nous a donné la description. On y roit toujours figurer l'armoire, qui est le meuble principal, parce quil renferme tout ce que le paysan a de précieux, son linge, ses papiers, ses économies; le lit garni de sa paillasse, de ses oreillers de balle d'aroine, de ses deux draps (linceulx) et de sa couverture de laine; la huche au pain. Plus d'une pièce de ce mobilier provenait du chàteau

1. Viollet-le-Duc, Dict. d'urchitecture, vo Maison.

2. Cité par Babeau, Vie murale, p. 18. 
ou de labbaye du voisinage, qui sen était délait au prolit de la chaumière, pour lis remplacer par un meuble plus moderne et plus a la mode '. La paurreté de ee mobilier ne lavait pas tonjour's sinvé : les maraudeurs, en vidant les tirnirs, avaient parlois aussi brisé ou briló les menbles?

si le mobilied de nos paysans, plus complet et plus commode peut-itre que celui de leurs ancildes, lui est bien inférieur en solidité et en beanté, leur régime alimentaire est incontestablement meilleur.

Firomage, poyre et pain

Est repiss de vilain.

dit un proverbe du $x^{2} r^{\circ}$ siecle ${ }^{3}$. Si l'on ajoute à ces aliments le lait frais ou caillé (mathon), le heurre, les fruits, loignon, lis eivelte, l'échalote dont ils frottaient leur pain d'orge et d'aroine, la sonpe et le lard, on aura tout l'ordinaire les paysans. L'eau claire élait leur boisson habituelle: Qu'emprte dans sa besace ce faucheur en allant au travail? tout simplement du pain et des poires cuites. Il en fera son premicr repas. A midi, sa femme lui apportera du fromage et du lard et lui fera bouillir une soupe, pendant quả l'orée du bois il goùteria un peu de fraicheur et de repos ". Quand, apris leur journée, les vignerons

1. Babent, Opus laul., i6, n. 2. Viotaft-le-Duc, Dicl. du mobilier, ro Amoire, Bahnt.

2. $\quad$. . . . . . . . Les villages champestres

Sans portes et plancher, sans meubles el fenestres.

(Alвtgxí, Les Tragiques.)

3. Prorerbes frans., p. p. Le Rorx ne Lixcr. A l'iew of Fraunce (1598), par D.lluwisox, secrétaire de l'ambassadeur d'Angleterre, trad. p. Emeniqu, 1). 15 is.

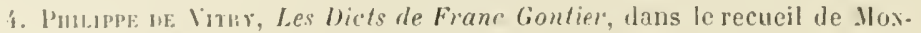

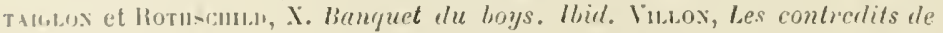
Frane Gontier daus le Grond festument, èl. Longuon... "Les glaneurs, esquels faull de la fouare, les batteurs qui ne laissent ail, oignon ne eschalote es jardins. "Haminas, l'antagruel, III, 11.

5. Gitcane1, Les plansirs des chumps, 1:is:3. 
rentrent à la ferme, on leur sert ì souper un plat de choux pour deux, du pain à discrétion et fuel,puefois, à titre de douceur, un morceau de fromage. Bien sourent, il est vrai all cours ou à la fin d'un travail fatigant, le patron ajoutait un régal à cette maigrre pitance, lantù de la bière, tautôt un oison ${ }^{1}$.

Les reillées étaient remplies par des travaux domestiques. Le mari, le dos au fen, teillait du chanvre ou raccontrait ses boltes. La femme filait. Le reste de la famille raccommodait les instruments de travail. A certains jours, on se réunissait entre voisins et voisines dans des fileries, des escraignes et des braries ${ }^{2}$ égayées de commérages, de récits légendaires et de contes gaillards ${ }^{3}$.

Les réunions en plein air élaient fréquentes aussi. Elles étaient consacrées à la danse et à des jeux d'adresse et de force, tels que le bibelol, la courteboule, la lille, la choule ou soule : La danse élait le délassement habituel du travail. Un poète du $\mathrm{xv}^{\mathrm{e}}$ siècle nous montre les "ousterons gaillards dansant au bout du champ" " d'où ils riennent

1. Pierrot voyant en biens foisonnante l'année, Pour rire, choisira quelque bonne journce El à l'aoust dedie fera tuer l'oison Festiant ses chartiers ct toute sa maison.

Ibil. lonberville. p. 360. Chatelier, Itist. des classes agric. en Bretagne. -icener, Paysans Franc-Comtois des environs de Pontarlier au xinte s. Acad. de Besançon, 1887.

2. Parce qu'on s'y donnait rendez-vous pour broyer du chanvre. C'était aussi à tiller le chanvre que se passaient les ecraignes et de li leur nom.

3. Noel du Fall. Propos rustiques, 40. Sebillot, Contes des paysans et des pécheurs.

4. La bille est peut-être la même chose que la soule.

5. Gavenet, Ubisupra. Il est fàcheux que le mot ousteron ne nous soit pas resté, non plus que celui d'aouteur, dont se sert Gotbenville et qui a la mème origine. Dans les vers suivants on entend résonner la mesure marquee par le talon vigoureux des rustiques danseurs :

Puis dit Gontier : Or sus a ma requète,

Souffle, Riflart, une danse bieu priso

Fin altendant que la nappe soit mise

Clacun fit feu de tripper é saillir.

Chacuu fit feu de frapper de la bolte, 
denlever la récolte. Comme ses chansons, charue province avait sa danse. accompagnée d'un instrument particulier. En Poitou, on dansait au son de lit cornemuse; la volte provençale était ryllumíc par les timbales; le haubois, le violon et les tambourins composaient l'orchestre des bals bourguignons ef champenois; les Bretonnes avaient rendu populares les passe-pied et les branles ${ }^{1}$. Les jeux opposalient dans descamps contraires village à village, et, dans le mème village, gens mariés à célibataires, surexcititient les rivalités et les amours-propres, et, par suite de la folle ardeur des adversiares, entrainaient des accidents, auxquels la soule donnait lieu plus que tous les autres. Ils élaient accompagnés de nombreuses libations ${ }^{2}$. Tout élait prétexte a réjouissances, les fètes religieuses tout d'aljord, mais aussi les travaux des champs, les chasses, les érénements de famille. On connait les frux de la Saint-Jean, on connaît moins peut-ètre les combints entre filles et garçons le jour des Saints-Innocents, les momeries de l'Assomption où l'on promenait de maison en maison un objet quelconque 'mreloppé de linges qu’il s'agissait de deviner et qui ressemblait à un marnot, à un mome enmaillolé, les dictiers de NoëI, cantiques populaires que les enfants allaipnt, le 2.; décembre au soir, chanter de porte en porte pour recueillir quelques pièces de monnaie.

P'armi les distractions des paysans la lecture, on le devine, tenait encore moins de place que parmi celles du chàtelain. Non qü̈ls fussent absolument illettrés. En Provence, du moins, ceux qui étaient un peu aisés, étaient

Chacun fit feu de sa dame assaillir,

Chacun fit feu de mener sa mignolte.

Le lianguel des hoys, $\mathrm{xv}^{\mathrm{e}}$ s., dans le recueil de Moxtaigon el Rotuscm.b, $x$. Sur le gout et le talent de la danse daus les basses classes, voy. DaL. I.I.⿴囗т), Op. laurl., p. 183.

1. Mrimoires de Mn'gurrle de Valois (année 1569/, coll. Michaud.

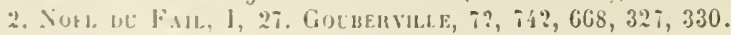


capables de tenir leur comptabilitín ; mais il suffit de regarder autour de soi pour faire la différence entre linstruction qui aide aux premiers besoins de la vie et celle qui l'ennoblit et la charme. La littérature qui alimentait l'imagination populaire, légendes, chansons, était une littérature orale. Il arrivait pourlant, par suite d'une circonstance particulière, que certaines œurres et même des œurres écrites pour les letlrés, pénétraient dans un milieu habituellement fermé à la vie intellectuelle. Cette circonstance, cétait le plus souvent le zèle d'un maître d'école ou d'un propriétaire roisin, qui se faisait un plaisir' de réunir, les jours de fête, les villageois, pour leur lire des lirres consacrés par une éclatante popularité, comme le Calendrier des bergers ${ }^{2}$, les Fables d'Esope, le Roman de la Rose ${ }^{3}$, le Livre de Matheolus, les Faiz, dictés et ballades de $\mathbf{1}^{\mathrm{e}}$ Alain Chartier, les mystères d'Arnoul et de Simon Greban, les œurres de Guillaume Crétin, les Vigiles du roi Charles VII de Martial d'Aurergne". Le succès de ces livres dans les campagnes restait d'ailleurs fort loin de celui des almanachs. L'almanach, c'était l'encyclopédic des ignorants et des simples. Plus simples et plus ignorants que tous, les paysans y trouvaient les lumières dont s'éclairait leur empirisme, les prédictions qui remédiaient à leur's yeux à l'incertitude des lois de la nature, les échappées sur l'idéal dont leur àme rudimentaire avait besoin. Et ce n'était pas seulement les paysans qui les prenaient pour guides, le sire de Gouberville tenait compte pour l'époque de ses travaux des conseils de Nostradamus. Ouvrons le plus répandu de ces almanaclis au commencement du xvil ${ }^{e}$ siècle, le Grand calendrier et

1. Сu. DE Rıввe, Les familles et la société..., p. 12.

2. Composé par Jeinax de Brie en 1379.

3. Sous la forme rajeunie que lui avait donnée Marot. G. PArIs, La litterature francaise au moyen age, 2e éd. p. 17?.

4. Noel du Fail, Propos rustiques, I, I3. 
compust des bergars, composé par lo berger de la GrandHunlugne publié pour la premiere fois en 1602 , et dins les éditions postérieures dlupuel on retronve le Calendrier des brigers de Jean de Brie ${ }^{2}$. Nous y trourerons des motions sur la commaissance des temps, des prieres, un eximen de conscience, des principes d'anatomie, des conseils d'hygiène, des recettes médicales, de l’astrologoie.

Ce n'est pas seulement, on le sait, par la foi aux almanaclıs que se manifestait la crédulité des campagnes, mais cncore par les superstitions qui les peuplaient de fées et de fuitunds, personnages capricieux, tour ì tour malfaisants ou firorables, qui jetaient des sorts stir les inimaux et se haissaient désarmer par des présents, personnifications des phénomènes et des forees de la nature, dont les hommes qu'elle absorbe, intimide et séduit, n'ont jamais pu se passer ${ }^{3}$.

Pent-ètre aurions-nous dù commencer ce chapitre sur léconomie rurale de la France par l'étude de lagriculture elle-même, de sés méthodes, de ses produits, de sil place dans la richesse nationale, mais, nous l'arouons, les hommes, leur vie matérielle et morale nons ont attiré tout Jabord et nous arons gandé pour la fin l'art qui les faisait virre. On pense bien. d'ailleurs, que, sur retle partie de notre sujet, nous ne powrons qü̈ndiquer les principales différences qui distinguent l'éporque de Ilenri IV et la nôtre.

Le systime de culture unirersellement suivi itait

1. Voy. aussi la Pronosticulion des laloureurs, 15il, dans le recueil de Montalglox el de liomiscinlo, II.

2. La premicre idition sortit des presses de Pierre Garnier, libraire a Truyes, rui ne cessa de le réimprimer dans le format in- $\mathfrak{i}^{\circ}$. L'exemplaire rue nous avons eu sous les yeux et qui date de 160? in - 40 ), porte tontefois le nom de Nic. lioxans et indique Paris comme lieu d'impression. Viny. Vatice sur Jehan de lirie, par P.utu LAcnorx, en tête du Bon Berges.

3. Voy. notamment Inacur, Les Fées aumoyen âge. 
l'assolement triennal ou biemnal. L'assolement triennal, on le sait, divise le domaine en trois parties : la première est semée en hiver, la seconde au printemps, la troisième est seulement labourée et reste en jachère. Des deux parties entre lesquelles le domaine se trouve dirisé par l'assolement biennal, l'une reçoit les ensemencements d'hirer et de printemps, l'autre est laissée en guérets. Deux années et une année sur trois, dans la première rotation, une année sur deux dans la seconde, charque sole est donc ensemencée ou livrée au repos ${ }^{1}$. Ce n'est que de nos jours que l'agronomie, éclairée par la connaissance des terrains et servie par les engrais chimiques, a su, en faisant succéder sur le même sol les plantes à racines pirotantes (luzerne, trèfle, etc.), et les plantes à racines eherelues (blés, orge. aroine), substituer le régime de l'alternance au régime de la jachère ${ }^{2}$. Encore faut-il ajouter yue le nouveau système n'a pas triomphé partout dans notre pays et que l'ancien n'a pas perdu tous ses défenseurs ${ }^{3}$.

Les céréales, on le voit, formaient la base de la rotation en usage au temps de Henri IV. Elles étaient, en effet, le produit le plus important de l'agriculture française. Comme elles fournissaient l'aliment principal de la classe inférieure dans notre pays, elles furent toujours l'objet particulier de la faveur et des encouragements du pouvoir. Cette fareur arat même conduit à certaines exagérations : pour ne pas laisser diminuer, pour augmenter la production des céréales, on arait fait arracher des vignobles ${ }^{4}$, on s'était livré à des défrichements excessifs.

1. Debisle, Études sur la condition des classes agrioules, 297-298, 304-319. Bastiat, Considérations sur le métayage dans Journal ces économ., 1816. De Chatelier, L'agriculture et les classes agric., 215-216. Roscuer, Economie politique rurcle, trad. par Vogen, préface par L. PAssy, 8i-Ss.

2. Rozrer, Contrs d'agriculture. L. de LA vergate, Economie rurale de la France.

3. Bastiat, loc. cit. L. de Lavergae, Op. lauel.

4. Délibération des états de Bourgogne de la fin du xvi siecle demandant l'arrachage des vignes qui ont envahi les plaines et qui réduisent Ie 
Connu en Normandie dès 1:60 1 , le sarrasin arait fait, trente ans apris, son apparition en Bretagne et avait été pour la population nécessiteuse de cette province une grande ressonrce?. Quelquefois la récolte des céréales était assez. abondante pour permeltre l'exportation; d'autres années, au contraire ${ }^{3}$, elle ne suffisait pas à la consommation. Dans une lettre circulaire ${ }^{4}$ écrite le $f^{\text {er }}$ octobre $1: 39.3$, au lendemain d'une récolte très inférieure aux besoins, llenri IV recommande aux autorités municipales d'attirer le blé étranger en rassurant les marchands qui pouvaient craindre la saisie et en leur faisant espérer qüll sera taxé à un prix rémunérateur. Les provinces les plus fertiles en céréales étaient la Touraine, le Pays Messin, le Quercy, la Guyenue, le Languedoc, la Provence, la Picardic, le Soissonnais, la Brie, le Bassigny, la Normandie, mais surtout la Beauce quion appelait le grenier de la France .

La vigne renait, dans les richesses naturelles de la France, immédiatement après les céréales. La viticulture sétait propagée un peu partout, et ce n'est pas sans étonnement qu'on la rencontre dans des latitudes qui nous paraissent aujourd'hui lui être tout à fait rebelles. Cette dispersion s'était en partie produite par suite de cette idée que chaque province et mème chaque circonscription plus petite constituait un monde économique fermé, qui devait trouver toutes ses ressources en lui-mème. Toulefois on remarque, dès l'époque de Henri IV, la préoccu-

terrain propre à la culture des céréales. La proposition fut rejetće comme attentatoire à la liberti des propriétaires. Congrès scientifique de France, XXV'e session, p. 388.

1. DeLlsise, op. laUUl.

2. "Car, d la vérité, sans ce grain qui nous est venu depuis soixante ans. les gens pauvres de ce paysauroient beaucoup i souffrir, combien qüil amairrisse fort la terre. " Noel de Fatl, Contes... d'Eutrapel, xxix.

3. Jielation de Badloer (1603-1605), I, 8i.

4. Lellires miss. W. i13.

5. Causes de l'extrème cherté. Ubi supru, p. Iï. I'mltppas, II, 336.

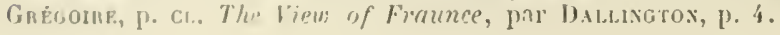


pation d'approprier les cultures aux terrains et anx climats et de ne pas persister dans celles qui sont désarouées par la nature. C'est ainsi que la viticulture avait été abandonnée en Normandie, en Picardie, en Bretagne ${ }^{1}$. Si elle occupait une zone beaucoup trop étendue encore, elle le devait non seulement à la considération que nous avons dite, mais encore à ce qu'elle exigeait moins de capital que la culture des céréales et offrait au petit propriétaire un travail plus rémunérateur ${ }^{2}$. Il résultait de son extension que le rin était abondant et peu coûteux et que l'usage en était assez répandu pour que l'auteur du Discours sur' les causes de l'extréme cherté ait cru pouvoir écrire en 1 \$̈86 que tout le monde en buvait, assertion dont il faut préciser la véritable portée en ajoutant que ce n’était pas pour tout le monde une habitude, que les paysans ni même les ouvriers n'en buvaient qu'exceptionnellement.

L'énumération des crus en renom fera connaître ce qu'on pourrait appeler les migrations de la viticulture ainsi que les variations du goùt. Dans les vins rouges ou clairets on distingue trois groupes: celui de l'Orléanais, celui du Vivarais (Montélimar, Villenenve-de-Berg, Tournon) et celui de la Bourgogne (Sens, Auxerre, Tomnerre, Joigny. Chablis, Seurre ef Beaune). A ces trois groupes il faut joindre quelques crus isolés : ceux de Canteperdrix ${ }^{3}$ et de Bagnols (Gard), de Ris (Ris-Orangis, Seine-et-Oise), d'Ay (Marne), d'Arbois (Jura), de La Rochelle, de Castelnau et de Moussengirard , et le cépage de Picardent, cultivé encore aujourd'hui sur les territoires de Marseillan, de Florensac et de Pomerols dans l'Hérault ${ }^{5}$. Parmi les vins

1. Théatre d'agric., I.

2. A. Youxg, Voyages en France, IJ, 189.

3. Commune de Beaucaire, Gard.

4. Legraxd v'Arssy, Iistoire de la vie privée des Francais, éd. de Roquefort, III, 20.

5. Moullefert, Les vignobles ei les vins. 
hlanes, les plus recherchés élatient ceux đ'Orléans, qu'on appreciait meore plus que ses vins rouges, cenx de l'Imis, du Vivanas (Juyeuse, Lalrgentiere, Montréal, Curnas'). de Beame, de Lembras (Dordogne, canton de Bergerac), ceux du Laonnais (Coucy qui était un vignoble royal, Beaurieux, Parguan, Jumigny, Cuissy), cenx de l'Injou, de Lourbu en Languedoc, de IIontréal, de Gaillac, de Rabasteins, de Nórac, de Graves, les muscats et blinquefles de Frontignan et de Mireval (Hérault). Sans égaler ceux que nous venons de nommer, les plants anjourdhui obseurs ou discrédités d'Argenteuil, de Vanves, de Meudon, de Montmartre et d'autres du terroir sablonneux des environs de Paris, passalent pour donner un vin tries sain ${ }^{3}$.

Après le vin, la boisson la plus recherchée par nos ancètres était le cidle et le poiré. La bière ne renait. quapris et fon n’en buvait que dans les pays privés de pommes et de poires, tels que certains endroits de la Picardie. L'hỵdromel remplaçait le vin dans les pays où manquait la vigne et oì le miel ibondait, du côté des Ardennes, par exemple.

Nous ne ferons (qu énumérer, avant d'ilriver anx prairies et ì l'élevage, certaines cultures peu répandues. Lil canne it sucre était cultivée en Provence. L'ambassadeur d'Angleterre Carew nous apprend que le roi en fit planter dans les

1. Ardeche, arrondissement de Tournon, canton Saiut-peray.

2. P'LeunY, Les vins du Laonnois. Bullclin de la Saciété académique de Luan, XX 1874).

3. Thérilre d'agrie., I, 209-260. Boucuet, Serées, I et II, 2j0. Étexxe et

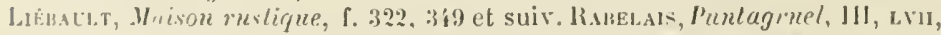

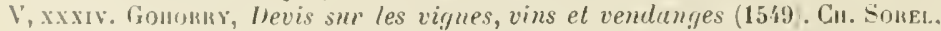
Les visions admirubles du pulerin du l'arnasse, 1635. Consat, Crulilies hustily gobled up in five monlhs travels in Frunce, 1611. Loxpon. Grotoror, Les rins lilanes d'Anjuz dans Bullelin de la Soc. indusl. d'Anjou (1860). P'Hs,ilpsis, II. 330\%.

4. Voy. sur la pomolngie normande les détails uinutieux donnés par

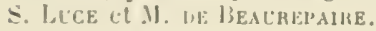


iles d'Hyères, étendant ainsi les essais qui avaient déjà été faits sur le continent, aux environs de la ville elle-mème ${ }^{1}$. Mais cette culture resta aussi limitée que celle du riz, que nous tirions presque entièrement de l'étranger et que l'on achetait très cher et à la livre, comme le sucre ${ }^{2}$. Le pastel ne venait bien que dans le Lauraguais ${ }^{3}$. Le Dauphiné fournissait les meilleures châtaignes. On trourait le safran en Aurergne et dans l'Albigeois". Le sel était assez abondant pour former l'un des principaux articles de nos exportations. On en recucillait en Saintonge, en Lorraine, en Bourgogne, en Provence, en Languedoc, en Guyenne; celui de Saintonge était le meilleur et le plus facile à conserver $^{\overrightarrow{5}}$. On récoltait en Normandie, en Bretagne et dans une partie de la Picardie du lin et du chanvre tle très bonne qualité ${ }^{6}$; la culture en était assez étendue pour donner lieu à un commerce avec l'étranger.

L'importance des prairies dans l'économie rurale arait été parfaitement comprise par Olivier de Serres. "Sur l'herbage, écrit-il, comme sur un ferme fondement toute l'agriculture s'appuie. Aussi voit-on que, moyennant le bétail, tout abonde en un lien, tant par le denier liquide qui sans attente en sort, que par les fumiers causans abondance de toute sorte de fruits. "En l'absence de toute circonstance de nature à modifier cette répartition, la part des bois et des prairies dans le domaine rural devait, d'après lui, être des deux tiers. En réalité, les pâlurages

1. Birch. Dexis, Description géory'. el hist. de l'Amérique septentrionale, 167:, I, 17. Dexis et Chassixit. IIyeres ancien el mod., 400-401.

$\therefore$ Recueil de ce qui se passe duns l'assemblee du commerce... dans les Documents inéd.

3. Théatre d'agric., II, 428. Ріва c, Les plaisirs de la vie rustique. OEuvies, éd. Courbé, p. 130.

4. Pibrac, Ubi supra. Pilllippson, II, 337.

5. Causes de l'extrême cherté, 153. Reg. journaux de LEsToile, nouvelle édit. (1574), I, 46.

6. Econ. roy., VI, 319. Discours préliminaire par l'abbé Texier en tête de la section Agriculture de l'Encyctopédie méth. 
élaient loin doccuper la place que le savant agronome leur issignait. Des droits de lépaissance, dont les uns étaient réservés aux habitants des communautés, aux communiers (pitures vices ou grasses), dont les autres étaient acquis à tout le monde (vaine pilure), suppléaient à l̈insuffisance des pacages dans lia propriété privée. Le droit de vaine pâture sexerȩait sur les prés après la première coupe et mème après le regain. En général, les propriétaires pouvaient s’y soustraire en se clòturant; était le principe dans les pays de droit écrit et mème ailleurs. Certaines coutumes pourtant imposaient au propriétaire l'obligation de subir la vaine pàture. Les paroisses dont les territoires étaient contigus, jouissaient, sous le nom d'entrecours, du droit de faire pàturer leur bétail sur leurs communaux respectifs ${ }^{2}$.

Ces conmunam avaient été, dans le cours des siècles et surtout pendant les guerres civiles, usurpés par lẹs seigneur's. Les paroisses grevées les avaient elles-mèmes aliénés à vil prix. On a vil qu'un édit rendu en 1600, au mois de mars, leur accorda, pendant quatre ans, la faculté de les racheter au prix coutant ${ }^{2}$.

La théorie des prairies artificielles élait connue. Dès 13̋89, Ch. Estienne et Jean Liébault en avaient indiqué la méthode ${ }^{3}$, mais les propriétaires avaient peu profité de la lẹon. La pratique ne s'en répandit guère davantage après quOlivier de Serres ent tracé la distinction des prés naturels et des prairies artificielles, en même temps quil décrivait l'irrigation en lomme qui en a la longue expé-

1. Coutume du bailliage de Sens (1506), titre xv; du bailliage d'Auxerre, de l'évèché et comté de Verdun, de Bordeaux (1520), art. cx, de la baronnie de Linieres en Berry (1539), de Vitry-le-François (1509), chap. xr. LoIsel, Insl. coul., nos 2'5, 24i. Boucien b'Angis, Code rural. Boncfir, Les inconvénients des droils féodaux, p. 9. Mentrs, Répertoire, vo Vaine palure. Rrviene, IIist. des biens communaux en France, 1856. Gisssox, Communaux et communantés dans l'anc. droit frang. Revue hist. du droit, 1891.

2. Frenixville, Trailé de jurisp. sur l'orig. et le gouv. des communanx, p. i-8, 3\%. 11'. Cahier du tiers état aux états de Blois, 15i6. Рісот, III, 389.

3. L'agricullure el maison rustique, 2:99. 
rience'. En admettant, sur la foi de Grégoire? qui n’en donne pas la preuve, que le roi ait créé, d'après les préceptes du grand agronome, des prairies artificielles dans plusieurs de ses domaines, il n'en résulterait pas que cet exemple ait trouvé beaucoup d'imitateurs. La propagation systématique des prairies artificielles n'a eu lieu qu'au xín siècle et, même alor's, elle rencontra une telle résistance qu'il fallut, pour la vaincre, accorder aux propriétaires des privilèges, des exemptions de dimes, par exemple ${ }^{3}$.

En dépit des avantages dont la vaine pâture, les communaux et le parcours faisaient jouir les petits éleveurs, la production du bétail était peu développée et fort inférieure déjà, par exemple, à celle de l'Angleterre. L'élevage, du moins, arait le mérite de soumettre aussi peu que possible le bétail à la stabulation, on préférait le laisser pâturer en liberté, au risque d'éprouver des difficultés pour s'en rendre maitre ${ }^{f}$.

C'était principalement en Berry et, à un moindre degré, en Auvergne, en Picardic, en Bretagne, en Sologne, dans lile-de-France, en Normandie, dans le Valentinois, dans les monts Corbière qu'on s'adonnait à l'élevage ${ }^{5}$. On se livrait à celui du cheral en Bourgogne, en Normandie, en Bretagne, en Auvergne, en Poitou, en Gascogne, dans le Perche, la Bresse, le Lavedan ${ }^{6}$, mais la production cheraline était très insuffisante et pour les besoins de la vie civile où le cheval restait le moyen de transport le plus employé et pour la remonte de la cavalerie qui constituait encore la force principale des armées. Olivier de Serres regrette

1. Théalre d'agric., chap. II du V'Je livre.

2. Loc. cit.

3. Dareste, 26i. Condorcet, Éloge de Duhamel de Monceau.

4. Voy. dans le livre de raison de Gouberville la fréquente mention des battues organisées pour s'emparer du bétail, des chevaux surtout.

5. Théatre d'agric., I, 558. Philippson, II, 33i.

6. Mèm. de J.-A. de Thou, Michaud et P. Xl, 30c. 
que la France, riche en races de chevaux ${ }^{1}$, soit obligée de tirer d'Allemagne, d'Angleterre, d'Italie, de Corse, de Sardaigne, d'Espagne, de Turquie, de Transylvanie la plus grande partie de ceux dont elle a besoin ${ }^{2}$. Le Danemark et lit Flandre en fournissiaient aussi. La création des haras fut une des qquestions qui occupèrent la commission du commerce dont nous dirons ailleurs la'mission et les travaux. Le roi en élablit ì Meung-sur-Loire et ì Saint-Léger dans le comté de Ilontfort-l'Amamry ${ }^{3}$ et subventionna la création d'une jumenterie entreprise par Marie de Neufville, femme de Jacques Paillard d'Urfé, dans le marquisat de

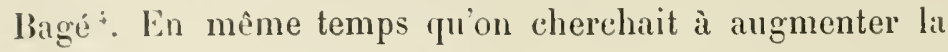
production, on songeait ì diminuer l'importation et à conserver au pays l'argent qu'elle lui coùtait. Laffemas proposait de défendre cette importation aux nationaux et d'obliger les étrangers, qui pourraient seuls s'y livrer, à employer en marchandises françaises le profit yüils en tiraient ${ }^{5}$.

La réputation des bœufs du Limousin et de la vallée dAuge conme des reaux de la Brie ${ }^{6}$ n'autorise pas à affirmer que l'élevage de la race bovine füt très perfectionné, et en réalité deux espèces seulement relevaient la France de lintériorité oì elle était restée dans la production du bétail : l'espèce ovine pour fla quantité et la qualité ${ }^{i}$,

1. "XNy a-t-il point de bonnes races de cluevaux... en divers lieux du royaume yue t'on nomme chevaux de païs?" Gonorry, op. laud.

¿. Théatre d'agric., I, 542. Gонони, loc. cil.

3. Recueil de ce qui se passe... Ubi supra. IsaAc Lafremas, Ilistoire du cummerce dans Cinner et Daxjov, 421. Arrêts du Conseil d'État, Bibt. nat., mss. franc., 18169, fol. 102 vo. 18163 fol. 150 ro. Sully gagnait de l'argent en achetant en Allemagne des courtauds qu'il revendait cher en Gascogne. Economies roy, collection Michaud, 1, 378. Sur l'élevage du cheval, voy. Théatre d'agric, vle lieu, chap. $\mathrm{x}$.

4. Arret du conseil du 27 janvier 1605 . Bibl. nat. fr., 18168, fol. 52. Sur l'élevage du cheval, voy. encore Beatreparine, Noles el documents concernant lanrienne administration des haras en Normandie, 1860.

5. La commission, édit, etc...

f. (iononry, loc. cil. Le Rolx de Lixcy, Prov. frane. Dallington, p. j).

i. "... Castrati particolarmente, i quali, par la qualita delle erlue che 
l'espèce porcine pour la quantité tout au moins. Les laines françaises étaient très recherchées à l'étranger. Les plus fines venaient du Berry, de la Sologne, de l'Ile-de-France, de la Normandie, du Valentinois, des monts Corbière ${ }^{1 .}$

Là où le bétail est insuffisant, l'engrais l'est aussi. Dans certaines provinces, d'ailleurs, par incurie ou par syslème, on ne fumait jamais les terres; c'était le cas de la Prorence². Ailleurs on était plus éclairé; dans le Maine, dans d'autres provinces encore, on appréciait tout le profit que tire la terre du parcage des moutons ${ }^{3}$. Si un dicton du $\mathrm{xvr}^{\mathrm{C}}$ siècle recommande de donner au bétail une abondante litière, c'est surtout pour avoir plus de fumier. Dans certaines régions, notamment dans certaines parties de la Gascogne, on meltait la marne all-dessus de tous les amendements". L'écobuage n'était guère pratiqué que dans quelques cantons des Ardennes ${ }^{6}$, mais le brülis, qui en diffère peu, était plus répandu ${ }^{7}$. On y recourait surtout quand, au lieu de laisser reposer la terre, on lui demandait une récolte deux années de suite ${ }^{8}$. Les autres amendements en usage étaient, outre le fumier d'écurie et d'étable, la fiente du colombier ou colombine, le varech, le sable marin, le conpost provenant des boues et du curage des viviers et enfin lia chaux qui ne passait pas pour exercer une action très rapide ${ }^{9}$.

mangiano e per l'aere che spirano, sono in quel paese molto piu saporili che non è il vitello d'assai... "Relation de Deovo, 1598, Lbi supra.

1. Théatre d'agric., I, 3.58. ANdré du Cuesne, 490.

2. Qhavereau de beaujev, évêque de Senez. De laudibus Provinciax, 1550. Cité par Grégoire, op. laut., cxxx.

3. Betox, cité par Doniol, Histoire des clusses agric., 345.

4. Et plus met-on de paille en l'estable et plus il y a de fumier. LE liocx DE Lixcr, Prov. franc., vo Fumier.

5. B. Paussr, Recepte vérilable par laquelle tous les hommes de la France pourront apprendre ì multiplier et augmenter leurs thrésor's, 1563. Préface.

6. B. Palissy, cité par Grégoire, cxxx.

7. Tollemer, 317. On sait que l'écobuage consiste à enlever la superficie de la terre avec les racines et à les brủler, tandis que le brùlis se réduit à brúler les chaumes aprẻs la récolte.

8. Bersard Palissy, op. laud., $50 \%$.

9. Golberville, 306. Tollemer, p. 31\%. Le Rocx de Lixcr, prov. franc. 
Si nous ne nous Irompons, les faits que nous venons de mellre sous les yeux de nos lecteurs ont dù les préparer aux conclusions qüil nous reste ì leur présenter.

I larènement de IlenriIV, l'agriculturesubissait une crise qui durait depuis vingt-sept ans environ et qui arait appauri les grauls propriélaires, ruiné la petite culture, multiplié et aggravé les servitudes féodales, déclassé en partie la plèbe rurale en lui laissant des habitudes de désœuvrement, des ferments de défiance et de révolte. Près de dix ans sécoulèrent encore avant que la population agricole se rassit et reprit racine de façon ì se prêter à une étude qui ne peut ètre féconde que quand elle sapplique à une société au repos ou, pour mieux dire, livrée ì une activité réglée.

Voici ce que étte étude nous a montré : une agriculture peu intensive, bien quaucun engrais naturel ne lui soit inconnu; la prépondérance des céréales dans les assolements; la dispersion mal entendue de la viticulture; l'insuffisance des pàturages, et, par suite, de l'élevage; l'exploitation sans ménagement des forêts; le règne de la routine ou, si l'on reut, de la tradition, menacé, dans un arenir encore éloigné, par l’apparition d'un livre où la doctrine, appuyée sur l'expérience. fonde l'agronomie française.

Bien qu'il ne manquàt pas de grands domaines, la proIriété foncière, par suite de l'égalité des partages ', était plutôt morcelée. Le crédit agricole n'existait pas et l'intérèt b́evé que l'argent rapportait dans les offices et les f'ermes bloignait les capitaux de l'agriculture, comme de l'industrie et du commerce. Les grands propriétaires résidaient encore sur leurs terres, bien qu'ils se senlissent déjà altirés vers la ville et la cour. (Yuand ils n exploitaient pas eux-mèmes, ils avaient des fermiers, des colons partiaires

I. "L.es partages sont la ruine des maisons de village ", ecriviat Gr'Y Crontat.t.e. 
et des locataires emphýtéotiques. Girîce à leurs longs baux, fermiers et colons partiaires, et, à plus forte çraison, locataires emphytéotiques, jouissaient arec sécurité du fruit de leurs travaux et de leurs dépenses. En revinche ils trouvaient dans leur bailleur un seigneur qui exerçait sur eux, concurremment avec le roi, les attributions de la souveraineté. Malgré les charges de eette souveraineté, malgré le trouble que les guerres civiles et les usurpations qui en avaient été la conséquence y avaient apporté, les rapports des grands propriétaires et de leurs tenanciers tendaient à reprendre leur ancienne familiarité.

Dans la renaissance agricole qui suivit les guerres civiles, une grande part doit ètre accordée à la royauté. Le bien que la monarchie de l'ancien régime a fait, elle a eu bien plus de mérite à le faire que les gourernements centralisés des temps modernes, car sa bonne volonté a été souvent contrariée par les autonomies locales, par l'apathie nationale, par ses propres instruments. Si l'opinion, représentée surtout par les états généraux, lui a souvent inspiré ses meilleures résolutions, il faut lui tenir grand compte de l'énergie qu'elle a dù déployer, avéc un système administratif et fiscal aussi vicieux, pour les faire triompher. Henri IV, pour ne parler que de lui, a exonérél'agricul ture du passif arriéré qui la grevait et réduit d'un quart le montant de la taille,dontelle supportait le principal poids. Illui a donné la sécurité. Bien qu'il n'ait pas fait, comme l'a dit M. Poirson, de la liberté du commerce des grains le régime normal et permanent du pays, bien qu'il l'ait assez souvent subordonnée aux circonstances, il en a adopté le principe et il a réussi à le faire presque constamment prévaloir. Il eut à combattre pour cela les préjugés du temps et les résistances locales. Ce ne fut pas sur ce point seulement qu'il s'y heurta. Quand il entreprit de dessécher les marais, le pays refusa ses capitaux, et les populations qui devaient 
profiter le plus directement du desséchement et dont il arait si serupuleusement ménagé les droits acquis, entravirent les travaux. Sully et Olivier de Serres, bien que linfluence de celui-ri ait été lente à se répandre et soit diffieile à saisir, doivent partager avec Henri la gloire d'aroir rendu l'essor ì l'agriculture nationale. 


\section{CHAPITRE II}

\section{L'ÉCONOMIE INDUSTRIELLE}

Qu'on les considère au point de rue moral ou au point de rue économique, quelle différence entre le milieu que nous quittons et celui où nous allons entrer! Au lieu de travaux réguliers comme les saisons, dont les méthodes et les procédés se modifient peu et lentement, au lieu d'une population qui ne connaît d'autre groupement que la famille, dont les seuls liens sont des liens de roisinage et de commune dépendance, dont la vie et la pensée sont absorbées par le Iabeur quotidien, qui n'apprend les événements publics que par des échos ragues et infidèles, nous nous trouvons en présence de travaux qui, sans égaler la mobilité, sans passer par les transformations perpétuelles de l'industrie contemporaine, répondent, en dépit de la réglementation, aux sollicitations, aux exigences du progrès, du goùt et de la mode, en présence d'une population divisée par ses occupations professionnelles en groupes qui s'observent jalousement et dont chacun recèle lui-même certaines divisions, avide de nouvelles et de spectacles, ne manquant janais ni des unes ni des autres, prompte à se passionner pour les questions qui y sont en jeu, passant facilement de la curiosité à les suivre et à les commenter au désir de jouer un rôle dans les érénements.

Les dissensions civiles avaient atteint l"industrie moins 
directement que l'agriculture; mais elle n'arait guère moins souffert. Mieux protégées que les eampagnes contre le pillage mais excitant plus de conroitises, les villes n'échappaient pas aux réquisitions, anx contrihutions de guerre exigées pilr les deux partis, calholiques et protestants, royaux et ligneurs. Leur mise à sac faisait si bien partie des lois de la guerre, qu'elle avait ses règles. Elle était limitéc à trois jours : un pour piller, un pour emporter et le troisième pour négocier et fixer la rançon de ce yuion roulait bien laisser aux raincus ${ }^{1}$. Parmi les artisans, les uns s'enrôlèrent au service du premier chef de partisans venu, les autres émigrèrent, d’autres grossirent les bandes de mendiants formées par les réfugiés des campagnes. Cette immigration dans les villes ful un des soucis les plus grands des municipalités urbaines qui en complirent tant d'autres. Déja embarrassees des paures que le chômage et la diminution des affaires multipliaient parmi leurs administrés, elles voyaient arec inquiétude aflluer aux portes cenx du plit pays. Bouches inutiles, bras sans ourrage, moralité suspecte. maladies contagienses, intelligences avec l'ennemi, esprit de sédition, c'est là tout ce quilles pouvaient en attendre. On leur fermait les portes, mais, trompant la surveillance, ils se glissaient isolément dans les villes ou y pénétraient en masse. moitié de gré, moitié de force. Alors on les expulsait en y employant des bourgeois commis ì cet effet sous le nom expressif de chasse-coquins ou bien on les embrigadait, en les marquant d'un signe particulier, dans des chantiers de démolition et de terrassement ${ }^{2}$. La peste, la

1. Mémrires de La Noue, collection Michaud, I, IX, 602.

$\therefore$ Registres du bureau de lu ville de Paris, p. p. Guésx (année 1596), 1). 237, 238, 211-212, 24:3, 249. Jémoires de Jean birel, bourgeois du Puy,

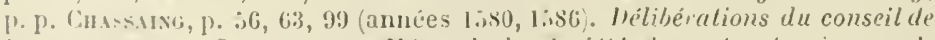
la commune de Careassonne. Wém. de la soriélé des arts el sciences de C'arcussonne, II (1856), I's octobre 1586 et :2: novembre. If décembre 1596. 
famine renaient périodiquement décimer ces agglomérations usées par la misère ${ }^{1}$. Il y arait en de tout temps dans la classe ouvripre des instincts de turbulence et de rérolte,

17 avril 1587. Mémoires sur la ligne dans le Laomnois, p. A.т. Rıchart, p. p. la Société académique de Laon 1867 (année 1590). Délibération de l'úchevinage de Chauny du 8 février 15:5 dans Bulletin mensuel de la société académique de Chauny, I, 28I (1886). "Fut fait un riglement concernant les pauvres... que les forts et vigoureux travailleroient aux forts et que tous les gueux porteroient une marque de plomb sur laquelle seroient les armoiries de la ville "1597. Diaire de Jacoces Merbli... A A ch. hist. de Saintonge. V (187x). Canno, Histoire de Heanx, p. :76. Leprors, Mistoire de Chartres, 11, 986-287. LAFrexas. Reigl. gen..., p. 12.

1. Sans entreprendre de justifier par des faits particuliers cet apercu de la détresse des villes, citons quelques exemples qui en préciseront et en animeront les traits généraux. En 159 le capilaine huguenot Merle, ayant surpris Ilende, l'avait livrée. pendant dix ou douze jours, au massacre et au pillage, et avait mis les habitants i rancon. Bulletin de la Societé d'agriculture, industrie, sciences et arts de la Lozère, Ill (1852), p. 9\%. Bourgen-Bresse avait été pris et saccagé arrêt du conseil d'État, 10 février 16i03. Bibl. nat. fr. I81v66, Arnay-le-Château avait été pillé et saccagé trois fois, la llèche quatre, la Ferté-llilon avait été assiégée i plusieur's reprises et entiẻrement sareagée, Dreux arait été mis à sac Reg. du conseil d'État de 159 '. Bibl. nat.fr. 18159 , fol. $\left.19 \mathrm{v}^{\circ}, 358 \mathrm{v}^{\circ}, 466 \mathrm{v}^{\circ}, 47 \mathrm{v}^{\circ}\right)$. Un arrêt de la même année parle des pertes subies par Châteaudun ḋ la suite du passage des armées, de la prise et de la reprise de la ville (fol. 60 ), un autre des pertes et misères souffertes par les habitants de V'endôme lorsque leur ville fut prise (fol. 67), un troisième remet à Joigny ses tailles arriérées à cause des grandes pertes et ruines soulfertes durant les troubles (fol. 92; il est question dans le même registre de la "notoire paurreté " des habitants de Brienon-l'Archevêque "advenue à l'occasion des troubles, passages et séjour des gens de guerre " (lol. 160), des "pertes, ruynes et rarages soutlerts par les habitants de Mlalay-Vicoute, tant au passage, séjour des gens de guerre que à la prinse et reprinse de lad. ville faicte à trois direrses foys " ( fol. $458 \mathrm{r}^{\circ}$ ). Ln arrêt de 1599 nous apprend que Noyon avait été pris deux fois, que les deux tiers de ses maisons avaient été brûlées, que la ville arait été décimée par une épidémie Bibl. nat. fr. 1816 , fol. 48 . En $15 \%$, Provins se rachète du pillage par une contribution en nature (BockQuelot, Hist. de Provins. II, 159), elle subit des réquisitions et des contributions de guerre multipliées (p. 166, 16i note). La peste s'y déclare en 1581, reparait en 1582, puis en 1586 , à la suite de la famine; elle y régnait encore à la fin du xrıe siècle (p. 165-166). A la même époque, les foires et le commerce y' etaient entièrement ruinés, de $\mathbf{1 5 0 0} \mathrm{chefs}$ de famille il n'en restait pas 500, les villages des environs itaient presque déserts (p. 193194). Dans le roisinage, Chalautre-la-Grande arait été saccagée et détruite en 1586 par les troupes du due de Guise. La soumission de la Normandie au roi n'y avait pas rétabli la sùreté des communications, en 159' le commerce $y$ était encore impossible (Arrêt du eonseil du ?i nor. 1594. Bibl. nat. fr. 18I59, fol. 462 vo). Voy. encore Hist. de ce qui s'est passé en Brelagne pendant les guerres de la Ligue, par le chanoine 1 lonEAt. 
mais ils avaient èté le plus souvent contenus par la vigilance du pouroir et par le sonci le l'existence professionnelle. Entretenus pourtant au sein des réunions de confréries et te compagnonnage, ils avaient fait explosion le jour où la sininte linion, prechant la guerre rivile dans foutes ses rólises, avait armé les gens de métiers, les avait fait entrer dins ses conseils, leur avait appris à trancher des allaires d'Etat ${ }^{2}$. Est-il besoin d’ajouter après cela que la déférence les ouvriers pour leurs patrons en avait été fortement alteinte ${ }^{2}$ ?

La situation misérable de l'industrie était en partie imputable ì son organisation même. Cette organisation recélait des germes de dicadence que les troubles politiques avaient fait mûrir et éclore. Les rois des merciers qui araient commencé au $x^{\circ}{ }^{\circ}$ siècle à exercer une certaine autorití sur les mereiers ${ }^{3}$. c'est-ì-dire sur les marchands en gros de certaines provinces obligés par la nature de leurs allaires à aller de foire en loire, avaient, à une époque que nous ne pourons préciser, mais qui est antérieure à François $\mathrm{I}^{\mathrm{er}}$, étendu cetle antorité sur tous les marchands et artisans. Persome ne pourait exercer m métier sans aroir obtenu à leniers comptants des lettres de mailrise du roi des mercier's dans la juridiction duquel il était placé et qui percerait en outre tous les six mois des droits de risite et l'apprentissage: En revanche les rois des merciers avaient eharge de veiller à lia police des métiers. François Ir tenta, mais sans succès, de réunir à la

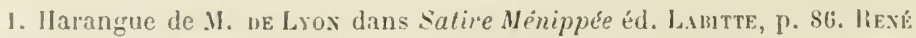
Brwors, De l'instilution et ahus des confiéries, 15is. Bodiu, Les six livers de la liepublique, 1580.

2. JaFFEMAs, lieigl. gen., p. 12.

3.... De loute ancienneté, il est acouslumé avoir en notre pays de Beaujulais un prévôt et maitre des merciers fréquentans foires et marchés pour unantenir Ies franchises, libertés et usages entre eux... usités. Younination d'un privit des merciers de Reaujolais en 1427 par lit duchesse de Bourbon. linlletin de la śoripté d'rimulation de lAllier, X, P. I23.

i. P'rémbule de l'édit d'avril ligr. Fostaxus, I, $11 \% 1$. 
couronne ces droits et cette police. Les rois des merciers contimuèrent à percevoir ces taxes, concurremment arce les gardes-jurés, et les uns comme les autres commirent une foule de malversations et d'abus. Ces gardes-jurés, nélant plus élus par les corporations, mais nommés par les rois des mereiers ${ }^{1}$, s'entendaient avec eux pour tirer de leurs charges le plus de profit possible aux dépens des membres des corporations, auxquels ils faisaient acepter lours exactions en tolérant leurs malfaçons et leurs fraudes ${ }^{2}$. Les maîtrises n'étaient derenues aceessibles qu'aux fils et aux gendres de maitres ou aux candidats assez riches pour se concilier la bienveillance de ceux-ci par des présents et des banquets ${ }^{3}$; ì Paris, ces banquets coùtaient aux candidats de 60 (ว66 fr. 29) ì 200 écus (1887 fr. 63). Les apprentis riches faisaient à prix d'argent abréger le temps de leur apprentissage ${ }^{*}$. C'est en rain que le candidal, qui n'arait pour lui que son mérite, se tirait à son honneur de l'épreuve longue et conteuse du chef-d'wurre, ses examinateurs refusaient le plus souvent leur approbation à une œurre que beaucoup d'entre eux auraient été incapables d'exécuter ${ }^{3}$.

Mais lindustrie n'était pas universellement soumise au régime des maitrises et des jurandes; bon nombre de villes ne le connaissaient pas. Celles où il était en rigueur se distinguaient par le nom de villes jurées ou villes de loi. Même dans celles-ci, bien des métiers étaient libres et le

1. Édit d'avril 1597 , art. 4.

2. Ibid. "Deffences seront faites à tous maistres jurez... de plus lever sur la communauté de leur mestier autres deniers que ceux... mentionnez. aud. reglement et d'en abuser comme ils ont fait par le passé sous prétexte de pieté... "Reigl. gen., p. 25. Voy. l'énumération des abus commis par les jurés dans un document publié par M. Levasseur, Ilisl. des classes ouvr., II, 99.

3. Édit. de déc. 1581. Foxtanon, 1, 1091. "... au lieu de festins et autres frais qu'il lui faudroit faire,.. " Reigl. gen.. p. 2?.

千. Édit de déc. 1581. Ubi supra.

j. Ibid. 
restaient jusqu'au jour oì leur importance croissante les fitisait ériger en corporations. Ce régime ne sétendait pas l'ailleurs aux villages ni aux bourgades. Là où elle avait ¿̇é mise à mème de porter ses lruits, la liberté avait-elle ité moins fertile en abus que la réglementation? C'était tout le contraire. La licence y était poussée si loin que les habitants des villes oì l'industrie et le commerce étaient libres, étaient réduits ì faire leurs achats et leurs commandes dans des villes jurées ${ }^{1}$, situées quelquefois à quinze ou vingt lieues de celles quils habitaient ${ }^{2}$.

Il est plus facile de se représenter en gros ce que l'industrie française pourait être devenue en 1.389 par suite des guerres civiles et des vices inhérents à sa constitution que de spécifier les pertes éprouvées par telle ou telle industrie particulière. On peut le faire cependant pour plusieurs d'entre elles.

Les draps français avaient joui d'une grande réputation et avaient été très recherchés au Levant et jusque dans l'Inde. Mais les malfaçons, farorisées par les troubles, avaient discrédité et presque entièrement ruiné l'industrie drapière. Elle produisait quatre fois moins quarant les guerres civiles. A Provins, où dix-huit cents métiers marchaient autrefois, à Senlis, à Neaux, à Melun, à SaintDenis, dans d'autres localités des environs de Paris, la fabrication s'était pour ainsi dire arrêtée. La plus grande partie de la laine recucillie en Languedoc, en Provence, en Dauphiné, au lieu d'être filée et tissée dans le pays, passait en Italie d'où elle nous revenait manufacturéc sous forme de serges de Florence, d'étamets, de ras de Milan ${ }^{3}$.

1. Edit de déc. lis1. Vbi supra.

2. Préface du Reigl. gan. Avis des corporations de Paris a la suite de la Commission, édit el purtie des mémoires de l'ordre et establissement du commerce generat des manufucturcs en ce royaume, Paris, Psutoxiser, 1601 , in-40.

3. Reigl, gen., [. 11. 
Les Anglais inondaient le royaume de leurs draps, de leurs futaines, de leurs bureaux, de leurs bas de tricot, comme de leur chapellerie et de leur cordonneric ${ }^{1}$. La fabrication des serges et des camelots, ce qu'on appelait alors la sayetterie, avait été très florissante à Amiens; en $1: 36$ elle avait tellement perdu de son activité que cinq à six mille ouvriers étaient réduits au chômage et ne vivaient que d'aumônes ${ }^{2}$. Les teinturiers parisiens qui, au milieu du siècle, teignaient annuellement six cent mille pièces de Irảp, en teignaient à la fin moins de cent mille ${ }^{3}$. La réputation des cuirs français arait été perdue par le défaut de conscience des tanneurs qui tannaient en moins de trois mois des cuirs qui leur demandaient autrefois une année ou deux ${ }^{4}$. Avant les guerres civiles, l'industrie des soieries faisait vivre à Tours près de quarante mille personnes, en 1596 le nombre des fabricants était réduit de huit cents à deux cents ${ }^{3}$. A la même date, une revision des règlements de la fabrique lyonnaise était rendue nécessaire par une désorganisation presque complète imputable à la même cause ${ }^{6}$.

Certaines industries cependant avaient résisté au malheur des temps. Rouen continuait à faire de la draperie fine, ses draps étaient célèbres sous le nom de draps du sceau ${ }^{7}$ qu'ils devaient à la marque qui en indiquait la provenance et en garantissait la qualité. La vaisselle d'argent de Paris avait

1. Reigl.gen., p. 18. Advis et remonstrances à M.Y. les commissaires députés dis roi, $1600, \mathrm{p} . \mathrm{i}$.

2. Monuments inèd. de l'hist. du tiers état, II, 903 note. Procés-verbaux de la commission du commerce dans Crampoluox, Documents historiques extraits de la Bibliothénue nationale, IX, $106-108$.

3. Laffexas, Recueil de ce qui se passe en l'assemblée ducommerce, p. 24́,

4. 1. Laffens, Hist. du commerce, p. 419. Reigl. gen., p. 13, 14.

5. Cahier des remontrances que les délégués de Tours doivent porter á l'assemblée des notables de Rouen, analysé par .M. Grracdet, Hist. de Tours, II, 59.

6. Inventaire des arch. municipales de Lyon. Reg. BB 133, année 1596.

7. Reigl. gen., p. 11. 1. Laffemas, Hist. du commerce, p. 120. 
conservé son excellent titre et sa réputation ${ }^{1}$. Les serges de Limestre, c'est-ì-dire les seruges fines fabriquées i Rouen, à Dieppe, à Fécamp et ailleurs, pouvaient remplacer aree avantage celles de Florence, sil faut en croire des juges fort próvenus, il est vrai, en fareur de lindustrie française? L'un d'enx, Laffemas, en disait autant de celles que Sommières en Languedoc s'stail mise à fabriquer vers l'avènement de Ilenri IV. En 1:396, Nimes savait donner aux siennes laspect du ras de Milan, Chartres imitait le ras d'Arschot ${ }^{3}$; quelques années plus tard, les drapiers de l'aris, intéressés, ne l'oublions pas, à faire valoir la fabrique française, mettaient les draps de Paris, de Rouen, de Heanx, du Berry, de Beaurais, etc., bien au-ılessus de la draperie étrangère *. Dans les dernières années du $x \%^{\circ}$ siècle. l'industrie des toiles était assez développée en Yormandie et notanment à Rouen, en Bretagne, en Barrois, en Champagne et spécialement à Troyes, à Laval, à Chàtellerault pour donner lieu à un commerce d'exportation". Louviers, Saint-Quentin, une partic de la Tormandie faisaient des toiles fines qui passilient pour valoir les toiles de Ilollande ${ }^{6}$.

Qu'il y ait quelque complaisance dans la préférence que les contemporains auxpuels nous derons ces renseignements accordent aux produits français, nous sommes porté à le croire; il n'en est pas moins incontestable que les deux industries françaises les plus importantes, les seules qui eussent contribué jusque-là au commerce d'exportation, la draperie et les toiles, se ranimaient dans les dernières années du siècle, à mesure que la pacification du pays

1. LAFFEMAs, Ilist. du commerce, loc. cit.

2. lieigl. gen., loc. cit. Avis des corporations.

3. Reigl. gen., p. 15-16. Avis des corporations.

i. Ivis des corporations.

S. Ibirl.

6. Reigl. gen., p. 16. 
faisait des progrès. Cette sorte de renaissance toute spontanée, et à laquelle le gouvernement n'eut aucune part, se manifestait, on l'a ru, dans une région assez étendue, dans (les centres assez éloignés l'un de l'autre. Les symptômes d'activité industrielle quil nous reste à signaler ont un caractère plus local et plus spécial, ce ne sont plus des traditions qui se renouent, ce sont des créations dont l'origine se précise pariois par une date ou par un homme. Dans les dix dernières années $d u x v^{\circ}{ }^{\circledR}$ siècle s'introduisait à Dourdan l'industrie des bas de soie et de tricot ${ }^{1}$. Un peu avant 1396 , deux Flamands apprenaient aux habitants de Senlis et des villages roisins à faire de la dentelle de Flandre ${ }^{2}$. Ce n'est pas le seul exemple d'étranger's venant sétablir dans notre pays et y apportant des industries nourelles; si beaucoup de nos ouvriers sétaient expatriés, en revanche des colonies d'artisans étrangers étaient renues braver nos agitations intérieures. Ainsi, en 1581, d'habiles corroyeurs suisses sétaient fixés en Béarn ${ }^{3}$ et y exerçaient l'art de donner aux peaux de bœuf la façon du buffle, à celles de chèvre la façon du chamois, assez bien pour faire concurrence anx cuirs d'Allemagne. Sous leur influence la préparation des peaux de buffle et de chamois, que des négociants de Bayonne allaient chercher à Candie et dans les Etats barbaresques, avait atteint en Béarn une grande perfection ${ }^{4}$. Dès 1 389 , Poitiers travaillait toute espèce de cuirs it l'imitation de ces cuirs exotiques ${ }^{5}$. Les maroquins de la Rochelle éclipsaient ceux de Flandre, gràce aux fabricants tlamands qui sétaient établis dans cette ville dont les pri-

1. Reigl. gen., p. 10 .

2. Ibid.

3. Reigl. gen., p. 10. M. Polrsox (III, 240), trompé par l'ancienne orthographe de Béarn (Biard), s'est donné beaucoup de peine pour découvrir le lieu dont Laffemas a voulu parler et a fini par l'identifier avec un bourg du Lyonnais.

4. Reigl, gen., p. 1i.

5. Ibid. 
vilèges et l'autonomie les avaient peut-ètre attirés ${ }^{1}$. Vers 1596, un maitre corroyeur de Nérac en Gascogne, nommé Bernardin, savait apprèter les cuirs de façon à les meltre it lépreuve des armes blanches. Il y arait trois ou quatre ans que Hontpellier avail commencé ì faire des velours, les satins, les talletas; cette ville se distinguail également par ses futaines blanches ${ }^{3}$. A côté les anciennes labriques de soieries de Lyon et de Tours, si épronvées, mais non détruites, sétablissait à Paris, sous la direction d'un induslriel, nommé Godefroy, une manufacture de soieries et de brocards ì laquelle semblait réservé un brillant avenir".

Henri IV nétait pas malheureusement en mesure d'encourager ces témoignages de l'aclivité renaissante de ses sujets. Lor'sqüil s'occupa de l'industrie pendant la période militante de son règne, ce ne fut pas le plus souvent par intérêt pour elle, mais pour lui demander des ressources extraordinaires, toutes différentes de celles qu'elle fournit dans des temps réguliers. C'est ainsi quau mois de janvier 1396 , il rétablit des offices de contrôleurs, visiteurs, marfueurs de euir's ${ }^{j}$, dont la création ne se justifiail que par la nécessité de payer la solde arriéréc des troupes suisses. Cet édit fut aussi impopulaire que préjudiciable ì lindustrie des cuir's. Il souleva l'opposition des autorités locales, provorua des émeutes parmi les gens de métiers et ne fut exécuté quavec beatroup de peine. Uniquement préoccupés d'augmenter les produits de leurs charges, les contrôleurs-marqueurs ${ }^{6}$ marquaient tous les cuirs

1. Reigl. gen., P. 16.

2. Ibid., p. 9.

3. Ibid., 1). 16.

4. Ibid.

5. Fontanos, I, 1168. Lédit de creation est de 1585.

6. Ces places étaient données à la faveur, sans tenir aucun compte de la compétence. Ainsi un fourrier de la grande écurie du roi est contrôleurvisitcur et marqueur des cuirs de Poitiers. Arrêt du Conseil du 13 octobro 160\%. Jibl. nat. fr. Isı i?, fol. 29). 
qu’on leur présentait et les nombreuses industries qui emploient cette matière s'en trouvaient à la fois trompées et discréditées. Néanmoins l'édit fut maintenu et survécut non seulement à la guerre civile et étrangère qui le rendait excusable, mais même au roi qui l'avait rendu ${ }^{1}$.

On peut rapprocher des créations d'offices les créations de maîtrises. Il y avait toutefois cette différence entre elles que, tandis que les premières faisaient renchérir les marchandises, les secondes tendaient à les faire baisser en développant la concurrence. Leur danger, éétait que les maìtrises pouvaient tomber dans les mains des premiers renus et ouvrir ainsi à des gens sans capacité l'accès des professions industrielles. Aussi les corporations demandaient qu'elles ne fussent délivrées que sur leur désignation. Elles ne trouvaient pas toujours des accuéreurs. Les corporations avaient tant de moyens de rendre à ceux-ci l'exercice du métier difficile et peu profitable, tant de façons de les vexer et de les dégoùter que souvent les lettres de maitrise ne se plaçaient pas. En 1608, il y en arait une foule qui étaient dans ce cas et dont les plus anciennes remontaient jusqu'à l'avènement de François II, elles faisaient l'objet d'un trafic et passaient de main en main en se dépréciant de plus en plus. Elles avilissaient dı mème coup celles qui avalent èté créées par Henri IV ou

1. L'opposition des municipalités et des corps judiciaires se manifesta notamment au Mans, à Lyon, à Orléans, à Soissons, à Château-du-Loir, à Châtellerault (Arrèt du conseil du 15 février 1596. Bibl. nat. fr. 18162). Des èmeutes éclatèrent au Mans, à Lyon, à Rouen, à Troyes, à Caen, etc. (Arrêts du 15 février et du:26 aoút 1598). Les états de Normandie, dans leur sessiou de décembre 1598, réclamèrent la révocation de l'édit. Rorullard de Beacrepalre, Cahiers des états sous Ilenri IV, I, 117. En 1600 et 1601 , Laffenas et les cordonniers de Paris exprimèrent le même vœu. Remontrances en forme d'édit et Avis des corporations. Un arrêt de 1618 confirma l'existence des contrôleurs, visiteur's et marqueurs créés à Laval en exécution de l'édit. La Beauldere, Recherches sur les corporations d'arts el méliers du comté-pairie de Laval, p. 10. 
"fui ponvaient l'ìtre à l'avenir '. Aussi le roi rendit. le 8 juillet l60s, une déclaration réroquant tontes celles qui araient ité créées avant son arènement et qui araient été délivirécs depuis.

Les succès décisil's de llenri IV dans le cours de l'année 1.596 lui permirent de soceuper de l'industric avec des vues plus désintéressées et plus libérales. La convocation d'une assembléc de notables conduisait naturellement à examiner la situation gémirale du pays, ì sonder ses plaies, it rechereher les moyens de les fermer. Lorsque cette assemblée se réunit à houen le 't norembre 1:396, le roi lui snumit² les projets quil avait reçus de plusieurs partienliers sur les moyens de relever l"industrie nationale. Le plus remaryuable était un plan d'organisation industrielle rédigé par Barthélemy Laffemas sous le titre de Règlement général pour dresser les mamufactures en ce royaume ${ }^{3}$. Les idées de Laffentas, même celles quil partage avec son temps, sont bien it lui, en ce sens qüil se les est faites lui-même et qüil ne les a pas puisées dans les lirres. car il nélait rien moins qu'un lettré, mais dans la longue pratique des affaires *.

Ce personnage est moins connu par lui-même que par son fils, Isaac, qui ne jouit pas dans l'histoire d'une tries bonne réputation. Né peut-itre en $1: 3 \%$ ì Beausemblant en Dauphiné, facteur d'un grand commeresant, commerçant ensuite pour son propre compte, altaché rers $1: 366$, en qua-

1. Jien entendu les lettres de maitrise neètaient pas vendues directement par le roi ni par les concessionnaires, elles étaient attermées à des traitants qui les alfermaicnt d'autant moius cher qu'elles étaient plus nombreuses. theg. du conseil d'État de 1599. Bibl. nat. fr. 1816', fol. 3.

2. Reigl. gen.

3. Palis, Clalige de Moxtreule, 1597 , in-80.

i. "... Pour n'avoir iceluy autheur jamais esté aux escolles, et ce peu qu'il a apris a esté en faisant traffic de marchandise tenant l'argenterie du roy... ". disait-il Ini-meme. Le quntrième advertissement du commerce faict sur le debvoir de l'aumosne des pauvres desdié aux riches el amaleur's du bienpul,lic, etc. Paris, Mertayer, 1600, p. 1\%. 
lité de tailleur valel de chambre, à la maison du roi de Nararre, puis, à partir de $1 \% \overline{76}$, fournisseur de son "argenterie $n$, il avait fait à tous ces titres de très grandes allaires. Elles ne lui araient pas toujours réussi. Ce n’est pas, croyons-nous, qu'elles eussent été mal conçues ou mal conduites, mais le malheur des temps les avait fait tourner contre lui. Décret sur ses biens, décret sur sa personne, emprisonnement, il avait, à l'exception de la faillite et de la cession de biens, auxquelles il se vante de navoir jamais été réduit, connu ce que la carrière commerciale peut réserver de plus amer et de plus humiliant. Il arait éprouré l'impuissance de l'activité et de l'intelligence en lutte arec des circonstances sous lesquelles tant d'autres commerçants contemporains avaient succombé comme lui mais il arait eu, de plus qu'eux, le gont et le don de se rendre compte des causes de ses revers et de méditer, pour le profit du public. la réforme des institutions, des mœurs, des abus dont il avait été vietime ${ }^{1}$.

Le plan qu ïl présenta au roi en 1396 était arrèté dans son esprit dès $1383^{2}$. Il fut très probablement appelé à le soutenir derant lassemblée des notables ${ }^{3}$. Les mesures générales qüil préconisait, en dehors de la sériciculture et de la création de l'industrie des soieries, consistaient à rendre universel et obligatoire le système des maitrises et des jurandes; à établir des chambres syndicales de deux degrés investies de la police et de la juridiction des métiers, les unes pour chaque corporation, les autres pour

1. Correspondance de Srmox Lecoute aux archives de lliòtel-Dieu de Toulouse. Cabinet des titres, registre 202 et dossiers bleus. LAfremas, Sources de plusieurs abus... Advertissement et reponse aux marchands et antres oil il est touche des changes, banquier's et banqueroutiers. Сh. Prader, Un marchand de Paris au XVIe siècle dans Mémoires de l'Académie des sciences, inscriptions el b.-lettres de Toulouse, 1889 et 1890. Pavl Lafpitte, Notice sur Barlhélemy Laffemas dans Journal des économistes, mai $18: 6$.

2. Reigl. gen.

3. Ibict. 
tontes les corporations d'un diocise; à protéger l'industrie nationale en interdisant lexportation des matieres premieres et l'importation des objets manufacturés; it attirer les ourriers étrangers par la naturalisation; ì eréer une caisse de secours pour les gens de métiers infrrmes et des atelier's pour les mendiants valides et les jemnes détenus. C'e quill y a de plus original dans ce plan, c'est l'idée de syndicats professionnels dispensant, autant que possible, les corporations de recourir ì la justice ordinaire. Laffemas avait trouve dans les institutions de son temps le principe de ce système. car les corporations exerçaient dejjà une certaine juridiction sur elles-mêmes, mais cette juridiction itait très limitie et peu sćricuse; il l'átendait et la fortifiait, se servant ainsi d'un organe atrophié pour obtenir le mourement, lautonome et la vic.

Ce projet souteva diverses objections. Les uns Ini reprochaient de faire du noureau; les autres, s'en prenant à lindustrie elle-mème, faisaient remarquer qu elle entraìne dérogeance, quiclle enleverait, en se développant, trop de bras à l'agriculture; d'autres enlin appréhendaient les danzer's que ces syndicats électifs pouvaient faire comrir à la société si longtemps agitéc par les associations et les réuuions. Laffemas reprit la plume pour réfuter ces objections. Il se défendit de vouloir innover, affirmant qüil visait au contraire à faire restaurer l'ancienne police industrielle altérée par les guerres civiles; il proposait pour modèle ¿i ses concitoyens l'Italic où l'exereice de l'industrio et du commerce n’était pas incompatible arec la noblesse ${ }^{1}$; il contenait que l'industrie ne ferait pas tort à l'agriculture et que les paysans pourraient même employer les loisirs que leur laissaient les travaux des champs ì certains travaux industriels; enfin ćétait, disait-il, à la faveur des confréries 
que s'étaient tenues ces assemblées séditieuses dont on craignait le retour et les syndicats mettront précisément fin à ces assemblées ".

Les magistrats, les officiers municipaux qui représentaient exclusivement le tiers état dans l'assemblée ${ }^{2}$, ne pouraient être farorables à l'idée de faire de la classe industrielle une classe indépendante, sadministrant, se jugeant elle-mème, se passant autant que possible des lribunaux ordinaires. Des rues de Laffemas on ne retrouve, dans le cahier de doléances adopté par les notables le 2.j janvier 1:397, que celles qui ont trait à la protection de l'industrie nationale et ì l'élablissement des ouvriers étrangers en France. L'assemblée exprima le vœu que le roi interdìt la sortie des laines et autres matières premières, ainsi que l'entrée des soieries et draperies, du fil, des passements et des étoffes d'or et d'argent, qu'il farorisit, au contraire, par la suppression des droits de doune, l'importation des soies et laines brutes; elle demanda que les ouvriers étrangers qui viendraient travailler en France trois ans durant obtinssent les droits de régnicoles sans avoir besoin de lettres de naturalité ${ }^{3}$. Du reste l'analogie des vœux de Laffemas et de ceux de l'assemblée n’inılique pas nécessairement que celle-ci ait suivi les inspirations de l'écrivain; le système protecteur, la naturalisation des étrangers étaient des idées courantes, que le publiciste et l'assemblée purent exprimer indépendanment l'un de l'autre.

Quoi quil en soit, les abus dont souffrait l’industrie avaient été signalés, la question d'une réforme industrielle avait été posée devant les notables. Ce fut incontestable-

1. Sa Réponse aux difficultés proposèes à l'encontre de son règlement est publiée à la suite du règlement.

2. Voy. la composition de l'assemblée dans Potrsox, Mémoires el documenls nouveaux, p. $3 \mathrm{I}$.

3. Cahier de doléances, dans Porrson, Mém. et documents, p. 6j. 
ment là l'origine de lédit d’avril 1:397'. Quant à lönfluence sous laquelle cet édit fut conçu, il ne faut la chercher ni dans l'écril de Laflemas ni dans les délibérations des notables, son esprit nest pas difficile ì découvrir, puisqüil sannonce lui-même comme remeltant en vigueur et complétant celui de décembre $1: 381$. Le but de celui-ci arait été de restaurer lorganisation industrielle du moyen age en faisant disparaitre les alus que le lemps y arait introduits, de généraliser le régime des corporations et de l'álargir dans une certaine mesure. Il avait confirmé les slatuts, rétabli l'élection des gardes-jurés, interdit les banquets et les droits de confrérie, condamné l'usage que les corporations faisaient du chef-d'ourre pour écarter les candidats. Il avait ôté à la corporation son caractère étroitement local en autorisint les maitres reçus dans les villes qui étaient le siège d’un parlement, d'une sínéchaussée. dun bailliage, d'un présidial, à exercer dans le ressort de ces juridictions. Ies maitres des faubourges à exercer dans la ville, ceux de Paris ì cxercer partout. Enfin il avait un côté liscal: il établissait un droit d'entrée graduć suirant les métiers, qui élaient d'après leur importance répartis en trois classes. Les troubles du royaume l'empêchèrent d'ètre exécuté. Henri $\mathrm{IV}$, dont l'attention était appelée sur La décadence de lindustrie et qui cherchait partout des moyens de remplir le Trésor, śppropria la réforme de son prédécesseur. Son édit uniliait l'organisation industrielle en érigeant tous les méticr's en jurandes; les artisans qui exerçaient des métiers libres whtenaient la maìtrise sous la senle condition du serment, faveur personnelle dont ne deraient pas bínéficier ceux qui sétubliraient dans la suite. Les membres des corporations durent renouveler le serment de maitrise. 'qui n’arait été reçu que par les 
rois des merciers ou leurs délégués, e'est-ì-dire par des gens sans qualité, et prendre de nouvelles lettres de maìtrise. Les rois des mereiers, leurs lieutenants et oflicier's étaient supprimés. Aussitôt après la prestation de serment, les gens de métiers devaient se réunir et procéder à l'élection d'un ou dleux gardes-jurés (urt. 't). L'édit de 1:381 réservait au roi le droit de créer dans chaque métier trois maitrises dont les titulaires seraient exempts de chefd'œuvre (art. 1); la mème disposition se retrouvait dans l’édit de 1:397. Ce n'est pas le seul article où apparaisse l'esprit fiscal dont ils procédaient en grande partie l'un et l'autre. Sous prétexte des arantages quils leur procuraient et pour indemniser le fise des droits indùment payés aux rois des merciers depuis l'époque où François $I^{\text {er }}$ avait ordonné leur suppression, tous les marchands et artisans élaient soumis à un droit variant d'un écu soleil (9) fr. un demi-écu (4 fr. 7ö) dans les grrandes villes et de la moitié dans les endroits moins importants. Les banquets de réception étaient interdits.

II serait injuste d'attribuer cet édit à une pensée purement fiscale; il y aurait, d'autre part, de l'areuglement à méconnaitre quil est inspiré en partie par le désir de se procurer des ressources pour payer la solde arriérée des Suisses, car ce désir ne prend pas la peine de se dissimuler. Mais surtout il faut se garder d'y voir avec M. Poirson linauguration de la liberté industrielle. Ce qui a trompé M. Poirson, c'est que l'édit accorde la maîtrise à tous les artisans qui, au moment de sa promulgation, exercent des métiers qui ne sont pas érigés en maitrises et en jurandes; mais il n'y a là qu'une de ces dispositions transitoires comme on en trouve toujours dans les lois qui substituent une organisation uniforme à une organisation disparate. Il y a toujours alors des droits acquis à régler, des situations à faire cadrer avec le r'égime nouveau. C'est ce que 
fail Henri IV en élerani au rang de maitres, sans leur rien demander yuin serment, les industriels et les commergants restéson dchors d'un systìne que le règlement général de $1: 38$ n'avait pas réussi ì faire prévaloir dans tout le pays. Que l'on considere les dispositions essentielles et permanentes de l'édit. on y reconnaitra une ourre de resfanration et non d'innovation. Loin d'ètre abolies, comme des entraves ginantes pour l’industrie, les épreures imposées aux candidats à la maitrise élaient confirmées et ramenées ì leur but primitif, comme des garanties également commandies par l'intérèt du public et par celui des corporations. Larticle qui réserve au roi le droit de créer dans chaque méticr trois maitrises en faveur de personnes n'ayant pas fait de chef-d'aure, dit assez clairement que l'immense généralité des artisans reste soumise à cette condition. Si l'édit nost pas plus explicite à cet égard, c'est quill ne fait que confirmer, en létendant aux commerȩants, le règlement ginéral de $1: 381$, il lui suffit lone de sy référer, et c'est ì l’aide de ce règlement qu'il faut comprendre ses réticences et son esprit général ${ }^{1}$.

II. Plitippson ${ }^{2}$ a contesté avant nous la portée exagérée attrilutée par M. P'oirson à l'édit d'arril 1997 , mais il a invoqué contre l'interprétation de M. Poirson un fait inexact et que les preuves alléguées par lui sont bien loin d'établir. La preuve que l'édit n’étahlit pas la liberté du travail, c'est, dit-il, que le nombre des maitrises resta limité. Présentée sous cette forme générale et absolue. son affirmation est erronée. Le nombre des maîtres n'était pas, dans la plupart des corporations, directement et expressément fixé; ce qui est vrai, e'est que les maîtrises étaient deremues inabordables pour ceux qui ne pouraient

1. L'f́dit dit d'ailleurs expressément qu'il faut se guider dans son appliration par le régiement général (art. 6.

2. Heinrich IV und I'hilipp III. Berlin, 1876, II, 349 note 2. 
supporter les frais fort onéreux que les maîtres en exercice et les délégués des rois des merciers imposaient aux aspirants. En principe, les corporations restaient ouvertes à tous ceux qui avaient rempli les conditions de la maîtrise, mais ces conditions avaient été tellement dénaturées qu'elles en fermaient l'accès à presque tous les candidats sans fortune ou qui n'avaient pas de parents parmi les maîtres.

L'édit de 1:997 ne fut guère mieux observé que le règlement général de 1581. Il avait le tort, aux yeux des corporations, de leur imposer des sacrifices pécuniaires et d'introduire dans leur sein des concurrents sans titre. II y en eut parmi elles qui obtinrent nne réduction des droits, la plupart remboursèrent les acquéreurs des lettres de maîtrise eréées par le roi $^{1}$ ou payèrent aux parties casuelles la finance à laquelle ces lettres avaient été taxées. L'édit fut bien accueilli par certains industriels exerçant des métiers libres et heureux de s'en assurer le monopole, ainsi que par les membres de certaines corporations qui linroquèrent un peu abusivement pour se détacher de ces corporations et en former de nouvelles ${ }^{2}$. Lopposition quil souleva, les malversations et les abus dont se rendirent coupables les commissaires chargés de le faire mettre en vigueur, en firent surseoir l'exéeution ${ }^{3}$.

1. Cette double faveur fut accordée aux merciers de Paris par un arrêt du 18 janvier 1598. Bibl. nat. fr. 18162, fol. 54.

2. "Quoy que la finance volontairement payée dans les coffres du roy Henri IV par la communauté des marchands maistres plumassier's, panachers, bouquetiers et enjoliveurs de... Paris leur ait procuré les assurances d'un establissement honorable, ainsi qu'il est déclaré par le premier art. desd. statuts de juill. 1599. "Collection Delamare, Arts et mét., VIII. Bibl. nat., ms, fr. 21 1998 , pièce 15\%. En exécution de son édit. IIenri IV érigea en jurande le métier de découpeurs-égratigneurs-gaufreurs sur étolfes. Même coll. fr. 21792 , fol. 232 et suiv. Cahier des brodeurs et des taillandiers aux états de 1614. Archives nat., série k.

3. Arrêt du conseil du 19 aoùt 1599 . A Tours, le commis à la recette des droits fut emprisonné par ordre de l'échevinage (25 aoùt 1598). L'échevinage de Poitiers forma opposition it l'exécution de l'édit, et en conséquence 
La ville de Lyon, yui avait fait valoir ses privilèges pour itre allrumehie de son application, obtint gain de cause ('n $16066^{\circ}$. En 1602, en 1608 il y avait encore nombre de villes oì il n'existait pats de jurandes², et les rois des mereiers navaient pas encore disparu en 161 ', puisqu à eette date le tiers état inserivait dans son cahier de doléances le rueu de leur suppression ${ }^{3}$.

Laffemas ne se laissa pas lécourager par l'aceueil que les notables araient fait it son projet, il ne ressal de provoquer la sollicitude du roi en faveur de l'industrie et du commerce du pays. Dans le plus imporlant des mémoires quill lui adressa à ce sujet, il présentait sous la forme d'un édit un plan de réformes où l'on retrouve en partie les idcies sur lesquelles les notables avaient en à se prononcer. P'our fortifier ces idées de l'approhation de la classe compétente, il recueillit, de l'aveu du roi. l'avis desprincipales corporations parisiennes. Cette enquète, ouverte en 1398 , dura jusquen 1600. P'rohibition des produits nanufacturis à l'étrauger, défense d'exporter les matires premieres, établissement d'un nouveau droit de mirnue d'un sol par live sur les articles fabriqués pour remplacer le revenu des

le súnéchal de P’oitou relusa de le publier et de le faire exéculer. Le conseil lui ordonna de passer outre par arret du 28 nor. 1.59s. Fr. 18163, fril. 93. Le roi dut envoyer des commissaires á Angers, à Saumur, i . lix, i Toulouse, it Bordeaux, a Troyes, pour en assurer l'enregistrement et li publication. Arrêts du conseil des 13 jans. et 1't fúvrier 1598 . Fir. 18162 ,

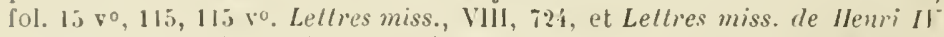
conservées dans les archives municipales de lroyes, publiées par I. Boutiot. Troyes, 1857 , in-8 ${ }^{\circ}$, p. 56.

1. Arrêts du conseil du 24 janvier 1598. Arrêt ordonnant ì l'échevinage de Lyon de justifier de leur's privilèges et jusque-là de surseoir á l'exécution de lédit. 211 janvier 160 \%. Fr. 18162, fol. 55. Inventaire des arch. 11unicipales de Lyon. Reg. IBB 137, 138. Levasseur. II, 161.

2. Lellresmiss., I, 62i, Doe. inéd., p. I66. "N"estoit le mestiel de sellier juré de sorte que qui vouloit travailler d'icellıy le pouvoit faire. "Sentence de l'écherinage de Bourges rendue le i déc. 1595. Tolbeau IE Malmxxtve, Les anciennes corporalions ouvrières it liourges, p. 20't. "... is villes on il y aura maistrise et jurande. "Cahier" des honnetiers anx états de 1614 .

3. Cahier du tiers état, p. ?li. 
douanes extérieures, unité des poids et mesures, création d'un contrôkeur, d'un intendant et d'une chambre du commerce, revision et réforme de l'organisation des corporations par une commission de donze anciens commerçants nommés par l'échevinage parisien, application de cette nouvelle police aux artisans et marchands suivant la cour, désignation par les corporations des titulaires des lettres de maitrise, taxe des salaires des ouvriers et surveillance de leur conduite par les gardes-jurés, arbitrage de cenx-ci sur les différends entre gens de même métier, altribution anx mêmes de la connaissance en première instance des plaintes contre les maitres, abolition des confréries, ouverture d'ateliers publics pour faire travailler les paurres, tels étaient les moyens que Laffemas proposa au roi pour rendre à l'industrie sa prospérité et sur lesquels il consulta les corporations parisiennes.

Sans se prononcer sur tous ces moyens et en faisant le leur côté certains vorux inspirés par des intérêts particuliers, les corporations adhérèrent aux principales idées de Laffemas; elles se montrèrent surtout unanimes, à une exception près, à réclamer la prohibition des produits de Iindustrie étrangère. La seule qui ne s'associa pas à ce vœu, qui se déclara même contre la prohibition, fut celle des merciers, qui vivait exclusivement du commerce et dont le commerce s'alimentait, en grande partic. de marchandises étrangères ${ }^{1}$.

Par lettres patentes du 13 arril 1601 , le roi nomma une

1. Voir pour ces deux paragraphes les Remontrances en forme d'cid et les avis des corporations imprimés à la suite dans l'édition originale qui porte pour titre : La commission, edit et partie des memoires de l'ordre et establissement du commerce general des manufactures en ce royaume. Paris,

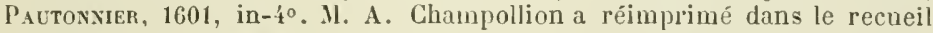
précité les Remontrances en forme d'édit. Ce fut Laflemas qui résuma par écrit les rœux des corporations dans leur ensemble pour éviter les redites qu'aurait présentées la rédaction des voux de chacune en particulier. Cette rédaction fut faite par-devant notaires el soumise aux corporations qui y signalèrent une omission. 
commission de dix-sept personnes pour examiner le projet l'édit de Laffemas et les documents à lappui et pour préparer, après avoir procédé, si besoin élait, à une nourelle 'nquête, des rìglements sur le commerce et lindustric '. II suffisiit de la présence de sept de ses membres pour rendre ses délibérations valables. Eille arait le droit de citer devant elle, par tous les moyens de publicité et au hesoin par huissier, les personnes et les corps qui pouraient hui donner des renseignenents utiles². Complétée ou modifíe par d'autres lellres patentes du 10 juillet $160 \mathrm{I}^{3}$, elle adoptir, après quelques séances, un projet de réformation du commerce qui, soumis au conseil, fut approuré par lui. Comme, par suite de la mort de plusieurs le ses membres et de limpossibilité de plusieur's autres d'assister aux séances, elle nétait plus en nombre, le roi la renouvela et roulut que désormais leux marchands de Paris, ćlus par leurs confrères, prissent part aux délibérations ${ }^{4}$.

Il est regrettable qu'on n'ait pas conservé le projet de

1. Cette commission se composait des sicurs de Rambouillet, chevalier de l'ordre, de Verdun, président au parlement, d'llacqueville, président au grand conseil, de Charmeaux, président à la chamhre des comptes, de Rebours. président i la cour des aides, de Rancher, président de la troisième chambre des enquítes du p̧arlement, dozembray, président des remuites du parlement, de Nicolas Prevost et liaoul le Feron, conseillers de lí chambre des comptes, du prévôt des marchands, d'un échevin, de Vicolas te Beauclerc, trésorier géneral de France i Paris, de Cardin le Bret, avocat général a la cour des aides, de Charles du Lys, substitul du procureur genéral au parlement, de Galliot Mandat, conseiller et secrétaire des finances du roi, de Rolsert des l'rés, inocat au parlement, de Charles Poussemolte, secrètaire du roi, de sa maison. couronne de France et de ses finances, faisant fonction de secretaire.

2. Voy. les lettres patentes dans Cinsupoltiox, p. xin.

3. Elles sont visées dans celles du 20 juillet 160\%. Cila upolliox, p. 2.

1. Lettres patentes du 20 juillet 1602 . Ibiel., p. I. La nouvelle commission etait formée des sienrs de Rambouillet, de Rebonrs, Cardın le Bret, ithirles du Lys, Charles Poussemotte et liobert iles l'res, membres de l'anrienue, du juésident Jeannin, de Jles Braselonue, de lirieux et Vicolas (Chevalier, conseillers au parlement, de Charles lienoit et Pierre de Pincé, cunseillers de lia chambre des comptes, qui remplaraient les membres morts uu culpiches. A ces douze membres de droit pouvient se joindre le prérôt de's marriands at les echerins ou l'un d'eux et deux commersants parisicus elus. 
réformation si rapidement délibéré et roté par elle. On roit du reste, par les termes dans lesyuels en parlent les leftres patentes du 20 juillet 1602, qüil n'avait pas été positirement adopté par le conseil, puisqu elles assignent précisément pour tâche à la commission de l'examiner' de noureau et de l'arrèter définitivement. Les procèsrerbaux de celle-ci ${ }^{1}$ montrent par leur silence quelle se déroba à cette tâche et qu elle ne revint pas sur le projet en question. Ciest même un l'ait digne de remarque que le peu de place occupée par la réforme de l'organisation industrielle et commereiale dans les délibérations de l'assemblée et à quel point elle négligea cette partie de son programme. On ne peut expliquer son abstention par l'opposition des corporations à toute modification du régime existant; tout au contraire elles aspiraient à la suppression des abus qui s'étaient développés dans leur sein a la faveur des guerres civiles et à la restauration de leur ancienne discipline 2 . Nous royons mème certains fabricants d’Amiens, dont la profession n'est pas autrement spécifiée. présenter requète à la commission pour obtenir un règlement sur leur industrie, et la commission décider qu'elle examinera leurs anciens statuts pour en proposer' un nouveau au roi ${ }^{3}$. Parfois aussi ceétait spontanément qu'elle abordait ce trarail de revision et de codification de la législation industrielle et commerciale, mais ce n'était jamais sans des tàtonnements bien explicables par la disproportion de cette tàche arec ses moyens. Tantôt clle songeait à procéder métier par métier et commençait par

1. Nous ne possédons pas de procís-verbaux antérieurs à la reconstitution de la commission (20 juillet 1602) et il est fort douteux qu'il en ait èté rédigé. Ceux qui nous sont parvenus commencent au $1 i$ août de la même année.

2. Lettres patentes du 20 juillet 1602 . Ubi supra. Remontrances en forme d'édit dans Champollox, p. xxxm. Avis des corporations à la suite de ces Remontrances, éd. orig. p. i.

3. Procés-rerbaux de la commission dans Champoliox, p. 9i. 
la draperie, tantit, adoptant la méthode de Lalliemas, elle affrontait un travail d'ensemble et ordonnait le dépôt au grefle des statuts et des riglements professionnels ainsi que des mémoires signalant les abus dont l'abolition était demantie. De quelque façon qu'elle s'y prìl, elle s'arrêtait dicouragie.

l.'st qu'en effet une pareille mission, qui l'amenait it exammer loutes les requêtes des intéressés, à prononcer sur lemrs prétentions contradictoires, à se faire une opinion s IIr une foule de questions techniques, dépassait évidemment les forces et la compétence des quinze ou seize personnes que le roi avait prises dans les cours souveraines ct les rangs élevés de l'administration. Pour l'accomplir, il anrait fallu une commission permanente, où l"industrie et le commerce auraient été plus largement représentés. C'ent de ces denx intérèts de permanence et de compétence que Laffemas avait tenu compte en demandant la création d'un conseil de conservateurs du commerce, composé de douze persomnes rétribuées, appartenant à la magistrature et à ladministration et se renourelant par moitié tous les ans et celle dime commission de douze notables anciens commerçants et industriels parisiens, nommés par l'échevinage et chargís de faire un règlement général pour tous les corps de métiers du royaume. Son plan comprenait aussi la création d'un surintendant ou contrôleur général du commerce. Le roi réduisit les deux conseils qui faistient partie de ce plan ì un seul, composé, comme on l'a $\mathrm{v}^{\prime}$, de magistrats et d'administrateurs, auxquels furent associés deux négociants, et conféra à Laffemas la commission de contrôleur général ${ }^{1}$. Le conseil de conmerce, lepuis le monnent où il fut reconstitué (20 juillet 1602) jusqu'iu 26 octobre 1604, tint cent soixante-seize séances.

1. En attendant qu'elle devint une charge en titre d'office. Voy. les lettres de rommission du lis nov. Ico2. Procis-verbaux, p. 30. 
Sil naccomplit pas la revision et la refonte du régime industriel et commercial, il adopta, dans l'intérèt d'un grand nombre dindustries particulières, des mesures que nous aurons à signaler et à apprécier quand nous nous occuperons de ces industries.

En même temps qu'il essayait d'anéliorer le systìme des corporations, Ilenri IV exemptait de leur étroite réglementation les hommes quil jugeait dignes de cette faveur par leur talent et par leur originalité. Il existait déjà sous ses prédécesseurs des asiles ouverts à la liberté et au progrès des arts mécaniques. Il en augmenta le nombre en installant dans la grande galerie du Lourre qu'il venait de terminer des artisans d'élite, en y créant une réritable école de beaux-arts et d'arts industriels. Dès 1600, la grande galerie était occupée par un certain nombre de ces ouvriers hors ligne ${ }^{1}$. Les vexations des corporations vinrent les y troubler. Le roi rendit alors, le 30 juin 1607 , des lettres patentes autorisant les hôtes du Louvre à travailler pour le public, et les apprentis formés par eux à sétablir dans tout le royaume sans faire de chef-d'œurre ni prendre de lettres de maîtrise. Malgré ces lettres patentes qui ne furent enregistrées par le parlement qu'arec certaines restrictions, ces artistes privilégiés restèrent en butte aux persécutions de leurs adversaires et furent entravés dans le droit de travailler pour le public et de faire receroir leurs apprentis à la maîtrise. Mais le roi confirma leurs priviléges par d'autres lettres du 222 décembre 1608 qui acceptaient une partie des réserves formulées par le parlement et tenaient les autres pour non avenues. Elles exemptaient les protégés du roi des visites et de la police des corps de métiers, ouvraient l'entrée de la maîtrise à leurs apprentis sur le vu d'un simple certificat de leur maitre, dispensaient

1. Berty, Topographie hist. de Paris, II, 100. 
ces apprentis de se firire inserire au parquet du Chatelet, assuraient anx maitres la conservation de leurs privileges dans le cas où ils quitteraient la galerie sans leur faute, mais obligeaient les orferres, comme l'avait voulu le parlement, à faire marquer leurs ouvrages par les gardesjurés de la corpuration. Les irtistes, les inventenrs et les savants auxpuels elles accordaient le logement et les arantages qui y étaient attachés, étaient Jacol, Bunel, peinlre, valet de chambre du roi, Abraham de la Ciarle, horloger. valet de chambre, Pierre Courtois, orfève, valet de chambre de la reine, Franqueville, sculpteur, Julien de Fontenay, graveur en pierres lines, ralet de chambre, Nicolas Roussel, orfève parfumeur, Jean Séjourné, sculpteur fontainier, Guillaume Dupré, sculpteur et contrôleur général des poinçons des monnaies de France, Pierre Varinier, coutelier et forgeron d'épées en acier de Damas, Laurent Setarbe, ébéniste faiseur de calbinets, I'ierre des Martins, pein tre, Jean Petit, fourbisseur, loreur, damasquineur, Étienne Raulin, fabricant d'instruments de mathématiques, Alleaume, professeur de mathématiques, Maurice du Bout, tapissier de haute lisse, l'ierre du Pont, tapissier de tapis du Levant, Marie Bourgeois, peintre, valet de chambre, sculpteur, ouvrier en globes mouvants et autres inventions mécaniques. Les lettres patentes rendues en faveur des hommes distingués que nous venous de nommer furent enregistrées le 9 janvier $16099^{1}$.

Henri IV eut aussi l'idée détablir au Lourre un musée de machines, d'inventions mécaniques, de modèles industriels; il demanda à Sully ${ }^{2}$ un projet pour l'installation de ‘ musée, mais eette idée ne fut pas réalisée et il laissa à 
dautres l'honneur de créer le Conservatoire des irts et métiers.

Ce n'est pas dans ses efforts en grande partie infructueux pour réformer l'organisation générale de lindustrie que Henri IV se montra original et créateur; il n'ent pas au contraire de modèle ni de précurseur dans la tentative de faire de la France un pays industriel en la dotant d'industries nouvelles ou en rendant la vie à des industries rqui dépérissaient.

La première qui l'occupa fut celle des soieries. Elle méritait cette sollicitude à cause de l'usage très répandu des étoffes de soie au $\mathrm{xvl}^{\mathrm{e}}$ siècle. Par suite de cette loi qui fait que le goût de l'épargne diminue et que celui des dépenses improductives augmente dans les sociétés qui ne jouissent pas de la sécurité du lendemain, le luxe s'était beaucoup développé pendant les guerres civiles et se manifestait notamment par un goût pour la soie qui avait gagné jusqu’à la bourgeoisie, jusqu'au peuple. Les négociants en soieries qui, avant les dernières années du $\mathrm{xvl}^{\mathrm{e}}$ siècle, n'étaient que cinq ou six à Paris, s'y étaient multiplićs à l’infini ${ }^{1}$. Ce gont des étoffes de luxe coùtait annuellement à la France, d'après l'estimation de l'homme le plus compétent en pareille matière, 13. Laffemas ${ }^{2}$, six

1. Reigl. gen., p. T. Lafrexas, La faron de faire et semer la graine de meurier... 1604, in $-8^{\circ}, \mathrm{p} .31$.

2. Recueil de ce qui se passe en l'assemblée du commerce, 1604, dans Chislrolliox, p. 284-255. Dans sa Réponse à MM. de Lyon (p. 3-4), Laffemas estime à sept millions d'écus d'or (66 496721 fr. 28 ) au moins l'importation tant des soies que des soieries venant d'ltalie. Ailleurs (La commission, édit... ducommerce général.., p. 37), il fixe approximativement à 2500000 écus (23748 829 fr. 03) la valeur de la soie qui entre annuellement en France. Dans un document officiel, la valeur de la soie étrangère introduite dans notre pays est évaluée à trois ou quatre millions d'écus d'or (le 2849859 i fr. 83 à $37998126 \mathrm{fr}$. 45). Mandement du 7 décembre 1602 . Isıuвert, XV, no 163. LE Tellier, marchand de soie et auteur de plusieurs ouvrages de sériciculture, porte d deux millions d'écus (1×999063 fr. 22) le chiffre de l'importation des soieries étrangères. Brief discours, etc. Voy. plus bas sur l'auteur et l'ourrage. Dans la Commission, edit, etc... 
millions d'écus (:36997189 fr. 67). En effet, les decuments que Laflemas, en sa qualité de contrôleur général du commeree, at ens entre les mains, doivent faire préférer son estination, qui est d'ailleurs confirmée par P. Cayet ", il celle d'Olivier de Serres qui ne porte qu'i ynatre millions d'écus (37998 126 lr. 4.3), la raleur des soieries importées.

Pour comprendre la préoccupation que cette inportation inspirait au gourernement de Ilenri $\mathbf{I}$, il faut se rappeler que, le muméraire étant alor's considéré comme la valeur par excellence. lexcédent des importations sur les exportations représentait, aux yeux des hommes d'Étal du temps, une perte sans compensation. Celte doctrine ćconomique, Ini fut érigée plus tard en systime et presque en dogme, sous le nom de balance du commerce, donnait une grande importance à ce goùt passionné des soieries et à l'insuffisance de la production nationale pour y satisfaire. HenriIV ne fut pas sans doute le premier de nos rois qui tentat, en naturalisant che\% nous l"industrie des soieries, d'affranchir notre pays du tribut que notre anour des étoffes de luxe payait à l'étranger, mais aucun de ses prédécesseur's n’avait conçu ce projet dens d'aussi rastes proportions et ne l'avait embrassé arec tant d'ardeur.

Sous n'arons pas it remonter anx plantations de muriers laites en Provence, soit, comme le dit Olivier de Serres, à la suite de l'expédition de Charles VIII en Italie ${ }^{2}$, soit plutôt, comme le dit II. de Gasparin ${ }^{3}$, par suite des rap-

parties onises par Cummolnox), l'estimation de Laffemas ne dépasse pas cinc millions d'écus $474976.38 \mathrm{fr}$. 06) : "Il peut venir des itrangers tous les aus quatre is cinq mil balles le soie et plus que vallent au moins chacune 500 icus... et outre six mille balles de tleurets, frizolle el prétunche que nous mettrons seulement pour six mille balles de soie it la raison susilite..."

l. Chronologie sept., p. 64, anno 1599.

2. Thécitre d'agriculture, éd. I80i, in-4o, $11.10 \mathrm{~s}$.

3. Recueilde mémoires d'agricullure et d'éconsmie rurale. Müriers, vers is soie, III, i2-73. 
ports que la domination de la maison d'Anjou à Naples amena entre la Provence et les Deux-Siciles, nous nirons pas à nous occuper non plus pour le moment des fabriques élablies avant Ilenri IV à Tour's et à Lyon. Il suffira de dire qu à la fin du $x^{\prime}{ }^{e}$ siècle, on cultivait le mùrier arec succès non seulement en P'rovence, mais en Languedoc, dans les Cérennes, dans la principauté d'Orange, dans le comtat Venaissin ; cet arbre brarait mème le climat moins chaud de la Touraine, le climat rigoureux de Saint-Chamond et de Saint-Romain dans le Lyonnais. La soie quon recueillait dans ces direrses régions ne le cédait pas à celle de l'Italie. Tels étaient, au témoignage de Laflemas * et avant que IIenri IV soecupât de la sériciculture, les points assez nombreux et d'une latitude assez différente où elle florissait.

C'est en 15096 que le roi manifesta pour la première fois son intérèt pour l'industrie de la soie. Il fil planter cette année dans le jardin des Tuileries des mùriers de trois ans qui réussirent si bien qu'en 160 ' ils paraissaient avoir plus de vingt-einq ans ${ }^{2}$. Ce fut aussi, on se le rappelle, en 13996 que l'assemblée des notables demanda que le marché français fùt fermé aux soieries étrangères, sans savoir si l'industrie nationale était en étal de l'approvisionner', sans chercher à lui donner une vigoureuse impulsion.

Henri IV tomba dans la même errenr. Les fabricants de soieries de Tours sétant faits forts de suffure aux besoins des consommateurs, le roi, contrairement à l'avis de Sully ${ }^{3}$, se laissa arracher par eux, au mois de janvier $1 \% 99$, un édit qui prohibait l'entrée des étoffes de soie, d'or et d'argent '. Mais ils s'étaient abusés ou avaient abusé le roi sur

1. Reiglement general.

2. Lafrenas, La facon de faire et semer la graine de mürier, p. 29.

3. Economies roy., IV, 53-54.

4. Isambert, XY, 21\%. P. Gayet, Chr. sept., 6i. J.-A. De Thou, V, 838 . Les Lyonnais araient combattu la prohibition dans des mémoires qui répon- 
leurs moyens et sur les besoins du marché français, leur fibrication resta fort au-dessous de la demande, le prix des soieries haussa d'une façon considérable et le public se plaignit. Les intérêts des banquiers ct des fermiers de la domane de Lyon, aux revenus de laquelle les soieries italiemes contribuaient pour une large part, furent alteints. Leurs plaintes, jointes au mécontentement général, déciderent le roi, qui se trourait alors dans celte ville, à ripporter son édil 1600$)$.

Tout en se montrant dè $1: 96$ partisan de la sériciculture, IIenri avait hesoin d'itre édifié sur la valeur des objections élerées contre elle, sur la question de savoir jusqu'à quel point le climat de la France était favorable à la culture du murier, à l'élève des vers à soie. Ce ful Olivier de Serres 'qui leva ses demiers doutes à eet égard. Le savant agronome se trouvait ì la cour en 1.999, c'est lui-même qui nous l'apprend. Il est permis de croire qu il y arait été appelé par le roi pour l'entretenir de cette question, il est certain du moins quil le fit. En composint son traité La cueillette de la soye par la nouriume des vers qui la font (1599), it oléissait à une invitation partie du trône'. Dans ce traité

daient a ceux des manufacturier's tourangeaux. Non contents de cela, ils envoyerent au roi des délégués qui lui firent remarquer que la défense de limportation ferait perdle au Trésor 400000 écus (3 799812 fr. 64) par all. L.infatigable Laffemas prit la plune pour réfuter leurs alguments. Les brochures des deux partis furent soumises aux corporations parisiennes pour aroir leur avis. Cette lutte entre une ville mannficturicie et une ville de commerce et de banque autant que de fabrique est digne d'attention. Voy. B. Lafremis, Réponse it messieurs de Lyon, lesquels venlent empescher 'ompre le cours des marchandises d'Italie avec le préjudice de leur's foires el l'abus aux chunges, Paris, Prevosteau, 1598, in- $8^{\circ}$.

1. Dédicace de ce traité qui a été reproduit dans le Théatre l'agricullure. J.-A. IE THov, VI, 169. Parmi les propagateurs de la sériciculture, il ne faut pas oublier le jardinicr nimois, francois Traucat. Voy. son lis-rours abrégé lant sur les vertus el les propriétés les meuriers, lant blunes que noirs, uyant petiles meures blanches et petites noires, qui ont semblables fruilles, propres a nourrir les ver's it soie el uussi propres it servir tant aux rorps lumains qu'ì faire bean.c meubles el ustensiles zle mesnage. Composé far F. T. maistre jardinier en lin ville de Nimes en Languedoc, qui, depuis 
il exhorte l'échevinage parisien à encourager la culture des muriers et signale les chàteaux royaux de Madrid et de Vincennes conme pouvant en contenir trois cent mille. II combat cette idée que la culture du mùrer et l'élève des rers à soie ne sont possibles que dans les pays chauds; comme preure du contraire, il allègue la soie recueillie à Leyden par les soins de la duchesse d'Arschot, et il pose en principe que le mùrier peut venir là où vient la vigne. Il recomnaît seulement que la récolte de la soie est plus lardive sous un climat froid. II estime ensuite le produit, la valeur de la récolte. Un millier de feuilles nourrit une once de graine de vers, chaque once rend cinq ou six livres de soie, dont chacune vaut 2 ou 3 écus au moins ( $19 \mathrm{fr}$. ou $28 \mathrm{fr} .50)$. Chaque once rapporte donc au moins 10 ou 12 écus $\left(9 \% \mathrm{fr}\right.$. ou $11^{\prime} \mathrm{fr}$. ). Quant à la main-d'œurre, il suffit de cent ou cent vingt journées pour recueillir et transporter dans les magnaneries de quoi nourrir dix onces de graine, et ce travail peut ètre fait en grande partie par des femmes et des enfants. Le surveillant de la magnanerie sera payé 3 ou 4 écus (38 fr.), outre sa nourriture. Le prix de la graine de vers est insignifiant et doit être compté, arec la construction de la magnanerie, parmi les premiers frais d'établissement, car, bien quil soit nécessaire d'acheter chaque année un peu de graine nouvelle pour conserver la qualité de la race, la rente de la graine recueillie par l'éleveur lui permet d'acheter des œufs. L'élève des ver's a l'arantage de ne pas détourner des travaux des champs, car c'est avant la récolte, anx mois d'avril et de mai, qu'il conrient d'y donner ses soins. 0 . de Serres déclare que la

lan 1564, a planté ou fait planter es provinces de Langnedoc et Provence plus de quatre millions de meuriers... Jédié au roi. Paris, 1606. Le 16 décembre 1602, Traucat s'associa avec Étienne Aigue, marchand de Bagnols, pour l'exploitation d'une pépinière de mùriers. P $\mathrm{EECH}$, Une ville au lemps jartis..., $8^{\circ}$. 188i, 532. Voy. aussi Éloge de Traucat, par II. Vincexs SarntLacrest, dans les Mémoires de la Soc. centrale d'agricult., 1817, p. 468. 
P'icardie, la Normandie, la Bretagne ne sont pas, à l'exception de quelques cantons, farorables ì la sérierculture, mais quelle convient à la Champagne, à l'Ile-te-France, ì la Bomrenge, an Nivernais. au Beanjolais, an Miconnais, au Lyonnais, an lierry, à l'Orléanais, an Limonsin, au P'oitou, à la saintonge, à la limyeme, ì la Giscogne. Il domne ensuite des reggles pour l'établissement de la mûreraie, il italilit que le rer, nourri du murier blanc, donne une soic plus line que celui qui est nourri du murier noir, bien yuion tire bon parti de la soie plus grossière lournie par relui-ci dans certanes parties de la Lombarlie. it Anduze. ¿ Alais. dians d'autres endroits des Cévemnes. It piasse ('nsuite aux conditions dans lesquelles on doit élablir la magnanerin, recommande la senence te rer d'Espague comme la meilleure, en constalant la réputation que celle de Calalie al acquise depuis quelques anmées a cause de sil fécondili: puis il s'ocenpe successirement de l'éclosion des vers, de la formation et du devidage des cocons.

Lamnere qui suivit la publication de la Cueilletle de la swye. (1). de Serres et le sienr de Bordeaux, baron de Colonces. surintundant général des jardius de France, furcut clargés de recueillir en Provence, en Languedoc et en Vivarais, des plants de mûrier pour les jardins royanx : Au commencement de 1601, 0. de Serres put en enroper it Pallis quinze à vingt milte pieds. Ils furent plantes aux Thileries, dans le pare de Madrid² et ì Fontiineblean". Ceux du jardin des Tuileries réussirent si bien qu au bout de deux ans et demi ils dépassaient la taille humaine la plus élevée. Des magnaneries furent construites dans ces trois résilences royales, sous la direction du Lucquois Manfredi Balbani, qui sètait chargé de farre renir

1. Thritie d'ugriculture, II, 108 .

2. P. Cayer, Chronologie s"pléncire, anno IC03. II, 25!).

3. Econonies royales, anno 1605. 
de Geneve des personnes propres ì diriger les plantations'. En 1603 lorangerie des Thileries fut transforméc en magnanerie pour y faire éclore la graine de rer a soie que le roi arait fait renir d'Espagne 2. La magnaneric qui y existait déjà contenait un atelier pour les premières préparations de la soie ${ }^{3}$. Au chàteau de Madrid on ne se livait pas non plus exclusivement ì l'élève des vers, mais anssi au moulinage, à l'organsinage de la soie'. Lin 1602 Paris reęut du Languedoc soixante mille mùriers yui, replantés par les Parisiens dans leurs jardins, reprirent bien ${ }^{5}$. Laffemas, (qui nous l'apprend, ajoute quaprès aroir comparé les soies recueillies ì Paris aux meilleures soies italiennes, à celles de Sainte-Lucie en Sicile, de Bassano, de Bologne, on constata que quinze onces de soie l'rançaise valaient dixhuit onces de soic italienne ${ }^{6}$. Or Laffemas devait ìtre mieux informé que J.-A. de Thou qui prétend que le climat des environs de Paris compromit le succès de ces tentatives?

Henri IV invita le conseil lu commerce ì délihérer sur les moyens les plus propres à doter la France de la sériciculture et de l'industrie des soieries. Le conseil passa deux contrats, l'un le 20 aoùt, l'autre le 1 '́ octolse 1602 , pour la fourniture de plants et de graine de mùrier, ainsi que de semence de vers, dans les quatre généralités de Tours, de Lyon, de Paris et d'Orléans. La principale différence qui

1. J.-A. DE Thou, 169. Théâtre d'agriculture, 1I, 111. Recucil de ce qui se passe en l'assemblée du commerce, dans Cinarolion, p. 285. Letlres miss., I, 206. Bibl. de l'Institut, coll. Godefroy C.IVI.

2. Lettres miss., $\mathrm{VI}, 63$.

3. Théâte d'ugriculture. Ubi supra.

4. P. Caret, Chronologie sept., 11, 259.

5. B. Lafrenas, la preuve du plant et proffit des meuriers. Paris, PsuTONXIER, I603, P. 13.

i. Ibid., alt. is.

7. VI, 169. " Nous avons recogneu en ces trois dernières années, écrit Le Tellier en I602 dans la dédicace a Mme de liosny de son Discours contenant la manière de nourrir tes vers a soye et la tircr avec figures et interpretations d'icelles, que les soyes faictes en France sont plus belles et [jus fines que les estrangeres." 
distingue ces contrats, c'est que le premier lixe le bénéfice des cutrepreneurs pour la fourniture des quatre généralités a 13 ícus (123 fr. :00 par paroisse, tandis que le second leur accorde une roblihution en hloc de 120000 livres' (3ïi) 7.il fr. 94). Ce dernier stipulail que, l'année suivante (1603), quatre antres grinéralités seraient approvisionnées de plant, de graine et da semence et qu'en lib)'toutes les généralités seraient mises en état de cultiver le mùier et délever des rer's à soie. En mème temps que du plant, de la graine et de la semence, les deux entrepreneurs devaient distribuer des instructions et envoyer dins chaque élection, un an apris la plantiation, des personnes capables de guider la population. Ce contrat était passé pour six ans². Le projet en fut approuve par un arrèt du conseil du 4 octobre $1602^{3}$ ct il fut conclu le 14, ainsi que nous l'arons dit. Homologać par lettres patentes le 23 du mème mois, il ne lui manquait rien pour être exéculé, lorsque les objections du sieur de Bordeaux, intendant général des jardins du roi, en firent surseoir l'exécution. Ces objections, que nous fait connaìtre le rapport du sieur du Lys, délégué par la commission pour les disculer et faire accepter le contrat, furent appuyées par Sully, qui y joignit les siennes. Mais le délégué de la conmission, assisté d'un des entrepreneurs, cn triomphal et fit adopter le contrat par le conseil. On y ajouta seulement une clause qui donnait satisfaction à la première ohjection du sieur de Bordeaux, en obligeant les entrepreneurs ì créer des pépinières de mùricr blatue dans les quatre geinéralités, pour remplacer graluitement les plants distribués anx proprićtaires et morts sans leur faute ". L'n mandement royal du 7 décembre 1602 adressé aux élus régla l'exécu-

1. P'rores-rerbaux dans Cilımpolusos, p. 10-23.

2. Ilierl.

3. Ihal. p. 23. Cf. Lettres pratentes de ratification la 23 octobre, p. 27.

4. Addition faite l. 3 lícembre au contrat du 1 i octobre Ic02. Procésverbaus, p. ii. 
tion du contrat. Il prescrivait les mesures suivantes. Les élus répartiront entre les paroisses de leur élection, à l'exception de celles où, pourdes causes diverses, la culture du mûrier ne peut réussir, du plant de deux à trois ans et de la graine pour pépinière, plant et graine qui seront fournis par les entrepreneurs, conformément au contrat passé arec eux. Les communautés déclareront au greffe de leur élection le nombre, l'ìge, la grosscur des minriers existant déjì dans la paroisse, afin que les entrepreneurs puissent leur procurer des œufs en proportion des moyens que la paroisse offre pour les nourrir (art. 1). Arec le plant, la graine et les wufs fournis par les entrepreneurs à raison de 7 lir. $10 \mathrm{~s} .(21$ fr. 92$)$ pour le cent de mùriers, une pépinière, une mùreraie et une magnanerie seront établies dans chaque paroisse, soit par la communauté, soit par certains habitants, soit par le seigneur du lieu qui ne dérogera pas en le faisant. Les entrepreneurs distribueront en mème temps des instructions imprimées sur la culture du mùrier, l'élève des ver's, le dévidage des cocons. Les communautés ou ceux qui, dans chaque paroisse, auront fait les frais d'établissement de la pépinière, de la mûreraie et de la magnanerie vendront des mùriers blanes à tous ceux (qui en voudront acheter (art. 2, 3, 4, 6). La distribution de la graine, du plant et des $\propto u f s$ se fera du $1^{\text {er }}$ au $S$ arril 1603 en présence d'un commis de Laffemas (art. 3). A partir du $1^{\text {er }}$ arril il sera enroyé dans chaque élection un ou plusieurs experts qui y résideront trois mois au moins pour apprendre aux habitants la culture du mûrier et l'élève des rer's et pour acheter, à raison de 9 francs la livre (28 fr. 06), la soie recurillie la première année (art. :̈). Pendant cette première annèe, les propriétaires de mùriers laisseront prendre gratuitement les feuilles par les personnes qui dans chraque paroisse entreprendront l'élève des vers. 
Le contrat passí avec les entrepreneurs et le mandenent qui an rigghat l'exécution étaient bien concus pour le sucèes 1e Lentreprise. Distribution ì bas prix du plant, de la graine et des aufs, débit assuré de la soic yui était achetie par les entreprenenr's ou par l'bital, direction de gens experts, tout ae rémissait pour lui assurer la faveur de la population. Mallenrensement les entrepreneurs napporlìent pas d'exactitude dans lexécution do leurs engagements. Ils auritent dì fournir le plant et la grime dans les trois derniers mois de 1602 ou, atu plus tard, anx mois de lévier et de mar's de lamméc snivante. An mois d'arril 1603, le plant et la graine n'étaient pas encore arrivés et, la saison élant passée. les mùriers ne pouvaient ètre semés ou plantés qu au printemps de l’ammée suivante. C'était une annéc de perdue. Le roi se plaignil de ce retard ì la commission'. II nist donc pas exact de dire, comme le fait II. Poirson ${ }^{2}$, que la distribution du plant, de la graine et des œufs eut lien du ler an 8 arril llill3. C"est là ce qui était stipulé par le contrat, mais cest ce qui ne se fit pas.

II y eut d'autres mécomptes. Lé cultuateurs ne nonIrèrent aucum empressement a acheter du plant et des unfs3. Dans l'élection de Blois, par exemple, les entrefreneurs ne purent distribuer que six onces d'œufs '. Les propriétaires de mùriers ne voulurent pas laisser prendre les fenilles gratuitement. Aussi les vers éclos en 1603 manquèrent de nourriture et périrent ${ }^{5}$. La commission essaya vainement dobtenir des leltres patentes pour vaincre la résistance des proprićtaires, le chancelier objecta le droit de propriété et conseilla d'employer la persuasion ${ }^{6}$. Lit pourtant ce

1. Procis-verbaux, p. 86 .

$\therefore$ III, 2 i0.

3. Procis-verbaux. Séance du 11 avril 1603 , ए. 80.

i. Proces-verbaux, p. 101 .

5. Hid. Siance du 27 mai 1603, p. 95.

(i. Seances du 11 arril et du 27 wai 1603, p. 80 et 95. 
que la commission demandait, était simplement l'application de l’art. 7 du mandement du 7 décembre 1602 , article qui enjoignait aux propriétaires, à peine de 30 livres d'amende 87 fr. 69), de laisser cucillir les feuilles de leurs mùrier's pendant la première année pour approvisionner la magnanerie créée dans chaque paroisse. Il semble résulter d'une déclaration royale du 24 mars 1603 , dont nous n'avons pats retrouré le texte, que ceux qui s'étaient chargés d'établir dans leur paroisse une pépinière, une mùreraie et une magnanerie avaient essayé dimposer aux paysans l'achat de plant, de graine et d'œufs, car cette déclaration les afhranchit de cette obligation. Malheureusement elle eut pour effet de désintéresser de l'entreprise les élus qui se considérèrent comme dispensés de la diriger ${ }^{\prime}$.

Bien que les experts enroyés dans les quatre généralités de Paris, d'Orléans, de Tour's et de Lyon pour diriger les plantations eussent déclaré à leur retour qu'elles pouraient réussir", la mortalité des vers à soie en 1603 semblait donner raison aux adversaires de l'entreprise. Le champion le plus ardent de la sériciculture, Laffemas, combattit dans une brochure ${ }^{3}$ les conséquences défarorables qu'on tirait de cet accident. Selon lui, le climat n'est pour rien dans la mortalité des vers; elle tient à ce qu'on ne les a pas fait éclore de boune heure et à ce quion n'a pu leur donner autant de feuilles qu'il leur en fallait. Les vers ayant éclos tardivement, les feuilles ru'on leur a domnées n’étaient plus assez tendres et la chaleur était trop grande. Les propriétaires de magnaneries qui ont pris soin de les faire

1. Procès-verbaux, p. 8 .

?. Le Tellier, Brief discours contenant la maniere de nouririr les ver's à soye. Paris, 1602, in-fol. Mem. et instructions pour l'etablissemcnt des meuriers, etc. Paris, 1603 , in $-4^{\circ}$.

3. Le plaisir de la noblesse et autres yui ont des eritages aux champs sur la preuve certaine et profict des estauffes et soyes gui se font à I'aris et les

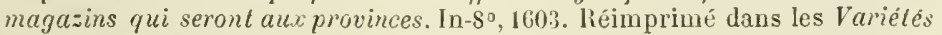
list. et litt., VII, 303 . 
éclore plus tôt ont recueilli de la soie. Par exemple, les vers élerés dans lhotel de Retz à Paris ont fourni en 1603 dix-huit livres de soie. qui ont donné un bénéfice net de 6ił écus' (607 fr. 97i).

Il s’agissait maintenant de régler l'exécution du contrat pour l'année t60'. On se rappelle que, dans les intentions des contractants, la première partie de l'entreprise derant ìtre réalisée à la fin de 1602 ou au commencement de 1603 , la sériciculture derait itre introduite en 1603 dans quatre généralités nouvelles et en 1604 dans tout le royaume. Ce plan n’arait pas été exécuté, puisque en 1603 la plantation des mùriers et l'élève des rers n'avaient été essayées que dans les quatre généralités de Paris, de Tour's, d'Orléans et de Lyon et que le succès n'avait guère été obtenu que dans la seconde ${ }^{2}$. Il fillail désigner maintenant les quatre généralités où l'expérience serait continuée, non plus en 1603, comme le portait le contral, mais en 1604. La commission du commerce mit quelque lenteur à faire ce choix. Le 29 aoùt 1603 , les entrepreneurs lui firent sommation d'y procéder et de leur payer 30000 livres (\$7687 fr. 98), montant des deux quartiers qui leur étaient dus sur les $1200003307 \% 1$ fr. 94) à eux pronises ${ }^{3}$. Le 10 octobre, nouvelle sommation ‘. Le conseil du roi décida que, l'annéc suivante, la sériciculture ne serait introduite que dans la généralité de Poitiers et que la somme allouée à l'entrepreneur serait de 20000 liv. tom ( 384088 fr. 6:3). Le plan purimitif, on le roit, était singulièrement réduit, on renonçait, au moins pour le moment, à généraliser la

1. Le plaisir de la noblesse et autre...., 308-310.

2 . Sur les achats de graine et de plant par l"échevinage de Tours et la propagation de la culture du mûrier sur les remparts de la ville et ailleurs, voy. le mémoire de II. Cuaupolseac, Congrés scientifque de France, X广o session, tome ler, et les délibérations du corps de ville, notamment i la late du 6 déc. 1603 et de mars 160t, aux archives municipales.

3. 'roces-verbaux, p. $11 ;-118$.

4. Hiit., p. 125 . 
production de la soie. Quelles étaient les causes de ce recul? Pourquoi le gouvernement ramenait-il à des proportions beaucoup plus modestes une entreprise si largement conçue? Bien que Laffemas nous représente le roi comme très satisfait des soies recueillies en $1603^{1}$, c'est probablement par les mécomptes de cette année que s'explique cet abandon du plan originel. A une nouvelle sommation des entrepreneurs la commission répondit que l'intention du roi était de résilier le contrat et de restreindre l'entreprise au l'oitou pendant l'année $1604^{2}$. Le 23 décembre 1603 , elle passa un contrat avec deux bourgeois de Paris, Jean Le Tellier ${ }^{3}$ et IIugues Cosnier pour l'introduction de la sériciculture dans celte province. Les deux entrepreneurs sengagèrent à fournir cent mille mûriers blancs de deux ans et de deux à trois pieds. cent vingt-cing livres de graine, deux cents onces d'aufs et deux mille exemplaires dimstructions, movennant la somme de 18000 livres ( $.2612 \mathrm{fr} .79)$. Ils avaient besoin, pour exécuter le contrat, de l'agrément de Sully, gourerneur du Poitou; le surintendant, qui. malgré ses préventions contre l’industrie de la soie, se prêtait aux vues du roi et manifestait mème lintention de planter des mìriers à Rosny et à Sully ${ }^{5}$, la leur accorda ${ }^{6}$. Mais cette fois encore l'entreprise se heurta à l'espril routinier des paysans. Ceux du Poitou, occupés aux salines, refusèrent le plant, la graine et les œufs, les entrepreneurs ne purent en faire prendre que par les gentilshommes '.

Cependant linitiative privée essayait dintroduire la

1 Le plaisir de la noblesse, p. 313.

2. Séance du :8 nuvembre 1603. Procès-verbaux, p. 133.

3. Marchand de soie et auteur du brief liscours et des Mémoires el instruclions précités.

4. Procès-verbaux, p. 175-180.

5. Dédicace du Brief discours à II me de Rosni.

6. Procès-verbaux, p. 129.

i. Ibid., p. 191 . 
sirieiculture en Normandie. En 160\%, Chartes Benoit, maitre passementier et moulinier en soie, ef le Languedoeien Isaac Mayaflre, étahlis à Rourn, présenterent au roi des échnutillons de la soie provenant de terme magnaneries. Henri IV en fut satisfait et, sur lemr requete, demanda an parlement de Rouen de faire mettre ì leur disposition par l'échevinage, pour une périodede vingt ans, la maison du Bauf courommé, sise rue Saint-Vivien, qui ¿tait une propriété municipale'. L'óchevinage esquira cette demande et les deux associés ne trouvirent pas plus d’appui auprès du parlement, lorsyu'ils sadressèrent à lui pour conlraindre les propriétaires de muriers ì leur vendre à prix taxé les fenilles nécessaires ì la nourriture des vers. Lu arrèt du $1: 3$ juin $160 \%$ leur permit seulement de s'entendre avec les propriétaires, ce quïls avaient vainement essa sé de faire précédemment. L'entreprise, si peu secondẹe par les autorités lociales, échoua au bout de quatre ans ${ }^{2}$.

On ignore lissue d'mu autre essai frit en Normandie en exécution du plan général conçu par Henri $\mathbf{W}$. Il saggit d'une pépiniere créée ì Darnetal par un Flamand, Jean Vin der Veken, et pour l'entretien de laquelle il s'adjoignit un Nimois, simon Legal, qui sema deux cent quatre-vingtcinq mille pepins de mùriers blimes ${ }^{3}$.

Le roi essaya dle gagner à son entreprise la faveur et l'appui du clergé, qui pouvait ètre un anxiliaire si précieux, lant comme propriétaire d'me grande partie lu sol qu ì canse de son influence sur la population agricole. Il ménagea entre les députés de l'ordre et les entrepreneurs une con-

1. Mandement au parlement de Rouen du 23 aoùt 160 i. Lellres miss. VI, $28 \mathrm{i}$.

?. liosselix, bucuments uuthenthiques el inédits pour servir à lhistoire de lin marne normande el du commerce ronenuais. Rouen, in-80, p. 116-120. litublissement ì kouen en 160 i dune manufacture de soieries... Communiçtion de M. Floquet à l'Académie de kouen, 1837.

3. GOS=ELIX, P. 120-121. 
rention pour la fourniture de plant et de semis aux bénéficiers. Il obtint des députés généraux du bureau de Paris un mandement (décembre 160\%) enjoignant aux évèques du ressort du bureau de faire semer et planter par les bénéficiers et communautés de leurs diocèses respectifs le plant et la graine que comportait l'étendue de leurs propriétés. Plusieurs évêques avaient obéi arec empressement à ce mandement et déterminé la part dans laruelle le clergé de leur diocèse devait contribuer à la propagation de cette culture. Mais l'heureux effet de ce mandement fut compromis par un second qui déclarait que le précédent n'arait aucun caractère obligatoire et qui encouragea le mauvais rouloir et la résistance. Pour en triompher, le roi ordonna la création d'une pépinière de einquante mille mùriers blancs au moins dans chaque diocèse par les soins et aux frais des entrepreneurs qui vendraient, principalement aux ecclésiastiques, te la graine et du plant. Ils devaient jouir d'une indemnité d'un sol (14 c.) par mûrier tout planté et du monopole de la vente ${ }^{1}$. Le roi chercha à stimuler le zèle de l'assemblée du clergé en faveur de l'entreprise, mais, dans la réponse faite à ses exhortations par l'archevêque de Sens, président de l'assemblée, on sent percer, sous les protestations de seconder son dessein, les préventions de l'ordre contre une culture destinée à alimenter un luxe que ses deroirs et les convenances lui défendaient d'encourager ${ }^{2}$.

En s'efforȩant de développer la culture du mûrier et l'élève des vers à soie, Henri IV roulait rendre plus abondante et moins coûteuse la matière première qui sert à la fabrication des soieries, il n'aurait donc accompli que la

1. Déclaration du 16 nov. 1605. Foxtaxos, I, 1051.

2. Procès-verbal de l'assemblée du clergé tenue du 27 juillet 1605 au 2 't avril 1606. Collection des proçs-verbaux des assemblëes générales du clergé, in-fol., 176i, I, p. 765. 
moitié de sa lìche sil n’avait pas cherehé en mème temps i augmenter la production de ces tissus en créant de nouvelles manufactures, en donnant plus d'extension aux anciennes. Il ne voulait pas seulement que la France fabriquàt tontes les étofles de soie nécessaires à sa consommation, il espérait, ainsi quil le declarait à l'ambassadeur d'Angleterre ', qu'elle fournirait anx besoins de l'Angleterre, des Pays-Bas, du Danemark, des pays de la Baltique. Dès 1602 il existait à Paris une manufacture de soieries dont Sainctot était le principal directeur ${ }^{2}$. Une autre, fondée dans la même ville sous le patronage du roi par Noël Parent et ses frères, n’eut pas des débuts heureux. Les fabricants furent condamués par sentence du Chitelet à vider leur atelier, situé près du Temple, pour n'avoir pas payé leur loyer. Sur leur requète, la conmission du commerce, au mois de février 1603, délégua deux de ses membres pour dresser inventaire des métiers et du matériel et mettre le tout sous séquestre ${ }^{3}$. Cet insuccès ne découragea pas le roi. La même année, au mois d'aoùt, il prenait sous sa protection la manufacture de sainctot, auquel il associait Jean de Moisset, contròleur de l'artillerie, des menus et alfaires de la Chambre, N. Camus ", C. Parfait et Élouard Colbert, et gratifiait leur association de grands privilèges. Les affaires de la société devaient comprendre le tissage des étoffes unies et façonnées, ainsi que le battage et la fabrication du fil d'or et d'argent façon de Milan. Le roi accordait aux associés la qualité de commensanx de sa maison, les anoblissait, leur assurait pendant douze ans le monopole de la fabrication des soieries a

1. Sil Geonge C.AiEw, A Relation of the state of France... Loc. cil.

2. Procès-verbaux, p 109.

3. Hiil., p. 68-6?.

4. Sur Nicolas Camus ou Le Camus voy. O'Rentw. Mémoires sur la vie pubtique el jrivée de Claude Pellol, 1, p. 137-138. In-80. Curampros. Jean de Moisset est le fermier général des aides. 
Paris et celui de la fabrication de l'or et de l'argent filé dans tout le royaume, exemptait leurs ouviers étrangers du droit d'aubaine et conférait à tous ceux qui auraient travaillé chez eux pendant un certain nombre d'années le privilége de s'établir sans faire de chef-d'œurre ni prendre de lettres de maîtrise, sur la simple production d'un certificat délivré par eux. En outre il leur faisait un prêt de 180000 livres ( $326127 \mathrm{lr} .90)$ sans intérèt et avec faculté de n'en rembourser au bout de douze ans que 150000 ( $438439 \mathrm{fr}$. 92), en d'autres termes il leur faisait don de 30000 livres (87687 fr. 98). Il conservait cependant à Devieux dit Mercuri, son valet de chambre parfumeur, et à ses associés, le droit de fabriquer de l'or et de l'argent filé, ainsi que des soieries rehaussées d'or et d'argent, mais à condition de recevoir la soie des concessionnaires et de faire marquer par cux leurs marchandises ${ }^{1}$. Le 23 février 1604, Sainctot, Moisset et consorts s'associèrent un tireur d'or milanais, Jean-André Turato. L'année précédente, Turato avait obtenu, sur la proposition de la commission du commerce, 3000 livres (8768 fr. 80 ) pour ses frais de premier établissement, une pension annuelle de 1200 livres (3ä07 fr. :32) et le monopole de l'or lilé façon de Milan pendant dix ans, à charge d'apprendre son art à des Français ${ }^{2}$. Il était établi à l'hôtel de la Maque, rue de la Tixeranderie. La commission du conmerce, saisie par arrèt du conseil du 4 septembre 1604 du conflit entre lui et Mercuri ${ }^{3}$, exprima l'avis que défense fùt faite ì celui-ci de faire concurrence au premier jusqu'à ce que l'édit d'août

1. Édit d'août 1603 . Isanerrt, XV, $\mathrm{n}^{0} 168$.

2. Procès-verbaux, p. 34, 43-4', 51-53, 65. Arrêt du conseil d'État du 13 Iév. 16(03. Arch. nat., Coll. des arrêts du conseil, à la date.

3. Turato rencontra un autre concurrent dans un de ses compatriotes nommé Gerome Gerôsmes (sic). Le conseil, ayant á juger leur différend, les soumit à une sorte de concours, dont nous ignorons le résultat. Arrêt du 16 mars 1(i03. Coll. des arrêts du conseil. Arch. nat., à la date. 
11003 rendu en favem de Sainctot et de ses associés. déjà enregistré par le parlement et la chambre des comptes, le fiat également par la cour des aides et la cour des monnaies'.

Sil fallail en croire P'. Cayet ${ }^{2}$, l'industrie exercée à lat Maque n’aurait pas consisté seulement dans la fabrication lu fil d'or et d'argent. 'Turato aurait finit aussi des brocalts, des soieries rehaussées d'or et d'argent, des satins, des damas historiés. Ces riches étoffes, dont I'. Cayet parle en honme qui les a rues, bien quïl en altribue la fabrication à Duboul, c'est-ì-dire à un tapissier de hante lisse établi an Louvre ${ }^{3}$, il arait pu les adnirer ì la Maque. mais il a antidaté ses sonvenirs d'un an en les rapportant à l'année 1603, car les étolles en question ne pouvaient ètre que le produit de la collaboration de Sainctot et de Turato, qui ne fut que la conséquence de l'association formée entre eux le 23 févricr 160't. Le balteur d'or milanais ne faisait, anx termes mêmes de son privilège du 1.j février 1603, que fabripuer le fil d'or et d'argent que Sainctot et ses associés mettaient cm-uite en ouvre dans leurs tissus. Du reste, leur association arec Turato fut rompue à une date que nous ne pouvons préciser, mais qui est antérieure au 28 février 1606. 1 cette époque, Turato prétendait empècher ses anciens associés de fabriquer du fil d'or et d'argent facon de llilan, mais le conseil du roi lui donna tort et déclara que cenx-ci pouraient se livrer par eux-mêmes à cette fabrication ". La liquidation de la société formée entre Sainctot et Turato II était pas encore terminée en 1607 , car, le $1: 3$ mars de cette année, le conseil du roi condamnait ce dernier à rendre compte de sa gestion devant des arbitres".

I. Séance du joctobre 1604, dans l'rocés-verbaux, $\mathrm{p}$. :61.

2. Chronologie sepl., p. 2:9, à l'année 1603.

3. Voy. plus bas.

4. Arrêt du 28 février 1606. Bibl. nat. fr. 181;0, il la date.

$\therefore$ Collection des arrêts du conseil, il la date. Arch. nat. 
La manufacture de soieries et de brocarts de Sainctot fut l'objet de la sollicitude constante de Henri IV. Ici, comme dans beaucoup de ses entreprises, il eut à lutter contre le formalisme des gens de robe. Le chancelier fit des difficultés pour expédier les lettres octroyant aux directeurs de la fabrique la subrention de 60000 écus (369971 fr. 89) qui leur arait été promise, et cenx-ci menacèrent de se retirer. Le roi assigna d'abord ces $1 ; 0000$ écus sur le produit des aubaines '. Sainctot et ses associés se portèrent adjudicataires pour huit ans d'une partie de la ferme du sel et obtinrent du roi la préférence sur leurs concurrents, à offres égales. S’il se produisait des offres plus arantageuses, la subrention derait ètre assignée sur le prix du bail ${ }^{2}$. En 1607, Ilenri écrit an président du Vair de Jui envoyer pour sa manufacture d'étoffes de soie et d'or un Espagnol et ses deux compagnons rqui excellent dans le travail de ces étoffes, tel quill se fait au Levant, et qui, après aroir habité Constantinople, se trourent maintenant à Marseille ${ }^{3}$. Il fit construire, place Royale, pour y installer les ateliers de Sainctot, un bàtiment qui, commencé en 1604, était achevé en $1606^{\circ}$.

1. Lettres miss., IX, 48,50 .

2. Lettre de IIenri $1 \mathrm{Y}$ à Sully, Ior mai $[1604$. Economies royales, VII, $i 2-i 3$.

3. Lettres miss., VII, 438.

4. P. CAyet, Chron. sept., II, 283. Plocès-verbaux des assemblées du clergé, I, p. 765. l. Lafremas, Ihist. d" commerce, p. \$13, 4l4. Sur la manufacture de Sainctot roy. encore la relation de Carew dans Birch, p. 434. J.-A. DE Thou, VI, 1:0, la déclaration royale d'avril 1605 contenant don aux entrepreneur's des manul'actures de soie, or et argent filé à la façon de Milan, de 6000 toises de terre dans le parc des Tournelles. Reg. du conseil. Bibl. nat. fr. 18174, fol. vin ${ }^{\times x}$, des lettres patentes du 28 sept. 1604 autorisant le sieur Colbert à quitter l'association (Reg. du parlement), et un arrêt du conseil du 19 mars 1607 oldonnant au trésorier de l'Epargne d'assigner aux entrepreneur's 3000 livres $(8768 \mathrm{fr} .80)$ sur le bail des cartes. Arrêts du conseil, à la date. Ilenri IV' voulait concentrer sur l'emplacement du palais des Tournelles les industries de luxe qu'il cherchait à créer en France. Procès-verbaux, p. 212. Sully avait un projet différent sur l'affectation de cesterrains. Econ. roy., VI, 336-337. Ce fut l'industrie des soieries à ramages 
II soccupait en mène temps à créer des manufactures ailleur's qừi Paris. An moment où il partait pour la campagne de Savoie juin $\$ 600$ ), B. Laffemas lui présenta Noël Parent qui se faisult fort de fabrirpuer des crepes aussi bien yu à Bologne, ainsi que tous les genres de soieries oì excellaitl'Italie'. Le 27 mai 1603, un ancien fabricant de soieriesde Lyon,nomméde la Vialle, proposa à la commission, de l'aveu de Sully, de fonder celte industrie à Mantes dont le surintendant arait le gourernement ${ }^{2}$. Lannée suivante, le roi s'y rendil avec toute la cour', fit planter' dans tonte l'étendue du bailliage, sous la direction d'Olivier de Serres, un nombre considérable de mùriers blancs et établit dans le chàteau deux moulins et ringt métiers pour la fabrication des crêpes fius, façon de Bologne 3. Cette manufacture fut dirigie par Noïl Parent et par ses frères qui, plus heureux qu à Paris, réussirent à égaler les crèpes de Bologne, à créer cette industrie en France et mème à faire avec une igale perfection toute espèce de soieries '. La commission sollicita en sa faveur les privilèges de commensal du roi et des gages fixes, et il reçut une subvention de 3000 livres $(8768 \mathrm{fr} .80$.) pour frais de premier établissement ${ }^{5}$.

C'est encore un membre de la même famille, Étienne P'arent, 'qu'on troure à la lête de l'industrie des satins de

(jui donna naissance au Jardin des Plantes. Un horticulteur, Jean Robin. cut l'idée de créer un jardin fleuriste pour fournir des modèles aux brodeurs et aux tisserands de soie, et ce fut ce jardin. né des besoins de la mode, qui servit plus tard i l'étude de la botanique et de la médecine. Qciciemat, Ilist. du costume, p. Áti.

1. LAFFEMAs, Le naturel el profit admirable du menrier... Paris, 160i, p. 16.

2. Procés-verbaux, p. 95.

3. Wouts., Mantes, listoire, momuments, environs. In-80, 18.52, p. $56-57$. Procès-verbaux. P. 239.

4. Laffeas abi supre, p. 16-1i. Procés-verbaux, 11. 280-281.

5. Procès-verbaux, ibid. Arrèts du conscil du 10 mars 1607 , du 27 mars 1608 et du $1 i$ férrier 1609. Bibl. nat. fr. 18173. P. CA 1 ET, Chronologie sept., p. 284, année 160 i. 
Bruges et damas cafards ${ }^{1}$ qui süntroduisait à Troyes à la mème époque. En 1604 il ńcrivait à Laffemas qu’il avait commandé deux cents métier's livrables à la Saint-Rémi ${ }^{2}$, et son associé, Jean Sellier, présentait des échantillons" à la commission du commerce. Le 150 aoù de la même annéc, le roi accordait à celui-ci un monopole de vingtans " La commission proposa de conférer des lettres de noblesse à lui et à deux de ses associés et de gratifier ses deux principaux ouvriers de lettres de naturalité, sills étaient étrangers, et de l'exemption d'impôts, s'ils étaient Français. Uutre le monopole de la fabrication en France, l'impétrant devait ètre protégé contre la concurrence étrangère par la prohibition des soieries de ce genre, aussitôt qu'il serait en mesure de pourvoir à la consommation nationale. Il s'engageait de son côté à faire battre le plus tôt possible trois ou quatre cents métiers, à employer autant d'ouvriers français qu'il pourrait et à n'apprendre le métier qu à des Français En 1604 ou $1605^{6}$ le roi priait Sully de faire payer au mème entrepreneur 3047 écus (28943̈ fr. 07) (que celui-ci était renu réclamer à Paris pour les frais de son entreprise et qui, d'après les pièces par lui fournies, lui étaient bien réellement dus.

De Provence la commission du commerce recerait aussi des offres. Le sieur de Barthélenty, contròleur des traites à Arles se déclarait prèt à y entreprendre la propagation de la culture du mùrier et la création de manufactures d'étoffes, notamment de soieries et de brocarts,

1. Damas mêlés de soie et de fleuret.

2. Procès-verbaux, p. 226-227.

3. 1bid., 229 .

4. Ibid., 232 .

3. Séance du 21 aoùt 1604. Procès-verbaux, p. 234-23\%.

6. Ce qui nous porte à préférer la date de 160 'à celle de 1605 que l'éditeur des Lettres missives a assignée à la lettre du 25 mai, c'est qu'Ét. Parent annonce à Laffemas, le ter août 160 '́, la prochaine arrivée de Tellier. Ibi.d., p. 226-22i. 
ì l'imitation des tissus qui se fabriquaient en Italie, en Espagne et en Orient. Ces offres étaient aceeptées et l'on tombait d'accord des conditions suirantes. Barthélemy fomrnira la province de plant et le graine de mùriers blanes yui lui seront payés par les localités à raison de $100 \mathrm{~s}$. (14 fr. 6it) le cent de murrers et de 't livres ( $11 \mathrm{fr}$. (69) la livre de graine. Une commission, composée du premier président du parlement d'Lix, d’un président de la chambre des comptes of de ceux que ces deux magistrats sadjoindront, réglera la distribution du plant et de la graine, ainsi que les moyens d'en recouver le prix sur les habitants. Barlhélemy établira dans la province dix-huit ateliers, six ì Mix, six ì Arles et six ì Marseille, pour fabriquer les étolfes en question et obtiendra un privilège de huit ans pour les étolfes façon d'Italie et de douze ans pour les étolfes façon du Levant. Ce monopole ne préjudiciera pas aux droits des industriels qui sont en possession. Les apprentis qui seront, autant que possible, des Français resteront quatre ans en apprentissage et ne pourront sétablir que leux ans après en ètre sortis. Les ourriers etrangers deviendront Français en vertu d'une simple déclaration délirrée sins frais. Ils seront, comme les ouvriers regnicoles, exempts de toute charge personnelle tant qu’ils n’abandonneront pas le métier. Les apprentis nauront besoin pour sétablir que l'un certiticat de l'entrepreneur. Les soies pourront ètre tirées d'Italie, en attendant que le royaume en produise en assez grande quantite. Barthélemy deviendra de contrôleur des traites d' $\Lambda$ rles contrôleur général des traites de la province, il sera anubli, ainsi que trois de ses associés '. Ce projet de traití fut présenté au conseil et en 1604 il n’attendait plus que l'homologation royale. 
Les bas de soie nous renaient de l'élranger. Nos incètres, d'après Laflemas, en usaient quatre paires par an lont chacune leur coùtait quatre étus ${ }^{1}$ (38 f $\mathrm{l}^{\circ}$.). Le conseil du commerce, qui n'aceucillait pas seulement les propositions des inventeurs et des industriels, mais qui prenait aussi l’initiative des mesures propres à fonder en France des industries nouvelles, voulut y introduire la fibrication des bas de soie et de laine. Elle ne trouva pats de moyen plus efficace que de permettre à tout le monde de s'y livrer. sous certaines garanties?

Les efforts de Henri IV pour créer de nouveaux centres de production ne lui faisaient pas oublier ceux qui existaient déjà. En accordant aux fabricants tourangeaux, sous l'empire d'une illusion qui ne tarda pas à se dissiper. la prohibition des soieries étrangères, il les avait autorisés par une conséquence naturelle à fabriquer tous les articles que la France tirait des pays roisins. Plusieurs d'entre eux abusèrent de cette autorisation pour employer dans le tissage de certains velours de la soie écrue; ils prétendaient ne faire en cela qu'imiter ce qui se pratiquait en Italie. Ils réussirent même à convaincre leurs conlrères et les gardes-jurés de la corporation de la supériorité de la soie écrue sur la soie cuite ou à obtenir subrepticement leur approbation ${ }^{3}$. Mais le roi, éclairé par les représentations des fabricants tourangeaux mienx avisés et par le témoignage des manufacturiers de Paris, revint sur cette dérogation aux anciens rìglements de fabrique et défendit l'emploi de la soie qui ne serait pas bien cuite, décrusée, blanchie et teinte *

1. Reigl.gen., p.s.

2. Séance du 4 mai 160 '. Procès-verbaux, p. 185-18s.

3. Voy. la délibération du corps de ville rapportée par $\mathbf{~}$. Champorseau dans son mémoire sur l'industrie séricicole en Touraine. Loc. cil.

千. Henry... à... nostre cour de parlement i Paris. Les m $^{e s}$ juréz et particulliers ouvriers en draps d'or, d'argent et de soye de... Tours nous ont faict 


\section{Nous arons dit le trouble profond que les guerres religieuses avaient jeté clans la fabrique de Lyon. Les}

remonstrer que fen le roi Lonis unziesme... auroich fait venir en ce royaume quelques ourliers du paysdlitalie, desquels il auroiet estably la residance en lad. ville de Tour's... affin de faire fes ouvaiges de draps d'or, d'argent et de soye anparavant inusités en France et l'apprendre i ses subjects... les auroit honores de plusieur's grandz privilleges, et reiglé led. mestier [par] plusicur's stafuts, par lespuels il est porte, entre autres choses que 11 ul e $^{\mathrm{e}}$ dud. mesticr ne pourra euploier ancune soye qu'elle ne soict premierement cuitle, hlanchie et teinte en bonne tainture, sur peine de perdre lin sore et les ourraiges qui en seroient firictr, lequel reiglement auroict esti gardé par les exposins... et, tontes les fois que se seront trouvé des contraventions ausd. statuz, elles ayent esté repares et corrigies par le bially de Tourainc et par arrests de mostred. court, en sorte que plusieurs fuis des draps ou il s'est trumé de lin soye creue ont esté confisquiz et quelquefois bruslés publicquement et les delinquans condammés en plusieurs grandes auendes, toulellois depuis, par motre edit du mois de janvier mil cinq cens puntre-vingt-dix-nenf, nous avons permis de faire par tout nostre rovaune toute sorte de draps d'or, d'argent et de soye qui se font a Milan, riennes, Lueques. Florence et antres villes ditalie. et touteffois quelines onviers puticullier dud. westier se sont licenties de contrevenir aud. reiglement, soubz prétexte qu'ilz roulinient faire croire que les velours à lit rrice qui se font a Mlilan et autres lieux d’utalie ne sont point entière ment de soye cuitte et bianchie, telienent que yuelques ungs d'entre eulx ont faict la thoille et tresme dud. velomrs it la grice de soye qui n'est pas cuitte, suivant led. reiglement. et, pour se garmutir des saisies que les exposans out faict faice sur enx, ilz unt ubtenu nos lettres du dixiesne jour de juing mil six cens quatre, par lestuelles nous avons permis a tous ouvriers qui voudroient faire les draps de soge des facuns de Milan, Luçues, llorence, Venize, Naples, Boulongne, Rhere, Modene, Genues, Genefre, Chambery, Avignon, Espaigne et autres provinces etrangeres de foire la fabricquation dezd. draps de soye telle... qu'elle se faict esd. lieux... en conséquence desquelles lettres, nostre billly de Touraine, sans s'intformer auttrement de l'usaige desd. villes... auroict donne sa sentence du treiziesule jour de septembre dernier, par larpuelle il auroict ordonné que les ourricrs dud. mestier jouiroient du contenu en nosd. lettres, a la charge neammoingtz rue, es velours plains et autres draps qui se decouppent, ilz ne fmurroient emploier aucune soye escreue, en juoy faisint nostred. bailly ou son lieutenant a paisiblement permis ausd. nurriers d'emploier de lis soie creue es velour's fizuréz et aulres estoffes qui ne se decouppent point, et nennmojngtz nous avons este ndvertiz par plusieurs notables fourgeris et marelıans de nostred. ville de liris et par les ouvriers en draps d'or et d'argent et de soye que nous avons faict venir expres pour faire en urstred. ville de Paris telz ourrajges rui se font esd. vilies ditalie, que en toutes especes de drap de soye, soict de velours figuré ou aultres, il n'est luint permis en ltalie d'umploier de soye escrene ef qui ne soict bien cuitte, Dlanchie et tainte, parce que les soyes escreurs ne peuvent prendre bunne tainture et questant emploices it faire la thoille et tresme des velours, elle teruit le lustre du drajt, joint que la thoille et tresme des velours yui n'est faicte de soye bien cuitte couppe le poil desd. velours 
mesures de Henri IV ne furent pas toutes de nature à la relever. La substitution du pastel à l'indigo désormais proscrit ne fut pas considérée comme un progrès par les teinturiers lyonnais ni par le consulat qui demandèrent la liberté d'user des matières colorantes employées jusque-là ${ }^{\natural}$. Les fabricants s'émurent bien darantage encore de l'édit somptuaire de 1608 qui défendait, en mème temps que l'importation des soieries étrangères, l'usage des soieries indigènes. Il menaçait l'existence de la première industric de Lyon, qui comptait alors environ deux mille métiers et sept à huit mille ourriers. Les intéressés firent porter leurs remontrances au roi par l'un des leurs, Ambroise Aubin, qui obtint sans aucun doute le rappel de l'édit ${ }^{2}$. Heureusement l'influence de Henri IV

qui se pelle incontinant et ceulx qui veulent emploier lesd. soies non cuittes n'y sont pousséz d'autre affection que pour faire proffict au dom. maige du public, d'aultant que ung drap qui est faict de soye escreue et semble qu'il y ait plus de soye qu'il n'y en a, à cause de quoy en toutes les fabricques d'Italie tous les draps, de quelque espece et laçon qu'ilz soient, oú il $y$ a de la soye escreue et non bien cuitte, sont reprouréz et confisquéz... ce qui a meu les maistres juréz dud. estat d'ourriers en soye dud. Tours et la plus grande partie des maistres particulliers joinctz arec eulx d'appeller de lad. sentence de nostre bailly de Tours ou son lieutenant... et, d'aultant que le proces est pendant devant vous, ilz nous ont très Iumblcment supplié voulloir declarer sur ce nostre volonté... Pour ce est-il que nous, après avoir faict reoir à nostre conseil nostre edit du mois de janvier mil cinq cens quatre vingtz dix-neuf, noz lettres dud. dixiesme juing mil six cens quatre, arec les attestations de plusieurs notables nuarchans et ouvriers en soye de... Paris, en datte du dix huictieme jour de decembre dernier, te tout cy attaclié soubz le contre-scel de nostre chancellerie, de l'advis de nostred. conseil..., ordonnons, declarons... que tous draps de soye qui se feront en larl. ville de Tours et autres lieux soient faictz de bonne soye bien cuitte, descreue, blanchie et teinte en bonne teinture, faisant tres expresses deffences à tous ourrier's en draps d'ol, d'argent et de soje d'en emploier qui ne soient bien appareillée (sic) suivant leurs statuts... (6 janvier 1605 . Registré au parlement de Paris le 15 janvier 1605 . Arch. nat. $X^{13} 8645$, fol. 200$)$.

1. Inventaire des arch. municipales de Lyon. Reg. BB 140. Inventaire Chape aux Arch. de Lyon, VIlI, $36 i$.

2. Inventaire des arch. municipales de Lyon. Portefeuille AA 155. Les négociants en soieries de Paris firent aussi une déunarche auprès du roi pour empêcher l'exécution de l'édit. Lestolce, Registre-journal de Henri IV (collection Ilichaud et Poujoulat), p. 531. 
sl11 la fibringe lyonuaise ne se réduisit pas à res mesures malencontrenses; clle se manifesta aussi par la protection yu il accorda ì un Lyonnais, Claude Dingon, fabricant de soicries et de brocarts, l'un de res obscur's inventeurs dont le nom reste ignoré. non senlement de la postéritó, mais quelquefois mème de ceux qui ścnrichissent de leurs découvertes. Clande Dangon dota sa ville nataie du métier ì la tire' et de la fabrication des façonnés yui devait tant contribuer à la renomme et à la richesse de lindustrie lyonnaise. An mois de mars 1607, il obtint le titre de maitre ouvrier du roi en draps d'or, d'argent et de soie ì Lyon, un privilege de cing ans et lis direction de la falurication des étofles nourelles de son invention dans la ville et tout le royaume? ${ }^{2}$. Déjì en $160 . j$ ses concitoyens livaient indemnisé par un don de 200 lirres tournois (38' fr. .9.) des dépenses qüil arait faites pour introduire chez eux ses relour's taffetas et autres tissus d'un noureain genre et pour aller an présenter des échantillons au roi". Pour monter ses métiers. pour fournir aux lrais de premier établissement il avait dù contracter des dettes; le 11 août 1607, un arrèt du conseil lui alceorda une surséance de six mois qui fut renouvelée par un autre arrèt du 12 févicr $1608:$

11 ne linudrait pas croire que les villes dont nous renons de parler fussent les seules où l'on fabriquàt des soieries. Reins, pour ne mentionner que celle-la, comptait en 1600 cinquante-quatre maitres ouvriers en soie ${ }^{5}$ qui

1. On peut voir dans le musée industriel de Lyon mu modile réduit dı métier inventé par Co. Daxiox.

$\because$ Lettres patentes de mars 1607 enregistrées au parlement le dernier avril 1fil. Arelı. nat. Registres du parl. $X^{12} 8617$, fol. $227 \mathrm{ro}^{\circ}$. Voy. aussi

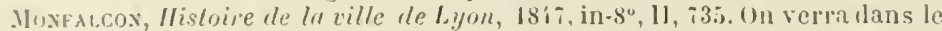
mémoire public en appendice $\left(n^{\circ} \mathrm{l}\right)$ eu quoi consistaient ces étolles nouvelles. 3. Inventaire des arch. municipales de Lyon. Keg. BB li2.

f. Arch. nal. Arrits du conseil i la date. Bibl. nat. fr. 18173, fol. 66.

5. VARIX, Archives de Reims, stululs, II, 375. 
firent modifier leurs règlements pour les rendre aussi conformes que possible à ceux de leurs confrères parisiens ${ }^{1}$. Tout en restant très inféricure à la demande, la fabrication indigène s'était beaucoup déreloppèe?.

Si nous avons cru devoir entrer dans l'exposé minutieux des efforts de ILemi IV pour faire de la sériciculture et de l'industrie des soieries une branche importante de la production nationale, e'est que, selon nous, la conception d'une entreprise, les moyens employés pour la faire réussir n’offrent guère moins d'intérèt que ses résultats. L“intelligence et la perséverance méritent d'attirer l'attention de l'historien, même quand elles ont été déployées en pure perte, parce qu'elles proroquent des réflexions instructives sur les causes de leur impuissance et qu'elles offrent le spectacle attachant de la rolonté aux prises arec les circonstances. Toutefois, on essaierait en vain de le nier, la première question ru'on se posera toujours au sujet d'une tentative qui n'a en rue que la prospérité matérielle d'une société sera nécessairement celle de savoir si elle a ourert une roie nouvelle à l'activité nationale et augmenté la richesse et le bien-ètre du pays.

Pour résoudre cette question en ce qui concerne la sériciculture, il ne suffit pas de constater qu'elle se trouve de nos jours, comme arant le règne de Henri IV, Iocalisée dans certaines provinces, qu’elle ne s'est pas généralisée au mème degré que la viticulture, par exemple, dont Olivier de Serres la rapprochait au point de vue des conditions climatériques. Ce fait n'autorise pas à considérer le dessein du roi et de ses auxiliaires comme chimérique; la négligence des gourernements qui ont succédé au sien, des érénements d'un ordre général peuvent

1. Varix, p. 376 .

2. LAfFexis, Reigl. gen., p. 7. La facon de faire et semer la graine de meurier..., 1C04. p. 31 . 
lexpliquer, sans qüil soit néeessaire de sen prendre aux vices inherents à l'entreprise ou aux moyens employés pour la meltre à exécution. C'ést à la fin du règne yuil fant nous plicer pour nous remetre compte des résultats.

0r: nous tromons dìs cette éporpue les preures péremptoires que le succes navait pis répondu aux esperrances. Lin 1610, un $\mathrm{s}^{\mathrm{r}}$ Maressé, ancien archer de la garde, proposait au noureau roi de renouveler des essais qui llaraient échoué, d’après lui, que par suite des moyens d'exécution ${ }^{1}$. Dans un mémoire anonỵme, publié deux ans plus tard sur les paures des hospices, nous lisons qu il ne subsistait ancune trace de l'entreprise de Henri IV?. II y a là de l'exagération. Montchrétien est plus près de la verité quand, tout en constatint que le roi n'arait pas réussi ì augmenter autant qü̈l le voulait la production de la soic et en rendant responsables de cet insuceès ceux qüil arait chargés de la réalisation de ses intentions, il reconnaît que la sériciculture a, gràce à lui, acquis une certaine extension dans les régions où elle existait déjà ${ }^{3}$.

1. Proposilions failes au roi par Marr. M., conlenant les moyens de rendre la srie aussi commume en France qu'elle lest à la Chine et pur loute l'Ihalie et l'Expagne, 1610. Cité par Gaspanx, Mémoires d'agricullure el d'économie murale, $11,68$.

$\because$ Mémoire concernant les pauvres enfermés adressé it IJenri de Gondi, eviofue de Paris, 161?. Archives curienses de l'hist. te France, XX, ?64-65.

3. "Aussi nostre grand IIenry... print lor't à cœul le dessein de faire ahonder la soye en ce royaume..., ce ruui sans doute eust pu réussir à son rontentement..., si ceux lá, sur qui S. II. se reposoit de la conduite de cette allaire, l'eussent secondé avec un jugenent égal á son allections. Tout $c_{r}$ qui nous en est revenu de bien, c'est que le desir qu'il fist naistre en plusieurs de s'iccommoder dn profit des soyes a produict ce fruict qüil s'es fait maintenant en l'rovence, Languedoc, Daupluiué, Touraine, Lionnois, Beaujolois et divers autres lieux de la lrance a plus de quatre ou cinq cens uille livres... ear, pour ce qui concerme la falırique. chacun scait-il pas que depuis longtemps nous l'arions it Lion et i Tours ?" Truiclé de l'économ. politique, 1615, p. 98. Montchrétien exhorte le roi et la reine mere it encouragres lil siriciculture el l'industrie de la soie, dont le défanl de persévẻrance des Francais a empêché, malgré les ellorts de Henri 11 , la fondation definitive. Ibid., p. 99-100. Ioy. aussi p. 129.

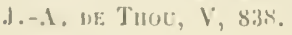


Le témoignage de Montchrétien se trouve confirmé pour une région particulière, la Touraine, par le rapprochement de deux faits séparés l'un de l'autre par près le quatrevingts ans. En 1607 Henri IV accordait à un $\mathrm{s}^{\mathrm{r}}$ Taschereau le privilège héréditaire de planter et d'exploiter des mùriers dans le parc de Plessis-lez-Tours et ses dépendances ${ }^{1}$. Or nous trourons en 1693 un des descendants du concessionnaire dirigeant au mème lieu une pépinière de 800000 mùriers blancs qui servait à entretenir et à propager la sériciculture dans le pays². L'entreprise de 'Taschereau n'avait ılonc pas été éphémère et ce n'est pas seulement, on peut le croire, en 1693 qu'elle avait commencé à porter des fruits. Nous sarons, d'autre part, que l'industrie des soieries fut très florissante à Tours pendant la première moitié du $x$ ru $^{\mathrm{e}}$ siècle ${ }^{3}$. Les efforts de Henri avaient donc obtenu un eflet quelquefois durable, plus souvent passager et limité. L'exemple ru'il avait donné en plantant des múriers, en établissant des magnaneries avait trouvé d'assez nombreux imitateurs parmi les courtisans, les grands seigneurs, le haut clergé, les ordres monastiques, l'orlre de Malteł. Nous avons déjà parlé de la soie recueillie dans le jardin de l'hôtel de Retz. Sully, les secrétaires d'État, le premier valet de chambre Beringlıen avaient fait des plantations de mùriers pour plaire à leur maitre ${ }^{5}$. Mais si un certain nombre de griunds

1. Chanpolseav, loc. cit.

2. Boislisle, Correspondance des contrôleurs généraux avec les intendants, J, $\mathrm{n}^{\circ} 1185$.

3. Cuevalier, La décadence de la manufacture de soieries à Tours. Mémoires de la sociélé archéologique de Touraine, V, 361.

4. Gasparis, Op. laud. Cal'ew a exagéré en disant : "... he IJenri IV) has caused most of the gentlemen and possessioners of his realm to plant mulbery trees in their grounds for the nourishing of silk-worms " p. 430 . Isaac Laffemas a exagéré encore plus en écrivant que la production de la soie indigène pouvait sulfiı aux besoins du pays.

5. J.-B. I.e Tellen, Brief discours... Dédié à la duchesse de Sully. Paris, Pautonner, 160\%. B. Laffemas, Lettres et exemples de li feu royne mére, comme elle faisoit travailler aux manufactures et foumissoit aux ouvrier's 
proprétaires était entré daus la voie ouverte par lui, la masse des petils cultivateui's, qui exploitait dès lors la plus grande partie dusol, ne l'avait pas suivi, le clergé, dans son ensemble, n'avait pas mis au service de son jorojel toute sa puissance do propagande. Le sueces local et particl qu'il obtint resta loin de la grandeur du plan 'püil avait conç'u.

L.e pays, en aceucillant froidement sa tentative, obéit-il it une routine arengle ou se rendit-il compte des obstacles 'qu celle rencontrait dans les circonstances physiques, dans la nature les choses? Les partisans de la sériciculture, Olivier de Serres, Lalfemas, affirment, en siappuyant sur lexpérience, que le climat de la France n'est contraire ni ì la culture du murier ni à l'élève des vers a soie, ils font ressurtir combien la cueillette du mùrier, les soins a donner aux vers sont faciles et pen eouteux, la cueillelte pourant itre laite par des femmes et des enfants et ne dítournant mullement, non plus que le travail de la magnancrie, des travanx agricoles; ils inroquent les résultals obtemus : daprès eux, la soie recueillie en France, mème dans les régions tempérées, vaut ou mème lépasse en qualité la soie italienne. En regard de cette opinion nous derons mettre celle des incrédules. des adversaires, celle de sully qui déclarait à Henri IV que le printemps était trop froid et trop tardif pour l'éclosion des ver's et li végétation des mùriers, que ces arbres ne pouvaient pas donner avant quatre ou einq ans une régétation suffisante pour nourrir les vers ${ }^{1}$, celle de certains Italiens de bon jugement qui, consultés par George Carew sur les chances de l'entreprise, lui répondirent qu'elle

de ses propres deniers. Paris, Pactowner, 1602, in- $8^{\circ}$. Le premier valet de chambre, Beringhen, était un personnage remuant et en crédit qui sut se faire intéresser dans plusieurs entreprises, notamment dans une exploitatim le forges et de fonderies.

1. Economies rayules, Coll. Michaud, I, 515. 
finirait par échouer, les vers ne pouvant vivre ou au moins donner de bonne soie arec une température aussi froide que la nôtre ${ }^{1}$. De ces deux opinions, sur la valeur desquelles il n'appartient qu'aux liommes spéciaux de se prononcer, le pays semble avoir partagé la seconde. Le roi lui-même parait s'ètre découragé; c'est ce qu'on peut conclure de l'abandon d'une partic du plan primitif, de sa répugnance ì user de contrainte, à imposer la sériciculture aux cultivateurs. Sans rouloir condamner son initiative, nous ferons remarquer que, comme le reconnaìt 0 . de Serres, l'élève des vers ne peut ètre entreprise utilement à moins de deux ou trois mille pieds de mûriers et que les mûriers ne rapportent qu'au bout de einq, six, sept ou huit ans ${ }^{2}$. N'estce pas assez pour expliquer la réserve des petits cultivateurs? Les grands propriétaires seuls pouvaient supporter de pareils sacrifices et, s'il fallait s'en prendre à quelqu'un de la disproportion entre la largeur des rues et les résultats, ce serait la noblesse et le clergé qu'on devrait en rendre responsables ${ }^{3}$.

Les fabriques de soieries établies par Henri IV à Paris, à Troyes et à Mantes survécurent-elles à leur fondateur? Les anciennes fabriques de Lyon et de Tours acquirent-elles sous son règne un développement nouveau et durable? II. Poirson * n'a aucun doute à cet égard; il fait houneur à Henri IV de l'importance que l'industrie des soieries a prise dans la production nationale ${ }^{5}$, il fait remonter jusqu’à lui

1. Dans Birch, p. 431.

2. Théâtre d'agriculture, p. 114, 120,15i.

3. Les tentatives faites par Colbert en 1670 pour propager la culture du mûrier ne furent pas plus heureuses, bien que les intendants ne se fissent pas scrupule d'en faire planter d'autorité. Lettres de Colbert publiées par M. P. Clémext, IV, 233, note 2.

4. III, 281-289.

5. "On évalue la production des soieries dans le monde á deux milliards de franes, et la France y figure pour une valeur de 1200 millions." Foxtpertus, Le mouvement économique aur. Etats-Lnis et au Canada, dans l'Économiste français du 25 nov. 1883. 
les manufacturesqui existent ou qui existaient, au moment où il ńrivait, à Paris et en Picardie; les deux tiers de celles du Midi lui devraient, à l'en croire, leur existence, culles de Lion, de Tours et de Montpellier, leur essor. Mais si l'on cherche sur quoi sippuient ces affirmations, on ne décourre que quelques textes empruntés à Latlemals qui prourent seulement les espéranes que le projet du roi faisait naitre chez l'apôtre le plus fervent de l'industric séricicole ${ }^{i}$ et $u 11$ seul document ${ }^{2}$ se ripporlant véritablement ì la question, mais d'où il résulte seulement que la falsrique de Lyon était en décarlence sous les successeurs immédiats de Henri IV.

l'oint n’était besoin, pour faire apprécier la persistance de l'élan imprimé par le roi à l'industrie des soieries, de rerhercher, comme l'a fait II. P'oirson, l'état de la production et de lexportation au milieu du xvin siècle, à la fin de l'ancien régime, sous la Restauration, sous la monarchie do. Juillet, tàche trop difficile pour être entreprise ainsi incidemment et à la légère; c'est à des témoins aussi rapprochés que possible de l'année 1610, de l'époque où les mesures prises par le roi avilient pu produire leurs fruits et oì un autre gouvernement n'avait pu en compromettre le succes, quill faut demander des renseignements sur le sort des établissements fondés par Ileuri IV et sur l'extension qu il a pu donner à ceux qui existaient avant lui.

Au lendemain mème de sa mort, peut-ètre dès les dernières années de sa vie, les maisons formées à Paris sous son patronage avaient disparu ${ }^{3}$. La fabrique de satins de Brugres et de damas cafards établie à Troyes ne paraît pas avoir mieux réussi, car non seulement elle est restée in-

1. Polksox, III, 281, note 1; 283, note 1. Vuy. aussi le passage tiré d'IsaAc J.AFFEMAS, P. 281.

2. Polnsox. HII, 285 .

3. Nëwoire précité concernant les panves enfermés, 1612. Enquête füte en 1610 sur le commerce et l'industric séricicole de Lyon, ả l'appendice. 
connue au dernier historien de cette ville ${ }^{1}$, mais elle n'a laissé aucune trace dans les archires municipales ni dans les archires départementales de l'Aube ${ }^{2}$. La manufacture établie à Mantes sous les yeux du roi et sous la direction des Parent fut, au contraire, on l'a ru, une création durable et féconde.

Si nous passons aux deux anciens centres de production, à Tour's et à Lyon, le premier nous offre une activité que nous avons déjà constatée, qui ne s'est arrètée que dans la seconde moitié du xvil ${ }^{\mathrm{e}}$ siècle et dans laquelle l’influence de IIenri IV peut revendiquer une part. Quant à la fabrique lyonnaise, elle ne s'était pas relevée, à la fin du règne de IIenri IV, de la décadence qu'elle subissait à la suite du commerce local, depuis la mort de Henri $\mathrm{II}^{3}$. La ville était moitié moins riche qu'elle ne l'avait été vingt ans auparavant * Questionnés officiellement sur les moyens d'y soutenir l'industrie en déclin, sur le nombre des ouvriers en soie et sur la manière de développer l'industrie qui les faisait vivre, les consuls montraient les ateliers déserts, les ouvriers décimés par la guerre ou ayant porté dans d'autres villes ou même à l'étranger les arts qui faisaient la prospérité de Lyon ; proposaient le rétablissement du commerce comme l'unique remède aux souffrances de l'industrie et estimaient à onze ou douze mille le nombre des habitants 'Tui gagnaient leur vie dans la fabrique des soieries et celui des métiers qui íabriquaient des soieries communes à dixhuit cents, au lieu de sept mille qu'on comptait autrefois. I leurs yeux, il ne suffisait pas, pour empècher la sortie de l'argent français qui préoccupait le nouveau gouvernement, de développer la fabrication de ces étoffes ordinaires, il

1. Bостіот, Histoire de Troyes.

2. Renseignement dû à II. Francisque André, archiviste de l'Aube.

3. Voy. l'enquête publiée en appendice.

4. Relation de G. Carew dans Birch, p. \{31-\{35. 
fallait introduire à Lyon la fabrication des riches étofle: fiçonnées dont ils comptaient vingt types diflérents, et ils désignaient Claude Dangon comme le seul homme capable de faire réussir cette fabrication nouvelle, ì laquelle il se livrait déjì avec succís et quil apprendrait à ses compatriotes, sïl recevait liassistance pécuniaire du gouvernement. Le consulal demandait en même temps pour Danģon la confirmation des priviliges qüil tenait du feu roi ${ }^{\prime}$ et quil eut à défendre contre ses confrìres². Les nouveaux types créés par ee grand industriel attirèrent toujour's lattention et l'intérèt de la municipalité ${ }^{3}$, mais il ne fut pas mis en possissiou des moyens qui lui aurajent permis de tirer la fabrique lyommaise de la crise où elle languissail. En 1619 , le chiffre des ouvriers en soie à l'aumône s'élevait at plus de six mille ${ }^{4}$ Lyon n'en dut pas moins à Claude Dangon, avee la fabrication des façonnés, la source de sa richesse future, et le patronage accordé par IIenri IV à cel éminent manufacturier doit le faire considérer, malgré la staguation permanente de l’industrie séricicole à Lyon pendant tout son règne, comme le premier auteur d'une prospérité que Napoléon et la Restauration devaient porter à son apogée ${ }^{5}$.

1. Inventaire des arch. municipales de Lyon. Reg. BB I4ti, annce 1610.

2. Ibid. lieg. BB 14i, année 1611 .

3. Visite faite par le consulat des ateliers de Pierre Dangon, maitre ouvrier [le successeur, probablement le fils de Claude] pour le roi en étolles d'or, d'argent et de soie, afin d'examiner " diverses sortes de manufactures desdits drapt\%, non encore jamais venz en France, quil a presentement sur ses metiers. "Deseription de ces étolles Jont le fini et l'éclit merveilleux engagent les échevins ì delirrer, d'aprés son désir, au liabricant un certificat constatant qu'il a detache deses metiers des echntillons " qu'il dict rouloir soubdain envoyer en la ville de Paris pour les faire venir et scavoir si elles [les etofles] agreeront en cefte forme, ete. "Ibill. kes. BB 149, année 1613. loy, aussi sur la fabrique lyonnaise et sur Ct. Dasoon, Monfat.con, Ilisl. de la ville de L.yon, II, 735-i37.

4. Ilid. Reg. 155, année 1619 .

5. Montchrétien ne connait pas d'autres centres de fabrication que ecux qui existaient avant Ilenri $\mathrm{W}$, Tours et Lyon 'p. 98). Pour lui cette industrie reste foujours a fonder en lirance dans les proportions que le roi avait 
La fabrication du drap était bien plus répandue en France yue celle des soieries. Toutefois elle ne pourait suffire à la consommation nationale qui arait recours à l'Angletere pour les draps communs, à l'Italie et à la Flandre pour les anticles de luxe. La draperie française, quoique ruinée par les guerres civiles, parait avoir repris, dans les dernières années du $\mathrm{xr}^{\mathrm{e}}$ siècle, une certaine activité due, non aux encouragements de l'État, dont l̈industrie n'avait pas encore attiré l'attention, mais au rétablissement graduel de la paix publique. La protection de Henri IT ne fit pas plus défaut à la draperie qu'à la soierie; nous en avons pour garant $G$. Carew qui atteste les efforts du roi pour affranchin la France de l'importation des draps anglais, sans nous faire connaître les moyens qu'il employa dans ce but ${ }^{1}$. Si son intérèt pour lindustrie de la laine ne se manifesta pas par un projet d'ensemble analogue à celui dont la sérieiculture et les soieries furent l'objet, e'est qu'il ne sagissait pas iei d'une industrie nouvelle à créer, mais de fabriques déjà existantes à ranimer. Nous avons dit que la commission du commerce entreprit de donner aux industries de la laine une police nouvelle; ce ne fut pas sans peine qu'elle put obtenir des corporations intéressées un projet de règlement. qu'on n'a pas conservé, qui ne devait pas, d'après certains indices, se recommander par des idées nouvelles et qui n'exerça aucune influence sur la fabrication ${ }^{2}$. En dehors de celte vaine tentative, nous n'avons à signaler aucune mesure générale inspirée par l’intérêt de la draperie. Nous devons donc nous borner à faire connaître celle que les

voulu lui donner et qui seules pouvaient mettre la production du pays en rapport arec si consommation, lui permettre de se suffire à lui-urèue et même de fournir aux besoins des nations voisines. Voy. le passage cité plus haut, et dans le méme ourrage, p. 199.

1. Op. land., p. \&3?.

2. Procès-verbaux, 110-111, 114, 115, 121, 1:2, 123, 124, 126, 152, 153, $15 \pi, 159,181$. 
sayeteursd'. Imiens obtinrent de lacommission et du conseil. En 1603, alors que leur industrie ne sétait pas encore relevie de sa décadence, ils se plaignirent, et léchevinage arec eux, de l'enchérissement des filés cansé par la concurrence étrangère. Des marchands élangers au pays venaient acheter les lilés diuns les villagers et les marchés, aux paysuns, aux petils filateurs et à des marclands en gros, pour les exporter ou les revendre aux tisserands à un prix élevé. La conmission proposa d'interdire la rente des filés a Imiens et dans la banliene ailleurs qu'au marché et de délendre l'exportation '. Ln arrèt du conseil du 28 février $160 \div$ adopta ces propositions et leur donna force de loi, "n y ajoutant, conformément au vou des sayeleurs, la défense de cumuler les métiers de filateur et de peigneur de laine. La commission et le gouvernement oubliaient qu'en protégreant les tisserinds, en s'efforçant d'abaisser pour eux le prix de la matière première, ils portaient atteinte aux intérèts des filateurs ${ }^{2}$. S'il faut en croire Montchrétien, lindustrie du drap. tont en étant répandue dans presque toutes les provinces, se trourail en déclin dans les années qui suivirent la mort de Henri IV : tel bourg du royaume, où l'on faisait autrefois de la draperie pour plus de quatre ou cinq cent mille livres, nen produisait plus que pour une valeur de trente mille. Ce qu'il y a de certain, c'est que le marché français continuait à être envahi par les draps étrangers; les drapiers parisiens le constatent en le déplorant dans le cahier de doléances qu'ils présentèrent iux états de $1614^{3}$.

La production des toiles était plus considérable encore en France que celle des draps, elles l'était asser pour 'ju'clles formassent un article important de nos exporta-

1. Séance du 18 juillet. Procis-verbaux, 106-I0S.

2. Ker. du cunseil. Arch. nat. E 6a, f, 185.

3. Arch. nat., $k, 67, n^{\circ}: 0$. 
tions'. Parmi les lieux de production, nous citerons seulement la Normandie et spécialenent liouen, Caen et Louviers, İa Bretagne, Laval, Chìtellerault, Troyes, le Barrois, la Champagne 2. L'exportation aurait été plus considérable encore si l'étranger n'était venu enlever nos filasses et nos étoupes ${ }^{3}$, comme il enlevait nos laines et nos soies.

En 1604 le roi d'Espagne interdit l'entrée des toiles de Hollande dans ses États; ceùt été l'occasion pour notre pays de s'emparer de ce marché, si nos toiles avaient pu remplacer celles des Provinces-Unies. Ce fut à cette époque que deux marchands de Rouen, Jean Wolf et Antoine Lambert offrirent au roi d'établir dans cette ville une manufacture de toiles fines à l'imitation de celles qui se fabriquaient en Brabant, en Flandre, en Hollande. Ils s'engageaient à faire venir des ouvriers de l'étranger, ̀̀ prendre en France la moitié de leurs apprentis, à établir les curanderies pour blanchir comme on le faisait dans ces trois pays, c'est-à-dire d'une façon supérieure au blanchiment pratiqué en France *. Ils demandaient que le roi arançàt à chaque chef de métier, qui viendrait sétablir à Rouen, pour ses frais de déplacement et d'établissement, 2:3 écus (237 fr. 49) imputables sur le prèt fait aux entrepreneurs. Ils fixaient ce prèt à 100000 écus (949933 fr. 16) remboursables en dix ans. Ils demandaient aussi la création d'une halle à Rouen pour vendre les matières premières et les produits de leur industrie, le titre et les privilèges de commensaux de la maison du roi, le droit de

1. HoXYCHRÉTIEX, p. 89.

2. Avis des corp., p. 5. Morry, Ilist. de Louviers, II, il.

3. Et, comme l'on afferme, toutes les fillasses de lyn, de chanvre et estouppes dequoy l'on faict lesıl. toilles estranges sont prinses et enlevées de France, mesmes des pays de Champaigne, Picardie et Bourgongne. " Traité du commerce. Bibl. nat. Fr. 2085, f. 15.

4. Procès-verbaux, 92-93. 
tenir un magasin de " mereeries " it l'aris sans être soumis anx visites du bureau de la ville, la faculté d'acheter ì létranger pour 30000 écus (47976 fr. :88) par an de fil. de cendre gravelée, de savon et d'autres matieres nécessaires à leur industrie, le privilìge d'aroir aux faubourgs de Rouen une brasseric oì les brassenrs rouennais n'aumient rien a voir. celui de premdre du sel blanc pour les hesoins de leur industrie sans piyer gabelle. Les tisserands étrangers qui viendraient sétablir en France devaient ètre traités commeregnicoles, exempts dimpôts, placés sous la surveillance exclusive des deux entrepreneurs. Ces propositions furenl soumises il la commission du commerce qui les inlopta sous certaines restrictions. Elle s'en remettait au roi pour le chiffre de la subrention sollicitie par les entreprencurs, elle ne leur laissait la surveillance de lindustrie nouvelle que pendant huit mois, temps quils devaient mettre à profit pour rédiger et lui présenter un projet de statuls et de rìglements qui recevraient la validation royile ${ }^{1}$. La manufacture. établie au faubourg Saint-Sever et connue sous le nom de la grande tissanderie, fut autoriséc et constituée par des lettres patentes et par divers contrats enregistrés le 30 janvier 1606 au parlement de Rouen. Elle se composait d'ateliers pouvant contenir $3: 30$ métiers à tisser et de deux curanderies, dont chacune devait employer rinquante onviers. Elle compta 1:30 métiers la première année, 200 autres la sujvante. Les directeurs obtenaient un prèt de $1: 30000$ livres \$438 439 fr. 92 . Leur fubrication, toute nouvelle en France, comprenait le linge de corps, de table "et autres ouvrages currés, damassés, figurés ou rayés l'or et d'urgent ou de soie, de toute couleur ou farcon ”. " Ils fondèrent à Mantes

1. Procés-verbal de la séance du 3 septemb:c !60i. I'rocis-verbaux,

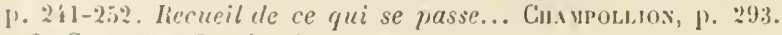

2. Gosseus, Op. lauel., p. 1:0-1'́1. 
une autre manuficture de toiles fines, liacon de Hollande, pour laquelle le roi leur allona une subrention de 90000 lirres ' 263063 fr. 9:i). Mantes possédait encore à la mème date, en 1607, un établissement du même genre dirig̨é par Thomas Robin et également subrentionné par le roi ${ }^{2}$. II lut anssi question d'établir celte inclustric à Troyes et les chefs de l'entreprise fiasaient espérer une diminution de $10 \mathrm{~s}$. ( 1 lr. 4 (i) par aune sur le prix des toiles de IIollande ${ }^{3}$.

Quel fut le sort des manufactures de toiles fines londées sous le patronage de Henri IV? M. Gosselin, qui a contribué à mettre en lumière les origines de celle de Wolf et Lambert et qui arait sous la main les dépôts d'archives les plus propres à nous éclairer sur son avenir, s'est déclaré hor's d'état de dire ce qu'elle était derenue ‘. Nous avons été plus heureux pour les établissements dirigés à Hantes par les mêmes entrepreneur's et par Thomas Robin; deux ans après la mort de Henri $\mathbf{I V}$, ces établissements n'existaient plus ". Caen, au contraire, n’arait pas laissé dépérir l'art de la lingerie qui, avec les flanelles (lingettes) et les bourses brodées, faisait sa renommée industrielle. Elle devait la beauté de cette lingerie principalement à l'une de ses anciennes familles, les Graindorge dont chaque géuération, pour ainsi dire, depuis 1460. arait fait faire un noureau progrès à la fabrication. Parmi les membres de

1. Arrêt du conseil du 25 aoủ $160 \%$. Arch. nat. à Ia date.

2. Arrèt du conseil du lí août 1607. Mème collection. J. A. DE Tuoc, VI, 170 , anno 1603 .

3. LAFFeuAs, Le naturel et profit admirable du meurier... Paris, 1604. Sur le projet de Henri IV d'affranchir son royaume de l'importation des toiles fines de Ilollande, voy. CAREw, dans Birch, p. 430. Voy des preures de sa sollicitude pour les entrepreneurs de cette industrie. Leltres missives, VII, 3 it; IX, no 88 .

4. Ouvr. cité, p 1 \&l.

ј. "Tesmoin..... les toilles facon de IIollande à IIantes.... dont aujourd'huy il ne parait marque ne vestige. ". Mémoire anonyme concernant les pauvres enfermés, ubi supra. 
celte famille. le panegyriste des plus illustres Caennais de son temps. le doclemr Jacques de Cahaignes, a distingué surtout Antré firaindorge qui au linge de table uni ajouta le linge broché dornements giométriques et de fleurs; Richard, fils d'André qui inventa le linge damassé orné de fignures d'animaux et diamoiries; Michel, fils an̂é de Richard qui poussa encore plus loin les procédés de fabrication et forma une foule délìres qui les répandirent en France '.

Lindustrie des futaines, assez récente en France ${ }^{2}$ et qui arait ses principaux centres à Rouen et it Troyes ${ }^{3}$, soulliait des malfaçons et de la supériorité d'apprèt et de teinture des futaines étrangères, principalement de celles d'Angleterre * Lin fabricant, originaire des Pays-Bas, Paul l'inçon, apporta en France lint de teindre, de friser et diapreter les futaines et basius comme on le faisait chez nos roisins, et sollicita les encouragements de la commission du commerce. Les épreures auxquelles il fut soumis. l'opinion des gens compétents lui furent entièrement farolables. Fort de lapprobation de la commission, il se mul à appliquer son procélé à Paris, à Rouen, à Troyes ut à Tours, fit renir des ouvriers étrangers et se crut dies lor's autorisé à solliciter un privilegge. Le 3 mars 1606 il en obtint un de dix ans, à condition de prendre autant d'apfrentis français quil pourrail, d'observer les ròglements qui seraient faits plus tard sur son industrie, de ne pas teindre ni apprèter daprès les procédés ordinaires, et sans

1. Cahagnesii Eloyiornm civium Cadomensium cenlurin prima. Elogia 1: et 29. 1609. J.A Rile, Mémoires sur Tancien commerce de Caen dans Mérn. de läsociélé d'agriculture el rle commerce de Caen, 1836. Bombeatx, bes anciennes maisons morumentales de Caen. Bulletin monumenlal, 18 io.

$\therefore$ l'pocis-rerbanx, 1. $16 i$.

3. Hal., p. 161,169 , et Lettres pat. accordées il l'aul l'incon le 3 mars 1606.

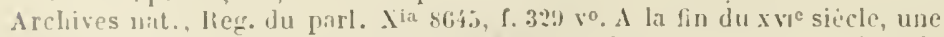
manulacture de fulaincs fut etablie a Nimes; c'est la preuibe en late de cette ville. P'tran, Lne ville au temps jadis..., 1. bli.

i. Cissuroussis, p. 16i-168. 
préjudice des concessions analogues antérieures ${ }^{1}$. L'année précédente, le roi avait accordé pour huit ans à Michel Pierre et à Luc Taschereau le monopole de la fabrication des futaines à Tours et en Touraine. La munivipalité renonça, en faveur de cette industrie, à l'impôt du sol pour livre sur toutes les matières premières et sur les produits manufacturés ${ }^{2}$.

Nous ne sommes pas en mesure de nous prononcer sur le succès définitif du procédé introduit en France par Pinçon ni de dire si l'industrie des futaines et des basins se ressentit d'une façon notable et durable de lintérêt que le roi et plusienrs municipalités ${ }^{3}$ manifestèrent pour elle ${ }^{4}$.

Nous ne pouvons que répéter à propons de l'industrie des bas de laine ce que nous arons dit de celle des bas de soie. Introduites à Dourdan à la fin du $\mathrm{Xv}^{\mathrm{e}}$ siècle, l'une et l'antre avaient reçu de la commission du commerce des statuts qui en rendaient l'exereice libre à tout le monde, sous la condition d'observer les prescriptions relatives à la qualité et au poids et sous la garantie de marques de fabrique ". Trente ans plus tari, elles avaient pris une extension dont le point de départ doit remonter à Henri IV ${ }^{6}$.

Nous aurons passé en revue toutes les industries des tis-

I. Lettres patentes précitées et Champollion, aux pages visées par la table vo Futaines.

2. Arrêt du conseil du 8 férrier 1605. Bibl. nat., Fr. 10843. Grraldet, Ilist. de Tours, 1 i9.

3. LAFFEMAs. Le naturel et profil admirable du meurier..., p. 16.

4. Il. Gosselin, si bien placé pour suirre la destinée de l'établissement de Paul Pinço à Rouen, n’a pu ici encore que poser la question de savoir ce qu'il était devenu, p. 141.

5. Séance du 4 mai 1604. Champolliox. 185-188.

i. " Le duché d'Estampes et pays de Dourdan est remply d'un nombre infini de personnes qui s'occupent... de mieux en mieux à travailler en bas de soye et d'estame... "Nouveau reglement general sur toutes sortes de marchandises et manufactures qui sont utiles et nécessaires dans ce royaume représenté au roy pour le grand bien et profit des villes et autres lieux de la France par M. le marquis de la Gomberdiere, 1634. Réimprimé dans Fovruier, Variètes hist. et litt., 111, 109. 
-ns: sur lespucelles nous arons pu recucillir des renseignements, quind nous aturons mentionné un projel formé pour utiliser une nouvelle maliere textile. Olivier de Serres ayant sommis au roi les cesais heureux qu il avait faits pour tausformer en tissus les filaments de l'ícorce de minrier hlinc, relui-ci linvila à faire connaitre an public sa déconverte. Ce fut pour répondre à celle piorocation que le savant agronome publia l'opuscule intitulé: La seconde richesse du meurver blune, qüil reproduisit dans le Thécitre d agricullure '. On utilisail déjil lécorce du tilleul, particulièrement ì Louves-en-Parisis, pour la corderie et la toile grosiere, l'ortie pour la toile fine ${ }^{2}$. La commission du commeree proposa d'accorder à Olivier de Serres pour lexploitation de son invention un privilege de vingt ans. arce exemption dimpôts pendant la mime période et des avantages pour ses commis ${ }^{3}$. Ce privilige lui ful conféré par un arrict du conseil du 2.3 mars 160 \% :

1 l'arènement de Henri IV, l'industrie de la tapisserie itail, comme loutes les antres, en décadence ". La manufacture de haute lice, fondéc par François $I^{\text {er }}$ dans le palais de Fontainebleau et dirigée suceessivement par le I'rimatice et Philibert Delorme, n'existait plus, depuis que les fils de Catherine de Iédicis avaient abandonné celte

1. Chap. Xil du Ve lieu.

$\because$ Theatre d'agricullure, 11, 14i-list.

3. Seance du 2 septembre 160:3. Cilsupol.10x, 1. 119-1?(1).

i. Arrêts du conseil. Arch. nat., i la date.

$\therefore$ " Aujourd'huy \& jany 1599 , le lioy... desirant retablir en son royaume lia uanufacture de tapisserie de laute lisse..." Brevet de la charge et intenlance de la manufacture de tapisserie le haute lisse en faveur du sieur de

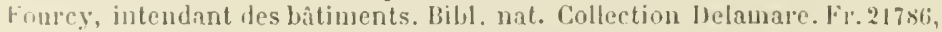
f. :5.). ".... la tapisserie de haulte lice qui a cy-derant lleury en reste d. vlle l'aris et dèlaissée et discontinuie depuys q.1. annies... "licmon1rances du bureau de la ville art sujet des priviliges accordes en 160 i à Jarc de Comans et i Francois de la Planche. J.-J. Gumfner, IJisloire généme de ln tupisserie; tapisseries francaises, Renaiscance, p. 109. "I,es manufirtures de tapisselice que les desordres des regnes precedents avaient aholies. "Sicvul, Antupules de l'aris, II, 506. 
résidence '. L'atelier créé par Henri II à Paris, dans l'hôpital de la Trinité, avait au contraire subsisté ${ }^{2}$; à côté de cet atelier destiné, comme tous ceux du mème établissement, à apprendre un métier à des enfants orphelins et paurres, on complail sans doute à Paris et en province un assez grand nombre d'atelier's privés ${ }^{3}$, mais notre pays n'en faisait pas moins renir de l'étranger, particulièrement de Flandre, la plupart des tentures qui décoraient les églises et les appartements.

Ce fut en 1597 que Ilenri IV établit rue Saint-Antoine, dans la maison professe des Jésuites, devenue vacante par suite de leur expulsion, et sous la direction de Girard Laurent, auquel il associa plus tard Maurice Dubout, une manufacture royale 4 . Du premier de ces artistes on ne connait que le nom. On en sait un peu plus sur le second, que les historiens appellent à tort Dubourgä; il était sorti de l'école de la Trinité et il exécuta pour l'église Saintllerry, en vertu d'un marché passé le 2 septembre $1584^{6}$, une suite de tapisseries représentant les scènes de la vie de Jésus-Christ, dont deux fragments sont parrenus jusqu i nous ${ }^{7}$. Lorsque les portes de la France se rouvrirent pour

1. Guiffrei, ouvr. cité, 1-2, 79.

2. GulfFBer, 79 .

3. Il existait en effet partout des corporations de tapissiers, mais tous les tapissiers n'étaient pas des fabricants de tapisseries. Ce terme n'était pas moins compréhensil que celui même de tapisserie ; on l'appliquait aux fabricants et aux marchands de certains tissus et, comme de nos jours, aux marchands d'une foule d'objets et d'étoffes d'ameublement. Voy. LAcorDAlre, Notice historique sur la manufacture des Gobelins et de tapis de la Savonnerie. 1853 , p. $12, \mathrm{n}^{\circ} 2$.

f. IA COR JaIRE, p. 28.

5. Sauval, Palila Cayet, Lacordare. P. Cayet s'est trompé plus graveunent encore en faisant de Dubout un étranger et un fabricant de soieries et en mettant sa manufacture i la Maque. Chronologie sept., p. 259. Con Michaud et Poujoulat. Rıchen, all rapport de Sacral (II, 50s), a partagé ces deux erreurs.

6. Et non 159', comme le dit Sauval et, d'après lui, M. Lacordaire. Le marché a été publié pour la première fois par M. Guıfrey, p. 92.

7. L'uu est conservé au musée de Cluny, l'autre au musée des Gobelins. Gulffrey, $89, \mathrm{n}$. 2. 
les Jésuites, à la fin de 1603 , la manufacture à la lête de laquelle se trouvaient toujours Laurent et Dubout fut transportée au Lourre'.

Ses produits faisaient l'admiration des étıangers. L'ambassadeur anglais, George Carew, dans sa relation sur l'état de la France écrite en 1609 , nous apprend que ces tippisseries, où n'entrait ni or ni argent, contaient pourtant, ì cause de la perfection du trarail, 16 couronnes l'aune (14.9 fr. 6.j); il ajoute qu elles étaient recherchées par les cardinaux et les princes italiens ${ }^{2}$. Nous sarions déji que les tapisseries fabriquées au Lourre étaient des tapisseries de haute lice ${ }^{3}$; gràce ì Carew, nous sarons qu'elles nétaient pas rehaussées d'or ni d'argent et nous connaissons bien dès lor's les caraclires par lesfucls elles se distinguaient, au point de vue technique, de celles dont nous parlerons tout à l'heure. Le roi avait attaché à l'atelier du Louvre un peintre, Toussaint Dubreuil, et un sculpteur, Tremblay * Henri Lerambert, son peintre ordinaire, foumissait aussi des patrons pour les tapisseries le haute lice. A la mort de Lerambert, en 1610, Guillaume Dumée et Laurent Guyol obtimrent, à la suite d'un concours, le brevet de peintres ordinaires". Les apprentis, sortis de l'atelier de Laurent et le Dubout, jouissaient, comme tous ceux qui araient appris leur métier dans la galerie du Lourre, du privilège de

1. LACOHU.tRE, p. 28, n. 3 .

2. In his new buildings at the Lourre, the first place finished was ilelivered to some Netherlanders, who work in haute lice with such curiousness, as every Flemish ell of that tapestry amounteth to sixteen crowns, though it hath neither silver nor gold in it : and at that price some cardinals and other princes of Italy cause suits thereof to be made for then. $O p$. laud. On voit que les souvenir's de Carew l'ont trompé sur la nationalité de Laurent et de Dubout.

$\therefore$ Ving. le brevet de .11. de Fourcy cité plus haut.

4. Sacial, II, p. 506. Guifrier, p. 10\%.

5. GLnt lay, Les m thufaclures parisiennes de tupisseries. Mém. de l'hist. ale J'aris, XIX, ï. 
s'établir sans lettres de maîtrise et sans chef-d'ouvre. En fondant des établissements particuliers, ils propageaient les procédés de la haute lice et préparaient la restauration de cette industrie déchue, la manufacture royale exerçait par eux sur l'industrie privée l'influence d'une école modèle.

Cette manufacture survécut longtemps à Ilenri IV, on peut dire qu'elle lui survit toujours. Longtemps après sa mort, on retrouve au Louve Girard Laurent et Maurice Dubout, leurs fils les y remplacent, et la translation même de la manufacture de haute lice du Louvre aux Gobelins dans le dernier tier's du $\mathrm{xrr}^{\theta}$ siècle $^{1}$, ne peut faire oublier son origine, pas plus qu'elle n'a altéré essentiellement son caractère.

En même temps qu'il fondait à Paris une fabrique de tapisseries de haute lice, Henri IV songeait ì attirer en France des tapissiers flamands. Déjà, sous le règne de son prédécesseur, en 1583 , le projet d'établir à Tours la fabrication des tapisseries de Flandre avait été conçu², puis, selon toute apparence, abandonné. Dès 1599 , la pensée de faire renir des tapissiers flamands était arrêtée chez le roi et les termes du document qui nous révèle ce fait autorisent nême à dire que des négociations araient déjà été engagées dans ce but". Nous ne pourons déterminer d'une façon précise l'époque à laquelle les deux artistes auxquels Henri IV s'était adressé répondirent à ses arances; ce qu'il y a de certain, c'est qu'au commencement de 1601 c'était un fait accompli, puisque, le 12 janvier de celte année, le roi les plaçait sous la direction de l’intendant général de

1. Guiffrey, p. 10 i

2. Archives municipales de Tours. Délibérations du conseil de ville. Henri IV arait repris ce projek, mais la mort l'empêcha d'y donner suite. Giraudet, Hist. de Tour', 180.

3. "... espérant aussi [le Roi] que le dessein qu'elle a de faire venir des Païs-Bas grand nombre d'ouvriers pour travailler ausd. tapisseries réussira... " Brevet précité du $\mathrm{s}^{\mathrm{r}}$ de Fourcy. 
ses bitiments, II. de Fourcy, déja chargé de la manufacture de haute lice '.

Quel était le genre de fabrication que Mare de Comans ct François de la Planche apportaient de leur pays? Cette question pouvait, jusquà ees derniers temps, présenter quelque incertitude. Le brevet précité du sieur de Fourcy, en date du 4 janvier $1 \$ 99$, dit jue c'est pour concourir à la restauration de la tipisserie de haute lice que le roi se proposiait de faire renir des ourriers des Pays-Bas? P. Ciacet, qui parle des ouvrages de Comans et de la P'anche pour les avoir rus, les considère comme des ouvrages de latute lice ${ }^{3}$. Pour .I. Lacordaire, c'est aussi des ouvriers haut-licier's qui vinrent se fixer à Paris'. Iais nous croyons que ces autorités ne peurent prévaloir contre le texte si heureusement découvert par II. Guiffrey. Dans les remontrances présentées par le bureau de la ville contre les privilèges accordés aux deux associés nous lisons: "Et d'aultant que la tapisserie de haulte-lice qui a cy devant flemry en ceste dite ville et délaissée et discontinuće depuys quelques années est beaucoup plus précieuse et meilleure que celle de la marche dont ils usent aux Pais Bas, qui est celle que l'on reult establir ${ }^{5}$. " Il est impossible de souhaiter un texte plus décisif. Que llenri IV ait eu, en 13099 , l'intention de faire venir' en France des tapissiers haut-liciers, on doit l'admelle, mais il est certain que ceux qui y sont renus, que Mare Comans et François de la Planche ne fabriquaient pas de tapisseries de haute lice, qu'ils ne pouvaient par conséquent fabriquer que des

I. Lacordare, p. 30. Un compte de dépenses de la même année constate un don de 200 éeus (1899 fr. 90) fait à Francois Verrier ou Vessier, tapissier flamand, pour l'attirer en France avee d'autres ouvriers. Gitffney, p. 109.

2. Voy. le passage cité plus haut.

3. Chronologie sept., p. 258-259, à l'annće 1603.

4. P. 30 .

5. GCAFFEY, P. 103. 
tapisseries de basse lice qu'on appelait alor's tapisseries de la marche, à cause des marches ou pédales qui distinguaient le métier de basse lice.

La fabrication des deux artistes flamands ne se différenciait pas seulement de celle du Louvre par la disposition horizontale de la chaîne sur le métier. Ce qui la caractérisait aussi, c'était les rehauts d'or et d'argent dont ils enrichissaient leurs produits. En même temps que des tapisseries de luxe, ils en fabriquaient de plus communes de la même qualité et du même prix que celles des Pays-Bas ${ }^{1}$. $P$. Cayet vante la vérité et la vie qüils savaient mettre dans leurs ouvrages ${ }^{2}$.

Les débuts de Jarc Comans et de François de la Planche à Paris ne furent pas exempts de difficultés. Ils subirent plusieurs pérégrinations ${ }^{3}$ avant de trouver aux Gobelins une installation définitive. L'argent leur manqua. Ils avaient supporté les premiers frais d'établissement et fait face jusqu'en 1606 arec leurs ressources personnelles aux dépenses courantes. Henri IV espérait qu'un eapitaliste, nommé Largentier, s'associerait avec eux, mais celui-ci, n'ayant qu'une foi médiocre dans le succès, se borna à leur prèter à intérèt et ne roulut pas partager les risques de l'entreprise. Ils firent donc appel au roi ${ }^{4}$ qui, placé entre la nécessité de faire des sacrifices pécuniaires et la perspective de voir avorter une œuvre qu'il avait à cœur, se décida à leur accorder des arantages considérables. Dans les lettres

1. At another place called the Gobelins there is other tapestry wrought of rich stuff and quality, most of it consisting of gold threads wich 1 have not seen any where but there, and likewise other ordinary suits of tapestry of all sorts, of the price and goodness, that they are made in the Low countries. G. Carew's Relation dans Birch, p. 434.

2. "... et ne se pourroit jamais rien voir de mieux, ny pour les personnages auxquels il semble qu'il ne leur reste plus que la parole, ny pour les paysages et histoires qui sont représentées après le naturel... " Chronologie sept., p. 259.

3. LACORDAIRE, p. 33.

4. Lettre de Henri $1 \mathrm{~V}$ a Sully, 21 juillet 1608, Lettres miss., VI, 643. 
patentes du mois de janvier 1607, rien n'était oublić pour assurer leurs intérèts et llatter leur amour-propre, non plus que pour naturaliser en France leur industrie. Ils obtenaient, pour une période de quinze ans ${ }^{1}$, un monopole excluant aussi bien la fabrication et la rente en France que l'importation étrangère. Les matières premières employées par eux étaient, ainsi que leurs ourrages, exemptes de tous droits, leurs ourriers étrangers traités comme regnicoles et aflranchis de toutes tailles, subsides, gardes et impositions. Le roi prenait à sa charge les frais de leur établissement à Paris et ailleurs et concourait aux dépenses de l'entreprise par une subvention de 100000 livres tournois $292.293 \mathrm{fr} \cdot 28$ ). Tels étaient les avantages accordés à leur' industric. Ils recevaient en mème tenups des distinctions honorifiques et certains avantages personnels : ils étaient anoblis, devenaient commensaux du roi, ses pensionnaires pour la somme annuelle de 1300 livres (4384 fr. 40) chacun, obtenaient l'autorisation d'exploiter des brasseries de bière partout où ils roudraient, étaient garantis contre les conséquences de leur expatriation et avaient leurs causes commises au parlement de Paris. En échange de tant de faveurs, ils prenaient l'engagement de ne pas vendre leurs tapisseries plus cher que celles qu'on importail des PaysBas $^{2}$ et de maintenir constamment en activité quatrevingts métiers, dont soixante à Paris et vingt à Amiens ou dans toute autre ville de ieur choix. Le roi devail placer dans leurs ateliers vingt-cinq apprentis la première année et vingt les deux années suivantes. Ces privilèges soulevèrent les protestations du bureau de la ville, protecteur naturel de l'intérèt des tapissiers parisiens, mais le roi n'en

1. I. Lacordaire dit vingt-cinq ans (p. 32), mais nous avons préféré suive l'analyse très complète donnée par .I. Guiflrey, p. 108.

2. (on sait par la relation de Carew qu'ils étaient fidèles a cet engagement. Voy. plus haut. 
tint pas compte. Il ne cessa d'étendre sa protection sur les directeurs des Gobelins. Au mois de mars $\mathrm{t} 607$, il presse Sully de leur faire payer leur subrention de 100000 liv.; sans quoi ils ne pourraient, dit-il, continuer leurs traraux 1. La mème année, il écrit à son ambassadeur dans les Provinces-Unies de les assister dans un procès quïls renaient de perdre à Amsterdam et qu ils poursuivaient en appel à la Haye 2 .

En pourvoyant libéralement à l'établissement de la tapisserie de basse lice à Paris, Henri IV assura l'avenir de cette industrie, il fut le fondateur des Gobelins. II resterait à savoir si les nouveaux ateliers créés par les élères des Gobelins à Paris ou en province furent assez nombreux pour faire de la tapisserie de basse lice, qui était déjà une industrie locale, une industrie nationale et pour rendre pratique et applicable la prohibition des tapisseries étrangères établie par le roi dès $1 \% 99^{3}$. C'est surtout aux érudits de province qu'il appartient de nous éclairer sur cette question en retrouvant les traces des fabriques qui purent être créées dans diverses parties de la France sur le modèle des Gobelinst.

C'est encore Hemri IV qu'on trouve à l'origine de la manufacture de la Savonnerie. Un étranger, Jean Fortier. dont la nationalité nous est inconnue, fit agréer par la commission du commerce le projet d'établir en France lindustrie des tapis façon d'Orient. La commission proposa de lui accorder une arance de 3000 livres (8768 fr. 80), de

1. Lettres du 15 et du 29 mars 1607 . Lettres miss., V11, 131, 155.

?. Ibid., V1l, 450 .

3. Édit de janvier 1599 défendant l'importation des tapisseries, camelots, bureaux et autres étoffes mêlées de soie manufacturées aux Pays-Bas et ailleurs. Registre du conseil. Bibl. nat. Fr. 18165, f. 67 vo $^{\circ}$. Arrêt du 11 sept 1601 défendant l'entrée des tapisseries étrangères à personnages, bocages ou verdures, dans LACORDaIRE, p. 31.

4. M. Gulfraer a montré la voie. Mém. de la Soc. de l'hist. de Paris, XIX, 101 . 
mettre gratuitement ì sa disposition les locanx nicessinires et de lui conférer le droit de surveiller l'exercice de cette industrie nourelle jusqu'ì ce qu'elle cût étè réglementée par le roi. Il prencit l'engigement de former en trois ans des apprentis français qui ne pourraient néanmoins sétablir et lui faire concurrence que deux ans après être sortis dipprentissage ${ }^{1}$. On ignore pouryuoi le silence se fait tout a coup sur Jean Fortier. Dans le compte rendu des diliberations et des résolutions de la commission qu'il publia en $160 \%$, Laffemis range son projet parmi ceux que la commission arait adoptés, mais que le conseil n avait pis encore exanninés ${ }^{2}$. Quoi qu'il en soit, l'idée de créer en France l'industrie des tapis de Turguie ne fut pas abandonnée, et ce que Jean Fortier n'avait pas finit, Pierre Dupont le fit. En 1601. le roi ordomma ì M. de Fourcy de faire construire pour lui sons la galerie dlu Louvre un logement et un atelier ${ }^{3}$. Le 4 janvier 1608 , il lui accordait un brevet de logement", qui ne faisait sans doute que rígulariser une jouissance de fait déjà constatée par le premier état des artisles logés dans la grande galerie $(1607)^{5}$. George Carew parle des tapis tissés exclusivement en soie et inités des tapis per'sans qu'il arait vus au Lourre ${ }^{6}$. La mort de IIenri IV mit en péril l'entreprise de Pierre Dupont,

1. Séance du 23 juillet 160 i. Cunmpoliox, page 211-213. Voyez aussi page :00, 202.

$\therefore$ Art. 21. Chanpollox, p. 292.

3. Lacordalike,p. 39-40, d'après l'ourrage de Pienre locpoxr, Stromatourgie ou de l'excellrnce de la manufacture des tapis dits de Turquie nourellenient eslablie en l'rance suus la conduite de noble homme P'ierre du Pont, lapissier. ordinaire du Roy estlits ouvrages. A Paris, en la galerie du Lonve, en la maisun de l'autheur. 1632, in- $\uparrow^{\circ}$. Bibl. nat. Réserve. MI. Dsncel et J. Gltafrer ont publie une nouvelle édition de cet ourrage pour la société de l'histoire de l'arl frangais.

4. Public par II. L.icondine, p. 39.

5. GUtFFHEY, p. 104.

(j. "Besides, at the same place [au Louvre] are wrought sundry sorls of rich carpets made all of silk after the fashion of those of Persia. $n$ Dans Birch, [. 43i. 
mais celui-ci fit appel à Louis XIII en 1626, s'associa Simon Lourdet et fut installé en 1627 dans la maison de la Saronnerie, près Chaillot, arec le privilège de fabriquer toute sorte de tapis, d'ameublements et d'ouvrages du Levant en or, en argent, en soie et en laine. Pour l'industrie des tapis du Levant, comme pour celle de la haute lice et de la basse lice, l'histoire aura ì déterminer l'importance de son extension et de sa production, mais ce qui est acquis dès à présent, e'est l'initiative de Henri IV et le succès qui la couronna.

Nos pères tendaient leurs intérieurs de cuirs gaufrés, peints, argentés, dorés, qui, bien que dus à un travail tout différent de celui des tapisseries, doirent en être rapprochés, parce qu'ils servaient au même usage. C'était surtout l'Espagne qui excellait dans cette industrie. Un fabricant de cuir doré, Scipion de Rozan, présenta requête au roi pour obtenir pendant dix ans le monopole de la fabrication de ces tentures qu'il se faisait fort de fabriquer arec la même perfection que nos roisins. Sa requête fut renvoyée à la commission du commerce. Celle-ci, qui avait déjà eu à examiner une demande lu même genre émanée d'un autre industriel, après aroir consulté des experts et ru des échantillons du savoir-faire du pétitionnaire, proposa de lui accorder un privilège de dix ans pour le cuir doré drapé qui constituait une invention nouvelle, et de cinq ans pour le cuir doré façon commune '. Un arrêt du conseil du 21 aoùt $1604^{2}$ et des lettres patentes de même date ${ }^{3}$ conférèrent à Scipion de Rozan un privilège décennal qưil devait partager arec Nicolas Grancotte, sans distinguer, comme l'arait suggéré la commission, entre le cuir doré drapé et le cuir doré connu précédemment. Les ateliers

1. Séance du 9 avril 160t. Champollion, p. 1 ił.

2. Bibl. nat. Fr. 10843 à la date.

3. Arch. nat. lieg. du Parl. Xia 8645 , fol. 207. 
furent établis aux faubourgs Saint-Honoré et Saint-Jacques; l'on y faisait travailler des paurres '.

On a vu que l'industrie des maroquins llorissait ì la liochelle ì la fin du $\mathrm{xw}^{\circ}$ siècle, mais elle paraît y être restée localisée jusqu'au moment où Henri IV alcepta les propositions d'un négociant flamand, nommé Guillaume Albert, pour l'établir en grand dans notre pays. Le plan de celui(i consistait à faire venir un grand nombre de fabricants de Gand, de IIalines, d'Amsterdam, d'autres villes des Pays-Bas, et de fonder, arec le concours des capitalistes de son pays et du nòtre, une société pour l'exploitation de cette industrie dans toute la France. Il mettait à son entre. prise des conditions que le roi accepta. si exorbitantes qu'elles fussent, tant il était frappé de la consommation considérable de maroquins qui se faisait en France et du profit que ses sujets trouveraient à fabriquer eux-mèmes ce qu'ils tiraient de l'étranger. Guillaume Albert obtint un monopole de vingt ans; les certificats de capacité délivrés par lui devaient aroir la mène valeur que des lettres de maitrise, les directeurs de manufactures et les ouvriers étrangers deviendraient Français après un séjour de trois ans et seraient exempts du guet et de la garde urbaine. Le roi sengageait ì ne pas augmenter pour l'entrepreneur et ses associés, pendant la durée de leur privilège, les droits d'entrée sur les peaux, les cuirs et les matériaux nécessaires à leur fabrication; les produits manufacturés étaient affranchis de droits de douane, de péages, passages, traites foraines, etc. L'exportation des peaux de chères brutes était interdite ${ }^{2}$. C'est sans doute à une entreprise

1. Palya Cayet, Chr. sept., p. $28\{$ i l'année 160 '. Voy. aux arch. municipales de Lyon un acte notarié du 11 mars 1606 par lequel Grandcotte permet a Demasso et Vitaille, Napolitains, d'exercer peudant deux ans dans celte ville le métier de tapissiers en cuir doré et drapé.

2. Les lettres palentes de privilèges sont datées d'août 1608. Arch. nat. lieg. des bannitres, Y' lif f. 18. On ue s'itome pas yue les cours souve- 
aussi largement conçue que la France dut un développement de la fabrication qui lui permettait, quelques années après la mort de IIenri IV, de se suffire presque entièrement à elle-mème ${ }^{1}$.

Les industries dont il nous reste à parler sont trop nomhreuses pour pouroir nous arrèter longtemps et trop diverses pour pouvoir être soumises à une classification. Nous les aurions même passées sous silence, si la multiplicité et la variété des industries et des découvertes auxquelles Henri IV accorda son patronage ne contribuaient pas à faire connaitre l'activité industrielle de son temps et l'intelligence du sourerain, ouverte à toutes les idées, sympathique à tous les progrès.

En entreprenant de dérober à Venise le secret de ses verreries, Henri IV ne faisait que suivre les traces de Henri II, mais les cristalleries créées par ce prince à saint-Germain-en-Laye n'avaient pas subsisté au delà de Charles IX ${ }^{2}$. Le duc de Nevers, Italien d'origine, arait relevé à Nevers cet art italien que nos rois avaient laissé dépérir, et il avait joint à la verrerie de cristal blanc la verrerie colorée et irisée ${ }^{3}$. Ce fut lui qui poussa le roi à faire revivre celte industrie ${ }^{4}$. Dans les entreprises encouragées par Henri IV. il faut distinguer celles qui furent dirigées par des Italiens et celles à la tète desquelles se trouvent des Français. En 1597 , deux Milanais, Vincent

raines aient protesté contre des privilèges aussi éteudus. Yoy. lettres de jussion pour l'enregistrement pur et simple des précédentes adressantes a la chambre des comptes. 27 août 1609. Ibid., f. 25.

1. Montchrétien, p. 106-10خ. Voy. aussi La Gomberdière dans Fourisier, recueil cité, p. 119.

2. J.-A. DE Thoc, VI, 169-170, anno 1603. P. CAYET, Chronologie septénaire, 259, même année.

3. P. LAyET, loc. cit. "Iline vitrariae... artis artifices egregii, jussu tuo, accersiti... "Épitre dédicatoire de Gaston de Claves à Louis de Gonzague, duc de Nevers en tête de son Apologia Argiropeiae el chrysopeine adver'sus Thomam Erastum. Nivernis, 1590.

4. P. Cayet, loc. cil. 
liusson et Thomals Bartholus, établirent ì liouen une verrerie qui ful encouragíe par Henri IV. Leur entreprise nityant pas réussi, ils devinrent les associés de Jacques Sirrode, autre Italien qui exploitait depuis longtemps des rristalleries à Paris, à Nevers et ì Lyon avec son frère Vincent Sarrode et son neven Horace Ponte ${ }^{1}$. En aoùl 1597 . le roi accorda aux sarrode et à P'onte l'antorisation d'en chahlir une atutre à Melun en interdisant la création de maisons rivales à P’aris ou à la distance de trente lienes de cette ville, sans préjudice toutefois des élablissements actuels ou futur's de Feugère et de P'icrre ${ }^{2}$. Comme maisons françaises, nous signalerons les verreries fondées à Rouen par un Provençal d'tix, François de Garsonnet, qui obtint du roi, le 8 mars 160.3 , un privilège de dix ans pour la Normandie, privilège qui lut renourelé pour la même période par Louis $\mathbf{X} 1 I^{3}$, les cristalleries fondées à Paris et ailleurs, en 1606 et $160 \overline{7}$, par Jean Maréchal qui renait de décourrir de son róté le secret de faire des verreries à l'instar de Venise : Maréchal présenta requète pour obtenir un privilege à Paris et dans un rayon de trente lienes, ou plutòt pour parlager celıi dont jouissail déjà Feugère. Le 10 férrier 1609, le conseil du roi le lui accorda provisoirement et en attendant l'information à linquelle sil requète devait donner lieu. L'entrée et la vente de tous les cristanx ne sortant pas de ses ateliers ou de ceux de Feugère élaient interdites, les cristaux ilaliens étaient

1. Gossel.1., 126-128. Is A MBEnt, $\mathbf{X V}, 161$. Dés 1:94, Jacques sarrode sollicitait le privilege le cette industrie a Lyon ou il l'avait introduite le premier. Nous u'hésitons jas en effet à reconnaitre Jacques Sarrode dans le Saignes sacrado au sujet duquel Ilenri IV écrivit a .I. de Bellierre une lettre du i octobre 159't publiée par .I. IIalphen.

2. Is IUBERT, lor. cit.

3. Gossel.I. J. 128.

4. Lettres pat. pernuetlant à Maréchal d'établir une verrerie a Paris. Fév. Ictur. Lettres pat. permettant à Beringhen, Vernezon et Maréchal d'ëtáblir des verreries a Paris et dans d'autres villes, Mars 1607. Reg. du parl. a la diste. I. LAFrenas, Hist. du commerce, p. 421 . 
seuls exceptés ${ }^{1}$. La manufacture parisienne de Maréchal survécut à Henri IV et fut confirmée dans ses privilèges en $16: 30^{2}$. Les Sarrorle, de leur côté, qui sálaient distingués dans la verrerie avant Henri $I T$, conservirent jusyu’à la fin du siècle dernier la réputation qu ils y avaient acquise; ils propagèrent cette industrie dans plusieurs provinces, notamment en Poitou et leur maison de Never's en derint le centre pour la France et mème pour l'étranger ${ }^{3}$.

Des manufactures de faïences et de poteries blanches et colorées furent établies à Paris, à Nevers, à Brisambourg. en Saintonge : Les frères Varicq, de Delft, qui avaient introduit en France la fabrication d'un nouveau genre de tuiles courbes et plombées, obtinrent un privilège pour toute espèce de tuiles et de carreaux simples ou émaillés, de faîtages ${ }^{3}$ et d'autres objets propres à la décoration des édifices, se virent protégés contre les rexations des couvreurs et encouragés dans le projet d'étendre leurindustrie qui comptait déjà des établissements dans plusieurs villes, notamment à Paris et à Orléans ${ }^{6}$.

Le blanc de plomb ou sous-tarbonate de plomb, qui seprait aux peintres, aux médeeins, aux rétérinaires, venait de l'étranger. La commission du commerce proposa d'accorder pour dix ans à Claude Duhamel, maître plombier et fontainier, le monopole de la fabrication dont il avait découvert les procédés, à charge de ne vendre qu'en gros à raison de 1.5 livres (43 fr. 84) le cent, de foumir tous les épiciers et peintres de Paris et de la prévùté

1. Bibl. nat. Fr. 18175 à la date.

2. Arch. nat. Reg. des ordonnances enregistrẻes au parlement, à la date.

3. Boutillier, Histoire des gentilsñommes verriers et de la verrerie de Nevers dans Bulletin de la Soeiété nivernaise (1886), XII. Le Vaillant de La Fieffr, Les verreries de la Normandie, 1876, in-8.

4. Ј.-А. ше Thоo, ubi supra.

5. C'étaient sans doute des faitages en faïence peinte et vernissée, comme un en roit au museje céramique de Sévres.

6. Lettres pat. du 28 mai 1599 , du 13 mars 1600 , du 16 octobre 1603 , du 15 mai 160', du 21 mai 1609 . Reg. des ordonnances du parl. ḋ la date. 
et d'apprendre la fabrication à des Français '. En 160', la France fabriquait du blane de plomb beaucoup meilleur et moins coùteux que celui de létranger ?

La commission du commerce accueillit aussi farorablement deux imentions dues ì l'horloger du roi, Antoine Ferrier on Férrier ${ }^{3}$. Elle proposa de lui accorder un brevet de ringt ans pour l'exploitation d'un procédé permettant de joindre ensemble sins soudure les tuyaux de plomb servant à la conduite des eaux. Elle y mit comme condition yue linventenr apprendrait son procédé à des Français". Elle sollicita également en faveur de Ferrier le privilège dexploiter penlant ringt ans ses systemes pour faire tomrner les moulins à tous les rents sans déplacer le corps du moulin et pour faire monter l'eau plus facilement que parr le passé ${ }^{5}$.

La fabrication des faux fut établie ì Vizille et ì Voiron en Dauphiné dans les dernières ammées de Henri IV. Les entrepreneurs, qui araient fait des frais considérables et qui royaient leur industrie menacée par les produits étrangers, moins con̂teux et inférieurs, sollicitèrent la prohibition des faux étrangères et le monopole de la fabrication en France. Le conseil d'État, auquel leur requète arait été renroyée. fut d’aris de restreindre la prolibition et le monopole aux provinees qu ils étaient en mesure d'approvisionner, cest-it-dire au Dauphiné, à la Provence, an Languedoc, an Lyonnais, an Forez, au Beaujolais et à la liresse ". Nul doute que des lettres patentes,

1. Procis-verbaux if-i6, 8 i. Recueil de ce qui se passe... loc. cit., : 85.

$\therefore$ P. Catet, Chronologie seph., p. 28'1.

3 C"est sous celte dernière forme que son nom se présente dans une lettre à l'échevinnge de Paris du 20 juin 1606 par laquelle IIenri IV le nomme garde de lit porte de la Tournelle ou de Saint-Bernard, Lettres miss., 11, 627.

4. Séance du 8 avril 160:3. Procés-verbaux, p. S0. Cf. P. C.dvet, Chronologie sept., p. 28;, anno 160 i.

5. Procès-verbaux, p. Iol.

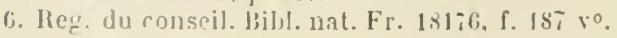


conformes à cet avis, n'aient été accordées anx hommes qui avaient doté le sud-est de la France d'une industrie nouvelle.

Nous renons de passer en revue la plupart des entreprises industrielles qui furent proroquées ou encouragées par le gourernement de Henri $\mathbf{I V}$, en indiquant, autant que possible, le sort qui leur échut. Nous devons en finissant jeter un coup d'œil sur l'ensemble de l'industrie française à la mort du roi et mettre ainsi le lecteur, qui connaît déjà sa situation au moment de son avènement, à même de se rendre compte du progrès accompli.

Des deux industries principales de la France, la draperie et les toiles, la première était en décadence et continuait ì souffrir de la concurrence étrangère. Pour les toiles communes, la France était à la tète de la production et par la

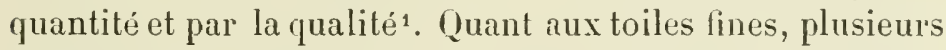
manufactures fondées sous le patronage du roi et avec le concours d'ouvriers hollandais subsistaient encore ${ }^{2}$. Nous étions restés les premiers dans la chapellerie qui était surtout active à Bourges, à Orléans, à Paris et à Lyon ${ }^{3}$. La France importait encore des bas de soie pour une valeur de plus de trois millions de livres par an (809492 fr. 10), mais la fabrication de cet article s'était introduite à Rouen ${ }^{5}$ et florissait dans le IIurepoix et la Beauce, en mème temps que la fabrication des bas de laine ${ }^{5}$. De toutes les industries qui avaient attiré l'intérèt de Henri IV, aucune ne l'arait occupé d'une façon plus suivie que la soierie, mais le succès final était loin d'aroir répondu à sa sollicitude et à ses sa-

I. Voy. plus haut et Moxtchnériex, p. 86-89.

2. Voy. plus haut, et Mostchrétiex, loc. cit.

3. Montchrétien, p. 8 i.

4. Ibid., p. 102 .

5. "Et d'autant que les bas d'estames que l'on appelle communs... se fabriquent à Dourdan et lieux circonvoisins de Beausse..." Statuts des bonnetiers de Paris. 1605. Bibl. nat., collection Delamare, Fr. 2179?, pièce 137. 
(rilices. Il n arait pas réussi à populariser la sériciculture et, aulaut quon peul en juger par les documents ou par le silence mène de lhistoire, les nouvelles manufactures de soieries, à l'exception d'une seule, ne lui aritient pas survicu, tandis que, parmi les anciennes, celle de Tours seule prospérait. Toutefois le germe de la renaissance de la fabrique lyonnaise arait été semé, et, parr la protection qu’il accorda à l'inventeur du métier à la tire et des façonnés, Ilenri IV mérite d'être considéré comme le père d'une des industries qui font le plus d'homneur is notre pays. P'all un heureux contraste, tout ce yül avait lait en faveur de la tapisserie avait réussi et éest à lui quïl faut faire remonter l'origine des robelins et de la Saronnerie. La tannerie était une des industries les plus florissantes du royaume et, grìce à la surveillance qui s'exerçait sur les cuirs étrangers, la concurrence étrangire ne lui faisait pas de tort. Cependant, quelques aunėes après la mort du roi, les cuirs ayant beaucoup perdu de leur qualité, elle était sur une pente qui pouvait la ramener au discrédit et ì la stagnation où le roi l'arait tronrée. La fabrication des maroquins était assez développée pour suffire à la consommation du pays ${ }^{2}$. Celle du papier avait encore plus d'importance, car non seulement elle égalait nos besoins, mais elle donnait lieu à un commerce d'exportation. Seulement, depuis la mort du roi, la papeterie française arait à redouter la concurrence des Anglais qui avaient établi en France des moulins i papier ${ }^{3}$. Enfin nos verreries et nos cristalleries avaient fait preuve de vitalité et, si Venise conservait le monopole des

1. Voy. ci-dessus, et Montcunérien, p. 106-:07.

2. Voy. plus haut, et Moxtchuétiex, p. 10i.

3. MoxtcukÉTIEx, p. 116-117. A Troyes notamment la papeterie était très active. Lille fut protégée contre la concurrence de la Lorraine, où s’étaient ctablis des moulins it papier, avec le concour's des plus habiles ouvriers de Troyes, par un arrêt du conseil du 10 mars 160\%, prohibant la sortie des chillons et l'entrée du papier pour tout le royaume. Bibl. nat. Fr. 18168 a la date. 
grands miroirs ${ }^{1}$, la petite miroiterie s'était perfectionnée chez nous.

Lorsqu elle perdit son roi, la France travaillait à reconquérir le rang industriel qu'elle occupait sous Henri II et l'où les guerres le religion l'araient fait descendre. Plusieurs branches d'industrie étaient redevenues florissantes. Beaucoup d'autres, en revanche, continuaient à végéter ${ }^{2}$. An reste, pour exprimer la mesure dans larpuelle le succès arait récompensé les efforts du roi, nous ne saurions mieux faire que d'emprunter les termes d'un contemporain 'que son esprit d'observation, son expérience des affaires rendent le meilleur juge de cette question : "Nostre feu Roy..., dit Montchrétien, a fait comoitre en beaucoup de subjets l'honorable passion qu'il avoit d'embellir son royame de toutes sortes d'artifices. Il a receu rolontiers ce qu'on Iuy a proposé à ceste fin, l'a favorisé d'avantageux privilèges et quelquefois a fourni le principal nerf qui donne le mourement... Ces bons mouremens... ont été suivis de différens effects, les uns profitables, les autres non du tout respondans à la sincérité de ses intentions. " Montchrétien parle ici des entreprises nouvelles, des fondations que le gourernement de Henri IV a prises sous son patronage. Mais, ì còté de ces créations qui sont quelquefois un peu artificielles, il y a le mourement spontané et général d'activité industrielle qui se déreloppe sous la seule influence de la sécurité et de la bienreillance du pouroir. Il n'y a pas de symptòme plus significatif de ce mourement que l'importance croissante des villes. Or si plusieurs d'entre elles, comme

1. En 1632 un Vénitien était sur le point d'établir en France rindustrie des miroirs de grande dimension. Le résident de la Sérénissime République, entretenant le doge de limportance qu'il y a à faire avorter cette entreprise et à rappeler dans sa patrie ce mastro de specchi grandi, dit: "Quest'arte difar specchi grandi non si trova che a Venetia e sarebbenovissima qui..." Copie des dépêches des ambassadcurs vénitiens. Bibl. nat. Filz3. 82, no 440 . Voy. aussi LeVasseck, Il, 200.

2. Moxtchréties, p. 10 \%. 
Lyon, ne sétaient pas relerées, ', la plupart renaissaient de leur ruine arec une telle rapidité et un tel éclat qu'elles semblaient n'aroir jamais souflert ou aroir liré de leurs soulfrances une ardeur plus grande it travailler et is rivre. Ce nétait pas senlement des villes importantes comme Marseille, Rouen, Angoulème, Périğueux, Limoges. Agren, la Rochelle qui étaicnt devenues plus populeuses et plus prosperes quarant les troubles; des villes secondaires, comme Marans, Luecon, Chiteaudun, Gien, Niort, Thier's. fiailac, attiraient l'altention par les aflaires dont elles étaient le centre². Paris, comme sous le second empire, servail déjà de modèle à l'émulation d'embellissement, d'affaires et de plaisirs qui sétait emparée des chefs-lieux, plus ou moins importants, de la vie provinciale. Sa population dépassait 400000 àmes. La multiplicité et la beauté des constructions, laccroissement de la circulation faisaient de la capitale un sujet de fierté pour ses habitants, d'admiration pour les étrangers et daus le fomillis pittoresque de la eité du moyen àge seébauchait déjà raguement la ville sy̌métrique et imposanteque nous avons sous les yeu ${ }^{3}$.

1. Fraxcesco Gregony 1'] Enxi attribue a cette ville en 1596 une population de 100000 âmes. Voy. sa relation publiée par Rixxaco dans Bullelin de la Sociélé rle l'histoire de Paris, XII, 1 s85.

¿. Braxtòne, Grands capitaines français. Amiral de Châtillon, èd. Lalanne, IV, 328. Meliciae Galliae... auctore Mathia Quado. Francfort-sul-le-Ilein, 1603. Papire. Massox, Descriptio fluminum Gulliae, 1618, p. 39, 46, 59' 6 .681. Deseriptio orue maritimae ab ostio Carentonis amnisusque ad ostium Ligeris. Bibl. nat. Lk.11742. Voyages de Montaigne, éd. 17i4, II, 454.

3. Paprike Jassos, Jescriptio fluminum Galtiae, p. 235. Jeax Cechl Fues, Admiranda tialliarum. Paris 16:8. "Quelle vilenie qu'on ne puisse meshuy quasi plus aller par Paris á rause des carrosses et des charrettes dont le nombre accroit chacun jour! J'ai vu le temps que les petits enfants jouroient au rolant sur le pont Nostre Dame aux jours de fête... tant de batimens qu'on elere... Les etrangers qui passent dansParis se plaignent qu'on ne peut roir la ville à cause des maisons. "Le secrélaire de saintImocenl, 1615. "Paris, que le feu roi Ilenri le Grand a orné de tant de grands et magnitiques batimens que dun desert que tu etais durant la truerre civile, il en a fait la plus riche, la plus populeuse, la plus auguste et la plus celebre ville de tout l'univers." Advertissement in la France louchant les litelles quion seme contre le gouvernement, Ifili. Relations de fiussoni et Cani (1611), Jans Bakozzi et Bercher, sèrie ll. 


\section{CHAPITRE III \\ L'ÉGONOMIE GOMMERGIALE}

$1^{\circ}$ LE COMHERCE INTÉBIEUR.

Si nous continuons à nous laisser conduire, dans l'étude de l'économie sociale, par la succession naturelle des phases de la production, nous arrivons au commerce. Déjà sans doute l'agriculture et l'industrie ont en vue des opérations commerciales, déjà l'une et l'autre se livrent à ces opérations et réalisent sur les marchandises qui sortent de leurs fermes et de leurs ateliers un premier bénéfice, mais il existe une classe qui se voue exclusivement à l'achat et à la vente de ces marchandises, ì leur transport et à leur répartition suivant les besoins des consommateurs. C'est la classe des commerçants. Ne créant que des valeurs et non des produits, n'ayant prise sur l'imagination ni, comme l'agriculture, par la poésie du milieu ni, comme l'industrie, par les transformations surprenantes ou séduisantes de la matière, inséparable de la spéculation, le commerce a souleré certaines prérentions qui ont été jusqu ì contester ses services. Alors surtout qu'il se borne à rapprocher l'offre et la demande et se réduit à la commission, il a été souvent considéré comme un rouage parasite qui ne fonctionne qu'aux communs dépens du producteur et du consommateur. Il n'obtient une sympathie sans mélange que lorsqu'il porte et propage à l'étranger l'influence française soit en $y$ 
expédiant des marchandises soit en y envoyant des colons. Trant de le surre dans un domaine oir il ennoblit et gagne sa cause en la confondant avec celle du patriotisme, avant de voir comment le commeree extérieur disposait de l'excédent de nos produits sur les besoins de la consommation indigèue, il faut étudier daus quelle mesure et de quelle faģon il pourroyait à cette consommation.

Chaque fois que nous abordons l'élude d'une des branches de la production nationale, c est par le lamentable tableau du mal que lui ont fait les guerres civiles, quil laut le commencer. Si souvent ripprochés, confondus par leur solidarité dans la vie économique du pays, l'agriculture, lindustrie, le commerce le sont encore par leurs communes épreures. De cette analogie de situation et par conséquent de méthorle résulte une certaine monotonic mais cette monotonie ne contribue-t-elle pas, en fortifiant l'impression pénible inspiréc par les souffrances du pays, à donner un sentiment plus vif de la rérité?

Naturellement les troubles civils avaient alteint surtout le commerce en gros, de ville à ville, de région à région. Les roies étaient impraticables et peu sûres. Les routes, laissées à l'abandon, usurpées par les riverains, effacées par la régétation, à peine reconnaissables aux quelques ormes ${ }^{1}$ qui les bordaient encore, ne se distinguaient plus de la campragne. Les ponts étaient en rumes, les bacs ne répondaient plus à l'appel des royageurs. Il fallait quelquelois, pour trouver une route carrossable, se détourner de trente ou quarante lieues². Le commerce

1. Ces ormes avaient été plantés en exícution d'une mesure générale prise par Ilenri II en 155\%. On les appelait vulgairement des Ilenris. Journal de Jean Glumeau, piêtre de Boniges au XVIo siècle, cité par Bounquelot dans sa notice sur ce journal. Mémuires des anliquaires, 18 í.

2. Lafremas, Ilist. du Commerce, Elats de Normandie, novembre 1593, [1. P. 13. DE Reackepaine, I, 5\%. Arrit du conseil d'Etat, janvier 1:55 dans

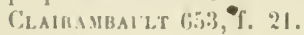


abandonnait ses anciens itinéraires et délaissait des villes à la prospérité desquelles il avait largement contribué. La Fere, par exemple, perdait ainsi ses relations commerciales arec la Thiérache et l'Artois. (Yuand le roulage ne se résignait par à ces longs circuits, il essayait de s'ouvrir une route nourelle, à còté de l'ancienne, dont il cmpruntait, autant que possible, le tracé et cet itinéraire, une fois frayé, était adopté et remplaçait la rraie route.

Voies anciennes et voies ébauchées par la circulation étaientégalement peu sûres. Les périls étaient nombreux et, si l'on était assez heureux pour échapper à l'un d'eux, ce nétait guère que pour tomber dans un autre. Fondrières, bandes de loups, troupes de brigands, rexations des gourerneurs et des chàtelains, il était bien difficile de sauver sa personne ou sa bourse de tant de dangers.

Cherchait-on à s'y soustraire en prenant les voies fluviales, on y retrouvait à tout le moins les mêmes exactions. Les péages y pullulaient, aussi vexatoires dans leur perception qu'illégitimes dans leur origine et arbitraires dans leur taux. Ils étaient exploités par des lermiers sans scrupule qui, de connivence avec ceux qui les araient usurpés, multipliaient pour la navigation les entrares et les retards afin de s'en faire payer le rachat. Lentement les chalands avançaient sur les cours d'eau obstrués par les éboulis des lerges, par les moulins, par les pècheries. De lieu en lieı ou à peu près il fallait s'arrèter, alıorder, amarrer près des bureaux, attendre le péager absent à dessein et acheter le droit de continuer sa route en payant à un commis. Les arches des ponts étaient quelyuefois barrées par des chaînes qu'on ne pouvait faire lever qu'après avoir longuement marchandé. On ne pouvait franchir ces arches, rétrécies par les moulins qui s'y 
adossaient, quaree une grande prudence el liassistance desmaitres des ponts, espèce de surveillants de la navigation et de pilotes auxquels étaient dus, pour ce service, de noureaux droits tarifés suivant le nombre des ehevaux de halage'. Tout ì coup le bateau touchait et échonait, le lit de la rivière ayant été arbitrairement exhaussé par les riverains, et le renflouge était un nowveau prétexte aux revendications des péagers. Nul compte n'était tenu du prineipe qui exemptait les denrées destinées à la consommation du propriétaire ni de celui qui interdisait de perceroir denx fois sur les mèmes marehandises. à l'aller et au retour ni de la franchise accordée à celles qui étaient transportées aux foires de Lyon². Sur la Loire les péages étaient si multipliés qu’ils rapportaient par an, tant au roi quaux ligueurs, un million 600000 écus (1:31992\%0 fr. ว̈8) et qu'un bateau qui partait de Nantes avec une elırge de sel de 20 écus (237 fr. 49) n'arrivait ì Nevers qu'après a roir payé en droits de circulation 100 écus (9.49 fr. 9̋̈) c'est-ì-dire le quadruple de sa valeur. En 1306 on eomptait sur la Loire et ses aflluents cent vingt péages, en $1 \% 68$ le nombre des péagers s'élevait à plus de deux cents ${ }^{3}$. De Rouen à Paris le total des droits pour une petite barque de marchandises s'élevait à 1000 écus (9499 fr. 33$)^{*}$. Les gouremeurs de Vernon, de ChâteauGaillard, de Mantes et de Meulan, celui de Noyon avaient ajouté aux anciens tarifs des péages sur la Seine et la Vorse de nouveaux droits que leurs péagers pereevaient arec arbitraire et sans délivrer d'aequits ${ }^{5}$. La narigation

1. Registres du bureau de la ville de I'aris, 13 scptembre, 19 et 25 octobre, 29) novembre 1595 .

2. Matheu de Vac\%elles, Trailé des peages, 1550. Arrêt du conseil du If unars 160 i. Bibl. nat. IIss. Franc, 18167 a la date.

3. Cheralien, Navigation commerciale de la Loire an $\mathrm{x}^{\mathrm{e}}$ el au $\mathrm{xvT}^{\mathrm{e}} s$. Mémoires de la Sociélé archéologique de Touraine, II, 226.

4. Relation de P. Duodo (1598 dans A linerr, XI, Append., P. 169.

5 . Registres du burean de la ville, if février 1598. 
du Rhône, de l'Isère ${ }^{1}$ et de toutes les voies fluviales souffrait des mèmes abus.

Il y eut un moment où, par suite de l'insécurité, les charrois cessèrent dans le Lyonnais. En Normandie le commerce s'arrêtait devant les exactions ru'il subissait ì Quillebœuf et dans les autres villes situées sur les rivières. Sur la Seine, dans l'Angoumois ${ }^{2}$ et ailleurs le trafic fluvial s'interrompait, ètait anéanti ${ }^{3}$.

Ce fléau des péages et des taxes de circulation était d'ailleurs, on le sait, très ancien et les guerres civiles niavaient fait que le rendre plus criant.

Elles avaient amené aussi la ruine de certaines foires jadis llorissantes, telles que les foires de Poitou *

Le commerce qui se renfermait dans l'intérieur des villes, qui se réduisait à la consommation locale, échappait à ces dangers, à ces vexations. Mais là encore les effets des troubles civils se faisaient sentir. Quedeboutiques fermées, que de conmerçants, de commis, de garçons de magasin sans ouvrage! Les uns grossissaient les troupes de mendiants qui promenaient dans les villes inquiètes leurs mines faméliques et faisaient queue à la porte des hôtels et des couvents pour attendre la desserte, les autres s'enrôlaient dans les bandes de détrousseurs de grands chemins ou dans ces associations de roleurs, dont

1. Mandement de IIenri IV du 10 aeùt $160 i$. Arch. nat. Reg. du parlement, $\mathrm{X}$ ias646, fol. $1 \mathrm{X} \times \mathrm{XV}$.

2. Requête présentée à IIenri IV en 1590 par les geutilshommes de I'Angoumois et de la Saintonge partisans de sa cause citée dans Lievre, $L a$

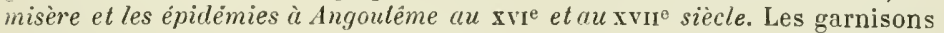
auxquelles on faisait atteudre le paiement de leur solde, arrêtaient, pour se payer, les bateaux. Lettre de Sabatéry à Simon Lecomte. Bordeaux, 27 novembre 1581. Papier's Lecomte aux archives de I'Hôtel-Dieu de Toulouse. Délibération prise à Bordeaux en jurade le 18 décembre 1583. Снамpollion, Mélanges historiques, II, 485.

3. "Suippe, petit fleuve.., ne porte basteaux à raison des ponts et bacs, desquels les seigneurs prennent gros revenus ". Cil. Estiexse, La guide des chemins, p. $22 \%$.

4. Les sérées de Guillaume Bouchet, xxxv'e serée. 
les affiliés se reconnaissaient ì des cérémonies et à un argot particuliers et qui dissimulinient leurs inarouables moyens d'existence sons le métier de porteballe et de camelol'.

La démoralisation des classes conmerçantes était, en effet, pour le commerce, la conséquence la plus grave et la plus triste des guerres civiles. Les halitudes sont la meilleure sauvegarde des vertus de la population inférieure. l'amour du gain par le trarail en est la source et, une fois que cette source est tarie, elles disparaissent avec elle. Le spectacle seandaleux et allíchant des grandes fortunes réalisćes par la coneussion et l'agiotage, la diminution des afficies avaient déclassé une foule de marchands qui se lançaient dans les opérations usuraires ou "se ruaient, comme dit un contemporain, sur les états et sur le doux maniement des finances ${ }^{2}$ ".

Le souverain qui se trouvait appelé ì porter sur cette plaie économique et morale un oil attentif et une main délicate, ne semblait pas particulièrement préparé à cette tàche. N'avait-il pas été le premier des bandoliers avant

1. Ayant l'âgre de neuf á dix ans, craignant que mon père me donnât le fouet pour quelque faute commise, ... je prins résolution d'aller tronver un petit mercier qui venoit sourent à la waison de mon père et... résolus m'en aller avec lui. Il n'étoit coesme, n'ayant parvenu à ce degré... La vie genereuse des marcelots, gueus et boesmiens..., 1596. I'ar. hist. et litt., VIll. "L'antiquité nous apprend et les docteurs de l'argot nous enscignent rqu'un roi de France ayant établi des foires à Niort, Fontenay et autres lieux du Poitou, plusieurs personnes se voulurent mêler de la merceric; pour remérlier á cela. les vieux merciers s'assemblèrent et ordonnirent que ceux qui voudroient a l'arenir etre merciers se feroient recevoir par les anciens... puis ordonnèrent un certain langage entre eux avec quelques cérémonies pour être tenues par les professeurs de la mercerie. Il arriva que plusieurs merciers mangèrent leurs balles, néanmoins ne laissèrent pas d'aller aux susd. foires, ou ils trouvèrent grande çuantité de pauvres gueux. desquels ils s'accostierent et leur apprirent leur langage ct cérémonies. Les gueux réciproquement leur enscignirent charitablement à mendier. Voila d"ou sont sortis tant de braves et fameux argotiers. "Juryon ou lungage de largot réformé, au t. V'lll des Joyeuselés, cité ibid. 153, no 1. Coesmelotier, camelot, nom d’argot donné aux merciers et colporteurs atliliés il la confréric des roleurs de grands chemins. S.ucral, liv. V, I, ilf.

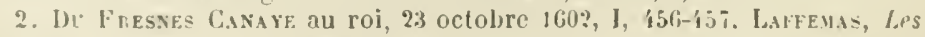
moyens de rhusser la gueuserie, etc. 
d'être le roi de France? Son indulgence, sa sympathie n'étaient-elle pas acquises au soldat peinant sous la cuirasse, mal payé, irrégulièrement nourri qui se laissait séduire par " dame picorée "? Est-ce à la cour des Valois, est-ce dims les camps où il avait troué ses pourpoints, qüil aurait pu apprendre à sintéresser à ce monde casanier dont la vie śécoulait dans le demi-jour d'une boutique, quil aurait pu comprendre comment ces gens-là travaillaient à leur manière à la prospérité et à la grandeur d'une nation? Mais, en cela comme dans le reste, ce fut son mérite de savoir, pour retourner un de ses mots célèbres, cesser de faire le roi de Navarre pour faire le roi de France.

Dans la législation et l'administration commerciales qui sautorisent de son nom, tout certes ne fut pas original ni désintéressé. Sur plus d'un point il ne fit que reprendre une idée abandonnée, une tentative arortée de ses ancêtres et plus d'une fois il obéit à une préoccupation fiscale. Les mesures de circonstance eurent aussi leur part dans son curre. Parmi elles il faut ranger la prorogation des échéances. Déjà l'édit de réduction de Paris du 28 mars 1994 arait annulé les saisies faites sur ses habitants et déchargé provisoirement les débiteurs, jusqu’à l'adoption d'un arrangement amiable entre eux et leurs créanciers, du paiement des intérèts antérieurs à ceux de l'année courante ${ }^{1}$. Moins de deux mois plus tard, le 16 mai, un arrèt du conseil autorisa les commerçants parisiens désireux d'obtenir un délai pour le paiement de leurs dettes, à se pourroir derant le lientenant civil. Cet arrèt défendait en même temps la continuation des assemblées qui avaient eu lieu pour rédiger et signer des pétitions en rue de cette surséance et exercer une sorte de pression sur l'autorité ${ }^{2}$. P'lus tarl

1. Poirson, I, 5ji.

2. Bibl. nat. IIss. Franc. 18159 , fol. 193 ro. 
une prorogation générale ful accorléc au commeree parisien. Le 29 aout 1399 elle ful prolongée de quatre mois '. Elle niavait pas eneore atteint son terme que de nouveanx répits étaient sollieités ?.

Ce ne fut pas seulement par la suspension des échéances que le gomvernement vint en aide aux débiteurs embarrassis, ce fut aussi, on le sail, en les lihirant d'une partie des intérèts arriérés. Lédit de juillet 1.j9\%, statuant sur les rentes constituées avant $1: 389$, réduisit d'un tiers les intérèts échus depuis celte année jusqu’à la fin de $1: 593$ ". Les débiteur's retardataires dont la dette ne dépassait pas une année d'interèts, furent mis à l'abri de la saisie et autorisés à se libérer du capital par quartier en mème temps que de lintérèt de l'année courante . Ces facilités et ces remises étaient commandées par la banqueroute chronique dont les créanciers de l'État étaient victimes. En 1590 les rentes de $1: 38$ n'élaient pas encore payées et le fonds des impositions affectées à leur paiement nétait pas même suffisant pour fournir à un quartier de l'année courante ${ }^{\circ}$. Tandis que la situation des débiteurs était équitablement allégée, la jurisprudence sauregardait les droits des créanciers en les relevant des preseriptions et péremptions dinstance qui auraient pu les faire déchoir de leur droil aux intérêts pendant la période de 1594 à $1598^{\circ}$.

Nous avons dit l'entrainement des eapitaux vers des placements très rémunérateurs pour ceux qui les faisaient mais improductifs au point de rue général. Pour les ramener vers le commerce, comme vers l'agriculture et

1. Arrets du conseil i cette date.

2. Arret du conseil, 21 novembre 1598. Bibl. nat. Iss. Franc. 18163, fol. $89 \mathrm{v}^{\circ}$.

3. Fontanon, $1,7 i 2$.

4. Déclaration du 16 avril 1595. Foxtanos, I, 7i!!.

$\therefore$. Délibermtions du bureau de la ville, 17-2i juillet 1595.

fi. Co. Le P'ReStRe, Questions nolubles, chap. LXI. 
lindustrie, le roi, sur les instances de Sully, réduisit l'intérêt légal du denier douze au donier seize, c'est-ì-dire de huit un tiers à six un quart pour cent ${ }^{\prime}$. Il ne faisait par là que remettre en vigueur un édit de Charles IX resté impuissant.

$\mathrm{Si}$, en dépit de cet édit, l’intérèt s'était maintenu au taux de huit un tiers pour cent. était en partic parce que des banqueroutes répétées araient fortement ébranlé le crédit. Les proprićtaires eux-mêmes ne trouvaient ì emprunter sur leurs biens-fonds qu'à force de cautions et à un taux usuraire. L'opinion publique arait réclamé la mort contre les banqueroutier's frauduleux, et l'ordonnance d'Orléans (1560) Lui arait donné satisfaction. Mais les tribunaux reculèrent devant l'application de la peine capitale et se contentèrent de l'amende honorable, du pilori et des galères à perpétuité. Tel fut le châtiment subi en 1609 par un marchand de la rue Saint-Denis, Guillaume Pingré, qui avait fait une banqueroute frauduleuse où étaient intéressés de notables personnages et qui fut arrèté à Valenciennes, dans les États de l'archiduc ${ }^{2}$. Le lendemain de sa condamnation, la place de Paris fut de nouveau émue par une autre banqueroute dont le passif s'élevait à 400000 écus ('4045246 fr. 05) ${ }^{3}$. Une aggravation dans la pénalité devenait opportune. Sully, qui avait déjà fait rendre en 1602 un édit contre les banqueroutiers ", en provoqua un autre au mois de mai $1609^{5}$. Cet édit confirmait l'ordonnance d'Orléans, prononçait la peine de mort contre les coupables, frappait de nullité les transports opérés par eux aux dépens de leurs créanciers, ordonnait la punition exemplaire de

1. Édit. de juillet 1601. Isambert, xv, 262. Économies royales, I, 105. Legrain, Décade, 81?.

2. Registre-journal de Lestoile, 508. Mercure francais, I, 1609 .

3. Registre-journal. Ibid.

4. Économies royales, $V, 240$.

5. Il l'a inséré dans les Économies royales, V, 339-341 comme étant son œurre. 
ceux qui prenaient faussement celte qualité el défendait les concordats ${ }^{1}$. Laffemas qui, neuf ans auparavant, demandait le retour ì la pénalité draconienne de lordonnance de $1.360^{2}$ dutitre content et lopinion, indignée et inpuictée par tant le " trous ì la muit " ${ }^{3}$, ne le fut pas moins. Quant à l"üterdiction des concordats, elle aurait de quoi surprendre si l'on ne savait qu’ elle était dirigée contre les commerçants qui, en emportint largent de leurs créanciers, laissaient un mandative pour transiger arec eux et, celte transaction une fois accuptée bon gré mal gré par les créanciers, revenaient jouir effron tément à la barbe de ceux-ci de l'argent dont ils les araient frustrés '. C'était ces concordats prémédités par les débiteurs, imposis aux créanciers que l'édit arait en rue. Dautres. arec aussi peu de bonne foi, faisaient cession de loin et par procureur, contrairement à la loi qui exigeait que le cessionnaire fùt présent et procédât en personne ${ }^{3}$. II y en avait encore qui trompaient leurs créanciers en simulant, de concert arec leurs femmes, une sipuration de biens. en metlant leur actif sous le nom de celles-ci. Laffemas demanda que la femme complice de son mari fùt responsable sur ses propres, que la séparation dr. biens ne pùt aroir lien qu après une enquète faite par dix notables commerçants étrangers à la famille et non suspects de connivence ${ }^{6}$. Il dénonerait aussi lhabileté avec laguelle les cessionnaires dissimulaient le bonnet rert, qui les signalait à la méfiance et à la déconsidération publiques ` Au sujet de ce signe infamant les coutumes et la juris-

1. ISA МвERT, $\mathbf{X V}, 3$; 9 .

2. liemonlrance en forme d'édil, art. xis.

3. Nous disons aujourd'luni trous it la lune.

i. Legras., Décarle, 833-83i.

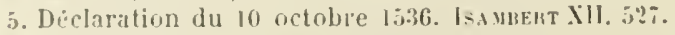

(i. Remonstrance en forme d'édil, art. xi.

i. "... pour obrier aux fraudes de ceus qui, ayant fait cession. ne laissent de pruter le chapeau noir et le petit bonnet vert au dessous qu'it grand peine peut on voil." Adcertissement sur les crimes cles bunquerouliers, I6ur. 
prudence ne furent pas toujours d'accord; tantôt il était inposé a tout cessionnaire sous peine de perdre le bénéfice de cession, quill fùt de bonne ou de manvaise foi; tantôt il n'était que la punition de cette derniere; lantôt enfin le cessionnaire en était exempt et devait seulement abandonner en justice sa ceinture ${ }^{1}$.

Ce fut aussi pour affermir le crédit par la sécurité des transactions qü̈l fut défendu aux notaires d’insérer dans leurs actes la clause de renonciation au sénatus-eonsulte Velleien et à l'auhlientique $S i$ qua mulier. Ce séuatusconsulte, on le sait, arait pour but de protéger les lemmes contre elles-mèmes en frappant de nullité les obligations qu'elles pourraient contracter pour autrui. Elles araient tellement pris l'habitude de renoncer à cette tutelle légale pour intervenir dans les contrats et engager leur lien dotal en garantie des obligations de leur mari que cette renonciation était devenue de style. Précisément à cause de cela il arrivait aux notaires de l'omettre. Ce silence insolite pouvait être interprété comme une réserve du droit de la femme et autoriser une demande en nullité. Par suite de la déclaration d'aoùt 1606, les femmes qui étaient parties dans un acte furent par cela mème ralablement obligées et labsence d’une clause dont l’insertion était prohibée. ne put désormais être inroquée contre sa validité

Dans tout ce que nous renons de rapporter il n'y a rien qui atteste chez IIenri $I 1$ un goùt plus vif et plus éclairé pour le commerce que chez ses prédécesseurs, et ce n’est pas non plus dans l'édit. si important d'ailleurs, de 1.597 quil apparaìt comme norateur en cette matière, car il n'a

1. Botcher, Bibliothègue du droit français, I, 4́f. Cunadodas Le Caron, Memorables observations tu droit francais, vo Cession. Recueil de plusieurs arréts notables, p. p. Locet, vo Cession de biens. Jugement du lieutenant général de Laval du 9 septembre 1581 et arrêt du parlement du 16 janvier 1608 dans Fontaxor (1611), I, 764, 76..

2. IS.AMBERT, XI, no 18 ? 
fait quy reprendre l'aurre mort-née de son prédécesseur immédiat. Mais il ý eut deux choses originales et fécondes qui distinguèrent son rûle à cet égard : d'une part il créa le premier une commission pour reviser l'organisation industriclle et commerciale et encourager les industries naissantes, les entreprises d'intérêt public; de l'autre il améliora et déreloppa à un haul degré les voies de communication. Sur la commission du commerce nous n'arons rien ì ajouter à ce que nous avons dit dans notre chapitre sur lintustrie. Yous devons, au contraire, faire comnaitre les progrès qui siacomplirent sous son règne dans les ponts et chaussées et dans les roies de navigation.

On vient de roir l'élat où se trouraient les uns et les autres ì la suite des guerres civiles. Cet état n'était pas entièrement imputable à celles-ci, il tenait aussi à l'absence dime administration centrale des ponts et chanssees. Abandonné aux autorités locales, aux seigneurs et aux villes, ce service public n’était pas administré arec l'unité et le désintéressement qu'exigent les intérèts génèraux. Ilenri IV le centralisa en créant par un édit du mois de mai 13099 un grand royer de France. On sait que Sully fut le premier titulaire de cette charge. Ses attributions étaient purement administratives et le contentieux restait à la juridiction ordinaire. Mème dans l'ordre administratif, sa création nentraina pas celle d'un personnel noureau. Les agents placés sous l'autorité du grand royer existaient déjà : cétait les voyers particuliers, et, là où il n'y en avait pas, les officiers locaux ordinaires et parmi eux, au premier rang. les trésoriers généraux. Surchargés ou peu zélés, ces fonctionnaires obéirent arec peu d'empressement à l'autorité nouvelle à laquelle on renait de les soumetlre; une declaration du 7 juin $160 t^{1}$ autorisa alors le grand voyer

1. Vu,vox, Eludes historiques sur ladministration des roies mubliques en France an xir" el un xwme siecle, I, l'ieces justif., no $\mathrm{i}$. 
à se désigner un lieutenant dans les administrations locales '. Remède probablement inefficace, car ce lieutenant, ne touchant pas de gages pour ses nouvelles fonctions, dut mettre peu d'ardeur ì les remplir. Les royers farticulier's n'étaient pas les seuls agents spéciaux que le grand royer eût sous ses ordres, les intendants des turcies et levées de la Loire en relevaient également. Au moment où se pacifiait le pays, ces digues tombaient en ruines. Ceux que l'on nommait à la charge, alors unique, d'intendant, s'y succédaient trop rapidement pour pouvoir sy rendre utiles. En la confiant à $\mathbf{M I}^{\mathrm{e}}$ Jacques Chevreux, au mois d'avril 1:994, Henri IV étendit la durée de ses fonctions. A la mort de Jacques Cherreux (1597), le roi ne lui donna pas un successeur en titre d'office. L'emploi fut tenu en commun et en commission par Pierre Fougeu, sieur d'Escures et Barthélemy Savorny. Puis, satisfait de leurs services, Henri le dédoubla en deux offices d'intendants qui leur furent conférés. Leurs attributions consistaient ì faire les devis, à adjuger et à taxer les travaux, à arrêter les états des fonds destinés à en faire les frais, à disposer de ces fonds et même à juger les contestations soulevées par ces diverses opérations. Ils devaient se partager les gages de leur prédécesseur qui touchait 3000 livres $(8768 \mathrm{fr}$. 80). Toutefois la chambre des comptes, hostile, comme toutes les cour's soureraines, aux juridictions spéciales, n'enregistra ces pouroirs que de l'exprès commandement du roi et en réservant les questions litigieuses aux juges ordinaires et la vérification des états de recette aux trésoriers généraux ${ }^{3}$.

1. Sully eut, par exemple, pour lieutenant dans la généralité de Bourges le sire de Corbet Boyer. Recherches sur les anciennes voitures publiques dans le Berry et surtout à Bourges dans Mémoires de la Sociélé historique... du Cher, II (1882), p. 155, no ?.

2. Édit de janvier 1603. Vignox, 1, Pièces justif., $n^{\circ} 3$.

3. Vignox, 1, Pièce's justif., nº3. 
Le voyer de Paris ne dépendait pas du grand royer, mais lu lieutenant civil. Le 13 aout 1.399, celui-ei lui donnait commission pour inspecter les ponts et chaussies de la ville, de la prévôté et de la vicomté, les faire réparer par les seigneurs justicier's et les autres autorités particulières chargées de leur entretien, forcer les riverains ì délaisser le terain usurpé, faire établir des bormes et planter des ormes pour fixer la lareeur des roies'. En 160' Sully remboursa au royer de Paris le prix de sa charge et la fit réunir ì celle de grand royer?

Lautorité le celui-ei ne sétendait que sur les pays d'élections. Dans les payss d'états la direction des travaux le voirie appartenait à un commissaire général qui recerait ses pouroirs et ses instructions du parlement de la province ${ }^{3}$.

Chaque année, les officiers locaux qui, sous la direction du grand voyer, soccupaient des travaux publics e'est-àdire ses lieutenunts, les trésoriers de France, les intendants les turcies et levées et les élus partaient en chevauchées pour constater l'átat des ponts et chaussées. Ces cherauchées avaient lieu au mois de février. C'est le moment oǹ les eaux sont le plus hautes, où les chemins ont le plus souffert le l'hiver, où l'on peut le mieux apprécier l’importance des réparations nécessaires et en dresser le devis. Les travaux, après aroir été soumis à l'autorisation du grand royer, étaient mis en adjudication et s'exécutaient pendant la bonne saison. C'était ì l'entrée de la mauvaise, aux mois de septembre et d'octobre, qu'on procédait au toisé et

1. Vigsox, no 2.

$\therefore$ Defanare, Traité de la police (continuation de Le Clere du lirillet), IV', (j)8.

3. Voy. ilrêt du parlement de Grenoble sur la réparation les chemins en Dauphiné, 23 mai 1605 . Ibid., no 7 . Butx Duraxd, Le Duuphiné en 1598 d:uns bulletin de la socièté départemenlale d'urchiologie et de statistique de la livime, 186\%. 
¿ la réeeption. Dans leurs chevauchées, les délígués du grand voyer devaient s'enquérir des péages, des travers et en dresser état afin de faire contribuer les titulinires aux frais de réparation. Leur devoir était aussi de s"informer des abus commis dans l'emploi des deniers octroyés aux villes pour les travanx publics et de les dénoneer ì leur chef. Ils vérifiaient enfin et lui envoyaient les ítals des recettes et des dépenses faites par les trésoriers et les recereurs, car toute la comptabilité des travaux publics passait sous ses yeux ${ }^{1}$. Suivant la déplorable tradition qui accordait à des particuliers en faveur des délégations de l'autorité publique, certaines personnes avaient obtenu des commissions les autorisant à faire exécuter des travaux, à šingérer dans l'administration de la voirie; e'était autant de brevets d'impunité délivrés aux exactions. Le roi déclara que les pouvoirs de ce genre ne seraient valables que lorsquils auraient reçu l'attache du grand voyer ${ }^{2}$. Mais celte déclaration ne triompha pas d'habitudes invétérées; c'est ce que témoigne un arrèt du 14 mars 1606 qui réroque les commissions délivrées pour la réparation des chemins et défend d'en expédier sans le visa déjù exigé.

Nous avons parlé des obligations des péagisles en matière de voirie. Un arrêt du conseil du 2 avril $160 \ddot{3}$ renonvelit aux trésorier's généraux la mission de surveillance qui leur avait déjà été confiée à cet égard ${ }^{3}$. Il ne parait pas avoir beaucoup amélioré les choses. Les populations dénonçaient l'incurie des péagistes et le roi, passant par la grande route de Picardie, reçut directement des plaintes contre l'abbaye de Saint-Denis et le due de Nontmoreney. Le 11 avril 1609 un arrèt du conseil ordonnait encore que commandement serait fait par le grand royer à tous les

1. Vignox, Pièces justif., no 5 .

2. Déclaration du 7 juin 1604 . Vig xox, Pièces juslif., no 4.

3. Ibid., $\mathrm{n}^{\circ} 6$. 
péagistes, sous peine de saisie de leur's péages et harrages, de mettre en bon élat, dans un délai fixé, les ehenins dont lentretien élail à leur charge'.

C'est anx roies urbaines, anx rues et particulièrement anx rues de l'aris que s'appliquait l'édil de décembre 1607. II fut rendu pour remédier aux conséquences de la facilití avec laquelle les seigneurs justiciers de la capitale gui exerçaient dans leur ressort la police de la voirie, accordaient des permissions préjudiciables à l’intérèt général. Toul administratif qüil soit, c'est un document bien pittoresque. Il éroque un lacis de roies étroites, fangeuses et sans trolloirs, surplombees d'ouvrages en encorbellement, de jardins suspendus, obscurcies par les aurents et les enseignes, encore rélrécies par les degrés, les montoirs, les jambes étrières, les contre-fenètres, encombrées par les marchandises et les matériaux, bordées de façades luyantes ou rentrues, souillees par les ordures ménagères qu'on jette des maisons, enlaidies par les défrorues et les drapenux qui se balancent aux fenetres, bref un Paris incommode et nauséabond, dépourvu de perspective, de grandeur et de beauté mais fourmillant d'attrayants détails. Et en même temps qu il nous transporte dans le Paris du xvir siècle naissant, il pose le principe niveleur de l'alignement et trahit le rêve des rues larges, rêre et principe d'où sortira peu à peu un Paris monumental et grandiose où tout sera sacrifié à la symétrie, à l'effet et au décor. Cet édit attribuait le contentieux de la roirie ì la chambre du trésor?.

Des trois conditions que toute anlministration semble devoir réunir, unité, spécialité, compétence, celle des travaux publics, telle quielle avait été organisée par Henri IV et Sully, possédait en partie la premiere, les deux autres lui faisaient déliuut. La direction et le contrôle

1. limox, l'ières justif., no 9 .

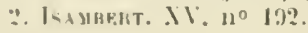


supérieur y étaient attribués à un fonctionnaire unique, mais ce fonctionnaire n'était pas secondé par des agents de son choix, exclusivement voués à leurs fonctions, préparés par des études techniques à les remplir. On ne trouve dans cette administration ni ingénieurs ni conducteurs des ponts et chaussées ni agents voyers. C'est ì une vieille institution, c'est aux maîtres des ouvres de maçonnerie et de charpenteric quelle va demander les connaissances professionnelles dont elle a besoin. Nous rencontrons sous IIenri IV plus d'un ingénieur, Louis de Foix, Érard, IIugues Pelletier, mais on ne fait pas appel à leur compétence pour les travaux de voirie ${ }^{1}$. Les voyers particuliers de certaines rilles et les intendants des turcies et levées sont les seuls agents qui fassent de ces travaux lẹur affaire principale, mais, ne tenant pas leurs pouvoirs du grand voyer, ils conservent à son égard une certaine indépendance. Les premiers en abusent. On ne peut déplacer un évier, toucher à une enseigne, boucher un trou à un aurent, mettre des barreaux à une fenètre ou y poser un pot de fleurs sans leur payer un droit discrétionnaire ${ }^{2}$. A l'absence d'un personnel spécial et docile il faut ajouter la nature précaire des ressources. Une partie des fonds affectés aux traraux publics est assignée sur des taxes appartenant à des particuliers et il est bien difficile d'empêcher ces particuliers d'en appliquer la totalité à leur profit. Enfin il manque à ce service une juridiction compétente. Soit qu'il n'ait pas su sélever à la conception d'un système indépendant et homogène, soit quill ait trouvé plus commode et plus économique de se scrvir des rouages existants, Ilenri IV se contenta de donner un chef à une administra-

1. C'est au second que Henri IV destinait la direction des travaux du port qüil songeait à créer près de Bayonne et de Fontarabie. Mémoires de Groulart, 1601. Collection Michaud.

2. Laffemas, La commission, édit et partie des mémoires... 
tion sans unité. Heureusement ces délauls neélaient pas de ceux dont ce ehef, ì force d'intelligence et d'énergie, ne pouvait pas triompher, et il reste à voir si sully a su le faire.

Il est malheureusement impossible de donner une énumération complète des roules qui ont été ouvertes ou réparées, des ponts qui ont ité construits ou rélablis sous sés auspices. Entre la Guide des chrmins de France, dont la troisième édition fut publiéc en $1: 3 \% 3$ par Charles Estienne et li carte des routes postales dressée en 1632 par Sanson, il n'existe aucune nomenclature des routes, et ces deux flocuments sont trop éloignés de l'époque qui nous occupe pour que leur comparaison puisse nous éclairer sur les progrès réalisés à cette époque.

A défaul d'une stalistique complite, nous emprunterons it des sources diverses des renseignements partiels qui, par leur aceumulation, paraitront peut-être autoriser une conclusion d'ensemble.

On ne saurait trop regretter que les états généraux de voirie dressés par Sully en $1600^{1}$ et en 1609 ne nous soient pas parrenus. Le second surtout aurait été très instructif; il indiquait le montant de toutes les sommes levées, de $1: 398$ à 1609 , pour les travaux publics, qü̈ls eussent été entrepris par l'État ou par l'initiative privée, celles qui a vaient été employées conformément ì cette destination et celles qui en avaient été cétournées, ainsi que les moyens d'empècher à l'avenir de pareils abus ${ }^{2}$. On a conservé du moins les états généraux du produit des tailles, tant du luincipal que de la grande crue, de 1.399 à 16099 , et on peut en tirer sur le budget des travaux publies des lumières utiles. Ainsi on y voit qu'en 160' le montant de la grande crue depassa de $21: 3000$ livres $(628430 \mathrm{fr}$. :\%:3) le tolal de

1. Économies royales, I, 3 i.

2. Ibid., X, 214, 305 . 
l'année précédente, et cela en partie à cause des travaux (lu canal de Loire et Seine et du pont de Rouen '. L'état général sommaire de 1603 nous finit connaitre la somme affectée anx ponts et chaussées; cette somme s'élera ì 400000 livres (1 $169173 \mathrm{fr}$. 12), auxquelles il faul ajouter une sonme indéterminée pour le canal de Loire et Seine, pour la canalisation du Clain et de la Vesle ${ }^{2}$. En 1606 les ponts et chaussées et les mêmes travaux de canalisation absorbèrent 422000 livres ( 233477 fr. 64), sur lesquelles sans doute 400000 livres pour les ponts et chaussées, comme l'année précédente, et 22000 livres (64.304 fr. .52) pour les comrs d'eau en question. La réfection du pont du Rhône, à elle seule, absorba :3000 livres (14614 [r. 66) ${ }^{3}$. En 1607 la grande crue s'augmenta de 30000 livres (87 687 fr. 98) qui furent consacrées ì refaire les ponts de la Loire emportés par les inondations *. En même temps le principal de la taille, qui était, l'année précédente, de 976.3218 livres (28 543076 fr.) s'élevait, par suite des dépenses faites pour les ponts et chaussées, à 9813218 livres $(28683376 \mathrm{fr}$. 80). Ces dépenses se répartissaient ainsi : $1 \% 000$ livres (43843 fr. 99) pour la généralité d'Amiens, 18000 livres (\$2612 fr. 79) pour celle de Rouen et 15000 livres pour celle de Caen ${ }^{5}$. Sur le produit de la grande crue en 1609 ,

1. Économies royales, $\mathbf{X}$, 220. Ces états ont été reproduits par Fonвonxas.

?. 1bid., 2:i. Cf. VIll, 68.

3. Sur l'avis que m'a donné le $\mathrm{S}^{r}$ Parjon des ruines qui menacent le pout du Rosne en vostre ville, j'ai laissé fonds dans l'estat des réparations publiques de la généralité de Lyon de la somme de cinq mille llvres pour subrenir à cette dépense, mais, parce que la moitié de cette somme doit être prise sur vos octrois, je vous prie ne faire aucune difficulté de la faire mettre entre les mains du commis du sieur Arnauld à Lyon, trésorier des ponts et chaussées de france. L'œurre auquel j'al destiné cette somme est des plus importantes aucquels vous la puissiez employer et, pour cette occasion, lorsque vous me rapporterez l'état de la recette et dépense de vos deniers communs, je vous promets de passer cette partie sous le nom du Sr Alnaud, ainsi donc vous en demeurerez déchargé... Sully á l'échevinage de Lyon. Paris, 25 mai 1606. Arch. mun. de Lron AA 54 lol. 534.

4. Economies royales, $\mathrm{X}, 222$.

5. Ibid., X, 225-226, 
qui sélevait à 4446000 livres (14990 409 fr. 29), 870000 livres (2346292 fr. 71) furent employées aux travaux de la Lohre, de la Seine, de l'Aisme, de la V'esle. de la Vienne et du Clain, aux ports de Paris et de !ouen, anx fontaines de liungis, aux houes et au paré de la capitale, à la lour de Cordouan et aux réparations nécessitées par les inondations de $1608^{\prime}$.

Ces chiffres ne représentent que la part de l'État dans les travaux publics. Il faudrait y ajouter les sacrifices faits par les guénéralités et les villes, si l'on voulait connaître le total des sommes consacrées annuellement aux travaux de grande et de petite voirie. Ainsi, en 1606, la Normandie simposait pour ses dípenses locales 246381 livres (7201:3\% fr. 11), sur lesquelles $100 \% 00$ livres $(2937: 34 \mathrm{fr} .7 \%$ ) pour les travaux publics de la province. Cette dernière somme se décomposait ainsi: 33000 livres (964:36 fr. 78) pour les ponts et chaussées, 22.00 livres (6:3 $76: 3$ fr. 99) pour le pont de Rouen, 13000 livres (43813 fr. 99) pour ceux de Mantes et de Saint-Ciloud, 30000 livres (S7 687 Ir.98) pour le canal de Loire et Seine 2 . Les provinces et les villes dont les revenus ordinaires étaient insuffisants pour pourvoir aux dépenses des travaux d'intérèt local, se faisaient autoriser soit à contracter un emprunt soit ì perceroir une crue sur le prix du sel de gabelle, un droit d'entrée ou un péage. Elles envoyaient au grand royer des états au rrai, vérifiés par les trésoriers de France, de l'emploi de ces taxes ${ }^{3}$. Malgré celte précaution, cel emploi n'était pas toujours conforme à sa destination. Quelquofois aussi les comptables tardaient à rendre leurs comptes.

1. Economes royales, $15 \%$, 221, 223. Cr. Clamageran, Ilisloire de l'impúl, II, 359.

2. Lettre de Sully aux trésoriers généraux de France en Normandie. 5 decesubre 1606. Economies royales, IX, 218-?20.

3. Voy. les registres des lettres patentes enregistres par le bureau des finances de la généralité de Paris, passim. 
C'est ce qu'atteste un aŕêt du conseil du 33 décembre 160't qui, avant de faire droit à la requête de plusieurs villes pour obtenir des autorisations de ce genre, ordonne que les recereurs et payeurs de crues sur le sel compteront préalablement des deniers dont ils ont eu le maniement du

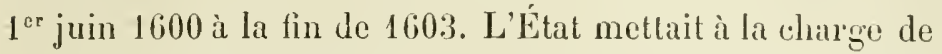
la région principalement intéressée l'arance des dépenses de voirie. Les entrepreneurs de transports par terre de l'Aurergne, du Limousin, du Languedoc et du Virarais appellent-ils la sollicitude du conseil sur l'état défectueux du chemin neuf qui traversait Lyon, le conseil répartit par tiers l'arance des frais de réparation entre la ville, les rive rains et les paroisses roisines et impose à ces rirerains les frais d'entretien '. Les taxes locales créées pour l'entretien des ponts et chaussées étaient supportées mème par les privilégiés ?

Quclques années avant la mort de Henri IV, la réfection de nos voies de communication par terre était bien avancée. Dès 1606 une partic des grandes routes avait été reparée ${ }^{3}$, elles étaient de nouveau bordées d'ormes qui avaient le double avantage d'en fixer les limites, de les protéger contre les empiétements des riverains et de donner de l'ombre aux royageurs ${ }^{4}$. Plus d'une fois ces arbres eurent à souffrir de l'impopularité du ministre qui les arait fait planter. "C'est un Sully, disait le paysan qui gardait rancune à ces belles routes des corrées qu'elles lui avaient coùtées ${ }^{5}$, faisons-en un Biron ${ }^{6}$ " et il décapitait

1. Arrèt du conseil du :20 janvier 1601. Arch. nationales.

2. Flobentin de Thierriat, Trois traites de la noblesse, 1606 . Arrêt du conseil du 28 juillet 1601 .

3. Palya Cayet, Chronologie septenaive, II, 282. Jeannix, A la mémoire de Henri quatrième, mss. cité par Pullppsox, I, 356, no 1 .

4. I. Laffemas, Histoire du commerce, 1606 dans Cluber et Daxjoc, XIV $415-417$.

5. Babeau, Le village sous l'ancien régime, 20 édit., 3i8-383.

6. Tallemant, Historiette de Sul'y. 
res trones dont le fenillage pouvait déjà abriter ses pénibles charrois. De pareils actes de vandalisme nétonneront personne. Il est plus diflieile d expliquer comment l'élargrissement des clienins, l'élagage et l'abalage des arbres prójuliciables à leur conservation et à leur usage eurent pour adversaires des hommes appartenant anx classes célairées, tels que les membres des états de Normandie ".

si heaucoup de grandes routes se trouraient, à la fin du règne de Henri $\mathbf{W}$, rendues à la circulation, il en restait encore beaucoup aussi où elle ne pouvait pas se faire. C'est à celte ípoque, en effet, et non à l'arènement du roi que se rapporte linformation si grareque nous avons empruntée it I. Lallemas ${ }^{2}$ et qui nous représente les marchands obligés, dans beaucoup d'endroits, de faire des létours de trente ou quarante lieues parce que les chemins sont défoncés et périlleux. Dans le passage auquel nous devons cette importante révélation, I. Laffemas ne dit pas, comme II. Poirson le lui fait dire ${ }^{3}$, que les chemins publics furent rétablis, il lone Sully de ses eflorts pour les rélablir, il exprime lespoir qu un jour viendra où ils seront redressés et facilement praticables '. Sil'œurre poursuivie avec tant d'activité par le grand royer n'allait pas plus vite, cela tenail beaucoup ì ce qu'elle devait ètre, en partie, accomplie par des péagistes trís insouciants de leurs devoirs. En 1609 le conseil élait encore obligé de les leur rappeler ${ }^{5}$. Racheter les péagres aux titulaires pour assurer aux roies de communication les ressources assignées sur leur produit, eùt étŕ une opération longue, délicate, peut-ître périlleuse pour un gourernement à peine sorti de la guerre civile. Dans la

1. Beaurepajae, Les ponts et chausses dans la généralilè de Rouen avont 17.5.9. Academie de Rouen, $18 \times 3$.

2. Ilistoire du commerce, p. 125.

3. III, 359.

4. Jafreas, Histoire du commerce.

5. Arrit du is avril 1609. Bibl. nat. mss. Franç. JiGG. 
mesure où l'administration du grand voyer pouvait agir directement, elle ne recula jamais, pour arriver à son but, devant les moyens les plus sommaires et, comme nous dirions aujourd'hui, les plus arbitraires. Par exemple, le fournisseur du paré de Paris faisait-il attendre les matériaux nécessaires au pavage de la rue Saint-Antoine, m arrèt du conseil autorisait le maitre paveur du roi à extraire des carrieres privées, en amont de Fontainebleau et ailleurs, tout le pavé dont il avait besoin et à réquisitionner pour son extraction, sa taille et son transport, hommes, roitures, bateaux, chevaux et harnais ${ }^{1}$.

L'admiration, si légitime d'ailleurs, de Poirson pour l'œurre économique de Henri IV l'a peut-être encore conduit trop loin quand elle lui a fait dire ${ }^{2}$ que tous les ponts existant avant 1599 furent rétablis. Si l'on s'en tenait aux documents authentiques et précis, cette assertion devrail être limitée aux ponts de la Seine, de la Marne et de l'Yonne, pour lesquels la dépense fut converte au moyen d'un droit de $1: 3$ sols (2 fr. 19) par muid de vin passant sous les ponts de Paris ou transporté depuis ces ponts jusqu'à ceux de Conflans, de Mantes, de Bonnières et de Beaumont-surOise ${ }^{3}$. Il n'est pas douteux, toutefois, que l'activité de Sully n'ait fait beaucoup plus et que l'affirmation si autorisée du président Jeannin ne soit très près de la rérité. "Henri fil, dit ce dernier, rétablir les ponts que la fureur des guerres avoit démolis, en bàtir de nouveaux ${ }^{4} . .$. " Non contente de relever les ponts en ruine, de débarrasser ceux qui restaient encore debout des constructions parasites qui entravaient la navigation ${ }^{5}$, d'en édilier d'autres, l'administration du

1. Arrêt du 18 novembre 1601. Bibl. nat. mss. Franç. 18165, fol. VllxxXY.

2. 111,360 .

3. Arrêt du conseil du 24 janvier 1598. PALma CAret, Chronologie septenaire, II, 282, année 1604 .

4. A la mémoire de Henri quatrième dans Philipsos, I, 356, no 1.

5. Arrêt du conseil, novembre 1593. Bibl. nat. mss. Franç. 18165 , f. 38, vo. 
grand royer accueillit le projet d'en établir sur toutes les rivieres anx endroits indiqués par les besoins. L’auteur de ce projel, Christophe Marie, dont le nom ent resté allaché à un pont de P’aris, sengageatit à construire en quatre mois ceux qui lui seraient commandés. Pour se rembourser de ses avanees et siassurer des bénéfiees, il obtenait l'autorisation de pereevoir, pendant quinze ans, un péage rachetable par les populations. Il se déclarait prèt à commencer les travaux six mois apris l'emregistrement de son privilige par les parlements du ressort ${ }^{1}$.

Les détails qui suivent ne concernent que certains ponts particuliers. Nous espérons, toutefois, qu'on ne les lira pas sans interèt, surtout à cause des lumieres quïls jettent quelquefois sur des questions générales.

Ln arrèt du conseil du 27 septembre 1.598 avait imposé sur le Languedoc, pendant dix ans, une contribution de 6000 écus ( $: 36997 \mathrm{fr}$. 18) destinée à acherer le pont de brique de Toulonse depuis longtemps en construction, mais les états de Languedoc assemblés à Pézenas en $1 \% 99$ avaient commencé par réduire ì 4000 écus $(37998 \%$ 12) et à six années la quotité et la durée de cette imposition, puis ils en avaient, quelque temps après, sursis la levée pendant leur procis avec la ville. Sur la requête de celle-ci, un arrèt du conseil du 21 mars 1602 rétablit l'impôt au chilfre fixé par larrèt de 1598 .

Les habitants de la Ferté-sous-Jouarre avaient présenté requête au conseil pour faire contribuer les élections de Meaux, de Coulommiers et de Chatean-Thierry aux frais de la reconstruction du pont de la ville rompu pendant lis giverre civile. Ils faisaient remarquer que les grands chemins qui mettaient le plus directement en communication P'aris, Chıilons, Metz et la Brie venaient y aboutir. Leur requète 
fut renvoyée aux trésoriers généraux de France à Paris. Les travaux, dont le devis avait été dressé par des maitres jurés maçons, charpentiers et d'autres métiers, furent adjugés par les trésoriers généraux au prix de 2462 écus 30 sols (23292 fr. 12). Sur le ru de ces pièces, le conseil ordonna, le 28 juillet 1601, que le tiers de cette somme serait levé sur les habitants de la Ferté pour payer les réparations les plus nécessaires et que le reste serait pris sur le fouds affecté, dans l'état des finances de l'année suivante, à la réparation des ponts et passages. Estimation, adjudication, répartition des dépenses, on trouve là les prineipaux éléments de la procédure suivie dans les entreprises de travaux publics.

Les habitants de Grenoble avaient obtenu de Henri III, pour trois ans, un fouage d'un écu et demi "sur l'universel dudit pays " pour refaire deux arches de leur pont. Ils demandèrent à son successeur la confirmation de ce droit que la guerre les avait empèchés de lever. Celui-ci le remplaça par un octroi de 13 sols (2 fr. 19) à percevoir jusqu'à concurrence de 2500 écus (23648 fr. 82) sur chaque charge de vin entrant à Grenoble par terre ou par eau ${ }^{1}$.

Signalons enfin l'enquête ouverte par les trésoriers de France de Soissons sur l'utilité de la reconstruction du pont de l'Aisne détruit pendant les troubles ${ }^{3}$; l'autorisation donnée aux habitants d'Orléans d'emprunter 12000 livres (3̈307̈ fr. 19) pour réparer leurs ponts endommagés par les crues de la Loire; la restauration du pont d'Avignon commencée en 1604 et à l'occasion de laquelle le roi revendiqua arec succès son droit exclusif de propriété ${ }^{3}$; l'achìvement du Pont-Neuf, commencé au mois de mai 1:378, ouvert à la circulation au commencement de 160 s et

1. Arrèt du 28 juillet 1601 .

2. Arrêt du conseil du 11 août 1601 .

3. Economies royales, VII, 321 et suiv. 
triminé en 1607'; la construction du pont Marchand à Paris commencé en 1.i9s et terminé en 1608: celle du pont de Rouen commencé probablement en 160 't, date oì il en est question dans l'état de la grande crue de la taille, et terminé certainement en 1 lios ${ }^{3}$; la construction du pont qui joint le faubourg de Blois à la ville; l'achievement du pont de Chatellerault sur la Vienne commencé par Catherine de Médicis; l'établissement du quai et du port de la Saône acherée en 1609:

$\mathrm{Si}$ améliorées que fussent les voies de terre, le conmerce, par une juste appréciation du beau réseau hydrographique que les étrangers, depuis strabon ${ }^{5}$, ont toujours considéré comme un privilège de notre pays, conservait sa préférence pour les roies lluviales. Cest pour nos ancètres que le mol de l'ascal : "Les fleures sont des chemins qui marchent " a en toute sa vérité. Mais ils marchent lentement et l'on sait combien cette lenteur était aggrarée, combien la batellerie élait entravée et découragée par la cupidité et l̈incurie. Nous arons ì roir maintenant ce que IIenri IV et Sully ont fait pour développer la circulation par eau.

Les états généraux de finances dressés par le surintendant nous ont déjà appris le nom d'un certain nombre de cours d'eau dont son administration s'est occupée. Le Clain et la V'esle, affluents de la Vienne et de l'Aisne, figurent sur les états de $160 \%$ et de 1609 , la Vienne et l'Aisne sur celui de 1609 seulement.

Les travaux destinés à rendre le Clain navigable depuis

1. Pat.Ma Caver, C'tronologie seplenaire, 28:. Rergistre-joumal de Ilenrill, 1). 100 et d'llenri IN, 1). 415.

2. Lettres patentes accordant au sieur Marchand l'autorisation de construire un pont it la place du Pont-aux-IIeuniers, janvier 1598. Registrejournal d'llenri IV, 489.

3. Lettre de IIenri IV a Sully, 6 septembre 1608 . Economies royales, $\mathbf{X}, 98$.

i. Le vagage de France .. par le sieur Du Vernter, l6itl, p. p. 143, :03,

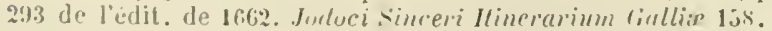

5. IN, I, 2. Voy. notamment les reliations de Dallington et de Carew. 
Poitiers jusqu'à son confluent dans la Vienne furent ad-

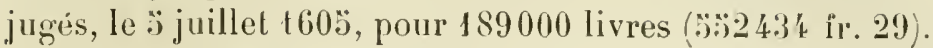
Le 19 octobre 1609 , ils étaient visités par deux trésoriers généraux de France en Poitou qui s'étaient assurés que, dès lannée précédente, la rivière avait été livrée à la navigation qui s'y était opérée d'une façon satisfaisante ${ }^{1}$.

Les contemporains de Henri IV avaient pu roir les restiges du canal latéral de Braine qui, commencé par François $I^{\text {er }}$, achevé par Ilenri II, avait rendu la Vesle navigable depuis Reims jusqu'à son embouchure dans l'Aisne. L'abandon lont toutes les entreprises d'utilité publique avaient souffert pendant les guerres civiles, arait laissé combler ce canal. Henri IV roulut restaurer l'curre de ses prédécesseur's. De 1599 à 1609 les documents nous montrent qu'on y travaille. En 1.599 une commission est nommée pour étudier le terrain, examiner les projets, dresser les devis. Les principaux habitants de Reims sont consultés sur les meilleurs moyens de réussir. On procède à de nouvelles expertises, à de nouvelles études préparatoires. La direction des traraux est confié à Thomas Cauchon, sieur de V'ezernay, trésorier général de France. En 16030 on s'occupe de faire porter bateaux à la rivière jusqu’à Sillery. Sa canalisation figure dans le budget des travaux publics de cette année et dans celui de 1609. II semble bien qu'elle a été conduite à terme et quill faut compter la Tesle au nombre des rivières, que Henri IV a ouvertes à la navigation ${ }^{2}$.

1. Procès-verbal de la visite du Glain dans Boncenne, De la navigation du Clain et de sa jonction ì la Charente et ì la Sèvre Niortaise, Poitiers,

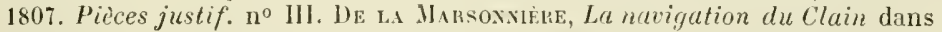
Bulletin de la Societé des antiquaires de t'Onest, ze série, t. I'III (1896). Et olim quidem propter obices inculta erat, nunc, illis remotis, navigatur. Pap. Masson, Descriptio fuminum Gallix (1618, 1. 89. VIGxov, I, 61. Delalande, p. 38s. Expilly vo Clain.

2. St. Prioux, IIisl. de Braine (18i6) p. 18s-191. Mémoires de P.sssot, 89118. Aujourd'hui la Vesle n'est pas navigable mais il ne faut pas en conclure qu'elle ne l'a pas été autrefois. Certains cours d'eau, jadis navigables, ont 
Il faut aussi y mettre la Vienne. Deux contemporains, qui écrivalent l'un et l'autre quelques années app'ès Ilenri IV, Papire Masson et le royageur allemand Zinzerling sont d'accord pour affirmer' qu'elle était navigable, au moins depuis Chatellerault ${ }^{2}$. Les traviux de camalisation lont cette rivière avait été l'objet et qui sont portés sur létat général des tailles de 1609 , avaient donc abouti. Le Limousin y gagna une voie de communication fort arantageuse arec la région de la Loire. Il en avait grand hesoin. De même que les relations entre ses diverses parties étaient rendues diffuciles par sa configuration physique, il restait, dans son ensemble, isolé des autres provinces et, pour le placement de son plomb, de son fer, de son bois, de son cuivre, de son papier, il n'arait pas d'autre marché que la région des Charentes, où il était obligé de transporter ces produits à grands frais par charrois et par mulets. Ce n’est pas seulement sur la région de la Loire quion songea ì lui créer un débouché, on roulut aussi lui ouvrir un accès sur le lérigord, la Guyenne et son littoral en rendant la Vésère navigable jusqu’à son confluent arec la Dordogne. Au moment où la proposition en fut faite, en 1606, l'entreprise parut trop lourde pour les finances royales. Elle fut soumissionnée successivement par le lientenant général du roi en Limousin, le sieur de Châteauneuf puis par un sieur de Lobriac et ses associés. Le premier obtenait, pendant quinze ans, le monopole du transport des bois ouvés par la rivière, le second la concession exorlitante de perceroir, pendant vingt, sur la

¿lé délaissés par le cummerce depuis que le développement du roulage, sins jarler de lextension plus tardive des voies ferries, a rendu les transports par tirre plus iconomiques.

1. Ilic vero [a Clıatellerau!l] navigiorun patiens Vigenna esse incipit. Pap. Masson, Descriplio fluminum Gulliw. 1618 p. 89 . Intluunt ipsum [la Loire potissini lluvii navigabiles : Elaver... Carus... Indrus, Vigenna, Lera et Meduana. Jurloci sinceri linerarium Gallia" $\langle 1616\rangle$. Preface. 
navigation, des droits arbitraires ${ }^{2}$. Nous ne savons si les travaux furent commencés.

Il y a encore une rivière qui a profité de la grande crue dont Sully nous a sommairement indiqué l'emploi, c'est l'A isne. Quelles ont été l'importance et l'efficacité des travaux entrepris pour améliorer son cours? C'est ce qu'aucun document n'est encore venu nous apprendre?

Dès 1393, le projet de canalisation de l'Orne, d'Argentan à Caen, était à l'étude. Le 24 juillet de cette année, le conseil donnait commission à Josué Gandouin, architecte ingénieur, de relever le cours de cette rivière. Le procèsverbal de cette visite, rédigé le $1: 3$ octobre, présentait l'entreprise comme peu onéreuse. Néanmoins elle ne fut pas exécutée ${ }^{3}$.

Un arrèt du conseil du 28 mars 1601 ordonna aux trésoriers de France à Clıàlons de faire inspecter par l'un d'eux, assisté d'experts le cours de la rivière de Bar-enRethelois pour rechercher les moyens de la redresser, d'empêcher ses inondations et de lui faire porter bateaux. Denx ans plus tard, un autre arrêt du 31 juillet 1603 imposa aux riverains, pour son curage entre Buzancy et Saint-Aignan, une taxe de 9000 livres (26306 fr. 39). C'était vraisemblablement pour la faire servir à la jonction de l'Aisne et de la Meuse qu'on voulait rendre la

i. Arrêt du conseil du 17 août 1606. Collection des Arch.nationales.

2. Il riest pas inutile de dire, comme acheminement i la solution de la question, qu'en $\mathbf{1 6} 1 \mathbf{1}$ l'Aisne était navigable depuis Pontavert (Aisne, ar'. Laon, c. Neufchâtel), tandis qu'en 1698 elle ne l'était qu'à partir de Soissons, exemple nouveau du recul subi sur plus d'un point par la navigabilité et indice que, du temps de IIenri $1 V$, elle a pent-être été assurée au delá de Pontavert. Cf. Le voyage de France par le sieur Du Verdier. (La $1^{\text {re édition }}$ est de 1641) et État de la France. Clamparne.

3. Mémoires de Groulart, 1602. Coll. Michaud, XI. Mémoire imprimé sur le projet de navigation de l'Orne depuis Argentan jusqu'à son embouchure audessous de Caen, par B., ingénieur hydrographe du roi, 1750. Arch. nat. F1+14?. Laxge, Mémoire sur le porl de Cuen, dans Mém. de la Société d'agriculture et de commerce de Caen, 1827. 
Bar navigable; on aurait donc fait par là le premier pas dans la voie qui devait mener à la eréation du canal des Ardennes. Mais rien n̈̈ndique que ces mesures préliminaires aient elles-mênes été suivies d'exéculion '.

Ce n'est pas, au contraire, ì un de ces projets, dont laccomplissement reste quelquefois doutenx, que nous avons affaire pour le Cher. La canalisation de cette riviere, de Saint-Imand is Saint-Florent, était, en 1606, en voie d'exécution. L’entrepreneur s’appelait Nicolas du Crocq. En 1616 le Cher est classé par Zinzerling parmi les rivières navigables ${ }^{2}$.

L'Eure et l'Ource furent ourertes à la navigation, la première quelques anmées arant 1603, la seconde un peu avant $1609^{3}$.

Lil commission du commerce patronna chaleureusement la proposition de rétablir, de la lière à Chauny, la navigation de l'(lise, interrompue, depuis l'origine des troubles, par la rupture des batardeaux et des écluses. Le gouverneur de la Fère, le sieur de Manicamp, sètait fait, auprès de la commission, l'arocal de cette entreprise qui derait permettre léchange des blés, des bois, du merrain, des ardoises, des fers et des toiles du Vermandois et du Laonnais avec les vins et le sel des provinces plus méridionales. Ln l'absence d'un capitaliste capable de faire les avances, il proposait de recourir à une taxe sur les marchandises transportées

1. Arrî́ts du Conseil et L.acallte, Les origines historiques du cunnl des Ardemir.s.

2. Arrets du conseil du 16 novembre 1606 et 18 septembre 160 . Jorlori siureri llinerarium... Préface. En l69s le Cher neutait navigable quà partir de Vier\%on (Etat de la France, III. Géneralite d'Orléons. Sur ce point encore il semble done y aroir eu recul.

z. "... l'Eure rendue navigable depuis quelques annies par artifires

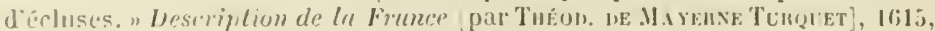
Lil dedicace est de 1603 " la rivinge d'Ourey fitite unvigalte de fraiche memoire, portant batemx plus longrs que larges..." Du binsse, Les anti-

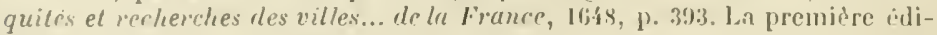
tion a éti publićce en 1609 . 
par la rivière ou ì une imposition directe sur les communautés appelées à profiter de cette uavigation. Il suggérait lïdée de confier la direction technique du travail à un Flamand expert, comme beaucoup de ses compatriotes, dans les travaux hydrauliques ou au maitre des a:urres de Vermandois. La commission adopta la pensée de demander aux contribuables des généralités de Paris, d'Amiens et de Soissons la somme nécessaile. Malheureusement l'affaire traînait au conseil, oì personne ne voulait la rapporter. Les commissaires pressèrent II. de Caumartin de la faire mettre à l'ordre du jour et recoururent au grand voyer lui-mème. In l'icard, le sieur Blondeau, conseiller au parlement, insista sur les arantages de l'opération, que sa connaissance du pars lui permettait d'apprécier mieux que personne, pour obtenir qu'elle fùt poursuivie jusqu'à Guise, ce qui ne coûterait pas beaucoup plus. Cette extension derait, disait-il, ouvrir le marché de Paris à une population réduite jusque-là à commercer avec l'étranger, dont elle itait limitroplıe, ou à vendre à vil prix, diminuer entre elle et ses roisins, sujets du roi d'Espagne des relations qui. à la longue, affaiblissent le patriotisme et faire de l'Oise une barrière pour notre payss entièrement ouvert de ce côté. Chargé d'une enquête sur les voies et moyens, Blondeau rupportait des lieux la conviction que le rétablissement de la navigation de l'Oise était encore plus facile qu'il ne l'avait cru. Les populations et notamment les habitants de Guise, qui avaient tant à y gagner, offraient de contribuer aux dépenses. Bradley mettait son expérience au service de l'entreprise, la commission multipliait les expertises, correspondait avec les gouverneurs et les municipalités pour obtenir leur concours ${ }^{1}$. Tout semblait donc faroriser ce

1. Séances de la commission du 10 décembre 160 ? i janvier, 12 décembre 1603, 3 février, 13 avril, '́ mai, 23,27 et 29 juillet 160 t. Comptes rendus, 36, 38, 48, 50. Recueil de ce qui se passe... dans Cinber et Duxoc, 
projet. P'ourtant, it en juger par le silence qui se fait tout d'un coup ì son égard, on le croirait tombé dans l'oubli. Cet ouhli, du moins, n’a pas été définitif ni peut-ètre bien long ear nous savons qu'en $16.3 . j$ l'Oise etait navigable du pont de Beautor au pont de Chauny ${ }^{1}$. 1) que le rétablissement de la navigation, dans celte partie de son cours, ait été accompli sous llenri IV ou sous son successeur, il faut toujours faire une large part, dans l'exécution, et à son gouvernement et à l'appui de l'opinion locale et contemporaine.

A la suite de traraux commencés dès 1571 , la Vilaine avait été ouverte, depuis $15 \% 8$. , à la navigation. Sa canalisation arait été exécutée par une société qui avait obtenu, pour cinq ans, en vertu de son cahier des charges, le monopole du produit de la batellerie et elle arait abaissé le prix des transports à un chiffre douze fois inférieur aux transports par terre. Ce produit fut anćanti, en mème temps que le commerce de la rivière, par les guerres civiles; le matériel, les bateaux, les travaux d'art furent détournés et détruits. Pour indemniser la société, Henri IV lui accorda, pendant quinze ans puis pendant cinq, la prorogation de son privilège?

Les voies navigables ont eu, dans le mourement commercial, au temps de Henri IV. une part proportionnellement plus considérable qu'au siècle dernier et de notre temps. Plus d'un cours d'eau qui, sous son règne, était animé par le passage des bateaux, l'embarquement et le débarquement des marchandises, la population et les itablissements que la navigation attirait sur ses bords. a été reconquis par la nature qui a éteint dans le calme

XII, 238, 239. Palma Cayet qui a copié le recueil dans sa Chron. septenaire, 28:3.

1. Matton, Canalisalion de l'Oise el de la fausse sambre sous Lmis XIV dans Bulletin de la sociélé ncadémique de Laon, XV'I I86i).

2. Arrêts du conseil d'État du 30 mars 1602 et du 21 juillet 1609 . Mss. frane. $181 \mathrm{G} ;$; i la date et $\mathrm{Arch}$. nat. Collection des arrêts du conseil. Levot, I'récis sur In canalisulion de la Bretagne. Annuaire de Brest el du Finistère (18:5), ए. 9\%. 
et la solitude l'agitation et le bruit d'autrefois. Sur certains cours d'eau qui sont restés navigables, la navigation a reculé devant les circonstances naturelles et sociales qui tendaient toujours à l'entraver. Ainsi la Seine qui n'y est plus acressible qu'à partir de Méry, aurait été, d’après Grosley ${ }^{1}$, parcourue, en amont de Troyes, par une batellerie fort actire. La Loire portait bateaux sur un parcours de plus de cent soixante lieues. Si son chenal n'était pas assez profond pour laisser ceux d'un fort tonnage remonter son estuaire, ceux de deux cents et trois cents tonneaux pouraient le faire ${ }^{2}$. Dès la fin du $\mathrm{xv}^{\mathrm{e}}$ siècle, elle ne l'était plus pour les bateaux pontés et quillés que jusquaux Ponts-ile$C^{2} e^{3}$. Le nombre des rivières navigables s'élevait à cent vingi et il y avait, en outre, une foule de cours d'eau flottables ${ }^{4}$. L'amélioration des routes et du roulage, la renaissance des abus qui avaient paralysé les transports par eau et qu'une législation énergique avait réussi à contenir et à réprimer ${ }^{*}$, déterminèrent la préférence du commerce pour les voies terrestres et l'abandon relatif des roies fluviales, envahies, du jour où elles ne furent plus défendues par une incessante surveillance et un entretien continu, par les empiètements des hommes et de la nature.

Le gowrernement de IIenri IV ne se contenta pas

1. Grosler, Mémoires historiques et critiques sur lhisloire de Troyes, éd. $1812, \mathrm{I}, 24$.

2. [Le P. Mathias de Saint-Jean, prieur des Carmes de Nantes, dans le siècle JEAx Eox], Le commerce honoruble ou considérutions politiques conlenant les motifs d'honneur et de profit qui se trouvent à former des compagnies de personnes de toutes conditions pour l'entretien du commerce de mer on France, composé par un habitant de la ville de Nantes, 4. Nantes, Guill. LE Monnen, 1646. PP. 317, 322. Cf. Annales de la Société acndémique de Nantes..., XXY (185i , p. i3. Gallolenec, La Loire navigable, dans Annales de geographie, 15 janvier 1897.

3. Godard Falltrier, Commerce des Hollundais en Anjou dans Mémoires de la société d'agriculture, sciences et arts d'Anjou. XXXVill.

4. "Nous arons six vingts rivières navigables et infinis bons ruisseaux." Le manifeste françois contre la trop grande présomption des Espagnols, 162.'.

5. Chevalier, Navigation commerciate de la Loire au $\mathrm{XV}^{\mathrm{e}}$ et $\mathrm{XVI}$ siècles. Ubi supra. Delaldxde, Des canaux de navigation, $17 i 8$. 
d'augmenter le mourement de la batellerie en améliorant le cours de nos voies fluviales et en reliant par des canaux latéraux celles qui appartenaient au mème lassin, il entreprit de faire commmniquer par des canamx à point de partage des bissins dilférents et mème d'établir, entre les deux mers dont la France est baignne, me ligne de navigation intérieure ininterrompue.

Pour accomplir ce dernier lessein, également grandiose par les diflicultés et les résultats, deux systèmes furent imaginés. Liun consistait à unir la Méditerranée et l'Océan par un canil se dirigeant du midi au sud-ouest. Ce canal avait lavantage dopérer la jonction des deux mers de la façon la plus directe et la plus économique, mais il u'amenait les vaisseanx que dans le golfe de Gascogne, e'estit-dire fort loin encore de la .lanche et de la mer du Yord. Le second syslème, heaucoup plus largement conçr, faisait pénétrer la lig̣ne de navigation dans le centre du pays, d'où elle se ramifiait en trois réseanx secondaires, l'un aboutissant à locian, l'autre ì la llanche. le troisième à la mer du Nord. La Saône, la Loire, la Seine et la Meuse mèlaient leurs eaux pour concourir à son établissement. Commençons par nous occuper du premier projet, de celui qui a été réalisé par le canal du Languedoc; c’est à lui quion a songé d'abord et, conme il n'est pas mème entré, sous Ilenri IV, dans la période d'exécution, il ne nous arrêtera pas longtemps.

Presque tout ce que nous en sarons, nous le derous à la lettre écrite par le cardinal de Joyeuse au roi le 2 octobre 1:398. Lorsque le cardinal partit pour Rome oui il était appelé par ses fonctions de protecteur de France, IIenri lui demanda de s'enquérir sur sa route des voies et moyens pour parvenir a la création du canal des DeuxNers dont le projel lui arait été soumis. C'est le résultat de cette enquète que ce prince de l'Église nous lait con- 
naitre. Pendant que le roi s'entretenait de la question aree le céliebre ingénieur. Louis de Foix, quil avait mandé pour cela auprès de lui, le cardinal faisait venir un élève d'Adam de Craponne, Pierre Reneau, de Salon, l’interrogeait sur ce que son maitre lui avait dit d'une entreprise dont il arait fait la proposition à Catherine de Médieis et l'enroyait en étudier sur le terrain la réalisation. Il consultait en même temps tous ceux qui pouraient lui fournir des renseignements utiles. Tous les gens compétents saccordaient pour dire que la Garomne et l'Aude étaient les deux rivières que le canal projeté derait mettre en communication. Son tracé rencontrait une difficulté naturelle. Sur les quatorze lieues qu'on derait lui donner, il fallail lui en faire gravir six ou sept pour amener les eaux aux Pierres de Naurouse, point le moins éleré de la chaìne des Corbières qui sépare les deux bassins de la Garonne et de l'Aude. Reneau triomphait de cette diffieulté en empruntant non à la Garonne mais à l'Ariège qui coule plus haut que les Pierres de Naurouse les eaux nécessaires à l'alimentation de son canal et en les grossissant de certaines sources de la Garonne emmagasinées dans un autre canal d'une lieve allant du chàteau Saint- Michel au col de Naurouse. Grâce à cette masse d'eau répartie sur les deux versants, les bateaux monteraient de la Garonne par des écluses à sas jusqu'à la ligne de partage et franchiraient cette ligne pour descendre dans l'Aude ou opéreraient en sens contraire le passage d'un bassin dans l'autre. Au dire des gens de l'art, il suffirait de donner au canal six pieds de profondeur pour lui faire porter des bateaux plats chargés de mille quintaux. Les dépenses, y compris les expropriations, étaient évaluées à 600000 écus 3699718 fr.97) et la durée du trarailà deuxans ${ }^{1}$.

1. Polrsox, IIistoive de Henri $1 \mathrm{~V}$, III, 393 et suir. et Documents sur les voies de navigation par eau, IV, no $\mathrm{i}$. DeLalaxde, Des canaur de navigation, 17 is. 
Peu ì peu le mojet du canal de la Garonne et de l'Aude était délaisse pour la ligne de navigation dont la création était la solution la plus contense mais anssi la plus féconde du problème de l'union des deux mers. Ce projet pourlant conservait encore des partisans. En 1604 la commission du commerce s'en occupait, et celui qui l'en avait saisi faisait valoir quill pourrait ètre exécuté en un an et pour une somme qui ne dépasserait pas 40000 écus (379!81 fr. 26), tandis que le canal entre Loire et Seine, aupuel on travaillail, demanderait trois ans et coùterait 180000 écus (1 $70991: 3 \mathrm{fr} .69)^{1}$.

La ligne de navigation qui tendait ì obtenir la préférence devait ìtre établie par la jonction de la Seine et de la Loire, de la Loire et de la Saùne, de la saône et de la Meuse. Son importance saute aux yeux : elle assurait la communication entre le bassin de la Méditerranée et celui de lOcéan, sur toute l'étendue de notre littoral océanique., ainsi quavec les mers qui en dépendent et qui baiguaient les pays les plus industrieux de l'Europe, et elle l'assurait par la France. Sul!y, qui ful le grand instigateur de cette belle entreprise, eslimail que, par le déplacement du trạnsit, clle pourrait faire perdre ì l'Espagne deux millions d'écus de revenus (18999063 fr.) et les faire gagner à notre pays². son exécution éviterait un royage de cing ou six mois le long de la péninsule ibérique. dans une mer infestée de pirates et le passage du clétroit de Gibraltar dont l'Espagne arait la elef $^{3}$.

Le grand voyer se mit de suite ì l'ourre. Il commença par la construction diun canal entre la soine et la Loire.

1... there has been a speech of making a canal from the Garonne to Rhune Lisez: Aude, which by lgde runneth into the Mediterranean sea

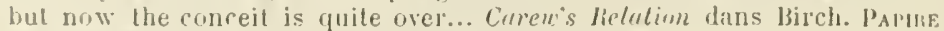
Massox, bescriplio flumimum Galliar, 161s, P. 191.

2. Ecronomies royales, Vil, 4 ti.

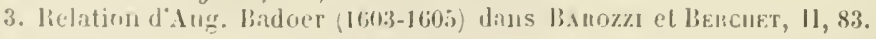


C'était une attention pour la capitale, à l'approvisionnement de laquelle ce canal levait servir '. Il alla plusieurs fois lui-même sur les lieux pour se rendre compte des moyens d'exécution ${ }^{2}$. Les difficultés étaient grandes, car cétait le premier canal à point de partage. L'entreprise fut soumissionnée par Hugues Cosnier, le 11 mars 160\%, au prix de 503000 liveses (1 476081 fr. 06). Ladjudicataire s'engageait à terminer le travail en trois ans et obtenait l'exploitation des moulins démolis et reconstruits par lui, le produit de la pêche dans le canal et l'autorisation de planter' et de cultiver sur ses levées les mùriers dont il arait entrepris la fourniture pour tout le royaume. Il dépensa en trois ans 180000 écus ( $170991 \%$ fr. 69) c'est-à-dire 33000 lirres (102302 fr. 6't) de plus que le prix de l'adjudication, auquel étaient renues probablement s'ajouter certaines allocations ${ }^{3}$. Les travaux avaient absorbe plus de 300000 écus (3033934 fr. 3 í) lorsqu'ils furent interrompus par la mort du roi. Bien qu'ils fussent presque terminés. le gouvemement de la régence, qui se souciait peu des vurres d'intérèt public et auprès de qui Sully n'était pas en faveur, les laissa dans l'état où il les avait trouvés ${ }^{4}$. Ils ne furent repris qu'en 1638 et le canal ne fut ouvert qu'en 1642 . Il partait de la Loire, près de Briare qui lui a donné son nom et, passant par Châtillon, joignait à Montargis le Loing qui se jette dans la Seine près de IIoret. II franchissait, ì l'aide de trente-trois écluses, les collines qui séparent les bassins de la Loire et de la Seine ${ }^{5}$.

Pour se rendre compte du profit que le conmerce pou-

1. Detexs, Histoive de la navigation intérienre, I, 8千.

2. Economies royales, VII, 316 .

3. Recueil... no 33. Palma Cayet, Chronologie seplenaire, 283. Arrits du conseil du 14 mars 1606 et 6 février 1610. Bibl. nat. inss. Franc. 1810 , fol. 163. 18177, fol. 159.

i. J. A. Thuani Historia, IV. $23 i$.

5. En 1665 Fléchier en comptait quarante-trois. Yémoires sur les Gronds jours d'Auvergne, 1862, in-s, p. 307. 
vilit tirer de ce canal, il fant songer aux riches contrées que trarcrsent ces deux flemres, alux produits naturels et industriels que la Loire et son prineipal afthent, l'Allier. ront chercher dans la région du plateau central et amènent sur les marehés dOCréans, de Paris et de Nantes: charbons de saint-Etienne ${ }^{1}$ et quincaillerie du Fores, coutellerie du Bourbonnais, denres agricoles et bétail de l'Auvergne, vins et bois de la Bourgogne et du Nivernais, fers et bètes ¿̀ laine du Berry, marchandises exotiques débaryuées à Marsille et allirées vers cette route par la crainte de lo doune de Lyon; il fant songer encore it la richesse agricol. de la Normandie et de la Beauce, aux ports de la basse Scine oì renait s'mmagasiner pour l'exportation l'excédent de la consommation intérieure.

La jonction de la Saône et parr suite du Rhône aree lit Loire formait le second tronçon de la grande ligne de navigation intérieure qui, sauf un transport par terre d'une. demi-journée de Lyon à Roanne. devait se raccorder sans solution de continuité à la navigation maritime. Les plans en furent arrètés sous Ilenri IV a mais ce ne fut que longtemps après. de 1783 à 1793, que le dessein en lul réalisé par la création du canal du centre ou de Charolais de Cihalon-sur-saùne à Digoin *3.

Le troisième tronçon, qui devait former le rameau du Tord-Est et assurer la communication entre la Méditerranée et la mer du Nord par la junction de la Saône et de la Meuse, ne donna mème pas lien à des études préliminaires et la pensée n’en fut pas recueillie par lavenir qui, pour alteindre au même but, eut recours ì d'ilutres moyens.

IIenri IV fit aussi étudier le projet d'unir la siône et Y Yonne. Il visait ainsi à ouvrir une nouvelle communication

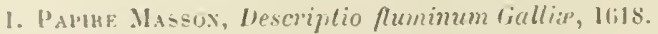

2. Relation de Badoer. Lbi supra,

3. Inttess, Histoire de la navigntion intérienre. 
entre le bassin de la Seine et la Bourgogne et préludait à la création du canal de ce nom, dont Saint-Jean-de-Losne ei Joigny forment les points extrèmes. On chercha ì se servil de l'Ouche qui passe à Dijon et se jette dans la saône à Saint-Jean-de-Losne. On se livia, sous la direction de Jean Bradley, maitre des digues du roi. à un examen du cours de cette rivière, dont le résultat fut consigné dans un procès-rerbal du 28 mai 1606. Cet examen fit reconnaitre combien il serait difficile de rendre l'Ouche navigable, et on songea alor's à creuser un canal latéral à cette rivière. Bradley s'offrit à l'exécuter en dix-huit mois moyennant 120000 francs $(3 \bar{\imath}+133 \mathrm{fr}$. 40), ì condition que la ville de Dijon prìt à sa charge l'acruisition du terrain ${ }^{1}$. Pour obtenir la somme nécessaire a lis construction du canal de Dijon à la saône, un arrèt du conseil du 17 aoùt 1606 établit un droit de $40 \mathrm{~s}$. ( $\ddot{j} \mathrm{fr} .8 \%$ ) par emine sur la farine rendue dans cette ville. En 1607 sully fit procéder à une nouvelle visite des lienx. On songea aussi à emprunter le cours de l'Armançon 'qui se jette dans l'Yonne au-dessus de Joigny et on en relera, à ce point de rue, les particularités. Hais les expertises et les devis des hommes de l'art ne mirent pas en mourement la pioche des terrassiers et ce ne fut pas arant $177: 3$ que les plans adoptés sous IIenri IV furent appliqués à la création du canal de Bourgogne.

Du réseau de navigation intérieure dont ce prince arait roulu doter la France il ne laissa pas une seule partie acherée et livrée à la circulation. Son nom, celui de Sully n'en doirent pas moins rester attachés à tout ce qui s'est fait depuis dans cette roie. La destinéc économique d'un pays est écrite dans sa constitution physique arant d'ètre déterminée par les aptitudes de sa population. La place à la

1. Detexs, Opus laud., 1, 36i. 
fois centrale et exentrique de la France en limope, son caratire en partie continental et en partic matime, la multiplicité et le voisinage de ses cours d'ean qui semblent se rapprorher pour sunir, la désigurient comme l'intermédiaire des échanges entre les diverses nations de l'Europe. comme le carrefour de ses voies commerciales les plus fripuentres. Henri IV et Sully curent conscience de sa vocation économique et, pour la mettre à mène de la remplir, ils firent revive le projet d'un canal du Midi déji conçu sous les règnes précédents et ne l'ahandonnìrent que pour en adopter un plus vaste et plus fécond. qui ourrait des issues an commerce francais et an commerce the transit sur une autre partie du littoral occanique, sur la Manche el sur la mer du Nord. El ils ne se hornerent pas il l'adopter, ils en entamèrent l'exécution arec tant d'ardeur et de méthode que l'avenir n'eut le plus souvent quà reprendre les données et les plans nés de leur inspiration ou éclos sous leur patronage.

Quels étaient, sur les chaussíes rempicrées, parées et drenues plus sures, sur les cour's d'eau camalisés et débarrassés des entraves ì la navigation, les moyens de transport ou, pour nous exprimer d'une façon plus précise. les moyens public:s de transport, les seuls dont le commerce lans sa généralité pût se servir? C’est ici peut-ìtre plus que partout ailleurs que la vie sociale et économique d. notre temps semble différer le plus de celle de nos ancêtres et yuion a peine à ne pas sourire de la lenteur des déplacements et des échanges d'iutrefois, yuand on la compare au nouvement rapide et perpétued de marchandisis et de voyageurs yui nivele aujourd'hui les prix, les idées et les mours.

Lr premier service de roitures publiques avait été créé -ous Charles $I X^{2}$. I’ar lettres patentes du 10 octobre $1: 37: ;$,

1. Lecs messifreries de l'Lniversité de Paris exislaient dijil, mais elles ne sprvilcut au public qu'accessoirement. 
Henri III avait aceordé à Antoine-Philibert de Cardaillac, sieur de Capelle, maréchal de Querey, le privilège des messageries de Paris, Orléans, Troyes. Rouen et Beaurais. Aux états de Blois de $1: 36$ et de $1: 388$, le tiers arait demandé la suppression de ce monopole ${ }^{1}$. La façon dont ces entreprises étaient exploitées noffrait, en eflet. anx royageurs et anx expéditeurs ni sécurité ni économie. Les voituriers ne saraient pas leur métier, les transports nétaient pas tarifés, libre carrière était laissée aux exactions.

Certaines municipalités araient organisé des messageries qui présentaient plus de garanties. Dans sa séance du -'t mars 1.588 , le capitoulat de Toulouse homologua un règlement présenté par le syndie des messagers jurés de cette ville pour trois services périodiques dont elle était le point de départ: l'un pour Paris, l'autre pour Lyon, le troisième pour bordeaux. Chacun de ces ordinaires partait lous les quinze jours. Il emportait les lettres et les paquets déposés au bureau des messageries et les distribuait aux destinataires. La úurée réglementaire du trajet entre Toulouse et Paris était de quinze jour's dans la bonne saison et de seize dans la mauvaise, en comptant le jour du départ et celui de l'arrivée; entre Toulouse et Lyon, il était de huit et de neuf jours, entre Toulouse et Bordeaux de cinq. Une réduction était prérue pour le cas où, la paix étant rétablie, la circulation deviendrait plus facile. Le tarif était de 8 sous ( 1 fr. 26) par once pour la première destination, de 6 sous ( 0 fr. 94) pour la seconde, de 4 sous ( 0 fr. 63) pour la troisième. On s'en rapportait, pour le perceroir, à l'indication du client écrite sur la lettre ou le paquet, mais, au cas où celle indication paraissait inférieure à la réalité, le port était taxé par le maitre du hureau ?.

1. PIсот, Histoire des élats généraux, III, 29, 203-20

2. Orig. Arch. de la chambre de commerce de Toulouse. 
P’ur un édit darril tög't Henri IV créa un surintendant genciral en titre dolfice do tous les coches publies '. Ses altributions consistaient it faire olserver le règlement et le tarif qui seraient arrêtés par le prévòt de Paris et à veiller sur le choix des voituriers et des chevaux comme en général sur le service ?. Larèt denregistrement du parlement de Paris, rendu sur lettres de jussion le 1.2 mai lö9:i. lixa le prix des plisees à un fécu un quart (1) fr. 8T) pour le lransport de Paris à Mrléans, Rouen et Amiens aller ef retour. Il imposa au surintendant des coches lobligation de faire deux fois par mois ot plus souvent. si cela ćtait néecssaire, rapport it la police sur les aluss de lexploitation.

Par eet édit Ilenri IN n'avait fait que soumettre au contrile du gourernement des entreprises privées, il navait pas fait des messageries un service public. Elles $n$ Cútaient devenues, par suite de ce contrôle, ni plus nomlreusen ni mème beancoup plus commodes. Quelques lignes seulement conlinuaient à ètre desservies. L̈̈nstitution ne saméliora pis quand la liberté fut remplacée par le monopole, adjugé au plus oflrant ou concéde i la faveur ${ }^{3}$.

Lil dehor's des messageries, le public pouvait recourir à la poste aux chevaux, qui élait fort chère el ne transportail pas de marchandises, et à des relais créés par l’industrie privée et dont l’existence est constatée par l'édil

1. Les corhes étaicut des roitures couvertes i quatre roues.

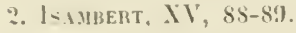

3. "... Led. contrat jar lequel S. M. auroit vendu, avec promesse de garanlie, a l'jerre le Lorain. á laculté de rachat perpétuel. le droit et ferme de tous les coches et carosses publiques de son royaumr itablis ou a établir..., arec inhibition... it tous autres den itablir, moyenmant le prix de... $\$ 4000$ écus \$12974 fr. il ... Fait detlenses aux d. charrons, carrossiers et tous autres de louer carrosses. coches, charreltee et clicvaux, soit pour les d. chimins de traverse ou autjement, sans le cougé... de lad. dame Anne de Bueil]... lad. dane... sera tenue... acheter les coches et carrusses ou charrettes... di present en la possessiun desd. carrussiers el charrons selon... lestimaljun... au dire de „ens á ce connaissant dont les parties crnviendrunt..."

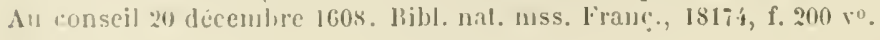


de mars $13997^{1}$, qui a pour objet de les organiser et de leur donner un caractire officiel. Le pays souffrait d'autant plus de cette pénurie de moyeus de trausport que les guerres eiviles araient prive beancoup de particuliers de leurs chevaux. L'édit de mars 1.397 arait pour but, on se le rippelle, aussi bien d'en fournir à l'agriculture, dont les bètes de trait araient été réquisitionnées el rolées par lus gens de guerre que de faciliter les transports. Nous avons déjà signalé son intérêt pour les cultivateurs, parlons maintenant de ses avantages pour le commerce.

Cet édit établissait sur les grands chemins et les chemins de traverse des relais séparés par la distance d'une traite ou journée c'est-à-dire de douze à quinze lieues. Leur exploitation derait être mise en adjudication par les deux généraux des relais créés en titre d'office aux gages de :\$00 écus ('t $749 \mathrm{fr}$. 76) chacun. Les adjudicataires, revèlus du titre de maitres particuliers des relais, étaient tenus d'aroir dans leurs écuries le nombre de chevaux jugé nécessaire par les commissaires du gourernement et de les louer, au tarif légal, pour le transport des voyageur's et des marchandises, le halage des bateaux et le travail des champs. Ces cheraux étaient marqués d'une H fleurdelisée, déclarés insaisissables, comme l'étaient déjà les cheraux de poste, et leur détournement était puni de mort. L’industrie des loueurs de cheraux cessa dès lors d'ètre libre et fut subordonnée à une licence royale ${ }^{2}$. Un règlement arrêté au conseil, le 12 mars $1: 397$, chargea les généraux on leurs subdélégués de déterminer les relais d'accord avec les juges des lienx, fixa la mise à prix par an et par cheval à 3 écus un liers (31 fr. 66) et le tarif des journées aller et relour, sans compter la nourriture, à 20 s. t. (2 fr. 92) par cheval ordinaire, à $2: 3$ s. (3 fr. 6:3) pour les cheraux d'amble, de somme

1. Préambule et art. vi.

$\therefore$ IsAMBert, $\mathrm{XY}, \mathrm{n}^{\circ} 111$, art. TI. 
et de halage, sauregatrda les chevaux contre labus que pouvaient en faire les voyageurs et maintint les messigers jurés de certaines provinees dans le droit d'en loner'.

Le public aceneillit fort bien l'organisation des nowreaus relais. Il les préféra ì la poste qui chait plus chère et nitsurait pas le secret des correspondan'es, de sorte que les écuries des maitres de postes se dégarnirent et que le port des dépèches officielles en souffrit. Après une expérience de cinq ans, les relais furent rémuis anx postes (édit d'aoùt 1602'. Le contróleur général des postes versa au trisor, pour prix de ses nouvelles attributions, la somme de :32600 écus² (30968' fr. 73). Les maittres généraux et particuliers des relais furent supprimés. Les relais passèrent sons la direction des maitres de poste qui lonèrent des chevax pour courir non plus seulement des postes mais des demi-poster c’est-à-dire des courses de moitié moins rapides et moins chères. Les lounurs de chevaux sétaient beaucoup multipliós. Gràce ì cette multiplicité. les étrangers pouvaient dérober leurs correspondances a lit surveillance. Désormais l'exereice le cette industrie subordonné, dans le réxime précédent, à une licence royale, fut sounis à une autorisation du contrôleur général des postes ${ }^{3}$.

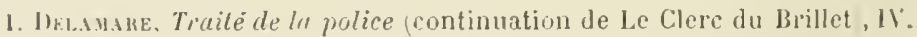
:99-601.

$\therefore$ D)L.M.MLE, IN, (i)1.

3. Fontavos, 11, 5.9. "Sur la rejute présentie au roi en son conseil par le sirur de La Valenue tendant a ce que... il plut i S. M. casser... le ritglement fait par le senechal et juges presiliaux de Nimes le xxv" novemlre IGøfi et autres qui pourroient depuis avoir ité faits sur l'établissemont des chevaux de relais de louage... rn... l'úlit de retahlissement de relais de chevaux de lonage de traite en trite sur les grands chemins, traverses et le lung des rivieres... en l'étendue de tont le royaume du mois de mars 15:- règlements faits par s. II. en son conseil sur l'établissement de relais et chevanx de louage de mars and, an, lettres pat. en forme l'édit donnces it Paris au wois d'aont 1602 contenant révocation de l'edit des relais de chesiux du mois de mills 1.97 ct réunion des relais aux postes avec dellenses i tuutes personnes, de quelutue qualité... qu'ils soient, de 
Les loueurs établis furent maintenus en possession moyennant le paiement d'un droit anuuel au contrôleur. Ln arrêt du conseil, rendu le 2't arril 1610 dans un procés entre eux et lui, réduisit ce droit à 6 livres (16 fr. 18) par an et par cheval ${ }^{1}$. Le personnel des postes et relais ne comprenait pas seulement des messager's à cheval ou checancheur's, mais des messagers à pied, des facteurs ${ }^{2}$.

Le commerce flurial était entre les mains d'associations ou, comme elles sappelaient, de comparnies anciennes et puissantes qui avaient le monopole des transports dans un flenve, dans son cours supérieur ou inférieur, quelquefois dans un bassin entier. La compagnie des marchands de l'eau de Paris et celle des marchands fréquentant la rivière de Loire étaient les plus célèbres. Toutes deux paraissent se ratlacher aux collèges romains (nautx Parisienses, nautæ Ligerici). La première, qui domna naissance à la municipalité parisienne, n’exerçait son monopole que dans une partie de la Seine ${ }^{3}$, mais la police de la navigation. dont celte municipalité était investie, s'étendait non seulement sur ce fleure mais aussi sur ses afluents : tarifs des transports, nomination des maîtres ales ponts, étalage des marchandises dans les ports, chablage et planchéage, etc., tout cela lui ressortissait * La compagnie des marchands fréquentant la rivière de Loire accaparait le commerce par eau dans tout le bassin de ce fleure, se

bailler ancun cheval á louage ni relais, sans l'expresse permission dud. sieur de La Varenne.... contrôleur général des postes et relais de France, ses fermiers ou commis, casse les règlements faits parle sénéchal de Beaucaire et Nìmes.... ) 22 décembre 1607 . Bibl. nat. Franc. 1817:, f. 146, vo.

1. Le Clere du Brillet, 601 .

2. Pilot, Postes el relais en Dauphiné dans Bulletin de l'Académie delphinule, XIX (1879), p. 417.

3. Voy. les travaux de LE Roy, Dissertation sur l'origine de lhilel de ville en tête de l'Histoire ae Paris de Félabien, de Depring De l'étal du commerce et de lindustrie de Paris au Xllle siecle et de Lecanos, Les origines de la municipalité parisienne. Mém. de la société de l'hist. de Paris, VIl et VIII.

4. Registres du bureau de la ville, bélibérations du 25 juin, 14 juillet 159 , 25 février, 8 mars, 13 mars, 13 septembre, 19 octobre 159.5 et pass. 
chargeait, moyennant un octroi concede par le gourernement, du balisage ef du curage et traviallait arec suces ì faire réduire et supprimer les nombreux prages perçus sur la navigation'.

Le service des coches deau pour le transport des royageurs, des batgages et des marchandises d'un certain rolume était exploité par des eoncessionnaires privilégiés. Dès 169:; il en existait un entre Melun et Paris". Corheil et Parrs étaient desservis aussi par des coches qui deraient it la premirre de ces villes le nom de corbillats, d'où nous est venu celui de corbillimds. Les corbillats faisaient deux royages par semaine. Le mardi ils partaient te Corbeil et revenaient le mercredi, ils repartaient le rendredi et étaient de retour le samedi. Ils étaient en partie halés ${ }^{3}$. Ln service du mème genre fut créé entre sens et la capitale. Le coche de Sens, qui était de la grandenr des corlfillats, quiltait cette ville le mardi it neuf heures du matin, arrivait à sa destination le jeudi ì eing lieures du soir, repartait le samedi à neuf heures dans la matinér et rentrait à Sens le mardi suivant à la mème heure. Le cahier des charges imposait au concessionnaire, Vincent de Limarque, archer des gardes du corps, l'obligation davoir deux bateaux, de faire partir celui de Sens, quill eût acheré ou non son chargement, dès que celui de Paris était de retour, de fournir caution et d'aroir des coffres solides pour la sùreté de l'argent et des marchandises précieuses. Le voviage de Scons à Paris était tarifé $20 \mathrm{~s}$. (2 fr. 92) par personne et

1. Maxtellabi, Mistoire de la communaulé des marchands fiéquentant la riviere de Loire el flenves descendant en icelle, "z rol. 8, 186i. Arrûts du conseil du 20 novembre 1607 et $2 i$ janvier 160 s.

?. "Louis Coasserat et Blaise Ronsseau, voituriers des bateaux appelés Iss coches de . Melun..." Reg. du bureau de la ville, 22 férier 159.

3. Arrèt du conseil du 20 janvier 1601. Arch. nationales. P.spine Missox, Descripliof fuminum Galliap (1618, p. $19 \%$. 
2:3 s. $(3 \mathrm{fr} \cdot 6.3)$ en sens inverse, parce ru'on remontait la Scine et l'Yonne. l'our le transport d'un muid de vin ou de verjus on payait $20 \mathrm{~s}$, pour un baril de salaisons $1: 3 \mathrm{~s}$. ( $2 \mathrm{fr} .19$, pour un quintal de morues $20 \mathrm{~s}$. et $40 \mathrm{~s}$. ("j) fr. $8 . .3$ ) par quintal de bagages. Les voyigeurs araient le droit d'en emporter gratuitement arec eux jusqu'à concurrence de quatre livres ${ }^{1}$.

La prospérité du commerce ne dépend pas seulement de la facilité arec laquelle, conformément à sa mission dans l'économie sociale, il transporte et distribue les marchandises. Pour remplir complètement cette mission, il a recour's à certains procédés, il bénéficie de certaines faveur's, il crée certaines habitudes d'où résulte, pour lui et pour la classe qui l'exerce, une certaine originalité juridique, économique et norale. Si le commerẹant, dans une société aussi aplanie par le frottement et aussi uniforme que la nôtre, se distingue encore par une législation, par des pratiques, par des mœurs même assez spéciales, il en était encore plus ainsi dans une société où tout arait sa tradition, sa vie propre, sa physionomie.

C'était d'abord la législation qui lui faisait une place à part. Si la classe commerçante n'arait pas encore son code, aurre réfléchie et laborieuse que la maturité tranquille de la monarchie persounifiée dans Louis XIT pourait seule enfanter, le droit commun arait déjà subi, dans son intérèt, des dérogations qui l'araient dépouillé de son formalisme pour l'adapter à des besoins, toujours sentis, de célérité, de simplicité et de confiance.

Le commerce conférait déjà aux mineurs et aux femmes marićes la capacité refusée habituellement aux uns et aux autres. Mais cette exception était strictement limitée aux

1. Arrêts du conseil du 13 septembre 1607. Arch. nationales. 
actes commereiax. Elle ne sippliquait pas seulement au mineur de vingt-cinq ans, àge de la grande majorité mais à celui qui narait pas encore vingt ans, ìge requis par les corporations pour parrenir ì la maîtrise ${ }^{2}$. Il leur suffisait, pour obtenir cette émaneipation spéciale, de se livrer ì des opérations commerciales. Le mineur commerçant conservait le droit de se faire restituer pour tous les actes qui ne se rapporticient pats it ses allaires professionnelles?

La femme mariće marchande publique engageait, pour la garantie de ses obligations commertiales, ses biens et sa persomne comme les biens de son mari. Mais elle ne jouissait de cette capacite que si elle excrçait le commerce a part et pour son compte et non si elle secondait seulement son mari dans le sien. Telle était, du moins, la distinction établie par la coutmme de l'aris, dont l'autorité était beaucoup phus grande que celle de toutes les autres. Iais eette distinetion n'etait pas universellement acceptée. Le jurisconsulte nivernais loquille, par exemple, en contestait la légilimité ou, du moins. la trourait trop absolue. Il suffisait à ses yeux que la femme se livrât an commerce au ru et au su de son mari pour ètre présumce agir arec son autorisation et pouvoir sengager personnellement ${ }^{3}$.

Les commerçants étaient soumis déjà, pour le recouvrement de leurs créances, à une prescription spéciale. Les marchands en détail et en gros qui navaient pas réclamé le payement de leurs fournitures, les premiers dans les six mois et les seconds dans l'année, couraient le risque

1. Arrit du fer juillet 158 visé par JoLsse, Commentaire de l'orlonnance ducummerce, éd. 1s02, p. 13.

2. Arrêt d'avil 1601 accordant restitution it un mineur qui a cautionné une dette etrangère à son commerce. Visé ibid.

3. Lillowanac, Haximes génerales du droit francais, 1605, livre 111, no cxir. Curaroxdas Le Carox, démorahles obsryutions, vn Marchans et un

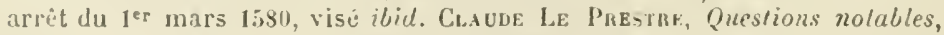
167.), 1). 65.5. Coqun.tr, Questions et réponses sur les articles des coutumes. $\mathrm{n}^{0}$ cul. Il faut remarquer que tous ces iutenrs se réferent á la jurisprudence du temps dont mous nous occupons. 
de se voir opposer une fin de non-recevoir, mais ce moyen n était pas valable entre marchands et ne pouvait être invoqué que par les clients qui avaient acheté pour leur usage'.

Contrairement à une opinion fort répandue, la preuve testimoniale n'était pas admise d'une façon illimitée en nutiere commerciale et l'article :3'́ de l'ordonnance de Moulins de 1.566 qui la rejette au-dessus de 100 livres (370 fr. 4s), recevait, même entre marchands, son application ${ }^{2}$. L'article $\ddot{~}$ de l'édit de création de la juridiction consulaire de novembre $\$ 弓 63$ ne parle, il est vrai, que de témoins, mais il faut l'interpréter en ce sens que leurs dépositions s'ajoutent à un commencement de preure par écrit ${ }^{3}$.

Nous venons de parler de la juridiction consulaire. Nous sommes amené par là à ce qui contribuait, plus que tout le reste, à assurer aux commerçants une situation juridique particulière.

A la différence de tant d'institutions, les juridictions consulaires ne sont enveloppées, ni dans leur origine ni dans leur progrès, d'aucune obscurité. La " conservation des foires de Lyon " fut leur premier modèle, et la conservation des foires de Lyon a été empruntée, sauf les modifications nécessitées par une adaptation nouvelle, aux foires de Champagne. On sait, du reste, que ce n'est pas seulement de la juridiction des foires de Chanpagne que les foires de Lyon ont hérité, que c'est aussi, sous la réserve déjà exprimée, de leur organisme tout entier et de leur rôle commercial. On sait aussi que cette transmission, indiquée

1. Ordonnance de Louis XII de 1512. art. 67 et. 68. Coutume de Paris, tit. vI, art. 1:6 et 12i. Cf. ordonnance du commerce, tit. 1, art. vil et vin.

2. Jugé le 26 février $158 ;$ que l'art. 5 't de l'ordonnance de Moulins qui défend la preuve par témoins au-dessus de 100 livres a lieu même entre marchands. Brilion, vo Marchands. Preuve testimoniale d'une promesse verbale qui excédait 100 livres a été rejetée entre marchands, 1618. Recueil d'arrêts du parlement de Paris pris des mémoires de feu II' Pierre Bardet, $1773, \mathrm{I}, 43$.

3. Jousse, Comment. de l'ordonnance de 16r3, tit. XII, art. xı, p. 248. 
par les circonstances, a été, pour ainsi dire, accomplie tont d'une pièce par la volonté de nos rois qui ont transféré aux secondes les privileges des premieres. Les juridictions consulaires de Toulouse (1:39), de Ronen (1:3:56) et de Parlis (1063) se raltachent l'une a l'autre par une filiation directe et alles se ressemblent encore en ce qu'elles sont tontes sorties du vou de la classe intéressie.

Néc la première, la juridiction consulaire de Lyon n'arait pas reçu dès son berceau toute l'extension qu'obtinrent à leur origine celles qui furent créées ì son image. Elle ne connaissait que des opérations qui araient lieu aux foires et non de toutes les causes commerciales. Mais l'édit de 159', en énumérant les questions de sa compétence, s’ibstient de cette restriction et range sans distinction dans cette compétence " les faits de sociétés, changes, voitures, négoces et marchandises et tout ce qui en dépend ». Les lettres royaux du 2 décembre 1603, après aroir paru la subordonner à la circonstance que les faits se sont passés aux foires, terminent l'énumération de ces faits par les mots : tant en foire que hors foire. Ce texte fut celui qui servit de fondement au conservateur pour établir le caractère permanent et général de sa juridiction ${ }^{3}$. La portée en fut consacrée par un arrêt du parlement de Paris qui prononça " que ledit juge conservateur connaitrait aussi - c'est-à-dire outre les faits de foire - les différends entre marchans pour fait de marchandise, comme les autres juges consuls du royaume, et

1.... Il est aisé de démontrer que jusques en 1602 Ie conservateur des fuires de Lyon] n'a eu que le droit de connoitre du commerce des foires parce qu'il n'avoit èté institué que pour connoitre du seul fait des foires. . . . . Si ce pouroir universel sur toutes les matières du crumuerce, tant en foire, que hors foire, cût été de temps imnémorial de la competenre du conservateur..., auroient-ils été [les Lyonnais] dans le cas de denander a llenri $1 V$ en 1602 de donner au conscrvateur une ampliation de pouvoir pour comnoitre du commerce en gěnéral, tant en foire que hors foire, ¿a l'instar des juges consuls du royaume?... " Réflexions sur l'usage de la rigueur de la contrainte par corps. XVIlles. Aich, de la Seine, BB. 509 . 
que, comme eux, il ne pourrait toutefois connaître des différends pour le fait de marchandise entre autres que marchans, encore quils eussent rolontairement procédé devant lui' '... ".

En assimilant le tribunal des marchands de Lyon aux autres tribunaux du mème genre, l'arrèt du 7 septembre 1610 marquait une fois de plus les limites de la juridietion consulaire. Pour qu'une cause lui fùt déférée, il fallait et qu’elle portât sur une question commerciale et que les parties fussent des commerçants. Il n'était pas superflu de rappeler ces limites, car', encouragés par la fareur des plaideurs, les juges consuls étaient en train d'attirer à eux une foule d'affaires qui ne remplissaient pas les conditions constitutires de leur compétence, telles que prêts d'argent, gages de serviteurs et autres causes purement civiles ${ }^{2}$. Il y arait eı un temps, au contraire, où ils avaient été obligés de défendre leur juridiction contre les usurpations et les entraves de la juridiction ordinaire ${ }^{3}$. Leur popularité, méritée par la simplieité, la célérité et l'économie de leur procédure, qui ne connaissait ni procureurs, ni arocats, ni épices, les avait soutenus contre cette hostilité et leur arait permis de devenir envahissants à leur tour. Dès le mois de décembre 1.566 , leur juridiction avait été introduite dans les principales villes du royaume ${ }^{4}$. Gràce à son intégrité

1. Sur la compétence de la conservation des foires de Lyon roy. Vaesen, La juridiction commerciale à Lyjon sous l'ancien régime, 1879, chap. 1 .

2. Déclaration de Louis XIII du 2 octobre 1610. Arch. nat., Collection Rondonneau, ADxi, 29.

3. Ordonnance de Henri IV. Paris, 22 férrier 1599. Recueil contenunt les edit:, etc. sur l'établissement... de la juridiction des consuls en la ville de Paris et autres. Paris, Dexis ThIerRy, 1705, in-í Déclaration de Charles IX. Bordeaux, 28 avril 1565. RondoxxeAt, ADxi, 29. Le tribunal consulaire, érigé par Ilenri IV à Dieppe en 1589, ne put, par suite de l'opposition du bailliage et de l'amirauté, entrer en fonctions qu'en 1643. Mémoires chronologiques pour servir à l'histoire de Dieppe, 1785, Il, 15 5.

4. Édit de décembre 1566 visé par MARÉchá, Traitédes changes et rechanges, 1625, p. 330. Elle arait été instituée à Troyes et à Bordeaux en 1563 et en 1564 , Mémoire et live de famille de Nicolis Dare, Avant-propos, p. 13. LaMothe, 
et ì ses lumieres, ses jugements étaient rarement infirmés'. Elle eut pourtant ses adversares. P'armi eux on sétonne de reneontrer Lallemas. Il semble, au contraire, que la synpathic du vallant publiciste aurait dì itre acquise à une institution qui relevait la dignité des commerçants en faisant d'eux des juges et assurait aux débals commerciaux une cxpédition économique et prompte. Laflemas ne nous a pas donné de bonnes raisons de son hostilité mais, ì lïnsistance arec laquelle il reproche aux juges consuls leur sérérité contre les commerçants embarrassés, à l'amertume de ses critiques contre ce quïl appelle "l’édil des quatre mois ", e'est-ì-dire contre l'édit de Moulins qui établissait la contrainte par corps contre les lébiteurs demeurés insolrables, quatre mois après la signification de leur condamnation, on est tenté de chercher l'explication de ses sentiments dans des rancunes personnelles, dans les épreuves de son orageuse carrière?

Règles particulieres sur la capacité et la prescription, juridiction et procédure spéciales, e’en était assez pour riparer les commerçants, au point de rue juridique, des autres classes de la société.

Quelques muls sur lancienne bourse it Bordeaur dans Acles de l'académie... re Bordeaux IX (18'7), p. 319 et Aneienne bourse de Bordeaux. Compte rendu des travaux de la commission des monuments historques de la Gironde, IIII $1851-52)$, p. 16.

1. Mémoire anonyme sur les pauvres enfermés adressé à Henri de Gondi, ivèque de Paris, 161:. Areh. curieuses de l'histoire de France, XV. Dans un procis plaide en 1702, le premier en date des tribunaux consulaires, la conservation des foires de Lyon était qualifiée "la juridiction la plus versée dans le négoce qu'il y eùt dans le royaume ". AcGeand, Áréts nolables des diffirents tribunanx du royaume, $1, \mathrm{n}^{\circ} \mathrm{ccc} x$.

2. LAFrmas, Les trésors et ichesses pour methe l'ktul en splendeur el monstrer an vray la vuyne des trumsois pur le traffic el néyoce des estrangers el empescher facilement les pelits procis en toules vacations, voir comme la justice des consuls loit estre supprimée et nutres belles raisons.... Le tout

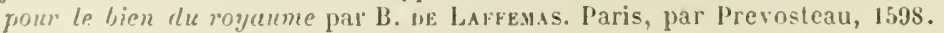
I'incrédulits ou l'ignorunce de ceus, qui ne veulent cognoistre le bien el repos te l'Estal el veair renaistre la rie heureuse des Frangois. I'aris, chez Jamet ct l'ierre Mettayer, 1600. Les discours d'une liberlé yènérale el vie heureuse pour le bien du peuple, I601. 
Ils s'en distinguaient encore plus au point de vue économique. Bien que l'édit de $1: 397$ fùt resté très loin par ses résultats des intentions qui l'avaient licté, il n’en arait pas moins augmenté le nombre des maîtrises et la plupart des commerçants ne s'en trouvaient pas moins, après plus encore qu'arant, classés dans des corporations. Si le vieux système dont elles étaient la base. avait en apparence résisté au mouvement des idées et des mœurs, si mème il s'était, à certains égards, étendu, il avait subi en réalité des modifications qui avaient accentué son esprit oligarchique, simplifié sa complexité, élargi son formalisme. L'évolution qui s'opérait dans le commerce se faisait sentir sur ce système principalement par la différence que la considération publique mettait entre les corporations, par la hiérarchie de plus en plus marquée qui s'établissait dans le sein de chacune, par le groupement des professions analogues, par limporlance croissante de certaines d'entre elles. Cette dernière observation s'applique surtout aux mereiers et aux fripiers. Les premiers étaient fort enviés, et il y avait dans leur situation de quoi justifier amplement un pareil sentiment. Réunissant dans leur's mains six branches de commerce, monopolisant le trafie de la plus grande partie des importations étrangères, s'abstenant de toute opération mécanique, "rendeurs de tout et faiseurs de rien ", ils tenaient en réalité la tête des six corps, dans les rangs desquels l'ancienneté ne leur assignait que la troisième place. Négociants en soieries et étoffes de luxe, en lainages, en mercerie, en orfèvrerie et joyaillerie. en quincaillerie, en épicerie et drogucrie, ils joignaient à l'exploitation de ces articles si divers le commerce en gros de tous les autres ${ }^{1}$.

1. "La mercerie contient en soi six états savoir est : 10 le marchand grossier qui débite en gros toutes sortes de marchandises; 20 le marchand de draps d'or, d'argent, de soie, demie ostade, sarges et toilles; $3^{\circ}$ marchands de toutes menues merceries ; $4^{0}$ marcliand jouaillier vendant orfe- 
Ils derançaient done, pour la concentration des marehandises, les grands magasins et les bazars de notre temps et sippropriaient, comme grossiers, les affaires les plus importantes ef les plus lucratives. Ils devaient d'ailleurs leur existence non ì une fintaisie gourernenentale ou a un caleul fiscal, mais à de v'ais besoins. Le commerce n'arait pu étendre ses opérations et ses risques sans domner naissance ì une classe qui se voù̀t spécialement ì assorlit les marchandises au goùt mobile et capricieux du public, à éveiller et ì diriger elle-même ce goùt, à commaître les cour's des diflérentes places et le crédit des divers clients et sans que celte classe se trouvât amenée et par ses services et par lintérêt des consommateurs à se placer entre eux et les fabricants, à attirer dans ses magasins les marchandises les plus diverses et à s'emparer du commerce de gros et de spéculation oì personne ne l'avait précédée. Mais cette nécessité n'était pás acceptée sans répugnance par des négociants qui se renfermaient dans un commerce spécial et 'pui se voyaient lermer le chemin des grandes affaires par des hommes d'une expérience et l'une portée supérieures. Les merciers ne se contentaient pas d'ailleurs de les enlever aux corporations, ils prétendaient s'arroger un droit d"inspection sur toutes les marchandises à leur entrée dans les villes' et heurtaient le sentiment de la majorité du monde industriel et commercial en se faisant

vrerie, picrres précicuscs, perles et tous antres joyaux; $5^{\circ}$ marchand quincaillicr; $6^{\circ}$ marchand épicier droguiste, sous lesquels sont comprins... tnus les autres états ci-apris déclarés. " Extrait des ordomninces, articles ct reglemens que le lioi veut... estre... Icnus... par son maistre visitenr et grénéral réformateur de marchandises de grosseries, merceries, jouailleries, etc.. 27 août 1607. Roxboxseav $\Lambda$ DI 143. Un mémoire rédigé au commencement du xvme siecle, au nom des maistres et gardes du corps des marcliands merciers de Paris, leur attribue même "le droit de faire le commerce en gros comme en détail de tontes les marchandises imagrinables...." . Arch. de la Seine, BB. 5583. Juridiction consulaire.

1. Ils prélevaicnt aussi un droit sur l'ouverture de charque foire nouvelle. C'ćtait la condition de leur présence is la foire. 
les champions de la liberté des importations, sur lesquelles portaient en grande partic leurs opérations. La malveillance les accusail d'aroir entre eux un argot et d'être affiliés ì des associations de mendiants et de volenrs de gramels chemins, avec lespuels leur vie nomade les aurait mis en contact. Il est possible qu'amenés par leurs fréquents déplacements dans des milieux inconnus, ils s̀y fussent assurés, comme les membres des compagnonnages, des correspondants et quïls eussent adopté des signes de reconnaissance et un langage de convention, mais le manvais renom qu'on leur faisait ne pourait ètre mérité que par les porte-balles c'est-i-dire par le bas-fonds de la corporation. Les reproches qu'on faisait aux fripiers paraissent avoir été mieux justifiés. La diffusion du luxe et surtout d'un luxe apparent et d'emprunt avait donné aux fripiers un rôle analogue à celui des marchandes à la toilette sous la monarchie de Juillet et au commencement du second empire. Ils tenaient un assortiment complet et rarié de tout ce qui se rapporte au vêtement et à l'ameublement et les tailleurs eux-mèmes, quand ils se trouvaient embarrassés pour satislaire à une commande pressée, n'hésitaient pas à reconrir à eux ${ }^{1}$. Ils devaient donc leur succès à de nouvelles habitudes sociales, mais ils le devaient aussi à des motifs moins légitimes. Juifs pour la plupart ${ }^{2}$ et fidèles à la vocation séculaire d'Israë], ils étaient receleurs et prêteurs sur

1. Je ne snis pas si tot sorti de ma couchelte

[C'est un fripier qui parle]

(Iue voiri des marchans qui sonnent ma clochetle

Demandant nn labit de serge de seigneur.

Done ô tailleurs dhabits ! vous nètes qu'artisans.

Et nous, qui les vendons, nous sommes les marehans.

Or jugez maintenant lequel est plus capable

Ou de celui qui vend ou celui qui travaille?

Discours de deux fripiers et de deux tailleurs, 1614. (Var. hist. el litt., v).

2. "... Les fripiers de Paris qui sont á la plus part Juifs... " Noel dU FAlL, Contes d'Eutrapel, XXIV. 
gages, senrichissaient des débordements de la jeunesse, étaient regardés comme ses corrupteurs et rendaient à leurs clients une foule de services inarouables et largement payés. Par ces pratiques clandestines ils pribtaient le flanc it leur's adversaires, irrités par leurs prétentions, alarmés par leur concurrence. Aussi Ies corporations parisiennes allaient-elles jusqu'ì demander qu'on les réduisît à Ieur ancienne zacation, c'est-à-dire à "laver, regralter et trafiqquer vieilles hardes " ou même qu'on Ies expulsât de Paris’.

Ce qui, avec les mercicrs et les fripiers, se faisait place, en dépit des résistances, dans la société, célait une classe commerçante indépendante des spécialités professionnelles, les dominant toutes, centralisant tous les genres de commerce, accaparant les grandes affaires. Ce n'était guère moins quiune révolution économique que cette classe, renant se superposer au système suranné du moyen ìge, était en train d'accomplir et celte révolution était trop impérieusement appelée par l'extension du marché et les préférences du public pour pouroir ètre compromise par les abus qui s'y mêlaient.

Nous avons parlé des six corps de métiers. Tout le monde connaît cette aristocratie commerciale qui, jusqu'au jour où les cent notables bourgeois investis du droit d'élire la juridiction consulaire parisienne furent tirés de son sein, ne se distingua guère du reste des corporations que par son rang daus les cérémonies publiques.

Il y en arait une autre; celle-là se composait des marchands et artisans suivant la cour. La cour était toujours le centre le plus brillant, sinon le plus sirr, des aflaires. P'artout oì elle se transportait, ses fournisseurs brevetés l'accompagnaient et jouissaient, pendant sou

1. Voy. les avis donnés par les maitres et gardes des métiers en 1::99 sur le projet d'édit de Laflemas dans l'édit. originale of les Gronts jours lenus

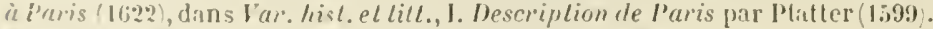
Mém. de la siociélé de l'hist. de l'aris, XillI, p. 19s. 
séjour, du privilège de faire, non seulement avec elle mais mème arec le public, des transactions qui échrippaient à la police et à la juridiction des corporations. Henri IV porta à trois cent ringt le nombre de ces fournisseurs et confirma leur's privilèges '. N'étant ouverts en principe que pour la cour, et le public n'y étant admis que par tolérance, le nombre de leurs magasins privilégiés était limité. Ainsi les douze marchands de rin suivant la cour, ne pouvaient ouvrir plus de deux caves et les vingt-cinq cabaretiers fournisseurs en titre qu'un cabaret, et ees établissements devaient ètre aussi près que possible du Lourre ${ }^{2}$.

Qu'il appartienne à ces groupes d'élite ou à la plèbe commerçante, qu'il soit entré daus une corporation par la voie régulière de l'apprentissage, du compagnonnage et du chef-d'œurre ou quill ait été dispensé de ces épreuves par sa naissance, soll argent ou la faveur royale, quïl ait été " passé maître " ou qu'il soit " maître de lettres ", le commerçant se trouve engagé dans une carrière où l'attendent également les entraves et la protection dun corps non moins jaloux de sa discipline que de son monopole.

La première condition quil lui faudra remplir pour réussir, sera de se rendre compte de ce qui entre chez lui et de ce qui en sort en marchandises et en argent, d'établir et d'aroir toujours sous les yeux son doit et son aroir. Nos ancètres, on le sait, n’y avaient pas manqué, et il n'est aucun de nos lecteurs qui ne connaisse ces livres de raison où l'on trouve des rérélations morales là où l'on n'arait le droit de chercher que des comptes de commerce ou de ménage.

Avant comme après l'ordonnance du commerce de 1673 qui ne prescrivait que le livre journal et sanctionnait cette

1. Arrêts du 15 juillet 1601 et du 31 mars 1605. Bibl. nat. Franç. 18168 , fol. 28. Lettres patentes du 16 septembre 1606 dans Delayare, I, 17?.

2. Arrêts du conseil du 29 octobre 1602. Coll. des Archives nat. Arrêt du 31 unars 160.j sur les cordonniers de la cour. Bibl. nat. Franc. 18168, fol. 28 . 
preseription par la menace de cunvertir la faillite en banqueroute frimduleuse ', les livres de commerce furent aussi nombreux que l'exigeaient les besoins et l'esprit d'ordre de chanue commeregut. Vers le nilien du xrme siòcle, un commerçant rémois, Jean Maillefert , n’en tenait pas moins d’une vingtaine, qui nétaient pas tous, il est rlai, consacrés à ses aflaires commerciales. Dans ee quï appelait le premier lirre secret, il inserivait les sommes dont il était débitenr et dépositaire. Dans un second livere secrel, étaient enregistrés, avee un mélange qui ne choynait far nos aïeux, la description des biens fonciers, leurs revenus, cenx de la succession de sa premiere femme, les naissances, les mariages et les morts de ses enfints, ainsi que les autres érénements domestiques. Le joumal relatait les lettres de change sousirites par lui et les autres opérations de chaque jour. Le grand lirre reproduisail en ahrégé les ventes faites en France et deijà portées en détail au journal. Il y avait un autre grand livre pour les aflaires avec l'étranger"; un livre des ventes et achats; un livre des leltres de change souscrites et tirées aux échéances des foires de Lyon et qu'on nommail le répertoire; un troisieme grand lirre contenant l'indication des capitaux et revenus; un livre d'achats où chiıque marchandise portait un muméro d'ordre; un livre de crédit indiquant le montant des dettes commerciales et les noms des créanciers "; un livre de eaisse où figuraient toutes les recettes et toutes les dépenses; un livre de bordereaux; un livre le copic de lettres où, au lieu de les copier littéralement, à l'exemple de certains de ses confrires, Maillefert se contentait de reprodure la substance des plus inpor-

1. Ordonnance du commerce. III, 1, XI, XI.

2. Voy. ses Mémoires, p. p. Il. Janart. $8^{\circ} 1890$.

3. Miallefert y renonca plus tard parce que les opérations sur les laines, l:1 draperie ot la mercerie, pour lesquelles il lavait commencé, s’ètaient depuis traities au comptant. 
tantes; un livre oì il inscrivait les noms de ses correspondants; un autre où étaient facturées les marchandises quion faisait emballer par arance, quand les affaires laissaient des loisirs, pour mieux assurer leur conservation; un livre des menus frais divisé en frais de ménage et frais commerciaux; un livre d'entrée et de sortie des marchandises.

Ainsi que nous aurons encore l'occasion de le remarquer, Jean Maillefert n'était en rien un commerçant ordinaire et la multiplicité, parfois assez peu justifiée, de ses livres de commerce n'était pas ce qui le distinguait le moins de ses confrères. La plupart restaient loin de cette spécialisation dans les écritures. Mareschal, l'auteur d'un Traité des changes et rechanges publié en 1620 ne compte que six livres de commerce : le journal qui porte aussi les noms de carnet, de brouillard et de mémorial, le grand livee, le livre de raison, le bilan, le livre d'achats et de rentes, le livre de copie de lettres. Dans son Instruction pour dresser livres de raison (1627) Claude Boyer en énumère sept, dont la destination est notablement différente de celle qui est indiquée par Mareschal : le brouillard, le journal, le livre de caisse ou brouillard sur lequel on écrit tout l'argent qui se paye et reçoit, le livre particulier des menues dépenses, le livre de copie de lettres, le livre de copie de comptes, le carnet des payements. A l'éporque de l'ordonnance du commerce, à côté du livre journal, qui est le plus important et le plus commun, on troure en usage le carnet ou brouillard, le grand livre, le livre de raison, le bilan, le livre des achats et des rentes ${ }^{1}$. C'est à peu près ceux dont Mareschal donne la liste et c'était les plus en usage.

On conserve aux archires de l'Hûtel-Dieu de Toulouse les papiers ${ }^{2}$ d'un grand négociant du $\mathrm{xrr}^{\ominus}$ siècle, nommé

1. Borisien, Commentaire sur l'ordonnance, III, II.

2. L'existence de ces papier's nous a été révélée par un intéressant travail de M. Pradel inséré dans les Mémoires de l'Académie de Toulouse, 
Simon Lecomte. Parmi eux se trouve son livre journal brouillard. C"est un ms. oblong en papier dont les feuillets sont cotés et paraphés et qui va de 1,377 a 13866 . On lit en tite : Jomulier pour la recelte des deniers qui se remettront tant de. Poitou, liourdenur. que autres lieux. Ce registre, où sont inscrits les paicments ì faire et les recouvrements, renvoie à un livre de erédit et à un grand livre.

A 12 daont [1:7\%] es mans de Jehan Lacombe $24: 4$ livres 1 sol recu de .I. nostre maicur pour son compte capital à présent au live de crédit. . . . . . . . . 24 4. ( T 047 fr. 03).

Et à 2 indit (septembre] 330 lirres recu du $\mathrm{S}^{\mathrm{r}}$ Alary, marchand l'Ally, crediteurau grand live a son compte a 300 liveses ( 1731 fr. 88).

Ceux qui soccupent de lhistoire du commerce et qui commissent les documents que le moyen igge nous a laissés sur celle histoire, notamment le Live de comptes des frères Bonis ', ne seront pas surpris de trouver lé

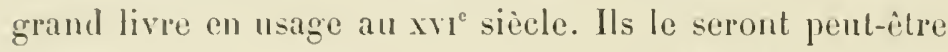
davantage de constater que la comptabilité en partic double était comnue et pratiquée en France dans la seconde partie de cette période. Ce système, en effet, n'a èté imaginé et dirulgué en Italie qu'ì la fin lu $x^{-e}$ siècle par le moine franciscain Luca Paccioli, et l'Italie a devancé de si loin la France dans la science commerciale qu'on pourait se demander si une méthode nouvelle enfouie dans un traité d'arithmélique publié à Venise en 1494 avait eu le temps de se répandre au siècle suivant dans le commerce français. Il ny a, il est rrai, dans le journal de Simon Lecomte qu'un mot qui prouve l'usage qu’il faisait de la comptabilité en parlie double, mais, si l'on se rappelle que cette

année 158\%, sous le titre: Un marchand de l'aris an .IVTo siècle (1591-1588). II. Pradet s'est plitcé, en les 'tudiant, an point de vue historique et bioglaphique, tandis que nous $y$ avons exclusivement cherclié les traces des usiges et des procédés commer ianx de l'ipoque.

I. Publié par M. Eu. Fontestlé en Ió5. 
comptabilité consiste essentiellement à listinguer et à personnifier, pour ainsi dire, les principaux chapitres de recettes et de dépenses, caisse, marchandises, effets à recouvrer, effets à payer, ete., à ouvrir à chacun un compte en inscrivant à son crédit tout ce qu ill donne et à son débit tout ce qu'il reçoit et à décomposer’ ainsi chaque opération en deux, peut-être estimera-t-on que nous n'avons pas attribué au mot caisse dans les articles suivants une portée exagérée :

$1383 \%$.

Caisse doit à 19 d'octobre aux sieurs Granier et Gestel 100 écus sol. 100 écus (9ł3 fr. 82).

$S^{r s}$ Pierre Granier et Questel en compagnie, marchans de Toulouse doivent avoir à 19 d'octobre la somme de 106 écus sol sec pour 100 écus de comptant qu'ils m’ont baillé à dépôt jusques aux paiemens de Roys ${ }^{1}$ et 6 écus 30 fr. 63) pour le charge et leur dois baillier letıre de change au temps des dépêches. A part ${ }^{2}$ par promesse [que] leur ai faite. Débiteur caisse pour cent écus. 106 écus (1000 fr. 4ว).

Sr Jean Delpech, marchant de Toulouse doit avoir à ă de novembre la somme de 300 écus sol sec (2831 fr. 4ă) pour autant qu'il m'a baillié à dépôt pour le payement de Roys à ă pour cent pour le change. Lui dois baillier lettre de changre au temps de payer à Paris par promesse. Débiteur caisse. . . . . . . . 300 écus.

Sr Carlier, marchant de Paris doit avoir à 100 de novembre la somme de כ̊s écus (ว̈ $349 \mathrm{fr}$. 6ł́) avec le change à raison de 5 pour cent que le $\mathrm{S}^{\mathrm{r}}$ Iehan Sarazin m'a baillé à dépòt jusques aud. paiement de Royes. Lui ai fait promesse. Débileur caisse de 360 écus. . . . . . . . . . . . . . 58s écus.

Sr Jehan Delpech, marchans de Tuulouse dnit avoir la somme de 470 écus ( $+43 \ddot{3} \mathrm{fr} .91)$ que m’a baillié de contant à dépòt pour les paiemens de lioyes à ä pour cent pour le change, qui fait en tout 300 écus (4719 fr. 08), pour laquelle somme lui ai fait promesse lui baillier lettre de change pour les paiemens de Rojes et lui dois délirer lesd. leltres dans le 20 de février prochain. Débiteur caisse de 40 écus. . . . . . . . . . . 500 écus.

1. A l'échéance de la foire des Rois á Lyon.

2. Apparait. 
M. Pugier, hourgeois do Toulouse doit avoir i 17 de norembre la

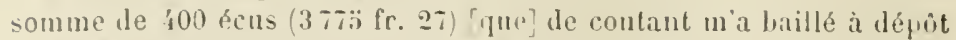
jusques anx paiemens de linges it i pour cent pour le change, qui est en tout 4zo éens (396i fr. 03). Pour la d. somme lui ai fait promesse de lui bailler lettre de change dans le 20 de férier paialite a Lyon. léhitenr raisse. . . . . . . . . . . 420 écus.

A reç le dépùt jusques aux paiemens le Palsques.

Caisse doit donner a 20 de norembre $72 \mathrm{i}$ écus $11^{\mathrm{s}}$ pour reste de son compleprécident. . . . . . 72' écus 11 s. 683 fr. 97).

Les "parties doubles " était le côté ardu de la science commerciale. Le commerçant émérite, qui nous ipprenait tout it l'hemre le nom et le nombre des livres de commerce, Jran Maillefert, déclare quelles n’exigent guire moins dipplication que toutes les parties réunies de la philosophie, qüll arait évidemment moins approfondie, et que les caissiers qui y élaient rompus gagnaient autant que les commis des finances. Cette science avait comme anjourdhui ses maitres ${ }^{1}$.

Quind on voit que, de notre temps, l'usage des livres de commerce est loin d'ètre général, on est porté à croire que nos ancètres saffranchissaient plus encore d'une comptabilité régulière. Il liut pourtant se metlee en garde contre une pareille conclusion. La vie des commerçants diutrefois, moins attiréc an dehor's par la mulliplieité des plaisir's et la facilité des diplacements, plus sédentaire et plus intime que celle de leurs suceesseurs, leur donnait pour la temue de leurs écritures plus de temps et peut-être plus de goint. C'étaient des gens calculatenrs, méthodiques, appliqués, pénétrés du sérienx et nuême de la dignité de leur profession. L'élément moral des livres de raison loit son origine an hesoin d'ennoblir par le sentiment du devoir les occupations et 
les existenees les plus modestes. Les lirres domestiques et de commerce qui viendront s'ajouter à ceux que nous connaissons déjà, confirmeront, croyons-nous, ce que ces derniers nous autorisent à dire de leurs habitudes d'ordre et de réflexion. Nous n'avons signalé que le livre journal de Simon Lecomte, nous aurions pu en signaler d'autres, par exemple un livre de recette des pastels récoltés dans le Lantarais et livrés à Ramon Guarric, marchand de cette plante tinctoriale établi à Saint-Pierre-des-Lages'. livre qui commenee au 11 juin $1520^{2}$, les livres de la maison de soieries dirigée par la famille toulousaine de Laran, qui ront de 1549 i $15: 59^{3}$, un livre de rente de pastels commençant le 17 novembre $1566^{\circ}$.

Ontre l'arantage d'éclairer les eommerçants sur leurs affaires, les livres de commerce pouvaient avoir celui de fournir en leur faveur, sinon des preures, au moins des présomptions. En prineipe r'était contre celui qui les tenait qu'ils faisaient foi et sa partie pourait toujours les invoquer contre lui ${ }^{5}$. Seulement süls confirmaient ses allégations, le serment pouvait être déféré à son adversaire ${ }^{6}$. D'un autre côté. la dirulgation des affaires dont le seeret était déposé dans les lirres de commeree, pourait nuire au crédit du commerçant. faciliter, à ses dépens, une concurrence déloyale, préjudicier, d'une façon quelconque, à ses intérêts. Avant mème lordonnance

1. Ilaute-Garonne, ar. Villefranche-de-Lauraguais, canton de Lanta.

2. Arch. de l'Hôtel-Dieu de Toulouse. C'est un registre oblong, relié en basane verte, dont les plats ả recouvrement sont serrés par un cordon.

3. Arch. de la Haute-Garonne. Fonds du parlement au Palais de Justice.

4. Arch. de l'llôtel-Dieu de Toulouse.

5. "Les papiers journaux ne servent que contre ceux qui les ont écrits ou contre leurs hériliers, si ce n'est en petile somme. "Arrêt de juillet 15ii, visé par Brillon, vo Livres de commerce. Cf. Boucuel, vo Livres des marchands. "... nous avons présenté une seconde requeste... a ce que ledit Thomas fuit tenu de faire apparoir de son livre de raison pour saroir si ladite somme lui est due. " Lemaire à s. Lecomte. Toulouse, 16 avril 1578. Papiers Lecomte. Arch. de l'llôtel-Dieu de Toulouse.

6. Toubeac, Institutes du droit consuluire, p. 468. 
de 1673 , le ligislateur sétait préoceupé d'écarter ce danger sans priver la justice ni les intéressés des lumières que la recherche de la vérité pouvait tirer de documents aussi autorisés, mais, sil en avait tronvé le moven, il n'avait pas encore réussi, à la lin du règne de Henri IV, à le faire exclusivement adopter. En septembre 1:393, ce prince avait renourelé la prescription de ne consulter les livres de commerce que par roie de représenlation et $n o n$ de communication, c'est-ì-dire en faisant faire, sans déplacement et au domicile du commerçant, par les magistrats, les extraits orlonnés par la justice. Mais l'édit de juin 162:; indique que la communication n'arait pas encore disparu des hal,itudes de la procédure ${ }^{1}$.

Le commerçant se réservait généralement le soin de tenir ses écritures². Quand il était arrivé à l'aisance, il laissait au contraire à des commis, à des garegons, ì des apprentis celui d'acheter, de rendre, d'auner, de peser et, i plus forte raison, de débiller, d'étaler, de serrer les marchandises. Ces conrtands de boutique, comme on appelait dédaigneusement ces modestes auxiliaires, s'étaient relàchés, sous l’intluence des guerres eiviles, de leur's habitudes de travail, de discipline et de déférence. Il leur restait de ces temps agités une turbulence qui les mêlait, dans les attroupements et les désordres de la prue, aux laquais et aux cleres de procuremrs ${ }^{3}$. Toutelois les rapports

I. Ordonnance du commerce, $11 \mathrm{I}, \mathrm{IX}, \mathrm{X}$.

$\therefore$ Némoires de Jean Maillefert. Nous insistons sur le mot généralement car nous avons tiré de ces mémes mémoires la preuve que les livres étaient tenus aussi par des caissiers. Voy. plus haut, On lit aussi dans mne lettre de J. Charpentier à Simon Lecomte. Toulouse, 8 juin 1582. (Papier's Lecomte. Arch. de l'llòtel-Dieu de Toulouse): "... n'estant point déclaré qui a écrit sur le livre de caisse ni journal..."

3. Vémoires de Cheverny. Coll. Michaud, X, ij!. "... apprentis et gens sans moyen qui se sont mis durant les troubles en plusieurs endroits oi l'on ne sauroit tenir ordre ne visitation... " I.AFrmas, Remonstrunces au peuple suivant les édits et orlonnances des Rois ì cause du luxe et superthité des soyjes el clinquants en leurs habils, li;01. Voy. anssi te passage tiré du Dialogue récréalif du marchand et du soldat $|1 ; i 6\rangle$, et cité plus haut. 
des patrons avec leurs inférieurs commençaient ì se ressentir de la réaction qui s'opérait en tout rers l'ordre et l'autorité. Les apprentis ne parlaient jamais à leur maitre que le chapeau à la main et, dans beaucoup de villes, à Toulouse, ì Bordeaux, par exemple, ils mangeaient debout it leur table ${ }^{1}$. Le patron veillait à l'accomplissement de leurs devoirs religieux et se rendait arec eux le dimanche à la messe paroissiale ${ }^{2}$. Lapprentissage et le stage qui le suivait duraient parfois douze, quinze et vingt ans ${ }^{3}$. Une éducation professionnelle aussi prolongée, s'accomplissant souvent dans la même maison, établissait entre son chef et les subalternes une intimité qui rendait leur collaboration plus féconde. Beaucoup de ces apprentis et de ces commis étaient des fils de famille; plus d'un entrait dans celle du patron et devenait son associé. Mais les premières années de l'apprentissage étaient ingrates et à peu près stériles; on mettait les apprentis à tout, on leur demandait des services qui ne les préparaient en rien à leur future profession. La mère de l'un d'eux écrit le 20 aoùt 1.579 : “... Vlon fils... est en prompt danger de perdre son temps chez le sire Gaban et Landria et non seulement en danger de ne rien apprendre mais en plus grand danger d'oublier ce qu'il savoit... de escrire et chiffrer... car ils l'emploient comme un journalier à leurs négoces de leur maison et héritage"." Sans nous dissimuler combien clles sont insuffisantes pour farre apprécier dans son ensemble la situation morale de l'apprenti, eitons encore deux lettres dont l'une fait entrevoir l'affectueuse sévérité de la famille, l'autre la rudesse du patron. Voici ce qu'écrit, le 11 mars 1:382,

1. Savary, Le parfail négocianl.

2. Ibid., p. 39 .

3. Ibid., p. 125.

‡. Arch. de l'llôtel-Dieu de Toulouse. Papier's Leconte. 
Catherine Rouillé à son fils Jean Charpentier qui est en apprentissage chez un certain Macan. à Toulouse:

Jelıan Charpentier, je recus rotre lettre par laquelle me mandez que deviez aller à lyon avec .1. Barde. J'en ai parlé à vostre père lequel ma dil... que ne saviez que cotte l'argent ì gagner. Touttefois lui ai prié vous laisser aller avec le congé et avis de M. vostre naistre et à lit compasnie de . I. Barde auquel, si y allez, vous gouvernerez arec honneur et rérérence à la compagnie que serez et aver moins de dépense que pourrez. Je ai été avertie que rous lantez avec la Bistade qui est un garcon déhauché qui ne bouge des jeux de paume. Ce nest pas pour parrenir et rous deffens de lanter telles personnes... Je vois par li lettre de $\boldsymbol{M}$. Barde... qui vous a mis en charge à recevoir quelque chose à la boulique. Je rous prie vous gouverner, el montrer le lieu d'où vous estes sorli ${ }^{1}$...

\section{C'est maintenant un patron qui parle:}

II. Lecomte, j’ai recu la votre du 23 de février dernier passé par mains de Jacques Dufonr rotre neveu... J'ai vu le contenu en la votre par laquelle me recommandez led. Dufour. Je vous prie croire que, pour l'amour de rous, je n'en ferai non plus que s'il étoit mon propre enfant et me peineroi de lout mon pouroir de lapprentre quelque chose qui soit a son profit et honneur pour l'avenir, rous assurant que à l'entour de moi ne demeurera oisif mais l'emploierai toujours en quelque clıose el mème is écrire et conıter, dont il a hon besoin..., car autrenent en peu de jours il auroit oublié tout ce peu qu'il en sait et j'espère qu'il ne perdra son temps, estimant qu'il sera de bon [le] commander, à ce que je puis connoitre, car, de ma part, je suis fort rude à mes serviteurs sans leur montrer caresse aucune, comme à la rérité il a besoin d'ètre tenu de court et avec moi la plus grande occupation qu'il aura, c'est de demeurer au comploir a écrire et autres offices qui sont requis par la ville ou aux Chartreux... Au demeurant je rous dirai aux condilions que je puis tenir led. Dufonr : c’est qu'il faut qu'il me serve quatre années en me payant la pension des deux années du prix desifuelles je me rapporte à vons et ce que aviserez, a la charge qu'il soit tenu vètu et chinussé et mène de chemises, car sur lout je désire que l'on se tienne nettement. 11 est mal rètu soit en manteau et autres habits qu'est besoin promptement lui en faire faire ${ }^{2} \ldots$

1. Arch. de l'llistel-Dieu de Toulouse. l'apiers Lecunte.

2. Sabatery a s. Lecomte. Bordeaux, 26 arrit 1588. Arch. de l'tlótel-Dieu 
Indépendamment de ces auxiliaires qui babitaient chez lui et partageaient sa vie, le commerçant en avait d'autres qui lui domnaient leurs concours de loin et arec une certaine indépendance; nous roulons parler des facteurs, des commissionnaires et des courtiers.

Le terme de facteur était, dans un sens large, synonyme de commis, mais, dans son acception rigoureuse, il désignait les agents qui faisaient des affaires pour le compte d'un commerçant dont ils étaient séparés par la distance. Nagissant qu'au nom de leur commettant, ils n'engageaient que celui-ci; ils n'étaient donc pas responsables de son insolvabilité et ne pouvaient être poursuivis personnellement que sils étaient désavoués par lui, auquel cas ils araient usurpé un ròle qui ne leur appartenait pas et naraient eu d'un facteur que l'apparence. Le commerçant pourait ètre assigné au domicile de son facteur. Il faut considérer comme une anomalie l'arrêt du parlement de Bordeaux qui déclarait le facteur incapable de donner valable quittance d'une somme due à son commetlant, ì moins l'y ètre autorisé par une procuration spéciale ou par une lettre au débiteur ${ }^{1}$, car la qualité

de Toulouse. Voy. trois contrats dapprentissage du ler juillet 15.5 , du 26 mai $155 i$ et du 19 avril 1562, p. p. Babixet de Rexcontine Jans Recueil de documents pour servir à l'histoire du commerce et de l'industrie en Angoumois. butlelin... de la Charente, 1850. p. 59.

1. Consultation de Charoxdas Lecanox. OEuvres, in-fol. I, rép. xxx. Buenus, Decisions, 114. Botches, vo Facteur. On lira avec interêt la lettre -uirante écrite par un commerçant à son facteur le 17 juillet 1585.

Au seigneur simon Conle de présent au logis des Ballances à Toulonse. Orig. scellé.)

De Paris ce 1 juillet 158.3.

"Simon Conte, je ne puis que je ne me plaigne bien et grandement et à fort juste occasion du tort que me tenez pour ne point vider vos comptes avec moi. . . . . . . . Vous savez le bien que je rous ai commis en vos mains il $y$ a fort longtemps. Vous m'en arez rendu compte pour ruelques années. Vous sare\% par les comptes que m'avez rendus tantòt pour une ou deux ou trois annécs les passedroits que je vous ai laits. Jen ai les comptes pardevers moi pour les vous montrer 
de fucterr résultait suffisamment d'arctes répétés et narait fas besoin d'être établie par une procuration.

Tindis que les facteur's n'agissaient que dans l'intérêt d'un commerçunt, les commissionnaires et les courtiers acceptaient les mandats de plusieurs. Par contre, ces mandats étaient limités à une opération déterminée ${ }^{1}$. Le courtier n'était quiun entremelteur qui rapprochait les parties et séclipsait pour les laisser conclure. Un édit de juin $1: 372$ avait érigé en titre d'office les agents de change et de hanque et les courtiers en marchandise qui itaient en exercice?. La plupart des courtiers étrient d'anciens maîtres des corporations qui avaient quitté les affaires avec plus de considération que do.

yuand vous voudrez. Je n'ai élé si rigoureux comme je sais que aucuns ont eté et comme je sais que pour le jour d'hui sont encore plusieurs maitres... de le sais... combien me coute l'achat des pastels que ave\% achetés en plus grand nombre... ifue vous ne deviez sans mon mandement ni aveu... Je n'ai jamais gagné 3 liv. $t$. par balle sur ancuns de vos achats ct je sais d'assurance... que, si jamais vous n'eussiez fail achat pour moi de pastel, qu'il m’en fut mieux il présent de plus de 10000 écus sol... lous savez combien me coute le procis que m'avez intentẻ et qu'avez perdı contre Jehan Du Casse (? par arrît de lis cour du parlement de Bordeaux. de retourne is vous dire... que les atlaires quavez manićes pour moi depuis l'an 15:2 me coutent plus de 10000 écus, en y comprenant les intéríts de mon argent couché en pastel qui a demenré plus de six ans sans aucun profit... si jamais je ne me fusse milé de pastels ains seulement de draperie qui est mon etat naturel, il me fut mieux pour moi... le plus de 10000 écus. Si les dernières six années qu'avez manié unes atraires dans Toulouse eussent été semblables anx cinq dernières années que Antrine Sagnier me les a maniées seulement á recevoir mes dettes et jayer. ules lettres de change, je sais combien il me seroit de micux.... Vous ne me rendez point compte des comptes, cedules et papiers... depuis rotre lernier departement de Paris, lequel compte est celui que vous demande 'que j"attends il y a six ou sept ans passés.

Signé: Jeax Roullè.

(Alch. de l'Hîtel-Dieu de Toulouse, Papicrs Laconti:).

1. Vụ̣, dans Fuévile, Commerce marilime de Rouen, II. n" 1:!, les chjections présentëes par l'échevinage de cette ville, le 24 novembre 1582, contre l'établissennent des courtiers.

2. Arch. nat. Coll. Rondonneau, Ald68. Leltres de provision le eourtiel nul IIavre délirrées jar IIenri II, 8 septembre 1583. Bonely, Hisloire du llurre. 1. Append., 3i. 
fortune et, en un certain sens, ils en dépendaient encore'. Quelquelois mème ils étaient nommés par elles". Les commissionnaires, quand ils s'abstenaient de garantir le succès del'affaire dont ils s'occupaient, ne se distinguaient guère des courtiers. Ils ne prenaient alor's qu'une commission simple qui était généralement de 2 pou 100. Dans le cas contraire, ils touchaient une double commission et étaient alors, suivant une expression restéc en usage, temus decroire ${ }^{3}$.

Gràce à ces représentants qui allaient chercher et conclure au loin les affaires, la vie du commerçant s'écoulait en grande partie dans sa boutique et son quartier.

Ces boutiques s'ouvraient sur la rue sous un are surbaissé; assez souvent la lumière y pénétrait par des devantures vitrées soutenues sur de légers chìssis. On y accédait soit directement de la voie publique, soit par une alléc qui conduisait aussi aux étages. On y ménageait généralement, au moyen d'une cloison à mi-hauteur, appelée, dans certains pays, mejan, une arrière-boutique, où vivait la famille, où s'empilaient les mar'chandises qui n'étaient pas couramment demandées. Qu'on ajoute une cuisine où l'on se tenait l'hiver, une cour intériemre où, dans les villes du Midi, on cherchait l'été la fraîcheur et quelques chambres au premier parfois envalies par les marchandises " et l'on aura une idée sommaire mais assez

1. Savany, Diction. du commerce, vo Courtier.

2. Arrêt maintenant ce privilège aux maitres gardes de la draperie de Paris, 9 juillet 1605 . Arch. nat., collection des arrèts du conseil.

3. La provisione é quel premio che si da al mercante che la le faccende tue per la sua fatica, e quando, oltro alla fatica, tu gli aggiugni anco il risico dello starti del credere, la provisione si dả doppia, ció̀ quattro per mille de cambi e quattro per cento delle mercanzie, ma gli amici si contentono di tre. Divavzati, Notizia de' cambi publiée avant 1591.

4. Puech, Nimes di la fin du XVle siècle, 1884, 8, p. 379. Babeau, Les bourgeois d'autrefois, p. 27. Quarré lierbourdox, Aspect de quelques maisons de Lille au commencement du XVII siòcle dans Ami des monuments, 1830, IV. 
exacte du milien oì se déroulait l'existence de la bourgreoisie commerçante.

Certains quartiers étaient, préférablement à d'autres, recherchés par certinins commerces. Il y avait lì une vieille tradition dont le présent oflre encore des restiges et qui est si conme quil ent ì peine nécessinire d'en donner des exemples.

La rue aux Fevres et le P'etil-Pont étaient le quartier exclusivement adopté par les marehands de drajśs d'or. d'argent et de soie '. Les merciers étaient groupés daus lenclos du Palais, anx Ilalles, au cimetière Saint-Jean et aux environs du Grand et du Petit-Chattelet ? Le heau monde renait dans la galerie du Palais fenilleter chez les libraires les livres noureaux, marchander les objets de parure chez les mereiers et les lingères, qui achalandaient leurs boutiques en servant les intrigues galantes de leur clientèle ${ }^{3}$.

Les maisons de conmerce ne se déplaçaient que très rarement. Elles s'iniposaient à l'attention des passants par des enseignes royantes et bizarres qui exprimaient gauchement et crùment, par l'image et par la légende, les instincts persistants et les impressions profondes de l'ame populaire: dévotion naïre, traditions historiques, loyalisme monarchique, émotions produites par les événements contemporains, gaieté gouailleuse et amic de l'esprit d’à peu

Babeac, Un marchand de province sous Henri IV dans Bulletin de la Sociéle i'economie sociate, VIII. Nalherbe à Peiresc, 5 janvier 1613 dans Wruves de Valherbe, édit. Lalanne. Funetiène, Roman bourgeois, 6'. Voy. un dénumbrement des boutiques occupées à Paris par les diverses professions dans la lielation de fr. d'lerni (1596). Bulletin de lu sociélé de l'histoire de

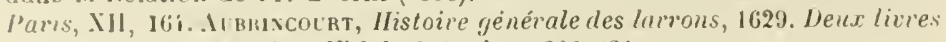
le raison, p. p. Santi et Vílal. Introd. p. 220-221.

1. Sivakr, le parfail négocianl, I, 17 .

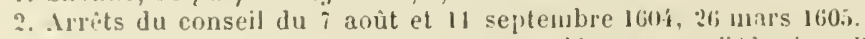

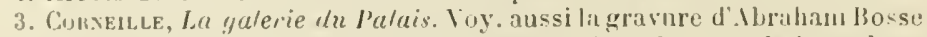
représentint la galerie du laalais et les vers qui en forment la legende et qui ont cte reproduits dans l'Jlistoire du commerce de PIGenXEN, II, sppend., III. 
près '. La loi en assurait la propriété et en défendait, dans le mème quartier, la similitude ${ }^{2}$.

Les commerçants du commencement du xvi siècle avaient garlé du spectacle des fortunes écroulées et des fortunes rapidement édifices dont les agitations de leur temps les avaient rendues témoins, un vif allrait pour la spéculation. C'est eet entrainement qui rendait suspects les marchés à terme, les ventes à crédit. Les grossiers espaçaient en quatre ou cinq échéances le payement de leurs livraisons aux détaillants ${ }^{2}$; ceux-ci, à leur tour, revendaient à crédit, même aux moins fortunés de leurs clients, aux laboureurs et aux vignerons ‘. Au fond, il n'y arait là que des marchés usuraires. Déjà l'ordonnance d'Orléans (1:360) avait prononcé contre les marchands coupables d'usure lia peine de la confiseation et interdit à d'autres qu'aux marchands le marché à terme ${ }^{3}$. Mais les mesures légales étaient restées impuissantes. L'existence d'une banque d'État ou, tout au moins, dun établissement de crédit fonctionnant au grand jour sous la garantie ou le contrôle de celui-ci, en faisant une concurrence victorieuse aux transactions clandestines et en jouant le ròle de régulateur du crédit, aurait été plus efficace. Cette vérité n échappa pas à nos ancètres et suscita dans ce sens plus d'une tentative. En 1.366 le comte de Retz proposa au bureau de la ville de Paris la création d'une banque au capital d'un million de livres $(3704793 \mathrm{fr}$. 37) qui serait pris sur les quatre mil. lions (1+819173 $\mathrm{fr}$. 49) provenant d'une loterie dont les

1. Ed. Focrsiek, Histoire des enseignes.

2. Brillox. Puech, Nimes à la fin du XVle siècle, 153-154. IIalbranche, Causerie à propos de quelques enseignes. Moxanzon, Enseignes et devises des magasins d'Angers dans. Yém. de la société d'agriculure. sciences et arts it Anger's, XL (18sí), p. lit.

3. Savarr, Parfait négociant, I, 16 ?.

4. Montcuréties, Truité de l'économie politique, éd. Funck Brentano, p. 260. LafFFemas, Remonstrance en forme dedit.. art. xir. Heux lives de raison, p. p. Santy et Vidal, P. 199.

5. Prcot 1I, 330-331. 
lots (biens-fonds, meubles, ete.), déjà réunis par lauteur de l'aris, seraient remis à la municipalité. Cette banque frêterait au denier dix sur cautions et sur gages. Les fondateurs céderaient à la ville le huitième du profit de la loterie et de la banque. Grìce à celle-ci, les emprunteurs niaraient plus à subir les exigenees des usuriers et les lrais ruineux des actes nolariés; le commerce trouverait largent nécessilire à ses royages an loin et à ses approvisionnements. Malgré ées séduisantes perspectives, l'échevinage parisien refusa de mettre son puissant crédil au service de cette entreprise ". Prìs d'un demi-siècle après, le 20 dícombre 1608 , le conseil d'ital approurait les staluts qui lui araient été soumis par le sieur de Fontenu, arocal an parlement pour la création d'une bunque de Franere. Linstitution quil baptisait de ce nom, stait une banque de dripôt et de prèt, non d'escompte et démission. Comme celle dont le conte de Retz arait conceu l'idée, elle était destinée à prôter sur cautions et sur gages. Lintérèt altribué aux actions composant le capital était légìrement supériem à l'intérêt légal el au cours du change des foires de Lyon. Son surintendant et ses contrôleurs étaient investis du poliroir de décerner contre ses débiteurs, sans l'intervention de la justice, des contraintes exécutoires. Les frais généraux étaient couverts par le prélèrement d'un droit proportionnel sur le mourement des fonds. Le capital de l'établissement de Paris était fixé à $1: 300000$ livres (4384399 fr. 20) et, dans cenx des provinces, suivant l'importance des villes. Les statuts ne devaient être enregistrés que lor'sque ce capilal aurait été souscrit. On peut affirmer quil ne le fu! pas, car la banque du sieur de Fontenu n’a laissé dautre trace dins l'histoire que

1. Regislies du bureau de la ville, P. P. Tueter, I' (année lig66). 
le projet dont on vient de lire les clauses essentielles '.

A part l'organisation défectueuse du crédit, le commerce jouissail, au commencement du $\mathrm{xvul}^{\mathrm{e}}$ siècle, des organes nécessaires à son existence et ì son essor. Lettre de change, sociétés commerciales, bourses, foires et marchés, procédure des faillites, tribunaux consulaires, tout ce qui facilite aujourd'hui les opérations commerciales, se retrouve, à un degré de développement inférieur, au temps de Henri $1 \mathrm{~V}$.

La lettre de change est toujours en substance ce quielle était en ce temps-là : un acte opérant un transport d'argent ou, comme on dit, une remise d'une place sur une autre. Alor's, comme aujourd'hui, le payement de la lettre de change dans un autre lieu que celui où elle a été tirée, était une condition essentielle. Pour ressembler tout à fait à celle de notre temps ou même à celle dont l'ordonnance du commerce déterminera les conditions légales, il lui manque la clause à ordre ${ }^{2}$, la faculté d'endossement qui en est la conséquence el la mention de la valeur reçue, espèces, marchandises ou billet. Faute de la clause à ordre, elle n'avait pas encore acquis cette facilité de transmission et de circulation qui l'assimile presque au billet de banque. Elle était payable à vue ${ }^{3}$, à jour préfix ${ }^{4}$, à usance ou à double usance et enfin à l'une des quatre foires ou, ainsi qu'on s'exprimail, à l'un des quatre payements

1. Nous en avons publié les statuts dans le Bulletin de la société de l'histoire de Puris, 1896.

2. "Ces mots : ou à son ordre ne sont pas de l'essence d'une lettre de change... avant $16: 0$ les cambistes ne les mettaient jamais dans leurs lettres." S.Miнy, Pareres, no 8 ?.

3. " ... ai écrit an sieur Anth. Sagnier de luy fournir 450 écus sol. (4 $247 \mathrm{fr} .18$ ) pour acheter lesdites marchandises et lui promets les lui rembourser à lettre vue. " Boyer à Lecomte. Bordeaux 17 septembre 1583. Papiers Lecornte.

1. "Il ne faut pas penser de payer lettres de change qui ont jour prefix aux cedules. " Michel Dusosoy à Simon Lecomte. Bordeaux 5 janrier 1575. Ibid. 
de Lxon. Liusince fixilt l'échéance ì un mois, la double usance à denx mois '. Laval chat déjit en usage el, comme aujourd'hui, le tiré recevait une lellee d'avis ${ }^{2}$. Au reste, la lettre de change nétail pas soumise a un formulaire arrite. Elle pouvitit, conme la suivante, ètre compue dans lis forme dime lettre ordinaire:

"Nonsieur. Ce petit mot sera seulement pour rous prier de payer deux juurs rue à II. de La Bornerie la somme de dix escus sol, pour semblal,le somme qu ai perne de conlant du sicur Monchatte Cerretany, de laquelle somme de dix escus ne lindlai mettre en compte, espérant dans trois jours vous érrire et fere rejonse d'me lettre que je reçus du jour dhier renant de volre part... Toulouse ce 23 janvier 1:38.2. Votre bon ami et serviteur : Lrcostr. " . Iu dos, le porteur a mis son reçu : "l'ai reçu les dix escus contenus en l'autre part par les mains dudit sieur Target ${ }^{3}$.

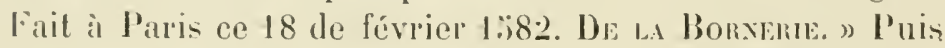
la lellre de change est revenue, lor's d'un règlement de compte, anx mains du tirenr qui l'a classeie dans ses papiers irec la rubrique : " lour(?) lettre de change du sieur -imon Lecomte en Toulouse le 2:3 janvier 1:82 pour 10 escus sol (9' f' $1^{\prime}$. 38) paiés à M. de La Bornerie le 10 isic) fevrier $1382 \div$. "

Voici une autre rédaction :

" Jisus Maria. Ln Paris ce seizième mai J:j79. Mons. Le-

1. Lat durée ligale du mois fut fixée a trente jours par l'ordonnance du rommerce. Sivaky, l'arfait négociant, I.

2. "J'ai recu la votre d'avis par laquelle me mandez accepter une lettre de change que tirez is payer à 11 . Pancy (?) de lit somme de 300 écus $2833 \mathrm{fr}$. 19 ) sur la parlie de 2000 livres $(6297 \mathrm{fr}$. 75) que je dois í $\mathbf{1 1}$. Roullier de l"an septante sept... " Carricre il Lecomte, Toulouse 3 novembre 1578. "... je vous supplie deliver à .1 . David, présent porteur les deux lettres de change de l(ion) livres (5038 fr. 20 ) avec ta lettre d'avis... " Jean Magnard it Corneille, 18 janvier 1.58. Papiers Leconte. Davanzati donne la formule de la lettre d'aris: "l lo ti rimetto per linclusa di Ber. Davanzati un mareo da salviati, presentala e riśpuotilu e torna a rimetterlo a me."

3. Valcutiu Target ou Targer bourgeris de Paris.

i. P’apiers Lecomte. 
comte, sil rous plaist, ferez tenir et ordonner provision par ceste seconle de change, si la première n’a esté acquittée. au quinzième juin prochain pour payer au sieur Valentin Targier à Paris la somme de :30 escus d'or sol (47/ fr. 9) et ce pour la valeur de pareille somme que j'ai de par deça reçue de lui comptant, dont à ce vous prie ne faire faute, priant Dieu que de mal rous garde. Pour $: 0$ escus ${ }^{1}$. "

L'acceptation par le tiré le rendait débiteur, non seulement par provision mais à titre définitif ${ }^{2}$, ce qui n'ôtait pas au porteur le droit de se retourner, en cas d'insolrabilité du tiré, contre le tireur. Le refus du tiré d'accepter ou de payer amenait le protèt, c'est-à-dire une sommation devant notaire d'aroir à accepter ou à payer et, faute de le faire, une protestation contre le tiré et le tireur. Parfois le premier, requis d'accepter, éludait et déclarait se réserrer

1. Papiers Lecomte.

2. Arrêt du 20 janvier 158 ' cité par Maiécial, Traité des changes, 1625 . Voici un exemple de protêt:

"Aujourd'hui quatorzieme jour de mai liś a ... six heures du matin, les notaires du roi n.s. en son Chatellet de Paris soussignés se sont transporté: de leurs études en la maison de honorables hommes Francois et Nicolas Gobelin, marchan el bourgeois de Paris demeurant es faubourgs de Paris dits de Saint-Harcel, oi illec etans Pierre Nivelle serviteur et... au nom de Jehan Cartier, marchand et bourgeois de paris ayant charge de lui, qui a mené lesd. notaires pour avoyr acte du contenu cy après, a prié et reçuis lesd. Gobelin, parlant á François Gobelin, de leur bailler et payer pour led. Cartier la somme de $\mathbf{2 0 0}$ ecus sol. (188i fr. 63) mentionnèe en une lettre d'eschange envoyée aud. Cartier pour la receproir desd. Gobelin par un nommé et signé Le Compte en date á Toulouse le 23 mars 158́, payable onze mois de vue, laquelle lesd. Gobelin ont jà rue au moven du protest á eux lait á la requeste dud. Cartier le $5^{\mathrm{e}}$ arril dernier et encore l'a exhibé presentement, protestant, au refus du change et rechange, de prendre denicrs a change et rechange et clioses qui font à protester en cette partie tant depuis led. premier protest que aupararant, qui a fait response que, en laisant lever les arrêts qu'il y a sur les deniers que il peut devoir aud. Le Compte faits a la requeste de plusieurs, il est prest de payer, dont led. Nivelle $\lfloor a\rfloor$ requis acte et ont signé la minute délivrée pour led. Jehan Carlier.

Nous soussignés, couratiers jurés des rechanges ả Paris certifions que celui qui baille argent à rendre à Toulouse à six ou huit jours lettre rue pour 100 écus (943 fr. 82 ) qu'il haille à Paris, en reçoit à Toulouse 104 (981 fr. 5i $)$ ou 105 (991 fr:). ce que certifions estre reritable. Fait a Paris, le lí de mai 1584. "Papiers Lecomte. 
-a liberte d’action i léchéance. C̈est ainsi que François (iobelin, mis en demeure, le 12 avril 1:38.4, d'accepter une lettre de change qui lui avait été présentée le 9 du mème mois, répondait que, le temps du payement vem, il verrait ce quil aurait à faire, sur ynoi le porteur, Jean Cartier, prenant cette réponse pour refus, sommait le tiré d'accepter ut, à faute de le faire, réservait ses droits ì tous dommagesintérèts et se faisait donner arte du tout par deux notaires ${ }^{1}$. Iprès le protit, le porteur pourait revendiquer contre le tireur la provision contre laquelle la lettre de change lui avait été délivrée ${ }^{2}$. A vant de tirer sur le tireur une nouvelle lettre de change pour se rembourser de la premiere et des frais du protî, le bénéliciaire lui notifiait le protèt et lui laissait un délai raisonnable pour pourvoir a la situation. "...je rous ai ćcrit ces jours passés, mande Nicolas Graillet a simon Lecomte le 16 juillet $1: 352$, vous donnant avis “omme j'arais fait protester la lettre de change de !' escus 28 s. t. (\$91 fr. :39) que maviez liate. Maintenant, avee commodité de ce porteur, M. Signier, jai bien voulu encore vous avertir afin que donniez ordre ì cette partie et que bientôt on en puisse estre paié, ensemble du protêt que jai fait faire. J'estime qu'on ne la rous tirera à paier' par "lelà moiemmant que bientost l'on aye de ros nouvelles ${ }^{3} .$. " Le porteur qui touchait la lettre de change, la laissait, avec son acquit au dlos, à celui qui la lui payait".

On a ru que les échéances des lettres de change étaient parfois assignées aux foires ou, comme on disait, aux payements de Lyon. On sait que ces loires araient lieu quatre fois par an, de trois mois on trois mois, quielles commençaient le premier lundi après les Rois, le premier

1. L'apier's Lecomle.

2. Irl'it du 8 mars 1606 cité par Marécual, Traile les changes.

3. Papiers Lecomte.

†. Michel Dusosoy a Simon Lecomte. Bordeaux, i janvier lis95. Boyer is s. Lecomte. Bordeaux, ter janvier [1581 ?] Ibil. 
lundi après Quasimodo, le 't aont et le 3 novenbre et qu elles duraient quinze jours. La clôture de chaeune élait suivie d'une assemblée générale de tous les commerçants, français et étrangers, qui y avaient pris part. C'est dans cette assemblée qu'était procédé à l'acceptation, au bilan et au payement, soit par compensation ou, suiran l'expression consacrée, par virement de parties, soit en espèces ou en effets de commerce, des lettres de change à échéance de la foire qui venait de se terminer' c'est là aussi qu'était fixé, d'après les renseignements apportés de tous les points de l'Europe par les commerçats yui sétaient rencontrés à la foire, le cours légal du change à Lyon et dauns les places de commerce de l'Europe occidentale ${ }^{1}$. Gràce à une tolérance qui comptait parmi les privilèges des foires de Lyon, les lettres de change tirées d'une foire sur l'autre rapportaient, par foire ou par trimestre, un intérèt de deux et demi pour 100 qui, sous prétexle quil était perçu pour le change, n'était pas considéré comme usuraire. Cet intérêt, sous le nom de change et rechange, se capitalisait et portait intérèt à son tour. Le commerçant qui, par exemple, arait tiré à Ia foire des Rois une lettre de change de 1000 livres, touchait, à la foire de Pìques, 102:3 livres et sa créance, reportée de foire en foire ${ }^{2}$, s'augmentait à chacune du change pour le capital primitif et d'un rechange pour chaque remise, sans compter le courtage, la provision et le change pour la différence des espèces ${ }^{3}$. D'abord justifié par

1. Davinzati, Notizia dè cambi, éd. Bindi, II, 430. Cl. Le Prestre, Questions notables (1645), chap. Lxxxir. Sxvary, Le parfait negociant, 111, 145. Goloschumt, Universalgeschichte des Ilandetrechts, I, 235 et suiv. Vaesex, La juridiction commerciale à Lyon sous l'ancien régime, (1879) 146-14i.

$\because$ Aux foires de Genève, l'iutérêt d'une foire a l'autre fut, dans le $\mathrm{xv}^{\mathrm{e}}$ siècle, de 5 p. 10n. BoneL, Les foires de Genève an $X V^{\mathrm{e}}$ siècle, p. 136.

3. Davanzati, Notizia dé cambi. Maréchal, Truité des changes. "Et font payer le change de remise, lequel, ajouté avec le premier change de trois mois, courtage et provision qu'ils font payer, avec la transmutation des espèces, figurée aux moins entendus á un tiers ou plus du principal..." LAFFenas, Remonstrance ell forme d'édit, art. xi. 
Iintérèt du commerce et par les risques et les frais résultant du défaut de parement et d'une nouvelle remise, le rechange était derenu, pour une foule de capitalistes yui navaient rien à faire arec le commerce ni les foires de Lyon. un placement usuraire en mème temps que hasardeux. Cette opération ne tentait pas moins les gens embarrassés et impréroyants qui y trouvaient la facilité de faire proroger de foire en foire leurs échéances. Si l'on pouvait ainsi réaliser un bénéfice sensiblement supérieur à 10 pour 100 , on risquait aussi de perdre le capital par la faillite de ceux sur qui les lettres de change étaient tirées'. Pour rassurer et encourager les capitalistes, des banquiers, movennant double commission, prenaient les risques à leur charge ${ }^{2}$ : des courtiers olliaient des lébiteur's solvables et se faisaient donner des commissions où le non du créancier restait en blanc et yui ne portaient que la somme prètée, le terme et le lien du payement. Gràce à cet anonymat, ce n'était plus seulement des financiers, des spéculateurs de profession yui se lirraient à ce genre d’opérations. vétait aussi des fonctionnaires et des comptables qui y engageaient les recettes publiques, s'exposant ainsi à ne pouroir faire lonneur aux payements assignés sur leurs caisses. Lagriculture, l'industrie, le rommerce y perdaient ce qu'y gagnait l'agiotage ${ }^{3}$. Les amis du bien public, qui essayaient de sexpliquer la stagnation, encore trop grande, du marché, jointe ì l'existence de tant de fortunes particulières, dénonçaient les " changes et rechanges " comme un des obstacles les plus graves au développement de la proinction :

1. Jans lesprice imagrinée par Davanzati pour explipuer cette opération, il ny avail pas moins de quatre faillites a craindre.

‥ INAXzit:, Loc. cll.

3. Yanecils., Tirailé ales changes.

4. "... banquiers et usurirrs qui faisoient (ainsi que lon voit ì présent) des monopoles scrus le nom de change et rechange..." L.mFenas, Remons- 
Les lettres de change nous ont insensiblement conduit à parler des foires, mais e'est un sujet sur lequel il faut revenir, car il mérite d'être traité non incidemment mais pour lui-mème.

Le moyen ìge n'avait pu soustraire le commerce assez. hardi pour sortir de l'enceinte des villes aux dangers qui le menaçaient qu'en lui ouvrant des asiles oì il trourait la sécurité, des franchises et des privilèges. Les foires étaient ces asiles. Des sauf-conduits presque toujours respectés protégeaient ceux qui s'y rendaient; une juridiction spéciale et sommaire réglait leurs débats; des voies d'exécution rigoureuses facilitaient le recourrement de leurs créances. Ces arantages avaient assuré le succès des foires de Champagne; la fiscalité, l'expulsion répétée des Lombards et Caorcins, le déclin de l'industrie drapière en Champagne, la création de relations directes entre la Flandre et l'Italie avaient amené leur décadence. De leur ruine naquirent les foires de Lyon. Ce fut grìce à des privilèges analogues, auxquels il faut ajouter la situation si farorable de la ville, l'esprit sćrieux et les habitudes laborieuses de la population, le génie commercial de la colonie italienne, que les foires de Lyon derinrent le marché commercial le plis important de l'Europe occidentale. Abolition du droit d'aubaine et de représailles, exemption du ban et de l'arrière-ban, du régime des maîtrises, des droits d'entrée et de sortie du royaume, tribunal de la conservation étendant sa juridiction dans toute la France et même, pour l'exécution des prises de corps, à l'étranger, Lyon arait tout obtenu au nom de ces foires ${ }^{1}$ qui, au

trances en forme d'édit, édit. Champollion dans Mélanges historiques (Documents inédits), IV, XV. "... par change et rechange la France de richesse est tombée en pauvreté. " LafFemas, Advertissement et response aux marchands et autres..., 1600. Dans ses Remonstrances, Laffemas demande la suppression des courtiers de change.

1. Privileges des foires de Lyon, p. p. Gulldaume Barbier, 16 ?. 
milieu dn $\mathrm{xr}^{\mathrm{e}}$ siècle, avaient fait tripler sa population?

l'ar lan importance internationale, les foires de Lyon iclipsicut de beancoup loutes les autres. On ne nous pardonnerait pas pourtant doublier celles qui, tout en nayant donmé lien qu à un mourcment d’atlaires régional, ont obtenu une popularité qui dure encore. Comment ne pals atcorder, par exemple, un souvenir a la foire SaintGermain? Ce fut justement au milicu duxve siècle pu elle afteignit son plus haut degré de rogue. A tontes les époques, lat mode, le bon ton. le luxe, la licence eurent à Paris un centre fatrori; sous Ilenri IV ce centre siaplela la foire Saint-Germain, comme il silppellera sous la Restauration le Palais-lioyal. Dans les houtiques alignées en rues, sétilaient les articles de lönlustrie parisieme et les coutenses fantaisies que les mercicrs receraient de toutes les pratles de l'lurope et mêne du monde. On venait à la foire pour les voir et pour les marchander; mais on $y$ venait tout antint pour jouer, pour se hiltre, pour ehereher des bonnes fortunes. Les chanhres situées an-ilessus des loges servaient surtout à cela. Au rez-de-chaussée les alfiares, au premier les rende\%-rous galants et le tripot: le marchand grannait ainsi de deux lisçons. La l'oule, la bidaulerie, l'accumulation de marchandises de prix, l'abondante circulation d'argent y finsaient beau jen aux charlatans, aux bonneteurs, aux filous ${ }^{2}$. Il y a dans les sociétés des milieux et des moments lont les gourernements ont souvent toléré les excès; mais cetle tolérance a toujours ressé quand le désordre public est venu dommer anx désordres privés une redoutable portée. C'est parce yue le pays se trouvait dans cette siluation, que la foire fut suspendue pendant six ans, et ne rourrit ses portes qu'en 1:i9:j. Ce fuc l'année suivante qu'y débuta une troupe de

1. Matmed de V'al\%elles, Trailé des pérges, 1550.

$\therefore$. Icisuxcocur, IIisloire générale des larrons..., 1629, p. 101, 108, 110. 
comédiens qui se produisirent également à la même époque à la foire Saint-Laurent et qui, essayant de se eréer daus lart dramatique une place modeste à còté de la Comédie française, de Ia Comédie italienne et de l'Académie royile de musique, passant, pour échapper aux persécutions de leurs puissants rivaux, par toutes les transformations, finirent par fonder, au commencement du xvin siècle, le genre, longtemps si populaire et si français, de l'opéracomique'. Nous derons aussi une mention à la foire SaintDenis ou du Lendit, à celle de Beaucaire où affluait la population du Languedor, à celle de la Guibray à Falaise dont les "finesses et monopoles " ont exercé la causticité de Noël du Fail ${ }^{2}$.

Le. retour de la sécurité publique ramena la foule aux foires lésertées et en fit créer de nouvelles ${ }^{3}$. Bien que l'assortiment des marchands de province fùt très varié il ne pouvait suffire à tous les besoins locaux, stimulés par l'émulation de bien-être et de luxe qui succède aux périodes de privations et de souffrances et les seigneurs, qui bénéficiaient des droits dont les foires étaient l'occasion, étaient toujours empressés à faire valoir sur ce point les intérêts et les rœux des populations. Mais l'ouverture d'une foire nouvelle était subordonnée à eette condition que, dans un rayon de trois lieues, il n'en existàt pas, le même jour, une autre. Les rois des mereiers, leurs lieutenants, les visiteurs et réformateurs généraux des marehandises, c’est-à-dire les

1. Rocllaxo, La foire Sant-Germain sous les règnes de Charles $I \mathbf{X}$, de IIenri III el de Ilemi IV dans llémoires de la Société de thistoire de Paris, III. Canpardon, Les spectacles de la foire. Introrl., rm-x, xx.

2. a... ses finesses de Ia Guibray qui est le reudez-vous des meschans complots et monopoles de toute la France..." Contes et discour's d'Eutrapel, II, 265.

3. Citons, entre autres exemples, la création, par lettres patentes d'octobre 160", des quatre foires du Ionastier dans la sénéchaussée du Puy-enVelay. Sociélé "gricole el scientifique de la II rute-Loire, III (1881-82), p. 181.

4. Inventrire d'un marchand tandais au milieu du . IVIe siècle, dans Revue des Sociëtés suvantes, VI (ISS:). 
antorités qui centralisaient lia surveillance régionale du commerec, étaient probiblement consultés surl'opportunité de ces créations. C'était eux aussi qui procédaient à leur ouverture avec un cérémonial qui était partout à peu près le mème. L’un de ces ofticiers, accompagné on non du per'sonnel de sa juridiction, lientenants, grreffiers, huissiers, parcourait à cheval el lépée nue le champ de foire. Devant lui étaient portés par des marchands un pavillon de talletis vert décoré des armes du seigneur et des torches de eire ardente également armorićes. Venait ensuite un bouf gras caparaçonné. Il élait ehevauché par celui des mercier's qui renait de son rendre adjudicataire dans les enchères dont la cérémonie avait été immédiatement précédée, et qui acquérait parfois, par celte adjudication, l'exemption de péages dans les terres seigneuriales. Le montant en était, dans certains endroits, partagé entre ses confrères. Le représentant du roi des merciers faisait largesse au peuplè en crimut arec tous les assistants: "Vire le roi et le seigneur et foires déployées! " El, en mîme temps, les marchands étalaient leurs marchandises, la foire était ouverte, le seigneur en était mis en possession et recevait la paricarte des droits qui lui étaient attribués. Une fille publique vêtue d’un peliçon, une truic suivie d'un areugle se joignaient parfois au cortège et ajoutaient aux réjouissances par lesquelles on fitait, aux frais du scigneur, l’inauguration de la nouvelle " bourse " dont il avait dès lors la protection et les profits ${ }^{1}$.

Les foires devaient survire aux raisons économiques, à l'organisation sociale qui leur arait domné naissance et araient fait d'elles un bienfait. Soutenues par l'esprit

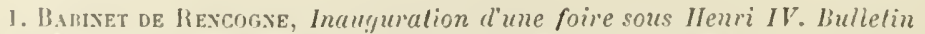
ré la saciélé archéologique el hist. de la Charente, XV (I865, p. 137. Hocuments inélits. Mél. hist., I, 217. Foires et marchés de Saint-Clémentin dans Arch. hist. du l'oitou, XX. 
d'autonomie locale, par l'attachement au privilige, par l'attrait du plaisir, elles ont traversé, non sans un déclin croissant, des temps où la sùreté des communications, la fixite des taxes fiscales semblaient leur enlever leurs avantages pour ne leur laisser que leurs inconrénients. Déjà, au temps de Ilenri IV, elles avaient trouvé des détracteurs; l’infatigable Laffemas avait composé un traité tout exprès contre elles. Il est vrai qüil n'a pas fait valoir à leur encontre les critiques qu'on leur adresse généralement; ce qu ïl leur reproche seulement, c'est de favoriser les importations étrangères et la sortie du numéraire ${ }^{1}$.

Les marchands grossiers qui les fréquentaient faisaient presque toujours partie de sociétés commerciales et c'est gràce à cela qu'ils pouvaient sans préjudice délaisser momentanément le centre de leurs affaires. Ce fut sous Henri IV que se produisirent les premières tentatives pour fonder des sociétés par actions, mais ces tentatives ne réussirent pas. Ce n'est pas, on le sait assez, qüil ait manqué sous son règne de ces grandes entreprises pour lesquelles un appel financier au public paraissail tout indiqué, travaux de desséchements et de canalisation, propagation de la sériciculture, colonisation, fondation d'industries nouvelIes, etc., mais ceux qui se mirent à la tête de ces entreprises paraissent s'être contentés de joindre à leurs capitaux personnels ceux d'un petit nombre d'associés; ils ne semblent pas aroir constitué des sociétés analogues à celles qui, attirant les petites épargnes par le montant peu élevé des parts et le fractionnement des rersements, facilitant leur négociation par la transmission au porteur, ont rendu possibles les grandes entreprises des temps modernes et $y$

1. "Audit premier traité est représenté le mal que lont à présent les foires franches en ce royaume et la création d'icelles, estant cause que les estrangers enleventles tresors en tous endroits. 'Les discours d'une liberté génèrale et vie heureuse pour le bien du peuple, 1601. 
ont intéressé tontes les classes. On ne reneontre à l'époque qui nous occupe que la société en nom collectif, la sociétí en commindite simple, el, sous le nom de société anonyme, la société en participation. La seconde est celle qui mérite le plus l'altention parce quelle offrait aux classes auxquelles le commerce était interdit, amx nobles, amx eeclisiastiques, aux officiers publics te moyen d'y engager leur capital sans compromeltre ni lemrs hiens au delia de lenr apport ni leur nom. Les actes de société élaicnt généralement passés sous seing privé et les commereants repoussaient, comme une entrave tris gênante, l'obligation de les faire devant nolaires '. L'ordonmance de Blois (1:39) avait preserit l'enregistrement de ceux qui créaient des sociétés entre étrangers. En voici un pour la formation d'me société destinéc it faire le conmerce du pastel. On remarquera que l'un des associés, outre sa parl dans le capilal social, apporte son aclivité en qualité de goérant et reçoil, à. ce titre, un traitement:

"Lian l:iz't et le vingt-troisienue jour du mois de juillet ont été accordés les pactes de compagnie entre sieur Andıé de Jesse, marchand de Toulouse d'une part et sieur Antoinc Gailhard, marchand de Lauraguais d'autre comme s'ensuit :

" Est pacte que les d. de J. et G. mettront en fonds en lad. compagnie, chacun pour sa part, la somme de $ّ 000$ livres tomrn. (17093 fr. 27) en deniers claires et liquides pour ètre employés cn cognauhe de pastel tant au lieu de Monlgailhard, Villefranche de Lauragois que autres lieux circonvoisins.

"Il est pacte que la merchandise achetée de l’argent le lad. compagnie se partira au tymon (sic) et où el quand que l"une partie auroit plus fourni d'arcent que l'autre it l'achat d'icelle merchandise, tirera au sol la livre plus du pastel agtavat et suivant l'argent qui y aura mis.

" $l 1 e m$ est jacte que tous les achats de cognauhe de paslel que led. G. a dẻjü faits ou léra pendant lad. compagnie cu la présente anuée... seront au profit dicelle et n'en pourra faire d'autres achats parti- 
culiers pour lui ni pour autres personnes, se ce n'est pour lad. compagnie... et, avenant qu'il accomodat aud. de J. l'y mettre plus d'argent que de lad. somme..., led. G. sera tenu de l'enployer aux mêmes conditions de lad. compagnie et, ledl, achat fait, sera tenu d'en bailler le compte par le mème aud. de J. quand par lui en sera requis.

"Item est pacte que led. G. sera teuu faire porter et metlre toute la cognauhe qui se achetera pour lad. compagnie daus les villes de Villefranche et Hongaillard pour ètre en plus grand assurance et ce que coutera le lougge de la boulique qüil conviendra avoir dans Villefranche se paiera aux dépens de lad. compagnie et les autres seront aux dépens dud. $\mathbf{c}$.

"Item est pacte que la cognauhe que proviendra desterres dud. G., de ses parsonniés ou mouldures du molin sera mis à part et étant bonne et marchande sera comptée comme le prix commun dud. achat reviendra ou comme raudront ordinaurement les recettes circonvoisins an choix dud. de J.

"Item est pacte que led. G. sera tenu faire ou faire faire led. achat par gens de bien et intelligents en lad. merchandise el, pour ses peines, vacations et frais qu'il pourra avoir soufferls, tant pour faire charroier, piller, trier, baigner et virer led. pastel jusques à trentesix voultes, louaiges de boutiques, sauf celle de Villefranche..., led. de J. lui donne, pour chacune charge de pastel qui se truvera ètre à sa parı, $20 \mathrm{~s}$. tourn. (3 fr. 42), en foi de quoi avons accordé ces présents pactes... à Toulouse... '. "

Quand on connaît les habitudes professionnelles d'une classe, on est en voie d'en connaître l'esprit et les mœurs. Qu'on y ajoute son éducation, sa situation sociale et l'on aura réuni, ou peu s'en faut, les influences qui déterminent sa physionomie morale. C'est cette physionomie des commerçants et des artisans, car il n'y a pas lieu, à ce point de vue, de distinguer les uns des autres, que nous allons essayer de dessiner.

Si l'on grattait ces gens d'atelier et de boutique du xvı ${ }^{e}$ siècle naissant, on trourerait un fond ligueur. Ils restent profondément attachés à leurs dérotions paroissiales,

1. Signé par les deux parties et par un seul témoin, bien que l'acte parle de deux. I'apiers Lecomte. 
à leurs confréries . Depuis que IIenri III arait seandalisé la piété grave et dicente de la bourgeroisie parisiemne par les malsiandes religieuses de ses pénitenls. les confréries sétident beancoup multiplices. Lei, d’ailleurs, comme pour la Ligue, le roi narait fait quencourager par le patronage officiel un mourement fivorisi pár des cilconstances passagères et par des sentiments íteruels, par des instincts grossiers comme par des aspirations élevées. Besoin de trouver dans des réunions intines un soulagement an anxiétés publiques et particulieres, élan de mysticisme, altachement finatique ì la religion nationale, dérotion superstitieuse à un saint local, à un patron familier, goût de linsouciance et de la gaieté cherehées dans les épanchements de la table, ambition des homenrs et des titres, si burlesques fussentils comme ceux de la à sa guise. de Danse comme il lui pluit, de Mignon, de Roi et de Reine qu'on aljugeait aux enchères au profit de la caisse sociale, tout cela arait contribué ì la fortune des confréries. Un érudit de la Marche en a compté plus de trente-quatre pour quatorze localités de celte province ${ }^{2}$. A Sarlat, au $\mathrm{xv}^{\mathrm{e}}$ siècle, on en trouve onze. On roit des gens qui sont affiliés à quator\%e confréries ${ }^{3}$. Ce n’est pas seulenent la sobriété, la moralité privée qui avaient habituellement à soullril de ces réunions entre roisins ou camarades de même métier, cétait aussi la tranquillité publique qu'elles pouvaient mettre en péril en fortiliant, en échauffant, par la solidarité, de vieux instincts d'opposition et de turbulence. Vienne, en effet, à soufller un rent de fanatisme ou de sédition, il fera remonter ì la

1. Rexé Bexolst, De l'inslilution el abus des confiéries, 15i8. Babeat, Les bourgeois d'aulrefois, 321 .

2. Bosvirux, Documents relalifs aux confieries de la Wurche dans Wémoirss de la socicté des scionces naturellcs et arch. de la Creuse, V (1857), p. 41 i.

3. Gèrand, Le livre terrier de Pierre Botınelle, notaire de sarlat dans Bulletin de lit societc hist. et arch. du I'erigurd, XI (188i), p. 321. Némoires d'Eustache l'iemond, p. 1 f́g. 
surface les ferments assoupis et précipitera ces lourgeois paisibles ì de déplorables excès. Ils conservent au raitelier les armes arec lesquelles ils ont successirement défendu la cause de la rébellion et celle de l'ordre' ${ }^{1}$, arec lesquelles ils accomplissent encore le pacifique service de la girnde urbaine, et ce n'est pas sans complaisance quïls les montrent. Sils se font peindre, ce sera dans un costume militaire?. Ils ont grardé des temps d'anarchie le goùt de réprandre les nouvelles hasardées, de disculer, de trancher lis alfilires d'État ${ }^{3}$. Mais ces traditions et ces instincts persistants sont comme recourerts aujourd'hui par le respect d'une autorité qui sait se faire obéir, par la jouissance de la sécurité et du bien-ètre, par la passion de s'enrichir, d'obtenir tous les honneurs dont l'ambition leur est permise, de sélever ou d'élever leurs enfants à une condition supéricure. Les étapes de cette ascension sont toutes tracées : c'est par les dignités de la corporation qu'ils débutent, elles les condui-

1. "... Ies aulnes des boutiques sont tournées en pertuisanes." Satire Nénippée, éd. Labitie, p. 81. "Le marchand quittoit son commerce pour sauter à la hallebarde... La rue Saint-Denis avoit ses compagnies de lanciers. "Mémoires du duc d'Angoulême cités par Polnson, I, 5ł. Babeau, Un marchand de province sous Ilemri $1 \mathrm{~V}$. Bulletin de la société d'économie sociale, 16 janvier 1883. Les fils hériteront de la manie d'avoir des armes, de la tentation de s'en servir qu'on reuarque chez leurs ligueurs assagis de pères; Retz nous montre les artisans parisiens, daus un moment d'effervescence populaire, travaillant à côté de leur's mousquets. Mémoires (16j1). Coll. Ilichaud et Poujoulat, p. 300.

2. Voy. dans Le berger extruvagant de Sorel (liv. vur, p. 1:8) l'histoire d'un "menuisier gentilhomme ", caporal de la milice bourgeoise, qui se fait peindre sous les arnes, en wrande tenue.

3. Satire Ménippée, p. 86. "Aujourd"hui il n'y a boutiqne de factoureau, ouvroir dartisan ni comptoir de clergeau qui ne soit un cabinet de prince et un conseil ordinaire d'État..." Vers 1614. Ilornay cité par Maren, lialerie philosophique du .IVIe siècle, II, :i1. "Quand le saretier a gagné, par son travail du matin, de quoi se donnel un oignou pour le reste du jour, il prend sa longue espée, sa petite cottille, son grand manteau noir, et s'en va sur la place décider des intérêts de l'Élat. "Les entretiens du diable boileux, pasquil dı même temps. Itid. "Nous somnes en un temps qu'il n'y a petit pelé de secrétairc de Saint-Innocent, clerc, pédant, magister crolté, artisan qui re se mẻle d'écrire et de parler des affaires d'Élat... » Conférence d'Ariste, I'unurge et Gueridon, ver's 161'́, p. 290. 
sent aux charges municipales'; enfin, quand ils auront fait fortune dans les afficires, ils emploieront leur capital à l'acquisition d'un de ces innombrables oflices que le pouvoir central et les villes ne cessent de créer, ou le placeront dans les parlis, ou le feront valoir dans les changes et rechunges. Ils sont dis lors sur le chemin de l'opulence et de la considération. Leur habiletí et leur honheur feront le reste. A une époque où largent mène ì lout, où il eflace la bassesse le l'origine conme les souillures du pasio et nivèle les rangs, dans une société qui est au lond une lémocratie puisque les fonctions publiques et par suite les privileges y sont à rendre, leur arenir dépend de spéculations heureuses, des services qu'ils pourront rendre aux gens puissants, du prix quils sauront y mettre. Si la noblesse n'a pas été pour eux la conséquence légale des charges qu ils ont remplies, ils pourront l'acquérir à deniers comptants ${ }^{2}$ ou s'en parer sans droit et par une tolérance accordée à la fortune ${ }^{3}$ ou, au pis aller, l'obtenir pour leur postérité féminine par des alliances arec des nobles authentiques ". C'est le temps où le connétable de Lesdiguières épouse Marie Vignon, fille d'un fourreur de Grenoble, veuve d'un marchaml drapier de la mène ville ${ }^{3}$; où le duc de Brissac s'allie avec la fille

1. Voici un exemple qui apparlient au dernier quart du xwn siecle mais qui convient aussi bien à son début. En J68' Jean l'ages, marehand d'Aniens, est nommé jeune garde de la communauté des nerciers; le $2 i$ avril 1688 i) est choisi pour porter la chàsse de saint Firmin à la procession générale: en Ilis9 il est désigné pour porter le dais a Saint-llartin sa paroisse et, le 20 août de la même année, il e:t nommé ancien garde; en 1695 il devient chef des postes de milice bourgeoise; en 1706 il est élu consul. Ganxien, Notice sur Jean Pages dans Mémoires des antiquaires de P'icardie, $V(185 x)$.

$\therefore$ En 1606 Ilenri IV rendit des lettres de noblesse. Picot, 1 , 75.

3. Citons seulement, entre tant d'autres, l'exemple de l'ierre Michel, seigneur de Souscarrière, marquis de .lontbrun. Voy. la notice de M. Chevecoecn sur ce curieux personnage. Memoires de la Société de l'histoire de Paris, IVI.

4. "La femme ignoble mariée avec un gentillomme est anoblie. "FLorextix de Tumbalat, Trois trailés de la noblesse, 1606.

5. Talleyant, IIstoriette de Lesdiguieres. 
de Rocher Portail, partisan de basse origine ${ }^{1}$; où un tanneur de Meulan, Nicolas Le Clerc, marie les siennes à un président à mortier au partement de Paris, à un premier président de la chambre des comptes de Rouen et établit les autres aussi bien; où son fils, sous le nom de M. de Lesseville, devient maìtre des comptes à Paris ${ }^{2}$; où le fils d'un boulanger de Chinon achète la charge de prévôt de l'lle-de-France ${ }^{3}$; où le fils d'un marchand linger est maitre des comptes"; où celui d'un tanneur d'Autun s'appelle le président Jeannin ${ }^{5}$; où Castille, son futur gendre, quitte le commerce pour être nommé receveur du clergé ${ }^{6}$; où le fils d'un chandeleer passe intendant des finances ${ }^{7}$; où celui d'un paysan de l'Anjou, La Bazinière, obtient la charge de trésorier de l'Épargne ${ }^{8}$; oì un marchand de soie voit le sien siéger au parlement ${ }^{9}$.

A côté des inquiets et des ambitieux, en trop grand nombre, qui envoyaient leurs enfants aux écoles pour les faire entrer dans les fonctions publiques et qui croyaient s'élever eux-mêmes en y entrant, il y avait des artisans et des commerçants plus sensés qui n’attendaient la richesse et la considération que de leur probité et de leur habileté professionelles et qui n'aspiraient qu'à en laisser l'héritage à leurs enfants. Il y avait du mérite de leur part à ne pas rouloir sortir de leur sphère, car, sils avaient chance d'y trouver la lortune, il leur fallait vaincre, pour y joindre l'honneur, un préjugé enraciné. L'idée si juste et surtout si utile que le commerce doit être estimé parce qu'il enrichit
1. Ilistorietle de Brissac.
2. Historiette de Rocher Portail.
3. Historietle de Petit Puis.
4. Historielte dAnt. Le Haistre.
5. Son historiette.
6. Ibid.
7. Itistoriette de Bordier et ses fils.
8. IIistorielte de La Bazinière.
9. Tallemant, Générosités. 
l'Étal, répugnait autant ì l'esprit français qu elle semblaut naturelle it l'esprit d'un Itilien ou d'un Anghais. Legrs de l'honneur cheraleresque, dont la France avait été la vraie patrie, celte prérention interdisait anx gentilshommes ruinis par les guerres civiles, aux calets de fimille noble pourvus d’une légitime insuffisante, avee l'exercice avoué du commerce, le moyen de reconstituer leur patrimoine et les réduisait à des moyens d'existence bien plus contraires à la dignitér. La royauté avait bien apporté des tempéraments ì la dírogeance, qui était encourue à l’origine mème pour la vente des produits du cru ${ }^{2}$, mais ces tempéraments araient été timides et peu efficaces ${ }^{3}$; ici, conme toujours, la loi avait été moins forte que l'opinion. L'usage pourtant accordait aux marchands la qualité d'honorables lommes et le tilre de sire et de messire". Leurs femmes prenaient celui de demoiselle par suite de l'inévitable extension que subissent tous les tilres honorifiques, car, à s'en tenir ì la rigueur le l'éliquette, il aurait dnètre réservóaux femmes mariées de la noblesse. Le chaperon était la marque distinctive de leur conditiou, si bien qu'on les appelail des chaprronières. En y restant fidies, elles cherchaient ì ressem-

1. LAFFends, Trésors el richesses pour meltre l'État en splendeu', art. :69.

$\therefore$ Edit du 4 avril ISio. Isanibert, XII, no 301.

3. Charles IX exempta de ta dérogeance la noblesse de Marseille, de Normandic et de liretanne qui se livrait au commerce. Sully répétait souvent que la France nacquerrerait jamais l'ascendant sur ses rivaux et ses adversaires tant que le commerce maritime $y$ entrainerait dérogeance. TII. LEFÉvie dU Grand Ilanel, liscours sommaire de la navigation et du commerce. Dedicace à la reine mère. liouen,1650. La coutume de Troyes permettait aux nobles de se livrer au commerce sans déroger. Gro-LEy, Mém. hist. el cril. sur l'histoire de Troyjes, II, I6I (éd. 1812). Le metier de maitre de forges ne faisait pas perdre la noblesse. Celui de verrier itait auvre de gentilhomme. Ilenri IV anoblit plus d'une fois des inventeurs et des introducteurs d'industries nouvelle's en France.

4. "... aussi les uarchans sont les derniers In peuple qui portent qualité d'honneur, estans qualifiés d'honorables lommes... " Borcurt, Tiésor..., vo . Marchands.

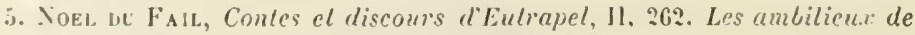
la cour dans Vtrieles historiques el litleraires, $\mathrm{N}, \mathbf{3}$.

6. "... Le chaperon qui étuit la vraie marque et le caractere de la bour- 
bler par le reste de leur toilette, notamment par la hauteur de leur's collets montés et empesés ', par les points coupés dont elles se couvraient le sein ${ }^{2}$, aux femmes de qualité; à défaut du masque, apanage de ces dernières, elles portaient le loup ${ }^{3}$.

En acquérant la richesse, en forçant les classes supérieures, par les crédits qu'ils leur accordaient et les services pécuniaires quïls leur rendaient, à compter arec cux, les commerçants ne se relevaient pas du dédain dont ils étaient victimes; on usait de leurs complaisances, on ne les en méprisait pas moins ". La scène de Don Juan et de Vlonsieur Dimanche s'est jouéc bien souvent avant que Molière l'ait écrite. Quand ces classes se relìchaient de leur arrogance, cétait plutôt en faveur des financiers, des traitants, des parasites du plus bas étage qui étaient sourent associés ì leurs prodigalités et les servaient habituellement dans leurs embarras.

Le mépris met à l'aise la conseience de ceux quil humilie, ils cherchent souvent à s'en consoler et à s'en venger par la ruse et la fourberie. Beancoup de commerçants avaient pris ce parti. Nous arons parlé des opérations clandestines des merciers et des fripiers. Ils ne furent pas les seuls ì chercher dans l'usurc un supplément aux béliéfices professionnels. Un procédé très employé consistait à prèter à un intérèt exorbitant aux fils de famille en dissimulant le prêt sous une rente fictive de façon à éviter une rescision pour incapacité ${ }^{5}$. Est-il besoin après cela de parler de

geoisie." Firnetiére, Roman bourgeois, éd. Ed. Fournier, 185í, p. 30. La grande division arivée ces jou's demiers entre les fermmes et les filles de Hontpeltier avec le sujet de leursquerelles (1622),dans Var. hist. et litt., VII, 219.

1. Sores, Histoire comique de Francion, éd. Colombet, 199-200.

2. Le salyrique de la cour. Var. hist. et litt., III.

3. Quicherat, llistoire du costume, 43 í.

4. "S'il y a mespris au monde, il est sur le marchant.... " L.Affemas, Traité du commerce de la vie du loyal marchand..., 1601.

5. Cleyrac, Usance du négoce ou commerce de la banque, des lettres de change, 1659. F cretière, Le voyage de Mercure, 1661. 
l'habitude de surfaire la marchandise, du charlatanisme et des ruses qui la faisaient valoir et en dissimulaient les délauts, des falsifications, de la tromperie sur la yualité et le poids'? Quand le passe resscmble amtant au présent, l'historien ne peut que signaler en passant leur analogie, cest ¿̀ maryuer leurs différences qüil doit surtout sattacher.

La vie des commerçants offrait d'autres compensations que celle dexploiter le public qui les dédinignait. Ils prenaient leur part de ce bien-itre, de ce luxe, de cet amour du plaisir qui, après avoir élé, pendant les guerres eiviles, le privilìge d'une minorité, se répandaient, an commencement du $x{ }^{\circ}{ }^{\circ}$ siècle, dans la société tont entière. On en trouvait peu comme ce sire llemiot dont nous parle Lestoile ", qui shabillait, les dimanches et fìtes, d'une petite robe doublée de taffetas, d'un justaucorps rayé de bandes de soie de différentes conleurs et qui, par ses manieres comme par son costume, personnifiait " la simplicité et prud'homie des bous marchands d'autrefois ". Plus rares encore étaient ceux qui portaient le béguin ì l’antique, le justancorps de drap court, une ceinture de grosse lisière, le haut-de-chausses clérical avec haute braguette, la gibecière au côté, les souliers d'étoffe ì pointe de cuir et la barbe rasée ${ }^{3}$. Le premier luxe, dans tous les temps, parce

1. H. Estıexie, Apologie pour Ilérodole, éd. Ristelhüber, 1, :300-301, 319. 320-3:3, 324-327. La promenade des bons hommes ou jugement de nostre siècle, I622. Sonel, Les visions admirables du pelerin de l'anasse. Les bigarrures el touches du seigneur des Accords, id. 16:0, p. 49. "L'ail des tailleurs." ['roverbe. Ils jurent de n'avoir non plus d'étot]e de r'este qu'il n'en peut tenir dans leur rril. Orous, Curiosilés francraises, llifo. Voy. aussi les dialogues publiés par funscors Penore, chanoine de Chartres sous le titre: Le bourgeois poli. C'est un guide de conversation couforme aux couvenances mondaines. Dans ceux de ces dialogues qui ont pour interlocutenrs des matrchands et des clients, on troure le même boniment et le mîme marchindage qu'aujo:ard'hui. Rien de caractéristique de l'epuque. Var.

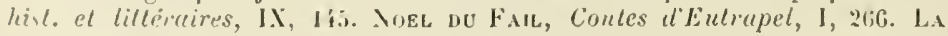
BruYéne, Des biens de forlune.

2. Jomrnal de Henri $\mathrm{N}$, éd. Jounust, X, I-3.

3. Lu chasse un vieil grognard de l'untiquite. l'ar. hist. et litlérarres, III, 3i. 
que c'est celui qui confond le mieux les rangs, a étè le luxe du costume, et cétait celui où se complaisait le plus le monde des magasins el des ateliers. C'est coillés d'un castor à l'imitation des gens de qualité, rêtus d'un habit de soie et d'un manteau de peluche que les commergunts, Laissant à des commis le soin du magasin ${ }^{1}$, se rendaient à la Bourse ${ }^{2}$, sur le Pont-Neuf ou sur le Mail pour traiterleurs affaires ${ }^{3}$.

Leurs demeures se ressentaientaussi du progrès dn bienètre et du luxe. "Quelle insolence, s'écrie Pierre Mathieu ", que les bourgeois et les marchands batissent des châteaux aux champs et des palais aux villes! " Les portes cochères se multiplient avec les carrosses ". "C'est l'un des principaux pactes du mariage - lit-on dans un livret publié neuf ans seulement après IIenri IV -- que de stipuler une maison à porte cochère et un carrosse pour Mademoiselle ${ }^{6}$." Le goùt de la villégialure se répand dans la bourgeoisie. D'élégantes maisons de campagne, couvertes d'ardoise et entourées de vergers avec des eaux vives, offrent un délassement à leurs loisirs, une jouissance à leur vanité ${ }^{7}$. La distribution intérieure se perfectionne; on sétudie à rendre les pièces indépendantes, à éloigner les privés de la salle ou salon, à empêcher par une antichambre l'accès direct de la chambre ${ }^{8}$. On commence à dissimuler sous des

1. La chasse an vieil yrognard, 56-5i. Les caquels de l'ucconchée, éd. Fournier, 238 .

2. I Paris elle se tenait en plein air, dans la grande cour du palais. Voyage a learis de Tuonas Corrate, Mémoires de la Société de l'histuire de P'uris, VI, p. 32. Encyclopéalie méthodique, vo Bourse.

3. La chasse au vieil grognard.... "Lhomme de boutique est vêtu comme le gentilhomme. " Ioxtcunétıex, Traité d'économie politique.

4. Histoire de France... durant sent années de paix, 11, 266.

5. Dis 1.89, à Bordeaux, il n'y avait pas plus de conseiller sans carrosse que sans robe rouge. J. De Gacfieteau, Chronique bordeloise, année 158:). Babeav, Les bourgeois d'autrefois, p. 25.

6. Plaisants gatimatias d'un Gascon et d'un Provençal nommés Jacques Chagrin et Ruffin Allegret, 1619.

7. La chasse an vieil grognard..., p. 59. Aubrixcourt, IIistoire générale des larrons..., 1629, p. 260-261.

8. La chasse a vieıl grogrard..., 58. Un financier dit à Henri IV de la 
tentures le crépi criard des murs ${ }^{1}$. Lal vaisselle d'argent auggmente de plus ìn plus ì còté de celle d'étain. Le mobilier, bien éloigné de la profusion moderne, reste sobre et froid ${ }^{2}$.

Les plaisirs deviennent plus raffines ${ }^{3}$. On se promène au cours à pied ou, si l'on peut, en carrosse, au petit pas pour voil et étre vu; on fait des parties de plaisir, des culeaur ì la campagne; on va manger des frilises et des petits pois dans les guinguetles de Vaugirard, de Meudon et de saint-Cloud; on sinvite ì souper entre voisins, les dimanches et jours de fètes, et à ces serces chaque convive apporte son plitt:

Le théitre était aussi l'un des plus vifs plaisirs de la moyenne et de la petite bourgeoisie. Ce n'éticit pas seulement les troupes de passage qui répondaient d'une faron intermittente ì un geoût d'autant plus vif qu’il était moins exigeant, il tromait parfois ì se satisfaire d'une façon hahituclle. Des amateur's, commerȩants, artisans, gens de loi, se faisant à la fois anteurs, impresarii et comédiens, aliptaient à la scène certains épisodes de l'Ancien et du Tonveu Testıment, des paraboles. ıles légendes hagiograpliques puis, quand ce vieux répertoire commença à lasser le public, des sujets profanes; se procuraient des décors ct un matériel scénique sommaires, recrutaient une troupe dans la jeunesse de la ville, la formaient et l'entriinaient par leurs leçons et leur exemple. Les municipa-

maison qüil fait construire qun"il "la faisoit... sans salle ni antichambre derant sa chambre (car plusieur's, sans être de grande qualité commencoient déja à y en mettrej.... n. Mémoires de Fonlenay Mareuil, coll. Michaud, 21 , col. 2 annice 1610 .

1. Caiguels de l'uccouchee, 239 .

$\therefore$ Babac, les bourgrois d'autrefois, 27. Un marchand de province sous II $\bullet$ III I $I V$.

3. La chusse au vieil grognard ... Des délectations du lemps passe.

4. Funfitike, Roman bourgeois, ed. Asselineau, 51, 82, 86, 109. Cotgrave définit ainsi la serée: "A gossiping or good fellowlike mecting of neighbours... whereto everie one brings or sends his dish ". Cite par Bi) $₫$ FFÉ, loles sur la cie privée à la Renaissance. Revue de l'aris du 15 sept. 1896. 
lités subrentionnaient ces entreprises dramatiques. Pendant treize ans, à Draguignan, un notaire, Textoris et un chaussetier, Gaudin, furent associés pour jouer et faire jouer devant leurs concitoyens des moralités et des mystères. Un procureur, Mussoni, succéda ì Textoris, mais il ne sut pas résister à la tentation de rajemir son répertoire par des personnalités, et les susceptililités qu'il soulera, le forcèrent ¿l la retraite ${ }^{1}$. A une époque où la vie religiense et la vie profane multipliaient les cérémonies somptueuses et touchantes, la passion le la mise en scène s'était tellement répandue qu'on la troure jusque dans les villages. En 1.560 des paysans d'Amnet en Brie organisent la représentation de lhistoire de Joseph et louent à un fripier des costumes dont on a conservé la liste?

L'ignorance est encore bien grande chez les artisans et les commerçants, plus grande encore chez leurs compagnes, car les ordres religieux qui se rouent à l'enseignement des filles, les Ursulines et les Feuillantines commencent seulement à ouvrir pour la jeunesse féminine des maisons d'éducation. En 1602, les habitants d'Aurillac demandaicnt au conseil du roi que les chefs des confréries de métiers n'issistassent plus anx assemblées consulaires, "car ces chefs de métiers, la plupart ignares, ne peurent sainement juger des affaires, ains donnent ordinairement les roix selon les brigues et menées ${ }^{3}$. "Plus tard, Toubean, dans ses Institutes de droit consulaire, va jusqu'à écrire que beancoup de marchands ne savent ni lire ni écrire. l'ourtant, à Paris surtout, le goùt des plaisirs de l'esprit semble

1. Textes relatifs ì des représentations scéniques à Draguignan aux Xì $X^{\prime} I^{\circ}$ et XVII siérles communiqués par M. Mhreun dans lievue des Sociétés savantes, XXXilli, p. 461.

2. Elle a été publiee par le baron Pichon dans le Bullelin de la Sociéle de l'histoire de Paris (1852) sous le titre: Une représentation théditrale dans un village de Brie au $\mathrm{IVI}^{\mathrm{e}}$ siecle.

3. Bibl. nat. mss. Franc. 18166 it Ia date. 


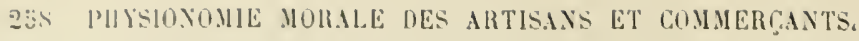

¿areiller chez eux : daus laudituire des comrs publies et des scrmonnates qui se piquent de bean langagere, dans le parterre qui applatudit les tragédies d'Alexamdre Ilandy on rencontre des commergantio et des artisins '.

Ces hourgeois du commencenent du siecte annoncent dojià cenx que Moliòre, dans sa seconde moitié, dessincra d'une louche si lihre, si vigoureuse el si sobre. Il y a toutefois celte diflérence que les premiers, encore conlusionnés des secousses de près de vingt ans de guerres civiles et non entierement diogrises de leurs chimères politiques, s'ourrent seulement à la junissince de la sécurité, du bien-ètre, de la sociabilité, tandis que les seconds, completement assagis et disciplines par plus de vingt ans de pouroir absolu, sy épanouiront.

1. La chasse un vieal grognard... 


\section{CHAPITRE IT \\ L'ÉGONOMIE GOMMERGIALE}

$2^{\circ}$ LE COMnERCE EXTÉRIEUR.

En abordant le commerce extérieur, entrons-nous dans un domaine vraiment différent de celui que nous quittons? On peut se le demander. La fonction économique reste la même. Les procédés, les institutions, les organes destinés ì la remplir, les mœurs et l'esprit qu'elle développe, ne se modifient pas. C'est souvent les mèmes hommes qui commercent au dedans et au dehors. Il semble qu'il n'y ait de changé que le marché qui s'est agrandi. Cela est vrai, mais cette simple altération de proportion entraine avec elle une conséquence importante. Elle donne naissance à des rapports internationaux, et il suffit de cet élément de plus, pour introduire dans un sujet déjà si riche d'aspects, des aspects nouveanx : législation doumière, marine marchande et militaire, droit maritime, système colonial, etc. Tout à coup l'horizon sélargit et le commerce du monde se déroule devant les yeux. Si l’on n’y prenait garde, celui de la France, le seul dont nous ayons à nous occuper, viendrait s'y perdre comme la partie dans le tout. Mais plus le pays qu'on découvre est raste et séduisant. plus il importe d'y tracer et d'y limiter sa route. C'est uniquement pour reconnaître, pour relever les traces de nos compatriotes, que nous devons nous y engager. Quand ils 
nons ! ippillatitront, ce seril ou comme exportateurs ou comme importateurs ou enfin conme commissionmaires et cntrepreneurs de transports. Tels sont les trois caractères arec lesquels ils se présentent dans leurs relations arec l'étranger; tels sont ceux que nous allons successivement envisager.

COMMLRCE D'EXPOLTITION.

Au temps de llenri IV les articles d'exportation de lit France étaient, en fait de produits naturels, les grains, les vins, le sel, le pastel, les huiles, l'eau-de-rie, le safran, le micl, les laines, le bétail, les chitaignes, les graisses, les pruncanx, le bois, les chardons it foulon, les meules de moulin et, pour les produits manuficturés, le papier, les draps, les toiles, les étamines de Reims, les bougrans de Troyes, la sayelterie d'Aniens, la dominoterie ${ }^{1}$, la quincaillerie du Forec, le fil, les écritoires, la poterie, les soicries".

L'Espagne et le Portugal étaient le marché le plus important de nos exportations ${ }^{3}$. Elles n'auraient linit pour'tant que balancer leurs importations si nos blés, dont lit péninsule faisait venir quelquefois pour une valeur de 3 on '́ millions d'écus (28 49899' fr. 84 ou 37998126 fr. 4.) c.), n’araient amené un excédent en notre faveur. Elle ne

1. On entendait alors par lii les crucifix, les objels de dérotion et limageric. I'laidoyers d'Expilly. Plaidoyer VII.

2 Plaidoyers d' lixpilly. Plaidoyer VIl : Sur la defense du commerre aver lEspugne en 160\%. Leltre de Jacrques Robin au chancelier. Liouen, 20 aout 160\%. Areh. des allaires etrang. linance, 760 , fol. 116 ; Relition de Conlarini (IG13-1616) dans Le Rolazioni degli stuli Europei... nel secolu Xl'Il, raccolte ed annotate da X. Barozzi el dal G. Berchet. Sirie Il. Francin, I, 537. Causes de l'extréme cherlé. publié par Furman, lariétés hist el lill.,

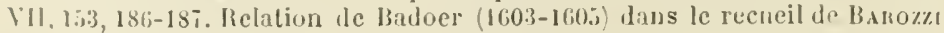
et Brincufr, I, 8i. Déclaration royale du ?l déc. 1605, Arch. nat., coll. liondonneau, série chronologique, à la date. Leltres el umbassales de Fresnes Canaye, 1, !cii.

:. Letlire précite de dacipues Robin.

i. J'ridoyers d'Expilly. Ubi supra. 
pouvait se passer de nos grains ${ }^{1}$. Nos toiles y étaient également très recherchées. En 1609 la Normandie lui en fournit pour plus d'un million d'écus d'or ( 1011311 : fr. 12) et la Bretagne pour plus de trois millions (30.339.34.3 fr. $37 \overline{7})^{2}$. Cette exportation aurait même été plus considérable si elle n'avait rencontré la concurrence de la contrefaçon suisse et allemande qui, profitant de la diminution de la production française amenée par nos troubles intérieurs, s'était en partie emparée, grâce à l'infériorité de ses prix, des marchés roisins ${ }^{3}$. Nousplacions au delà des Pyrénées pour plus d'un million d'écus d'or de papiers, d'ćtamines de Reims, de sayetteried'Amiens et de mercerie:. Par un contraste qui se manifestait aussi dans la littérature et les mœurs, le paysqui se trouvait le plus séparé du notre par la politique était celui qui s'en rapprochait le plus par l'intérêt économique. Par elle-même et abstraction faite de ses riches annexes des Pays-Bas et du Milanais, l'Espagne produisait peu et son trafic, sans cesse menacé par les corsaires anglais et hollandais, ne consistait guère qu'à échanger les marchandises des Indes occidentales contre les marchandises européennes qu'elle recerait des pays de production. C'était principalement de la France qu'elle tirail de quoi alimenter ce trafic. Toutefois, à la fin dı règne de IIenri IV, l'Angleterre et la IIollande nous faisaient à cet égard une redoutable compétition et nos importations dans la péninsule araient sensiblement diminué. Cela tenait aussi à ce que les colonies espagnoles araient cessé d'écouler tous leurs produits dans la métropole et sétaient mises, malgré les défenses de Plilippe III,

1. Relation de Contarini. Ubi supra.

2. Lettre précitée de J. Robin.

3. Ibid.

4. Du Fresne Canare signale en :602 une décroissance dans limportation de la mercerie; l'Espagne était arrivée à s'approvisionner en partie chez elle. Lettre de Du Fresnes Canaye au roi, 23 octobre 1602. 1, $456-457$. 
it commereer directement arec les Indes orientales par l'océain Pacilique.

L: Espagne n'en resta pas moins, pendanl le règne te llenri $\mathrm{IV}$, notre tributaire. Elle nous empruntait même des brats. Chaque année, des trompes nombreuses d'émigrants passaient les Pyrénées et s'embatuchaient ehe\% nos voisins pour la moisson et les travaux des champs. On les appelait des garaches (gararhos)'. Le moyen le plus efficace d'amener à composition le gouvernement du lini Caliolique quand il entreprenait contre nous une guerre de tarifs ou quand il ne protégeait pas suffisamment nos compatrioles contre l'anmosité de ses sujets, cétiait de sevrer ces derniers des importations françaises. Henri IV y recourul deux fois. Le 3 aoù! 1601, en représailles des mauvais traitements dont les lirançais avaient été victimes et de la violation de lambassade française par la justice espagnole, il interdit le commerce arec les Élats de Philippe 11 I et sanctionna cette défense par l'emprisonnement et la confiscation des marchandises. La seconde fois, ce fut en 160\%. Pour atteindre le commerce hollandais qui continuail à se faire sous le courert de la france, le snouvernement du Roi Catholique avait, l'amnée précédente, frappé d'un droit de 30 pour 100 les marchandises à destination ou en provenance de notre pays. A cette prohilition dissimulée, Henri répondit par une prohibition expresse. Mais cette prohibition n'était guère moins préjudiciable à ses sujets quà ceux de son adversaire ${ }^{2}$

1. Carew's Relation. Mémoires de Tatannes, 1). 8:. Le manifeste francois contre lit trop grande presomptiun des Espagnols, I62i. Ce nom venait de la ville de Gajp, dont la région montigneuse fournissait une partie de ces iuigrants. Dans la l'rovence et le combtat Veuaissin on apjelle encor' garots les montagnards qui descendent des Mpes on des Ceronurs pumr venir chereher du travail dans ees eontrées phus ferliles. Voy. Tu. Rintsiser.,

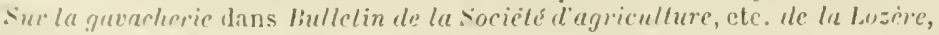
II (18:is, p. 4: i.

2. Le syndic des Etats du Béarn el de Navarre sopposa i la vérification 
et il y eut une sorte d'émulation à la tourner. Le commerce marilime surtout ne put être empêché. Les passeports stipulaieut bien que les bitiments français ne chargeraient et ne déchargeraient rien dans limmense empire qui obéissait au roi d'Espagne; mais il n'était pas bien difficile de dissimuler, au cours du royage, la violation de cette clause, ni de tromper an retour sur la provenance de la cargaison '. Les informations, les inspections organisces par Sully, qui tenait heaucoup ì faire repentir nos voisins de leur maurais procédé, furent imprissantes². C'était surtout du littoral de lOcéan, entre la Loire et la Giaronne, plus particulièrement des Sables-d Olonne, qui justement, par une sorte d'ironie, se trourait dans le gouvernement du surintendant, que partaient les vaisseaux coupables de ce conmerce interlope. Il y avait, dans le nombre, des raisseaux anglais ${ }^{3}$. Un des inconvénients de cette mesure était en effet de faire passer cette branche de nos exportations aux mains des Anglais qui, toujours ì l'affìt de pareilles circonstances, achetaient en masse les toiles et les grains de France pour les transporter dans les États de Plilippe III. Un autre inconvénient était de diminuer les traites foraines". La prohilhition suscita une active contrebande, et, parmi ceux qui s'y livraient, il y eut jusqu’à des gouverneurs de provinces et de villes". Le roi, tout le premier, dérogeait, en faveur de certaines personnes, à une mesure trop préjudiciable pour être rigonreusement appliquée. Cette gnerre com-

de l'édit d̈̈nterdiction altendu que c'ètait vouloir ruiner le pays qui élail fort pauvre et ne subsistait que de la vente de ses denrées aux Espagnols. Mémoires de La Forre, I, 172.

1. Arrêts du conseil da 10 juillet 1604 . Arch. nat.

2. Thuani historia, VI, 230. "Audit mois de mai fut envoyé un commissire du roi pour informer contre ceux qui avoiput trafiqué en kspagne." Diaire de Jacrnes Verlin sur les choses... qui se sont passées en La Rachelle.

3. Economies royales, 1II, :25-?9, 117, 163, 166, 2:31-2:32.

4. Hiel., 251, 234.

5. Ibid., $231-232$. 
mereiale, entre deux pays qui étaient en paix depuis cinf ans, était trop funeste à l'un et à l'autre pour durer longtemps. Jakques $\mathbf{J}^{\text {er }}$ qui néğociait la sienne arec l'lespagne, nflrit sa médiation. Les négociations souvrirent en Angleterre entre notre amhassideur, Christophe de Ilarlay, sieur de Beammont, et ceux du Roi Catholique et des Pays-Bas auprès du roi Jacques, mais elles trainèrent en longueur jusqu ì ce que sully ent reçu mission de les poursuive tout seul arec le nonce Buflalo, agissant comme médiateur, ballhazr de Zuniga, ambassadeur d'Espagne en France, et Alexandre Rovidius, sénateur de Mlilan. Le traité fut signé par ces plénipotentiaires, le 13 octolne lito'. Il abolissat le droit de 30 pour 100 et rélahlissail les anciennes relations commerciales de la France et des pays soumis à la domination de Philippe III. La reprise de ée relations était si vivement désirio en France, que le roi n'attendit pas, pour autoriser le transport du blé en Espagne, la ratification du Roi Catholigue'.

Nos vins, notre pastel, notre sel, nos linines trouraient leur principal débonché en Angleterre. Les raisseaux anglais, qui $y$ transportaient les vins de Bordeaux, formaient une réritable llotte que nos roisins appelaient la llotte de Bordeaux, et qui se déchargeait ì Londres de plus de la moitié de sa cargaison². Bordeaux était anssi pour eux l'entrepôt et le port d'embarquement des pastels du Lantraguais ${ }^{3}$. Ils recherchaient nos laines, qui étaient plus fines que les leurs, pour faire des creseaux, des serges

I. Ilenri IV i sully, 1 i octobre 1604. feconomies royales, VII, 26i-?69. Voir arret de mainlevée par provision des navires et marchandises saisis prour iufraction it la prohibition da commere avee l'Espagne et les l'ays. Bas, 16 décembre 160i. Arch. nat. Arrits du conseil il la dale. "Audit mois 'novembre l60i? a été permise la traite des blés en Espagne. "Diuire de J. Merlin sur les choses... qui se sont passées it La liorhelle.

2. dournal de l'ambassade d'llurault de Miisse en 1597-1598, fo 2:3, vo Arch. des allaires étrangeres. Jorlsci sinerri Ilinerarium Galliap (IGIsi) l'reifice.

3. Papiers de Simon Leconte aux archives de l'llòtel-Dieu de Toulouse. 
de Limestre, ete, ils les achetaient aux lieux de production, et les faisaient embarquer à Bayonne, à Saint-Jeande-Luı, à Narbonne, ì l'ecquais, à Aignues-Mortes, à Martigues'. C'était aussi le chemin de l'Angleterre que preniient en partie nos toiles, particulierement nos bougrans, notre papier, notre fil; elle nous achetait également du bois, des pruneaux, des écritoires, de la poterie, des chardons à foulon, des meules de moulin, des soieries ${ }^{2}$, etc. Ces importations égalaient le chiffre des importations anglaises.

On est tenté de s'en étonner, quand on connaì la jalousie avec larquelle l'Angleterre se réservait son marché, et l'ardeur qu'elle mettait à envalır les marchés étrangers. Elle arait définitivement acquis, sous Élisabeth, le sentiment de sa véritable vocation, ef était entrée résolument dans la roie qui, trop souvent aux dépens du droit des gens, derait en faire la première nation maritime et commerçante du monde. Elle s’était émancipée de la dépendance commerciale où l'araient tenue jusque-là les villes hanséatiques, ce qui avait amené une rupture complète entre elle et l'Empire. Elle sétait créé arec la Russie, les pays de la Baltique, le Levant, les États Barbaresques, etc., des relations directes qui étaient entretenues par autant de compagnies privilégiées. Plus elle donnait d'essor à l'initiative, à l'esprit des affaires et à l'amour du gain qui distinguent sa race, plus elle se défendait chez clle de la coneurrence étrangère ${ }^{3}$. Que l'on compare ce

1. Némoire pour l'établissement du trafic, commerce et négoce de mer en France. Bibl. nat., coll. Brienne, 319 , fol. 1. Le texte porte Morcesques, oủ nous arons cru reconnaitre une altération de Martigues.

2. "... goods transported from France to England since 1572 on canvass, buckram, paper, thread, inkhorns, prunes, pots, teazles, millstones, silks, wood and wines. "Calendar's of state papers. Domestic series. Elizabeth, 1601-1602. p. 270,

3. Sur le développement du commerce anglais á la fin du xvie et au commencement duxvir siècle. Voy. BeEr, Allgemeine Geschichte des Welthandels, 2 Abth., chap. 8 . 
que disent it eel égard Ilurault de Maisse sexprimant

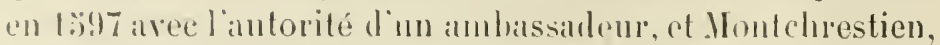
parlant. peu d'années apress la mort de II'nri IV, d'une silualion dont il avait été témoin pendant son síjour au delì de lis Manche, on verra eombien les Anghais restirent, pendant toute la duréde son règne et en dépil du traite de rommeree de 1606, fidiles au systeme prohibitif. L'importation de nos drapsen Angteterre était interdite'. Il en ritait de mème de toutes les marchandises que pourait fournir l’industrie britannique, of, pour celles qui lui blaient inconmes, l'importateur français devait domner aution quill emploierait l'argent provenant de leur vente ¿̇ l'achal de marchandises indigènes ${ }^{2}$. Les nôtres ne pouraient ètre vendues quà̀ une compagnie de fondation royale, qui avit le monopole du commerce avec la France, et qui faisait par conséquent la loi aux rendeurs ${ }^{3}$. lilles étaient, en outre, soumises, à leur entrée comme ì leur sortie, à un droit appelé coutume d'alranger, qui cititit plus fort d'un quarl pour nous que pour les commerrants des autres pays. Jacques ${ }^{\text {er }}$ avait étendu cette majoration à différents droits d'entrée et de sorlie '. C'était aussi spécialement sur nous que pesaient ceux de scuradge. de quayage et de surveyor. Enfin l'entrée de

1. Moxtcnnestex, Trailé de léconomie polilique, p. 92. Rouen,

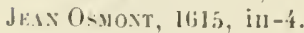

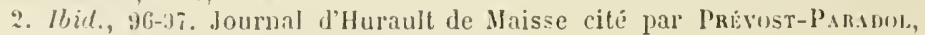
Elivabeth et Ilenri II (1863), p. 90.

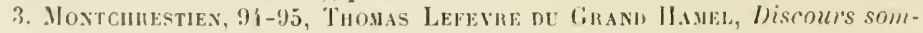
maive de la narigution el du rommerce de France, liouen, 1650, in-f: lemsaxgat, Mission de Thumery ste linissise, I, fis.

i. "...le Roy d'Angleterre, depuis son advenement a lit couronne, a mis j) lusienr's nowvelles impositions sur plusieurs marchandises entrates ou sortantes de son royaume que par cy devant on levoit sur tums esgalemint timt subjels questrangers; mais depuis il a octroyé an lond Crommeveld d. haussey ces chardres d'une qualriesme part sur la marchaudise applateInute aux lianeris ot, les ayans de nonvean tous rohils it la moilice. wn les continue tousjonrs sur nous ef mons faist on tousjours payer le double

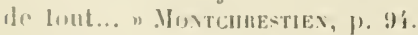

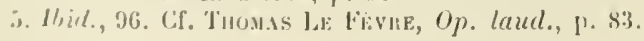


certains produits français tels que les cartes, la fleur d'annidon, était absolument interdite'.

Nos exportations pour l'Italie consistaient en draps, en toiles, en étamines de Reims, en sayetterie d'Amiens, ('n merceries, en quinciallerie, en blé. en bétail. En 1609 leur' chiffre sélerait ì un million d'écus d'or (10 11:311:3 fr. 12 ) an moins. Elles étaient balancées par les importations. Les échanges entre la France et la Flandre ne donnaient pas lien à un solde en numéraire. Ceux entre la france el l'Allemagne, se compensaient aussi presque également ${ }^{2}$.

COMNERCE D'MPORTATIOX.

Les importateurs appartenaient le plus souvent au pays de production. Il y arait pourtant des Français, qui se mêlaient d'acheter an lieu d'origine les marchandises étrangères et de les revendre en France. Leur nombre n’était pas aussi grand quil aurait pu l'ètre, si la législation et l'esprit de nos voisins s'étaient montrés moins hostiles aux concurrents venus du dehors.

Le traité de Vervins obligeait les rois de France et d'Espagne à accueillir dans leurs royaumes leurs sujets respectifs. Henri IV n'y manqua pas et c'est ainsi qu'interprétant largement cette stipulation, il refusa de livrer à Élisabeth des Irlandais au service du Roi Catholique, que la tempète avait forcés d'aborder en France ${ }^{3}$, c'est ainsi encore quil prit sous sa protection des Portugais établis à Nantes dans un intérèt commercial, que la population

1. Kermaingant, Op. laul., I, 458.

2. Expllty, Lbi supra. Nous devons signaler, en ce qui concerne la Flandre, le temoignage très dilférent de Du Plessis Mornay qui, au sujet des l'ays-lias, écrit en 158i, c'est-á-dire à une éporque où nos exportations étaient moins importantes: "Le pays vit principalement de lit France...." Jiscour's sur les moyens de diminuer l'Espagnot dans Mémoires el corresp., II.

3. Ilenri IV i Elisabeth, 5 octobre 1599. Lellies miss, V, 168. 
voulait faire expulser'. Les Espagnols, an contraire, étaient tres inhospitaliers pour nos enmpatriotes, el maltraitaient fort nos négociants. Lidelelentalo ${ }^{2}$ avait la principale responsabilité de ces avanies. La suspension des relations commerciales, arrêtée, comme nous larons dit, en 1601 , contraignit le gourernement de l'ksemrial ì ne plus les courrir de sa tolérance. Une ordomnanee, publiće dans tous les ports de la péninsule et notifiée par les soins de Ilemri I à tous les Français qui y trafiquaient, assura ì ceus-ci, it condition qü̈ls ue transporteraient pas de marehandise ennemie, laceueil et le traitement auxquels le traité de Vervins leur domnat droit. Cetle condition laissait la porte onverte ì de nouveaux conflits, car la France ne pouvait pas plus renoncer au profit du transit entre les Provinces-Unies et l'Espagne, que le Roi Catholique ne pouvait permettre ladmission des marchandises hollandaises dans son royaume. Ce fut encore lintroduction clandestine de ces marehandises que le gourernencnt de Philippe 111 insoqua, en 1606, pour en fermer l'entrée aux Rochelais, sujets si peu obéissants du roi, ajoutait-il, qu ïls ne méritaient pas son intérèt ni sa protection ${ }^{3}$. Nos commeregants n'ayant pas eu moins à souffrir de la malveillance intéressée des autorités locales que de celle de l'Adelantado, notre gouvernement obtint, la mème année, que leurs causes fussent soustraites a la juridiction de cos autorités et déférées au conseil. Les vexations qui attendaient nos commerçants en Espagne, ne Ies empêchaient pas d'aller en assez grand nombre y chercher fortune. La colonie française était assez considérable dans les principales villes de la péninsule, pour y aroir des con-

1. Lebeitr, the commerce de Nantes, 18:it, in-S, p. sĩ.

2. Amiral iles galires.

3. Lettre de Puisieux à La Boderie, 3 novembre 1606. Ambassades de La Boderie, 1, 10 '. 
suls qui élaient nommés par elle, commissionnés par le Roi Catholique et pourrus par le roi de France de lettres de prorision ${ }^{1}$.

Ceux de nos commerçants, que leurs affaires attiraient en Angleterre, avaient encore plus à se plaindre que ceux qui séjournaient en Espagne. L'exportation les laines anglaises leur était interdite, le monopole en appartenant à une compagnie indigène de fondation royale ${ }^{2}$. Le droit de sortie sur les serges, les futaines, les bajettes, les bombazins, les mocades, les camelots, les bas d'estanc était beaucoup plus élevé pour nos compatriotes que pour les autres étrangers ${ }^{3}$. Celui sur l'étain était du double, en attendant que l'exportation nous en fùt interdite pour' ètre réservée anssi ì une compagnie privilégiée ‘. Nous avons déjà dit que nos nationaux subissaient une augmentation d'un quart dans le droit d'entrée et de sortie perçu sous le nom de coutume d'étranger, nous avons parlé des droits de scavadge, de quayage et de surveyor. Le traité d'alliance défensive, signé à Blois le 29 avril 1:372, entre Charles IX et Élisabeth, avait complètement sacrifié les intérêts français, en accordant aux Anglais des arantages commerciaux dont les Français n'obtenaient pas la réciprocité. A la rérité, ce traité ne régissait plus officiellement les relations commerciales des deux pays. Il avait cessé d'ètre en vigueur, parce qüll n'avait pas été renouvelé par le roi dans l'annéc de son avènement ${ }^{5}$. Les négociations

1. “... Lettres de commission du roi d'Espagne du 6 juin 1607 par Iesquelles, sur la nouination faite par les marchans français de la personne dud. Dufiur, il auroit été commis à l'exercice dud. consulat. Ordonué que, dans trois mois aprẹs la signification du présent arrèt, ledit Dufau prendra de S. II. Iettres de provision dud. oflice de consul de la nation française à Séville... autrement lui a inhibé... de s'entremettre en l'exercice dud. consulat.... " Bibl. nat. luss. fr. 18175, f. 208.

2. Moxtchrestien, 9?. Th. Le l'evine, SI.

3. Th. Le Fèvhe, 8\%.

4. Loid, et Moxtchrestien, 96 .

5. Sir Ralph IVinwood's Memorials of affairs of State, London, 1725, 111, 
de l'Angleterre arec la France, de $1: 99$ ì 1604 , eurent précisciment pour but d'en obtenir le renourellement, et cest par suite de son abrogation lacite, que les Anglais furent de nonreau sommis au droit diubaine dont il les avait exemptés. Mais, en fait, les Anglais nen joussaient pas moins des avantages qu il leurarait concédés, et dont ils sétaient hìtés de profiter : ils avaient établi des entrepôts ¿̀ Rouen, à Caen, à Dieppe, ì Bordeanx " ; ils inondaient le marché français de leurs draps communs, dont les gens de la campagne ne pouvilient se passer, parce que l'industrie française ne leur en ollrait pas d’unssi économiques. mais qui étaient sourent fort défectueux ${ }^{2}$. La saisie de ces draps, prononcéc par arríl du conseil du 21 arril 1600 , le règlement adoptí par le conseil ì leur égard, la prohibition des étolfes de couleur unies donnèrent lien, entre les deux gouvernements, à de longues négociations auxipuelles mit fin le traité de commerce du2'́tévrier 1606. Ce traitś réroquait larrèt en question, et soumetlait les contestations auxquelles la qualité des draps anglais pourrait donner lieu, au jugement des commissaires des deux nations qui, sous le nom de conservatemes du commerce, devaient ètre établis dans les villes fróquentées par les commerçants anglais et français. Le mème traité prépara la solution d'une question qui était un sujel de grief pour les Inglais, et qui avait occupé une place importante daus les négociations : nous voulons parler des impôts que les villes, servant d'entrepôts aux marchandises anglaises,

"... demeurera encore en!re leurs successcurs, pourveu que, dans l'an apres que l'un desd. princes sera lécédé, son sucresseur déclare par antbassadeur et ses lettres au survivant qüil accepte les uêmes conditions et reut contracter la mpme confédérition... mais si dedans l'an, etc..." Исмокт, Corps dipl., l, part. 1, p. 212.

1. Ln arrêt du parlement de Normandie du joctobre 1 s.93 avait méme arcorde aux commercants anglais, établis a Caen, les priviléges des bourgcois de cette ville, notamment l'exemption du droit de sortie pour les toiles, bougrans et canevas. Tu. Le Fevire, Op. land., p. 190.

2. Winrood à Cecill, 12 juin 1601. Winwood's Memorials, 1, 331 . 
avaient mis sur ces marchandises, et qui s'ajoutaient ¿ux impôts d'État. Par exemple, les officiers municipanx de Rouen avaient doublé le droit d'octroi sur les draps anglais. Le commerce britannique avait été atteint par des taxes établies à Caen sur les creseaux (Kerseys), le plomb, l'étain, la cire, les harengs et par un droit d'entrée d'un éeu couronne (9 fr. 3̈3) par tonneau sur les vaisseaux abordant en Normandie '. Le traité, en confirmant les droits levés dans les deux royaumes au profit de l'État, et en ordonnant que le tarif en serait affiché dans les lieux publics, mit les municipalités des villes d'entrepoits en demenre de produire au conseil les lettres autorisant ces taxes, dont la perception devait ètre provisoirement continuée (art. 3 et '4). Enfin la situation des commerçants résidant dans les deux pays fut considérablement améliorée par l'abolition du droit d'aubaine. Ce vieux droit féodal et barbare s'exeresait d'une façon qui le rendait plus odieux encore; à la mort d'un marchand étranger, ses livres de commerce élaient examinés, souvent dérolés; ses caisses, ses comptoirs déralisés; on saisissait et on mettait sous sérquestre les biens de ses associés et mème de ses confrères, sous prétexte des relations d'affaires qu'ils araient pu aroir avec le défunt, et ils ne pouvaient obtenir mainlevée de la saisie qu'à prix d'argent. Le droit d'aubaine ne produisait qu'une somme insignifiante, que l'ambassadeur anglais Winwood estime à 200 couronnes (1870 fr. 68) par an. et

1. Calentars of stale papers. Domestir series. Elisabeth (1595-1603), p. 503, 2ic. Jucques lor. p. 229. "Par nos lettres patentes en forme de déclaration données a Fontaineblean le 1:e jour de norembre [160:3], nous arons ordonné qu'il seroit levé es villes maritimes, ports et haves de nostre duché de Normandie sur cenx de nos sujets dicelle province á la sortie et sur ceux des autres provinces ou estrangeres à leur entrée à raison de trois lives pour tonneam, selon le port et grandeur d'iceux vaisseaux, de quelque marchandise qu'ils soient chargés, excepté que, pour tonneau de charbon, mats, planches et bois ả bâtir, il ne sera païe que :0 sols seulement. " 11 mars 1604 . 
dont le roi gratıfiait le premier renu, mais il faisait perdre au pays bien darantage. Les marchands étrangers, exposés anx avanies que nous renons de décrire, se contentaient. d'envoyer leurs facteurs et leurs commis, qui logeaient en garni, et n’apportaient que la quintité de marchandises dont ils espéraient powoir se défaire immédiatement. Une fois affranchis du droit d'aubaine, les négoeiants élrangers nauraient plus de raison pour ne pas renir sétablir en France arec leurs familles, y former des approvisionnements considérables, et faire profiter notre pays de leur industrie ${ }^{1}$.

En 1603, la commission du commerce élabora et fit approuver par le conseil un projet dédit réglant la situation des marchands étrangers en France. D’après ce projet, ils pouraient, dans les trois mois postérieurs ì la promulgation de l'édit, sétablir à Paris et dans d’autres villes désignées par le roi et y faire le commerce en gros les matières premières, ainsi que des produits manufacturés en France ct des produits manufacturés à leétranger qui n'avaient pas leurs congćnères dans notre pays. Pour jouir de ce privilège, anquel s'ajoutait l'exemption du droit d'aubaine, ils devaient obtenir des lettres de naturalité, qui leur seraicnt accordées un an après qüils auraient lixé leur domicile dans l'une de ces villes, et qüils y auraient apporté des marchandises pour une valeur de 2000 écus au moins (18999 fr. 06). Ils pouvaient même jouir, dès la première année, de l'exemption du droit d'aubaine et du droit de faire le commerce dans ces conditions, en fournissant la preuve quils possédaient un capilal de 2000 icus, et en donnant caution de prendre, ì la fin de lannee, des lettres de naturalité et de continuer leur commerce en france. Dix ans après la rérification de ces lettres, ils devaient

1. Winwond a Cecill, 18 mars 1602, I, 3:19. 
ètre, sous condition de rester dans notre pays, absolument assimilés aux nalionaux ${ }^{1}$.

On roit que nous nous occupons autant de la situation des commerçants étrangers établis en France, que de celle des Français appelés par leurs affaires dans les pays étrangers. C'est qu'il y avait corrélation entre elles. La réeiprocité, alors mème qu'elle n'existait pas, restait le principe de ces relations internationales, la règle reconnue sinon appliquée, le but vers lequel elles inclinaient. Elle était méconnue, à nos dépens, dans celles que nous avions arec les Anglais. Nous l'arons dit et nous le répétons. Mais il ne faut pas croire que le régime dont jouissait chez nous le commerce étranger, fùl beaucoup plus libéral. Nous renons de roir que ce commerce ne pouvait se faire qu'en gros ", dans certaines villes, toujours sous le coup de saisies proroquées par les corporations, que la perspective du droit d'aubaine l'obligeait à limiter ses approvisionnements et à les ćcouler rapidement, enfin qu'il avait à subir les exactions des gourerneurs et des municipalités ${ }^{3}$. Il n'en est pas moins vrai que les négociants anglais qui avaient des établissements en France, causaient, gràce à l'abondance et au bon marché de leurs marchandises, un préjudice considérable à notre industrie et à notre commerce.

La Hollande et la Flandre nous envoyaient des serges

1. Comptes rendus de la commission, p. p. Chumpollios-Flieac dans les Documents historiques inélits tirés des collections mss. de la Bibliothèque royale, $1 \mathrm{~V}, 25,26,60-62,83$.

?. A l'époque où écrivait Montehrestien (1615), les négociants étrangers avaient cependant réussi à tourner eette défense et à rendre en détail et en boutiques. Seulement, leurs boutirues nétaient pas sur la rue, p. 43.

3. Le 17 juin 1600 , le lieutenant général du bailliage de Rouen condamne à l'amende un marehand tlamand pour avoir déchargé des balles de chanvre dans cette ville, sans la permission de l'échevinage. La sentenee renouvelle la défense faite aux étrangrers d'emmagasiner des marchandises sans cette permission, comme de les rendre à des étrangers n'ayant pas acquis droit de bourgeoisie et de les vendre au détail. Ces étranger's ne pourront vendre quä la halle. Collection Roxnoxxesu, série chronol., à la date. 
do Lejde, des camelots de Lille, des toiles, des savons, du heurre, des fromages et cétait en partie par les soins de commergants francais que ces produits entraient en France.

C'itait aussi sur ses vaisseaux qu'arlivaient la morue et le hareng dont elle faisait une si grande consommation. La pùche et le commerce de la morue lui appartenaient mème presque exclusirement, et étaient nos pècheur's normands, bretons, rochelais et basques qui en approvisionnaient les autres pays'. C'est surtout du littoral compris entre Ilendaye et Cilp-Breton que partaient les bateanx qui allaient pècher ce poisson à Terre-Neuve. Il y avait longtemps du reste que ces parages étaient fréquentés par les pècheurs basques, comme l'attestent l'ancien nom basque de l'ìle de Terre-Neure (ile de Bacalaos, ile des Morues) ${ }^{2}$ et celui d'ile de Cap-Breton que conserve encore, en somenir de l'ancien port de l'Adour, l'ìle voisine de la Nouvelle-lícosse. La topographie de Terre-Neuve offre une foule de noms de lieux, encore reconnaissables sous leur forme britannique, qui sont empruntés aux environs de Saint-Malo et qui témoignent de l'aflluence des pècheurs malonins dans ses eaux $^{3}$. Ce fut pour ses sujets de Saint-Jean-de-Luz et des villes roisines, que Henri IV songea en 1601 à créer entre Bayonne et Fontarabie au port de reluge bien nécessaire sul' cette côte dangereuse. A défiut de ce port, leur's

1. Moxtchestiex, p. 138. Un voyageur anglais, Packhurst, rapporte en 1578 qu'il a rencontré cent eiıquante vaisseaux franeais pêchant la morue a Terre-Nenve. Kotтеккам, Gesch. d. colonisation Amerikas, 11, 21:, d'aprés Ilackluyt. Ln arrêt du conseil du 7 août I60 déclara que la prohibition du commerce avec I'Espagne ne sappliquait pas au commerce de la ınorue, puisque ce poisson n'était pas un produit de notre pays, et autorisa les Basques à apporter leur pîche en Espagne, pour'vu qu'ils l'y transportassent directement et sans aborder en France.

2. Yous devons dire cependant qu'A. Reumont a essayé d'établir l'étymologic germanique de ee mot dans une nole de son travil sur Jean et Sébastien Cabot. (Archivio storico ital., II, dispensa v1, p. 42I).

3. Axrone, La fondation d'une république au temps de la Ligue. Mém. de la Sociélé académique de Maine-et-Loire, dXV (1871), p. 43. 
vaisseaux étaient contraints d'hiverner dans ce.ui de Pasages, en territoire espagnol ${ }^{1}$. Le Havre ne devait plus qu'aux bateaux terre-neuviers l'activité qui animait encore le sien. Pour l'augmenter, le roi affranchit les pècheurs havrais de l'impôt du sol pour livre qui frappait la morue ${ }^{2}$.

Si la France garda le monopole de cette pêche, elle se laissa peu à peu. léposséder par les Hollandais de celle du hareng ${ }^{3}$. Le nombre de raisseaux lollandais que ce poisson attirait dans la mer du Nord s'était élevé de 100 et 120 à 600 , à $700^{\circ}$ et mème à $1: 300^{\circ}$. Il y avait là de quoi éveiller les susceptibilités de l'Angleterre; n’était-ce pas dans ses eaux, dans une mer qui était comme une dépendance de son territoire, que ses rivaux maritimes recueillaient de quoi remplir " ces tonnes infectes qu’ils transmutaient en tonnes d ${ }^{\circ}{ }^{6}$ ? ") Le 6 mai 1609, Jacques I ${ }^{\text {er }}$ interdit aux navires étrangers la pêche du hareng sur les côtes d'Angleterre, d'Écosse et d'Trlande ${ }^{7}$. Cette défense, dirigée contre les Provinces-Unies, atteignaî̀ aussi, à un moindre degré, nos pècheurs, particulièrement les Dieppois. Ceux-ci se plaignirent ì IIenri IV qui fit solliciter par son ambassadeur une exception en faveur de ses sujets et qui obtint seulement que l'effet de la prohibition serait suspendu pendant un an ${ }^{8}$.

La France importait des États Barbaresques (Maroc, Algérie, Tunis et Tripoli) des cuir's, de la cire, des laines, du corail. Elle arait peut-ètre été la première à nouer des

1. Mémoires de Claude Grouslart, coll. Petitot, xu1x, p. 407.

2. Bonely, Hist. du Havie, II, 279.

3. Montchrestiex, 139.

4. La Boderie au roi, 20 juin 1609. Ambassades de M. de La Boderie en Angleterve (1750, in-12), IV, 364 .

5. BEER, Op. laud., 2 Abth., 202.

6. Minnelet, Précis d'histoire de France, 184?, p. 253.

7. LIeteren, IIistoire des Pays-Bas, trad. Delahaye, 1618, in-fol. 562, vo.

8. Sur cette affaire voy. Ambassades de M. de La Boderie, IV, 332. 
relations commereiales aree l'Alrique septentrionale, mais, dès 1:ian, son exemple avait élé suivi par les Anglais, les Hollandais et les Flamands qui étaient devenus pour elle, dans ces pariges, des rivaux redoubables'. La pieche et lia préparation du corail avaient lieu à Mascara en Algérie. Le monopole de ee eommerce appartenait à une ancienne compragnie, la Compagnie du corail, dont le capital se composail de vingt-1]ualre actions (quarutz), ì la majorité desquelles seprenaient les délibrírations. Un arrêt du conscil, du 8 février $1600^{2}$, eonfirma le mode d'administration et les priviligges de cette socićté. Ún autre arrèt, du même jour, rendu sur la requête du consulat de Marseille, lobligea is continuer par cette ville l'importation du corail et des atutres marchandises quielle lirait des Étals Barbaresques ${ }^{3}$.

1. Montcunfstiex, 131-13\%. "Mais les Anglois, Flamens et Hollandois l'ont [le tralic en Barbarie] entrepris depuis 60 ans... " Tho.n. Lli lívue, P. 56.

2. Arch. nat., coll. des arrêts du conseil.

3. Sur la requeste [présentée] au koy en son conseil par les assuciéz de l'ancienne compagnye du corail affin de faire revocquer le tiltre et qualité de gouverneur rue les sieurs de Moissac freres s'ittribnent au lieu de Mascaretz en Barbarye ou s'exerce le traffic du corail... combien... que telle entreprise puisse donner subject au Grand Seigneur par la permission duquel ils exercent led. traffic de le revocquer... au lieu quauparavant lis allaires se traictoient par tous les associéz... i la pluralité des quarat\% qui sont en nombre de vingt quatre en tout, dont lesd. de M. n'en font que quatre... Le lloy en son conseil, avant que faire droict sur la revocation de pouvoir donné ausd. srs de M., ordonne qu'ils seront assignéz et ouys en icelluy pour après 5 estre pourveu... et ce pendant veult... que les privileges octroyés à lad. compagnye du corail... leur soient conservés et le traffic continué entre lesd. associez suivant les advis qüilz prendront... it la pluralité des quaratz conformement it larrest provisionnel du $\mathrm{xxu}^{\mathrm{c}}$ janvier... 8 févier 1600 . - Sur la requite présentée au lioy par les viguiers, consuls et habitans de la ville de llarscille à ce que... deflences... soient faictes i Thomas et Antoine Lenclu (?), s' de Moissac... de transporter ailleurs qu'en lad. ville le traffic dud. corail, cuirs, cires, laynes et itutres marchandises qui viennent de Barbarye ny de s'ayder d'autres mariniers, pilutes ou ouvriers pour la manufacture dud. corail que des subjects de s. M... poü le «rand préjudice que leur ville qui est ansise en lieu sterille et ne se peut conserver ou acroistre qu'avec le commerce recerroit si ce diverisscment commancé par lesd. I. contre lia volonté... des autres assories... estrit... rontinué, outre l'interest de s. .1. pour les droicts quj se lerent sur les marchandises qui arrivent itu port d'icelle... Le lioy... 
Nos vaisseaux rapportaient des Açores le bois de teinture, le tabac, les cuir's, la cochenille débarqués par les navires qui y faisaient reliche en venant des Indes occidentales. Ce commerce, qui arait cessé à la suite de la tentative des Français pour semparer des iles en $1: 383$, arait un peu repris sous Henri IV, mais l'impôt mis par ce prince sur les marchandises de cette provenance et la surveillance plus sévère exercée par l'Espagne, le ruinèrent définitirement'.

Tous entretenions avec les îles du Cap-Vert et la côte occidentale d'Arrique (Sénégambie, Cûte d'Or, Guinée) un commerce assez actif. Comme il arrive toujours dans le trafic avec les populations sauvages, la valeur de nos importations dans cette région y était très inférieure à celle de nos exportations; nous y échangions de la menue quineaillerie et de la bimbeloterie contre de l'or' en poudre et en lingots, de l'argent, des perles et des pierreries, de l'ivoire, de l'ambre gris et noir, des cuirs, de la gomme arabique, de la cochenille, du tabac, du poivre, de la maniguette et enfin contre des esclares très durs au travail qui étaient transportés au Brésil.

Nos compatriotes avaient, dans les pays où ils faisaient des affaires, des bureaux, des magasins, des commis; ils y résidaient assez souvent mais s'y fixaient peu. Ceux qui s'expatriaient sans esprit de retour, cétaient ceux que le chômage, la misère, l'appàt de salaires plus élerés chassaient de leurs foyers, et ceux-là ne pouvaient trouver de moyens d'existence que dans le travail manuel ou dans des emplois subalternes ${ }^{2}$. Ils ne contribuaient donc en rien au développement du conmerce national.

ordonne ausd. s $^{\text {rs }}$ de $\mathbf{M l . .}$ de faire venir en lad, ville selon qu'il souloit... le corail, cuirs, cires, laynes et autres marchandises qu'ils amennent de Barbarye... S février 1600 . Arch. nat. Conseil des finances, à la date.

1. TH. LE FÈvre, 65-66.

2. "... la plupart de nos hommes sont contrains d'aller chercher ailleurs lieu d'employ et de travail, qui en Espagne, qui en Angleterre, qui 
Si les Français étaient peu tentés de fonder des établissements dans des pays civilisés mais fort inhospitaliers pour leurs concurrents commerciaux, étaient-ils allirés darantage par ces pays nouvellement décourerts, en grande partie inexplorés, dont les Portugais et les Espagnols avaicut montré la route aux autres nations curopécnnes? En abordant cette question, nous n'avons pas l'intention de faire l'hisloire des essais de colonisation tentés sous le règne de Ilenri $1 \mathrm{~V}^{r}$; nous ñavons ì nous en oceuper qu'iu point de rue de leur influence sur le commerce extérieur de la france.

Les progrès rapides des IIollandais dans les arehipels de la Sonde el des Moluques, et la fondation de la Compagnie lollandaise des Indes orientales (20 mars 1602) ${ }^{1}$ deraient inspirer à Henri IV lïdée d'appliquer à une tentative analogue les épargnes et l'activité du peuple qu'il avait pacifié et qui s'enrichissait sous ses yeux. Déjà une compagnie privée de minchands de Saint-IIalo, de Laval et de Vitré, sans attendre le patronage officiel, arait fait partir, le 18 mai 1601 , deux navires, l'un le Croissant de 400 tonneaux, l'autre le Corbin de 200 , et arait montré le pavillon français dans des mers qui ne le connaissaient pas. François Pyrard de Laval a raconté l'histoire de celte expédition, dont il avait fiit partie ${ }^{2}$. S'il en revint malade el plus paure (février 1611), il lui dut des succès d'imour-propre qui purent arloucir un peu ses déboires. La relation de son royage eut tant de lecteurs, qu'elle parvint, en einq ans, à sa troisieme édition (1611-161:3), et il fut lui-même fort recherché par un public avide d'entendre de sa bouche ses

en Allemagne, qui en Flandres. "Moxtchiestiex, p. 35. Il est certain que l'auteur, précierupé par la pensée de faire ressortir les dangers de notre situation économique, a exagéré cette émigration.

1. Sur l'origine et le rapide développenent de la colonisation hollandaise aux Indes orientales, voy. BeEn, Op. luul., 2. Ablh., p. 179-180.

$\therefore$ loyages de Frangrois Pyrard de Lacal, ldili, 1, 4. 
observations et ses impressions, indice remarquable de la curiosité cxcitée par ces riches et mystérienx pays ${ }^{1}$. En 1603 , l'attention du roifut attirée sur eux par un imbassadeur de Perse, qui était venu lui demander son appui pour en chasser les Portugais. Il refusa de s'associer à des actes d'hostilité contre l'Espagne ${ }^{2}$, avec larpuelle il était en paix, et conseilla à l'ambassadeur' de s'adresser aux provinees de IIollande et de Zélande ${ }^{3}$. L'année suivante, un homme qui avait fait plus d'un voyage dans les contrées du Pacifique et qui les comnaissait bien ${ }^{4}$, Gérard de Roy, s'associa plusieurs personnes, entre autres Antoine Godefroy, trésorier de France à Limoges, et demanda au roi d'autoriser la création d'une compagnie de commerce dans ces régions. Cette Compagnie assumait tous les frais de l'entreprise, moyennant un monopole de quinze ans à partir de son premier voyage. Le roi lui désignerait un port pour y équiper sa flotte et faire entrer en franchise les marchandises rapportées de ce voyage, lui fournirait deux canons par vaisseau et des munitions de guerre et obtiendrait pour elle du prince Maurice la permission d'acheter ou de faire construire des vaisseanx dans les Provinees-Unies et d'en tirer des marins. Enfin la participation aux affaires de la société ne devait pas entraîner dérogeance. L'association était ouverte à tous pendant six mois après le retour de la première expédition, moyennant un apport de 3000 livres (8768 fr. 80) au moins. Ces conditions furent homologuées, le $1^{\text {er }}$ juin 1604 , par un arrèt du conseil qui désigna Brest

1. Lefizelier, Le voyageur Francois Pyrard est-il né à Laval? Bullelin de la Socièlé de l'industrie de ln Mayenne, III (1855), p. 57.

2. On sait que, depuis 1580 , le Portugal et ses colonies faisajent partie de la monarchie espagnole.

3. Calendar of state papers. Colonial series. East Indies. China and Japan, $\mathrm{n}^{\circ} 323$.

4. "... la cognoissance particuliere que vous avez des ports et havres des Indes orientales pour les royages par vous cy devant faits. "Bibl. nat. Fonds Brienne, 319, fol. 110. 
pour port d'attache. Le 29 juin, la commission de capitaine général de la flotte royale des Indes orientales fut délivrée ì Gérard de Roy. Elle lui domait pouroir de faire construire et d'éfuiper' des vaisseaux, lui permellait de s'emparer de ceux qui altaqueraient les siens, et de garder pour lui et ses associés les quatre einquièmes de la prise, et lui ordonnait de réunir le plus tôt possible sa flotte à Brest pour meltre ì la roile ${ }^{1}$. Les choses 11 allèrent pas au gré de l'impatience du roi. En 1609, la Compagnie n'arait encore fait partir aucun navire. En revanche, une partie du capital, fixé ì 4 millions d’écus à la comronne (404:32460 fr. :30). avait élé versée; quatre bitiments allaient lever l'ancre à Saint-Malo; la plus grande partie de la flotte était achelée; un marin renommé, Simon Dansa, devait escorter les convois arec sa llollille, que d'autres voiles viendraient grossir ${ }^{2}$. Le président Jeannin, chargé de négocier une trève entre. l'Lspagne et les Provinces-Unies et très partisan des royages d'exploration ${ }^{3}$, arait profité de son séjour aux Pays-Bas pour procurer à la Compagnie des hommes et des navires; il se servait pour cela d'un certain Isaac le Maire, originaire de Tournay et dévoué à la France, avec lequel il avait des entrerues secrètes; il consultait le cosmographe d'Amsterdam Planciusł. Un IIollandais, Peter Lintgens, soccupait aussi de recruter dans son pays des marins et des ouvriers ${ }^{3}$. Ces préparatifs causaient aux Provinces-Lnics un vif mécontentement. Leur agent, Aerssens, reçut l'ordre de protester contre l'établissement de la Compagnie et contre les moyens employés pour la constituer, contre le rôle qu'on voulait donner au Flamand Dansa, contre l'embauchage de marins

1. Mas. Brienne 319, fol. 110.

$\therefore$ Culendars of stale papers, même série, no iti\%.

3. Marc Lescarbot dans la dédicace de son Histoire de la Youvelle France atu prẻsident Jeannin.

4. Végociations du présidenl Jeannin, coll. Pelitot xm, 2ii et suiv.

5. P'uldprsox, Heinrich IV and Philip III. 2 Theil, ]. 3is. 
hollandais. Cette protestation était accompagnée de paroles comminatoires : les IIollandais menaçaient d'aborder les vaisseaux français et de pendre tous les Flamands qui sy trouveraient ${ }^{2}$. A la suite de cette déclaration énergique, formulée en 1610 , le silence se fait sur cette entreprise, et le silence ici, comme il arrive sourent, indique cette phase d'ajournement et de recueillement où les grandes aflaires s'enlisent ou mùrissent.

Celle-ci n'était que suspendue ${ }^{2}$ : le gouvernement de Louis XIII la reprit. La Compagnie fut constituéc par un édit en $161 \%$, et la flotte de l'amiral Montmoreney fit deux royages qui mirent en évilence les dispositions favorables des indigènes et l'hostilité des IIollandais ${ }^{3}$. Malheureusement, cette institution n'eut jamais qu'une existence légale : les Provinces-Unies conservèrent le monopole du commeree des épices et jamais la concurrence française ne le mit en péril. Il serait passé à notre pays et le commerce de l'Europe avec l'Extrème-Orient aurait dès lors ad opté la voie qu'il suit aujourdhui, si IIenri $1 V$ avait pu réaliser les rues del'un de ses meilleur's serviteurs; dans son Discours sur les moyens de dimimuer l'Espagnol écrit en 1.591, Du Plessis Mornay indiquait comme un de ceux qui devaient l'atteindre de la façon la plus sensible l'établissement d'une lignne de navigation qui, partant des Moluques, de Diu, de Goa,

1. Calendar's of state paper's. Même súrie, nos 469,473 , 4i6. Réponse de Ilenri IV aux représentations d'Aerssens le 23 février 1605 cité par $M_{A s s o x}$, Hist. du commerce du Levant, p. 37?, no 4 .

2. "... le feu Roy... a souvent désiré... l'établissement d'une telle compagnie qui, toufefois, n’avoit pas encore réussi mais maintenant, etc...." Louis Xlll à l'échevinage et aux habitants de Bayonne pour les convier a participer à la création de cette compaguie, 6 décembre 1618. Bulletin du comilé historique, III, 156 et Massox, llist. du commerce franģais dans le Levant, 1. 109, 113. La stérilité de cette tentative n'empêchait pas, bien entendu, les royages particuliers aux Iudes orientales. En 1610, le vaisseau le Montmurency en rapportait des épices, sur lesquelles il réalisait un bénéfice net de 400 p. 100. Memoires chronologiques pour servir à l'hist. de Dieppe (1785) I, 395.

3. Thoman Le Fèvre, 105. 
d'Ormuz, etc., aboutirait ì Suez, d’où les marchandises seraient transportées en six jours ì dos de chameaux jusqüi Beyrouth, Mlep, Tripoli de Syrie, Damietle. Mlexandrie, etc., et reprendraient la mer pour ètre débarquées dans les principaux ports du hassin de la Méditerranée ${ }^{1}$.

Complètement stérile fut l'autorisition donnée en 1608 par IIenri IV au sieur de Llopital, de fonder au Cap, par la conquète, des établissements quill posséderait sous la souveraineté du roi".

Si la France trourait la place déjà prise dans les Indes et l'archipel Indien par les Portugais et les IIollandais, elle rencontrait dans les deux Amériques des colonies déjà arrivées à un assez grand développenent pour affecter l'indépendance, et dont l'Espagne, leur métropole, se réservait, avec un soin jaloux, le débouché et les produits. Les Français, qui tombaient dans les mains des Espagnols et qui élaient soupçonnés de faire le commerce arec l's colonieshispano-américaines, étaient mis à mort ou envoyés aux galères. Vaincment, les traités avaient tracé une ligne qui séparait la zone ouverte à la liberté du trafic et celle qui restait abandonnée à la piraterie et au droit du plus fort ; qu ïls les trouvassent dans la première, c'est-à-dire au nord du tropique du Cancer et à l'est du méridien des Açores, ou dans la seconde, c'est-à-dire au sud et à l'ouest, les lispangnols faisaient subir le même sorlt à nos compatriotes ${ }^{3}$. Il nous était impossible de fonder, dans les pays occupés par eus, des colonies ni mème des comptoirs, tant que nous ne disposions pas d'une marine militaire capable de protéger nos vaisseaux marchands.

1. Jans Mémoires el corresponilance de Du l'Lessis-Monxay, II.

2. PHuppsis, Ubi supra, 3ii-3is.

3. TH. Le l'Ève, Op. laud., 6', 9i-99. Remontrance présentée au roi et a son conseil par les capitaines de la marine française dans Levor, Ilist. de lirest, I, 93. 
C'est vers l'Amérique du Nord qu'il faut tourner les yeux pour voir des efforts suivis et couronnés dans une certaine mesure de succès. Les entreprises de colonisation dans la Nouvelle-France, qui comprenait le Canada et l'Acadie c'est-à-dire la Nouvelle-Écosse, exercèrent une influence sćrieuse sur notre commerce.

Au marquis de la Roche (1:39) et à Chauvin (1:399), succéda une Compagnie formée par le commandeur de Chastes et où entrèrent les principaux négociants de Rouen et de La Rochelle. Le privilège de la traite des pelleteries lui fut accordé.

Le commandeur de Chastes fit entreprendre par deux officiers de la marine royale, du Pont-Gravé et Champlain, un royage d'exploration du cours du SaintLaurent et des pays quilil arrose. Ce voyage révéla l'existence de richesses naturelles qui étaient propres à attirer les colons : pêcheries, bois de construction, prairies, mines de cuivre et de platine.

A la mort du commandeur de Chastes, qui eut lieu pendant ce royage (1603), Pierre du Guast, $S^{\mathbf{r}}$ de Monts, gentilhomme saintongeais, derint le chef de la colonisation. Le roi le nomma son lieutenant général en Acadie, du $40^{\circ}$ au $46^{\circ}$ degré. Sa commission portait qu'il rechercherait et exploiterait les mines d'or et d'argent et autres, le roi se réserrant le dixième du produit ${ }^{1}$. Henri IV accorda à de Monts et à ses associés le monopole du commerce pendant dix ans ${ }^{2}$. Les commis des traites foraines ayant saisi ringt-deux balles de castor expédiées par lui en France, le roi lui en donna mainlevée et déclara que les marchandises provenant de la Nouvelle-France ne payeraient que

1. On trouvera sa commission en date du 8 novembre 1603 dans Marc Lescarbot, Mist. de la Nouvelle-France, $2^{\circ}$ édit., 1612.

2 . Lettres du roi adressantes aux amirautés du royaume, 18 décembre 1603. lbid. 
les droits d'entrée dus par celles du cru passant diune province dans l'autre ${ }^{\prime}$.

Henri IV faisait respecter le privilege de la Compagnie de la Nouvelle-France par les nations étrangères. C'est ce que constate une lettre où il demande aux Etats-Crénéraux des Provinees-Lnies d'y interdire le trafic ì leurs nationaux. Ce privilège était une des raisons qui empèchaient le parlement de Rouen d'enregistrer la commission de de Monts. Dans les lettres de jussion que le roi hii adressa le 17 janvier 160 ', il représente que l'entreprise n’a pas le caractere d’un véritable monopole, puisquïl est permis i tout le monle d'y participer en entrant dans la Compagnie ${ }^{3}$. Cette Compagnie fut constituée par acte notarié passé à Roven le 10 févier 160 \%. La répartition des frais et des bénéfices était fixée au sol la livre. De Monts rersait en son nom et an nom d'un groupe de commerçants ronennais dont il garantissait l'entrée dans la société, le montant approximatif du tier's du capital c'est-ì-1lire 18000 livres $(; 2612 \mathrm{fr}$. 79). D'iutres capitalistes, se portant forts pour un aulre groupe de commerçants appartenant à la ville de Saint-Jean-de-Luz, versaient 10000 livres (29 229 fr. 33) ì valoir sur un autre tiers qu'ils s'engageaient à souscrire. Pour la souscription du dernier tiers, on comptait sur les commerçants de La Rochelle. Ce capital n'était destiné qu’à l'équipement de deux navires et aux frais d'un premier voyage'.

Le centre principal de la traite des fourrures était ì Tadoussalc. De Monts créa un second entrepôt à l'ortRoyal (aujourd'hui Annapolis) et il y transporta la colonie. En 1606, commença sérieusement l'exploitation agricole.

1. Lettres du roi a la cour des aides de liouen, aux maitres des ports, officiers de l'amirauté et des traites foraines de Normandic, 8 fúvier 1605.

2. Lellies miss., VII, i6.).

‥ Letlres miss., V'II, 897, 899 .

4. Gos-elsi, La Nommandie au Cunada. Académie de Rouen, 1872. 
De nouveaux voyages d'exploration mirent en évidence la fertilité du littoral depuis le $4:^{\mathrm{e}}$ degré et demi de latitude jusqu'au $41^{\circ}$, et la colonisation semblait appelée ì réussir lorsque, au commencement de 1607, sur la requête des marchands de Saint-llalo, le eonseil du roi enleva à la Compagnie son monopole. Celle-ci qui déjà, l’année précédente, avait souffert de la concurrence des Basques et des Ilollandais, se royait privée par l'arrêt du conseil du moyen de relever ses affaires; il ne Iui restait qu'à se dissoudre ${ }^{1}$. Cependant, en présence des preuves fournies par de Monts sur la richesse et l'avenir de la colonic, le roi renouvela pour un an le privilège et, encouragée par cette faveur, la société fit partir trois vaisseaux en mars 1608. Les colons qu'ils amenaient, dirigés par Champdoré et Champlain, repeuplèrent Port-Royal et fondèrent Québec (1608).

Champlain dirigea dès lors ses explorations dans le Cauada proprement dit. En 1609, il occupa l'embouchure de la rivière des Iroquois, affluent du Saint-Laurent et le lac Champlain. Il créa au saut Saint-Louis un noureau comptoir et un nouvel établissement et, aprẻs la mort de IIenri II', remonta jusqu'aux lacs du cours supérieur du Saint-Laurent.

Quels furent, au point de vue eommereial, les résultats des décourertes et des établissements de Champlain et de ses prédécesseurs? Les ressources naturelles du Canada et de l'Aearlie sont attestées par toutes les deseriptions ${ }^{2}$ et mieux encore par leur prospérité actuelle. Cuirs, fourrures, mines, bois de construction, chanrre, grilins, pèehe, etc., il y avait là de quoi alimenter un mouvement d'affaires fort actif aree la France et l'Europe. D'un autre cùté, le

1. Lescarbot, 591,592. Le P. de Rochemonteix, Les Jésuiles el la NouvelleFrance au $\mathrm{XTH}^{\circ}$ siècle, I, 20 .

2. Lescarbot, Champlain, Denys. 
public manifestait pour tout ce qui touchait aux " terres neures " un vif intérèt ${ }^{1}$, qui finit par proroquer un courant important d'émigration ². Mais au début les émigrants se composèrent en majorité de vagabonds, de mendiants, de condamnés graciés pour la eirconstance, de gens tarés quion embarquait de gré ou de force et ì qui manquaient également et les capitanx et le goùl du travail $^{3}$. La partie saine et laboriense de cette population soccupa presque exclusivement du commerce des fourrures et des cuirs. Le Père Charlevoix écrit qu'en 1608 l'attrait du négoce des pelleteries avait presque lait abandonner en Acadie la culture de la terre, au point que les colons étaient menacés de disette". Ce fut à ce négoce que les explorations et les fondations des de Monts et des Champlain donnèrent le plus d’impulsion. En 1608, il attirait sur les côtes d'Acadic et au Canada plus de quatre-ringts raisseaux ${ }^{5}$. Il y eut aussi une autre industrie qui proliti de ces essais de colonisation : ce fut la pèche. Elle devint plus active, elle exploita de noureaux parages. Nous parlons de celle que renaient faire, pendant trois mois de lannée, nos pêcheurs des côtes de l'Oecean. Quant à la pèche sur place, qui aurait évité à nos terres-neuviers un aussi long séjour dans des mers glaciales, qui leur aurait permis de faire trois royages par an au lieu d'un, puisqu'ils n'auraient eu qu'à venir charger le produit de celle des colons, elle ne sorganisa pas d'une façon sérieuse ${ }^{6}$.

1. Descun ups. Les découverles et l'opinion en France au X'le siècle. Revue de géogrrephie, .ivi.

2. "... la multitude "l'hommes qui vont aux terres neures. "Mémoires de Tavannes, coll. Michaud, p. 8:.

3. La rencontre merveillense de Piellaigretle avee Uo Guillaume revenant des Champs Élysées... (1606) dans Var. hist. el litt., III. L'archi sot, 1605. Hirl., Vil. Pанкмах, les pionniers frangais dans l'Amérique du Nord, p. 165.

4. Hisloire de la Noucelle-France (174) 9) vol. in-12, I, 190.

j. Loyages de Champlain, cités par Porksox, III, 586, no2.

f. LECCARHot, Sis. DENYs, Descriplion géographique el historique des cúles de l'Amérique seplentrionale, 1, 94. II, 249. 
La traite des pelleteries devint moins lucrative lorsque, la prorogation du privilege de la Compagnie de de Monts ayant expiré le 7 janvier 1609, il fut libre pour tout le monde ${ }^{1}$. Les saurages firent alors payer les peaux de castors beaucoup plus cher. "Aujourd'hui, écrit Marc Lesearbot", depuis la liberté remise, les castors se vendent an double de ce que le $\mathrm{S}^{r}$ de Monts en reliroit. Car l'avidité a été si grande quà l'envi l'un de l'autre, les marchands ont gâté le commerce... " Cette hausse, qui atteste l'importance prise par le trafic des pelleteries, pourait en arrêter l'essor, car il faul de gros bénéfices pour allirer et r'etenir' les commerçants dans une voie nouvelle et liasardeuse. Ce danger ramena Henri IV au monopole. La Compagnie privilégiée crééc en 1613 par Champlain et qui lut ouverte, moyennant le rersement d'un capital, à tous les négociants, ne fut que la réalisation d'une idée à laquelle l'expérience arait fait revenir le gouvernement précédent.

La politique coloniale, conme on dirait aujourd'hui, eut, en ce temps-là aussi, ses partisans et ses adversaires. Parmi ces derniers on n'est pas étonné de rencontrer Sully. Il est difficile de contester la clairvoyance qui l'amenait à détourner notre pays de " la conservation et possession de telles conquêtes comme trop éloignées de nous et par conséquent disproportionnées au naturel et à la cervelle des François, que je reconnois, à mon grand regret, n'aroir ni la persévérance ni la prévoyance requises pour telles choses et qui ne portent ordinairement leur vigueur, leur esprit et leur courage qu'à la conservation de ce qui leur touche de

1. Arrêt du conseil du 9 octobre 1609 permettant aux Malouins, aux Bayonnais et a tous les sujets du roi, de commercer librement au Canada, malgré le monopole du $\mathrm{S}^{r}$ de llonts, qui sera indemnisé des frais de ses voyages dans ce pays par la somme de 6000 livres (16 180 fr. 98), laquelle sera répartie, pour lannée présente, par les juges des amirautés de SaintNalo et de Bayonne, sur les navires ayant trafiqué lad. année audit pays à proportion du tonnage de chaque vaisseau. Bibl. nat. Franç., 18176, fol. 4.

2. P. 611-612. 
proche en proche et leur est incessamment présent devant les yeux, comme les expériences du passé ne l'ont que trop fait connoitre, tellement que les choses qui demeurent séparées de notre corps par des terres ou des mers étrangìres ne nous seront jamais qu'ì grand'charge et ì peu d'utilité ${ }^{1}$ " En Amérique pourtant, l'arenir devait Ini donner tort, car, si nous n'avons pas conservé nos colonies américaines, cetle perte a étó la consífuence de nos revers en Europe heaucoup plus que de nos fautes coloniales ef elle n’a pu eflacer l'empreinte du génie français sur des pays où les sympathies des populations indigènes avaient accueilli nos premiers pas?

COMMERCE DE COMHISSION.

Les documents que nous avons recucillis ne nous présentent jamais des commerçants français faisant la commission à l'étranger pour leurs compatriotes. Ce silence sexplique par les obstacles que le commerce français rencontrait dans la législation et les mours des nations voisines $^{3}$. Quant anx commissionnaires agissant en France pour le compte de l'étranger, il faut distinguer les commissionnaires d'achat et les commissionnaires de vente. Les commissions d'achat s'exécutaient librement; elles favorisaient le commerce national et ne faisaient tort ì personne. Il en était autrement des commissions de vente; elles amenaient sur le marché des marchandises étrangères, créaient une concurrence ì nos négociants et amraicut rendu illu-

1. Sully au président Jeanniu, 28 férrier 160s. Cinq cents Colhert, 2v:3 fol. 236.

2. Pankux, Les pionniers frans'ais dans l'Amérique du Vorl, p. 201-205.

3. "Que Vos Mnjestés prennent la peine de s'enquérir si nos miltchands, ont quelques commissionnaires, j'enten frour manier leur argent et leur amasser les marchindises du pays au préjudice des citoyens, Espangnols en Espragne, Anplois en Angletere, Wumans en Flandre. Si l'on rous en nomme un, ce sera un corbeau blanc." Moxtchisestien, p. \$i. 
soires les restrictions apportíes à cette concurrence et le monopole des corporations. Aussi ne pouvaient-elles légalement ètre exécutées que par des commissionnaires ayant un caraclère officiel, limités en nombre et daus les conditions où leurs commeltants auraient pu rendre enx-mêmes c'est-à-dire en gros, dans les marchés et après examen des gardes jurés ${ }^{1}$. Ces commissionnaires en titre d'office furent créés par un édit du mois de mar's 1.386 qui, rappelant les ancienues ordonnances mises en oubli, n'autorisitit les étrangers à vendre que dans les foires et, en dehors des foires, sous les réserves que nous venons d'indiquer. Les commissionnaires institués par cet édit étaient tenus, lor'sqüils faisaient une vente au comptant, de payer leur commettant dans les vingt-quatre heures; dans les ventes à terme, ils garantissaient la solvabilité de l'acheteur et faisaient connaître son nom et le prix au rendeur, auquel ils remettaient l'argent quinze jours après l'échéance. Ils lui avançaient, sur sa demande, les frais de transport et le montant des impôts, dont ils se remboursaient sur le prix arec un intérêt de $10 \mathrm{p}$. 100 . Ils donnaient caution et étaient solidairement responsables enrers leurs mandants qui ponvaient avoir recours sur leur bourse commune. Leur commission était de 6 deniers pour livre, e'est-à-dire de 2 et demi p. 100. Ils ne pouvaient être commerçants ni s'associer arec des commerçants. Enfin, ils étaient exempts des charges publiques ${ }^{2}$.

Nous avons dit qu'en droit les négociants étrangers ne pouvaient s'adresser qu'ì ces commissionnaires pour faire vendre leurs marchandises en France. Nous arons semblé indiquer, par là, qưil en était autrement en fait. Telle est en effet notre pensée. L'édil de 1386 défend formellement

1. Il en était de mime pour les marchandises des forains, mais nous n'avons à nous occuper ici que des marchandises étrangères.

2. Fontaxon, I, 10:5. 
et sous des peines sévères à d'autres et nolamment aux commerçants, de vendre pour le compte de négociants élaungers ${ }^{1}$. Mais la pratique interdite par cet édit était bien tentante et en mème temps bien facile à dissimuler; aussi nos commerçants ne se laisaient-ils pas faute de s'y livrer, dautant plus que les règlements de leurs corporations ne le leur défendaient pas et qülls trouvaient là un accroissement fort profitable de leurs affiires. Il n'y avait, à notre connaissance, que les statuts des mereiers qui le défendissent ${ }^{2}$. C'eùt été là une exception considérable, vu le grand nombre d'irticles qu'embrassiat la mercerie, si cette interdiction avait été observée, mais Savary nous apprend que de son temps elle ne l'était pas. Elle ne l'était pas davantage sous Ilenri IY. Montchrétien, qui écrivit quelques années après la mort de ce prince, nous apprend que les étrangers faisaient faire leurs ventes comme leurs achats en France par des commissionnares ou des facteurs et déplore l'extension que ce mode de procéder donnait à leur commerce, il déplore aussi - et par là il justifie notre affirmation - le concours quills trouvaient à cet égard che\% nos compatriotes ${ }^{3 !}$.

Ils pouvaient, du reste, se passer de ce concours, car ils avaient en France de nombreux commissionnaires de leur pays auxquels ils préféraient s'adresser. Profitant de la libéralité avec laquelle le nôtre prodiguait les lettres de naturalisation, des Espagnols et des Portugais judaïsants, des Anglais et des Flamands qui avaient de bonnes raisons

1. "Aussi est défendu a tous marehans ou autres habitans desd. villes de prester leur nom ou marque ausd... forains ny vendre lesd. marchandises par commission sous lenr nom ny autrement, sous peine de confiscation de marchandises et de 500 escus (4i19 fr. 09) d'amende it l'encontre de celuy qui l'aura... vendue... par commission. "lioxtaxon, loc. cil.

2. "... delfendons a tous marchands... estre courtier commissionnaire pour aucun etranger ou forain..." Ord. de juillet 1601, art. 10, dans Recueil dordonn., shuluts et réglements du corps de lamercerie, 1767.

3. 1. 43, 48, 3i, 7i. 
pour quitter leur patrie, ouvraient, pour le compte de leurs compatriotes, des maisons de dépôt et de commission et ne restaient parmi nous que le temps de faire fortune ${ }^{1}$. Le gouvernement n'envisageait pas cette immigration avec la même inquiétude que ceux à qui elle venait faire concurrence. L'intérêt majeur à ses yeux, c'était de ranimer et de dérelopper le trafic. Là où la population manquait pour cela, il n'hésitait pas à l'attirer du dehor's. C'est ainsi qu'il accueillait favorablement l'idée de Boissise, son ambassadeur en Angleterre, de faire de Calais l'asile des Flamands et des Wallons rictimes des lois anglaises contre les catholiques et même de certains Anglais inquiets de la persécution religieuse que la mort attendue d'Élisabeth pourait déchainer contre eux ${ }^{2}$. Déjà beaucoup de Hollandais et de Zélandais s'établissaient dans cette ville pour y faire, sous le couvert de la France, le commerce avec

1. " Les étrangers corrompent nos mœur's et nous ruinent le trafic. Les villes de cette province sont pleines d'Espagnols et Portugais judaïsants, Anglois et Flamands de la religion p. r. qui, bien souvent bannis de leur pays, nous apportent leurs mauvaises habitudes..., séduisent les François qu'ils prennent à leur service, attirent à eux tout le trafic étranger. Font les Espagnols et Portugais tout le trafic pour Espagne et Portugal, les Anglois et Flamands celui de leurs provinces comme commissionnaires des étrangers, au lieu qu'ils devraient tous passer par les mains des Francois et nacheter rien de la première main, et cela sous ombre de lettres de naturalité qu'ils ont jusqu'à présent obtenues avec trop de facilité, non pas arec dessein de demeurer en France, car ils n'y font aucunes acquisitions d'immeubles ny font construire aucuns vaisseaux et, ayants tout leur bien en une cassette, le transportent quand il leur plait. . . . Nous ne leur oserions porter rien de ce qu'ils font ou peuvent faire en Ieur pays qui ne soit confisqué, bien que, par le traité de 1606 , registré en 16007, art. 13, par lecuel il semble que l'on ait, de gaieté de cœur, trahi la cause et l'honneur de la France, les marchandises angloises apportées en France étant jugées vicieuses, il ne nous soit pas loisible de les confisquer, Mess. de Maisses et de Boississe, commissaires s'étant contentés qu'il leur seroit enjoint de les reporter en Angleterre et encore sans payer aucun droit de sortie... "Lettre du $\mathrm{S}^{\mathrm{r}}$ de Lauzon á Richelieu au nom des commercants de Rouen. Rouen, 11 novembre 1626. Arch. des aff. étrang. France, 781, f. 78. Pour les commissionnaires étrangers en vins à Bordeaux, voy. Jublian, Hist. de Bordeaux, 410-41.

2. Boissise au roi, fer janvier 1600. Le roi á Boissise, 12 janvier 1600 . Kermalvant, Mission de Jean de Thumery, sieur de Boissise, 11. Élisabeth devait mourir trois ans plus tard. 
l'Espagne que l'état d'hostilité de celle-ci et des ProvincesLnies ne leur permettait pas de faire ouvertement et directement '.

Ln arrêt du conseil du 1.3 arril 1.39 .3 créa dans les villes les plus commerçantes, à côté des commissionnaires érigés par l'édit de mars $13 ̈ 86$, des courliers privilégiés pour le change, la bannue et la vente en gros des marchandises étrangères. Leur ministère neétait pas obligatoire mais il derait chre asse\% recherché, car, lorsquils contresignaient un acte de rente, leur signature emportait hypothèque sur les biens de l'acheleur. Paris en eut huit, Lyon don\%, Rouen et Marseille quatre, Amiens, Dieppe et Culais un, Tours, La Rochelle et Bordeaux deux, Toulouse trois. D'autres charges devaient être créées dans les villes où le besoin sen ferait sentir². Cette limitation d'ailleur's n'eut d'effet que pour les courtiers de change et de banque et le courtage des marchandises étrangères resta libre ${ }^{3}$.

COMUERCE DE TRANSPORT.

Les voies de communication et les moyens de transport dont la France était dotée servaient naturellement aussi bien aux marchandises étrangères, expédiées à l'étranger, qui ne faisaient que traverser notre territoire, qu à celles qui y étaient consommées. En faisant comnaître ces voies de communication et ces moyens de transport, nous avons derancé ce qüil y aurait à lire ici du commerce de transit

1. Lux plaintes de Cecil contre ce commerce interlope, Boissise répond: "Quelle apparence... de leur refuser cette retraite, dont les Etals recevoient grand avantage et commodité. Car cela faisoit vivre la jlupart des marchans d'IJollande et Zélande qui tenoient au lieu de Calnis leurs facteurs et, sous Ie nom des francois, faisoient leur trafic accoutumé et que cux-mêmes toléroient à leurs sujets d'aller en Espagne ou y emroyer sous le nom de ros sujets [du roi] ", ltsirl., I, 531-532.

2. Arch. nat. Coll. Rondonncau A11116.

3. Savary, Dict. du commerce, vo Courtier. 
qui s'opérait par terre. Nous n'avons à ajouter qu'une observation.

Elle se rapporte à l'influence fâcheuse exercée sur ce commerce par nos douanes extérieures et intérieures. En obligeant par une déclaration de 1:38:3 toutes les marchandises de Flandre, d'Angleterre, d'Allemagne à destination de I'Italie et du littoral méditerranéen de l'Espagne à passer par la douane de Lyon, Henri III fit perdre à la France la plus grande partie de ce transit: la Flandre et l'Angleterre créèrent alor's une ligne de transports directe par mer arec litalie ${ }^{1}$. Les communications par terre entre la Flandre et l'Allemagne d'une part, les péninsules ibérique et italienne de l'autre s'opérèrent par le Luxembourg .

On commençait pourtant à ne plus traiter les marchandises qui n'entraient dans notre pays que pour en sortir sur le mème pied que celles qui y trouvaient leur débouché. Si l'on n'avait pas encore eu l'idée d'établir pour elles des acquits-à-caution et des entrepôts francs, on accordait des passe-debout, nous roulons dire des réductions des droits de douane. En 1606, des marchands milanais sollicitent du conseil un passe-debout pour des marchandises expédiées d'Espagne et d'Italie en Flandre et en Allemagne ${ }^{3}$.

Cette remarque faite, toute notre attention appartient maintenant au commerce de transport maritime.

La nature n'arait rien refusé à la France de ce qui est nécessaire au développement d'une marine marchande: fer, bois en abondance pour la construction ${ }^{4}$, chanvre

1. Fonboxisas, Pecherches et considérations sur les finances de France, I, 70- $i 1,43 i$.

2. Des marchands de Milan regrettent " le grand tour... quil leur convient faire passans par le païs de Luxembourg pour conduire es païs de Flandres et Allemaigne les marchandises qu'ilz lont renir d'Espaigne et Italie... "Cela à eause ds la douane française. Arrêt du conseil du 21 mars 1606. Bibl, nat. Ylss. Fr., 18170 à la date.

3. Arrêts du conseil du 21 mal's 1606 et du 18 norembre 1608.

4. Relation de Badoer dans Barozzi et Berchet, p. 91. Le commerce honorable... par un habitant de la ville de Nantes, 16:6. "ll se trouve des 
excellent et poix pour la voilure et le gréement ', habiles charpentiers de navires, population de pêcheurs nombreuse, ne se bornant pas ì la pèche còtière, mais habituée à aller pècher le hareng sur les còtes d'Écosse et d'irlinde, la morue et la baleine en Amérique.

Malgré ces ressourees naturelles, notre marine marchande était inférieure à celles de l'Espagne, de l'Angleterre et de la Hollande. De ces trois marines, la première était en déclin, la seconde se relevait arec Élisabeth de lia décadence où l'araient laissée tomber Édouard VI et Marie Tudor, la troisième élait à son apogée. Dans un ménoire présenté en 1603 à Jacques I ${ }^{\text {er }}$, l'un des plus grrands esprits du temps, sir Walter Raleigh compare lin marine et le commerce de son pays à ceux des Provinces-Unies. Il nous apprend que cétait celle des Provinees-Unies qui transportait dans la Poméranie. la Pologne, le Danemark, la Norvège, la suède, l'Allemagne el la Russie presque toutes les marchandises de la France, de l'Espagne, lu P'ortugal, de la Turquie, de l'Italie et de l'Angleterre. Celle-ci nenroyait anmullement dans les pays de la Baltique qu'une centaine de vaisseaux et son commerce ne se faisait presque qu'arec Elbing, Konigsherg et Dantzig, tandis que les armateurs hollandais y enroyaient environ 3000 raisseaux et élaient en relation d'affaires avec toutes les villes de cette région. Le commerce hollandais était représenté dans tous les ports et toutes les villes de France, le commerce britannique dans eing ou six seulement. Les Provinces-Unies possédaient autant de vaisseanx que onze

meilleurs charpentiers du monde pour bastir et construire des navires de toutes sortes... à Djeppe, llonnefleur et au Harre, et de fort bon bois pour cet elfect aux forests prochaines, avec tout ce qui y est necessaire d'ailleurs pour les equipper, appareiller et mettre hors." TH. Le Fivin:, $O p$. land., 30.

1. Memoire pour l'établissement du traffic, commerce et negoce de mer en France. buesne, 319, fol. i. 
États ensemble, y compris l'Angleterre; elles en construisaient un millier par an. Leurs transactions avec la Russie, pour lesquelles, ringt ans aupararant, il leur snffisait de deux vaisseaux, en occupaient maintenant trente ou quarante et étaient encore en voie d'accroissement. Celles des Anglais avec cet État, si actives pendant soixante-dix ans, n'avaient plus besoin en 1600 que de quatre vaisseaux, de deux ou trois en 1602 . Et cependant les Provinces-Unies manquaient de bois de construction et de marchandises propres à développer le fret. Aussi n'élaitce pas les produits indigènes qui composaient leurs cargaisons navales mais les produits étrangers, dont le transport leur était de préférence confié parce que, grâce à l'effectif réduit de leurs équipages, leur fret était plus économique. Tandis qu'un navire anglais de 100 tonneaux ne pouvait ètre manœuvré que par trente hommes, huit marins hollandais y suffisaient ' ${ }^{1}$. Cette infériorité du commerce maritime britannique est confirmée par d'autres témoignages. Citons seulement un document anglais qui constate en 1.598 la décadence manifeste des ports de Newcastle, de IIull, de Boston, de Lynn, de Southampton, de Pool, de Weymouth, de Bristol el de Chester ${ }^{2}$.

Quant à l'infériorité de la France sur la Ilollande, l'Espagne et l'Angleterre, elle s'explique par plusieurs raisons: petitesse des bâtiments qui ne résistaient pas à la mer ${ }^{3}$, insuffisance de marins, maurais état des ports *, défaut de

1. Yémoire cité et analysé par Livosay, History of ancient commerce and merchant shipping (187') II, 162-164. Cf. Fonboxists (I, 425) sur le dévelloppement de la marine marchande des Provinces-Unies en 1669, et BEER, Ubi supra, 186, 201.

2. Calendars of slate papers. Demestic series, Elisabeth, p. 2.

3. L'édit sur l'amirauté de mar's 158 t́ avait encouragé la construction des navires de plus de 300 tonneaux. Art. Lxxi1. PArdesst's, Recueil des lois maritimes, $1 \mathrm{~T}, 295$.

4. C'est ainsi que notre infériorité dans le commerce maritime est expliquée dans des mémoires rédigés au commencement du règne de Louis Xlll par des navigateurs ou des marchands, et aualysés par Dareste, 
colonies, inégalité de traitement de notre marine marchande et de celle des autres nations, morcellement de l'autorité maritime par suite de l'existence des amirautés, absence d'une llotte de guerre capable de protéger notre commerce par mer.

L initiative de Ilenri IV se manifesta à l'égard de la marine marchande comme de toutes les branches de la richesse publique. Dès 1.i99, il encourageait ses sujets à construire el à acheter des vaisseaux, dans l'espoir de ravir à l'Angleterre et à la Hollande le commerce de transil avec l'Espagne, qui contribuait tant à la richesse de ces deux pays. Celte prétention risquait mème de nous brouiller arec l'Ingleterre '. L'année suivante, il fit procéder à une visite des ports el dresser l'état des réparations dont ils avaient besoin 2. Beaucoup avaient souffert des guerres civiles. Harfleur ${ }^{3}$, Douarnenez araient été demantelés. Ruiné de fond en comble par Eder de Fontenelle, Penmarch n'offrait plus que des vestiges informes de son port, de sa jetée de $1: 300$ mètres, de ses fortifications et était derenu la lande solitaire et romantique dont les sentiers, par leurs noms de rues des Marchands, des Changeurs, des Argentiers, rappellent à peine au voyageur absorbé par le charme grandiose du paysage, quil foule des roies jadis populeuses el animées : Les ports sûrs el assez profonds pour receroir de rrais navires étaient rares; le Languedoc n'en avait pas un seul ${ }^{5}$. Notre littoral océanique n'oflrait

1list. le ladministration, II, 250-251. Le manque de marins, signalé par ces mémoires, ne contredit pas absolument ce que nous avons dit du grand nombre de pêcheurs.

1. Culendars of slate papers, p. 156.

2. C'est du noins ce que dit Forbonnais sans en produire la preuve $(I, 39)$; nous avons vainement cherché ce devis de travaux qui aurait lant d'intérêt.

3. Supplique adressèc au roi, le 28 septembre ligh, par lBrissac, gouverneur dHarfleur. Dunowt et Legn, Histoire dHarfleur (1863), D. 4.;.

4. Lejeari, Sur l'hisloire des ports du Finistere dans Bullelin arch. de l'Assoriation brelonne. 111 (18:31), p. 133.

¿. "... le Languedoc n`it point de ports assurés ni capables de recevoir 
pas non plus assez de refuges, et Henri IV, on s'en souvient, voulut en ouvrir un à nos vaisseaux près de Bayonne et de Fontarabie. Dans ses Remontrances en forme d'édit, Laffemas proposait de soumettre le commerce maritime ì un règlement élaboré par d'anciens négociants le Bordeaux, de houen, de Narbonne et de Marseille et accordant des privilèges à la marine marchande nationale '. Convaincu, comme lui, au moins sur ce point, de l'utilité de la protection, dont les autres pays lui donnaient l'exemple, le roi mettait des droits de tonnage et d'ancrage sur les vaisseaux étrangers ${ }^{2}$, réduisait des deux tiers, en faveur des pècheurs du Ilarre, le droit d'écu par tonneau établi, en 1603, sur les bateaux pêcheurs de morues et de harengs, et distribuait à leurs armateurs des primes prélerées sur le produit de ce droit ${ }^{3}$.

La marine marchande et la marine militaire étaient placées sous l'autorité de l'amiral de France et des amiraux de Bretagne, de Guyenne et de Provence. Délivrance des congés et passeports, connaissance des rapports de royages, des prises et de toutes les causes maritimes, nomination du per'sonnel *, telles étaient les principales attributions de ces grands officiers. Henri IV n'y retrancha rien; il ne chercha mème pas à ramener à l'unité ces pouvoirs indépendants les uns des autres. A la fin de son règne, on n'a pas d'autre simplification à signaler dans cette organisation que la réunion de l'amirauté de Bretagne à l'amirauté de

que de petites barques. " Remontrance à ceux de la religion $p . r$. du bas Languedoc, 1629. Merc. franç., XV, 385.

]. Art. $x$.

2. Of late there has been raised a crown a ton on all ships trading thither. Calendars of state papers. Womestic series, 2it. Arrêts du conseil des finances, 21 mars 1600,13 aout 1602. Arch. nat. Lettres miss., VI, 5 s.

3. Roessler, Le Iluvre d'autrefors, 1883, p. 23.

4. Arlêt du conseil du 10 mal's 1607. Mss. Franç., 18171, fol. 161 vo. La connaissance des assurances avait été attribuée aux juges consuls. Toy. sur les conflits de juridiction entre les consuls et les amirautés, Pardessus, IV, 226. 
France, qui comprenait déjà celle de Normandie et P'icardie et se trouvait dans les mains du duc de Damville. L’amirauté de Guyenne et l'mmirauté de Provence avaient encore une existence propre. M. de Chatillon arait la première, et la seconde était attachée au gouvernement de Provence, qui appartenait alors au duc de Guise ’.

Il y arait en un temps où la France disposait d'une marine militaire respectable. Francois I ${ }^{\text {er }}$ et IIenri II araient entretenu de vingt-cinq ì trente galères qui leur avaient permis dentrainer Gènes dans leur alliance, d'intercepter les secours enroyés par Charles-Quint dans le Milanais et le royaume de Naples et de tenir en respecl la Toscane et le Sourerain-l'ontife. Mais les guerres religieuses amenèrent la ruine presque complète de nos forces navales ${ }^{2}$. Toutefois, cette ruine n'était pas encore accomplie en 1:372. Nous lisons en effet dans la relation d'un ambassadeur vénitien antérieure à celle qui nous apprend celte décadence, quà cette époque la marine du Levant c'est-à-dire de la Méditerranée se composait de dix-huit galères el de dix-sept vaisseaux de 400 à $1: 300$ tonneaux ${ }^{3}$. Le déclin de notre puissance navale ne fit que s'accroìtre sous IIenri III, malgré les efforts de ce prince pour la relever. En 1394, le nombre des galères étail si réduit que les condamnations aux galères ne pouvaient ètre exécutées et que cette peine dut être commuée en celle du bannissement ${ }^{\ddagger}$. Le roi se préoccupait dès lors d'équiper, de réparer celles qui lui restaient el d'en faire construire de nouvelles. Au commencement de $1.39 \%$, il faisait demander pour leur entretien $1: 30000$ écus (1 424929 fr. 74) aux états de Lan-

1. Carew's Relalion, p. $\$ 29$.

$\because$ Relation de Gussoni et Nani dans le recueil de Barozi et Berchet, I, 45.

3. Veclation de Contarini dans le recueil d'Alberi, série I, IV, 23.5.

4. Ilcnri $1 \mathrm{~V}$ au parleuent de Normandic, 29 janvier $15 \% 4$. Lelles miss., 11., 93. 
guedoc et la même somme aux états de Provence '. A la fin de cette année, il chargeail son ambassadeur à Constantinople, Savary de Brèves d'en obtenir du sultan dix ou douze avec leur chiourme, en attendant celles qu il se proposait de faire construire et armer sous peu ". Le due de Retz, général des galères, reçut des ponvoirs pour recruter des forçats. Le roi poursuivit auprès de l'assemblée des notables l'assignation d'un fonds spécial pour l'entretien de celles qu'il roulait aroir à Marseille ${ }^{3}$. Le 4 férrier 1.397 , il annonce l'intention d'affecter une partic des recettes publiques de cette année à en entretenir douze au moins en état d'armement ${ }^{4}$. Il en fit mettre, en effet, de suite sur chantiers, comme on l'apprend par une lettre du 8 juillet $1597^{5}$. En 1600, à la suite d'une inspection de nos ports et de notre flotte, celle-ci fut réparée ${ }^{6}$, quelques galères furent mises à flot ${ }^{7}$. Le roi projetait d'en construire et d'en armer ringt pour le printemps de l'année suivante, et, pour se procurer des chiourmes, il songeait à acheter des esclaves en Orient. Dans la crainte d'indisposer le Grand Seigneur, il ordonnait à son ambassadeur de le sonder à ce sujet ${ }^{8}$. Obligé de restreindre ses rues, son ambition se réduisit à en faire sortir des ateliers de vingt à trente en tout, dont dix en 1601. Au commencement de cette année, il y en arait cinq d'armées à Narseille et une en état d'ètre mise à la mer. Quant aux quatre autres, elles

1. Commission au sieur de Maisse, 25 janvier 1595. Collection des arrèts du conseil aux Archives nationales.

2. Lettre à Savary de Brèves, 11 décembre 1595. Letlies miss., IV, 475,600 .

3. Lettre du 23 janvier 1597. Llid., 675.

4. Ibid., 685 .

5. Ibid., s05.

6. Forboxyais, I, 39.

7. Lettre de Savary de Brèves, 10 juillet 1600 . Lettres miss., V, 247.

8. Lettre à Savary de Brèves, 31 oct. 1600 . Lettres miss., loc. cit., 33 t. Ce projet se réalisa au moins dans une certaine mesure : il 5 avait en 1607 des Turcs sur les galères du roi. Ambassades de La Boderie, II, 360. 
deraicnt être fournies toutes prètes, sauf la chiourme, pour '40000 ducals, par un Génois, Francesco Lommelino'. Hemi rèvait de porter la puissance navale de la France ì un point quiefle n'arait jimais alteint sous ses prédécesseurs 2. Il avait traité arec plusieurs armateurs, il arait pris à son service Simon Dansa et ses vaisseaux, il se proposait d'enrôler d'autres eapitaines, hollandais et danois. La mort vint interrompre l'exécution de ses desseins. Il laissait la marine de grerre moins puissante qu'elle n'avait été sous Charles IX. Elle se composait de quatorze galeres, qui ı appartenaient même pas à l'État mais étaient

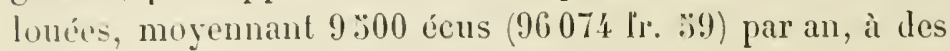
particuliers. Elles restaient armées huit mois. Le reste du temps, le roi ne payait que l'entretien des galériens, et les équipages étaient licenciés; mais ils se tenaient prêts ì répondre au premier appel. En peu plus grandes que les galeres rénitiennes, celles du roi avaient vingt-huit bancs de rameurs; lentes à la nage, elles étaient assez bonnes voilières. Elles quittaient rarement le port, de sorte que l'équipage était peu expérimenté. La flotte statiomnait tout entière dans la Mćditerranée; pour la défense des côtes de l'Océan, on comptait sur les vaisseaux que le Danemark et d'autres puissinces maritimes fourniraient en cas de besoin ${ }^{3}$. Il ne faut pas s'étonner que cette flotte, si peu nombreuse et si mal montée, n’appartint mème pas au roi. La marine anğlaise, beaucoup plus considérable que la nôtre, se composait aussi en partie de raisseaux armés et équipés par des particuliers.

1. Dêpêche de Winwood à Cecill, 2f janviel 160I, I, 380. Leltres el ambassades de Fresnes Canaye, I, I71, 188. "J'ay lettre du sr Lonsellino de Gennes, lequel m'asseure que, dans pasques, prochaines, nous aurons douze bounes graléres prestes et equipées à Marseille. "Lettre de Fresne Canaye à II. Ie Bréves, 21 mai $1603,1,2^{\circ}$ partic, 13. 199.

2. ... he is ever hammering uper building a navy for the sea, which, if he should eflect, might prove an evil neighbour to your Mlajesty's dominiOHs. liAEW, isi.

3. Lelation de Gussoni el Naui (1610) dans le liecueil de Barozzi et Berchet, 1, 45s. 
Si nous nous sommes étendu sur l'insuffisance de la marine de guerre, e'est uniquement paree fu'il en résultait pour notre commerce un manque presque alsolu de sécurité.

En effet, notre pavillon protégeait très imparfaitement notre marine marchande, mème contre les puissances secondaires. Ainsi la route suivie par les vaisseaux français qui se rendaient de Marseille en Italie, tracée de façon à leur faire éviter les pirates barbaresques, les exposait, en revanche, anx exactions du duc de Savoie. Après avoir érité les îles d'Hyères, qui étaient un nìl de pirates ${ }^{1}$, ils gagnaient la haute mer puis se rapprochaient de la côte rers Antibes et la longeaient jusqu'à Gènes. Mais, lorsqu ïls passaient devant Villefranche, les croiseurs de CharlesEmmanuel les forçaient d'y relàcher pour payer une taxe de 2 p. 100 sur la valeur de leur cargaison. Si nous qualifions cette taxe d'exaction, e'est qu'elle était vexatoire et contraire à la liberté des mers, car elle reposait d'ailleurs sur un titre sûr et plusieurs fois renouvelé; Charles VII l'arait concédée aux durs de Savoie, Louis XI et François I $^{\text {er }}$ la leur avaient confirmée ${ }^{2}$. Henri IV força CharlesEmmanuel à y renoncer, mais, après la mort du roi, elle fut rétablie ${ }^{3}$.

Henri pouvait atteindre ce prince et il le lui prouva d'une façon éclatante, mais comment, sans une force navale imposante, faire respecter le pavillon français par les Barbaresques? Les ordres du sultan n'étaient pas obéis par le vice-roi d'Alger, par le bey de Tunis ni par le roi de Maroc ${ }^{4}$. En 1602, le nombre des Français mis à la cliainne

1. Henri IV avait eu l'intention de les coloniser et d'y établir des chantiers maritimes. Pulcrppson, 2. Abth., 378-379.

2. Bibl. nat. Franç.. 3944, fol. 59.

3. Henri IV au duc de Savoie, 6 juillet 1603 . Lettres miss., VI, 126 et Picot, IIistoire des états généraux, IV, 135-136.

4. Lettre à Savary de Brèves, 8 juillet 1597 . Lettres miss., IV, 805 ; V, 586. 
par les corsaires algériens dépassait, disait-on, deux ou trois mille ${ }^{1}$. 1)ans ses instructions du 26 juillet 1604 à son anbassadeur à Constantinople, le baron de Salignae, IIenri II l'estimait à trois mille quarante-cinq et évaluait à un million (2922932 fr. 80) les pertes inlligées par les Barbaresques aux Marseillais et amx Provençanx². Le roi faisait des exemples : la mème année, il fit couler une galiote algéricune et couper la tête au capitaine ${ }^{3}$. Mais ces actes isolés de répression ne pouvaient mettre fin à un brigandage qu'on n'aurait pu déraciner qu'en l'attaquant dans ses repaires. Ilenri le reconnaissait, et on trowve un aven implicite de son impuissance, dans un arrèt du conseil défendant anx vaisseaux, qui ne sont pas assez forts pour se défendre, de longer les côtes soumises à l'autorité du Grand Seigneur". On ne se résignait pas tonjours à cette impuissance. On essayait de détruire la pirateric chez elle. Marseille faisait marché arec le lieutenant du capitaine malouin Beanlieu qui, moyennant une prime de :300 écus ( 036 (1?. \$6), allait brûler sous la Goulette, en 1609, vingttrois baitiments tunisiens ".

La vie lucrative et arentureuse de corsaire arait séduit, on le sait, plus d'un clirétien. Peudant trois ans, le

On ne s'étonne pas de limpuissance du Disan à protéger notre commerce contre les corsaires algériens, quand on sait que la population tout entierre de la Rẻgence, depuis les reis jusqüà la populace, ne vivait que de la piraterie, et que vouloir lui fermer cette source de profits, c'était la réduire au desespoir et à la révolte. Voy. H.-D. ne Gкаммохт, Relations enlre la France el la Régence d'Alger an II'll $^{\circ}$ siècle, $1^{\mathrm{re}}$ partie : les deux ranons de Simon Dansa, p. 1-4.

I. Lellies miss., $\mathrm{V}, \mathrm{r} 0 \mathrm{~T}$.

2. Ambassade en T'urquie de J. de Gontaut Biron, baron de Salignac, p. p. Gontalt Banon, l'ices juslif.

3. Letlies miss., V, 65 '.

i. 17 juillet 1603 . Arch. nat. Les vaisseaux devaient avoir un tonnage de i000 quintaux et un équipage suffisant pour se défendre. Sur les piraterics les Barbaresques voy. encore Lellies miss., V, 547-518, 68?-683, 703, VII, iil-iiz et pass.

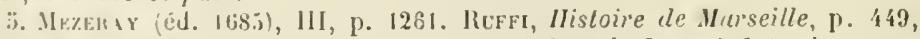
cité par Ilsssos, Ilist. du commerce fiangais dans le Levanl, Introd., xxvıl. 
Flamand Simon Dansa avait, sous le drapeau de l'Islam, fait la chasse aux bàtiments chrétiens; puis, désireux de faire une fin, il avait obtenu de Henri IV son pardon et la mission de convoyer et de protéger ees mêmes bitiments ${ }^{1}$. Ce qui est moins connu, c'est que les Barbaresques entretenaient des intelligences dans les provinces maritimes, même avec des officiers du roi, et que les occasions farorables leur étaient signalées. Le capitaine Fouques, capitaine ordinaire de la marine royale du Ponant, en donne des preuves curieuses dans un mémoire publié en 1612. Ce mémoire articule des laits précis et cite des noms recueillis par l'auteur pendant sa captivité et à la suite d'une enquète sur le lilloral de Provence et de Languedoc ${ }^{2}$.

Le gouvernement français demanda aussi réparation au sultan pour la destruction du bastion de France ${ }^{3}$. On appelait de ce nom un établissement situé sur la côte, à la frontière de l'Algérie et de la Tunisie, à douze lieues environ de Bône. Fondé en 1561 par deux marchands marseillais, il se composait de magasins, d'une chapelle, d'un cimetière, d'un hôpital, d'une forteresse et servait de comptoir pour la pêche du corail et le commerce des produits barbaresques. Il se complétait par des magasins à La Calle, au cap Nègre, à Bône, au cap Rose et à Collo

Les pirateries des populations musulmanes du littoral méditerranéen s'expliquaient par leur organisation exclusivement conçue en vue de la course et par leur fanatisme

1. Grammont, Histoire d'Alger, p. p. 148,149.

2. Arch. curieuses de Cismer et Daxjou, I, série xv. Confirmé par un mémoire sur le trafic qui se trouve à la Bibl. nat. Mss. Franc., 3653, fol. 67, et que 11 . Pigeonneau fait remonter aux dernières années du $x^{2}{ }^{e}$ siècle, mais qui semble n'appartenir qu'aux premières du xin'.

3. Heuri IV à Brèves, 19 juillet 160 't. Lettres miss., VI, 688 .

4. On en trouve la description dans le chap. iv de l'Itistore de la Barbarie du P. Das (1618). En I606 Savary de Bréves, voyageant en Algérie sans caractère officiel, négociait avec le dey dans l'intérêt du commerce franças et pour obtenir la reconstruction du bastion. Lettres miss., VII, 30. Gramilont, list. d'Alger, p. 55. 
religieux. Il est triste d'avoir à ajouter que notre marine marchande n'avait guère moins à soufrrir de celles dont les auteur's appartenaient ì des nalions chrétiennes et officiellement amies.

Ciest de liangleterre que nous arions le plus à nous flaindre sous ce rapport ' . En 1602 , les Mnrseillais estimaient ì plus de 1200000 (11399 1.37 fr. 93) ou 1300000 écus (1'4 2'92! 9 fr. 12) les pertes que ses corsaires leur avaient fait éprouver². Nos lébats avec elle à ce sujet s'envenimaient d'autres puestions d'intérêt at d'amour-propre qui en sont inscyparables. Ciest ainsi qu clle outrageail notre dignite en forçant nos vaissealux it baisser parillon devant les siens ${ }^{3}$ et à subir, dans les conditions les plus humiliantes, le droit de risite'. Les griefs de la France nétaient pas généralement accucillis par l'ancienne alliée et la "bonne amie " du roi dans un espril d'impartialité et de bienveillance. Légitimes ou non, elle avait aussi ses motifs d'aigreur. Sévérité des autorités françaises pour les draps anglais de mauraise fabrication, impots noureaux sur ses sujets trafiquant dans notre pays, retards dans le remboursement des sommes prêtées au roi Iorsqüll conquérait son royaume, paix de Vervins, ambition léçue sur Calais, tout cela Ia disposait plutôt à demander des réparations qu'à en accorder. Au sujet de la pirateric, elle opposait ses récriminations aux nôtres. Son gouvernement prétendait que la marine britannique patissait aussi de nos

1. "Cette mer [Méditerranée] est si inlestée de corsaires qui prennent tous le nom d'Inglais, qu'il n'y a presque plus de moyen d'y trafiquer. " Du Fresne Canaye à de Vic, 9 mai 1603, 1, liv. 11, p. is?.

2. MAssox, Op. luud. Introrl., p. xxiv.

3. Economies roy., coll. Michaud, II, 4 i3.

4. "... si on doit se resigner a le subir, du moins tenteroi-je de conrenir avec eux que, quand ils voudront lexercer sur un de nos navires, ce sera á eux de l'abrirder avec leur bateau et uon pas les Francois qu'ils contraindront à aller a eux, comme ils les $\mathrm{y}$ forcent constamment par semonce i coups de canon. 0 lioissise il Villeroy, fer et 25 septembre 1599. Kenuangant, Mission de lioissise, I, 299. 
corsaires, qüil y avait des Français sur les vaisseaux flamands armés en course à Dunkerque ${ }^{1}$. Le grand-amiral, Lord Howard écrivait, le 7 octobre 1399 ', à Thomas Edmonds, l'ambassadeur d'Angleterre, que la France arait donné anx Anglais des sujets de plaintes bien mieux justifiées qu'elle n'en avait elle-même, que les prises faites par les Français s'étaient élevées, dans les huit dernières années, à 400000 livres (1 16917.3 fr. 12) ${ }^{2}$. En 1599, Neville réclamait satisfaction pour la prise d'un raisseau anglais par les Marseillais ${ }^{3}$.

La reine eùt été d'ailleurs mieux disposée envers la France, qu'elle n'aurait pas eu le pouroir de supprimer des habitudes très fructueuses pour les particuliers, et qui s'autorisaient de l'honneur et de l'intérèt national. Le grand amiral, les premiers personnages de l'Angleterre, la souveraine ellemême étaient intéressés dans les prises maritimes ${ }^{4}$. Le premier trafiquait ouvertement des passeports achetés par les étrangers pour se mettre à l'abri des corsaires anglais ${ }^{5}$. Il poursuivait rigoureusement ceux contre lesquels il recevait des dénonciations, mais uniquement dans le but de confisquer leurs biens à son profit, et il refusait de les faire servir à indemniser les victimes ${ }^{6}$.

Élisabeth toutefois ne pouvart éluder d'une façon constante les instances du roi. En 1598, l'équipage de la Diana

1. Henri Neville à Cecill, 28 décembre 1599, p. 141. Rien d'impossible à cela; en 160 i Ies armateurs de Dunkerque chercheront á attirer des pilotes et des matelots par de grands avantages et IIenri IV sera obligé de défendre à ceux de son royaume de passer au service d'un prince étranger. Puisieux à La Boderie, 13 mars 1607. Ambassades de La Boderie, II, à Ia date.

2. Тн. Bırсh, Op. laud., p. 14.

3. Winwood's Memorials, p. 114 .

4. Lettres miss., V, 266.

5. Prévost-Paradol, Élisabeth et Henri IV, daprès le journal de Hurault de II isse. Voy, aussi Lettres miss., IX, 4.

6. La Boderie á Villeroy, 23 sept. 1606. Le même à Puisieux, 22 oct. 1606. Puisieux à La Boderie, 3 nov. 1606. Ambassades de La Boderie en Angleterre, 5 vol. in-12 $(1750)$, aux dates indiquées. 
de Londres fut poursuivi '. Le 8 février de l’annéc suivante, parut une proclamation défendant anx capitaines concessionnaires de lettres de marque contre l'Espagne, de porter prejulice aux vaisseaux de Fance, d'Écosse et des autres nations neutres. Le 3 janvicr précedent, une commission avait ité nommée pour examiner nos réclamations². De son côté, Ilenri en inslitua une, le 19 juillet, pour connaitre des actes de piraterio sulis par les sujets de la roine et informer de cenx dont nos compatriotes pourraient souffrir. Ses jugements deraient etre sans appel ${ }^{3}$.

Une troisième fut constituće à la fin de 1601, pour régler la réparation des dommages causés par la pirateric et élablir entre les deux États la liberté du commerce et de la narigation. Elle siégea sans préjudice des deux premières. Elle sen distinguait par son caractère et par sa mission. D'une part, en effet, elle était internationale " et semblait devoir aboutir, grìce à des débats contradictoires entre les représentants des deux payss, à une transaction délinitive sur les griefs respectifs. De l'iutre, elle ne devail s'oceuper du passé que pour le liquider, non pour en instruire, tiiche dérolue aux premières, et elle était surtout appelće à déterminer les rapports futurs de la France et de l'Angleterre. L'accord sefit conditionnellement dans son sein sur les points suivants:

Les leux sourerains garantissent respectivement à leurs sujets la liberté du commerce.

L'irmateur, le capitaine ou l'écrivain fournira à l'amirauté deux cautions qui pourront être poursuivies lorsque le baitiment aura été employé à la piraterie.

1. Calendar's of state papers, p. 45.

2. Pymer's Furlera, éd. origr. Xvi, 36t, 368. Neville it Cecill, 15 mai 1599.

3. IsAuвEит, XV, 224. Winuord's memoriuls, 125, 1:8, 1:1.

4. Elle ritait composée, pour l'Ingleterre, du conte le Nottingham, de limbert Cecill, de Inhn Fortoscue, de John Popham, de John llerbert, de Thomas Parry, de Daniel Dum, de Thmmas Edmonds et, pour la France, de Jean de Thumrry, sire de Boissise et de Christophe de Itarlay, comte de lieaumont. 
Des lettres de représailles pourront être accordées lorsqu’il n’aura pas été fait droit dans les trois mois à la réclamation du souverain ou de l'ambassadeur.

Les vaisseaux d'un Étal ne pourront pas saisir et inrêter les vaisseaux de l'aulre, lorsque ceux-ei ont arboré leur pavillon, mais le transport d'armes dans un pays en guerre avec l'une des puissances eontractantes est défendu, comme il est défendu en génciral d'ibuser de la liberté du commerce au détriment de l'une de ces puissances.

Défense de saisir dans les ports de l'une d'elles les vaisseaux de l'autre ou leur cargaison et de forcer l'équipage à la vendre, sinon à un prix équitable. Toutefois, chacune pourra, en cas de nécessité et moyennant une juste indemnité, s'approprier les navires de l'autre, ainsi que leur cargaison ${ }^{1}$.

Les sujets de l'une des puissances contractantes, qui tueront ou rendront comme esclaves les sujets de l'autre, seront passibles des peines les plus rigoureuses.

Les lettres de marque concédées seront réroquées. Les impétrants se pourvoiront devant les commissaires nommés par les deux parties contractantes. S'ils n'obtiennent pas justice dans les trois mois, ils pourront s'en faire délivrer de nouvelles. Elles ne seront expédiées à l'avenir que sous le grand sceau.

Les bàtiments mis en mer par l'ordre du souverain, ceux qui ont été appliqués à son service et immatrienlés sont considérés comme bàtiments de l'État, qui est responsable des dommages causés par eux.

La vente et le recel des prises seront défendus, à moins d'aroir lieu en rertu d'une sentence de l'amirauté. Il sera

1. Cet article défend seulement l'abus d'une pratique consacrée par le droit international et dont il est question dans le Guidon de la mer sous Ie nom d'arrett de prince. Pandesses, Recueil des lois marilines, 11, 407. On en trouvera p'us loin un exemple. 
égallement défendu de donner asile et assistance anx pirates; on devra, au contraire, les arrèter et les faire passer en justice'.

Ce projet de traité, rédigé en latin, est intitulé : Propositiones ultimo loco inter dominos commissarios hine inde agitulx. Nous navons lone affaire iei qu'it un projet en discussion. En effet, l'accord des commissaires des deux nations était subordonné à l'acceptation d'autres points sur lesquels, après une discussion de plusieurs mois, l'entente ne sétait pas encore faite ${ }^{2}$. Les commissaires convinrent de suspendre les conférences pour attendre des instructions et, cn 1602, ils dressirent acte de cette résolution.

Cette négociation fut stérile et, si nous avons cru deroir faire connaitre les clauses arrètées provisoirement entre les négociateurs, c'est qu'elles donnent l'idée du droit maritime de cette époque et des adoucissements, des progrès par lesquels il tendait, trop lentement, à se rapprocher du droit naturel. L'un des deux commissaires français, II. de Boissise, reçut l'ordre (1602) de quitter sans éclat la conférence pour revenir en France ${ }^{3}$. Élisabeth, qui n'avait renoncé qu'arec peine au droil de visite ", élevait de nouveatu la prétention de l'exercer pour' empêcher le transport des armes. Elle prétendait, en outre, s'approprier les vaisseaux et les marchandises qui étaient dans les ports anglais en payant leur valeur, droit qui est reconnu par le projet de traité, mais contre lequel Ilenri IV protestait dans une lettre aux commissaires français ${ }^{3}$.

Comme on le pense bien, Ienri IV ne se bornait pas à réclamer justice pour ses sujets; quand il n'avait pu

1. IIinwood's Memorials, I, 392-39i.

2. "... in quibus [difficultatibus] co usque processum est ut de quibusdam inter nos conventerit, dumuodo de relipuis quorque conveniret, quod hactenus nuilo modo fieri potuit." Ibirl., p. 391.

3. Letlies miss., Y, 752 .

4. Tu. Brincu, Op. laud.

J. 6 mars 160:. Lellies miss., V, 75\%. 
triompher de la force d'inertie, de la mauvaise volonté des gouvernements étrangers, il usait des armes que le droit des gens alors en vigueur mettait à sa disposition. Au mois de juin 1601, il réunit un conseil extraordinaire pour délibérer sur les moyens de tirer raison des préjudiees causés à notre commerce maritime par les Espagnols, les Flamands et les Anglais ${ }^{1}$. En 1602, il autorise les habitants de Marseille à saisir les marchandises et les navires des Anglais qui se trouvent en Provence ${ }^{2}$. Un arrêt du conseil du 13 juillet 160', accorde à un marchand rouennais des lettres de représailles contre les sujets de l'archiduc ${ }^{3}$. Le roi d'Espagne ayant autorisé conme un droit l'abus par lequel ses vaisseaux traitaient comme de bonne prise tous les bàtiments français porteurs de marchandises des Indes occidentales qui n'avaient pas été achetées en Espagne ou en Portugal, Henri IV fit réunir à Rouen en 1607, sous la présidence de l'amiral de France, une assemblée solennelle, composée des officiers des vingl-sept sièges d'amirauté de Normandie et des principaux capitaines du temps. Cette assemblée déclara que nous agirions de même, en vertu du droit reconnu par tous les traités, à l'égard des bâtiments espagnols trouvés au sud du tropique du Cancer et à l'ouest du méridien des Açores. Le lieutenant général de l'amirauté de Rouen procéda en même temps au recensement des navires étrangers amarrés dans les ports de Rouen, de Honfleur, du Harre et de Dieppe, en rue d'en faire l'arrêt et de les armer en course. Ces menaces de représailles firent respecter notre marine marchande, au moins pendant un temps, par la marine espagnole 4

1. Groulart, Voyglges en cour, 586-js7.

2. Lettres miss., V, 629 .

3. Collection des arrêts du conseil aux Arch. nat.

4. Tí. Le FÈvre, Op. laud., 99-100, 182. Remontrance présentée au roi et à son conseil en 1611́ par les capitaines de la marine de France dans LEvot, Hist. de Brest, I, 93. 
Le roi ne recourait à la course qu ì la dernière extrémité. Les Hollandais ayant pris un navire de Calais, le Saint-Georgrs, l'échevinage et les marchands de cette ville obtinrent du conseil des lettres de marque. Avant de les faire expédier aux impetrants, Henri ordonna à son ambassadeur, Buzanval, d’insister de noureau auprès des ÉtalsGénéraux pour obtenir restitution du navire et de sa cargaison'. Le 2't septembre de la mème année (1606), il écrivait à Aerssens, résident des l'rovinees-Unies, pour provoquer son intervention en faveur de ses sujets lésés par les Ilollandais et être dispensé ainsi de l'obligation d'accorder aux victimes des lettres de représailles?

Ii se servit aussi d'un autre moyen : ce ful de frapper les hattiments ou les marchandises de la nation à layuelle appartenaient les coupables d'un droit de tonnage ou d'entrée dont le produit était destiné à indemniser les victimes ${ }^{3}$.

La morl d'Élisabetl, l'avènement de Jacques I ${ }^{\text {er }}$ (1603), permetlaient de reprendre arec plus de chance de succès les négociations interrompues en 1602 . Le nouveau roi, pédant couronné, moins impérieusement dominé par l'anbition de la suprémalie maritime, était animé de dispositions paciliques. Dans une lettre à M. de Brères du 22 juin 1603, Henri IV exprimait l'espoir que l'avènement du premier des Stuarts methait un terme aux pirateries des Anglais. Il n'en donnait pas moins aux négociants marseillais et bretons l'ordre d'armer des vaisseatux en course ". Ce sujet n’était pas oublié dans les instructions de Sully, curoyé en ambissade pour félieiter le successeur dÉlisabeth. Les pertes que ees pirateries avaient causées au commerce français $\mathrm{y}$ étaient évaluées à plus diun million

1. Ilenri W a M. de liuzanval, 17 juillet lcot. Lelles miss, VI, 1,3i-6i3j.

$\because$ Lellics mis.., Vll, 3.

3. Th. La TEvat, Op. laud., 191. Letlre de llenri IV du 30 juin 1593 Lellies miss., III, s1:3.

i. Lelleres miss., VI, bis. 
d'écus d'or (9499:31 fr. 61) ${ }^{1}$. Jileques I ${ }^{\text {er }}$ n'essaya pas de nier les faits et il en rendit responsable le grand aniral : "Lorsque je lui parlai de piraterie, écrit Sully, il se fìcha contre l'amiral et ceux de son conseil qui voulaient soutenir ce qui s'y fait ${ }^{2}$ ").

Le traité du 24 février 1606 fut le fruit de ces sentiments plus conciliants. Parmi ses clauses, nous n'avons à signaler ici que celles qui avaient pour but de domer plus de sécurité au commerce maritime de la France.

L'exécution des lettres de marque entre Français et Anglais élait suspendue jusqu'à leur examen par le conseil des deux souverains; il ne pouvait en être délivré à l'avenir que sous le grand sceau et après aris domné à l'ambassadeur de l'État responsable. L'article 7 créait en principe des commissions internationales et spéciales, composées de quatre commerçants, deux Français et deux Anglais, qui, sous le titre de conservateurs du commerce, devaient être désignés tous les ans à Rouen, à Caen, à Bordeaux, à Londres et dans d'autres villes anglaises pour faire droit aux plaintes de leurs confrères ${ }^{3}$. Chose singulière, celles auxquelles la piraterie domnait lieu n'étaient pas portées devant ces commissions; c'était à l'amirauté que nos négociants étaient, comme par le passé, obligés de demander justice. Notre ambassadeur en Angleterre, Lefèvre de La Boderie, regrettait cette omission et espéra pendant un temps faire déférer ces recours aux commissions internationales ", mais il dut bientôt renoncer à cet

1. Economies roy., V. 392-394.

2. Sully au roi, 6 juillet 1603 . Ibid., VI, 123.

3. ISAMBERT, XV, 2!9i-301.

4. "Yrai est que l'on a omis dans ledit traité l'attribution de connaissance aux conservateurs du commerce des pirateries qui se feront par l'une ou par l'autre nation, qui étoit ce dont nous pouvious retirer darantage, parce que cela nous eût délivrés des injustices de cette amirauté et de la rigueur des lois d'icelle, qui est très grande. Je dois un de ces jours conférer avec eux sur ce que je leur en ai proposé, et, avec cetteoccasion, 
espoir et s'estimer heureux d'obtenir que le grand amiral nexerȩat son droit de confiscation sur les biens des conpables quaprès réparation du tort fait aux victimes.

Le gouvernement anglais mit du reste un grand empressement à donner au traité toute la validité dont il pouvait aroir besoin et manifesta une grande impatience à voir le gouvernement français en faire autant. Bien que celui-ci y fît plus intéressé encore, il ne parait pas s'ètre montré très soucieux de faire jouir ses nationaux de ses stipulations. En 1608, deux ans apris son adoption, les conservateurs du commerce n'avaient pas encore été nommés ${ }^{1}$.

Ce traité n'améliora, du reste, en aucune façon la situation de nos commerçants en Angleterre et, peu de temps après sa ratification ${ }^{2}$, l'ambassadeur de France était encore obligé de demander justice pour nos compatriotes ${ }^{3}$. Notre marine marchande ne fut pas mieux respectéc par les corsaires anglais que dans le passé '. Aucun scrupule, aucun intérêt politique n'étaient capables d'arrèter l'élan d'une nation qui aspirait à s'approprier exclusivement la souveraineté et la police de l'Océan, - mare clausum, comme écrira en 162:3 le théoricien de ses prétentions, Jean Selden - qui intéressait à cette entreprise toutes les classes de la société et qui y mettait une ardeur où entrait autant de patriotisme que de calcul.

je verrai si je pourrai gagner que toutes les poursuites des marchands, volés en mer, soient renvoyées par-devant lesdits conservateurs, au moins pour ce qui sera du civil. C'est chose, ce me semble, qui est très juste, et qu'ils ne peurent honnelement refuser, mais qui en eut touché quelque mot dans le traité, c'eût été nous ôter beaucoup de peine. "La Boderie à Villeroy, 29 septembre $1606, I$, a la date.

1. "IIs me pressent de nommer ici des conservateurs de commerce ne plus ne moins qu'ils en reulent. ete. "La Boderie à Villeroy. Ubi suma.

2. Il avait reçu en Angleterre, antéricurement au 29 septenibre 1666 , toute la validité possible. Lottre de La Boderie à Villeroy a cette date. En France, il avait obtenu la ratification royale le 26 mai de la même annéc.

3. Lettre de La lBoderie à Puisieux, 21 novembre 1 (;06.

4. Il suffirait pour s'en convaincre de voir les nouvelles réclamation: adressées par Hlenri 11 en 1607 au gourernement anglais. Lellres miss., Vil, $\mathbf{1 1 6 .}$ 
Le lecteur qui a eu la patienee de nous suivre jusqüici, aura été frappé du earactère négatif de ce que nous lui avons appris du commerce de transport maritime de la France. Nous avons dit qu'elle ne prenait rang, sous ce rapport, qu'après la IIollande, l'Angleterre et l'Espagne; nous arons indiqué les causes de cette infériorité, les efforts de Henri IV pous y remédier. On sait ce rui manquait à notre marine marchande pour rivaliser arec celles que nous venons d'énumérer, on sait ce qu'elle n'était pas; il nous reste maintenant à dire ce qu elle était, et pourquoi elle méritait d'avoir une place dans un travail sur le commerce extérieur de notre pays.

La France arait été longtemps lintermédiaire obligé, elle était restée l'intermédiaire le plus habituel des relations commer'ciales de l'Occident et du Levant. Ces relations ne s'étaient d'abord établies et maintenues que sous sa protection et sous son nom. Elle était, après les républiques italiennes, le premier pays chrétien qui fùt entré en rapport arec le monde musulman autrement que pour le combattre. Ce rapprochement, on le sait, avait été amené par la nécessité où s'était trouvé François Ier de se chercher partout des alliés contre Charles-Quint. Il avait valu à ses sujets le privilège du commerce dans les États du sultan, privilège qu'ils ne partageaient qu'arec les Vénitiens, arec cette différence que ceux-ci étaient traités en tributaires. Ce privilège datait du traité signé entre François $I^{\text {er }}$ et Soliman au mois de février 15336 (n.s.) ${ }^{1}$. Les capitulations de 1536 , qui furent la base de toutes les capitulations postérieures, ne plaçaient pas, il est vrai, expressément les autres nations européennes sous la dépendance de la nôtre, mais, comme le Iroit de faire le commerce dans l'empire ottoman et d'y aroir des consuls, lui était exclusi-

1. Yoy. Cimarrière, Négociations entre la France et le Levant, I, :\$3. 
rement réservé, les autres puissances ne purent y participer yu en prenant le parillon français, en naviguant sous nos auspices.

Les Anglais ne tardirent pas à saffranchir de cette tutelle. Lin 1379, un marchand de cette nation, William Harborn, envoyé en Turquie par Élisabeth, obtint. d'Imurath III, pour ses compatrioles, la liberté de négocier directement avec la Turquic'. En 1:381, la reine créa la Compagnie privilégiée du Levant en faveur des quatre marchands qui araient noué les premières relations commerciales avec la Turquie, et des huit associés qui devaieut se joindre à eux. Elle accordait ì la société un monopole de sept ans, mais avec faculté de le lui retirer en la prévenant un an d'arance ${ }^{2}$. IIarborn reçut pouvoir d'établir des consuls dans les ports et de faire des règlements pour le commerce britannique dans les États du sultan. Malgré l'opposition de la France et de Venise, il y créa des comptoirs ${ }^{3}$. En 1600, la Compagnie du Levant possédait quatorze navires dont le tonnage sélevait à 2790 tonneaux et les équipages à 603 hommes. Cela ne suffisait pas aux besoins de son commerce; elle en fréta cette année treize de plus pour ses relations arec la Turquic et la Sérénissime république ${ }^{4}$. Non contente d'avoir

1. Mlicphersox, Annals of commerce, 4 vol. in-4, 180j, JI, 165.

2. Ibid., 168-169.

3. Ibid., 170, 171. C'est donc à tort que M. Th. Lavalléc, dans un travail sur les relations de la France et de la Porte ottomane (Revue indépendante, tomes $\mathrm{X}$ et $\mathrm{Xl}$, affirme que l'Angleterre obtint la liberté de naviguer et de commercer sous son propre pavillon deux ans apres le renouvellement de la capitulation avec la lrance, c'est-a-dire en lis6. Si les faits que nous avons sirnales ne prouvaient surabondamuent que les Anglais conquirent leur independance ì cet égard avant l'époque indiquée par .l. Lavalléc, on pourrait citer ce passage des instructions remises le 23 septembre 158.5 à Jacques de Lancosme, $\mathrm{s}^{r}$ de Brives, ambassadeur à Constantinople : "... depuis peu de temps que $\$$. .1 . a entendu avorr esté mise sus une banuir.re anglaise a la poursuite de la royne dingleterre. "Cinaméne, IV, $427, \mathrm{n}^{0} 1$.

4. Calendars of state papers, I, 516 . 
conquis le droit d'arborer son pavillon sur les mers du Levant, l'Angleterre cherchait à y supplanter la France dans son protectorat sur les marines européennes, et à y ruiner par la piraterie le commerce français ${ }^{1}$.

Le roi, en même temps quill négociait le renouvellement des capitulations ${ }^{2}$, s'efforeca, sans grand espoir et sans succès, de faire replacer les Anglais sous sa bannière ${ }^{3}$. A sa mort, l'Angleterre conservait la grande situation commerciale qu'elle s'était rapidement aequise en Orient. 'Tributaire, avant 1579 , des armaleurs marseillais, dont les bàtiments lui apportaient les denrées du Levant et de l'Extrème-Orient (Alep était le principal entrepût de ces dernières) ${ }^{4}$, elle avait, en 1610 , des relations directes, politiques et commerciales, arec les États du Grand Seigneur, un ambassadeur à la Porte et des consuls dans les Échelles ${ }^{\circ}$.

En revanche, la France avait maintenu sa prééminence sur les autres puissances ${ }^{6}$. Les efforts du Roi Catholique pour aceréditer un ambassadeur à Constantinople araient échoué 7 , les atteintes ${ }^{8}$ portées au privilège de pavillon de notre pays araient été réparées, et notre ambassadeur,

1. IJenri IV à Boissise, 18 déc. 159", 28 sept. 1600. Kenunisgant, Op. laud., 1I. Salignac au roi, 7 aoìt 1609. Gonraut Biron, Amfiassade de Turquie. Sur la lutte de Salignac contre l'ambassadeur d'Angleterre a Constantinople, voy. passim la correspondance publice par M. de Gontaut Biron. Cet ambassadeur, nommé Th. Glauwer, fut un de ces agents qui, suivant la tradition britannífue qu'il est curieux de trouver déjá en vigueur, entreprennent et usurpent le plus possible de leur propre initiative, avec la perspeclive d'être approuvés ou désavoués selon le succès.

2. Lellres miss., IV, :25, 889,$890 ; \mathrm{V}, 30: 2$

3. Hhill., IV, 523, 761, 962, V, 2ti.

4. "... La plupart du négoce de France est rers Alep..." Salignac au roi, 12 agùt 1606. Goxtaut Birox, Ambassude en Turquie (1S89), p. il.

5. Hontchrestiex, 13i-135.

6. Notes sur quelques articles du lrailé de l:04, par Sarary de Brères et art. Iv, r, vi du même traité.

i. Discours fuil par le $s^{\mathrm{r}}$ de Brères du procéde qui ful tenu lorsqu'il remit entre les mains du roy lu personne du due d'Anjou.

s. En 160:, la protection des IIollandais et des Irlandais lui arait été enlevée. Lettres miss., V, 5'i-jłs. Les Anglais araient fait mettre sous leur parillon le commerce flamand. 
Savary de Brives, arait fait modifier, dans un sens farorable, les anciennes capilulations. Celle du 20 mai 1604, entre Henri IV et le sultan Achmet, soumet toutes les nations qui commercent par mer avec l'ompire oltoman, à lexception des Vénitiens et des Anglais, à l'obligation de naviguer sous la bannière du Roi Très Chrétion. Ses sujets obtiennent le droit d'exporter les marchandises dont la sortie est prohibe : cuirs, cordouans, cires, cotons en laine et en fil, blés (art. 7 et 12). Le traité applique en leur faveur le principe que le pavillon coure la marchandise, et déroge a celui que le pavillon confisque la marchandise. En d'autres termes, les vaisseaux français portant de la marchandise ennemie ne seront pas capturés, pas plus que les Français et les marchandises françaises naviguant sous pavillon ennemi (art. 9 et 10). Larticle 14 est dirigé contre les pirateries des Barbaresques. L'article $1: 3$ accorde à nos nationaux le droit de pècher le corail et le poisson dans lè grolfe de Stora Courcouri, dépendant d'Alger et sur toute la côte mauritanique. Leurs contestations entre eux sont soumises à la juridiction de leur ambassadeur et de leur's consuls (ar. 18). Nos compatriotes poursuivis en justice par des indigènes doivent ètre assistés d'un interprète (art. 3\%). Leur succession sera délivrée à leur exécuteur testamentaire et, sils sont morts intestats, aux ambassadeurs et consuls, pour les faire parvenir à leurs héritiers (art. 28). Les capitulations accordées aux Vénitiens leur sont applicables $(\operatorname{art} 38)^{2}$.

Bien que la France ne possédàt plus, à l'époque de Henri IV, le monopole absolu du commerce avec les Étals du Grand Seigneur, bien que la découverte du passage du

1. Dr:moxr, Carps sliplomatique, V, part. II, 39-42. Cf. pour les arantages nouveaux attribués a la lrance par cette capitulation, les observations que lui it consacrées Savary de Breves dians son Discours sur l'ulliance qu'a le roy arec lu Cirrum Seigneur et cle lulilité qu'elle apporte à la Chrestienté, p. ¿, et le traite de 1536 . 
Cap de Bonne-Espérance eût enlevé à notre marine marchande ure partic du transport des marchandises de l'Lxtrême-Orient, le port de Marseille n'en était pas moins l'entrepôt le plus important des produits levantins et orientaux. II n'occupa pas toutefois ce rang pendant tout le règne de ce prince. La guerre civile et la peste $(1: 80)$ l'en avaient fait déchoir. En 1599 , le commeree marseillais était presque entièrement ruiné. Ce fut pour le ranimer que le consul IIonoré de Montolieu proposa à la municipalité, le "̈̀ août de cette année, la création d'une commission qui devint plus tard le bureau et enfin la chambre de commeree. Les commerçants obtenaient par là des représentants pris dans leur sein, éclairés et capables de faire prévaloir leurs intérêts ${ }^{1}$. Si l'on compare cette décadence à la prospérité décrite peu de temps après la mort de IJenri IV par la relation rénitienne de Gussoni et de Nani, on roit que cette ville s'était entièrement relevée ct qu'elle était devenue la reine de la Méditerranée. Exposer son activité commerciale, c'est faire connaitr'e le mouvement presque entier du trafic arec le Levant, et en même temps presque tout le commerce de transport que la prépondérance des marines marehandes de la Hollande, de l'Angleterre et de l'Espagne avait laissé à notre pays.

Le port de Marseille, abrité de tous les vents, assez vaste pour receroir à la fois toutes les flottes européennes, contenait plus de 300 vaisseaux. Son trafic avec le Levant en occupait plus de soixante-dix. Ses bàtiments y transportaient des réaux espagnols, du corail, des soieries et des draps. Le numéraire, qui était l'un de ses principaux articles d'exportation, s'élevait, d'après les ambassadeurs

1. Précis de lhistoire de la chambre de commerce de Varseille, p. 1 en tête de l'Inventaire des archives historiques de cette chambre par O. Tessier. Marseille, 1878, in-1. Massox, Hist. du commerce de Levant. Introd., p. xxvHI-xxix. 
vénitiens, ì 2 millions et demi d'écus d'or (2:32828.97 fr. 81). Montchrélien, qui écrivait peu de temps après, l'entime à plus de sept millions d'écus (7079180\% fr. 8T), dont un tiers en monnaie française, et les deux tier's en espèces espagnoles, et son extination concorde exactement avec celle d'un Adrisan roi, qui appartient presque à lin mème époquel. Ce numéraire ne payait pas de fret, mais le patron du navire avait commission de l'employer en achat de soies grieges on de drogues et, a son retour, il tom hait :̈ p. 100 pour le fret et la commission. Outre les drogueries et les soies, les batiments marseillais rapportaient du Levant de la noix de gille, des épiceries de tout genre, des colons, des toisons de moutons, etc. Ce tralic était pour la plus grande partie un trafic de commission et de transport. Ces commissions renaient d'Espagne, d'Italie, d'Amsterdam, de Ilimbourg, de tous les pays de l'Oecident. Il se faisait aussi à Marseille des prêts à la grosse arenture, à 18 et 19 \%. 100 , remboursables, capital et intérèt, deux mois après le retour ${ }^{2}$. Veut-on connaitre le chemin que prenaient ces denrées, une fois arrivées à Marseille? Lne grande quantité des cotons en laine et en fil, des drogueries, de la soie était expédiée ì Vincenzo Malvasio, grand marchand en gros de produits levantius, établi à Finale près de Savone, qui les expédiait à son tour à Milan, ì Pavie, à Mlexandrie, en Piémont et en Lombardie. Elles trouvaient anssi leur placement à Gìnes et daus son territoire, oì étaient surtout importées beaucoup de soies legis, arlassines et buratines ${ }^{3}$. De Gînes, une partie de ces marchandises était amenée en

1. Mostchuessex, 1). 127. Allvis au roi de 161i, dans Arch. curieuses de lhisloire de firunce, 2e séric, t. I. Cite par Massos, Op. Inul. Introd., p. $x \times x$ xil .

2. - i danno oltan di cio danari a risego di nave alli marinari c ad altri conll ls e 1!) per cento, notli di ogui spesa, ed hamo tempo a pagar il capitale e pro doyo giunti a .Iarsiglia due niesi.

3. Lumis de diveraes rsprices de suies grèges venant du Levanl, de Perse, des lndes un de la Chine. 
barques à Livourne, dans le pays de Lueques, à CivitaVecchia, d'où elles se répandaient dans toute la Toscane et it Rome. Il en entrait aussi en Espagne par Barcelone et Valence. La plus grande quantité des soies grèges de tout genre, ainsi qu'me partie des cotons en laine et en fil, était envoyée à Lyon. Ces marchandises y acquiltaient les droits de douane et se plaçaient en France, à Anvers, dans la haute et la basse Allemagne. De Marseille à Lyon, elles ne payaient pas de droit de douane et le prix du transport ne dépassait pas deux ou deux et demi pour 100. Le moment où les ambassadeurs rénitiens se trouraient à Marseille était pour la ville, comme pour les affaires, un moment de renaissance et de développement. Il y avait tel jour où l'on y rendait plus de 300 balles de soie. On réparait les vieilles maisons, on en construisait de neuves et depuis deux ans la population augmentait.

C'était surtout aux dépens de Venise que le commerce de transport de Marseille prenait de l'accroissement. Comme on pense bien, ce qui altire surtout l'attention des ambassadeurs vénitiens sur cet accroissement, c'est le tort qu'il fait à leur patrie. Ils se demandent pourquoi les marchandises du Lerant passent par Marseille plutôt que par Venise. Ils expliquent cette préférence par différentes causes : les vaisseaux marseillais, moins grands et plus légers que les vénitiens, vont plus vite, et les équipages, étant associés aux bénéfices ${ }^{1}$, déploient plus de zèle et aussi plus de courage quand ils sont altaqués par les pirates. L'infériorité

1. Navigando alln parle. La part du capitaine et de l'équipage était généralement du tiers, les deux autres parts étant attribuées au bourgeois ou propriétaire du navire et aux victuailleurs. C'est ce qu'on appelait la navigation an liers par opposition à la navigation au fiet. Le premier mode de répartition était notamment adopté dans Ia marine normande pour les yoyages au long cours tandis que les autres se faisaient au firet. Giutlon de li mer 1618 , p. 58. Brearo, Documents relatifs à la marine normand: el à ses armements au $\mathrm{XVI}$ et $\mathrm{XVII}$ siècles, 1883. 
de Venise tenait encore aux nombreuses faillites qui avidient ćbranlé le crédit dans la république et aux pertes quo les pirateries lui avaient fait subir. Toutefois, aux yeux des ambassadeurs, ces raisons nétaient que secondaires. En elfet, les Marseillais étaient, plus encore que les Véniticns, exposés aux pirates, car ils étaient obligés de passer devant $\mathrm{Alger}$ et Tunis. Pour se protéger contre les Barbaresques, ils avaient même pris à leur solde Simon Dansa, auquel ils dommaient 7000 écus (70 791 fr. 80) par an, pour escorter leurs bàtiments jusqu'au delà de Malte et, lorsyue cet habile marin avait été pris par les corsaires tunisiens, ils avaient engagé un autre capitaine aux mêmes conditions. La vaie raison, cétait l'économie que le commerce européen trourait à se servir de la marine marchande marseillaise. Les Lyonnais, dont la ville était le principal débouché ou le prineipal entrepôt des marchandises du Levant, déclaraient qu'ils préféraient la voie de Marseille ì celle de Venise, ì cause des frais excessifs du transport sur les vaisseaux rénitiens. Les droits que les négociants Iyonnais aurajent en à payer dans les Échelles de Syrie, sills sétaient adressés ì des armateurs vénitiens, notamment le droit de coltimo, l'obligation de n'acheter qu'aux maisons vénitiennes ì l'exclusion des indigènes, le taux exorbitant du fret et des assurances, le cours peu élevé de l'or dans la république' étaient autant de motifs pour empêcher la marine marchande vénitienne de soutenir la concurrence de la marine marseillaise dans le Méditerranée. La relation de Gussoni et de Nani établit le total des frais que les marehandises expédićes des Échelles de Syrie à Lyon par

1. Dicono quelli di Lione, che da noi troppo è gravata la mercanzia, perchè in Soria, oltre quello che pagano gli altri, vi sono le spese di cottiuno, li noli ingordi, le sicurtà a prezzo eccessivo ed, oltre di cio, è necessario, che quelli che vogliono comprare per Lione comprino da noi, hanno anco il dinno delle monete valendo da noi l'uro meno. Banozza et Bencuet, série II, t. I, p. $\mathbf{4 9 5}$. 
Marseille ont à supporter, afin que la Seigneurie puisse les comparer aux frais du transport par Venise et réduire ceuxci sur le même pied que ceux-là, pour ramener ì cette ville la préférence du commerce. Les réaux espagnols, qui formaient l'article d'importation le plus considérable dans les Échelles, payaient en principe aux Tures 10 p. 100 d'entrée, mais beaucoup moins en fait ${ }^{1}$. Le fret pour l'aller et le retour coùtait $5 \mathrm{p}$. 100. Les Marseillais et les étrangers ayant épousé une femme de Marseille, y étaient exempts de droits d'entrée et de sortie. Les étrangers, qui n’étaient pas dans ce cas, payaient seuls : p. 100 sur les soies grèges et les drogues, et 1 p. 100 sur toutes les autres marchandises ${ }^{2}$. Le tiux des assurances pour l'aller et le retour était de 9 p. 100 . A ces frais, il faut ajouter un droit de 2 écus par balle pour payer le capilaine qui escortait les bàtiments marseilliais et un droit de 5 écus par balle pour le transport de Marseille à Lyon. C'était tout : ni droit de cottimo ni droit de quarantaine pour le séjour au lazaret ${ }^{3}$. La relation vénitienne oublie, à la vérité, le droit de 2 p. $100 \mathrm{au}$ profit des consulats de Syrie ${ }^{*} ;$ en outre, si le droit de cottimo ou droit de 2 p. 100 perçu par l'ambassadeur de France à Constantinople n'existait plus au moment où elle était écrite, il n'en avait pas été toujour's ainsi du vivant de Henri IV.

Ce fut ce prince qui créa celui-ci. A l'origine, il n'était payé que par les vaisseaux français. M. de Brèves obtint du sultan que les vaisseaux étrangers naviguant sous notre pavillon y fussent également soumis, ce qui fit du

1. Ia non si pagano mai tutti a gran giunta.

2. Cf. les droits perçus à Marseille en 1669 sur les négociants étrangers. Fonboxias, I, 430. Voir aussi I, 359.

3. Barozzi et Berchet, I, 493-497.

4. Sur les droits de consulat voy. Pocqueville, Mémoire hist. et diplomatique sur le commerce et les établissements francais au Levant depuis l'an $\mathbf{5 0 0}$ de J.C. jusqu'à la fin du XVII e siècle. Mém. de l'Acadèmie des inscriptions, année 18:33, X, 563 et suiv. Instruction du roi à Savary de Bréves, citée par Gontaut Biron, Op. laud., p. 29, n. 3. 
tort à notre marine mareliande'. Le roi demanda à son annbassadeur un état du produit de cette taxe, qui provoquait les plaintes des commerȩants et lui exprima son étonnement de n’aroir pas été avisé de la concession du sultan². Ceuxci en obtinrent la suppression, mais, en 1600 , Itenri IV la rétablit ${ }^{3}$. En 1602, sur les réclamations des habitants de Marseille, il en interdil la perception à son ambassadeur", mais celui-ci eut le crédit de la faire encore rétablir ${ }^{5}$.

C'est le commerce extérieur qui donne le mieux la mesure du développement de la production nationale, c'est lui qui rérèle le mieux les aptitudes, la rocation commerciale d'un peuple. Les exportations, ne portant jamais que sur l'excédent de la consommation intérieure, signalentles points où la production atteint son maximum; d'un autre côté, les opérations au dehor's, devenant, par suite de l'agrundissement du marclıé, plus complexes et plus délicates, exigent plus d'intelligence et d'esprit d'entreprise.

Les exportations de notre pays se distinguaient par la rariété. Les produits naturels y dominaient et plusieurs d'entre eux les céréales, les vins, le sel, le pastel lui assuraient presque des monopoles, mais les produits manufacturés, certains tissus, la mercerie, le papier, la quincaillerie y tenaient une place importante. L'ensemble s'équilibrait arec les importations et là où cet équilibre était rompu, cètait au profit de notre pays, qui encaissait un solde en numéraire. De là une circulation abondante de monnaies étrangères ${ }^{6}$.

1. Povqueville, Lbi supra, p. sití.

2. Lettre à 11. de Bréves, 5 février 1596. Leltios miss., V, 497.

3. Ibiel., V, 308 .

4. Ibid., 11,561 .

5. Mosrcunesties, 128-129. Hassov, Hist. du commerce du Levant. Introd., p. $\operatorname{xin}-x x x$.

6. Leghas, Décade, 85i, cité par Philippson, I, 3i0. 
Le progrès accompli est grand, mais il ne l'est pas assez pour avoir replacé la France au rang qu'elle occupait avant les guerres civiles. Les draps français, qui jadis approvisionnaient sans partage le Levant, sont remplacés maintenant par des draps anglais. L'Espagne n'est plus exclusivement réduite à la merceric française, elle en fait clle-même ${ }^{1}$. Ce commerce, qui, dans plusieurs de ses hranches, devait sa prospérité au goùt de nos industries d'art, est en souffrance ${ }^{2}$.

Les échanges ne s'en développent pas moins, sous l'impulsion d'un gouvernement toujours en éreil sur les intérêts publics, toujours empressé à les servir. Le transil par terre se sert volontiers des roies et des moyens de transport que la France met à sa disposition. 11 y recourrait plus encore, s'il ne se laissait décourager parfois par nos douanes extérieures et intérieures. C'est surtout par le canal de notre pays que s'établissent entre l'Espagne et ses anciennes provinces rebelles de la mer du Nord des relations clandestines, dont le vrai caractère ne trompe personne, et que lintérèt commun, plus fort que les passions nationales, renoue après que les gouvernements les ont rompues. Calais en est chez nous le principal point de départ, et y acquiert une importance considérable 2 .

Quant aux transports maritimes, c'est un des points où éclate le plus l'infériorité de notre pays. Il y arait trop peu chez lui de ces marchandises lourdes et encombrantes qui assurent un fret de sortie. Le fer et le bois étaient assez abondants pour suffire tout juste à ses besoins, notamment à la construction maritime, ils ne l'étaient pas assez pour donner lien à une exportation.

D'ailleurs, la marine marchande était tellement insuffisante, que cétait sur des vaisseaux flamands, hollandais et

1. Du Fresnes Canaye au roi, 23 octobre 1602, I, 456-457.

2. Voy. plus haut et Dallixgton, p. 12. 
anglais que se faisait le chargement des produits qui occupaieut le premier rang dans nos exportations, le vin, le pastel, le sel'.

La France prenait sa revanche dans le Levant. Elle y défendait avec sucè̀s ce qui lui restait d'une situation privilégiée qui avait étó entamée. Menacéc dans ses transactions directes arec les Échelles, elle se rattrapait par l'industric des transports maritimes, c'est-ì-dire par le genre d'entreprises oì clle était en général le plus arriérée. Sarary de Brèves évaluait à 30 millions de livres (8768798' fr. 12), le chiffre de ses affaires dans cette région ${ }^{2}$. Elles faisaient. en grande partie la fortune de Marseille, et Lyon si déchu en ressentait le bienfaisant contre-couj). Arboré sur la marine royale et sur les marines protégées, le pavillon fleurdelisé était celui que l'on rencontrait le plus dans la Méditerrancée. Dans l'Océan, notre patriotisme trouvait encore de quoi se réjouir. Si les IIollandais nous disputaient arec succès la pêche du hareng, nos terre-neuviers défiaient, pour celle de la morue, tous leurs concurrents.

Pour eux, comme pour tous nos bateaux de pèche et de commerce, les traitrises de la mer n'étaient pas le seul péril. Le brigandage maritime les guettait ${ }^{3}$ et les capturait, sous le prétexte qu'étant neutres, ils transportaient pourles belligérants de la marchandise de guerre, ou tout simplement de la marchandise. La force seule tranchait la question et la force, on le sait, était rarement du côté de la France. On souffre de la voir s'adresser à l'étranger pour aroir des

1. Pour le vin, voy. ce que nous avons dit plus haut. Pour le pastel, voy. la correspondance de Simon Lecomte. Quant au sel, Mlontchrétien dit (p. 72, 73 ) que son transport avait lieu par bateaux flamands et hollandais et rapportait aux 110 llandais 60000 écus $(606 ; 86 \mathrm{fr}$. 91) de fret par an.

2. Cité par \$assou, $O p$. laud. Introd., p. xxx. En 162i, il avait baissé de moitic. Louis XIII à d'Effiat, 13 août 1624. Papier's l'État de Richelieu, p. p. AVENEL, II, 2 '.

3. "Vos marchands ne peuvent sorlir de nos harres qu'aussitost ils ne soyent en proic aux Anglois et a toutes nations. "Du Fresne Canaye au roi. Uti supra. 
bàtiments, des marins, des chefs d'escadre qui conroient et protègent sa marine marchande.

Tandis que le marché français est envahi par les étrangers qui, lorsquïls ne veulent pas se fixer eux-mêmes dans notre pays, y trourent, soit parmi leurs compatriotes soit parmi les Frauçais eux-mèmes, des commissionnaires et des facteur's, les colonies françaises au dehors sont peu importantes. L'accueil fait par les nations européennes à ceux de nos nationaux qui s'expatrient, explique en partie ce peu d'empressement, mais l'attachement au sol et le peu d'aptitude à se trouver partout chez soi y sont aussi pour beaucoup. Pour peupler et exploiter les établissements de la Nouvelle-France, on trouve surtout, au début, des gens sans ressource et sans areu. Jetés dans un nouveau milieu, arrachés à leurs pernicieuses habitudes, moralisés par la solitude et la facilité des gains légitimes, ils pourraient peut-ètre déployer l’industrie et l'activité qui assurent l'avenir d'une colonie, mais il y faudrait une autorité énergique capable de les contenir, de les stimuler et de les améliorer; or, au point de rue colonisateur comme au point de rue religieux, la direction n'a pas été fortement organisée.

A côté des défauts inhérents à notre race et toujours persistants chez elle, le gouvernement n'a-t-il pas eu sa part dans l'insuffisance des progrès accomplis? En ne forçant pas les étrangers qui venaient vendre en France à faire remploi en marchandises indigènes, en leur permettant de remporter leurs marchandises défectueuses, sans mème payer de droit de sortie, au lieu de les confisquer, en n'obtenant pas par des mesures de représailles l'abrogation des lois étrangères qui traitaient nos nationaux avec une inégalité choquante, en ne réservant pas à notre marine marchande le monopole des transports à l'étranger, le gouvernement de Henri IV n'a-t-il pas laissé échapper l'occasion de placer ses sujets au 
premier rang des nations industrielles et commerçantes de l'Europe? Il s'est trouré de son temps et après lui des commerçants pour le lui reprocher mais, areuglés par leur intérêt professionnel, ils ont, croyons-nous, méconnu les ménagements que l'infériorité de notre marine marchande et de notre marine militaire et, ì un point de vue plus général, les lacunes de la production nationale obligeaient le roi à garder vis-ì-vis de l'étranger. Pour imposer à l'Europe et particulièrement aux nations maritimes, des mesures de protection et de prohibition en fareur de notre commerce extérieur d'échange et de transit, il aurait fallu pouvoir faire la loi sur les mers, se passer des autres, trouver che\% nous-mêmes la satisfaction de tous nos besoins. On sait combien nous étions loin d'une pareille indépendance et d'une telle suprématie. Le mélange de patience et de fermeté que l'on a remarqué dans les rapports de Ilenri IV arec des puissances qui disposaient d'une force navale supéricure à celle de la France, était donc le seul système dont il pût attendre des fruits. 


\section{CIIAPITRE V}

\section{GONGLUSION}

Les sociétés sont des unités organiques, où toutes les parties sont solidaires, dont toutes les fonctions concourent par un concert général à un effet commun. C'est déjàbeaucoup d'aroir montré le jeu de chaque organe mais, pour expliquer le mystère de la vie, il reste encore à faire voir les rapports réciproques de tous, le mouvement d'ensemble auquel ils aboutissent. Cette répercussion de l'une à l'aulre de toutes les opérations de la vie sociale est peutêtre encore plus grande et plus frappante dans le domaine économique que dans tout autre. Aussi nous a-t-il fallu faire un véritable effort pour ne pas être entraîné, par la connexité des phénomènes de cet ordre, à franchir les limites que nous nous sommes imposées en étudiant à part l'économie rurale, l'économie industrielle et l'économie commerciale, et nous ne sommes pas sùr d'y avoir toujours réussi. Cette méthode, un peu artificielle, était indispensable, et peut-être pouvons-nous invoquer en sa faveur les fruits qu'elle nous a donnés. Ce n'est pas, toutefois, sans une certaine satisfaction que nous en abordons une autre qui, en même temps qu'elle résumera les résultats de la première, suivra, sans plus s'astreindre à des divisions didactiques, l'enchaînement ininterrompu de la création et de la circulation de la richesse.

An moment où Henri IV montait sur le trône, la sura- 
hondance des espèces d'or et d'argent répandues en Europe depuis l'exploitation des mines du Pérou et du Iexique et surtout depuis la découverte de celle du P’otosi (154:5), arait, arec la réunion d'autres cireonstances d'une influence secondaire, sextuplé ${ }^{1}$ presque tous les prix. Le remède à la hausse, l'acheminement ì la baisse, on le connaît : c'est l'augmentation de la production. Mais la situation de la France semblait lui en interdire jusqu ì l'espoir. Elle était, ellederait être, pendaut huit ans encore, bien qu'avec une décroissance progressive, la proie de la guerre civile, et ce n'est pas de la guerre civile qu'on peut attendre le développement alternalif de l'offre et de la demande, qui abaisse et relève suceessivement les prix pour le commun profit des consommateurs et des producteurs, et répand l'aisance ehez les uns et ehez les autres.

La guerre intestine, tel est le triste legs dont hérite. Ie gourernement de Henri IV et qui entravera si longtemps sa marche et l'essor du pays, telle est la circonstance à laquelle il faut demander le secret du règne, l'explication de ses contrastes attristants et radieux. En résumer les conséquences éparses dans ce livre et les envisager dans leur ensemble, c'est une préparation indispensable pour faire comprendre l'évolution qui a été si lente à en éliminer les ferments.

Les luttes religieuses avaient accéléré le mouvement qui poussait la bourgeoisie à l'acquisition des terres seigneuriales et à l'envahissenent des fonctions publiques. Les familles nobles, décapitécs souvent par la perte de leur chef ou de leur héritier présomptif, avaient été appauvries par le ravage deleurs domaines, par la dépréciation des revenus qui leur étaient payés en argent, par la suspension ou la perte de leurs fermages, par l'égalité des partages, qui, dans certaines provinces, régissait les successions nobles comme

1. S'il fallait en croire Tavannes, elle les aurait même décuplés. Memoires. Coll. Michaud, p. 82. 
les successions roturières. Elles avaient été obligées de rendre ou d'hypothéquer leurs liefs à des roturiers ou d'emprunter sur gages à un intérêt qui s'élevait jusqu'ì 30 p. 100. En même temps que la hourgeoisie enrichie s'installait dans les chàteaux lélabrés de la noblesse ${ }^{\text {, }}$ elle s'emparait des charges de judicature et des bénéfices ecclésiastiques, autrefois réscrés en grande parlie aux cadets de la classe aristocratique, et redoutés maintenant par leur ignorance et leur paresse. Beaucoup de gentilshommes, dont le patrimoine avait été entamé, mais qui avaient pu conserver le manoir héréditaire, s'estimaient heureux d'y jouir d'un repos bien gagné, d'y réparer les brèches de leur fortune, d'y vivre largement et noblement, bien qu'avec épargne, des produits de leur cru. Tous n'avaient pas cette sagesse; un certain nombre ne résistait pas à la tentation de venir dépenser en une semaine à la cour leurs économies d'une année. La fureur du jeu en absorbait la meilleure part. Elle était si grande, qu'on jouait ses chevaux, ses armes, tout ce qu'on arait sur soi, et on se faisait si peu crédit, que le perdant derait s'exécuter tout de suite, dìt-il s'en aller en chemise. Ileureux les nobles qui, sous les drapeaux du roi ou de la Ligue, avaient su se saisir de quelque place forte et la garder ou la vendre à l'autorité légitime. Endettée ${ }^{2}$ et sans crédit, l'influence de la noblesse était encore affaiblie par les rancunes de la population du plat pays et même de la population urbaine rui avaient souffert de ses exeès ${ }^{3}$ et par la

1. Jullux, Hisloire de Bordeaux, 426,427. "... si l'on jette un coup d'wil au $x v 11^{\circ}$ siècle sur nos châteaux, nos fiefs et arrière-fiefs, on est tout surpris de les voir possédés par des seigneurs et écuyers dontles ancêtres vendaient du drap fabriqué à Château-Thierry. "Ventus, Notice sur Claude Vitard et sur l'élat de la socièté un .IVI' siecte, dans l'élection de ChàleanThierry. Annales de la Société hist. et arch. de Chatenu-Thierry, 1864.

2. Au moment oủ il écrivait, c'est-à-dire pendant sa captivité, de 1580 à 1585, La Noue, sur dix fawilles nobles, en comptait huit endettées.

3. Dès 158?, Lorenzo Priuli écrivait : “... si trova... molissima intelligenza 
jalouse compétition des gens de robe, qui ne sortaient plus, comme jadis, le ses rangs autant que de ceux du tiers et ne facilitaient plus, par cette doubie origine, le rapprochement des deux classes. Atteinte dans sa situation matériclle et morale, se rendant comple du danger dont la menaçait l'aseension du tiers état vers la propricté foncière et les hauts emplois de l'administration et de la justice, elle renfermait heaucoup de mécontents dont loccasion pourait faire des factieux.

Les guerres ciriles araient coìté eher au clergé envisagé dans son ensemble. En 1:398, l'ambassadeur rénitien, Petro Duodo, estimait à plus de 40 millions d'écus d'or (379981 26.' fr. 48) ce qüil arait payé, pendant leur durée, en décimes, en dons gratuits, en subsides de tout genre. Ajoutez à cela les cmprunts dont les intérêts avaient été mis ì sa charge et les usurpations dont il avait été victime. de la part des catholiques comme des protestants ${ }^{1}$. En dépit de tout cela, ses revenus dépassaient encore six millions décus d'or ${ }^{2}$. Mais, si l'ordre restait riche, beaucoup de ses membres étaient devenus paurres et, parmi les mendiants qui encombraient les rues, il y aviit des prêtres ${ }^{3}$.

Les troubles intérieurs avaient eu pour les différentes classes qui composaient le licrs état des conséquences assez direrses. La plus humble de toutes, celle des paysans avait été la plus éprourée. Écrasée d impôts, balayée par le flot incessant des troupes en marche qui l'emportait

tra la nobiltà e il popolo, essendo questo grandemente oppresso da una quantita grande di gentiluomini poreri che li tiranneggiano e vogliono vivere, vestire e lussuregriar a spese loro... "dans Albem.

1. Discours an roi par le sieur de Iloxlec..., 15i3, à la suite des Commentaires, éd. Ruble, V', 299.

2. LA Nole, Discou's politiques et militaires. Disc. v et xx. Advertissement sur la réception du concile de Trente par Du Plessis Monxay, 31 janvier 1583, dans lémoires el correspondance de Du P'LEssis Morxir, Il. Frocmenteac, Le secret des finances (1581). Épilie au lecleur, p. 8. Noen ut Fail, Contes et discou's d'Eutrapel, 1, 315.

3. Laffemas. 
avec Iui ou la rejelait dans les villes, n'abandonnant pourtant jamais sans espoir de retour le champ dont l'horizon bornait toute sa vie, la population rurale avait diminué de trois millions au moins, et ne suffisait plus aux travaux de la campagnue. L'abrutissement du désespoir l'avait réduite à une docilité d'enfant ${ }^{1}$.

Les commerçants et les artisans avaient vu considérablement baisser le chiffre de leurs affaires, et leurs rentes avaient été trop sourent supprimées pour pouvoir suppléer à la perte de leur clientèle ${ }^{2}$. Les uns avaient été chercher à l'étranger le travail qu'ils ne trouvaient plus dans leur pays; les autres avaient déserté leurs ateliers et leurs magasins pour prendre leur part des agitations de la place publique; tous, se serrant, dans la désagrégation générale, autour des institutions qui protégeaient leur mon opole, se coalisaient dans leur's assemblées corporatives pour maintenir le cours éleré des marchandises et relever celui des façons.

ll y a toujours des gens qui s'accommodent des malheurs publics et qui réussissent même à en tirer profit. A la fin du $\mathrm{xrr}^{e}$ siècle, cétaient les gens de robe, de finances, de bureau et une foule d'officieux qui n'araient pas de profession avouable. Tous les services de la vie sociale, depuis les plus élevés jusqu'aux plus modestes, depuis les fonctions de premier président du parlement jusqu'à la profession de mouleur de bois et de rendeur de foin, avaient été érigés en offices. Cela revient à lire que tous donnaient lieu, aux dépens du public, à la perception de

1. “... in tanta dejezione e miseria, che piccioli lacchè di dieci o dodici anni fanno per le strade prigioni gli uomini di 30 e 40 anni e lor donno le taglie, come ne ho pur veduto qualcuno. " Relation précitée de P. Duodo, p. 157.

2. Relation de Duodo, p. 159. "... les rentiers ayant perdu cinq années de leurs rentes durant les troubles de la Ligue. "Remurques de Marbault, p. 76. Remontrances de Miron an consen, 22 avril 1605. Remontrances de Gaston de Grieu dans Francois Miron, par Jirox DE LESPINAY, 222, 224, 233. 
droits onéreux et souvent arbitraires, qui représentaient, sur le pied habitucl de 10 ou 20 p. $100^{\prime}$, l'intérèt du capital rersé par le titulaire aux parties citsuelles. Le produit de cés oflices devait ètre d'autant plus élevé que la possession de beaucoup d'entre eux était précaire, que les titulaires étaient exposés à les perdre par voie de suppression sans ètre assurés l'une indemuité, ou à en partager les profits arec des collegrues de nouvelle création. Les embarras des classes supérieures avaient suscité une foule d'agents d'aflitires et d'entremetteur's qui vivaient et s'enrichissaient de leur gène, de leur vanité, de leurs entrainements, de leur incouciance. Ainsi il y avait des courtiers qui se chargeaient de leur procurer de l'argent sur nantissement, sans leur faire comnaitre le nom des bailleurs de fonls, de sorte que, si ees courtiers renaient à mourir arant le remboursement, des gages, d'une valeur très supéricure ¿ la somme prètée, pouvilient ètre perdus pour l'emprunteur *. Les merciers, les fripier's se mêlaient de ce courtage. lls se chargeaient aussi de vendre les objets de prix dont leurs clients voulaient se défaire, et l'habitude de se procurer des ressources en détachant de leur mobilier un joyau, une pièce d'argenterie, etc., était si répandue dans les classes élevées, que II enri IV créa pour ce genre de ventes une sorte d'agence de conmission ${ }^{3}$. D'autres agents faisaient, avec un fort escompte, des avances aux gentilshommes obérés contre des billets en blanc et des lettres de changesur les foires de Lyon, et se prêtaient avec empres-

1. "... on sait bien que le roi ou le peuple paye les gages a la plupart des officiers à la raison de dix ou vingt pour cent... "Bons, République, VI, II, $910\langle$ éd. 1580).

\%. IRelation de Duodo.

3. Brevet accordé le 31 juillet 1602 à Philibert Beruyer et à Marie Caillault, si fille, leur permettant de revendre et colporter a Paris bagues, careins, perles ut toutes sortes de pierreries, objets d'orfévrerie, meubles et hardes r jui leur sont baillés à vendre par les particuliers. Bibl. nat. Mss. Franç., 21 i97, f. 146 . IIss. Delanahe, Arls el métiers, vol. vit. 
sement à leur renouvellement. La chicane, qui trouve surtout à s'exercer dans les temps où la violence a usurpé et embrouillé tous les droits, arait aussi enrichi beaucoup de praticiens. Elle était également favorisée par la multiplicité et la diversité des Lois, le nombre des juridietions et des gens de palais. On estimait que ceux-ci étaient plus nombreux en France que dans le reste de la chrétienté tout ensemble ${ }^{2}$. Mais, parmi toutes les eatégories de parasites qui détournaient à leur profit des capilaux perdus pour la production et donnaient à la société l'apparence de l'activité économique et l'éclat du luxe, aucune n'altirait autant l'attention que celle des financiers et des manicur's d'argent de tous les degrés, donneur's d'avis ${ }^{2}$, partisans, fermiers et sous-fermicrs et, plus que tous les autres, intendants et surintendants des finances. En quelques années, ces derniers avaient fait des fortunes prodigieuses. Ils habitaient des palais, y donnaient des fètes qui contrastaient

1. "... en un seul parlement de France, il s'en trouvera plus grand nombre [de procès] qu'en toute l'Italie... et plus de procureur's et arocats en un petit bailliage de ce royanme, qu'il n's a en la chambre impériale de toute l'Allemagne...." F. DE Gravelle, Politiques royales, 1596, p. 148. "... nous arons en France plus de lois que tout le reste du monde ensemble... et si avons tant laissé à opiner et dẻcider à nos juges, qu'il ne fut jamais liberté si puissante et si licencieuse. "Moxtalgre, III, XIII.

2. De tout temps, ladministration fiscale s'est mis l'esprit à la torture pour découvrir de nouvelles matières imposables; sous I'ancien régime, elle était secondée dans cette recherche par des officieux qui proposaient au gouvernement des expédients, dont ils se faisaient attribuer en partie le produit. Tout le monde pouvait se faire donneur d'uvis et, en le derenant, on obéissait á deux mobiles bien puissants : le plaisir d'inventer et l'amour du gain sans travail. Cette fièvre d'invention et d'enrichissement rapide enfantait les projets les plus bizarres, et plus d'un ne le cède guère à celui de ce personnage des Fácheux de Molière qui proposait "de la France.... En famenx ports de mer mettre toutes Ies côtes. "Quelques-uns de ces donneurs d'avis du temps de Henri IV se détachent de la foule des autres, et se présentent á nous avec une physionomie particulière: tel est Ange Capel, sienr du Lnat qui, entre autres avis, onvrit celui de faire consigner au demandeur, au début de toute instance, une somıne de 25 écus (237 fr. 49) à titre d'amende pour le cas oủ il perdrait sa cause et qui espérait tirer de sa part dans le produit de cette consiguation plus de 50000 écus de rente (474 976 fr. 58). MIarbault, Remarques sur les mémoires de Sulty à la suite des Economies royales, coll. Nichaud, p. 35 . 
douloureusement avec la misère publique, et constituaient ì leur's filles qui rivalisaient, comme leurs femmes, par la toilette et les bijoux, aree les princesses el les phus grandes danes de la cour, des dots de 40 et 30000 écus (379981 fr. 26

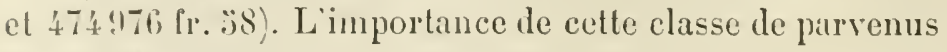
faisiait létonnement el le seandale des étrangers. "C"est un cas lamentable, écrirait en 1:i98 Dallington, secrétaire de l'imbassadeur d'Anglelerre, que, dans un beau pays et plein de noblesse, l'État soit gouverné et toutes les aflaires conduites par cenx de la robba longa, des avocuts, des procureurs et des gentilshommes de plume et d'encre, tandis que la noblesse elle-même, faute d'instruction, n'a pas d'emploi ${ }^{\mathrm{I}}$ ").

Cet art dexploiter la gêne des classes élevécs, de les ruiner gaiement en leur fournissant les moyens de prolonger une prospérité menteuse, la France ne l'avait pas apprise toute seule. Fuyant les vengeances auxquelles les exposait l'abandon politique de notre pays, espérant partager la fareur arec laquelle il accueillait tout ce qui renait du leur, ses artistes et ses ouvriers, son luxe raffiné et ses meurs aussi bien que son architecture, beaucoup d'Italiens étaient venus donner à la France des exemples et des leçons de cette science du change, lu crédit, de la banque et de l'agiotage, dans layuelle leurs compatriotes du xive siècle, les Biche, les Mouche, les Porruche, les Angroisselle et tant d'autres avaient été nos premiers instituteurs. Cette seconde émigration ultramontaine n'avait pas moins bien réussi que la première. Lỵon arait dù sa prospérité à sa colonie italionne, et les noms de Gondi, de Sardini, de Zimet, de Cenami, de Bonvisi, etc., rappellent la place considérable que les Italiens s'étaient faite dans l'État, dans l'administration fiscale et dans les afliires ${ }^{2}$.

1. Op. laud., p. 167.

2. Voy. notamment Discours poliliques de La Noue (éd. 1587). 
Ilausse des prix ${ }^{1}$, suivie seulement de loin par celle des salaires, stagnation de la production, diminution de la population en général, déclassement de la population laborieuse, développement de l'agiotage et du luxe, rien ne manquait à la société française vers $1: 398$, au moment où elle goùtait les premières douceurs de la pacification intérieure et de la pacification étrangère, de ce qui distingue un pays qui vit sur son capital au lieu de vivre sur son revenu et sur son travail.

Douze ans plus tard, au moment où elle perdit son roi, la France, tout en rappelant par certains. traits ce passé encore si récent, arait bien changé. Nous pourrions montrer de suite ce qu'elle était derenue, le contraste en serait plus grand. Nous préférons faire assister à sa transformation en $y$ discermant la part du roi, celle de ses conseillers, celle du pays. L'influence du gouvernement sera la première qui nous occupera, c'est la plus apparente, la plus facile à saisir.

L'un des services les plus essentiels qu'un gouvernement puisse rendre à la production, c'est d'alléger les impôts, de les proportionner aux forces contributives du pays, de les répartir équitablement. Malheureusement, IIenri IV avait hérité de ses prédécesseurs un régime fiscal doublement vicieux, d'abord parce qu'il épargnait la richesse ${ }^{2}$ et ensuite parce qu'il ne laissait entrer à l'Épargne qu'une

1. "... incredibile carestia.... " Relation précitée de Duodo, p. 170.

2. Cela n'est vrai, on le sait, que d’une vérité générale, à laquelle le lecteur apportera de lui-même les restrictions nécessaires. On serait, en effet, dupe d'une apparence en présentant le clergé et la noblesse comme exempts d'impôts. Les ecclésiastiques et les nobles, qui n'exploitaient pas eux-mêmes leurs terres, supportaient l'impôt foncier en ce sens que, leurs fermiers y étant soumis, les fermages en diminuaient d'autant. En outre, dans les pays de taille réelle, Languedoc, Dauphiné, etc., il n'y avait pas de distinction, au point de rue fiscal, entre les terres nobles et les terres roturières. Le clergé avait ses charges particulières qui, pour être en partie volontaires, n'en étaient pas moins très onéreuses. La noblesse parlementaire et municipale, à côté de laquelle la noblesse d'épée ne formait qu'une infime minorité, avait aussi les siennes. 
partie fort amoindrie de lis recette. Le budget de 1596 se soldait eneore par un délieit d'environ 10 millions de

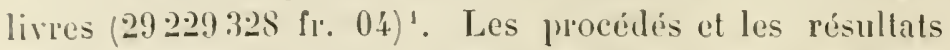
des premières années du règne n’avaient été, en effet, que la conlinuation du passi. Trois ans plus tard, en 1399, le défecit n’avait pas diminué ${ }^{2}$, lis delte publique

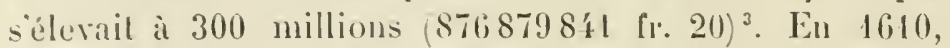
alle élait réduite ì $196(: 328: 378817$ fr. 20), ou même à 170 millions ( $\left.138461219 \mathrm{fr}^{\circ}\right)^{4}$. Les excédents avaient atteint, de 1600 ì 1609 , le chiffre de 4.8 millions et demi $(130-96288 \mathrm{fr} .9 \%)^{5}$. La taille avait été progressivement

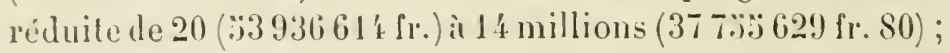
un arriéré de 20 millions sur celle de $1: 396$ et des années antérieures, avait été remis aux contribuables retardataires; en même temps, la revision et la réduction des exemptions, en augmentant le nomlure des tailables, araient allégí leur charge. Si impopulaire que fìt la taille, il y arait un impût encore plus odieux : cétait la gabelle. Si sully le soumit ì un contrôle plus sévère, sill se montra en même temps indulgent pour les détentenrs de faux sel ${ }^{6}$, il n’en réforma pas l'assiette et sappliqua ì en augnenter le produit par des crues suceessives.

Henri IV et Sully étaient partisans de la liberté d'exportation, de la libre cireulation des marchandises indigènes, du libre transit des marchandises étrangères. Mais la prudence leur défendait de toucher trop profondément au système de douanes intérieures et extériemres qu'ils araient trouvé en vigueur. La préférence du surintendant pour

1. Clanagerax, Histoire de l'impôt, lI, 285.

2. Clavagerax, II, 3i5.

3. Relation de Carew, p. 486.

4. "... in february 1 Goos he [Sully] had acquitted an hundred and thirty w. of that debt [de $300 \mathrm{~m}$. ]... " $/$ lid.

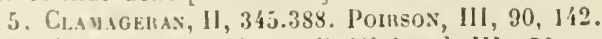

6. Economies royales, coll. Michaud, 111, 178. 
les in pôts indirects, le poussait d'ailleur's à leur demander les ressources nécessaires pour suppléer à l'insuffisance de l'impôt direct que l'intérèt de la classe agricole arait fait réduire. Voilà comment le souverain et le ministre se trouvèrent amenés à léroger à leurs inclinations et à leurs principes, en conservant et même en resserrant le réseau fiscal, qui paralysait en partie l'essor de la production.

Les lignes de douanes avaient été tracées de façon à suivre et à couper les roies commerciales les plus fréquentées. Le conmerce avait beau ètre appelé dans d'autres roies, il ne pourait s'y engager et devait prendre celles qui lui faisaient traverser la zone douanière.

Les importations maritimes ne se faisaient pas indifféremment par tous les ports. Le corail et les autres produits barbaresques ne pouraient entrer que par Marseille ". Cette ville était la seule sur la Méditerranée par où l'introduction des épiceries et des drogueries des Indes orientales fùt autorisée. Sur l'Océan elle n'arait lieu que par Rouen. Par terre, elle était réservée à Lyon

$\mathrm{Si}$ ces marchandises exotiques, après aroir, à leur débarquement à Marseille, payé le droit de douane qui était de '4 pour 100, remontaient la vallée du Rhône, elles ne tardaient pas à entrer dans la circonscription de la douane de Vienne ou, comme on l'appelait aussi, de Valence. Tout ce qui sortait des provinces riveraines du fleure, Provence, Languedoc, Vivarais, Dauphiné pour

1. Voy. plus haut le cliapitre sur le commerce extérieur.

2. Adjudication faite au conseil de la ferme de la douane des épiceries, drogueries et autres denrées abordant à Marseille et autres lieux du littoral pour quatre ans, à partir du ler janvier dernier, moyennant 4550 livres (13 $299 \mathrm{fr} .34$ ) par an. 17 mars 1607. Bibl. nat. IIss. Franc., 18171,

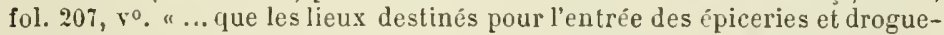
ries sont, pour le regard de celles qui viendront par la... Héditerranée..., Marseille, pour la mer Océane, Rouen et pour celles qui viendront par terre..., Lyon tant seulement... " Déclaration du consulat de Lyon du 11 septembre 1612. Arch. municipales de Lyon. Reg. BB 148 fo 106, vo et suiv. 
se dirigger vers Lyon ou tout ce qui, en sens inverse, venait du Lyonnais, du Forez, du Beaujolais, de la Bresse, de litalie et de la Savoie en passant par Lyon pour descendre vers le littoral, était soumis à cette douane, dont les bureaux étaient établis ì Vienne et à Sainte-Colombe' et qui, en 1601, était affermée 16000 écus ${ }^{2}$ ( 1.31992 [1. 50). Afin d'y échapper, les marchandises expédiées pour le continent se détournaient de leur itinéraire naturel, et graguaient, par des roies plus longues et cependant moins onérenses, leur destination. Les unes, pour arriver dans l'Europe centrale, septentrionale et orientale, opéraient leur transit en terre exclusirement étrangère, par le Comtat Venaissin, la Saroie, la Bresse, Genère et la Franche-Comte; les autres, qui devaient trouver leur placement dans l'Europe occidentale, suivaient la rive droite du lleure, traversaient le Languedoc, le Virarais, le Forez et, obliquant à l'ouest avaut de pénétrer dans le rayon de la douane, atteignaient l'Auvergne, prenaient l'Allier à Maringues et passaient dans la Loire qui les transportait à Orléans ${ }^{3}$.

Là où cessait la zone de la douane de Vienne, commençait celle de la douane de Lyon. Ce contact occasionnait mème des conflits. En 1607, les fermiers de la

1. "... la ferme de la douane de Vienne qui se lève sur toutes les marchandises, tant étrangères que autres, venans et se voiturans, tant par eaue que par terre, de nos pays de Provence, Languedoc, Vivarais, Daupliné et autres qui passeroient par ladite ville de Valence et Sainte-Colombe allans á Lyon, comme aussi sur toutes sortes de marchandises venant de Lyonnais, Forez, Beaujolais, Bresse, Italie et Saroie et autres fieux qui seroient chargées en nostred. ville de Lyon et se voitureroient en nosd. pays de Provence, Languedoc et autres lieux soit par eaue ou par terre..." " Arrit du conseil du 10 décemble 1605. Bibl. nat. Franç., 18169, fol. 65.

2. Lettres patentes de Ilenri IV du 3 mai I 601 contenant bail de la doune de Vienne au profit du nommé llubert pour deux anmées et huitmois, au prix de 16000 écus par an. Inventuire des arch. municipales de Lyon, VIII, p. 4it.

3. Matmec, Ilistoire de France, J, 396. Jeax de Serres, Incentaire de lihis loire de lirance, 1, 331-33i. Rovart, Du fuil de la gabel e. Bullelin de la ciélé niver nu ise des sciences, lettres et a'ts, V (1869), p. 48. 
seconde avaient usurpé la perception sur les marchandises à leur passage par le Dauphiné ${ }^{1}$. La douane de Lyon attirait dans cette ville les soieries, les étoffes d'or et d'argent et les autres articles levantins, italiens et espagnols. Leur introduction dans le royaume ne pourait s'opérer que par cette roie et, pour les introduire par une autre, il fallait le consentement du fermier et du conseil du roi ${ }^{2}$. La contrebande était très aclive et, pour l'empêcher, pour surveiller la circulation, la douane était obligée de poster partout des agents secrets qui lui coûlaient fort cher ${ }^{3}$. En 1609, les marchandises de contrebande répandues en France étaient si nombreuses que le fermier dut se transporter ou envoyer un représentant dans les provinces où il $y$ en arait le plus, pour sommer les détenteurs, à son de trompe et par cri public, de venir, dans les six jours, les faire plomber et payer les droits". Les importations qui payaient la douane, ne payaient rien à l'entrée du royaume".

La traite d'Anjou et trépas de Loire pesait sur le conmerce qui se faisait, par terre et par eau, entre l'Anjou et la Bretagne. En 1593, une nourelle réappréciation ${ }^{6}$ des denrées qui y étaient soumises, releva leur valeur et

1. Arrêt du conseil du 10 février 1607. Bibl. nat. Franc., 18171, fol. 99.

2. Arrêt du conseil du 30 décembre 1608. Franc., 1817t, fol. 218 .

3. Frousexteau, Le secrel des finances, 1581.

4. Arrêts du conseil du 30 octobre 1608 et 8 octobre 1609. Franç., 18174 , fol. $36 \mathrm{v}^{0}$ et 18176 , fol. 19 vo.

5. "Ç'a esté ung bon cuvre d'aroir par vous obtenu la vérification de l'exemption de douane à l'entrée du r'oyaume pour les marchandises venans en ceste ville. "Lettre du consulat de Lyon aux députés de la ville en cour, 14 août 160 '. Arch. municipales de Lyon AA 112, fol. 182. Arrêt ordonnant que les marchandises venant de Flandres, Angleterre, Allemagne, etc., et entrant par Picardie, Normandic et Champagne pour aller à Lyon, ne payeront pas droit d'entrée lá où elles entrent, mais que les marchands rapporteront certificat de la douane de Lyon de l'acquit des droits à Lyon, 30 septembre 1604 . Collection des arrêts du conseil.

6. Ou trouvera cette réappréciation à la suite de l'édit du 28 septembre 1594 qui la mit en vigueur, dans Ron donneau, série chronologione, $\mathrm{AD}_{1} 115$. 
diminua assez le transit pour provoquer les réclamations des engagistes ?

Plus au sud, les deux grandes richesses naturelles de la sitiutonge, le sel et le vin avaient à compter arec la traite de Charente. I'ar application de la pancarte que l'assembléc des notables de Rouen renait de faire adopter (1:396), les vins de Saintonge furent frappés, à leur sortie de la province, d'un droit de 't écus (38 fr.) par tomeau. Cette taxe porta le plus grand préjudice à l'exportation et au commerce et, s'ajoutant ì la perception générale du nouvel impôt, suscita dans les provinees de l'ouest une agilation qui, sans la présence et l'influence de Sully, aurait dógénéré en soulerement. Les représentations de la population intéresséc obtinrent une réduction du droit à 2 écus $19[\mathrm{r} \mathrm{r})^{2}$.

Les contribuables ne furent pas toujours aussi heureux. dans leur resistance. Un édil, dn 31 octobre 1600 , avait établi sur les toiles qui sortaient du royaume un droit de 1.2 den. pour livre. Vainement l'échevinage de Rouen fit remarquer combien les aflaires avaient déjà pàti de la réappréciation et de la traite domaniale auxquelles cet article venait d'être soumis, et combien l'on faisait le jeu de la concurrence étrangère qui nous avait dejjì supplantés pour d'autres arlicles. Le parlement el la cour des aides de Cormandic ement beau joindre leurs remontrances à res alvertissements, les éehevinages de Caen. du IIarre et de Dicppe eurent beau concerter leur opposition arec celle de l'écherinage de Rouen et enroyer ì la cour, pour la faire valoir, une députation commune, les étals provinciaux ement beau faire observer que le nouveau droit,

1. Arrít du conseil du 16 mars 1614. Bibl. nat. Franç., 18167 it la date.

2. Achut, Le commerce an IVI siccle. Le fisc et les vins de Sainlonge, dans lievue des provinces, juin 1866. Lettres patentes du 10 décembre 1605 , Bibl. nationale, Franr., 18169, fol. 68 vo. Ilanvilu, Eludes listorigues sur Cognac, 11. 
n'étant qu'une application de la pancarte, faisait double emploi avec les contributions par lesquelles la province s'était rachetée de celle-ci, le gourernement ne se rendit pas à ces représentations unanimes, des lettres de jussion répétées imposèrent aux cour's souveraines l'enregistrement de la taxe, et un édit du 28 octobre 1603, vérifié le 9 janvier 1604 , en prorogea la perception ${ }^{1}$.

Les résistances que nous venons de signaler nous édifient sur l'impopularité d'un genre de taxes auxruelles Sully donna une grande place dans son système financier. Cela s'accorde mal arec la fareur dont les impôts indirects ont toujour's joui, tant au point de vue fiscal à cause de la facilité de leur recourrement, qu'au point de vue de l'équité à cause de leur proportionalité. Mais ces arantages étaient singulièrement compromis à l'époque qui nous occupe, par le mode de perception de ces impôts. Ils étaient, en effet, personne ne l'ignore, affermés, et mettaient en jeu toute lindustrie des adjudicataires pour en augmenter le rendement. De là, une foule de majorations et de vexations que le contrôle de l'administration supérieure était impuissant à découvrir et à réprimer. Tout le monde sait que les bénéfices des fermiers étaient scandaleux; dans les douanes, ceux qui se rendaient adjudicataires pour 100000 écus (949953 fr. 16), n'en levaient pas moins d'un million (9 499 :31 fr. 61) 2 . L'arbitraire et l'insolence des commis, leurs lenteurs calculées, leurs procès-verbaux multipliés à plaisir, les détours imposés aux marchandises pour passer par les bureaux ajoutaient au prix de revient des faux frais considérables, et laissaient au cœur des marchands une profonde irritation ${ }^{3}$. Pour ne eiter qu'une preuve de

1. Caliers des etats de Normandie sous Ilenri $I V$, p. p. Beaunepane, I.

2. «... car ceux qui ont tenu les douanes, de ce qu'ils ont donné cent mil escus, en ont toujours levé un million. "LAffenas, La Commission...

3. P. Matruiec, Hisloire de France 1615), I, 346. Matthieu ne parle que 
la mulliplicité lien connue des taxes indirectes, nous dirons qu'un tomneau de vin dOrléans acquittait dix ou douze droits dillélents, avant d'être débité à la tarerne à P'aris'. D'ailleur's, s'il est rrai que les contribuables supportent souvent plus patiemment les impûts indirects que les impòts direets, e'est quand les transactions sont nombreuse's, les hénéfices abondants. Or', pendant la plus grande partie du rìgne de Henri $\mathbf{I V}$, il n'en fut pas ainsi. Au sortir des guerres civiles, les parsans, les artisans, les commerçants avaient eu à remplacer leur matéricl agricole, leur cheptel el leur's approvisionnements, à payer leurs delles. La demande fut lente à se produire et il fallut du temps pour que les commandes affuassent, pour que l'aisance générale se répandil peu à peu.

Du reste, les témoignages abondent sur l'excès de la fiscalité. Claude Groulart écrit que la paix n'a rien clangé aux souffrances du peuple; c'est en vain qüil est gouverné par un bon roi, un roi économe, "les dispensateurs de ses finances font pis que jamais, car on lève plus, on paye moins, le peuple est plus affligé que l'on n'a esté au forl des miseres ${ }^{2}$ ". Sans doute, quand le premier président de Normandie constate en ces termes que le poids des impôts et les malversations commises dans leur recouvrement nont fait quaugmenter, la pacification intérieure est toute récente, la paix arec l'Espagne rient d'ètre signée, les "dispensateurs des finances " qüil stigmatise s'appellent encore d'Incarville et consorts et c'est à cedui-ci nominatirement quill s'en prend de celle siluation, que l'élération de Sully à la surintendance ra, sur plus d'un point, profondément modifier. Mais franchissons quelques années : c'est

de la deune de Vienne, dont il avait recu le mandat de signaler les consérquences funestes, mais ce qu'il en dit s'applique à toutes les taxes douanieres.

1. Carew's Relalion.

2. Mémoires de Claude Groulart, année 1593. Coll. Michaud, XI, 580. 
Sully lui-même, c'est le roi que nous entendrons en 160 ', en 1606 , déplorer la lourdeur excessive des impôts, l'extrème paurreté du peuple de la campagne, la misìre croissant d'année en année ${ }^{1}$. Enfin si, pour la fin du règne, on interroge un autre témoin, l'ambassadeur anglais George Carew dont la relation a été éerite en 1609, la déposition que nous recueillons est plus attristante encore. C'est, nous dit-il, dans le gouvernement français un principe d'écraser les contribuables pour les empêcher de remuer². Aussi le peuple maudit le gouvernement et accuse le roi de vouloir être non le roi des Français mais le roi des gueux. Carew ajoute que les collecteurs de la taille poussent la rigueur jusqu'à vendre les portes, les fenètres, les tuiles de la maison des contribuables insolvables. De toutes les prorinces, la Normandie était la plus accablée ${ }^{3}$. Sully, se vantant un jour à l'ambassadeur qu'elle rapportait plus au roi que le roi d'Angleterre ne tirait de tous ses États : "C'est le moyen, lui répondit son interlocuteur, de faire désirer aux sujets de Sa Majesté Très Chrétienne un changement de maître, et d'attacher les Anglais au leur ${ }^{4}$. ”

Il est donc incontestable que le gouvernement de Henri IV ne fut pas un gourernement bon marché. Cela s'explique. Sully, - car c'est lui surtout qu'il faut ici mettre en cause, - a donné à la France de bonnes finances. Or de

1. Sully à Henri 1Y, 13 septembre 160 '. Économies royales, éd. Amsterdam, 1725, VII, 234. IIarangue de Henri IV aux notables, fin de 160 '. lbid., coll. Michaud,I, 620. Sully aux trésoriers de Rouen, 5 décembre 1606 . Ibid., II, 166, 2. 178. En 1603, les collecteurs se plaignaient de ne pas pouroir recouvrer les tailles "à cause de l'impuissance et paurreté du peuple ". Arrêt du conseil du 9 octobre 1603. Arch. nat., Collection des arrêts du ccuseil.

¿. Il est difficile de ne pas rapprocher celte affirmation de la déclaration de François ler à l'ambassadeur vénitien: "Non royaume est un pré que je fauche quand je veux ", et de l'assimilation du peuple aux mulets qu'on trouve dans le Testament politique. Il y a là une tradition.

3. Elle était la plus riche et payait le cinquième des tailles.

4. P. 463. Sur l'impopularité du roi, voy. la véhé mente et courageuse déclaration du maréchal d'Ornano dans Lestorle, X, 5, 
bonnes finances, on peut le dire sans paradoxe, cela coùte cher. Nous roulons dire qu'un gouvernement ne peut pas obtenir des excidents de recelte, faire ì l'amortissement sa part, racheter le domaine et les revenus publics engagés, désintéresser les usurpateur's de la souveraineté nationale, créer une réserve et un trésor de guerre sans demander beancoup à un pays qui se trouve dégrevé, d'autre part, du cinquième de limpôt direct. Le grand ministre ne put arrirer à ce résultat, sans recourir à des expédients préjudiciables en eux-mèmes à la production, et singulièrement aggrarés par le système de recourrement. Les protestations et lagitation populaires avertirent plus d'une fois le fise quil atteignait, dans les parties vives, une population endolorie par tant dannées de souffrances et plus d'une fois le fisc sarrita ${ }^{2}$.

Quand on a indiqué la proportion de l'impôt arec les forces contributives de la population, on ne connaît pas encore sa portéc sociale et morale. Il reste à savoir quel emploi il a reçu, dans quelle mesure il a serri au développement de la richesse générale sur laquelle il a été préleré. Si l'on se place à ce point de vue, le gourernement de Ilenri IV ne mérite plus que des éloges, car, si tel impôt a pu être onéreux, rexatoire, dommageable à la production, le produit des impôts, dans leur ensemble, a été, en grande partic, consacré ou à la liquidation d'un passé calamiteux ou à la dotation du travail national. Cette observation nous amène à rappeler comment ce gourernement a compris et servi les intérêts de l'agriculture, de l'industrie et du commerce.

Réduction de la taille, remise de l'arriéré, liberté du commerce des grains, insaisissabilité du bétail et des

1. Outre les exemples cilès plus haut, rippelons ce qui se passa à l'occasion de la création des marqueurs jurés de cuirs et de la généralisation du régiuse des maîtrises et jurandes. 
instruments aratoires, ficulté pour les paroisses de rentrer en possession de leurs communiux, établissement de relais où les cullivateurs purent trourer des chevaux, desséchement des marais, réforme de l'administration forestière, législation minière ménageant les droits de l'Étal et les droits individuels, voilà ce que l'agrieulture lui a dù.

Dans ce qu'on peut appeler la législation agricole de Henri IV, il n'y a qu'à louer. On ne peut pas en dire autant de sa législation industrielle. Ici, il se trouvait en présence d'une organisation séeulaire entamée et altérée par l'évolution économique, qui se défendait et se raidissait, pour ainsi dire, contre les exigences de cette érolution en se faisant plus exclusive et plus jalouse. Fallait-il l'abolir? On ne pouvait y songer. Mais il aurait fallu, du moins, ne pas l'étendre, ne pas y faire entrer les métiers libres que les convenances du public avaient créés, les laisser vivre et grandir à côté des métiers jurés, et s'en remettre à l'expérience du soin d'éclairer les consommateurs et le gouvernement sur les avantages et les inconvénients des deux systèmes. On sait, du reste, que ce fut moins à une préférence théorique qu'à une préoccupation fiscale, que le gourernement de IIenri IV obéit, en érigeant en jurandes et en maîtrises des métiers libres qui formaient dans le pays une minorité fort imposante, car des villes comme Lyon n'en connaissaient pas d'autres. Il était, au contraire, dans la véritable voie quand il cherchait à restaurer les institutions qui avaient fait la vertu et la légitimité des corporations dans leurs beaux jours. S’il s'en était tenu là, l'édit d'avril $1: 97$ aurait pu, comme des tentatives antérieures, rester impuissant, il aurait été, du moins, applaudi; il souleva, au contraire, on le sait, une opposition passionnée qui en fit ajourner l'application et conduisit, tout l'indique, à son tacite abandon.

La pensée d'une réforme de l'organisalion industrielle 
et commerciale survéent à ect échee. Elle répondait à un vou de l'opinion, elle sétait manifestée maintes fois dims les états-généraux, et la place quelle occupait encore dans les préoccupations publiques est une preure de plus qu'elle n'avait pas trouré dans l'édit sa satisfaction. L'une des tîches assignécs à la commission du commerce fut de la réaliser, mais l'on se rappelle qu'elle ne l'aborda en quclque sorte que pour l'éluder.

La création de cette commission doit être compltée à Ilenri IV bien plus que cet édit comme un témoignage de son intérêt pour l'industrie et le commerce. Bien qu'elle n'ait pas été conçue comme une institution permanente, bien que sa mission ait été de fait temporaire, elle peut être considérée comme la première de ces chambres de commerce et de manufactures qui ont donné à ces deux branches de la production nationale une représentation et des organes. Sans doute, aujourd'hui, on compose ces corps autrement; au lieu d'y mettre presque exclusivement des magistrats et des administrateurs, c'est-ì-dire des hommes dont le formalisme admet difficilement les conditions de simplicité et de célérité dont les transactions industriclles et commerciales ont besoin, on y fait entrer des hommes d'allaires. Hais les commerçants et les industriels, capables de traiter avec largeur d'esprit les questions se rattachant ì leur profession, étaient si rares alors, ils étaient, en considération et en lumières, si inférieurs aux gens de robe, que ceux-ci arrivaient ì représenter et à absorber, aux yeux du gourernement, le tiers état tout entier. 11 n'en est pas moins vrai rue, pour la première fois, des intérèts qui n’avaient jamais été envisagés que dans leur's rapports arec les corporations ou aree le fise, furent compris dans leur ensemble, et aree le juste sentiment de leur importance ef de leur influence sur l'économie sociale et la grandeur nationale.

Ces intérêts n'eurent pas d'ailleurs ì souffrir de l'incom- 
pétence de celte commission. Si elle se laissa à bon droit effrayer par la làche de refondre l'organisation industrielle et commerciale, elle accueillit arec sympathie et patronna arec zèle, quand elle ne les provoqua pas, toutes les entreprises nouvelles. Il y eut toujours entre le roi et elle une entente parfaite, et comme une émulation de bon vouloir à l'égard des découvertes el des projets qui sollicitèrent leur protection. La forme sous laquelle cette protection s'exerça, varia peu et ne pouvait guère varier : ce fut le monopole, l'affranchissement de la juridiction des corporations, l'exemption d'impôts, la naturalisation pour les étrangers, des subventions, des pensions, l'anoblissement ${ }^{1}$, en un mot, le privilège. Le motest impopulaire, il est vrai, mais il faut se rappeler d'une part arec quelles précautions, arec quel souci de l'intérêt général, le procédé qu’il désigne était pratiqué et, de l'autre, qu'il était la seule porte pour rentrer dans le droit commun.

Tout ce que le gouvernement de Henri IV a fait pour l'agriculture et pour l'industrie, on peut dire qu'il l'a fait en même temps pour le commerce, car c'est l'agriculture et l'industrie qui fournissent au commerce les produits auxquels il ajoute, par ses opérations, une valeur nouvelle. 11 ny a peut-être pas de partie de l'administration où éclatent le mieux l'intelligence et la passion du bien public de ce gouvernement que les ponts et chaussées. C'est à lui que remonte, comme il doit toujours remonter ì quiconque donne une impulsion suivie et crée une tradition, le principal honneur du beau réscau de voies de communication par terre et par eau, que les autres nations européennes ont envié à la France de l'ancien régime. Ce n'est

1. Par exemple, Ilenri IV conféra la noblesse ả Armand Crommelin pour avoir introduit de Courtrai à Saint-Quentin, en 1579 , la fabrique des linons et batistes. Gomart, Saint-Quentin pendant lı Ligue. Société académique de Saint-Quentin, 1848. 
pas seulement les travaux de voirie, mais les travaux publics en général qui ont été de la part du roi et de son ministre l'objet d'un gont et d'une application particulière, dont lexemple trouva dans le royaume de nombreux imititeurs'. Un contemporain ${ }^{2}$ a estimé à un million d'écus d'or (10 11:311:3 fr. 12) l'argent lépensé dans les bitiments, mais ce chiffre parait se rapporter exclusivement aux embellissements de Paris et des chateaux royaux, et il faut y ajouter les frais d'une fonle de constructions de pure utilité, telles que les fortifications de vingt-huit places frontières ${ }^{3}$ Or, on sait l'influence considérable exercée par les travaux pullics sur le mouvement général des affaires. Parmi les bienfaits dont le commerce fut redevable à Henri IV, il ne faut oublier enfin ni l'organisation officielle donnée aux relais ni les mesures pour raffermir le crédit.

llenri IV porta ses vues plus loin que le commerce intérieur. On le croirait réduit ì l'impuissance par la déchéance de la marine militare, et cependant, il trouve moyen de punir les pirateries barbaresques, de s'afranchir en partic de celles des nations maritimes, de faire consacrer par la Porte notre ancien protectorat sur toutes les nations chrétiennes commerçant au Levant, à l'exception de la Sérénissime République qui en est depuis longtemps exempte, et de l'Angleterre qui vient de s'y soustraire; de défendre contre celle-ci, arec un succès malheureusement incomplet, notre sécurité et notre dignité, de fonder la Compagnie des lndes orientales et la Compagnie de la Nouvelle-France.

Plus justement que Louis XIV, Henri IV aurait pu dire:

1. Économies royales, coll. Nichaud, I, 362, 2. Relation de Vendramin dans Alberi, série I, IV, 465. Mémoires de Fontenay Marenil, coll. Michaud, 21,2 . 2s. Légenile en tite de la gravire de Cl. Clastillon représentant la porte et place de liance au Cabinet des estampes.

2. Memoires de Tavannes, coll. Michaud, 280, 2.

3. CAnew, 43'. Hichelet, Histoire de France, XI, 142. 
l'État c'est moi '. Jamais gouvernement plus que le sien ne se ressentit du caractire du souverain. C'est sous les traits d'un lomme de quarante-sept ans, de stature moyenne, un peu prématurément blanchi par les fatigues et certains exè̀s, mais dont la rigueur et la somplesse sont ì peine entamées par quelques altaques de goutte, et dont le visage offre, dans son puissant relief, un air d'autorité et de bonté qui impose et séduit, qu’il faut se représenter la monarchie française en l'an 1600. Lintelligence est vive, la conception rappide, le sens pratique exquis, la mémoire excellente, le caractère beaucoup micux trempé contre les épreuves de l'adversité que contre les entrainements de la prospérité, le langage d'une souplesse qui le fait passer sans dissonance par tous les tons, d'une force inventive qui l'égaie par une foule d'expressions à fleur de coin. La bonté et le calcul ont une part égale dans la conduite. bonté natire, faite d'optimisme, de bonne humeur, de rigueur physique, confrmée par la vie qui, au lieu d'amerlume, a laissé un certain scepticisme et une certaine indiférence morale, calcul aiguisé par les fortunes diverses qu ïl a fallu subir, les milieux si différents qu’il a fallu traverser. Tout ici, en effet, vient de l'hérédité, de la race, la plus fine et la plus militaire de France, de l’éducation, de l'expérience; rien de livresque, comme disait son compatriote Montaigne qui écrivait comme Henri parlait. De là ce je ne sais quoi de prime-sautier, de familier, de nerreux, de hâtif, de court qui frappe dans sa pensée, dans son langage, dans son gouvernement, et qui n’exclut qu'en apparence la persérérance et la malurité. De là, de cette vie errante et toujours en selle, ce goût des délibérations courtes, des résolutions promptes, cette arersion des traraux sédentaires du cabinel,

1. Il est vrai que ce mot n'est jamais sorti de Ia bouche de Louis XIV, mais il exprime si bien sa pensée et l'esprit de son gouvernement, qu'il mérite, sous cette réserve, de rester dans l'histoire. 
ce besoin d'animer d'un mouvement physique la discussion des affaires, de les traiter debout, dans l'embrasure d'une fenètre, ou en se promenant dins les galeries du Lourre et de Fontainebleau. C'était tout le contraire de la méthode patiente, minutieuse, trainante de son grand adversaire, Plilippe II. Henri lui ne semblait donner que deux heures par jour alux allaires et, en réalité, par la façon dont il y faisait tout servir, les rencontres, les conversations, les plaisirs, il leur donnait tout son temps. Si, négligeant les parties éclatantes et comme héroïques de sa carrière, eelles qui, an lendemain de sa mort et jusqu à ce rue Richelieu lui disputat sa place dans l’imagination des peuples, ont grandi sa mémoire jusqu'à l'apothéose, on ne sattache qu à son administration intérieure et particulièrement ì son influence sur les intérêts économiques de son royaume, on admire son ouverture d'esprit, son intelligence des questions, sa confiance dans le succès des entreprises nouvelles, sa persivérance ì les soutenir, son souci de l'épargne, allié au goont de la grandeur, son application à développer toutes les ressources de son royaume qu'on a heureusement comparée ì celle d'un propriétaire à faire valoir son domaine. Telles sont les qualités dont le livre qu'on vient de lire offre lant d'exemples, et que Ilenri IV fit reluire en ces royales économies d' Étal, que son fidèle ministre à célébrées.

Nous renons de désigner Sully et, parmi les auxiliaires qui, sans jamais substituer lem direction à la sienne, ont éclairé et préparé les éléments de ses décisions, il n'en est aucun, on le sait, qui l'ait autant secondé. Iprès avoir été l'un des faroris de l'école philosophique du siècle dernier, Sully court risque, si l'on n'y prend garde, de derenir la vietime de l'école historique de notre temps. On lui en veut d'avoir si longtemps égaré l'histoire avee son grand dessein, de n'avoir reculé, pour avilir les autres serviteurs de son 
maître et partager exclusivement avec lui la gloire de tant de grandes choses, ni devant les mensonges ni devant les faux. On ne lui pardonne pas d'aroir fait de ses Mémoires, qui auraient dù être le guide le plus sùr pour l'histoire du temps, un livresemé de pièges, où l'on ne peut s'arancer que la sonde ì la main. Il y a une part de justice dans ces rancunes. Il ne faudrait pas pourtant se laisser entrainer trop loin dans cette voic par le goùt de démolition dont la critique paraîl à certains moments possédée. La méfiance arec laquelle on ne pourra désormais s'empècher d'aborder les Économies royales, ne les empèchera pas de rester le monument le plus important de l'histoire de IIenri IV. L'outrecuidance solennelle et gourmée de l'homme, son caractère cassant, son impopularité ne doirent pas faire oublier son amour sincère du peuple. Enfin, - et c'est surtout à ce titre qu'il nous appartient de sauvegarder sa vieille renommée, - ses mérites et ses services, comme administrateur, n'ont rien à perdre à la réaction qui s'accomplit contre lui : voirie, travaux publics, agriculture, mines, forêts, presque toutes les parties de son administration, sans parler des finances, dont elles dépendaient toutes, offrent les traces de sa conscience, de son zèle, de son intelligence. Sur tout cela, IIenri IV a vu souvent plus clair et plus loin que lui, mais il a débrouillé les matières, instruit les questions, préparé au coup d'œil du roi des solutions mûries.

Au-dessous de Sully, il y a deux hommes dont l'influence s'est fait sentir dans le domaine qui nous occupe et qui doivent nous arrèter : c'est Olivier de Serres et Barthélemy Laffemas. Le premier encouragea le roi à entreprendre la propagation de la sériciculture; par un ouvrage auquel le progrès des méthodes n'a peut-ètre pas ôté toute son utilité et n'a rien òté de son agrément, il contribua, dans une mesure difficile à déterminer, à la diffusion du goût de l'agriculture et des connaissances agricoles. 
Entre Olivier de Serres et Laffemas, il y a plus d'un contraste. Autant la vie de l'un, à part une courte participation anx guerres religienses, fut uniforme el tranquille, iutant celle de l'aulre, telle qu'on l'entrevoit par les échappes que nous ourrent les documents, nous apparait comme une lutle oprinititre contre la maturaise fortune. 'Tandis que le Théritre d'agriculture est surtout le fruit d'une expérience personnelle exclusivement ajpliquée au « ménage des champs net reflète un esprit mesuré, d'une aimable prudhomie, les nombreux écrits de Laffemas, arures de circonstance, d’improvisation et de polémique, révèlent par leur richesse de vues, par leur confusion, par leur incorrection, la fermentation intellectuelle du temps, la hardiesse et la fécondité d'esprit de l'auteur, son défaul de culture, les vicissitudes de sa carriere. Tout cela n'est pas de niture, bien an contraire, à diminuer leur intérêt. Si l'on essile de filtrer la matière un peu tronble resserrée diuns res lierets d'un aspect peu altriyiunt, on distingue trois déments: des doctrines commumes à ceux des contemporains qui se sont occupés des mêmes questions; des vues personnelles dignes d'attention; des contradictions et des prérentions. Quand il demande la libre admission des malieres premieres et la prohibition des produits manufaclurés qui ont leurs congénères dans l’industrie nationale, l'érection des métiers libres en jurandes et en maitrises, la peine capitale pour les lanqueroutier's, l'unité des poids et mesures, Laffemas ne se -ípare pas de son temps. Quand il sacharne contre les tribunaux consulaires et contre la contrainte par corps en matiere commerciale, il oublie sa prédilection pour les juridictions professionnelles et l'imjortance du crédit dont il se montre ailleurs si pénétré. De la même plume, qui lui a servi à prôner l'unification de lorganisation industrielle el conmerciale par l'extension des minttrises et jurandes, il réclame la suppression des 
"maîtrises inutiles". Mais, à cúté de ces tâtonnements, de ces partis pris, que d'idées originales, fécondes et pratiques! Comment refuser sa sympathie à son plan de chambres syndicales corporatives el de grands burenux ou chambres syndicales régionales, rattuchées les unes aux autres, et jouissant d'une juridiction et d'une administration autonomes, à son projel de créalion d'un conseil permanent du commerce, à ses caisses de secours pour les membres iudigents des corporations, à ses atelier's ou plutôt ses villages ou l'on aurait fait travailler, sans les réunir, les paurres valides des deux sexes et les enfants rebelles à l'autorité paternelle, à sa passion pour la moralisation des classes laborieuses, à son indignation contre l'agiotage, contre la gabelle, contre les affronteurs, contre la multiplicité croissante des marchands de vin; à son insistance pour obtenir la substitution d'un droit de marque du vingtième sur les marchandises à toutes les taxes rqu'elles supportent, etc.?'Toutes cesidées, rappelons-le, ont d'autant plus de prix qu'elles viennent d'un homme qui ne les a pas puisées dans les livres, mais dans une expérience chìrement payée. Elles se recommandent encore par le compte que l'esprit d'innoration y tient des institutions existantes. Personne ne pourait mieux apprécier que Henri IV leur caractère pratique et sagement réformateur. Si le contraste entre la gravité des sujets abordés par Laffemas et les fonctions de fournisscur de la garde-robe royale amena sur ses lèvres un de ces mots gouailleur's lont il était coutumier, il témoigna de son estime pour la personne et les idées de son tailleur ralet de chambre en le nommant contrôleur général du commeree, et en créant la commission du commerce pour exaniner ses propositions.

Tels sont les trois hommes qui se détachent de la foule des auxiliaires dont les noms ont en grande partie échappé à l'histoire, mais qui n'ont pas plus manqué à Ilenri IV qu'à 
tous les souverains qui ont su les distinguer et s'en servir.

Mais il est un concours plus étendu et plus indispensable: c'est celui de la nation elle-mème. Il est impossible de faire le bien d'un peupte malgré lui, et l'on a vin, plus d'une fois, les entreprises diutilite grinérale, les plus heureusement conçues, échoner contre liapathie ou les prúrentions des populations auxquelles elles devaient profiter. Quel empressement la France mit-elle à entrer dans les roies que son gourernement lui ouvrait, comment aida-t-elle it son relèrement. et finalement quel développement économique, quelle prospérité matérielle arait-elle atteint, grice à ses efforts propres et ì la direction éclairée de ce gourernement, quand son roi lui fut enlevé? Telles sont les deux questions, plus d’une fois dejit abordées dans ce lirre, sur lesquelles nous reviendrons en terminant.

L'ourrage quion vient de lire offre plus d'un exemple de la froideur ou mème de l'hostilité aree lesquelles le pays atecucillit certaines entreprises parties de linitiative officielle; il suffira de rappeler la généralisation de la sériciculture et le desséchement des marais. On ne peut demander à des classes absorbées par le souci quotidien de l'existence, c'est-à-dire à la majorité d'un pays, l'abnégation et la hauteur de rue qui peurent faire accepter des sacrilices dont le principal fruit est réservé à l'arenir. Cette préroyance et ce désintéressement ne peurent apparteni qu’aux pouroirs héréditaires qui, à la lumière des traditions nationales dont ils gardent le dépôt, voient, par delà les intérìts viagers des génćrations présentes, ceux des générations futures, et gouvernent pour cenx-ci plus encore que pour ceux-là. Hais ce n'est pas d'après des faits particuliers comme on en trouve dans tous les temps, quïl faut juger la part prise par le pays à sa propre régénération. Si l'on envisage le travail nationil dans son ensemble, on constate son activité croissante, on roit la classe rurale, la classe ouvrière déployer 
de plus en plus leurs qualités traditionnelles, l'une sa persévérance, sa sobrièté, son amour de l'éparģne, l'autre sa dextérité, son tour de main et son gout ${ }^{1}$.

La situation économique où IIenri IV laissa la France implique d'ailleur's que les effor'ts du roi pour dérelopper la richesse publique ont été puissamment et efficacement secondés par le pays. S'il en arait été autrement, il est bien clair qu’ils auraient été stériles. C'est seulement dans les dernières années du rìgne que la prospérité se dessine nettement. Encore semble-t-elle démentie par certains faits. En 1607, en 1608, les villes sont encore attristécs par des troupes de mendiants, d'estropiés, sourent fort gaillards, d'anciens soldats ou soi-disant tels, attendant la desserte aux portes des hôtels et des courents. Pas plus que la mendicité et le ragabondage, ni le rol ni mème le lirigandage n'ont entièrement disparu. En 1607, par exemple, existait à Paris une bande parlaitement organisce qui arait constitué pour elle-mème une juridiction complète siégeant au Port-au-Foin ${ }^{2}$. A la mème époque, un certain Téron, qui campait dans la forèt de Compiègne à la tête d'une troupe de brigands et déralisait les royageurs, fut condamné à la roue et ce ne fut qu'en $\$ 608$ que Guillery subit le mème supplice ${ }^{3}$.

Cet faits prouvent simplement qu'une socièté qui a ćté si longtemps livrée à l'anarchie, renferme, longtemps après que celle-ci a cessé, des réfractaires altardés qui n'acceptent pas le rétablissement de l'ordre et des habitudes régulières. Il n'y a rien à en conclure ni contre la diffusion du travail ni contre la séeurité publique. Les relations rénitienne et anglaise de Duodo et de Dallington, éerites en $1: 98$, ne con-

1. Citons notamment la façon dont Carew caractérise l'habileté manuelle de nos ouvriers: ".. especially the French being generally neat and nimble above all manner of manufacturers."

2. Lestolle, ẻd. Jouaust, $\mathbf{X}, 3,10$.

3. Voy. plus haut le cliapitre sur l'économie r'urale, 
viendraient plus à la France de 1610 , et celle-ci ne justifierail mime plus telle ou telle remarque attristante qui s'applique anx premières années du $x^{2}{ }^{e}$ siècle. Les dernières années de sa premiire décade ont été décisives, ct, pour sen convaincre, on n’a qu'à lire le tableau, si peu bienveillant pourtant, tracé par Carew en 1609.

C'est d’abord la sćcurité qui a été rendue aux affaires. Nous n'lésiterons pas, pour justifier une affirmation qui d’ailleurs n’étomnera personne, à invoquer le rève de quiétude, de sensibilité discrète et pure que toute la France fit avec d'Lifé aux rives du Lignon ${ }^{1}$. Dans celle exagriration sentimentale el poétique, il ý a une grande part de vérité et une part plus grande encore de sincérité. A travers ces temps souillés de licence et de brutalité, el si durs pour le faurre monde, court pourtant une veine de purelé, de prud'homie, d'instinct champìtre, de sociabilité que recueilleut et fortifient saint François le Sales, Du Vair, Olivier de Serres, Racan, l'hôtel de Rimbouillet. Le pays fut tellement hemreux de pouvoir vive et lravailler en paix, quïl se résigna au prix onćreux dont il lui fallait payer la reconstitution de l'organisation sociale, et qüil fonda dans son cour cette tradition de gonvernement paternel, que les troubles de la régenee de Marie de Médicis affermiront, et que lhistoire consacrera.

Cette sécurité avait été largement mise à profit. Cé n'est pas que lia France eùt conquis sur le marché du monde toute la place que l'abondance et la variété de ses productions, l’intelligence, lardenr laboriease et l'espril industrieux de sa population semblaient lui promeltre. Si l'Espagne était dans sa dépenelance commerciale, si ce lébouclée Iui ourrait indirectement celui des Indes occidentales, dans ses rapports arec les atutres États européens, ses importa-

1. Voyg ausi le début si connu des Mémoires de Maroules. 
tions et ses exportations siéfuilibraient à peu près exactement ${ }^{1}$. Si l'on veut avoir une idée complète de la richesse publique, que l'on faisait en ce temps-là consister surtout dans le numéraire, il ne faut pas tontefois tenir compte seulement de la balance du commerce. Les affaires, les plaisirs, l'agrément de notre pays y attiraient déjà beaucoup d'étrangers. C'était sourent des concurrents dont notre commerce s'alarmait à bon droit, mais c'ètait toujours aussi des consommateurs qui payaient largement les jouissances qui abondaient autour d'eux. C'est par la France d'ailleurs que s'opérait encore, malgré ses douanes intérieures et ses taxes de circulation, une grande partie du transil européen ${ }^{2}$. Ce transit laissait derrière lui beaucoup d'argent qui n'entrait pas entièrement dans les caisses publiques. De là, l'affluence de momnaies étrangères que nous avons déjà signalée. Il y avait en France, d'après l'estimation de Itenri IV, six fois plus de doublons et de pistoles espagnols qu'en Espagne ${ }^{3}$.

Cette affluence fut encore augmentée par un genre de spéculation qui s'est pratiqué dans tous les temps. Les monnaies étrangères étaient inférieures aux nôtres en poids et en titre et n'en circulaient pas moins pour une valeur nominalement égale. Cette différence entre la valeur réelle et la valeur conventionnelle, amena tout naturellement, en même temps que la surabondance des espèces étrangères, la sortie des espèces françaises. A côté des premières, il en circulait beaucoup de rognées et de fausses. Le trafic dès

1. Ce que nous avons dit, dans le chapitre sur le commerce extérieur, de la balance du commerce entre la France et les divers États, est confirmé par le passage suivant d'un ouvrage contemporain : "... de fait l'étranger, lıors mis l'Espagne, n'est tellement nécessité de nous que nous ne concertions ensemble qui se donnera plus de marchandises ou manufactures pour tirer l'argent de son voisin". Traité et advis sur les désordres des monnoies et diversité des moyens d'y remédier [par Fraxçols Le Bogue], 1600, p. 29.

2. "...the thorougfare of English, German, Spaniards, 1talians. "Carew's Relation.

3. Ibid. 
expèces inférieures en poids ou en titre, ce quon appelait le billomage avait pris heaucoup d'extension et élait assez lucratif pour amener plus d'un commerçaut à le préférer à ses allaires'. Le rrai remede, celui auquel on a recours aujourd'hui en pareille circonstance, aurait consisté à frapper de décri les monnaies défectucuses, en laissant à leurs détenteurs le temps de les échlanger contre des espèces légales, et ì faire, pour les renplacer, une large émission de ces dernieres. Ce fut, en effct, par une démonétisation quon commença 1 (i01) $)^{2}$. Mais les hôtels des monnaies ne se trouverent pas en mesure de metlre en circulation la quantité d'espèces nécessaire pour tenir lieu de celles qui en étaient exclıes. Les banquiers et les changeurs, qui faisaient le commerce des métaux précieux, enchérissant sur le prix quen domnaient les établissements monétaires, les accaparaient pour les revendre aux affineurs et aux orfìres". Ėn outre, le commerce étranger, gêné par ce décri, abandonna notre pays et se porta ailleurs: les foires de Genère y gagnerent ce qu'y perdirent les foires de Lyon * Les monnaies prohibées continuèrent d'ailleurs ì eirculer. Sully, car ce futlui surtout qui süngénia pour empècher l'exportation de l'oret de l'argent français, eut alors l'idée d'élever la valeur nominale de nos espèces métalliques, et de rétablir l'usage de compter par lirres, auquel l'édit de $1: 37$ avait substitué le compte par écus. L'écu d'or au solcil fut

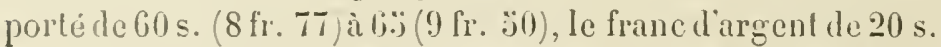
(2 fr. 92) à 21 (3 fr. 07), le quart d'écu de 13 s. (2 $\left.\mathrm{f}_{\mathrm{i}} .19\right)$ à $16(2 \mathrm{fr} .3$ ' $)$, le teston à $10 \%$ s. 6 den. (2 fr. 26), la pièce de

1. "Aucuns marchans quittans ie train de leurs marchandises ordinaires se seroient jettés à trafịuer de toutes sortes de monnoies... decrićes et ayaut cours. "Déclaration de février 1609. Fontaxon, II, 223.

2. Duclaration du 2 í mars 1601. Voy. préaubule de l'ordonnance sur les monnaies de septembre 1602 .

3. Traité el advis sur les monnoies..., p. Frane. Le Bogue, avocat général en la rour des monnoies, 1600, p. 20.

4. P. Mattuiet, Histoire de Ilenri IV, 163I, in-fol., III, fíG. 
$10 \mathrm{~s} .(1 \mathrm{fr}, 46)$ à $10 \mathrm{~s} .7$ den. ${ }^{1}$ ( 1 fr. $\left.; 3 ; j\right)$. En dehors de la cour des monnaies, cel éditne rencontra guère que des censeurs. Il jeta létrouble dans les transactions ${ }^{2}$ et ne réussit pas à prévaloir contre les habitudes et les hesoins. Les espèces décriées de létranger continuèrent à circuler" et les monnaies nationales, malgré la hausse ${ }^{3}$ qui semblait devoir décourager les spéculateurs, continuèrent à sorlir. Nous n'en donnerons d'autre preuve que la proposition faite, en 1609, par l'un des généraux des monnaies, Nicolas Coquerel, et qui tendait précisément à empêcher cette circulation et cette sortie. Coquerel proposait l'émission d'une monnaie unique d'or et d'argent, que l'on appellerait henriques. Les hemriques d'or deraient raloir 10 livres 8 sous (28 fr. 04), les demi-henriques $\breve{3}$ livres 4 s. (1't fr. 02), le quart d'henrique $\dddot{2} 2 \mathrm{~s} .(7 \mathrm{fr} .01)$ el le huitième $26 \mathrm{~s}$. (3 fr. :30). La valeur du henrique d'argent était fixée à $ّ 2$ s. ( 6 fr. 91), celle du demi-henrique à $26 \mathrm{~s}$. ( $3 \mathrm{fr}$. 4.5), celle du quart de henrique à $13 \mathrm{~s}$. ( $1 \mathrm{fr}$. 72 ), celle du huitième de henrique à 6 s. 6 den. ( 0 fr. 87). Cette proposition fut soumise à une commission, en mème temps que d'autres projets relatifs au mème sujet. Ce fut d'après son avis que fut rendu un édit, qui ordonna l'émission de henriques d'or de 12 livres $(32 \mathrm{fr} .36)$, de 6 livres ( $16 \mathrm{fr}$. 18 ; et de 3 livres $(8 \mathrm{fr} .09)$ et de henriques d'argent de $20 \mathrm{~s}$. (2 fr' 70), de $10 \mathrm{~s}$. (1 fr. 3.3) et de $ّ$ s. ( 0 fr. 67), qui décria les espèces étrangères et en ordonna le dépôt aux hùtels des monnaies où les porteurs en recevraient la valeur intrinsèque, déduction faite des droits et des frais de monnayage, et qui enfin démonétisa également les espèces françaises rognées et affaiblies".

1. Ordonn. de septembre 1602. Foxtaxox (éd. 1611), II, 227. Mémoires de Pussit, 105.

2. Voy. notamment Du Fresne Canaye à Béthune, 12 septembre 1602, 1, 449.

3. En 1609, l'écu d'or au soleil était monté jusquả i2 s. Leblaxc, Trailé. des monnaies, 573.

4. Mercure françois, année $1609, \mathrm{I}$, p. $356 \mathrm{v}^{\circ}$. 
Toutes les fortunes particulières se trouvèrent atteintes par la dépréciation de monnaies qui étaient dans les mains de tout le monde, et dont on ne pourait se défaire que sur le pied de la vileur réelle et en supportant les frais de la refonte. Vainement le gouvernement aurait essayé de justifier une pareille mesure en alléguant que les porteurs n'araient pu, sans violer la loi, receroir et colporter des espèces étrangères; force leur était bien de s'en servil puisque les monnaies françaises nétaient pas assez abondantes pour les transactions. Les remontrances du parlement et de la chambre des comptes firent reculer le roi devant l'application de l'édit. Il fit bien de reculer, mais, pour ctre encore peu senti, le danger auquel Sully et lui avaient voulu remédier nen était pas moins réel; en essayant de le conjurer, ils firent acte de préroyance et, s̈ils l'araient fait en sauregardant équitablement l'intérêt de tous les détenteurs d'espèces défectucuses, e'est-ì-dire de tout le monde, et en répandant dans la circulation, en assez grande quantité pour suffire aux besoins, des monnaies d'une valeur réelle égrale à leur valeur nominale, ils auraient évité au pays la crise monétaire qui paraît s'être produite au début du règne suivant ${ }^{1}$.

Les capitaux, comme la monnaie, étaient abondants et l'intérèt trỏs peu élerée ${ }^{2}$. Beaucoup de marchands étaient en même temps banquiers ${ }^{3}$. L'intérêt légal, on le sait, arait été réduit à 6 un quart p. 100, mais l’intérêt conven-

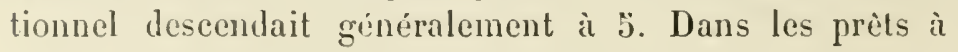

1. "... le trruble oú nous sommes à présent pour la difficulté des monnaies.... " .loxtchinestiex, éd. Funck Brentano, p. 180.

2. "France being now very rich and money at a very low interest." William Recher à Salisbury. Paris, I cr lécembre 1609. C'alender's of stale papers. Colonial series. Eastlndia, China and Jupan, no 469. Co.Amagus., II, 355 .

3. Nalland, Live de raison d'une famille de Brives a XITo sidele, dans Bulletin de la Sucièté scientifique, hist. et arch. de la Corrèze, III (188I), p. Gí0. Deux lives de reison $(151 i-1550)$ p. p. L. de Santyet AUg. Vidal (1896) gr. in-8., p. l't3-1i1. Fasc. IV des Arch. hist. de l'Albigeois. 
l'industrie et au commerce il était supérieur. C'est ce qu'on peut conclure a priori du taux légal, puisque ce taux arait été en partie adopté précisément alin de déterminer la préférence des capilaux pour les placements commerciaux et industriels. Les risques que courent ces placements justifiaient cette différence, que le législateur de 1807 a cru devoir maintenir. Ces risques seraient altestés au besoin par les nombreuses banqueroutes qui signalèrent les dernières années du règne, et anıenèrent une agravation de la pénalité. Ce qui rendait ces placements plus hasardeux et le crédit plus difficile ou plus onéreux, cétait lincertitude sur la solvabilité des emprunteurs. Les hypothèques étaient tacites, car l'édit de 1581 , qui subordonnait leur validité à l'enregistrement, arait été réroqué en 1588 par un autre édit et les formalités imaginées, sous le nom de nantissement et d'appropriances, pour on révéler l'existence aux tiers, étaient spéciales à un petit nombre de coutumes. En outre, elles portaient sur tous les biens et résultaient d'érénements qui échappaient à la connaissance du public. Tout acte notarié, toute obligation sous seing privé reconnue en justice ou derant notaires, toute condamnation, peut-être même tout acte de vente contresigné par un facteur entrainaient une hypothèque générale. Personne ne pouvait donc se flatter d'y échapper, car il suffisait, pour y être soumis, d'avoir passé un contrat ou perdu un procès. De là des revendications inattendues qui renaient trouble ${ }^{\circ}$ dans leur possession des acquéreurs de bonne foi et ruiner une foule de bonnes maisons ${ }^{1}$. Il n'existait pas plus de publicité pour les actes constitutifs on modificalifs de sociétés, au moins pour ceux entre regnicoles, car ceux

1. Ilenri IV et Sully renouvelérent la tentative dintroduire dans la loi le principe de la publicité. En 1603 ou 1606 , fut rendu un édit qui avait été préparé par Sully et qui reproduisait á peu près les dispositions de celui de 1581, mais il ne fut enregistré que par le parlement de Rouen et resta sans effet. 
où les contractants étaient étrangers devaient ètre enregistrés.

L'insécurité des placements d'alliares, jointe it d'autres circonstances, continuait à faire préférer à bien des capitalistes un autre emploi de leurs capitaux. Lal grande opération de rérification, de classement et de réduction des rentes publiques, accomplie par Sully en 160:;, en rayant les titres illégitimes, en convertissant, suivant la faveur plus ou moins grande due à leur origine, les titres réguliers, accrut la sécurité des créancier's de l'État, releva le crédit public et le cours des rentes, qui furent plus recherchées encore que par le passé. Les charges et les offices exergaicnt sur les capitaux un attrait encore plus vif. Ils rapportaient un interêt de 10 ou 20 p. 100 et donnaient un rang dans la société; depuis que la Paulette, en leur conférant le caraclère de biens patrimoniaux et héréditaires, arait ajouté à ces avantages la stabilité, leur valeur avait beaucoup augmenté. En 1607, les charges de conseillers au parlement se vendaient 42 (1309'7 fr. 39), 43 (134063̈ fr. 18) et 43000 francs (1.10300 fr. 77); à la chambre des requêtes, elles montaient à 30 ( $13 \% \$ 89 \mathrm{fr}$. 7.) et $3: 3000$ ( 171478 fr. 72). Une clarge de président coùtait 60000 écus (369971 fr. 90). La présidence du grand conseil dépassait 100000 (94998̈3 fr. 16). En 1609, la charge de président des enquètes fut rendue 48000 écus comptant (483̈429 fr. 333$)$, celle de président de la première chambre des requètes 38000 écus ( 384298 fr. 37), celle de conseiller à la même chambre 193000 écus ( $19720 \ddot{~ f r . ~ T ' t) . ~}$ Lejeay acheta celle de lieutenant-civil 70000 écus (7:38483 fr. 63), dont $130000(30.36: 30 \mathrm{fr} .76)$ pour les parties casuelles et $7 \ddot{3} 000(2: 32827$ [r. \$7) pour les épingles de la reine, de Concini et d'autres. Une charge de procureur du roi au Chàtelet était vendue 40000 écus (40 t 52' fr. 60). Celle de premier président de la cour des aides rerenait, 
avec les épingles et les pols de vin, à plus de 200000 francs $^{1}$ (623 3\%9 franes). Ces exemples se rapportent aux sommets de la hićrarchic sociale mais qu'on descende à ses plus humbles échelons, et l'on constatera le prix éleré qu'on mettait à aequérir une autorité quelconque, ì en recueillir l'honneur et le profit. A Paris, un office de porteur de charbon se vendait 700 ou 800 écus ( 7079 fr. 18 ou 8090 fr. 49), un office de mouleur de bois et de vendeur de foin 1000 ou 1200 (10 113 fr. 11 ou 12133 fr. T4).

Si les emplois publics faisaient toute l'ambition de la majorité de la bourgeoisie, il y arait, dans son sein, desgens plus aventureux et moins soucieux des apparences, rui se laissaient tenter darantage par les périlleux bénéfices de la spéculation. Quelquefois, d'ailleurs, c'était les mêmes. Le désordre des temps avait jeté sur la place une foule de valeurs, dont les violentes fluctuations favorisaient l'agiotage: titres de rente, provisions d'offices et lettres de maitrise, croupes dans les fermes et les partis, brevets de privilèges lucratifs de tout genre. Ceux qui jouaient sur ces valeurs étaient aussi ceux qui faisaient aux fils de famille, sous des ventes simulées, des prèls usuraires, qui se faisaient souscrire des billets à ordre en blanc et des lettres de change sur les foires de Lyon, dont le montant s'enflait de report en report. Remettant en vigueur les recherches ordonnées par son prédécesseur sur les actes d'usure, Hemri IV les attribua à une commission composée de membres du grand conseil. Ce ne fut là, à ses yeux, comme aux yeux de Henri III, qu'une mesure d’intimidation destinée à faire financer les coupables; elle pronve, du moins, à quel point les spéculations usuraires étaient répandues.

Ce n'était pas seulement le loyer des capitaux qui arait baissé; c'était, ou peu s'en faut, le prix de toutes choses. 
Cette haisse était due an développement de la production venant neutraliser de plus en plus la surabondance et la dépréciation du numéraire. Peu de choses y échappaient. La propriété rurale et les denrées agricoles itaient du nombre, parec que la premiere était avidement recherchéc, et que les secontes trouvaient ì se placer sur le marché extérieur. Celles qui la subissaient se maintenaient pourtant à des prix rémunérateurs, paree que la concurrence qui les faisait baisser était plus que compensée par le progerès du bien-être, du luxe et de la consommation. Le monopole des corporations secondait ce résultat, en restreignant la première. L'offre et la demande se balançaient dans ect équilibre instable, qui distingue les périodes de prospérité des périodes de erise, où l'excès de production amène l'encombrement et la dépréciation, et des périodes de liquidation, oì l'écoulement à perte de l'excédent et le ralentissement de la production ramènent la proportion entre les produits et les besoins et prépare le relèrement des cour's'.

Il resterait à donner une expression, à la fois mathématique et morale, i ce que nous renons de dire d'une façon abstraite du prix de la vie. Nous disons une expression morale, parce que la valeur des choses ne dépend pas seulement de la puissance comparée de largent à deux époques données, mais des exigentes rariables des générations successives en fait de bien-ètre et de luxe. Ce serait le dernier mot d'une étude historique de la richesse, la solution du problime du bonheur par l'histoire, par la connaissance du tarif mobile, si l'on peut ansi parler, des jouissances qui le constituent. On comprend que l'honneur de tronver celte solution ait séduit des esprits entreprenants et laborieux. En nous bornant à indiquer la valeur 
intrinsèque actuelle des sommes qui se présentent dans ce travail, nous arons suffisamment fait comprendre notre répugnance à nous associer à des résultals problématiques:. Mais il reste loisible aux lecteurs moins sceptiques et plus confiants d'appliquer à toutes ces sommes l'un des multiplicateur's adoptés par les divers systèmes. Nous nous bornerons it leu! domner le moyen de rapporter à l'étalon normal de la valeur les valeurs relatives particulières qu ïls auront cru pouvoir établir. Cet étalon normal, c'est le revenu annuel qui entrainait la gène, celui qui donnait laisance, celui qui assurait la richesse. On pourait vivre de son revenu quand il atteignait de 3000 (13484 fr. 15̈) à 6000 livres (16 $180 \mathrm{fr} .98)^{2}$. Irec 10000 livres (29 229 fr. 33), on était riche ${ }^{3}$, et IIenri III, dans ses jours de découragement, enviait le sort des gentilshommes qui possédaient ce revenu '. A la campagne, on pouvait mener avec beaucoup moins une existence honorable; un revenu de 2000 livres ( 3393 fr. 66) y suffisail, et mème le gentilhonme qui jouissait de 300 lirres (1461 fr. $4 \overline{4}$ ) de rente, pouvait garder son rang et, par exemple, prendre ses repas à part des paysans qüil faisait travailler". Mais, dans cette modeste situation, il devait, on le comprend, se soumettre à une sévère économie et, même arec cent (292 fr. 29) ou deux cents lirres (: $: 8$ ' fr. $ّ 9$ ) de plus, il lui était difficile de faire vivre une famille de quatre ou cing enfants ${ }^{6}$. On ne sétonnera pas après ccla qu'un maréchal ferrant, qui arait mis de còté 2000 livres de rente à Paris, s’estimàt content de son sort ${ }^{\top}$.

1. Leror-Beatlae, Traité théor. el prat. d'économie politique, III, 90.

2. Mémoires journaux de l'ierre de Lestoile (année 1609), X, 33.

3. Ibid. (année 1603), VIII, 108.

4. Mémoires de Turannes, p. 24.

5. Voy. plus haut, chap. $\mathrm{I}^{\mathrm{er}}$.

6. L. Noue, Discour's politiques.

7. Discours véritable de deux arlisans de Paris. 
L'étude qu'on vient de lire n’a rien amoindri des fatalités naturelles et historiques qui peuvent influer sur l'état économique d'un peuple, et semblent soumettre sa destinée à des lois nécessailes : nationalité accessible sur certains points, fiute de frontieres naturelles ou artificielles, aux attaques du dehors et contrariée par ce danger daus son déreloppement paciflyue; insuffisance des mines; rareté des bons ports; syslème liscal vicieux; habitudes léguées par une longrue anarehie; lacunes et défunts du caractère national. Mais il y a une chose qui nous est apparue d'une façon plus saisissante encore, c'est le triomphe obtenu sur ces fatalités par l'intelligence et l'ellort du pays, par l'esprit, la rolonté et le cueur du roi. La renaissance économique dont les dernières années du règne ont été témoins, la France, sans doute, l'a due beancoup à elle-mêne; mais elle la due plus encore ì son gouvernement. Ce u'est donc ni ì la doctrine, si en fareur, du fatalisme, ni ì celle, non moins goùtée, qui professe le peu d'inlluence ef, par conséquent, le peu d'importance des gouvernements, qu'une pareille élude vient donner mison. Elle nous enseigne, au contraire, pour notre consolation et notre espoir, qu'un peuple est capable de remonter, ì force d'énergie, la pente de la décadence, et que rien ne peut l'y aider darantage qu'une autorité forte et respectée, passionnéc pour l'intérêt public, en imposant le respect aux intérêts particuliers, ouvrant des voies nouvelles à l'activité nationale, stimulant ses hésitations et soutenant ses défaillances. 


\section{APPENDIGE}

AYIS DES NOTABLES NÉGOCIANTS DE LyoN SUR LES MOYENS DE RESTACRER LE COMNERE DE CETTE Y'ILLE.

(Arch. municipales de Lyon, BB, 146, fol. 130.)

Du jeudy neuviesme jour de décembre, l'an mil six cens dix, après midy, en l'hostel commung de la ville de Lyon, y estans.......

Sont compareus sieurs Amable Thierry, Claude Poculot, Anthoine Charrier, Yincent Richard, Claude Pellot, Jehan de Loeille, Loys Puget, Jehan Duboys, Marin Dausserria, Jehan Verges, Hannibal Robbio, et Vidal Rabeyrin, tous marchans de lad. ville, et encores André Coste, genevois, sur l'advertissement qu'ilz ont heu de Ia part du consulat de l'intervention du Roy et de la Royne-mère, regente, pour le restablissement dn commerce de ceste ville, auxquelz led. prevost des marchans a dict que, après plusieurs plaintes et remonstrances que lad. ville a faicl et qu'elle continue faire par ses deputés de la ruyne dud. commerce, et finablement leurs Majestés ont escript sur ce subiect à Messieurs les trésoriers de France la lettre de cachet dont a esté fuicte lecture par le greffier de lad. ville et qui sera cy-après enregistrée.

De par le Roy.

Noz améz et féaulx, aians considéré combien il importe au bien de noz subiectz et à la grandeur de nostre royaulme de faroriser le commerce et de l'accroistre par tous les moyens qu'il sera possible, soil entre noz subiectz de chacune province, ou entre nos subiectz et les estrangiers, nous arons délibéré de sçavoir en quoy consiste le principal trafficq qui se faict en nos provinces de Lyonnois, 
Forestz et lieaujollois, el de prendre advis de nos spéciaulx serviteurs des moyens desquelz on pourroil user pour l'augmenter, et d'aultant que les chirges que vous tenez lans nosd. provinces vous domment connoisance d'uné partie de ce qui se faich en la négocialion, el que nous arons toute assenrance de l'affection que vous portez it noslre service, nous arons voulu en recepvoir une particulière instruction de vous. Pour celle occasion, sy tost que rous avez recul la présente, assemb[1]és-rous, appelés avec rous les personnes que vous estimerez entendre aud. commerce; dressés ung mémoire de ce en yuoy il conciste avec les provinces circonvoisines; quel utiliti et quel proffict lesd. provinces en penvent receproir, quel moyen il y a de l'accroistre el mesmes d'establir les manufaclures qui défaillenl; faictes le mesmes pour le trafficq qui se faict arec les estringiers, tant par terre que par mer; adjoustez aussy à ce mémoire, bien particulirement, quel nombre il $y$ peult avoir dourriers qui gaiguent leur vie en la manufacture des soyes; quel moyen il y a d'aunmenter lesd. manufactures el de les accroistre, tellement que noz subiectz feissent en cela le pruffict qui va aux estrungiers, el y mectez aussi quelle quantité il peult avoir en Lyonnois le plan de meuriers blancz; quelles contrées seroient les plus propres pour en eslever el par ifuelle voye on pourroit exciter $n 0 z$ subiectz à en planter en leurs terres, et sur lo tout dressez ros mémoires par le menu el les enroyez au sieur Videsire Dumans, conseillier en nostre conseil d'Estat et Arnauld, intendant de $110 z$ linances, ausquelz nous avons donné charge de cest affaire; car tel est nostre plaisir. Donné ì Paris, le xvme jour de novembre 1610. Signé : Lous. Et plus bas : Puelipeaux. Et audessus est escript : A nos améz et féaulx conseilliers, les trésoriers généraulx des finances en la généralité de Lyon.

Aprìs la lecture de laquele lettre, led. sieur prévost des marchans a dict que lesd. sicurs trésoriers qui désirent centribuer tout ce qu'ilz pourront ì ung sy bon wuvre, ont baillé lad. lettre au consulat pour aroir sur ce lous les advis et mémoyres qu'il se pourra, aflin de pouvoir exécuter leur commission à l'utilité publique. Et c'est pourquoy lesd. comparaus et plusieurs aultres qui n'y sont venus, ont esté appelléz présentement puur leur faire veoir le contenu de la1. lettre, triticter arec culx de cest affaire par forme de communicalion et conférance, les priant d'y penser chacun it part soy et en communiçuer aux autres négotians, tant de la ville que des nations pour se trouver plus prestz en se conformant avec le corps de lad. ville quand ilz seront assembléz par lest. sieurs trésoriers pout en dire leurs opinions. 
Surquoy chacun des assistans aiant dict ce que bon luy auroit semblé et leur dire esté récapitulé, lesd. sieurs prévost des marchans et eschevius ont déliberé que les articles suivans seront baillés de leur part ausd. sieurs tresoriers qui seront priéz d'y aroir esgard et en charger leurs mémoires.

Sur les premier, deuxiesme et $\iota^{\text {me }}$ chefz de la lettre du lioy : En quoy concisle le commerce de lad. ville, tant arec les provinces circonvoisines qu'avec les 'estrangiers; quelle utilité et quel proffict lesd. provinces en peuvent receproir, et quel moien il y a de l'accroistre?

Que lad, ville, par le moien de sa situation, a tousiours été jugée l'endroict le plus propre de ce royaulme pour y establir le fondement du conmerce des Gaules. Elle fut bastie à ce desseing par les Romains qui en virent l'effect tout aussy tost. Nos roys l'out ainsy recogneu et y ont transféré les foyres de Brie et Champaigne comme au lieu qui, par information faicte par tout le royaulme et avec les voisins d'icelluy, fust jugé le plus commode pour $y$ attirer les estrangiers et remectre sus lesd. foyres, au grand bien de tout l'Estat, lequel en a tiré en toutes ses parties des commoditéz indicibles, tant et sy longuement que les privilleiges desd. foyres ont esté entretenus, d'aultant qu'il s'y faisoit ung sy grand négoce ramassé de tous les endroictz cogneus par les hommes, qu'il u'y aroit lieu plus célébre au monde, soit pour le faict des marclındises ou pour les changes, et néantmoingtz il ne luy est resté au jourd'huy qu'une seule merque, qui est d'avoir la prérogative sur toutes les plasses de l'kurope, à qui celle de Lyon baille la loy pour la constitution du pris des changes, tellement qu'il ne fault demander de quoy conciste le commerce de Lyon ny quelle utilité il en peult provenir s'il est une foys restitué en la splandeur où il s'est reu, mesmes du règne de Loys douziesme, François premier, et Henry deuxiesme, depuis lequel temps il est tousiours allé déclinant par la violance que les troubles, les nouvelles impositions et les nouveaux éedictz et partis ont faict aux privilleiges desd. foyres desquelz dépend tout leur fondement.

Le moien donc (non pas d'accroistre led. commerce, caril est comme évanouy), mais de le restablir en la pluspart, sera bien facile à leurs Majesté[s]; il ne fault qu'une seule patente, par laquelle tout ce qu'a esté faict, introduict et ordonné contre les privilleiges lesd. foyres ou dérogeant à iceulx, depuis le règne de Henry deuxiesme, soit révocqué, et déclairé que leursd. Majestés entendent que lesd. privilleiges soient, en tout et partout, maintenus et conservés, tant pour les regnicoles que pour les estrangiers 
deschargeant lad. ville et les marchandises qui viement ou seront négociées en icelle, de toutes lesu.impositions survenues depuis le regne dud. roy Henry deuxiesme, et declairant lad. ville et lesd. loyres exemptes et exieptées de tous edictz et contractz qui se troureront faictz depuis lesd. temps au préjudice de la franchise et liberté d'icelle ville, desd. foyres et des marchans, tanl regnicolles qu"estrangiers, qui les fréquentent.

Estant infallible jue la publication de cette bonne nowrelle, qui sera incontinent purtée le toutes partz, fera bientost reprendre a tous les negocians le chemin de Lyon, comme celuy auquel ilz peuvent, avec plus de seureté, de liberté et d'utilité, exercer leurs changes et nígoces.

Les troubles, et spéciallement les derniers, ont détourné le commerce de Lyon, ayans les marchans esté contrainctz de chercher des royes ${ }^{1}$ plus asseurées par mer ou par les Allemaignes et la Lorraine pouréviter l'infidélité et l'impiété de la plupart de ceulx qui suivent la guerre, et pour éviter aussi les daces et inpositions qu'elle aroitengendré. Et quand la paix universelle les a convié d'y revenir, ilz ont trouvé que tant s'en fault que lęsd. impositions eussent esté abolies, qu'au contraire on les avoit augrmenté et -qu'il s'en estoit simenté 2 des nouvelles, voire que par succession de temps on les aroit tellement dilité, que, par exemple, la douanne de Vienne, qui ne fust jamais establie que pour durer jusques à ce quatorze mille écus eussent estez levéz, a neantmoingtz continué et esté affermé telle foys aultant ou à peu près que la doanne de Lyon, soubz pretexte d'une clause glissée par surprinse dans le bail du fermier, par laquelle il a voullu estendre ses limites jusques en Italie, Allemaigne, Auvergne, Virarestz et Languedoc, ayant assubiecty toutes les marchandises venans desd. lieux à passer par ses mains, jaçoit que l'intention de l'imposition eust ésté de [ne] permettre la levée sinon sur les marchandises qui passeroient à Vienne ou sur le Rhosne, par le moyen de quoy la marchandise qui a payé à Vienne en renant à Lyon, luy paye encor un coup quaul elle descend à bas pour aller en Espaigne, Provence, Dauphiné, Virarestz, Languedoc, Saroye, liedmont et Italie.

L’augmentation aussy' de la douanne de Lyon a causé ung mesme mal au commerce, auquel la traverse de Bresse, la foreyne de Mascon, la patente el foreine de Janguedoc qui sont toutes nouveaultéz (desquelles, en tout cas, les marchandises qui sont

1. Le copiste a lu royres.

2. 11 faut probablement lire inventé. 
amenées ou chargées à Lyon doivent estre exceptées par lesu. privilleiges des foyres) apportent tant de désordre aud. commerce que, sy l'on continue de le fouler de tant de costés, en vain tenterat-on de le réduire en meilleur forme qu'il n'est à present, au contraire, comme il n'en reste plus que quelıues estincelles du costé de Marseille, elle sera bientost estouffée tout à faict, et aiusy l'une des principales villes de France denteurera ruinée et dépeuplée, la frontière la plus importante du royaulme, qui ne se peult conserver qu'avec ung grand nombre d'homes bien affectionnés à la coronne, se verra abandonnée, la source du commerce de ce royaulme qui estoit à Lyon sera tarie, les aultres parties de cest estat en seront grandement attenuées, et la douanne de Lyon tellement diminuée, que, nes'y levant plusque sur ce que les Lyonois en consommeront, le Roy n'en tirera comme rien, et les habitans de lad. ville qui ont d'ordinaire l'espée au costé pour la garde d'icelle, se trouveront de pire condition que tant et tant d'autres vilies qui n'ont et ne payent aucune douanne des marchandises qu'elles usent et ne sont subiectes aux gardes et aultres despences qu'il fault faire à Lyon.

Plusienrs edictz et pactes ont aussy beaucoup rapporté à la ruine du negoce de Lyon; les ungs par leur seule publication, et les aultres par les effectz, comme le conseil en pourra estre plus particulierement informé de visue, voir par ceulx qui auront en court la charge des affaires de la ville.

Conme de mesmes il seroit besoing de regler quelques désordres intervenus par succession de temps en l'exercice de l'office de corretier, parce que plusieurs qui le font se sont emancipés d'estre marchans et commissionnaires, et de mesme ont faict les voicturiers, ce qui cause beaucoup de mal et requiert bien prompte et severe provision.

Sur le quatriesme : Quel moyen il y a d'establir les manufactures qui défaillent à la ville de Lyon?

Il n'en fault poinct de meilleur que d'y remectre le commerce, car, lorsqu'il estoit florissant, il se faisoit à Lyon, en une sepmaine, plus de manufactures qu'il ne s'en faict à présent en tout ung an. La guerre a faict mourir une partie des ouvriers; la faim en a chassé une aultre partie qui est allée non seulement aux aultres villes du royaulme chercher sa vie, mais, qui est le pis, s'est retiré aux estrangiers pour y establir les manufactures quilz soloient venir querir à Lyon. Et toutesfois il ne fault pas doubter que, sy le concours et affluance du negoce se remectoit à Lyon, les ouvriers y arriveroient de toutes parı, pour la comodité de la vente, pour le bon vivre qu'il y faict, pour la liberté des maistrises des mestiers, et 
pour liancienne reputation de lad. ville qui dure encores et faict souhinter à tout le monde d'en reveoir les effect\%.

sur le ve, touchant le nombre des ouvriers qui faignent leur vie en la manufacture des soyes?

Tout ce que l'on peult dire de certain, est qu'il y a (en blanc) cens $n^{\text {res }}$ ouvriers qui font de petitz velours et taffetas plains et quelques petitz sattins rayés ou il lisseton, lesquelz $\mathrm{m}^{\text {res }}$ peulyent ayoir environ dix-huict eens mestiers au lien de sept mille que l'on y a veu au temps que les estrangiers estoient en la ville en grand nombre, y faisans venir leurs soyes el des ouvriers qui manufacturoient en grande quantiti. 11 y peult aussy aroir (en blanc) cens passementiers qui vivent assez paourrement de leur mestier; (en blanc) teincturiers; (en blanc) moliniers; (en blanc) plieurs de soye, quelques hailleurs d'eau, remondeurs et plicurs de draps, avec grand nombre de cardeurs, devideurs et devideresses, sy hien [que], par commune estimation, l'nn tient que de unze à douze mille personnes peulvent virre de l'art de la soye dedaus la ville de lyon.

Sur le $y^{e}$ : Quel moyen il y a d'augmenter lad. manufacture de soye tellement que les subiectz du Roy feissent en cela proffict qui ra aux estrangiers?

Il ne fault pas seulement augmenter ce qui est introduict à Lyon de l'art de la soye, comme l'on fera facillement sy le commerce s'y restablit, ainsy qu'il se veoit par l'cxemple du passé, car, en l'estat que led, art s'y exerce ì présent, c'est [trop] peu le chose, pour penser par ce moyen retenir l'argent en France. Il y fault establir encores de vingt sortes et plus d'ourrages d'or, d'argent et de soye qui ne le sont point à Lyon, qui sont grandz draps à grandz ramages ou compartimens, et pour ornemens d'esglise, meubles de princes et grandz seigneurs, et habitz d'homes et femmes, comme, par exemple, les velours turcz, ris, supraris et rissotailles des deux ou troys, quatre et cinq coleurs, à grandes et petites figures, les sattins fasson de prairie, fleurs des Indes, à la turque, en ligature de damas, à ramagres; à fleurs et aultres de plusieurs coleurs; les damas de mesmes, et les taffetas fasson de Turquie à deus faces et figurés, fasson de Millan, brocatels, frises sur frises et aultres estoffes de grand drap.

De toutes lesquelles estoffes qui sont celles qui emportent de France les escus à millions, le feu Roy llenri le Grand, que Dieu absolve, a voullu faire les establissemens a Paris avec une grande despence et curiosité indicible, mais vainement et inutilement, parcę̧u'il a fallu passer par les mains des ouvriers estrangiers qui ont esté subornés par ceulx de leur pays pour crainte qu'ilz ont de tel establissement. 
A Lyon, ung seul, nommé Claude Dangon, natif de lad. ville, ouvrier du Roy, est parvenu en perfection a la fasson de tous lesd. draps et y a desia dressé plus de vingt ourriers, y employant jusqu'aux petitz enfans de douze et treize ans, qui les font tres bien. Et sy led. establissement ne se faict par le moyen dud. Dangon, il n'en fault que peu esperer, d'ailleurs led. Dangon en peult mieulx que personne faire les ouvertures, car il se faict fort de fournir tous les ans vingt ouvriers sortans de sa boutique, qui fassonneront tres bien chacun d'eulx l'une desıl. vingt estoffes, voyre plus grand nombre selon la despence que l'on y vouldra faire, pourveu qu'il luy soit domné moyen d'en soubztenir les fraiz et que son labeur ne luy soit du tout infructueux. A l'ouyr parler, il semble qu'ung fondz annuel bien petit ì l'esgard d'ung sy grand ourrage et d'une sy grande utilité, pourroit suffire à tel establissement.

Le surplus des autres articles de lad. lettre concerne la quantité du plan de meuriers qui peult estre en Lyonnois; le moyen d'en faire planter davantage et les contrées qui sont propres à cela, depend de l'information que lesd. sieurs trésoriers peulvent sur ce faire de leur office.

\title{
I I
}

\begin{abstract}
GRAND LIYRE DE LA IAISON DE SOIERIES DES LARAN DE TOULOUSE COMNEXCÉ LE 2马̈ NOVEMBRE $10 ̈ 49$.
\end{abstract}

(Arch. du parlement de Toulouse au palais de justice, F 108.)

$$
+ \text { Ihs + Maria + }
$$

A l'houneur de Dieu et do la glorieuse Vierge Marie et de tous leurs saints et saintes de Paradis sera fait et coumensat lou present livre appellat le mannual tannat, en lou qual se escrivian toutz lous deuptes que ce faran d'aiscy en avant, loupual es estat coumensat le jour de Sainte-Chatherine $25^{3}$ jour du mois de nouvembre $15 \% 9$, per que plassia à N. S. J. C. et à la Vierge Marie et à tous lous saints et saintes de Paradis de nous donnar gratia de le acabar et nous donnar guasan et prouffit de bonne part. Amen Jesus.

Manual tannat suys appellat $1: 34$.

Ne varietur :

(Signé) : Boucher (?). 


\section{III}

VEXTE DE PASTEL.

(Papiers Lecomte. Areh. de lllôtel-Dicu de Toulouse, IIB 9'.)

L'an $1: 7_{2}^{2}$, le septieme jour de septembre, en Paris ont été faits les pactes qui s'eusuivent entre Laurent liergeron, marchand demeurant à Paris au nom de messieurs les Canayes et Pierre Col.... marchand de... Toulouse, ì savoir que lesd. Cols font vente aud. Bergeron de la quantiti de deux cens charges de pastel avec les tournes accontumées de la présente anıée, prise au lieu dessus ou aux environs de leur meilleure pille, moyennant la somme de $20^{1}$ tourn. pour charge, montant le tout à la sonme de $4000^{\prime}$ tourn., sur laquelle somme de $4000^{1}$ lourn. led. B. a baillé comptent auxd, C. la somme de $2100^{1}$ tourn. et pour le reste et parpayer d'icelles deux cens charges pastel leur a baillé lettre de change pour Toulouse....

\section{IV}

CORRESPONDAXCE COMNERCIALE TIREE DES PAPIERS LE SIHON LECONTE.

(Arch. de l'llòtel-Dieu de Toulouse.)

$$
\text { Boyer } \dot{a} \therefore \text { Lecomte. }
$$

Bordeaux, 25 janvier $15 i 8$.

M. Le C. le présent porteur qui a esté mon apprentis, s'en va de Tholouse pour travailler de son estat el s'eforcer de parvenir en plus grant legré que de servitude el, parce qu'il a ung bon home de pere et une bonne mere qui me sont recommandé, je vous prie, en cas de nécessité s'il avoit affere en nécessité de maladie, luy estre aydant tant en sa nécessité que de luy ayder à trouver mestre. Il est loyal, qu'est chose riche et qui me fait vous prier pour luy....

Votre meilleur amy,

BOYER.

Le mémie au méme.

Bordeaux, 3 férrier 1578.

Il commence par raconter dans tous ses détails physiologiques la maladie mortelle de sa femme, puis il ajoute : "Au reste notre Dieu 
nous visite d'autre facon, vous avertissant que en cette ville toutes sortes de marchandises sont estées taucées depuis huit jours.... à perte de ceux qui en ont, au moins d'une moitié et d'un tiers.... tellement que, sur les estames que je reçus [envoyées par Lecomte] ou sur autres marchandises tant de Paris, Poitou, Angleterre, que je commence de perdre el, si Dieu n'a pitié de moi, je y' perdré le tiers.... Le seigneur Pollis m'a åssuré, y a un mois, qu'il rous avoit escrit [que] le conroy estoit abolli.... Toutefois le Roi a imposé la trete foraine et est assise à Blaye.

Decheverry is s. Lecomte.

Agen, 12 février $15 \%$ \%.

... environ les deux heures après midi arriva un bateau.... et le patron qui le conduisoit déchargea 22 balles de la contremerque et, pour ce qu'il ne portoit point lettre de voiture, celui qui a la charge pour la contribution ne le vouleist laisser aller qu'il n'eust vu la lettre de voiture...

\section{" lehan Magnard à S. Lecomte, agent et institeur pour M. Rouillé de Paris..."}

Rouen, 11 février 1578.

M. Le C. je vous advise que, le xx. du passé, j'envoyé à M. Rouillé une lettre de change de M. Courneilhe d'Abey par Me Martin, gentilhomme de II. de Courmisson qui s'en alloit en cour. Je pense que, dans peu de jours, vous et moi en arons nouvelles, desquelles, tout aussi tost que je les recerrai, je vous en ferai part ou bien rous enverrai la lettre d'aris que led. $\mathrm{S}^{r}$ menvoiera....

\section{Decheverry à Simon Lccomte.}

Agen, 6 mars $15 i s$.

... Je rous avertissois comme Durhet etoit passé arec 400 balles de pastel, desquelles il en laissa 20 balles pour la contribution. Je me pensois que ce fut du votre. Toutefois led. Durbet me dit qu'il n'en etoit point et que, à faute de lıateau, laissiez à charge le votre et m'assura... que par les premiers bateaux que passeroient seroit grand cas s'il n'en y avoit du rotre... J'ai remontré à celui qui tiennent ( $\mathrm{sic}$ ) le compte de la contribution comme je faisois de grande dépense et que, pour le moins, il me laissat passer qq. 60 balles sans 
en laisser aucune balle. Il m'a promis m'en laisser passer 20 balles et j'espère avoir moyen avec le peager d'en faire passer autres 20 b. et, dusse-je lui donner qq. cloose,... rous supplie... de m'éerire... le nombre du pastel que avez chargé.... Geordi (:) Mellet ${ }^{1}$ m’a dit qu'il trouva à Bordeaux 2 balles plus qu'il n'etoit porlé par

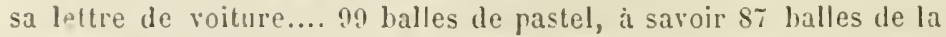
marque du filet et 12 billes de la marque des trois roses...

\section{Le méme au méme.}

Bordeaux, 18 mars bis.

... ai enroyé le compte du pastel que MIM. Du Prat et Armagnae ont reçu, par lequel pourrez avoir veu que Geordy ou Coquilhon ont perdu cinq balles, car tous les autres mariniers à qui vous avez ballé pastel, ont porté leur compte... Geordy.... me fit reponse que Fouquerolles les payeroit, si se trouvoit qu'elles fussent perdues mais que tant s'en falloil qui les eust perdues, car il a aporté plus de pastel que sa lettre de voiture ne portoit...

\section{Étienne Arnauld, maitre priseur de pastel.}

Jésus Maria en Toulouse.

13 juillet 15is.

M.... la présente... sera pour rous arertir que la marchandise que rous arez en Toulouse, Dieu merci, va fort bien. Au reste je vous prie affectueusement me faire tant de bien et soulagement que de me faire envoier une atestatoire par le moyen du $S^{r}$ lehan du Casse du pastel de M. Nicolas Targier de la quantité de 302 balles, que je en suis responsable envers le droit de la forane et déjà le terme et délai est it la fin de ce présent mois. Si je ne puis attester de lad. marchandise où esse qu'elle est, passé led. delay, lesd. $\mathbf{m}^{\text {es }}$ de la foranne ne feront faute me faire déplaisir come cautions de lad. quantité de 30: balles et pour led. Targier, à cette cause vous supplie... me fere.... que led. du Casse me envoye attestatoire ou lettre de luy pour faire aparoir où est lad. marchandise pour avoir delay. Au reste vous avertis que les toiles et cordes pour emballage de pastel viennent en grande valeur par deça que, si bon vous semble, en ferez votre provision par dela, si trouvez la commodité et, quant à la marchandise de pastel, elle descend à bon compte...

1. Mellet était un marinier, un entrepreneur de transports par eau. 


\section{Lemaire à S. Lccomte.}

Toulouse, 14 juillet 1578 .

Votre pastel se porte fort bien.... toutefois Ie Etienne dit que c'est trop peu de le virrer de quinze en quinze, comme vous m'avez mandé. Led. Me Étienne vous prie de lui mander un certifical de ducasse pour le pastel de M. Targé, d'autant que son délai se passe à la fin de ce mois....

De Paris, ce 6 aout 157 s.

M. Macault... la présente est pour vous dire comme le Sr Beausemblant me mit en main une cedulle de $5_{0}$ en ecus sol, laquelle.... il l'a fait faire en mon nom propre à payer dans six mois prochain tellement que je crois.... que, dans ferrier ou mars prochain au plus tard, en serez payé. Celui qui doit la cedule se nomme Rousselet, marchand bourgeois de ceste ville et, se pour lad. somme de 300 écus sol. avez affaire de notre etal de draperie et sarges rayées de Beauvais, je vous en envoirai et prendrai la cedule pour mon compte. Partant... pourrez quitter led. Sr Beausemblant et lui rendre sal promesse comme lien payée et acquittée, car.... dans Paris led. Rousselet est réputé pour bonne dette. Led. Beausemblant ne m'a fait aucun compte des interets. Fous pourrez vous en accommoder ensemble....

Votre serviteur et ami,

JEH.IN RUUILLÉ.

[P. S.]. M. Macault, je tiens la partie de 300 ecus sol pour bonne et hardiment lui rendrez sa cedule, car je tiens la cedule ci-dessus escrite pour bonne, car j’en ai parlé aud. Rousselot depuis nua letıre écrite.

\section{Lemaire a Simon Lecomte.}

Toulouse, 16 octobre $15: 8$.

... Je n'ai voulu fallir à vous avertir comme M.M. de la bourse ont fait assigner tous ceux qui ont pastel à Tonneins engagé pour la contribution due au lioi de Navarre aux fins qu'ils fussent tenus lé desengager d'autant qu'il disoit que le receveur de lad. contribution leur a écrit que, s’ils ne mettoient ordre que led. pastel fut retiré, et payé ce pourquoi il étoit engagé, que tout le pastel que l'on descendroit seroit arrèté.... 


\section{Biennois is S. Lecomte.}

Toulouse, 31 octobre $15 i s$.

... Encores ne soyez de coulume tirer lettre de change sur une cedule et encore fraichement echue, nonobstant ce, je le paiai aussitot que m'a été presenté...

\section{Jean Yion is. Lecomte.}

Anvers, novembre $15 i 8$.

... les teinturiers de drap usent pour le present plus que la moitié de l'anil de Parharie et de l'indigo le Port Ingade que fet un grand mal a pastel... Quant aux vins de Bordeaux nouveau, sont rendu en Zelaude $1 ;$ à 16 et 17 . Item de gros tonneau cleret et blanc selon la bonté, celle de Poitou de 10 a 11 et 12 liv. et mème selon la bonté....

\section{Abel Ionceau a S. Lecomte.}

Toulouse, 2 norembre 1578 .

I. pour ce que demierement je vous donné avis comme j’avois esté averti par le $\mathrm{S}^{r}$ Iehan Ilartin comme il avoit acquitté la lettre de change, suirant l'ordre que je lui en avois douné au sieur Jacques Remon et n'en ayant eu aucun avis de rous, it vous plaira ordonner par la première commodité que je sois payé de par deca, suivant la promesse que me fistes à vostre partir pour ce que, comme savez, je suis comptable de lad. lettre de clange...

\section{Michel du Sosoy à S. Lecomte.}

Bordeaux, 30 décembre 1578.

II. Lecomte, j’ai recu la vostre du 23 jour du courant avec une cedulle inclus du $\mathrm{Sr}$ Pierre du Treyl [?? , marchand chaussetier de cette ville de 301 liv. tourn., laquelle il m'a promis payer. J'ai accepté de payer vostre lettre de change de 613 liv. cl au temps sera payée lleu aidant. Par le compte à vous eirroyé rous trouverez que vous nous debviez 316 liv. 12s $9^{\mathrm{d}}$. Ledil compte vous a esté envoyé du $27^{e}$ jour de juillet. Depuis nous vous faisons hon 391 lir., assaroir est 480 liv. pour la vente de 30 balles pastel et 111 liv. pour vente de bariques, de laquelle partie nous est deu encores 47 liv. il fait mavais de recouver debtes en ce temps. Brief, rous faisant 
ainsi tout bon, nous vous debvrions $27_{4}$ liv. $7^{\text {s }} 3^{\text {d }}$. De la nous est deu 53 liv. $17^{\mathrm{s}} 1^{\mathrm{d}}(?)$, comme vous plaira voyr par le menu ou compte que nous vous envoyons avec la présente. liesteroit à vous deu 220 liv. $14^{\mathrm{s}} 7^{\mathrm{d}}$ et apresent nous payons pour vous, pour reste de vostred. lettre de change, la somme de 312 liv, reste que nous adrançons 91 lir. $9(?) 10^{\mathrm{d}}$ qui sera tant moins de vostre d. compte de temps qui vous est pour advis pour demeurer d'accord de nos comptes, car ainsi se trouvera couché sur nostre livre. Au reste je vois ijue vous avez qq. bon pastel de par dellà. S’il rous plaist nous en envoyer 3 ou 400 balles de la milleure sorte pour la prochaine foyre de mars, nous en scavons deja le debit...

Bordeaux, 6 mars 1579.

II. Le Comte... par icelle [lettre] vous disiez d'ètre par deça dans douze ou quinze jours mais, à ce que je vois, n'y êles encore, qu'est cause que par la presente vous veux prier nous donner provision de la somme de 180 ecus que avons avancé pour vous jusques à present... vous assurant qu'ai grand affaire de nos den., tant pour l'avance qu'il nous a fallu faire pour le louage de nos chais que pour le paiement de ce qu'élions reliquataires à la coustume aux derniers fermiers, tellement que, mercredi dernier, H. Bonault usa d'une façon etrange, tellement qu'il saisit trente balles de votre pastel dans le chay sans dire qui l'a perdu ne qui l'a gagné mais ribon ribene. Si l'avons retiré et sommes en grand peine tous en général de recouvrer de M.M. les nouveaux fermiers... acquicts des marchandises entrées dans l'année 1578 , tellement qu'il nous faut aller devant ces Mess. les généraux.

(Non signé.)

Du Prat ì S. Lecomte.

Bordeaux, 6 arril 1579.

... au 20 du courant a été ma dernière, par laquelle vous prions nous donner provision de 200 écus en déduction de ce que nous devez, vous assurant... que ce que nous reste nous revient à grand intérèt à cause de l'arance qui nous faut faire qu'est la cause que, voyant votre longue demeure, ai pris par deç la somme de 200 ecus, pour icelle somme être par vous payée par delà huit jours après leur vue au $\mathrm{s}^{\mathrm{r}}$ Barthélemy Sacaze, marchand de Toulouse, ce que vous prie faire... 
... au dernier du passé a été ma derniẻre copie d'autre avec la seconde d'échange de 200 écus, laquelle somme pense aurez payé au s. Sacaze qui est cause ne vous en dirai autre, sinon que j'espere en bref rous aller voir par delá et, sans votre partie de M. Testeu et autres, je y serois à present pour faire entendre à uos ennemis le contraire de ce qu'ils ont dit de moi... vous priant... me soustenir en mon honneur... Au reste, si vous fussiez élé par deça, la plus grande partie de votre pastel seroit vendu... le ma part, je ne puis rieu faire ni ne ferai que ne nous ayez donné antre pouvoir... nous arons vendu environ de $\$ 00$ balles pastel de II. Madron... nous sommes aussi après ì faire vente arec le $s^{r}$ Vezel de 4 ou 300 balles pastel de M. Rabauldi du pastel de la compagnic mais à present je n'y ai rien et me coute $2: 30$ ecus....

\section{Ticolus Coruel, apothicaire à Lyon a Simon Lccomte, marchand dementrant aux Balances à Toulouse.}

Lyon, 11 mai 1579.

Coquel raconte la mort de sa femme " arec un tel jugement et si bon sens qüil n'est possible meilleur et me pria que je prisse pour ma femme Jehanne de Commenes pour l'anitié qu'elle portait tous i nous et à notre fille. Sa mere etoit marice $[a ̀] \mathrm{s}^{r}$ Jehan Perret, oncle de ma frmme et parrain de ma fille... Je vous avise que nos freres et seurs et leurs enfans se portent bien. Notre seur Jaquema (sic) a un beau fils et font bien leurs alfaires. Aussi fait notre frère Narc I) Four. Il est revenu de la foire de Francfort en Almaigne et amene environ trente chevaux. 11 emporta Iò à 1600 ecus en argent et lettre de changre, dont une bonne partie étoit à soy et une partie qu'on lui a prèté et a bien vendu la moitié. Il espere y retourner ì la Saint Jean pour le beau profit qu'il fitil...

\section{B. de Villebais à Simon Lecomte, marchand de Paris a present a Toulouse.}

Bordeaux, 20 juillet $15 \% 9$.

II. depuis votre partement dernier de cette ville, je vous ai ecrit deux fois et, n'ayant point recu réponse..., j'ai encore ecril la presente... si je suis par trop importune... prendrez le tout en bonne part, vous ressouvenant des alfections que peuvent avoir les meres enver's leurs enfans... Je vous veux bien avertir que mon fils Tadé, celui que avez mis avec le sire Perastre, $m$ a ecril que de votre grace arez parlé aux sires Joseph fialan et de Landria touchant mon fils Jean 
de Lestrilhes que avez mis en leur maison pour aprentis et que leur arez remontré le lort que moi et mon fils pouvons recevoir de ce qu'il se sont distrait de tenir boutique... et que la reponse desd. Galan et Landria est qu’il ont laissé larl. boutique pour se liquide $[\mathbf{r}]$, à cause que la compannie entre eux faite finit et qu'il peut etre que les deux compagnons se separeront mais que led. C. vous a dit que, au cas qu'ils se separent, quiil a volonté de faire pour lui et que volontiers il preferera mond. fils à tous autres pour le prendre à son service..., l'employant à la marchandise et royage et que, à cause de ce qu'il pourroit aroir perdu qq. temps, il ne me demande pas de pension pour la seconde année... je vous veux aussi avertir de ma volonté en ce fait, c'est que, tant moinsque je ferai de frais et mises, :era mieux pour moi et pour mesd. enfants, pourvu que, en epargnant sa pension, il ne fut en rien retardé... je ne puis entendre ì quoi à présent il emploie mond. fils de tant que son frere Tadé m'écrit qu'il est toujours à leur metairie...

\section{Sabatery à S. Lecomte.}

Bordeaux, 28 décembre $15 \% 9$.

... vous ai voulu ecrire la presente tant pour vous donner a vis du cours des marchandises qui passent de pardeça, entre autres des pastels, lesquels ne sont bien en requète... je ne sais ce que ce sera pour cette foire de mars. Je pouvois vendre votre pastel à 18 liv. la balle à payer dans un an mes, ayant vu vos lettres..., n'ai voulu passer plus outre. Toutefois je baille une mestre $(s i c)^{1}$ de votre pastel à un Ecossois qui en a afaire de cent balles et au comptant... Je ne puis soit en truque ${ }^{2}$ ou autrement à terme d'un an me deffere de vos draps, sy ce n'est d'un bleu ecru qui étoit entemé, que ai reçu du s Boyer... il est descendu gran nombre... de vins du lıat pays, de nraniere qu'il y a longtemps que n'etoit descendu tout à un coup si grand quantité de vins et pense que s'en fera bon comple à 14 ou 15 ecus au plus haut vin de ville.... Draperie d'Angleterre est en peu de requête à cause du nombre [qui] en est arrivé....

\section{Sabatery à Simon Lccomte.}

Bordeaux, 13 mars 1580 .

M. Lecomte, la votre du $2^{e}$ du courant ai recue, par laquelle me recommandez la bonté de votre pastel... je ai fet et fais tout mon

1. Montre, échantillon.

2. En troc. 
possible, mème en ai ballé des essáys à deux ou trois, tant Anglois que Ecossois, car fiut que vous estimes que ne s'est vendu balle de pastel qui ne soit été asayé, d'autant que les Anglois sont resolus ne se chil ger de pastel que prealablement n'ayent fait l'ançay (sic). l'our le regirt de ros draps, il n'y a moyen les pouvoir vendre ne truquer, combien que je fais toui devoyer (?) it les vouloir truquer avee des vins de haut pays mais ils mont voulu laisser les rouges et prendre les meilleurs... Pour la presente foire, il ne s'est pas rendu que bien peu de pastel, si ce n’est l'homme de M. Vestos (??) qui a fiit rente de ses cent balles à des Anglois....

Dans une lettre du 20 mars 1580 , le mème correspondant dément la nouvelle que les pastels sont recherchés et confirme le contenu de la précédente.

\section{Le même au même.}

Bordeaux, 10 avril 1580.

La rente des pastels n'est guere echaufrée, dautant que les Anglois ne peuvent vendre leurs draperies, de sorte que ils [en?] ont tant emporté que à present n'ont moyen de payér]...

\section{Le méme alu mime.}

Bordeaux, 29 avril $15 \$ 0$.

Je lis vente hier de cent balles de votre pastel à raison de 20 livres la balle à payer au mois de mars prochain... à un Anglois nommé Edouard lien, marchand de Londres et seize balles à un autre Anglois nommé Thomas Bron, le tout à prendre des cedules sur de hons marchands de cette ville... quant aux draps il ne m'est possible de vendre une seule piece et en suis marri, d'autant que la gresse les mange... c'est pitié du peu de dépèche qu'a la draperie de pardeça, nuemes le grand nombre qu'il y en a, dont les Anglois sont fort elonnés... l'on les tient de court et we trouveront le eredit qu'ont fait par cidevant. Au demeurant je suis sur le point de bailler quatre pièces de votre drap, savoir trois rouges et un bleu des plus méchants à un nommé La liuade, lequel a un navire qui s'en va an voyage du lirésil, partie en marchandise et l'autre partie en „ूuerre... de façon que, moyenuant qu'il veuille prendre lesd. draps à yuatre livres ou à trois livres dix sols au moins l'aune, avec quelque tonneau de vin que je lıi baille, lui ai promis lui faire jusques à la somme de 150 ecus à 
raison de 50 p. 100 au retour de son voyage, prenant toutes aventures de mer et de guerre... toutefois, si ne voulez prendre lad. aventure..., je le prendrai pour moi et vous paierai lesd. draps au prix que se vendront de semblables....

\section{Sabatery à Simon Lecomle.}

Bordeaux, 14 novemble 1581.

M. Le Comte... le Sr d'Armagnac m'a fuit entendre depuis trois jours que, lors de votre depart de cette ville [Paris], vous lui donnates charge de vous faire faire qq. chartes parties des pastel qui ont été chargés pour Rouen et autres lieux, tant pour votre compte que pour celui de M. Roullier, qu'est la cause que je rous ai voulu écrire la présente pour ètre bien assuré du fait et, sauf meilleur avis, il me semble que, auparavant rien faire, il sera meilleur que vous envoyez la cantité et nombre dud. pastel, ensemble les marques et le nom qui faut qu'il soit nommés dans lesd. chartes parties, ensemble les dates, si possible est, et par votre mémoire nous en ferous suivant qu'en ordonnerez....

\section{Le méme au mème.}

Bordeaux, 27 novembre 1581.

... à 21 du courant vous ai ecrit, vous donnant... avis que je me doute que, en jeu de jours, la garnison de Mon Segeu (sic) ${ }^{\mathbf{1}}$ a délibéré d'aller arrêter tóus les bateaux qui monteront et descendront, comme ont fait ceux du MIas jusqu'à ce qüils soient payés de qq. partie qui leur est due, que, si cela est,... si avez quelque chose à charger le plus promptement ne sera que le meilleur....

\section{Du Prat a Simon Lecomte.}

Bordeaux, 27 janvier 1578 .

... à 20 du courant a esté ma derniere... par laquelle vous disois comme jestois marri de la longue demeure de vostre pastel pour ce que j'en eusse donné des essais à beaucoup de mes vieux chalands Anglois et Ecossois, lesquels vont partir depuis et toutefois ils seront pardeça dans la fin de mars..., comme ai fait aux sieurs Barthélemy Saccaze et Du Vergier de 17 balles pastel que leur ai vendu à 26 liv. la balle et le pouvois bailler à moins de 2öliv., suivant ce qu'il m'en avoit

1. Sans doute Monségur (Gironde, av. La Réole). 
écrit. An reste deça apres ne parlons plus de livres mais ecus... et ue passons ancun contrat ne charte partie que ne soit tout reduit en reus, tellement qu'il $y$ a motaires qu'il faut qu’ils aillent étudier à chiffrer et, ne pouvant ententre ces 10,12 et $1: 3$ c. de ecus leltement qu'ils sont tous neufs à leur estat par advis (sir), beaucoup de parties sont en arriere à cause du descry, tellement que ce yu'est de terme echu faut bailler terne 3 e' \& mois pour estre asseuré Brief ce descri a fait beaucoup de dommage... Tous chargeons pour Rouen ct Vantes et les frets valent pour Rouen 8 écus, pour Nantes \&́écus, i ceus $1 / 3 \ldots$.

\section{Sagnier i Simon Lecomte.}

De Bordeaux, ce 16 de novembre 1582.

.11. Ia derniere vous ay envoyé avec deux Iettres de clangre montaut ensemble $2: 37$ ecus... maintenaut je rous envoye une pour recevoir du $\mathrm{s}^{\mathrm{r}}$ Jehan Vidal demeurant près la maison de ville de la somme de 166 ecus, une autre sur le $\mathrm{s}^{\mathrm{r}}$ Arnauld de Tauret de la somme de 100 ecus, lesquelles je vous prie fere accepter et payer. Pour l'asseurance de 166 ecus, jai prins une promesse d'un marchand denommé Jehan de Connys, laquelle je vous envoye pour estre rendue, lors que serez payé de lad. somme dud. Jehan Vidal. Le tout me garderez pour satisfaire à quelque partyes que M. Rouillé doit ì Toulouse sans rien remeltre. J'ay rendu hier la vostre avec une de change pour recevoir de Pierre Boucher 200 ecus.... J'escris un mot au $s^{r}$ André afin qu'il mettent la partie entre vos mains ou qu'il me la tienne preste à mon retour.... Depuis avoir escrit la presente, je vous envoye une premiere de change pour recevoir à lettre vue cent escus sol sur le $\mathrm{s}^{\mathrm{r}}$ Iu las demeurant au Puys (?) clos.

\section{V}

A vous MH. TENANT LE SIEge PHESIDIAL E. THOLOSE.

(Arclı. de l'llòtel-Dieu de Toulouse. Papiers de S. Lecomte.)

Supplie humblement Symon Le Compte, marchant de Paris que, pour luy servir, auroyt besoin fere deux extraits, l'ung d'une lettre missive escripte et signée par George Sabatier, marchant de Bordeaux Is $x m m^{\circ}$ d'apvril dernier, l'autre d'une cedulle faicte et signée par Jehan Cliauvet, marchant de Tholose le xvil jullet mil VCLXXXII de la somme de deux cent cinquante ecus sol, appelés deux merchaus de ceste ville pour recognoistre lesd. lettres et saings, d'autant qu'il 
a besoin dest. extraicls et, dessaisissant des originaux, ce poun royent esgarer au préjulice du suppliant. I ceste cause plaise a vos fraces commeltre lest. extraicts au premier de vos urelfiers, appellé deux marchans, comme dict est, pour l'adven et recosnoissance. Si ferez bien.

\section{VI}

$M^{r}$ LE M.AITRE DES PORTS DE L.A RIVIEUE DE TOULOU:S OC VUTHE LIEUTENAMT GENERAL.

(Ar'ch. de l'llôtel-Dieu de Tuulouse. Papier's de S. Leconte.)

Supjlie humblement Simon Lecomte, marchand de Paris disant que, le $21^{\mathrm{e}}$ de juillet $13: 9$, il auroit fait charger en Toulouse cent quarante sept balles pastel et pour iceiles pris passeporls pour conduire à [hlanc] et Paris, sous obligation de rapporter certificat de la vente dest. pastels dans le delai de dix mois... ou, en defaut de ce faire, payer les droits du roi de foraine, de laquelle vente il lui a été impossible de faire apparoir lans led. delai, à cause que led. pastel est encore en nuture, partie en la ville de [blanc] et partie aud. Paris, en attendant qq. commodité pour icellui vendre.... ) demande renouvellement de delai.

\section{VII}

GOBELIN A LECUMTE.

(Ilid.).

Saint Marcel les Paris, 1't decenbre 1581.

... J'ai ven par volre lettre du 1 ö du passé l'etat auquel étoient lors les alfaires pour les passages de la riviere qui n'étoient encore gueres assurés, ensenble l'assurance qu'il rous plait me donner de la conduile de nos marthandises sitot que lesd. passages scront ouverts, de laquelle faisant état, j’espere qu'à preseut elles devront etre chargées si, suivant les nouvelles qui sont venues de Burdeaux en cette ville, les grarnisons ont été contanties par M. de Matignon.... 
LIVE JOLRXAL BROLILLARD DF, JEAX LFCOMTE.

('apiers de Simon Lecomte.)

$1 ; 381$

Jornalier pour la recette des den. que se remettront tant de l'oitou, burdeaux que autres lieux:

\section{5}

A 12 daout es mains de Jehan La Combe 24 t. 3 liv. tourn. 1 s. recu de II. notre maieur pour son compte capital à present au livre de credit. . . . . . . . . . . . . . . $24 t 3$

Et ȧ 20 de septembre 1069 liv. reçu de $\mathbf{M}$. nostre d. majeur nous a preté crediteur au livre de credit.

Et à 23 dud. 618 lir. arous emprunté dud. s" crediteur au livre de credil.

Et à 26 dud. 320 liv. recu de Pierre Faure faisant pour mess. Audruet (?) en vertu d'une lettre de change envoié par Pasteau.

\section{3}

Sur Antoine Soliniac... à 13 de juillet la somme de 3042 lir. de conte.

Et 159 ecus $313 \mathrm{~s}$. sont pour le change de la susd. somme a com. prins (sic) le couretage qui revient pour cent ż $1 / 4$ qui en tout a valu. . . . . . . . . . . . . 1599 liv. 36. s.

Et 216 ecus pour le change de la susd. somme que j'ai prins à depot jusques aux paiemens de la foire de Rouen 1506 à 61 \& tant a valu le change, remise arec le couretage. . . . . . 216 ecus.

\section{$13 ̈ 8 \ddot{3}$}

Sur Pierre l'ral, marchant de Toulouse doit aroir à 2 de decembre par casse la somme de 3:30 liv. m'a baillé à depotjusques aux paiemens de Roge a \& 1/2 pour le change... lui ai fait promettre lui bailler lettre de change dans le 20 fevrier prochain. . 363 liv. 40. 


\section{7}

Et à 2́́ dud. [septembre] 330 lir. reçu du Sr Alary marchant d'Alby, crediteur au grand livre à son compte à. . . . . ว̌วo.

Et à $20 \ddot{~ d u d . ~} 9 \ddot{3}$ liv. 13 s. arons reçu de La Vassor dOrleans pour laine burelle à lui vendue. . . . . . . . . . . 93̈ 1 . .

Et à 26 du d. 220 liv. reçu de Pierre Fanre faisant pour M. Audruet. en vertu d'une lettre de chanse envoié par Pasteau. . . . . 5:0.

\section{8}

Et à 21 de janvier วัว̆ liv. 6 s. 3 d. tant(?) ai emprunté de I. de frestes nostre maieur et c[r]editeur au liıre de credit à. . . . $35 \%$

Et 19 dud. [fevier] 1 ว̈00 liv avons reçu du s ${ }^{r}$ Cazoltes pour compte de M. Lautier pour pareille somme [que] Chanson lui avoit forni en bourse (?). . . . . . . . . . . . . . . . 1500 .

Et à 10 dud. [avril] 6 to lir. arons recu du $\mathrm{s}^{\mathrm{r}}$ Pierre Subreville en 200 ducats millares que led. Chanson nous a livrés. . . . $6 \mathfrak{1 0 .}$

\section{3}

Caisse doit à 19 d'octobre aux s ${ }^{\mathrm{rs}}$ Granier et Gestel 100 ecus sol. 100.

Caisse doit aroir à 20 d'octobre 80 ecus 14 s. pour autant bailler à Bernard Manens debiteur dud. II. à soll comple. . . . . S0 14 .

Sr Saurin, marchant de Toulouse, doit à $1 i$ de norembre à caisse la somme de 300 ecus lui en fait compler par Pierre Bonne Foy. . . . . . . . . . . . . 300 ecus.

Sr de Veires doit avoir à 27 de novembre la somme de 400 ecus pour une lettre de change de mess....

Pour être paié à Lyon à l’aciunit du Sr Touzin. . . . 4010 ecus.

Et 2 ecus pour la remise de 100 ecus à 2 pour cent.

$\frac{2-}{402 \text { ecus. }}$

1383

Caisse doit donwer à 20 de novembre 724 ecus $11 \mathrm{~s}$. pour reste de son compte précédent. 
1.386

M. Maryuant doit a 20 de fevrier la somme de rooo ecus pour deux leltres de chante paiables it Lyon id ces prochains paiements de la foire de Royes'.

Sr piere l'ral, marehand le foulouse doil avoir a 2 de lécembre par ca'i sse la so'nme de 350 ecus [que] ma baillé à dípuot jusques aux paicmeus de loyes à \& 12 pour [cent] pour le change, yu est en Lout $36:$ ecus ï s. Lui ai fait promesse lui bailler lettre de change daus le 20 fevrier prochain. . . . . . . . 300 ecus 4ïs.

\section{IIS}

LETTRES DE VOITLRE.

Papiers de simon Lecomte.)

Boyer à Simon Lecomte.

Bordeaux, 5 ferrier $15 \% 9$.

M. I.e Comle, je vous envoy une balle mienue que vous recevrez marquée d'un li et d'un li el une barrique marquée de la narque? au cỏlé et à un bout d'icelle the trois rondeaux ${ }^{3}$, laquelle balle reçus et barrique, le tout bien conduit sans ètre gàté, payerez a Francois la Lane ?, marinier du passage d'Igen dix livres pour son port et le tout une qarderez, esperant vous roir en bref....

Marque de la balle.

Marque de la barrique

Boyer a Lecomite.

Bordeaux, \& jaurier 15is.

II. I. Comte. Il vous plaira receroir de Jehan Bec, marinier de Toulonse deux ballots de toiles, matqués au bout de la marque au

1. La foire des liois, conne plus haut.

2. Iri lit reproduction de la marque commerciale.

3. Ici trois 0 accolis.

4 Cotte barrifue contentit des merluches, de la morue el des harengrs. C"étitit Ia "provision de carine " de S. Lecomte. Aree l'adresse, l'expéditeur met tries souvent le prix du port. " Payez de port 3 s." 
dos de la présente... et un barril de pois et une barrique où il y a dedans un quarteron de... merlus, etc... et le tout étant bien conduit payerez aud. Jehan Vec 20 lir. pour son fret....

\section{Sabatery a simon Lecomte.}

Bordeaux, 10 mai 1584 .

Au nom de Dieu en Bourdeaux ce $10^{\circ}$ mai 158t. M. Le Comte, la présente n'est que pour vous donner avis comme du jour d'hier avons chargé votre coffre en compagnie d'autres apartenant au $\mathrm{s}^{\mathrm{r}}$ de Besqua... dans le bateau de Colerat d'Agen marqué de la marque dehors, comme verrez par ma lettre de voiture, lequel a promis estre dans douze jours en Toulouse et, des la reception d'icelui, vous plera m`en donner un mot d’avis. Je n’ai osé bailler la clé à ce porteur arec la presente de tant qu'il est un marinier et qu'il connoit celui qui a chargé led. coffre, craignant qu'il ne le rencontrat en chemin mais je ne faudrai par le premier homme sur qui partira de la vous envoier....

\section{Guill. Boyer it S. Lecomte.}

Bordeaus, 8 juillet 1584.

II. Le Comte, je rous envoie votre coffre enclos dans le coffre de sapin marqué de la marque ${ }^{1}$ en la pagine de la presente dans lequel il n'y a rien que vos papiers... vous le recevrez de Nadal Froquade, marinier de Tolose... et le tout bien conduit lui payerez pour son port deux ecus et demi et, par ce qu'il aroit crainte que MM. les peagiers Iui demandent le peage dud. coffıe, je lui ai dit qu'il les assurat que dedans... il n'y a rien que papiers....

\section{X}

DOUANE DE LYON.

(Délibération du consulat de Lyon du 11 septembre 1612. Arch. municipales de Lyon. Reg. BB, 148, f. 106 to et suir.)

Du mardy unzieme jour de septembre l'an mil six cent douze apres midys, en l'hostel commun de la ville de Lyon, y estans les prévost des marchans et eschevins... intervenans en l'instance d'entre le fermier de la doanne dud. Lyon pretendant devoit lever

1. GB. 
les quatre pour cent sur les marchandises d'espiceries et drogueries qui les ont payé à Marseille d'une part et Claude Cottenet, marchand de lad. ville justiliant de ses acquiclz....

Dient par devant rous M.M. les commissaires deputís par le lioy pour le faict des doannes au burenu estably en cette ville:

Quils ont assez peu de sulyect d'intervenir en cette cause pour moustrer que la pretention dud. fermier est injuste, puis que desja cy devaut en pareil cas vous liavez condamnée comme telle.

C'est que, comme l'establissement de la doanne... n'a jamais été fait que pour imposer ung droit d'entríe en ce royaulme..., lorsqu'il fust faict, il ne selevoit aucune entrée sur les espiceries et drogueries à lyon ni ailleurs.

Car vous trouverez... que, le xvu juillet $1340, .$. Francois premier enroya en la ville de Lron la forme... que S. M. entendait estre observée pour la levée de ses droits sur l'entrée des marchandises renues d'llalie, Arignon el Comtat de Verisse...

Marchandises qui sont speciliquement declairées estre seulement les draps d'or, d’argent el de snye, toute espècee de crespes, canetilles, passemens, rubans, ceintures, frangrs, pannes, pourfilleures, oruemens, habillemens, fils d'or ou d'argent, soyes crues ou tainctes et toutes aures tissures et especes d'onvages de fil d'or ou d'argent et de soge... venans ditalic, Espaigne, Avignon et comté de Venisse."

Henri II ordonna le payement de droits d'entrée sur les épiceries et drogueries. Edit du 20 ou 26 mars $13 \%+3$.

"Que les lieux destinés pour l'entrée des espireries et drogurries sont, pour le regard de celles qui viendront par la Iéditerranée, ... Marseille, pour la mer Océane... liouen et pour celles qui íendıont par terre... Lyon tant seulement....

Il est donc vray que, sy bien le lloy a voulu lever sur les espiceries et droqueries quatre pour cent à Marseille, a Romen et es autres ports de la Rochelle, Nantes, Callais, depuis amplifiéz par ses ordonances, il u'a pas pourtant entendu que pareil droict fust levé a Lyon ains seulement de contraindre toutes les espiceries et drogueries venans par mer à entrer par lesd. villes et ports maritimes moienant les quatre pour cent et celles venans par terre it entrer en la ville de Lyon pour y payer le droit de doanne qui est deux el demy pour cent, oullre l'octroy de quatre livres pour ball et pareil i? roict de deux et demy sur les autros espiceries et drogueries, venans aud. I.yon, de quelque aultre endroit que ce soit, sans pour ce payer aucun droicl d'entrée aıltre part qưà Lyon. " 
Les échevins citentà l'appui de cette opinion l'edit du 3 octobre 1581 , la nouvelle apréciation du droit d'entrée du 11 sejtembre $13 ̈ 8$ ?.

"Car le droict de la doanne de Lyon et ceulx de l'entrée des drogueries, espiceries et autres marchandises estrangieres arrivans ailleurs qu'a Lyon ont bien cela de differenct qu'ils sont divers en quantité, sçavoir ceulx đle Lyon a raison les ungs de cinq et les aultres de deux et demy pour cent, au lien que ceulx qui se levent ailleurs sont à raison de quatre pour cent mais les ungs et les aultres ont cela de commun... en qualilé que ce sont tous droicts d'entrée...

L'on vous supplie... considérer combien grand a esté l'abbus des fermiers de Marseille, Rouen, la Rochelle, Bourdeaux, Nantes, Calais et aultres lieus où lesd. droicts d'entrée sont levés, qui, se servans du temps des troubles, out contrainct la pluspart des marchans de Lyon de payer les droicts d'entrée en ces lieux lá et celuy mesme de ceste deanne qui, par raison n'en pouvant lever aucune chose à Lyon, a faict des compositions secrettes de moittié ou anltre portion avec aulcungs pour induire les moings entendus à s'y laisser aller.

Car c'est ce qui a détourné ce grand commerce des espiceries et drogueries, des draps d'Angleterre, des marchandises de Flandres et d'Allemaigne, du royaume d'Aragon et aultres marchandises en nombre infini qui s'amenoient à Lyon et lesquelles les estrangiers y venoient achepter, soubz. le béuéfice de la franchise desd. foires, qui est dud. droict d'entrée comme de ceulx de la sortie mais qui ont aultre voye par l'injustice de l'oppression desd. fermiers. 



\section{INDEX ANALYTIQUE}

Abbeville (échevinage d'), 13. Alary, marchand d'Alby, ?2?.

Académie royale de musique, Albergement, 47.

243 .

Acadie, 283, 285, 286.

Achmet sultan . Conclut une capitulation avec llenri IV, 316 .

Acier de Damas, 10?.

Açores (iles). Leur commerce arec la France, 2ii.

Acquits-à-caution, 993.

Actes notariès, 2.

Adelantado, amiral des galères, 268.

Adour l'), riviere, 2i'́.

Aerssens, agent des ProvincesInies. 280.

Afrique. Notre commerce arec la côte occidentale d $-.27 ; ;-$ septentrionale. - Ses relations commerciales avec la France, 276.

Agents de change et de banciue érigés en titre d'office, 230.

Agiotage, 363 .

Agriculture. Son caractère social et-moral, 3-í.

Aigue (Étienne), marchand de $\mathrm{Ba}-$ gnols, 106, n. 1 .

Aigues-Mortes, 265 .

Aisne, rivière. Travaux qui s'y rattachent, 182, 188, 191. Pont, 18i. Obiter laudatus, 189.

Aix. Exécution del'édit d'arril 1597, 95, n. 3. Ob. laud., 12' .

Alais, 108 .

Albert (Guillaume), négociant tlamand, 15 í

Albigeois. Safran, 69 .

Alep, entrepôt des denrées de l'Extrême-Orient, 315. Ob. laud., :28\%.

Alexandrie, 28?.

Alger (vice-roi d"), 301.

Algérie, 275, ?76.

Alignement, $1 \%$.

Alimentation des paysans, 60-6il.

Alleaume, professeur de mathématiques, 102 .

Allemagne. Cuirs, 8.\%. É.hanges avec lia lrance, 26\%. Émigration des Français, 2ii, n. 2: - (Мarchandises $\left.d^{\prime}\right)$, 293. Ob. laut., i:, 294 .

Allemands viennent travailler aux mines, 36.

Allier (1', rivitre. Marchandises qu'il peut transporter, 200. $0 b$. laud., :338.

Almanachs, 6:3-6́t.

Alpes, 262, n. 1.

Amérique. Colonies espagnoles, 282; - du Nord, 283. Ob. laud., 288, 29'.

Amidon (fleur d') Son entrée interdite en Angleterre, $26 \%$.

Amiens. Coches entre celte ville et Paris, 204. Courtiers, 292;- (échevinage $d^{\prime},, 13,23 ;-($ fabricants d'), 


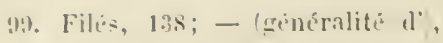
1:1, 1!13. Sayeteurs, 138. Sayetteric. \&:3, ?(it, : :11. Titpisseries, 150.

Amiraute de Normandie, 309. Amirautès, : :!):-2!!s.

Amsterdam, 1:1, 1:\%

Amurath III accorile a l'Angleterre la liberté de commercer lirectement arec la Turquic, 314-:315.

Ancrage droit d . ?9\%

Ancluze, 10 s.

Angers. Exécution de l'édit d'arril $159 \%, 9.2, \mathrm{n}, 3$.

Angilemont Hercule d", 43 .

Anglais. Leurs importations $c u$ France, s:3. Fabriquent du papier en France, 160. Yous enlivent le commerce dimportalion en Espiagrue, 2633. Nous font concurrence dans le commerce avec l'Afrique septentrionale, :ic. Fondent en France des maisons de deput et de commission, ?90-991. Leurs re lations commerciales avec la liussie, 295. Ob. laud., :91. Voy, An gleterre.

Angles (les. Gard, 29.

Angleterre. Draps, 13\%. Négociation pour le rétablissement du commerce entre la f'rance et les Etats de Philippe 111, 261. Nos importations en Angleterre, $264: 65$. Son developpoment commercial et son systime prohibitif, 265-267. Nos relations commerciales avec elle, :69-273. La pêche du hareng interdite aux etrangers sur ses côtes. 27i. Emigration des Francais dans ce pays, $27 i, n .2 ;-$ (marchandises d'), 293. Transportées par la marine des Provinees-l'nies, 29i. Sa marine marchande, 2!) 4 -296. Son coumerce de transit avec l'Esparne, 296. Ses pirateries et ses griefs, 30 í-310. Étalilit des relations counmerciales directes avec la Turquie, 314-31.i, 316;.0\%. laud., 2:2, il. $i 2,118, ?$ ? 19 . Voy. Anglais.

Angoisselle. Italiens ćmigrés en lirance, 33 i.

Angoulême. Sa prospérité, $16:$.

Angoumois. Coumerce lluvial, 167 .

Anil de Barbarie, 3 is.

Animaux nuisibles, ?1.

Anjou. Bail a complant, fit. Son commerce anec la lBretagne. i:339341):-(maison 1'), 10\%. Vins, 6s et 11. 3. Oh. laul., 15.

Anuapolis. Voy. Port-Royal.

Annet-en-Brie. lieprésentation dramatique, 2:5i.

Annonay Ardèche). Mines, 33. oi). laud., 13.

Antibes, :311.

Apprentis, :2:6-228, 380-381.

Aquitaine, 58.

Arbois Jura . lin, 67.

Archipel indien, 28:.

Arcons Marguerite d', femme d'Ol. de Scrres, 37.

Ardennes. Jyilromel, 6s. Écobuage, i3.

Argentan (Irne:, 18, 191.

Argenteuil. lins, 68.

Ariège, rivière. Coneourt au projet de jonction entre l'Aude et la Garonne, 19i. Ob. laud., 33.

Arles, 123, 12:.

Armancon, rivière, :01.

Arnauld (Etienne), maitre priseur de pastel, 376 .

Arnauld, intendant des finances, 368.

Arnauld, trésorier des ponts et chinussées, 181.

Arrêt de prince, $30 \%, 11$.

Arschot. Ras, si; - duchesse d"), $10 \%$.

Artisans. Leur physionomie morale, 2ii-?:s. Conséquence des guerres civiles pour eux, 331.

Artnis, 165.

Assemblée des notables à Rouen, 1 i. 
Assolements. 65.

Assurances maritimes, $297, \mathrm{n} .4$.

Ateliers publics, 35:3.

A ubaine droit d"), 2i1-?:2.

Aubignè (Agrippa d'), 60, n. ?. Aubin (Ambroise), 121.

Aude, rivière. Projet de sa jonction avec la Garonne, 19j-198.

Auge (vallée d'. Bouf, : 2 .

Aunis. Bait á complant, 46. Vins blancs, 6s. (16. lined., 26.

Aurillac (habitants d'), 25 i.

Authentique si qua mulier, 173 .

Auvergne. Bétail, :(0). Denrées agricoles, ?00. Hlabitations rurales, ¿s. Hines, 32, 33. Safran, 69. $O b$. leud., $43,12.1,71,182,338$.

Auxerre, 67 .

Avignon. Pont, 18\%. Soleries, 125, n. 4 .

Avis (donneurs d'), 33:3.

Ay Marne, Vin, 6i.

Aynay-le-Château saccagć, ia, n. 1 .

Bacalaos (fle de. Ancien nom de Terre-Neuve, 2i't.

Bagé (marquisat de. Jumenterie, $i^{2}$.

Bagnols (Gard). Vin, 67 .

Bail colonger, $4 i$; - à complant, $46 ;-$ à convenaut, $4 i$.

Bajettes anglaises, ?69.

Balbani Manfredi), Lucquois, 108.

Baleine. Piche, 294

Baltique (pays de la). Leurs relations commerciales avec l'Angleterre, 265. Ot. Inud., 118, :94.

Banque de France, 234 .

Banqueroute de l'Etat, 170.

Banqueroutes privées, 1;1-1i3, 361 .

Banques publiques, 233-235.

Banquiers, 360 .

Bar (la), rivière. Projet de la ren. dre navigable, 191-192.
Barbaresques. Leurs pirateries, 301-303,316, 3?0.

Barbarie, 276, n. 3.

Barde (M.). 2:28.

Barrois. Toiles, 8t, 139.

Barthélemy sieur de), contrôleur des traites à Arles, 12:3-124.

Bartholus (Thomas), Mlilanais, verrier, 156.

Bas d'estame anglais, 269.

Bas de soie, 125; - de laine, 143 ; - desoie et de tricot a lourdan, 85: - de soie à la fin du régne, 159.

Basché (Chicanous du sire de) 49.

Basques, 274, n. 1. 285.

Bassano. Soies, 109.

Basse Normandie. Ilabitations rurales, 59.

Bassigny. Fertile en céréales, 66.

Bastion de France, 303.

Bayonnais, 28i, n. 1.

Bayonne. Amirauté, 28i. Échevinage et habitants, 281, n. 2. Négociants, 85. Ob laul., 179, 265, 29\%.

Bearn ne vit que de son commerce arec l'Espagne, 262, n. 2. Corroierie, 85. Etats, 26?, n. 2.

Beaucaire (sènéchal de), 206, n. 3 .

Beauce. Bąs de soie et de laine, 159. Fertile en céréales. 66. Pauvreté de lia noblesse, 40 et $n$. 4 . Richesse agricole, 200.

Beauclerc (Nicolas Le), trésorier général de France à Paris, 98, n. $\{$.

Beaujolais. Vines, 32. Nomination d'un prévôt des merciers, 79 , n. 3. Propice à la sériciculture 108. Soie, 130, n. 3. O\%. laned., 1', 158, 338.

Beaulieu, capitaine malouin, 302 .

Beaulieu (Martin Ruze, sieur de). lieutenant général des mines, $3 \mathrm{i}$.

Beaumont-sur-Oise. Pont, 185. 
Beaune. fi., (is.

Beaurieux. lin, on.

Beausemblant en Dauphine, ss.

Beautor (pont do), 19'i

Beauvais. Mraps, si. Messageries, :1):3.

Bellegarde (Roger de Saint-

Lary, duc de, frand maitre surintendant des mines. $3 \mathrm{i}$.

Belon Pierre, 33. ก. 3.

Benoit Charles', conseiller à la chambre iles comptes, ?s. 11. '.

Benoit (Charles' Uaitre passementier et monlinier en soie a lioven, 1 lli.

Berg-op-Zoom, 20.

Bergeron (Laurent), marchand it l'illis, 3i'.

Beringhen, premier valet de rhambre, contrôleur général des mines. 3i. Sa participalion à la propagation de la sériciculture, 131 . Auloriséa etalulir des verreries, 106 .

Bernardin, maitre corroyeur à virac, 86.

Eerry. Bites a laine, 200. Draps. si. Elevage, $\because 1$. Fers, 200. Laines. i3. I'ropice it la sériciculture, 108 Ob. lavd., 18.

Beruyer (Philibert), revendeur lireveté, 332. n. 3.

Bétail, insaisissable, 21 : - de l'Auvergne, 200. Arlicle d'exportation, $\because 601)$.

Bêtes à laine du Berry, 200 .

Betterave. Culture nouvelle, 38.

Betz-en-Touraine, $4 i, n$. 5 .

Beurre, 2i'.

Beyrouth. 25?.

Bèziers (diocèse de), 14 .

Biche. Italiens étalulis en France, 93í.

Bière, 6s.

Billets à ordre. 36.3 .

Biron (maréchal de), 183.

Blanc de plomb, 1:5;-1;8.

Blois. Elats gencratux, 303. Pont.
1SS: - traiti de) entre Clarles IX el lilisaliell. ? $6: ? ;-$ ordommanre (e) $4 \%, 11,4,240$.

Blois élection de). Sériciculture, $11 ?$.

Bloncleau, conseiller an parlement, 193.

Bocage le llabitations rurales, 5 s.

Bodin, 2ú.

Bœuf du limonsin et de la vallíc d'Auge, 72.

Bois, article d'exportation, 260; - Ju Nivernais, $200 ;$ - de leinture, 2ii.

Boissise, ambassadeur de firance en Angleterre, :91, 2!)?, n. 1 .

Bologne. Soieries 125, n. ‘. Soies, 101\%. Oh. lauel., $12 ?$.

Bombazins anclais. 269.

Bon Berger (le', (í, II. :.

Bonnet vert. 17 ?

Bonnières. P'ont, 18.5 .

Bonvisi. 334.

Bordeaux. Convoi, 37..). Courtiers, 29:. Droits d'entree, 390. Entrepoits anglais, 270. Exécution de l'edit darril $1595,95, n$. 3. duridiction consulaire, 213, n. 4. Hessageries entre cette ville et Toulouse, 203. Neqociants, 29\%. Parlement, 229. Pastels. Yins, :6', ob. laud., :

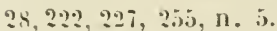

Bordeaux (sieur de), baron de Colonces, surintendant général des jardins de france. Sa part dans la propagation de la sericiculture, $10 \mathrm{~S}, 110$.

Bordelage, $40-i i$.

Boston, 295,

Bougrans, article dexportation, 260, 26:5; - de Troyes, 260. Ob. lauel., 270, 11. 1 .

Bourbonnais. Coutellerie, 200 . Nines, 32. Ob. land., 44.

Bourg-en-Bresse saccagé, $79, \mathbf{n}$. I. Bourgeois (Marie), peintre, sculp)tenl el mécanicien, 10?. 
Bourgeoisie. Son ascension so. ciale, :3:8-3:30.

Bourges. Chapellerie, $15 \%$

Bourges (géneralité de), 23.

Bourgogne. Caual, ?01. frappie de contributions, 1t. Danses, $1 ; ?$. Literage du cheval, 31 . P'ropice it li sériciculture, 108. Sel, 69. Toiles, 139, n.3. Vins, 6i, :o0). Ob. laud. 12.

Bourse de commerce, 25.

Boutiques, 2:31-23:.

Brabant. Tuiles, 139.

Bradiey (Humphrey), 29, :8, :9, 193.

Bradley Jean, waitre des digues, 201.

Bragelonne, conseiller au parlenent, 98, 11. 4 .

Braine. Canal, 15\%.

Braries, 61.

Brenne (la), $: 6$.

Brèsil, 2ii.

Bresse. Droit de traverse, 3i0. Elevage du cheval, $i 2$ Ot. lauel, 1is, 338 .

Brest, 279, 280.

Bretagne. Chants populaircs, 15. Son commerceavec l'Anjou, 3:39-3;0 Danses, 62 . Dowane congeable, $i$. Elevage, 71. Exportalion de son blé et de son vin, 2f. Llabitations rurales, 58. Lin et chanvre, 69. .Morceltement de la propriéte, 40, n. 3. Noblesse commercinle, 2.;?, n. 3. Paurrutéde sa noblesse, i0. Sa pitcification incomplete, Iti. Rebelle á la sériciculture 108. Toiles, 8', 139. Viticulture, 6i. loy, Coutume, Etats.

Breves Jacques de Lancosme, sieur de), 314, n. 3.

Breves (Savary de), anbassateur du roi à Conslantinople, $298,30: 3$, $114,316,3: 1-32: 3,3: 4$.

Briare. Canal, 192.

Brid'oison. 49.
Brie fertile en ceríales, 66. Mines, 33. Venux, i:, Ob.linul., Isf.

Brie (Jean de), 5l, (0:3, 11. ", 6i. Brigandage, 33.5.

Brinon-l'Archevêque soultre de la guerre, i⿱⺈, n. 1.

Brisambourg (Chal'.-Iuf.) laäences et poterics, $15 \%$.

Brissac (duc de', 2.50.

Bristol, :9\%.

Bruges, 123.

Brulis, 73 .

Bueil Anne de), 201, 11. 3.

Buffalo, nonce du Saint-iiege, ?6i.

Bugey. Albergement, 17.

Bunel (Jacob), peintre, $10 \%$.

Busson (Vincent), Milanais; verrier, $15,5-156$.

Buzancy, 191.

Buzanval, ambassadeurauprés des Provinces-Lnies, 310 .

Gaen. Émeute, 87, n. 1;- (écheri. nage de), 3ito. Entrepôts anglais, $270,2 i 1$. Toiles, 139, 1i1-142, Ob. laud., 191, 311.

Caen génèralité de), 23, 181.

Galaignes Jaccues de), 14 ?

Gaillault (Marie), revendeuse bre. vetée, $33 ?, n .3$.

Caisses de secours corporatives, 3:3.

Galabre. Vers à soie, 10 .

Galais. Centre de commercants élrangers, 291-292, 11.1 et du commerce de l'Espanne el des Provinces-Unies, :393. Courliers, 992. Droit d'entrúe sur les épiceries el droguerics, 359, 390. Letlres de marqute accordies i léchevinaśe, 310.

Calendrier des berger's (le, 51 , 63,61 .

Camelots, 168; - anglais, 269 ; de Lille, :T'í.

Campagnes. Leur repeuplement, il. 
Camus Nicolas ils.

Canada. Elablissements francais,

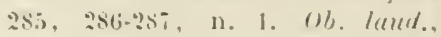
283.

Canal des Ardennes. 1:1?: - de buurgogue, :01; - de Braine, 1 s9: - da Centre ou de Charolais ?or - entre lin Garonue et l'Aude, 196195: - du Languedoc, de Loire et Seine, 181, 18:, 198-200.

Canalisation du Clain, de la Vesle. $181,188-189$.

Canayes Les', Migocianls, 3í.

Candie, 85.

Canne à sucre, lis.

Canteperdrix. lins, $6 i$.

Caorcins, 2íl.

Cap de Bonne-Espérance. "rojet d'y fonder des établissements francais, 28:. 0\%. luul., 31:.

Cap Breton, :iq.

Cap Breton ile de, iri.

Cap Vert (iles du). Notre commerce avec elles, ?:i.

Capel (Ange), sieur du Luat, 233, n. 2.

Capitaux. Leur abondance, 360.

Capitulations entre Francois jer et Soliman, 313.

Carcassonne (environs de). Mines, 33.

Cardaillac Antoine-Philibert de, sieur de Capelle, maréchat de (luercy, :0:3.

Carlier, marchand de toris, $: 23$.

Carrosses, 205.

Cartes. Leur entrée interlite en Angleterue, ? $;$;

Cartier Jean , marehand el bourgeois de laris, 237 , n. 2.238 .

Castelnau. Vin, $6 i$.

Castille, receveur du clerge, 2:i.

Catherine de Médicis. Ses lils abandonnent Fontainebleau, 14 í. Fait commencer le pont de Châtellerault, 138. Ob. laud., 15\%.

Cauchon (Thomas), sieur de
Vezernay, trésorier general de France, 18!.

Caumartin (M. de), 1.13.

Caumont château de, 43 .

Cavaliers. Ce que coútait leur enIretien, $1 \%$.

Cecill Robert', 306, n, \&.

Cenami, 33i.

Cèréales, 1 ij- 66 .

Cerretany Monchatte, :36i.

Cessions de biens, 17 ?

Gévennes. Mirriers, 11,3. Ob. laud., $33,108, ?(i 2, \mathrm{n}, 1$.

Chablage, :0\%.

Chablis, $6 i$.

Chaillot, pres Paris, 153.

Chalautre-la-Grande, détruite, i9, n. 1.

Chalon, ?00.

Châlons, 186 .

Châlons gènèralitè de, 23.

Chambéry. Suicries, $125,11.4$.

Chambre de commerce de Marseille, 31 .

Chambre des comptes d'lix 'président de la;, 12\%.

Chambres syndicales, 3.\%. .

Champagne. Danses, 62. Exportitiun de son blé et de son vin, ?i. loires, 211, 2il. Induslrie drapiere, ?t1. Nopice a la sériciculture, 108 . Toiles, si, 189. Ob. laud., 18.

Champdorè, : :s5.

Champlain. Ce quill fait au Canada, 285-2s6. Compagnie créée par lui, 28\%. Ob. land., ?83.

Champlain lac), 285.

Change. Son cours légal fixé à la fin des foires de Lyon, ?:3:).

Changes et rechanges, 210,250 .

Chanvre. Sa culture, Gy.

Chapellerie i la fin du regne, 159.

Chaperon. coitlure des femmes de comruercants, :-7\%.

Charbons de sinut-Eticune, 200 .

Chardons à foulon, itrticle d'expor. tation, :60). 
Charges. Voy. Ofâces.

Charles VI établit le droit régnlien sur les unines, 31.

Charles VII accorde aux dues de Sarole une taxe maritime, :301.

Charles VIII, $16 \mathrm{i}$.

Charles IX releve les commerieants de 11 dérogeance, :252, 3. 3. Crée le premier service de voitures publiques, 202. 06 . laul., ?1, 3?, 33, $155,171,300$.

Charlès (Marguerite, Ses crimes. 15.

Charles-Emmanuel, duc de Savoie, prélève une laxe sur les vaisseaux passant derant Villefranche, 301.

Charles-Quint, 298, 313.

Charmeaux (sieur de), président à la chambre des comptes, 98, n. 1 . Gharolais, ?00.

Charrier Antoine, négociant Iyonnais, 369 .

Chartres. Ras., 8i. Ob. laud., 13.

Ghartres (le vidame de), $41, \mathrm{n}$. ?.

Chasse (droit de), 19, 20, 50.

Ghasserat (Louis), ?08, n. 2.

Ghastes (commandeur de), forme une Compagnie pour le commerce en Amérique, :833.

Châtaignes, article d'exportation, $260 ;-$ du Dauphiné, 69.

Château sous llenril 1 ; , 5:-5:3.

Château-Gaillard gouverneur du). Ses exactions, 166 .

Château-du-Loir. Création d'offices, $s i, n .1$.

Château-Thierry. 4 千, 11, ?, 3:9, n. 1.

Château-Thierry (èlection de), 180.

Châteaudun. Souffre des guerres civiles, $79, n$. 1. Sa prospérité, 162.

Ghâteauneuf (sieur de), lientenant général du roi en Limousin, 190.

Châteauverds, s.
Ghatelet (le is Paris, 43 ; - Parquel du), 10 2.

Ghâtellerault. Crẻation d'offices, 8i, 11. 1. Pont, 18s. Toiles, s'i, 139. La Vienne narigable depuis celte rille, 190 .

Châtillon-sur-Seine, I:!).

Châtillon (duc de), $298 \mathrm{~s}$.

Chaumières, 58-5\%.

Chaumont-en-Vexin, $21 ;$, 24.

Chauny. Panves, is, n. ?. Pont, 19'. Ob. luud., 19\%.

Chauvet Jean, mascland de Toulouse, 38'.

Chauvin, 283.

Cher, rivière. Rendu navigable, 192 .

Cher (région du. Morcellement de la propriété, 40, n, 3.

Chester, 29\%.

Cheval. Son élerage, i1-i?.

Chevalier Nicolas, conseiller au parlement, $98 . n$. 4 .

Chevaux tirés de l'étıanger, i2.

Chevreux (M $\mathbf{M}^{\mathrm{e}}$ Jacques), intendant des levées et turcies de la Loire, 175.

Cidre, 68 .

Circulation et distribution de la richesse. Leur place dans l'ourrage, :

Cire, $2: 1$.

Clain. Canalisation, 181, 1s8-189. Travaux faits à son occasion, 18\%.

Clairets, vins rouges, $1 \mathrm{i} i$.

Clergè. Conséquences que les guerres civiles ont pour lui, 330. Son ròle dans la propagation de la sériciculture, 116-117, 131. Sa situation a la suite des guerres civiles, 43-4t: - du diocèse de Laon, $i t$.

Cochenille, 2ii.

Coches d'eau, 208-:09.

Colbert. Ses tentatives pour pro. pager la culture dı mûrier, 13:3, n. 3.

Colbert (Edouard), 118, 121, 11. ́. 
Colonies françaises. $19: 5$.

Comaus Jèròme de, ??!).

Comans Marc de, : $: !, 114,11, \overline{\text {, }}$ lisisl.

Comedie française, : 13.

Comedie italienne, ? 13 .

Commerçants. L.mp plysionomie

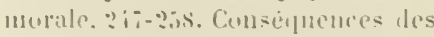
frueres cililes frour eux, :-.11.

Gommerce. sun caractice icomnminpe, llii-llii. Linislatinu rui lni

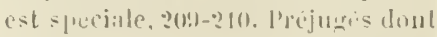

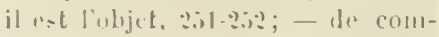

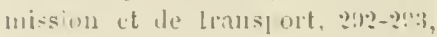
:31:-3:?.? :318-3:?1; - exlerieur: comment les lirangas penvent y premile part, as?-?(1):- martime. proj t de rinlement, ?!g-

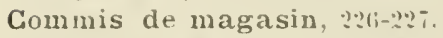

Commission commerce du, ?s:

Commission du commerce. :) 1(k), 1:3i-13s, li:, li3. 1ii, 13i,

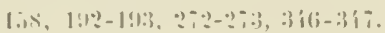

Commission internationale pour lit reprualion des domminges ridusis par la piraterie el l'cioblis. scrment de I liburti du commere

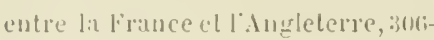
:31s.

Commissionnaires, 230-2:31; en litre al'oflice, ?k!); - ctrangers, $\because ! 9(1-?) !) !$.

Communautés agricoles, is.

Communaux. Leur rachat, ?1. Ob. laurl., il).

Compagnie an_laise du Levant, $31 \mathrm{i}$; - du corail, ?ili; - hollandaise thes Indes orienlales, :is: - des milrchands de l'enu ct des marchands fréruentint la riviere de Loire, : ?11-2014.

Compiègne forêt de, 335 .

Comptabilite en parlie double. $2: 22-2 \div 2$ i.

Comtat Venaissin. Miriers, 10.

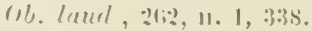

Concini, : $(6 ; \%$.
Concordats, $1: 2$.

Conflans. I'ont, 185.

Confréries. Leur déceloplement, ?is.

Conseil fremanent du commerce, 3.i3.

Conservateurs du commerce, :?: (), :311.

Conservatoire des arts et $m \dot{\epsilon}-$ tiers, 10?-10:3.

Constantinople, 1?1.

Consulats de syrie, 3?1.

Consuls en lispinge, :(i4-?(;).

Convoi de Burdeatux, 3ii.

Coquel Nicolas), apolhicaire a Lyou, 380.

Coquerel Nicolas, griniral des monnaies, :3!.

Corail. Sil priche el son commerce,

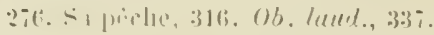

Corbeil. Cucle d'eau entre cetle ville et lialis. ars.

Corbet Boyer sire de, liculenout du pritud royer, li.s.

Corbières monts). lilerage, il. Laines, 73. Ob. laud, 1!1.

Corbillats. : 1 s.

Corbin le, mavire, ?is.

Cordonniers de Paris, $8 i, n .1$.

Cordouan tour de, 182.

Cornas, is.

Corporations. Influence de leur monopole sur les prix, 36i:parisiennes. Leurs virux, :)

Corps de métiers les six ils.

Corroyeurs suisses en Biarn, 8..

Corse, i:.

Cosnier Hugues, hourgeois de l'aris, trite pour lintroduction de lis sériciculture en Poilou, 115. Adjudicalisire du canal entre Seine cl Loire, 1!!).

Coste André', Genevois, $36 i$.

Costume des commercants et urtisans, 2.í.

Cóte d'Or, ?:ii.

Cotons, 31s. 
Cottimo (droit de', $3: 0,3: 1$.

Coucy. Vignoble royal, 68.

Coulommiers élection de), 186.

Courtiers, :30-2:31, $292,33: 2,-$ á Lyon, $3 i 1$.

Courtois (Pierre), orferre, 102.

Coutellerie du Bourbonnais 200 .

Coutume de Bretagne, $\{i, \ldots$. i - de Paris, :210; - de Troyes, 25:, n. 3 .

Coutume d'ètranger, droit de douane, en Angleterre, ?66, ?69.

Graponne (Adam de), 197.

Credit foncier, 40,74 ; - prive, 361: - public, 36\%.

Grêpes de soie, 12:.

Gréseaux (angl. Kerseys), 271; - anglais, :264.

Cristalleries. Voy. Verreries.

Crocq (Nicolas du), entrepreneur de la canalisation du Cher, 192.

Croissant (le), navire, 278.

Cromwell (lord), ?66, n. '́.

Croquants, 8 .

Grus renommés, 6 i.

Gueillette de la soie (la), 106103.

Guirs, :ii: - d'Allemagne, 85;dorés et drapés, 15:3-154; - (industrie des). à Poitiers, 85̆ à Nérac, 86 . Offices s'y rattachaut, s6$8 i$.

Cuissy. Vin, 68 .

Damas. Voy. Acier.

Damas cafards, 123, 134 .

Damiette, 282.

Damville (duc de), 298. Voy. Montmorency.

Danemark. Doit fournir des vaisseaux à la Fiance, 300. Ob. laud., 识, 118, 29 '。

Dangon (Claude), manufacturier en soieries, 128, 136, 373 .

Dangon (Pierre), manufacturiel en soieries, 136, n. 3.
Dansa (Simon), chef d'escadre, $280,300,303,3320$.

Danses, $191-(; \%$.

Dantzig, 294.

Darnetal (Seinc-lnf.). Sériciculture, 11 i.

Dauphiné. Albergement, 1 i. Bail ì complant, 46. Clıâtaigues, 6\%. Mlines, 32. Soie, 130, n. 3. O6. Luul. 10, 17, 25, 158, 337, 339.

Dausserria (Marin), nẻgociant lyonnais, $36 \%$.

Décimes, $43,41, n .2$.

Défrichements, 65 .

Delft (llollande), $15 i$.

Delorme (Philibert), 14i.

Demasso, Napolitain, 154, 1. 1.

Denrées agricoles maintienuent leur valeur, 36i; - de l'Auverme, 200.

Dentelle de I'landre a senlis, 8.5 .

Dérogeance encourue [lar suite du commerce, 25?.

Dessechement des marais, $2(6-2 ! 9$, 75-ici.

Détrousseurs de grands chemins. Leur popularité persistante, 16.

D sux-Siciles, 10 .

Devieux, dit Mercuri, parfuneur du roi, 119.

Diana (la) de Londres, vasscpan, 305-306.

Dictiers de Noël, 62 .

Die (Drôure), 38 .

Dieppe. Constructions miritiues, 294, 11. 4. Courtiers, 29): ; - (echevinage de), :340. Entrepôts anglais, 270. Juridietion consulaire, :13, II. 3. Serges, 8'.

Dieppois, 275.

Digoin, 200.

Dijon, :01.

Dijon (gènéralité de), 23.

Distractions des paysans, 61, 62, (ii3.

Distribution de la richesse. Voy. Circulation. 
Diu, ?Si.

Documents privés, :?

Domaine congéable, $i$.

Dombes les , ?li

Dominoterie. Article d'exportation, :(it).

Dons gratuits, i3.

Dordogne, rivicre, $13,190$.

Douane de Lyon. Marelıandises qui y sont summises, :389, :39)(0, Ob.

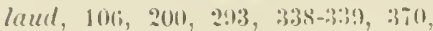
371 , 3ss.

Dounane de Vienne ou de Vialener. $33 i-335,31111.3,370$.

Douanes. Bénéfices dis adjudicataires, 3i1; - droil de), \$3i. Lenr intluence, 2!13:- interieures, 339$3: 0 ;$ - (livrues de), :33i.

Douarnenez. Dinanteli, 29).

Dourdan. lias de laiue, 159, n. 5 Bas de soie et de tricut, 8.5, 1 i3.

Draguignan. Representius dramatiques, 2i)i.

Draperie en France, 13i-138, 139; - de Rouen, 8:3: - de l'aris, si

Draps, article d'exportation, ?(60. Diminution de leur fabrication, s1: - anglais, :70-?:1; - de Paris, de Rouen, de Meaux, du Berry, de Beauvais, 8i; - du scean, 8:3.

Dreux saccagć, $i !$, n. 1.

Drogueries et épiceries. J)roils d'entree, 3!).

Droit de marchè, í.

Droit de marque sur les marchandises, 353.

Droit de mauvais gré loy. Droit de marché.

Droits d'entrée sur les épiceries et drogueries, 390 .

Droits d'usage des paroisses, ?1.

Duboys Jean), nigociant lyon. nais, $36 i$.

Dubourg. loy. Du Bout.

Du Bout (Maurice) directeur de limanufacture royale ile tapisserie, 10), 1:20, 1'i, 1i6, 1ii.
Duels, 13.

Dufau, consul de lirance a seville, ?(i). 11. 1.

Dufour (Jacques', 22s.

Duhamel (Claude), mailre plombier et fontainier, 15i-1;s.

Dumans (Videsire), consciller all conseil, sis.

Durnée (Guillanme), peintre ordinsire du roi, lík.

Dun (Daniel), sok, n. 4 .

Dunkerque. Corsaires, 305.

Duplessis de Come. Ses crimes, 15. Sa soumission, 16 .

Du Plessis Mornay propose la ligne de Suez pour le commerce entre les lndes orientales et l'Europe, 281.

Dupont (Pierre), Inpissier, 102, 152-153.

Du Pont Gravé, officier de la marine royale, ?\$3.

Duprè (Guillaume), sculpteur et contrôleur général des poineons des monmaies de France, 10?.

Du Vair, 356 .

Eau-de-vie, article d'exportation, 260 ,

Échéances prorogries, $169-1 ; 0$.

Écobuage, is.

Économie rurale. Clinp. $1^{\mathrm{er}}$. Plan du chapitre qui lui est cousacré, - . Circonstances historiques dont elle est atlectéc, 3-4.

śconomie sociale. Plan d'apres lequel clie est itudice, 1.

Écorce du mûrier blauc. Son emploi industricl, lí; - du tilleul, lii.

Écosse. La púche du hareng interdite aux étrangers sur ses côles, $: 7 j, 29 \%$.

Écouis Eure), 1?.

Ecritoires, arlicle dexportation, ?(i)

Édit d'avril 1597, 9?-96, 215: - de 
Folembray, 30; - de Rouen, 30.

Edmonds (Thomas), ambassadeur d'Angleterre, $305,306, \mathrm{n}$. 4.

Édouard VI, roi d'Angleterre, 295.

Elbing, 294.

Élevage, i1-i3.

Élisabeth, reine d'Angleterre, 265 , $267,291,291,305,308,310,314$.

Émigrants en Amẻrique, :s6; en Espagne, 26?.

Emphytéose, $4 i$ et 11.5 .

Empire d'Allemagne. Rompt ses relations commerciales avec l'Angleterre, 263.

Empire ottoman, 316.

Engrais, 73.

Enseignes, 23:-2:3?

Entrecours, $; 0$.

Entrepôts francs, 293.

Entreprises coloniales, 2ii-288.

Épernon, 5:.

Épiceries, 318; - et drogueries des Indes orientales, 337. Voy. Drogueries.

Épices. Leur commerce, 281.

Érard, ingénieur, 179.

Escraignes, 61.

Escurial (gouvernement de l" 268.

Espagne. Principal marché de nos céréales, 2i. Son commerce avec les Provinces-Lnies, ?68, 292, 323. Interdiction du commerce avec elle, 2if, n. 1. Met obstacle au commerce de la France avec les Açores, ?ii. Nos exportations en Espagne, 260-264. Le commerce arec elle interdit puis rétabli, 262264, 27', n. 1. Dépend conumercialement de la France, $356,35 i$, n. 1. Émigralion des Français en Espagne, 2ii, n. 2. Sa marine marchande, 294-295. Ses marchandises transportées par la marine des Provinces-Lnies, 294. Cuirs, 153. Commercants francais en Espagne, 268,269 . Soieries, 125, n. 4. Vers i soie, 108, 109, Ob. laud., i?, 12' $198,279,280,296$.

Espagne (roi d'). Tente vainement d'accríditer un ambassadeur it Constantinople, 315. Ob. laud., 139, 193, 267, 269 .

Espagnols 1raitent mal nos commerçants, 26s. Préjudices causés par eux au commerce maritime français, 309 ; - judaïsants fondent en France des maisons de dépôt et de commission, 290-2!)1. (0b. laurl., 2:s.

Espèce ovine, 2 .

Étain, 271; - anclais, 269.

Etamets et ras de Vilan, 81 .

Étamines de Reims, article d'exportation, 260, 2(i1.

Étampes (duché d'), 143, n, 6.

Étang de la Souterraine, 28.

Etats barbaresques. Produits que Ia France en tirait, 2i5-2ik. Leurs relations commerciales avec l'Angleterre, 265. 06 . laud., 85.

États gènéraux de $15 i 6$ et de 1588, 21 ; - de Blois, 5-6, 203.

États du Béarn et de Navarre, 262, n. 2; - de Bourgogne, 6.5, n. 4 ; - de Bretagne, 15; - de Languedoc, 43, n. 3, 186, 298; de Normandie, 8i, n. 1, 18'; - de Provence, 29!).

Eure, riviere. Renduenavigable, 19?. Europe. Son commerce arec l'Extrême-Orient, 281. O\%. laud., 20?.

Exportation des céréales, 66 .

Exportations de la France, 260267.

Exportations et importations, 322.

Extrême-Orient. Sưn commerce avec l'Europe, 281; - ddenrées de $\left.l^{\prime}\right), 315,317$.

Facteurs, 229-230.

Faiences. Etablissement de manufactures, $15 \%$. 
Faitauds. Voy. Fées.

Falaise. Foire de la Guibraye, " $i 3$.

Faubourgs Saint-Honoré et

Saint Jacques, i Paris, 1;i: -

Saint-Marcel, $: 33$, 11. 2.

Fausse monnaie, 13.

Faux. Leur fabrication, Lis.

Faux saunage, :2: 13.

Fécamp. Serges, 84 .

Fées et faitauds. lif.

Femmes. Leurs travaux agricoles, sli; - marices commerçantes, $209-210$.

Fermage, ij-ic.

Féron (Raoul le conseiller de li chambre des comples, 98, n. 1.

Fers du Bery y, :00.

Feugère dirige des cristalleries, 1;)(i.

Feuillantines, :ii.

Feux de la Saint Jean, 62 .

Fèvres rue aux $>$, à paris, 2:3?.

Fil, arlicle d'exportation, 260.

Fileries, (il.

Finale près de Savone, 318.

Fiscalite. $3: ?-3 ;\}$.

Flamands. Nous font concurrence dins le commerce arec l'Afrique septentrionale, 2i6. Fondent en france des maisons de dépôt el de commissiou. 29(1-29). Préjudice causé par eux au commerce maritine francais, 309. Ob. laud., :81, 2!) 1.

Flandre.Draperie, 13\%. Ses échanges avec la France, ?li , 27t. Émigration des Français dans ce pays, 27 , n. 2: - (marchandises de), 2933. Tapisserie, 145, 14i. Toiles, 139. Ub. laud., i?, 2'́l.

Florensac llerault), $6 i$.

Florence. Elotles de soie, d'or et d'artent, 1:26, 1. 4. Serges, 8i. 0b. laud., 81.

Flotte de lis Niditerranée, 300.

Foeneste (baron de', 4\%.

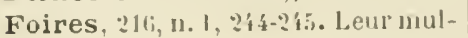

tiplication et curémonial de leur onverture, 2:3-?it; - de Beanraire, 213; - de Brie et de Champagne, 3(:); - de Chimuparne, :11; - de Champagne et de Lyon, ?'1:2i?; - de l'rancfort, 380 ; - de liencie, :39, 11. 2, 3is:- de Guibray, 2:3; - de Lyon, llis. ?11-

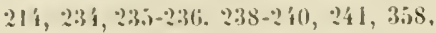
33i3; - Saint-Germain, 2i2; Saint-1)enis ou du Lendit, :13; du Monastier, 2'3, n. 3; - de Poiton, $16 i \bar{i}, 168.11 .1$.

Foix pays de). Mines, 33.

Foix (Louis de), ingénieur, 179, 196.

Fonctionnaires, 3:11-333\%.

Fontainebleau, 12, 108; - Carricres. 18;; - (palais de, Franrois ler y établit la manulacture de haute lice, liti.

Fontaine-Française (Cùle-d'Or'), i?.

Fontarabie, 1:9, 297.

Fontenay-en-Poitou. loires, 168. n. 1.

Funtenay (Julien de), graveur en picres fines, 10 ?

Fontenelle (Eder de), I(i, :296.

Fontenu (sieur de), arocat au parlement, 234.

Foraine de llâcon, 330 .

Forêts. Abus r fui s'y commettent, 30. Henri IV en réforme l'administration, :30-31.

corez. Quincaillerie, :200, :(60.06. luud., 1', 158, 338 .

Fortescue $(\mathbf{J} \circ \mathrm{hn}), 306$, n. '́.

Fortier (Jean), entreprend la manufacture des tapis dorient, 151$15 ?$.

Fougeu (Pierre), sicur d'Escures, $17 i$.

Fouques, capitaine ordinaire de la marine royale du Ponant, 303.

Fourcy (sieur de), intendant des

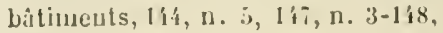
$15 \%$ 
Français dirigent des cristalleries, 155. Plus taxés en Angleterre que les autres ètrangers, $266, \mathrm{n}$. 4. Importateurs de marchandises étrangères, 26\%. Établis a l'utranger, 273-27t. Leur tentalive de s'emparer des Acores, 27i. Leurs entreprises colonisatrices, :i8. Comment ils sont traités par les Espagnols quand ils veulent faire le commerce en $\lambda$ mérique, :\$2. Capturés par les corsaires, 301302. Font la course, 305. Ob. laud., 158.

France. Sa vitalité, sa population, 10-11. Sa soumission à l'autorité royale, 1t-1\%. Insuffisance des mines, 35-30. Pays agricole, 40. Viticulture, 66. Élevage, $71-73$. Chevaux, i: et n. 1. Tannerie, 83. IIenri IV veut en faire un pays industriel, 10:3. lmportation des soieries, 103-10't. Sériciculture, 109. 132. Industrie des soieries, 118. $12 ?, 123,125$, n. 4. Soie, 130, n. :3. Soieries, 136, n. 3. Draperie, 13i138. Toiles, 138-14?. Futaines, 14?143. Les Jesuites y rentrent, 14j146. Tapisseries, 145-153. Maroquins, 15i-155. Verreries, $15 \%$. Fabrique de tuiles et de carreaux, 157. Blanc de plomb, 158. Fabrication des faux, 158-159. Industrie à la fin du règne, 159-161. Les Anglais y fabriquent du papier, 160 . Ligne de navigation entre les deux mers, 196-20\%. Sa destinće économique, :01-20\%. Prévention qui $y$ règne contre le commerce, 252. Ses exportations. ?(i0-26iT; Ses échanges avec la Flandre, ?67, avec l'Allemagne, 26i. Importations, $267,273-27 i$. Fait le transit entre les Provinces-Unies et l'Espagne, 268. Situation des marchands étrangers qui s'y établissent, 272273. Pêche de la morue et du ha- reng, 2it-?i5. Ses relations commerciales avec l'Afrique septentrionale, 275-276. Avec les Arores et les îles du Cap-Vert, 27i. Influence des essais de colonisation sur son commerce extericur, ?is. Hostilité de l'Espagne contre ses essais de colonisalion en Amérique, 282. Vente des marchandises étrangères, ?89-29?. Le commerce entre les Provinces-Lnies et l'Espagne se fait sous son couverl, 2:1-2!9?. Commerce de transit, $292-$ 293. Harine marchande, 293-298, 313. Ses marchandises transportées par la marine des ProvincesUnies, 29:. Marine militaire, 298300. Ses difficultés et son traité avec l'Angleterre. 30'-31?. Son commerce de transport au Levant, 31:3-322, 324. Exportations et importations, 32:. Draps, mercerie, transit, marine marchande, 32332' . Multiplicité des praticiens, 333. tomigration ultramontaine, 334. Sa transformation, 33.. Son régime fiscal, 335. Impôts directs et douanes, 336i-33i. Ses eflorts pour se relever, 35'-35.5. Sa situation économique en $1610,355-35 \%$. Sa sécurité lui donne le sentiment du bonheur, 3sti. Sa situation monétaire, $35-360$. Taux de l'intérèt et hypothèques, 360-361. Ob. laul.,

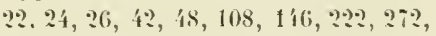
$280,283,294$.

France (nord de Ia). Main ferme, ii.

France (roi de), 26i, ?6?.

Francfort. Foire, 380).

Franche-Comtè, 338.

François I $I^{e r}$. Son édit sur les mines, 32, 33. Noblesse de son temps, 50-s1. Établit à Fontainebleau la tapisserie de haute lice, 14t. Commence le canal de Braine, 189. La marine militaire de son 
temps, s!s. Confirme aux ducs de sarnie une lixe maritime, 3mi, 313. livigle les droits de ha domane de L,yon, :3s!). Ob. laud, , s(1, :13.3.

François II. llines, 33.3 Ob. laud., $3: 333,5 i$.

Franqueville, sculpteur, 10\%.

Fret. Son prix, 3si.

Fripiers. Leur importance, ?li218. Font le courtage, 33:2.

Fromages, ?í.

Fronsac (château de), iis.

Frontignan. Vin, (is'.

Futaines (industrie des), $1:$ ? $1: 3 ;$ - de llontpellier, s?; - d'Angleterie, $1: 2,:(6 \%)$.

Gaban, commercant, :2\%.

Gabelle, :2:-2:3, :331;.

Gaillac Tarn-et-fiaronne). Sa prospérité. 16:2. Vin, lis.

Gailhard Antoine), marchand du Lauraguais, 2iti-2í.

Galères de la llolte du Levant, :301.

Gaudouin Josuè), architecte-intrénicur, 1!).

Gap, $: 2,2$, n. 1 .

Garde (Abraham de la), horloger, 10?.

Garenne (droit de), $50 \mathrm{et}$ n. 2 .

Garonne, riviere. Projet de sa jonction aree l'Aude, $19 \mathrm{i}-1: \mathrm{s}$. Ob. laud., 43.

Garsonnet (François de), dirige des verreries, 156.

Gascogne. Élevage du clicral, 71. Marne, 73. Propice a la sériciculture, 108. Ob. laud., 26, siti.

Gascogne (golfe de, 196 .

Gaudin, chaussetier it Draguignan, 23 .

Gaitiers, 8 .

Gavaches (Gavachos), ?(2). Cf. Gavots.

Gavots, 2(i?, n. 1. Cf. Gavaches.

Gênes. Étotles de soie, d'or et d'nrgent, 1?:, n. i. Ob. laud., 29:8, :301.
Genève. Foires, 338, 339, n. 2. Soic-

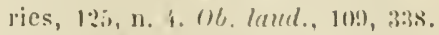

Gens d'affaires, $3: 31-33: ?$; de palitis et de finances, : $: 33: 3-3: 33$.

Gérosmes, 11!, n. :3.

Gévaudan, :13.

Gibraltar (dètroit de), 1!s.

Gien. Sa prospérité, 1 li?.

Glauwer Th., anhassadeurd'Angleterre it Constantinople, 31., n. 1.

Goa, 281.

Gobelins. La manufacture de laute .lice y est transféréc, 1ii, 199, 151, 1 (i).

Gobelin (Francois et Nicolas), marchands et bourgeois de t'ilris, :37, n. ?; - François ' :38.

Godefroy, manufacturicr en soieries, 86 .

Godefroy (Antoine), trisorier de France à Limogres, 2i9.

Gondi (les), 33 '.

Gondi (Henride), évique de Paris, $1: 30, n, ?$.

Gonzague Louis de), due de Nevers, crée à Nevers l'industrie de la cristallerie, 1.i.

Goussen (Conrad), ?s.

Graillet (Nicolas), 2:38.

Graindorge, famille de manufacturiers de Caen, Ift-1i?;-Andre, Richard et Michel, $1 \%$.

Grains, article d'exportation, ?(i0. Leur commerce, 2:3-26, i.j.

Graisses, article d'exportatinn, 20:0.

Grancotte (Nicolas, fabricant te cuir doré, 15:3, 1.it, n. 1.

Grand calendrier et compost des bergers composé par le berger de la Grande Montagne, fi3-rif.

Grand seigneur, ?:6, n. 3, ?:9, 302.

Grands propriètaires. Sonffrent moins des guerres ciriles, 9,74 .

Grand voyer, 17i, 1is, 18?, 18i, $185,15 \%$. 
Granier (Pierre), marchand de Toulouse, 22:3.

Graves. Vin, 68.

Grebau Arnoul et Simon!, 63.

Grenoble. Pont, 187.

Grieux, consciller au parlemenl, 9s, n. 4 .

Guarric (Ramon), marchand de pastel, :2.5.

Guast Pierredu), sieur de Monts, dirige la colonisation en Amérique, $28: 3-285,286,287$.

Guerres civiles. Leurs elfets, \&-8 ; - sur le commerce, 164-168.

Guillery (capitaine). Ses brigrandages et son supplice, 16 .

Guinée, $27 \%$.

Guise Aisne). Son intérêt dans la canalisation de l'oise, 193.

Guise (duc de), :Is.

Guyenne fertile en céréales, (i. Exportation de son blé et de son vin. 2'. Ilabitations rurales, 5\%. Sel, 69. Propice ḋ la sériciculture, 108. Ob. laut., 190.

Guyot Laurent), peintre ordinaire du roi, 146.

Habitations des commercants el artisans, 25.5-256; - rurales, 5659 .

Hacqueville (sieur d'), président au crand conseil, 9s, n. 1.

Haras, 72.

Hardy (Alexandre), poète dramaticue, 258.

Hareng, $2: 1 ;-($ pêche du), 27i?75, 29. 4 , 32'.

Harfleur démantelé, :96.

Harlay (Christophe de), comte de Beaumont, ambassadeur en $\$ 1$ gleterre, 26i, $306, \mathbf{n}$. $\mathbf{i}$.

Haute Normandie, $46, n .1$.

Hendaye, 27 's.

Henri II. Mines, 33. Manufacture de tapisserie créée par lui, $1 \%$. Cristalleries créées par lui à Saint-
Germain, lis. lait planter des ojmes le fong des routes, 164. Acliéve le canal de Braine, 1s\%. La marine militaire de son temps, 298. Etablit des droits d'entrée sur les èpiceries et drogueries, 38\%. 06. laud., $32.135,161$.

Heuri III. Modife l'administration des forits, 30. Noblesse de scn temps, in. Accorle le privilige de certaines nessageries, 203. Astreint certaines marchandises a passer par la donane de Lyon, 29:3. La marine militaire sous son règne, 298. 06 . lauel., 18i, 363, 36i.

Henri IV. lntérêt de son rïne pour l'ètude de l'économie sociale, 1. Ses mesures protectrices en faveur de l'agriculture, $7.8,11-14$, $17-20$. Fait une trêve avec Mayenne, 11. Ses mesures réparatrices, ?1. N’amébiore pas la gabelle, 22. Farorable à la liberté du commerce des grains, 23-26. Eutreprend le desséchement des marais, 2(i-2!). Réforme l'adninistration des forêls, 30-31. Fait faire une enquête sur les mines, 32. Son édit sur les mines, 3:3-34. Lecteur du Théalle d'argriculture, 39. Noblesse de son temps, 51-5́. Favorise l"importation des céréales, Gi. Établit des haras, i:. L'agriculture sous son regne, i4, 75-76. Retablit des olfices, 86 . Sa déclaration sur les lettres de maitrise, $s i-s s$. Son édit d'avilil 1597, 92.96. Installe des artisans d'élite au Louvre et les plotège, 10I-102. A lidẻe du Conservatoire des arts et métiers, 10:2 Veut faire de la France un pays industriel, 103. Développe la sériciculture et l'industrie des soieries, 104-136. Prohibe l'entrẻe des étolfes de soie, d'or et d'argent, 10\%. Ce qu'il fait pourla draperie, 13i-13s. fomlateur des établissements de 
haute lice, de basse lice et de Ia saronnerie, liti-15?. Fonde l'iudustrie des maroquins, lin-1,j. lait revive ln eristallerie, 15i15. L Lindustrie it la fin de son rigne, 159-1cio. Origrinalite de sun wurre en matiore commereiale. 173-1it. Crée un grand royer, 17 i. Comment il organise l'intendance des levies et turcies de la Loire, 1i.. Administration des traraux publics snus son règne, 179-1so. Elat des roies de communication par terre i la fin de son règne. 1s:3-lsi. liend la lesle navigahle. 1 s.?. Veut itablir une ligne de navigation intirieure inintermmpue, 196-202. Comment il rigrle les transports publics par terre, 20:3-20; Erige un tribunal consulaire it Dieppe, :1:3, n. 3. Auguente l. nombre des marchands et artisans suivant la cour, 209. Statue surles lisres de commerce, 226. Vend des lettres de noblesse, :50, n. 2. Anoblit des insenteurs et industriels, ?:?. n. 3. Lxportations de son temps, 2(i)?(ii. Interdit puis rétablit le comulerce ave les Etats de l'bilippe III, :(1;2-?(ii. Exerce sa protection sur des sujets de Philippe 111, ?6i-?(is. Veut creer un port entre Bayonne ct l'ontarabie, $27 i-27$. Essaye de faire maintenir ses sujets dans le droit de peclier le hareng dans les eaux arılaises, 27j. Met un impùt sur les marchandises provenant des Acores, ?7\%. Autorise la fondation d'établissements an Cap, ?\$?. Acenrde à de Ilonts le monopole du conmerce darts la Nourelle-France, 2x:3-2s.3. Ce qu'il fait pour la marine marchande et la marine militaire, :yfi-300. Impose a ChaylesEmmanuel sa renolleiation à une taxe maritime, 301. Ce qu"il vent faire nux iles d'llyires, 301, n. I.
Réprime la piraterie, $30 \%$. Réhabjlite Simon I)ansa, 30:3. Comm issions instiluees par lui au sujet de la piralerie el de la navigation, 306. Sa protestation contre lamel de prin. ce, 3us. Héprime la piraterie, 30!310. Ses plaiutes au grouvernement anglais, $31 ?, \mathrm{n}$. A Capitulation conclue par lui aree sultan Aclmel, 3|fi. Crée, supprime et rétnblit le droit de collimo, 321-3?2. Aurait-il pu faire plus pour le développement du commerce? 32:-3:36. Crie une agence de revendeurs, :3:3:. liégime liscal dont il hérite, $3: 1 \%$. Fiscalité de son gouvernement, :33-3it. Son wurre agricole, 3i 315. Son anve industrielle et commerciale, 345-348. Anohlit Armand Cronumelin, $3 \mathbf{i} 7$. Réprime les pirateries, restaure notre protectorat an Levant, fonde des compranies de commerce. Son portrait, 3is-350. Ce qu'il fait de Laflemas, 33\%?. Situation économique oi il laisse la France, 350́-336. Ses mesures monétaires, 3.58-3(60). Essaye d"établir la publicité des hypoiliéques, 361. Crie une commission contre l'usure, 3633. Manufacture de soieries i Paris, $372.0 b$. Luud., 11, I', 31, 3(i, Gí, 6is, lifi, Si, s!), 13(i, 11. 5, 1.8, 159, 16i1, 16i, 1is, 185, 188, 189, 190, 191, ก, ?, 19!',

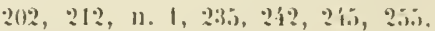
$2(88,278,281,290,35 \%$

Hèrault, ( $;$ i .

Herbert (John), 306, n. 4.

Hollandais. Essol qu'ils donuent à la pische du haventr, 275. Nous font roneurrence dans le commerre avec lifripue septentrimale, :ir. Leurs progres dans les archipels de la sonde et des. Woluques, ?is. Nos rivanx henreux pour la pielie du lareng, 3?'. Ob. lund., ?\$5, ?:), $29 \%$, n. 1,315, n. 8. 
H.llande. T'oiles, 8', 139. Scs importations en France, 273-274. Sa marine marchande, 29i, 2!)( Son commerce de transit avec l'Espagne, ?964. Ob. laud., 2961; - (province de), ?79.

Honfleur. Constructions maritimes, จ9:3, n. í.

Hôpital de la Trinité, lís.

Houblon, culture nouvelle, 38 .

Howard (lord), grand amiral d'Angleterre, 305.

Huiles, article d'exportation, 260.

Hull, 295.

Hurault de Maisse, ambassadeur en Angleterre, 266.

Hurepoix. Bas de soic et de laine, 159.

Hydromel, 68.

Hyères ( $($ arr). Plantations de canne à sucre, 69.

Hyères (îles d'). Plantations de canne à sucre, li9. Nid de pirates, 301.

Hypothèques. 361. Leur multiplicité et leur clandestinité, 40 ; - des récoltes, 20.

Ile-de-France. Elevage, 71. Laines, 73. - Propice à la sériciculture, 108.

Importations en France, 967-27\%: - par mer, 33i; - et exportation:, $32:$.

Impôts indirects, Abus de leur perception, 341-342.

Incarville, 34?.

Inde. Draperie française, 81 .

Indes (les), 38 .

Indes occidentales, débouchẻ pour la France, 356. Ob. laud., 261, $27 \%$

Indes orientales, 278, 280, 281, n. 2. 282,337 .

Indigo, 127,378 .

Industrie. Elfets produits sur elle par les guerres civiles, iิ-80; -
Irapière en Champagne, 2i1; textile. Sa renaissance, 8i-8.).

Industries nouvelles, 8.5 .

Instruments aratoires insaisissables, 21.

Intérêt. Son taur, 360-361; - légal, $111 ;-$ des rentes réduit et remis, 170 .

Irlandais, 267,315, n. 8 .

Irlande. La pêche du hareng inlerdite sur ses còtes, 275; - (còtes d'), :?94.

Iroquois (rivière des), aflluent du Saint-Laurent, 285.

Isère. Navigation, 167 .

Italie. Laines françaises, 81. Soieries, 122. Draps, 13i. Nos échanges avec elle, 267. Transit des marchandises pour ce pays, 293. Ses marchandises transportées par la marine des Provinces-Lnies, :9't. Route maritime de Marseille cn-, 301. Ob. lnud., 38, i2, 90, 104, 105, $121,125,125$, n. 4 , 22:2, ?41, 338 .

Italiens dirigent des cristalleries, 155. Émigrent en France, 3:31. $O 6$. laud., 1:32.

Jachère (rẻgime de la', 65 .

Jacques I ${ }^{\mathrm{e}}$, roi d'Angleterre, mediateur entre la France et l'Espagne, 264. Majore certains droits d'entrée et de sortie, 266. Interdit la pêche du hareng aux étrangers, 275. Ob. laud. 294, 310, 311. Jardin des Plantes. Son origine, $121, \mathrm{n} .4$.

Jeannin (présillent). Son origine, 251. Ob. laud., 98, n. 4, 280.

Jesse (André de), marchand de Toulouse, 246-2 $\%$.

Jeux d'adresse et de force, $(; 1,6 ?$.

Joigny. Soutfre des guerres civiles, 79, ก. 1. Ob. laud., 67, 201.

Joseph, patriarche. Soll histoire mise à la scène, $25 \%$.

Joyeuse, 67. 
Joyeuse (cardinal de), 196-19i, Jumigny. lin, (is.

Juridictions consulaires, ?।

?li, 2!i, 1t, i: - seigneuriales. Leur multiplicite el leur's abus, i:)sit.

Kerhanland. Ses crimes, 15.

Kerseys. Voy. Crézeaux.

La Bazinière. Snn fils derient trésolier de l'Éprarne, 251.

La Bistade, ??s.

La Boderie (Lefèvre de), ambassadeur de France en Anglcterie, 31 I.

La Bornerie (M. de), 236 .

La Casse, capilaine hugucnot, 8 .

Lacombe (Jean), 2:2.

La Fère (Aisne). Tort que les guerres civiles font il son commerce, 1(i,). Ob. laud., 1!)?.

La Ferté-Milon saccagé, i9, n. 1.

La Fertè-sous-Jouarre. Pont, $186-18 i$.

Laffemas (Barth.). Hoslilc il linlportation des chevaux, i?. Demande la suppression de certains offices, $8 i, n$. 1. Sa vie et son plan de réforme de l'industrie, ss-9)1. Mémoire (qu'il présente au roi, 9(i-9). Ses vrrux. Ninmmé contrôleur général du commerce, 100. Son évaluation de limportation des soie. ries, 103-106. Sa part dans la propagation de la séricicnlture, $10 \%$, $109,111,113,115$, dans le développement de lindustric des soieries, 122, 123. Parlisan de la sériciculture, 13:?, 13t. Favorable à l'aguravation de la pémalité contre les banquerouliers, 1:2. Adrersaire des juridiclions consulaires, 214 , et des foires, "2.5. Sa proposition an sujet flu commerce maritime, 2!) Ob. Irual., i(1, 11. 1, 8' i, 8s, 9\%, 12:;, $15 \%, 35 \%-353,37 \%$.

La Fite, chitcan, 8.
La Fite, capitaine lıuruenot, $\mathbf{i}$

La Flèche sacengie, i!), n. 1.

La Goulette. Bitiurents lunisiens y soul brìlés, 30 ?.

La Haye, 151 .

Laines, article d'exportition, 2(i0). leur juprorlation en Angletere, ?oif. - anglaises, 26:!. Ob. laud., i3.

La Magnane. Ses crimes, 1.).

Lamarque (Vincent de), archer des gardes du corps, ?os.

Lambert (Antoine), marchand de Rouen, 139, 1 i1.

La Motte Serrant. Ses crimes, 1:.

Landria, commercant,

Langoiran. Ses crimes, 1,.

Languedoc. Exportation de son blei et de son vin, 2i. Mines, 3?. Locataireric perpétuelle, ii. llabitations rurales, 5!). lertile en ciréales, fi6. Scl, (io. laines, s1. Muriers, 105. Soie, 130, 11. 3. 1111pusition, 186; - (canal du), 1)(; ; (étils du), 186; 29s. Na pas ile ports, 29k. Forine, 3i0. Ob. land. 25, si. $1018,15 \mathrm{~s}, 183,237,338$. (Bas, 29.

Lannion (Coles-du-Nord), 15.

Lantarais (Le), 295.

Laon, í.

Laonnais. Vins, 68. Ses échanges, $19 \%$.

La Planche (Francois de), tapissier llamand, 1í, 11. 5, lis-1:1.

Laran, commercants en soicries de Toulouse, 225. Grand livre de leur maison, $3 i 3$.

Larchant, prìs Nemours, 29.

Largentier, capitalisle, 1 i9.

Largentière, ris.

La Roche (marquis de), 283.

La Rochelle. Vin, (ii. Maroquins, 8is, 15i. Sa prospérité, lli2. Conrticrs, 29:. Droit d'entréc sur les épiccries et drogueries, 38:1, 3:00. - (Commercants dc), 283, 281. 
Lauraguais. Pastel, 69, 261.

Laurent Girard), lirecteur de la manufacture royale de lapis, 1 ii, 166,147 .

Laval. Toiles, 8i, 13:). Uffices se rattacliant í l"industrie des cuir's, $8 i, n .1 ;-$ (marchands de forment une compagnie pour le commerce des ludes Orientales, 27s.

La Varenne (sieur de), contróleur général des postes et r'elais, $206, \mathrm{n} .3$.

Lavedan. Élevage du cheval, i2.

La Villette. Une trève y est conclue, 14 .

Le Bret (Cardin), avocat génerat à la cour des aides, 98, n. 1, 4.

Le Clerc (Nicolas), tanneur it Meulan, 2.)1.

Lecomte (Simon), négociant, 2?1$22 ?, 225,228,229$, n. 1, 236, 237 , ก. ?, 238, 374, 375, 376, 377, 378, $379,380,381,382,383,38 \mathrm{t}, 385$, $38 i, 388$.

Légal (Simon), Nîmois, 116.

Le Havre. Pêche de la morue, 2is. Constructions maritimes, 293, n. 4. Pícheurs, 297; - (écherinage du), 340.

Lejeay, lieutenant civil, 36 ?

Le Mans. Création d'offices, $8:, n .1$.

Lembros, 68 .

Lenclu (? Thomas et Antoine, sieurs de Moissac, 276, n. 3.

Le Primatice, $14 i$.

Lerambert (Henri), peintre ordinaire du roi, liff.

Lesdiguières, 25, 52 .

Lesche-en-Brie, 29.

Lesseville (M. de), maitre des comptes, 251.

Le Tellier (Jean), bourgeois de Paris, traite pour lintroduction de la sériciculture en Poitou, 115.

Lettre de change, 235-2i0, 36:3, 3 is, 3i9, 381, 385, 386, 38\%.

Lettre de marque, 311 .
Lettre de voiture, $375,376,387$.

Levant. Ses relations commereiales avec l'Angleterre, 2(6;. Draperic francnise, 81 : - (denrées du), :315, 318. Ob. lant., 1?2.

Leviston, 18.

Leyde. Serres, 10i, 27i.

Lhopital (sieur de) autorisé it fouder des ćtablissements au Cap, 28:.

Lignon (le), rivière, sis.

Ligue (la), 11, 15: - de Iontélimart, 10; - des villains, 10 .

Lille. Camelots, 2ií.

Limoges. Sa prospérite, 162.

Limousin. Beufs, i2. Ses exportations, 190. Propice à ta sériciculture, 108. Ob. laud., 183.

Limoux (Aude), s.

Lin. Sa culture, 69.

Liugettes, flanelles, 1 il.

Litterature des paysans, (i3.

Liutgens (Peter), llollandais, ?80.

Livre de crédit, 385,386 .

Livres de commerce, 219-226.

Lobriac (sieur de), 190.

Locatairerie perpétuelle, 17.

Loches (mesure de), $i \bar{i}, \mathrm{n}$.. .

Lods et ventes, 45 .

Loeille (Jean de), négociant lyonnais, $36 \%$.

Loing (le', 19!).

Loire (la). Péages, 166. Canal de jonction arec la Seine, 181, 198, 199. Ponts, 181. Travaux qui s'y rattachent, 182. Crues, 187. Sa navigabilité, 195. Sa jonction avec la Saône, 198, 200. Marchandises qu'elle peut transporter, 200. $0 b$. laud., 196, 338; - (région de la), 190.

Lombardie, 108.

Lombards, ? 1 .

Lommelino (Francesco), Génois, 300.

Londres, 26i, 311.

Longueville (duc de), ?8. 
Lorain (Pierre le), :04, n. 3.

Lorraine. Sel, 69. Papeterie, 160, n. 3 .

Loudun. Yin, fis.

Loueries, 5i.

Louis XI confirme aux dues de Savole une taxe maritime, 301. Ob. luud., 12:, n. '.

Lonis XIII, 1.it, I.t6, 281.

Louis XIV, 38, 3. 4, 348, 34!), n. 1.

Louis XVI, $38,11.4$.

Lourdet (Simon), tapissier, 1.3.

Louviers. Toiles fines, 8 ', $13 \%$.

Louvre. Ilenri IV y installe des ouvriers d'élite, 101-10\%. Projel d'y elablir un Conservatoire des arts et métiers, 10\%. Tapisserie, liti, 1ii, 1i!), 15\%. Ob. laud., i?, $1: 0$.

Louvres (Seine-et-(Oise), 1'i.

Luçon. Sa prospérité, $16 \%$ ?

Lucques. Etolles de soie, d'or et d'argent, : :?i, n. i.

Luxe. Son dereloppement, 103.

Luxembourg. Transit des échanges entre la Flandre et l'Allemagne, l'Espanne et l'Italje, :9:3.

Lynn, 295 .

Lyon. Lne trive y est conclue, l't. lndustrie des soieries, $83,86,105$, $121 ;, 127,128,130,133-136,160,16 i 2$. Création d'uffices, $8 \%, n$. 1. L'édit d'avil 1597 n'y est pas applique, !). Cristalleries, 156. Chapellerie, 15\%. Chemin neuf, 183. Foires, ?11$212,23(1,234,238,211,358,3(; 3)$ Cours légal des clianges, 2:39. Ses mivilégres et sa population, ?il:4?. Messareries entre cetle ville et P'aris, :0:3. Douane, :01, :!!:3, 38\%. Entrepôt et débouché des marchandises du Levant, 320. Profite de la prospérité de Marseille, 32\%. Colonie italienne, 334. Entre des éfliceries ct drogueries des Indes, :337. Lestauration de son rommerce, 36i-3ii3. Prospérite et decadence de ses foires. Le cours du change $y$ est fixi, 369. Courtiers, 292, 3i1. Mécadence de lindustrie ct de laville, 3i1. Industrie de la soierie, 372. Lieu d'inportation pour les épiceries et drorneries, 38:); - (échevinage de), 2.5, 181, 11. 3. Ob. laud., 10, 1:?, 1(ifi, :90). :29s, :236, 3338.

Lyon (génèralitè de). Súriciculture, 109, 113, 11'.

Lyonnais. Mines, 32. Charrois, 167 . Muriers, 10\%, 373. l'ropice à lit sériciculture, 108. Soie, 130, n. 3. Courtiers, ?9?. Ob. luud., 11, tis, 338.

Lyonnais, partisans de la liberlé des importations, 105, n. 4.

Lys (Charles du), substitut du procurenr génirial au parlement, ?8, n. 1, 4, 110.

Macau, commercant is 'oulouse, $\because 28$.

Machecoul forét de), 16 .

Mâcon. Foraine, 370.

Mâconnais propice il la séricicullure, $10 \mathrm{~s}$.

Madrid (château de). Établissement séricicole, 109. Ob. laud., $10 \bar{i} ;$ - (Parc de), 10s.

Mail (le). Rendez-vous des commercants, 255 .

Maillefert (Jean), commercant rémois, 220, 221, ??4.

Main ferme, 47 .

Maine. Bail à complant, if.

Maire (Isaac le) de Tournay, sso.

Maïs, culture nouvelle, 38 .

Maisse (M. de), commissaire pour le traité de 16;6) avec l'Angleterre, ?) I, n. 1.

Maitres de forges. Leur professiun n'entraine pas derogeance, $25,11.3$.

Maitres des œuvres de maconnerie et de chitrpenterie, 179. 
Maitrise de l'Ile-de-Franee, 30 ; de Normandie, 30.

Maîtrises (creation de), 87.

Malay Vicomte soulfre de la guerre, i?, u. 1.

Malherbe, 58.

Malouins, 28i, n. 1.

Malte (ordre de). Sa participation á la propagation de la séricieulture, 131 .

Malvasio (Vincenzio), marehand en gros de produits levantins, 318 .

Manche (1a), 196, :20?.

Mandat (Galliot), conseiller et secrétaire des finances du roi, 98, n. 1.

Manicamp (sieur de), gouverneur de La Fìre, 192.

Mantes. Soieries, 1:2.

Mantes (gouverneur de). Ses exactions, 166.

Maçue hôtel de la', rue de la Tixeranderie, 119, 1:0).

Marais de Gaseogne, de l'Aunis, du Poitou, de la Dolnbes, de la Brenne, de Chaumont-en-Vexin, de Bordeaux, de Saey, 26, :8; de Lesehe-en-Brie, de TonnayCharente, du Bas Languedoe, de Larehant, Varnier, 29.

Marans (Char.-Inf.). Sa prospérité, $16 \%$.

Marchandes á la toilette, 2li .

Marchandises expédiées pour le continent. Leur itinéraire pour échapper à la douane de Vienne, 338.

Marchands font la banque, 360 ; de vin, 353 .

Marchands et artisans suivant la cour, 218-?19.

Marchès usuraires, 23:3.

Maréchal (Jean), verrier, 15(i-1:5i.

Maressé, archer de la warde, 130.

Marie (Christophe), 186.

Marie de Médicis, 356,362 .

Marie Tudor, 29'.
Marine marcliande, 29:-298, 323-324; - militaire, 298-300; normande, $319, \mathrm{n} .1$.

Maringues, 3:38.

Marne employé comule engrais, i3. Marne(la), riviere. Ponts, 18..

Maroc, 27 .

Maroc (roi de), 30 t.

Maroquins. Leur industrie est entreprise en grand, 15i-155; - à la fin du règne, 160 ; - de llandre, de La Rochelle, 8.5.

Marsay (sieur de), isi, n. 3.

Marseillan (IÍr'ault), (ii.

Marseillais. Pertes que la piraterie leur fait subir, 302. Enrôlent un lieutenant du eapitaine Beaulieu, 302,30 . Prise d'un vaisseau anglais, 305 .

Marseille. Sa prospérité, 162. Marehandises exotiques, 200 . Noblesse commercante, 252, n. 3 ; - (consulat de), 2if; - (viguiers, consuls et habitants de), 2i6, 1. 3 . Courtiers, 29:; - (habitants der 309. Lieu d'importation pour les épiceries et drogueries, 389 ; (négociants de), 297. Droits d'entrée, 390. Son commerce et sa prospérité, 31\%, 32:2, 32ł. Ob. laul., 41, n. 3, 121, 12', 299, 300, 301.

Martial d'Auvergne, 63.

Martigues, 265.

Martins(Pierre des', peintre, 102. Mascara (Algérie). Péclıe du corail, 2i6. Voy. Mascarets.

Mascarets en Barbarie. Voy. Mascara.

Matheolus (le livre de), (i3).

Mathon, lait eaillé, (io.

Maurice de Nassau, 27!.

Mayaffre (Isaac), Languedocien, a des magnaneries à Rouen, 11 (;) Mayenne (Charles de Lorraine, duc de) fait une trêve avec Henri $1 \mathrm{~V}, 1$ '. Meaux. Industrie drapiere, s1, st. Meaux (bailliage de), 50, n. 3 . 
Meaux (élection de), 1 si.

Méditerranèe. Ligne dc navigation entre elle et l'Océan, 196-20:?

Méditerranée (hassin de la). Projet de le relier aux ludes par Sue7, ?8:?

Mellet Geordi), marinier, :3iti.

Melun. Coche d'eau entre celte ville et Paris, ?08. Cristallerie, 1,ti. Industric drapicre, sl.

Mèlusine, il.

Mende (Lozire), rillie, i9, 11. I.

Mercerie expurtée, ?til.

Merciers favorables aux importo tions, 9:. Leur importance, 2lis216. Prennent des commissions de vente des etrangers, 990. Font le courtage, 3:32; - rois des), 21:3214. (1). laud., 2:??

Mercœur duc de), 11.

Merle, capitaine luguenot, 79, n. 1.

Méry-sur-Seine, 195.

Mesnil-au-Vast, i.;.

Messageries municipales, 203: - i Toulouse, Ibiel.; - le l'Lniversilé, 20\%, n. 1: - de P'aris, Orléans, Troves, Rouen el Beaurais, 20:3.

Métayage, is.

Métier à la tire, 1 ?

Metz, 186.

Meudon. Vins, 68 .

Meulan (gouverneur de). Ses exactions, lici.

Meules de moulin, arlicle d'exportalion, 200.

Meung-sur-Loire. llaras, i2.

Meuse (1a), 191, 196. Sa junction arec la Saône, 1!ns.

Michel Pierre, seigneur de SousCarriere, mirnjuis de Montbrun, $2511, n, 3$.

Michieli Giovanni). Sa relation, 10.

Miel, article d'exportation, 260.

Milan. Etolles de soie, d'or et d'argent, 12.1, 1. 1; - (marchands de), 293, n. 2. kins, 84.

Milanais, 21:1, ?98.
Mines. Personnel administratif, :3i. Ob. laut., 31, 36.

Mineurs commercants, 20:-? 10.

Mirande, helvidere, 53.

Mireval (Itérault). Vin, Gs.

Miroiterie, l(il.

Mobiliev du paysan, :9-(i).

Mocades anglaises, 26?.

Modéne. Suieries, 125, n. '́.

Moisset Jean de), contrôleur de lartillerie, des menus et atfaires Ie la chambre, I1s, 119).

Molière. ss.

Moluques, 2is, 281.

Mômeries لle l'lssomption, (i2.

Monastier (le) dans la sénéchausscie du Puy. lioires, 213, n. 3.

Monnaies,35i-3(60). Voy. Poinçons.

Monopole des engins et munitions de guerre, 19.

Monsègur Girondel. La garnison arrite les bateanx, :18:3.

Montargis. Canal, 199.

Montconnis (Claude de), 29.

Montélimar, $6{ }^{\circ}$.

Montgailhard, ?io, ?ii.

Montmartre, 68 .

Montmorency (Henri Icr, duc de) fait une trêve arec le duc de Nemours, 11. Ob. laukl., 1\%, 18, 19. $1 i i, 281$.

Montmorency (le), vaisseau, ?:81.

Montolieu (Honoré de), consul de Marseille, créateur de la chambre de commerce de celte ville. 317 .

Montpellier. Ses industries, $\$ 6$.

Montpensier (Henri de Bourbon, duc de), 18.

Montréal (.lude). Vin, bis. $O b$. linul., s.

Moret, 199.

Morue. Sa piche et son commerce, $274-275,291,321$.

Morvan. Llabitations rurales, is.

Mouche, Italiens éuigrésen lirance, :3i3i. 
Moulins (édit de), 21 ; - (trénéralité de, $23 ;$ - (ordonnance de), 211 .

Moussengirard (communc de l'arr. de Beaucairc, Gard). Vin, (bi.

Mùrier. Sa propagation, 3i. P'ilys de culture. Plantés aux Tuiteries, $105 ;$ - en Lyounais, $3 \% 2$.

Muscats et blanciuettes, (is.

Mussoni, procurcur a Driguignan, $25 \%$.

Nantes. Droit d'entrẻe sur les épiceries ct drogueries, 389, 3!)0. $0 b$. laud., 168, 200, $26 \%$.

Naples. Solerics, 12', 11. 4. 06 . laud., 105; - (royaume de), 2!)8.

Narbonne (négociants de), :29;; (ville et diocèse do), 14. Ob. laud.. 265.

Naturalisation (lettres de), 290. Nautæ Ligerici, Parisienses, 207.

Navarre. États, 262, 11. 2.

Navigation au tier's ct au fret, 319 , n. 1 .

Nemours, 29.

Nemours (duc de) fait une trêrc arec Hontmorency, 1\}.

Nérac (Lot-et-Garonne). Viu, GS. 06. laud., 86 .

Neufville (Marie de). Voy. Paillard (Jacques) d'Urfè.

Nevers. Cristalleries, $155,156,15 \%$. Faïences et poteries, 15i. Ob.laud., 166.

Neville (Henri), ambassadeur d'Angleterre en Francc, 33, 34, 30.5.

Newcastle, 295.

Nîmes. Serges, 84. Futaines, 1 'i 2 n. $3 ;-$ (sénéchal et juges présidiaux de), 206.

Niort. Sa prospérité, 16?. l'oires, 1 is, n. 1.

Nivernais. Bail ḋ complant, 46. Bordelage, 46. Propice da la séricicuiture, 108. Bois, 200. Ob. laur., it, ii, n. 1 .
Noblesse peu aisée, 40,52. Fait des allaires, 11 . Son genre de vie, il43. Sous linancois ler, $50-51$; sous Itenri $11,51-5 i$. Sa participalion à la propagation de la sériciculture, $131 ;-$ commercante, 252 ; - jnlluence que les guerres civiles ont sur elle, 3:28-3330.

Noix de galle, 318 .

Nord departeucuts du), 36 .

Nord (mel du), 196, 200, 202.

Normandie. Exportation de son blé et de son vin, 2i. Le fermage y remplace le mitilyage, 15 - $\mathbf{t} 6$. t'crtile en ceréales, ti6. Viticulture, 67. Lin et chanre, 69, 11. 1. Élerage, il. Laines, i3. Lnsécurité, 79. Toiles, 81, 139. Súriciculture, 108, 116. Verreries, 156. Interruption du commerce, 16i. 'Travaux publics, 182. Hichesse agricole, 2(00. Noblesse commercante, 252, 11. 3. Droit de tomnagre sur les vaisseaux y abordant, 271. Amirauté, 305. Parlement, 340. Cour desaides, Ibid. lmpôts, 3i3; - (états de), 8i, n. 1, 184. Ob. laud., 66.

Norvège, 294 .

Notables (assemblèe des), 88.

INotre-Dame de Paris chapitre (le), 29.

Nottingham (comte de), 306, n. 4 .

Nouvelle-Écosse, 27'́ loy. Acadie.

Nouvelle-France. Colonisation, 283-287, 325.

Noyers (château de) en Bourgogne, 16.

Noyon souffre de la guerre, i9, n. 1 ; - (gouverneur de). Ses exactions, 166.

Numéraire transporté au Levant, $31 i-318,321$.

Océan. Ligne de navigation avec la Méditerranéc, 196-202. Comment 
on pourvoit it la defense de ses cites, 300.

Ocean pacifique, 202.

Offices. Leur valeur, $36 \%-363$. Se rattacliant a l'industrie des cuirs, siti.

Oise (1') rendue navigable, 191-194.

Opera-comique. Son vilgine, :2:3.

Or file, faron de .Milan, 11!.

Orange (Vincluse), 36; - principaute (1)\% Miriers, 105.

Organisation industrielle. Ses abus, s(1-s:2.

Orient, 12f.

Orlèanais. Vins, ti. Propice i la siriciculture, 10 s.

Orléans. Vins blancs, (is. Crẻation d'offices, 87,11 . 1. Fabricition de tuiles et carreaux, 1.)i. Chapellerie, 15\%. Ponts, 18\%. Messigeries, 2013. Corhes entre cette ville et Paris, :06. Ob. laud., 200, 338; (généralites d"), 23. Sériciculture, 10!), 11:3, 11:; - ordonnance d', $171,2: 33$.

Orne. Projet de canalisation, 191.

Ortie. Son emploi industriel, 1í.

Ourcq (') rendue navigable, 19:2.

Ouvriers agricoles, $35-36$. Mineurs, 33.

Ozembray (sieur d'), président des répuétes du parlement, is. n. 1.

Paccioli (Lucas), moine franciscain italien, 22\%?.

Pacifique (contrées du). Création d'une Courpannic pour en faire le commerce, 279-281.

Packhurst, voyageur anglais, $2 i\}, 11.1$.

Pages Jean', marchand d'Aniens ?.:1), n. 1.

Palus de Bordeaux, 22 $2,28$.

Pancarte, impôt, 3î, :31.

Panisseau (Périmrd), $i$.

Papier. Sa fabrication à la lin du reigne, 160, Article dexportatiou, ?:(0), :(6).

Farent (Etienne, manufacturier eu soleries, 1:?-1:?3, 1:35.

Parent (Noël, manufacturier en soieries, 118, 1:?, 135.

Pargnan. Vin, fis.

Paris, teinturerie. Vaisselle d'arzent, S3. l)raps, dripiers, sí. Soleries, s6, 125, n. i, 13:3-13i. Cordontiers, si, n. 1.Plumassiers, 95, 11. 2. Sericiculture, 108, 109, 11'. Soleries, 118-1:1, 12:, n. i, 133, 13i. Le Temple, 11s. IIotel de la Maque, 119. Place Royale, 1:1. Parc et palais des Tournelles, 1:1, n. i. Manufacluriers de soie, 12. légociants en soieries, 127. 11. :. llitel de Rel\%, 131. Futaines, li?. Tapisseries, l45. Hôpital de la Trinilé, 115. Maison professe des Jesuites, lí. Erglise Saint-Merry, 1 15 . Louvre, lik, lii. Gohelins, 1ii, Parlement, 150, 201, 212. Yinmufacture de la Savonnerie, 1:1153. Chilillot, 153. Faubours Saint-lloworé et saint-Jariues, 1:i. Cristallerie. 15ti. Fülences et poteries, 15\%. Tuiles et carreaux, 15i. Chapellerie, 159. Sa prospérite, 16:. Banqueroutes, 171. Voirie, 1is. Son aspect, 17s; - (ports de), 18:. Boues et paré, 18:. Liue Saint-Antoine, 185. Pavé, 185. l'ont Marie. 186. Pont-Neuf, 18i188. Pont Marchand, 188. Lniversite, 20:2, n. 1. Messageries, :203. Coches, 201, 208-209; (coutume 1e), 210. Juridiction consulaire, 21:. Lourre, 21:9. Foire Saintliermain, 2'0. Palais Royal, ?'?. Foire Saint-Laurent, 213. liue aux Fivres. Petit-Pont. Enclos du Palais. Ilalles. Cinetière Saint-Jean. Girand et Petit Chatclet. Galerie du Palais, 232. Projet de binque, 2:3'; - bureau de la ville de), 2333,234 . 
Faubourg Saint-Marcel, 237, n. 2. Bourse. Pont-Neuf. Mail, 2is. Courtiers, 292. Association de voleurs, 355. Port at froin, 355. Ot. laud., 10, 14, 22, 4?, 43, 5i, 136, n. 3, 140; - (environs de), vins, 61. Industrie drapicre, 81 ; - (gẻnéralité de), 23. Sériciculture, 109, 113, 114, 19:3; - (prévôt de), :04. Ob. laud., 6í, 11. 2, 81, 12:, $137,166,167,186,187, ? 18,237$, $257,2 \% 2$.

Parisiens plantent des mûriers, 109.

Parjon (sieur), 181, 11, 3.

Parlement, 101, 10:? - d'Aix (premier président du parlement), 124; - de Bordeaux, 229; - de Nolmandie, 340; - de Paris, 34, 150. $204 ;$ - de Rouen, 18, 116;- de Toulouse, 25, 50, n. 3.

Paroisses autorisées à racheter les communaux et droits d'usage, 21.

Parry (Thomas), 306, 11. 4.

Partis dans les fermes publiques, 250.

Pasages (port de), en Guipuzcoa. 27.

Passe-debout, :993.

Pastel, article dexportation, 260 . Société pour en faire le commerce, 24ti-24i. Son inportation en Angleterre, 26:; - du Lauraguais, 69, 26't. Ob. laud., 12i, 37',37i. $376,377,379,381,382,383$.

Patente de Languedoc, 370 .

Paulette (la), 36\%.

Paupérisme, i8-79, 355.

Pavie, 50.

Pays-Bas, 118, 14?, 148, 149, 150, 15 f, 261, 280.

Pays d'état. Travaux de voirie. $17 i$.

Pays Messin. fertile en céréales, 66.

Paysans. Leur paniqueà l'approche des troupes, 5. Leur's associations secrètes, 9-10. Leur persévérance it se remettre au travail, 10,11 . Leur situation obérée, 20 . Influence des guerres eiviles sur eux, s'y-ji, 330-331. Leurs chaumières, 58-59: - du Poitou rebelles á la propagation de la sériciculture, 115.

Péages, $16 \%-107,17 \%, 178,18\{$.

Pecquais, 26.5 .

Pelletier(Hugues), ingénieur, 119.

Pellot (Claude, négociant lyonnais, 367.

Penmarch ruiné, 296.

Pensions multipliées par Ilenri II, 42.

Perche. Élevage du cheval, il. Habitations rurales, 59. Norcellement de la propriété, $40, n .3$.

Périgord, $i, 190$.

Périgueux. Sa prospérité, 16 ?

Perruche. Italiens émigrés en France, 331.

Perse (ambassadeur de), 279.

Petit (Jean), fourbisseur, 10 ?.

Petit-Pont (le) á Paris, :2:? .

Petite-Flandre, 29.

Petits cultivateurs, 45.

Pézenas, 186.

Philippe III, roi d'Espagne, frappe d'un droit prohibitif le commerce avee la lrance, 262. Interdit l'entrée de son royaume aux Boclielais, 268. Ob. laud., 261.

Picardent (cépage de), 6i.

Picardie. llines, 33. Fertile en céréales, 66 . Viticulture, 67 . Bière, $1: 8$. Lin et ehanvre, to. Elevage, il. Rebelle à la sérieiculture, $11 \%$. Soieries, 134. Toiles, 139, n. 3;(grande route de), 17i. Ob. laud., 47.

Pièmont, 38 .

Pierre (Míchel), manufacturier, 143.

Pierre, dirige des eristatleries, lib.

Pierres de Naurouse (les), 19\%. 
Pincé (Pierre de), conseiller de la chambre des comptes, 98, 11. 4.

Pinçon (Paul), manufacturier, 14:1 i:3.

Pingré (Guillaume), marchand parisien, $1: 1$.

Piraterie, $301-310,31: 2,316,320$, 3'?'.

Place Royale it Paris, 1?l.

Placements mobiliers recherchés, 40.

Plaisirs des commerçants el arlisans, 256.

Planchéage, 207.

Plancius, cosmographe d'Amsterdam, 280.

Plessis-lez-Tours (parc de), 131.

Plestin (Cütes-du-Nord), 1\%.

Plomb, 2il.

Plomberie, lis.

Plumassiers-panachers de $\mathrm{P}: \mathrm{i}-$ ris, 9j, n. 2.

Poculot (Cl a ade), négocianl lyonnais, 309 .

Poinçons des monnaies, 102.

Poiré, 68 .

Poitiers. Cuirs, 85; - (échevinage de). Son opposition á l'édit d'arril, 1597,95, n. 3. Ob. Laud., 86, 11. 6, І89; - (généralité de!. Sériciculture, $11 \mathrm{f}$

Poitou. Mlines, 32. Bail it complaul, 46. Danses, (i?. Élevage du cheval, i1. Propice à la sériciculture, 108. Sériciculture, 11\%. Verrerie, $15 \%$. Foires, 167. O\%.laud., 15, :6, 189, $222 ;$ - (sénéchal de), 95, n. 3 .

Polders, 29.

Pologne, 59, 2!) 4.

Poméranie, 29).

Pomerols (Iléritult), $s$ i.

Pomologie normande, (is, 11.

Pontavert (Aisme), 191, n. 2.

Ponte (Horace), Italien, exploite des cristalleries, 156.

Pont-Neuf, 25\%.

Ponts, 165-166, 185-188; - de
Rouen, 181; - du Rhône, 181; de la Loile, 181; - de lioven, 18:; - de Mantes el de SaintCloud, 18:; - de lseatutor, de Chauny, 1:); - (miaitres des), $168,20 \%$.

Ponts et chaussées. Leur arluinistration, lit-179. Travaux qui s'y raltachent, 1s(1.18\%. O\%. laud., 347-348.

Ponts-de-Gé, 19\%.

Pool, :is.

Popham (John), 306, 1. ' .

Population. Sa diminution, 331 ; - rurale a denx maîtres, 48-50.

Port d'armes, 19.

Port au Foin à Paris, 35\%.

Portail (Rocher), partisan, 251.

Porte-balles, 1 lis.

Portes cochères, 2.i.

Port-Royal (Amérique), ?s', 2s:.

Ports. Leur rareté, 296-297.

Portugais établis a Mantes, 267 ; judaisants, fondent en firuce des maisons de dépôt el de coumnission, 2:00-291. Ob. laud., 278, 279, 282.

Portugal. Nos exportitions pour ce pays, 2ino-2(i;. Ses marchandises transportées par la marine des Provinces-Lnies, 29\%. Ob. laud., 279 , ก. :

Postes aux chevaux, 201-207.

Poterie, article dexportation, 260.

Poussemotte (Cliarles), secritaire du roi, !s, n. 1, 4.

Pradel (le), domaine du Vivarais, 3i.

Prairies, 69- $i 1$.

Prés (Robert des), arocat au parlement, 98, n. I, 4 .

Prescription commerciale, 210 211.

Preét à la grosse aventure, $31 \%$, $382-38: 3$.

Preuves en malière commerciale, 211. 
Prévost (Nicolas', conseiller de la chambre des comptes, $98, n$. I.

Prévôt de l'Ile-de-France, 251 .

Primes aux amateurs, 29).

Prix. Leur hausse, 397-398. Lenl baisse, 36:3-36í.

Production. Sa place dans l'ouvrage, ?.

Produits barbaresques, 333 .

Pronostication des laboureurs (la), 6í, 1. 1 .

Propriété. Son régime, $1 i$; - foncière morcelée, 40, 7i. Angmente de valeur, 46 ; - rurale maintient sa valeur, $36 \%$.

Provençaux. Pertes rque la piraterie leur fait éprouver, 30 2.

Provence. Mines, 3\%. .lorcellement de la propriété, $40, n$. :3. Llabitations rurales, 59. Danses, 62. lnstruction des paysans, 62. Fertile en céréales, 6i6. Canne it sucre, 68 . Sel, 69. On n'y fume pas les terres, 73. Laines, 81. Industrie drapière, 81. Muriers, 104, 105. Sériciculture et soieries, 123-124. Soie, 130, n. 3. Ob. laud., 108, 158, 26:, n. 1, 33i.

Provinces-Unies. Leur commerce avec l'Espagne, 268. Leur opposition à l'expédition d'une tlotte française dans les Indes orientales, 280-281. Comuerce interlope entre elles et l'Espagne, 292. Leur marne marchande, 29:-295. $O b$. laud., $139,275,279,280,281,284$.

Provins. Souffre de la guerre, 79 , n. 1.

Pruneaux, article d'exportation, 260.

Puget (Loys), négociant lyonnais. 367.

Pugier, marchand de Toulouse, 22:.

Puy (sénéchaussèe du), 2f:3, n. 3.

Pyrard (François) de Laval, 2is$2 i 9$.

Pyrénées. Nines, 33.
Quartiers adoptes par certains commerces, ?:3?.

Quatre fils Aymon (les), 51 .

Quayage (droit de), 2(66, 269.

Quèbec, ?8:5.

Quercy, fertile en céréales, 66.

Questel, marchand de Toulouse, 2:23.

Quevaize, 17 .

Quillebœuf. Commerce, 16i.

Quincaillerie lu f'orez, 200, 260.

Rabasteins. Vin, 68 .

Rabeyrin (Vidal, négociantlyonnais, $: 367$.

Racan, 356 .

Race bovine, :2.

Raleigh (sir Walter), 29 '.

Rambouillet (hotel de), 356 ; (sieur de), 98, n. 1, i.

Rancher (sieur de), président des enquêtes du parlement, ,98, n. 1.

Bannou (les). Leurs crimes, 15.

Ras de Milan, de Chartres, d'Arscliot, 8'.

Raulin (Etienne), fabricant d'instruments de mathématiques, 10 ?

Rebours (sieur de), président à la cour des aides, 9s, n. 1, 4 .

Région rhénane. Bail colonger, 47.

Reggio. Soieries, 195, n. 4.

Reims. Soieries, 128. Etamines, 260. Ob. laud., 189.

Relais. Leur organisation, $204-207$. Ob. laut., 21.

Reneau (Pierre), de Salon, ingénieur, 197 .

Rennes (sénéchal de, 49, n. "2.

Rentes. Kéduction des intérêts, 21; - de l'hòtel de ville, 13.Ob. laud., $331,36 ?$.

Restauration (gouvernement de la), 242.

Rietz (comte de), 233, 23'; - (duc de), général des galères, 299; -(hòtel de), à Paris, 11', 131 .

Rhône (le). Navigation, 167. Pont, 


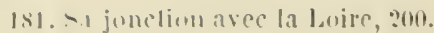

Rlıône vallèe du: 3:3:.

Richard Vincent, núrocian! lyonnais, 36 ; .

Rieux sieur de. Snu discours aux itits de 1.i!:3, li,

Riz. sil provenunce et sa cherte, (is).

Roanne Loire, 200

Robbio (Hannibal), Miguciaul lyonnais, 36i.

Roberval sire de, $3:$.

Robin Jean, horticulleur, 1:1. 11. $i$.

Robin Thomas, manufacturice. 1i1.

Rochefort (Fiard, ?).

Rochelais. lientric des litats de Philippe III leur est interlite, 2us.

Roi Catholique. lis. Espagne roi d\%, Philippe III.

Rois des merciers, s(1)-\$1, 93, 4, Mi.

Roman de la Rose le, il, (i:3.

Rosny Seine-et-Oise), 11:.

Rouen. llraperie, sis, si. Seriges, sí limeule, si, n. 1. Issemblée des notabies, 8s, !1. Sériciculture. 116 . . Jaison du Jiruf couronné 11 (i. Tuiles, 13!-1'?. Faubourg Saint. sever, 1'0. Futaines, 1\%2. Ver rerie, 1.j6. Mas de soie, lit. Sa jerns perili, 16i2. P'ont,181, 188. Porls, 1.:. Messageries, :20:3. Corhes entre cette ville et l'aris, $20 \mathrm{f}$. Juridiction consulaire, :12. Entrepouts anglais. Ziil, 2il. Importations étrangères. 273, n. 3. Courtiers, 292. Entrie des épiceries et drogueries des ludes, 3:37. Lien a'importalion purr les épiceries et drotrueries. 389. Jroils dentree, 390 ; - (ielse vinage de), 360; - nejgrociants de $28: 3,2 ! 17 ;-$ - parlement de, 116 , 6). leurl., 17, 18, 16it, 309, 311; (rencralite de), $23,181$.

Rouillé Catherine), :?

Rousseau (Blaise, ? 218, n. :
Roussel (Nicolas', orfive parfument, 10?

Rovidius Alexandre, sinatrur de Milin, :lif.

Roy (Gérard de), fonde une Cont. pagnie pour le commerce dans lez conlrées du Picilinue, 27!-2si.

Rozan (Scipion de), fillicint de cuir dori, 1:3-1;i.

Rozier l'abbé), anteur dı Truile d"ugricullure, 3s, n. 4.

Rungis fontaines de), 182 .

Russie. Relations commerriates avec l'.Ingletere, ?tio. Allaires des Provinces-Unies aver elle, $29.5 .0 / \%$. laud., 291 .

Ryant Saze (Giul), 29.

Sabatier George), marchand de Bordenx, 3sí.

Sables-d'Olonne les), :(i;

Sac des villes, is.

Sacaze (Barthélemy), marchind de Toulouse, 3:\%.

Sacy Marais de, 28.

Safran, article d'exportation, 260): - d'Auvergne, 61; - d'Albigeois, (ii).

Sagnier (Antoine), :2!!), n. 1, 235, n. 3.

Sainctot, manufacturier en soieries, $118,119,120,121$.

Saint-Aignan, 1!)1.

Saint-Amand (Cher), 192.

Saint - Chamond-en-Lyonnais. llûriers, Illi.

Saint-Denis.Industriedrapicre, 81.

Saint-Denis (abbaye de), $1 i i$.

Saint-Étienne (Loire). Charbous, 200 .

Saint-Florent, $1: 12$.

Saint-Francois de Sales, 3iri.

Saint-Georges (le), navire, 310 .

Saint-Germain d'Apchon, il, n. :.

Saint-Germain-en-Laye. Cris talleries, 1.5.). 
Saint-Jean-de-Losne, :01.

Saint-Jean-de-Luz, 2(6i), 2it ; (commercants del, 28 '.

Saint-Julien (Claude Grippon de), 32 .

Saint-Laurent, fleuve, 28:, $28 \%$.

Saint-Léger dans te comté de Montfort-l'Aminury). Ilaras, 22.

Saint-Malo, 2ít, 280);- (amilauté de), 28i, n. 1; - (marchands de forment une Compagnie pour le commerce des Indes orientales, $278,285$.

Saint-Martin (chapitre de) de Tours, 47, n. 5.

Saint-Martin-en-Lyonnais, 33.

Saint-Merry (église), à Paris, 14.5.

Saint-Michel (château), 197.

Saint-Michel-en-Grève, entre Lannion et Plestin, 15.

Saint-Offange (les frères), 15, 16.

Saint-Pierre-des-Lages, 2\%.

Saint-Pons (diocèse de), 14 .

Saint-Quentin. Toiles fines, "2i.

Saint - Romain - en - Lyonnais. Mùriers, 105.

Sainte-Colombe, siège des bureaux de la douane de Vienne, $3: 38$.

Sainte-Lucie en Sicile. Soies, 10!).

Saintonge. Bait à complant, 4 it. Sel, (i9. Propice à la sériciculture, 10s. Son sel et ses vins, 3 io. 06 . luud., 15i, 16i, n. ?.

Salignac (baron de), ambassadeur i Constautinople, 30:.

Santerre (le). Droit de marché, ii. Sanzay (Anne de). Ses crimes, 15. Saóne (la). Quai et port, 188. Sa jonction avec la Loire et lia Meuse, 198, 200. Projet de jonction avec l'Yonne, 200-201. Ob. land, 196, 201.

Sarazin (Jean), 223.

Sardaigne, i2.

Sardini, 33i.

Sarlièves lac de, en Auvergne, 25.
Sarrasin (blé noir), en Normandie, en Bretagne, lif;.

Sarrode (Vincent), Italien, exploite des cristalleries, likt.

Satins de Bruges, 122, 13\%:- de Montpellier, s6.

Saumur. Exécution de l'edit d'avril 1597, 95 11. 3; - (juge de), 25.

Savoie, 1??, 338.

Savoie (ducs de) obtiemnent la concession d'une taxe maritiue, 301.

Savonnerie (manufacture de la), 151, 15:3, 160 .

Savons, 2if.

Savorny (Barthélemy, 17 .

Sayeteurs d'Amiens, 138.

Sayetterie d'Amiens, article d'exportation, 260, 261, en décadence, 83.

Scavadge (droit de), $266,269$.

Seine la). Péages, 166. Commerce fluvial, 16i. Canal de jonction avec la Loire, 181, 198. Travaux qui s'y rattachent, 182. Pouts, 185. Sa navigabilité, 195 . Police de la navigation, 207-208. Ob. lauel. 29, 196, 209 - (basse) 200 ; - hassin de la), 201.

Sejournè (Jean), sculpteur fontainier, $10 \%$.

Sel, 69. Article d'exportation, 260. Son importation en Angleterre, ?(í.

Sellier (Jean), manufacturier en soie, 123.

Sénatus-consulte Velléien, 1:3.

Sènégambie, : 27 .

Senlis. Dentelle, 85. Industrie drapière, si.

Sens. Coche d'eau entre cetle ville ct Paris, 208-209. Ob. laud, it. 11. 2. 67 .

Sens archevêque de), 11 .

Serbaude (sieur de), '11, n. :.

Serges anglaises $269 ;-$ de Leyde, 2i3-2i4; - de filorence, 81 ; - de filorence, de sommières, sí; - 
de Nimes, si, - de limestre, si, $201-? 65$.

Sericiculture. IIenrill'entreprend de la propager, 106-13:3; - i la fin du rigne, 160.

Serres (Olivier de). Son origine, sa vic, son livre, $3 i-39$, il. Son inlluence, $i 6, \quad 351-352$. Trouve l'enploi industriel de l'écorce du murier, 143-14i. Ob. laud. 42, 45,

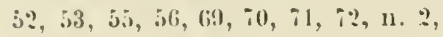
3. 73, n. 1, ii, 10i, $129,1: 9,356$.

Servage, $4 i$.

Setarbe (Laurent), ćbénisle, 10\%.

Seurre, $6 i$.

Séville. Consul de France, 269, n. 1 .

Sillery: 189.

Sociètés. Défaut de publicité, 36!$36 \%$ - Commerciales, $245-21 i$.

Soie. Sa préparalion, 12., en lirance, 130, n. $3 ;-$ en Touraine, 131 ; italienne, 109; - le ris, ardassine et buratine, 318.

Soieries il Lyon en désorganisation, 83 , it Tours en décadence, $8: 3$, it Lyon, à Tours, à l'aris, 86 , a Lyon et it Tours, 130, n. 3, i Troyes et à Mantes, à Lyon ef it T'ours, 13:3-1:36, a Paris, 133-13i, a 11 ontpellier, 13i, en Picardie, 13i, a Troyes, 13i, a la lin du rigne 159-160, i Lyon, 331 , a Tours, 12, n. 2, it Reims, 128. Leurimportation, 103-104tllenrill veut developper leur fabrication, 10.3, 117-129, 133-136. Nétier à la tire et faconnés, 128. Fabriques anciennes et nouvelles, 13:3-1:36. siluation de cette industrie à la fin du règne, 1:33-136. Leur production dans le monde, 133, n. 5. Article d'exportation, 260.

Soissons. Crication d'nffices, $8 \mathbf{i}, \mathbf{n} .1$. Pont, 187, Ob. laud, 191, n :2.

Soissons (généralité de), 2:3, 19:3.

Soissonnais, fertile en céréales, 66.

Soliman. Capitulatious sirnées entre lui et frameois Jor, 313.
Sologne. Elevage, il. Lames, i3.

Sommières. Scrues, si.

Sonde (archipel de la), ?is.

Souterraine (la), ?8.

Southampton, $29 \%$.

Souverain Pontife, .98.

Splandian, 18.

Stora Courcouri (golfe de), 31 (i.

Strabon, 188.

Strada Ottavio de), 28.

Suede, 59, 29\%.

Suez. Jdéc d'y faire passer le commerce entre les Indes et l'Europe, $25 \%$.

Suippe (1a), rivire, 167, n. 3.

Sully (Loiret). 11.'.

Sully (Max. de Bethunc, duc de . Iiodifications qu'il apporte a la gabelle, 23. Partisan du libre commerre des grains, 2:-20. Anteur de l'edit sur les mines, 33, 3i. liait le commerce des chevaux, 72, 1.3. son inlluence str l'igriculture, i 6 . Sa part dans la propagation de la sériciculture, $110,115,131$. Veut utiliser l'emplacement du palais des Touruelles, 121, n. 4. Ses objections contre la sériciculture, 13:? Fait réduire l'intérêt légal, 17. Fait agraraver la pénalité des banqueroutes, 1il. Créé grand voyer, 1ii. Réunit a sa charge celle de voyer de Paris, 176. Son auve en ce qui touche les ponts, 18;-186. Instigaleur du projet dunion des deux ners, 198-199. Contraire i la dérogeance encourue par suite du commerce, 25:, n. 3. Sa vigilance pour' rendre eflective l'interdiction du commerce avec l'Espagrne, 263. Négnocie le rétablissement de ce commerce, 26it. Contraire anx entreprises coloniales, $287-288$. Envoye en ambassade aupris de Jacques Ier, 310, 311. Ce quitil fait pour la gabelle, 336. Partisan de la liberté commerciale, :336. Calume 
l'agitation populaire en Saintunge, 340. Importance qu'il donne dans son systeme aux iupôts indirects. 341 . Sa valeur et son aurre, $350-$ 351. Ses mesures monetaires, 3.18. 360. Essaye d'obtenir la publicité des hypothèques, 361 , 1.1. Fait reviser et classer les rentes publiques, 362. $0 b$. laud., :36, 42, 10?, 105 , 1?2, 1:23, 151, 175, 178, 180, 181, n. 3. 183, 184, 188, 191, 201, $202,34 ?, 343$.

Surintendant des eaux et forêts, 30 .

Surveyor (droit de), $?(66,269$.

Tabac, ?:.

Tadoussac. Traite des fourrures, 281 .

Table de mer de llarseille, $11, \mathrm{n}$. औ. Tables de marbre, 31 .

Taffetas de Montpellier, 86 .

Taille. Réforme dans son assietle et sa perception et remise de l'arrjèré, 21. Ses réductions successives, 2?, Ob. laud., 3336.

Talan (château de) en Bourgogne, 16.

Tannerie en France perd sa renommée, 83 ; - à la fin du règne, 160.

Tapisserie de haute lice, 1 1 1 -1 í6; - de basse lice, 1 $1 ;-151 ;$ - de la Savonnerie, 151-15:3;-de Flandre, 14i-151. lmportation, 1:1, n. :3;à la fin du règne, 160 .

Target (Valentin, bourgeois de Paris, 236, 2.3\%.

Targier Nicolas, $376,37 \%$.

Tapissiers. Acception étendue de ce mot, 115, n. :

Taschereau. Obtient un privilège ponr la sériciculture, 131.

Taschereau (Luc), manufacturier, 143.

Teinturerie à Paris fait benucoup moins d'affaires, 83.
Temple i Paris, 118.

Terlon, eapitoul de Toulouse, 4:, n. 3.

Terre-Neuve. Pẻche de la morue, 2it.

Textoris, notaire de Dragruignan, ?5\%.

Théâtre d'agriculture, ourrage d'Olivier de Serres, $37-39$, 11, n.., $42, \mathrm{n} .1$.

Thèâtre d'amateurs, 256-25\%.

Thiérache (la), 165.

Thierry (Amable, négociant lyonnais, 36i.

Thiers. Sa prospérité, 162.

Thumery (Jean de), sire de Boissise, 30);, n. 4, 308.

Tixeranderie (rue de la) à Paris, 119.

Toiles, article dexportation, :260, :(i1. Frappées d'un droit de sortie, 3:1); - de llollande, 8', 139, 111, n. $3, .5 ;-$ de Normandie, de Bre. tagne, de Barrois. de Champague, á Rouen, à Troyes, i Laval, à Chatellerault, it Louviers, à SaintQuentin, 84. En l'rance, 138-1'?, 159 ; - de Normandie et de Bretagne, :(il. Importées en Angleterre, 26... Ob. laul., ?:it.

Toisons de woutons, 318.

Tonnage (droit de) sur les vaissenux abordant en Normandie, : :il. ob. lauel., ?:?

Tonnay-Gharente, ??.

Tonnerre, 67 .

Toscane, $: 98$.

Toulouse. Exécution de l'édit d'avrit $1597,95, \mathrm{n}$. 3. Pont, 186. Messageries, :0:3. Juridiction consulaire, :1:. Logis des Ballances, ?29. 11. 1. Courtiers, 29\%. Soieries, 3i3. Ob. lautl, : ?5, 4:3, n. 3, :?:?.

Touraine. Marcellement de la propriété, $40, n$. 3. l'ertile en céríales, 66. Mûriers, 105. Soie, 130, n. 3. Sériciculture, 1:31. Futaines, 1:3. 
o6. Luud., ii, n. i; - bailli de, I $\because \mathrm{i}, \mathrm{n}, \mathrm{i}$.

Tournelles parc et palais des). $1: 1,11 . i$.

Tournon, lii.

Tours. Soieries, $8: 3, \mathbf{s}(\mathbf{3}, 11 \%, 125$. 11. $\mathrm{i}, 30,12,3,131,133-133,133$, 11. , llan. Futaines, $1:-113$. Tapisseries, 1 'i. Courtiers, :!!)?.

Tours (gènéralité de). Serricicullure, 109, 11:3, 11í. Ob. lauil., $\because 3$.

Traite d'Anjou, :3:39-3:10; - de Charente, 3 in.

Traite foraine, $3 \%$.

Traitè entre la France et linglelerre, 291, n. 1, 311-31:?.

Transports publics pir terre, ?(1)?-?11;; - par eau, :201.

Traucat François), propagateur de la sirriciculture, 10\%, 11. 1.

Travaux publics, :3is.

Traverse de Bresse, $3 i 10$.

Tremblay (Barthelemy du, l ífi.

Trépas de Loire, :33!!-3; 0 .

Trésoriers de France en Languedoc, :(i.

Tripoli. 27.5; - de Syrie, 28:.

Troyes. Emeute, si, n. 1. Exéculion de l'edit d'arril $15 \% 7,95$, n. 3. Soieries, 1?:3, 13:3-1:35. Toiles, 13:9. 1'1. Putaines, li2. Papeterie, 160 , 11. 3. .lessageries, :n:3. Juridiction consulaire, :13, n. i. Coutume, 25, n, 3. Bougrans, ?(;0). Ob. laud., í, n. : lií, n. :2, 195.

Tuileries, 108; - orangerie des), 111\%.

Tunis, 2ii.

Tunis bey de), 301 .

'Turato Jean-André, tireur d'or, 11!), 1:20.

Turcies et levées de la Loire, 17. .

Turquie. Les marchandises Iransporties par la marine des Provincrs-luies, s!)'. Relations rom- merciales entre elle et lingleterre, :31 1-31s. 06. laud., i?.

Union $\left(\mathbf{l}^{*}\right)$. Crimes commis par ses adlicrents, 1.).

Université tle P'aris, : $0:$ ? n. 1.

Urfé (Honoré d'), 3ivi.

Urfé (Jacques Paillard d"). i:.

Ursulines, :5\%.

Vair (président du, 1:1.

Vaisselle d'argent à Paris, \$3.

Valence (douane de). Voy. Vienne (douane de).

Valenciennes (Yord), 1il.

Valentinois. Llerage, $i 1$. Laines, i3.

Valeur. Son étalon, :36i.,

Valois les), il, 16?.

Van der Veken Jean crée une pépinicre de mûriers, 116.

Vannes. Vins, tis.

Varicq (les frères) de Delft, fabricants de tuiles et de carreaux, 1 isi.

Varies (de), capitaine huguenct, $s$.

Varinier (Pierre), coutelier et forgeron d'èpées, |11:.

Veaux de la Brie, $; 9$.

Velay. llabitatious rurales, 58.

Velours à la grice, 12, 11 . i; de Montpellier, si.

Vendôme soullre des guerres civiles, i!), n. 1.

Venise. Suieries, $1: 5, n$. i. Verreries, 15.5, 15ti, 1(i)-1(il. Rivale malheureuse de Marseille, :31!)-3?! Ob. laud., :?:2, 31i, 31(i.

Venitiens. Voy. Venise.

Ventadour (Anne de Levis, duc de), ss.

Verdun sieur de), président au parlement, !s, ı. 1.

Verges (Jeau, nígoriant lyollnais, $36 i$.

Vergy (chateau de), en Boulgrogne, lli. 
Vermandois. Ses échanges, 1:2: - (maitre des cuvres de), 1!:3.

Vernezon, autorisé a établir des verreries, 156.

Vernon (gouverneur de). Ses exactions, 166.

Vèron, chef de brigiuds, 3i.

Verreries et cristalleries, $1 \mathrm{in}$, $15 i$; - a la fin du rène, 1(i)-llil.

Verrier ou Vessier Francois tapissier flamand, lis, n. 1.

Verriers font asurre de genfil. homme, ?5? n. 3.

Vervins traité de), $11,19, \therefore 1$, $\because 67, ?(68$.

Vesle (1a). Canalisation, 181. Travaux faits a son occasion, 18:, 18:.

Vézère (la), rivière. Projet de la rendre narigable, 190.

Vialle de la', manufacturier en soies, $1 ?$ ?

Vienne, rivièle. Travaux faits à soı occasion, 18:, 18\%. Pont. 18s. Rendue navigable, 190. Ob. laud., $18 \%$.

Vienne douane de $, 33:-338$.

Vierzon, 19:, 11. :2.

Vigiles $d u$ roi Charles VII, (i:3.

Vigne. Sonfrage. Nuages artificiels, 38. - Voy. Viticulture.

Vignobles, 65.

Vignon (Marie), femme du connétable de Lesdiguières, :iso.

Vilaine (la) rendue narigable, 194.

Villefranche. Taxe percue par le duc de Savoie sur les vaisseaux qui y passent, 301 .

Villefranche-de - Lauraguais. $26,2\}$ '

Villeneuve-de-Berg, 36,$3 ;, 67$. Villeroy (ferme de), $4.5, n .1$.

Villes. Leur renaissance, 161-16?. Villes jurées ou de Ioi, 81 .

Vincennes château de), 107 .
Vin. Sa grande consommation, bi. Article d'exportation, :260; - d'Anjou, 6is, n. :3; - de Bordeaux. Son importation en Augleterre, :(;i; de Bourgogne, lii, ?(o); - du Lannuais, 68, n. :?; - de l'Orléanais, $67 ;-$ de Saintonge, :361; de Vivarals, (ii; - blane, $(; i-6 s$; - rouge, $6 i$.

Virement de parties, :39.

Vitaille, Napolitain, lif, u. 1.

Viticulture, (f6-fis.

Vitré (marchands de, forment une Compagnie pour le commerce des Indes orientales, :is.

Vitry (Philippe de, (6), เ. i.

Vivarais. Vin, 67 , (is. 06 . laud., $1 \mathrm{i}$, $108,18: 3,3: 37,338$.

Vizille (en Dituphiné). Fabrication des faux, 158 .

Voies de communication par terre, 16i-165, 18:3-184. Par eau, 165-167, 188-195, 34\%.

Voiron-en-Dauphiné. Fabrication des faux, 158.

Vorse la). Péages, 16 ib.

Voyer de Paris, 1it.

Voyers particuliers, 179.

Wallons, 291.

Weymouth, 29.).

Winwood, ambassadeur d'Angleterre, ?i1.

Wolf (Jean), marchand de Rouen, $139,1+1$.

Yonne (l'), rivière. Ponts, 185. Projet de jonction avec Ia Saône, ?00-?01. Ob. laud., ?09.

Zamet, 3:3i.

Zélande (province de), : $: 9$.

Zélandais, 291, 292. n. 1.

Zuñiga Balthazar de), ambassadeur d'Espagne en France. 


\section{TABLE IOES MATIERES}

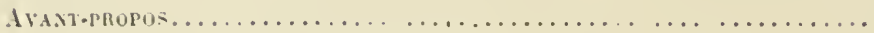

C11APITIRE I

\section{L’économie rurale.}

Caraclère social et moral de liagriculture. - Etlets des guerres civiles. - Résistance spontance aux désordres, - Yitalité du payss. - Mesures protectrices. - Persistance Ju brigandage. - Purt darmes et droit de chasse. - Situation obérée du cultirateur. Mesures riparatrices. - Taille et gabelle. - Commerce des griains. - Desséchements. - Forêts. - Mines. - Olivier de serres. Théatre diagriculture. - Agriculture et noblesse rurale. - Clerǵt. - Petits cultivateurs : le servagc. - Fermage et metayage. - Bail a complant et hordelage. - Baux i longue durée. - Communatutés rurales. - Dualisme de la souverainete. - Vie des grands propriétaires. - Rapports entreles classes. - Ouvriers agricoles. - Cultivateurs aisés., - Maison du paysan. - Mobilier du paysan. Nourriture du paysan. - Distractions du paysan. - Littérature du paysan. - liotation des cultures. - Céréales. - Viticulture. - Cultures diverses. - Pàturages. - Élerage. - Engrais. - Conclusion.

\section{CIIAPITIRE II}

\section{L'économie industrielle.}

Ellet des guerres civiles. - Abus de l'organisation industriclle. Décadence de certaines industries. - I'rospérité de certaines autres. - Renaissance des industries textiles - Industries unuvelles. Creations l'offices. - Creations de maitrises. - Barthélemy Lalleuas. - Plan de Latlemas. - Voux des notables. - Edit d'avil 1597. - Commission du fummerce. - Artistes privilégićs du Louvre. Projet d'un musce industriel. - Importation des soies el soieries. 
- Culture dumúrier. - L'importation des soieries interdite. - La Cueillette de la soye. - Premiers essais de sériciculture. - La sériciculture entreprise en grand. - L'cntreprise amoindric. - Essais dus à l'initiative privéc. - Appel au clergé. - Industrie de la soierie. - La sériciculture ì la fin du règne. - Causes de l'insuffisance du succès. - Fabriques anciennes et nouvelles de soieries. Fabrique lyonnaise. - Industrie de la draperie. - Industrie de li toile. - Industrie des futines. - Industrie des bas de laine. Tapisserie de haute lice. - Tapisserie de basse lice. -. Tapis d'Orient. - Cuirs dorés et drapés. - Maroquins. - Verreries et cristalleries. - Faïences et blanc de plomb. - Plomberic et faux.

- Conclusion..................................

\section{CIIAPITRE HII}

\section{L'économie commerciale.}

10 LE COMUERCE INTÉRIEUR.

Elfets des guerres civiles. - Prorogation des échẻances. - Remise des intérèts. - Intérêt légal et banqueroutes. - Cessions de biens. - Validité des contrats. - Administration des ponts et chaussées. - Travaux des ponts et chaussées. - Voies de communication a la fin du règne. - Ponts. - Voies fluviales. - Projet d'union des deux mers. - Canal entre la Garonne et l'Aude. - Ligne de navigation intérieure plus étendue. - Canal entre Seine et Loire. Projets d'autres canaux. - Grandeur de l'œuvre de canalisation. Transports publics par terre. - Transports publics par eau. - Législation spéciale aux commercants. - Juridictions consulaires. - Modifications du régime comparatif. - Merciers. - Fripiers. - Marchands et artisans suivant la cour. - Livres de commerce. - Comptabilité en partic double. - Commis et apprentis. - Facteurs. - Commissionnaires et courtiers. - Boutiques et groupement des commerçants, - Enseignes. - Marchés usuraires et banques publiques. - Lettre de change. - Lettres de change sur les foires de Lyon. - Foires. - Societés commerciales. - Physionomie morale des artisans et commercants..................

\section{CIIAPITRE IV}

\section{L’économie commerciale.}

$2^{\circ}$ LE COMMERCE EXTÉnIECR.

Exportations. - Importations. - Entreprises coloniales. - Commerce de cowmission. - Commissions pour le compte des étrangers. - Comuissionnaires étrangers. - Courtiers et commerce de transport. - Marine unarchande. - Amirautés. - Mariue militaire. 
- P'iraterie. - Traité du !' février loofi. - Commerce de transport au Levant. - Capitulation du ?() mai I60i. - Commerce de Ilarseille.

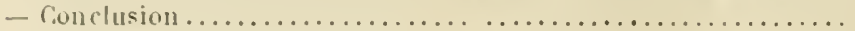

\section{CHAPTIL:}

\section{Conclusion.}

Les guerres civiles et la noblesse. - Les guerres civiles, le clergé et Io tiers itat. - Fonctiounaires et gens daffaires. - Gens de palais et de finance. - Régime tiscal. - Impoits directs et douanes. Douane de Vienne. - Douane de Lyon. - Douaneș intérieures. - Louanes. - luppôts indirects. - Fiscalité. - Olivre agricole de IIenri IV. - Oluvre industrielle et commerciale de IIenri IV. Portrait de Ilenri IV. - Valeur de Sully. - Olivier de Serres et Latlemas. - Concours du pays à la reuaissance économiyue. Situation économique en 1(ill). - Situation monétaire. - Taux de l'interet. - Régime hypothécaire. - Valeur des offices. - Baisse des prix. - Etalon de la valeur. - Conclusion.............. 327

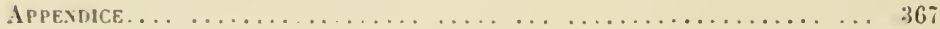

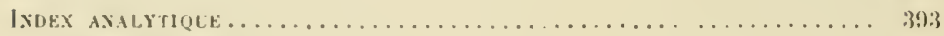

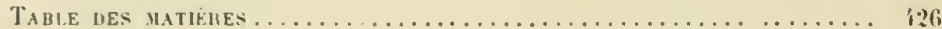











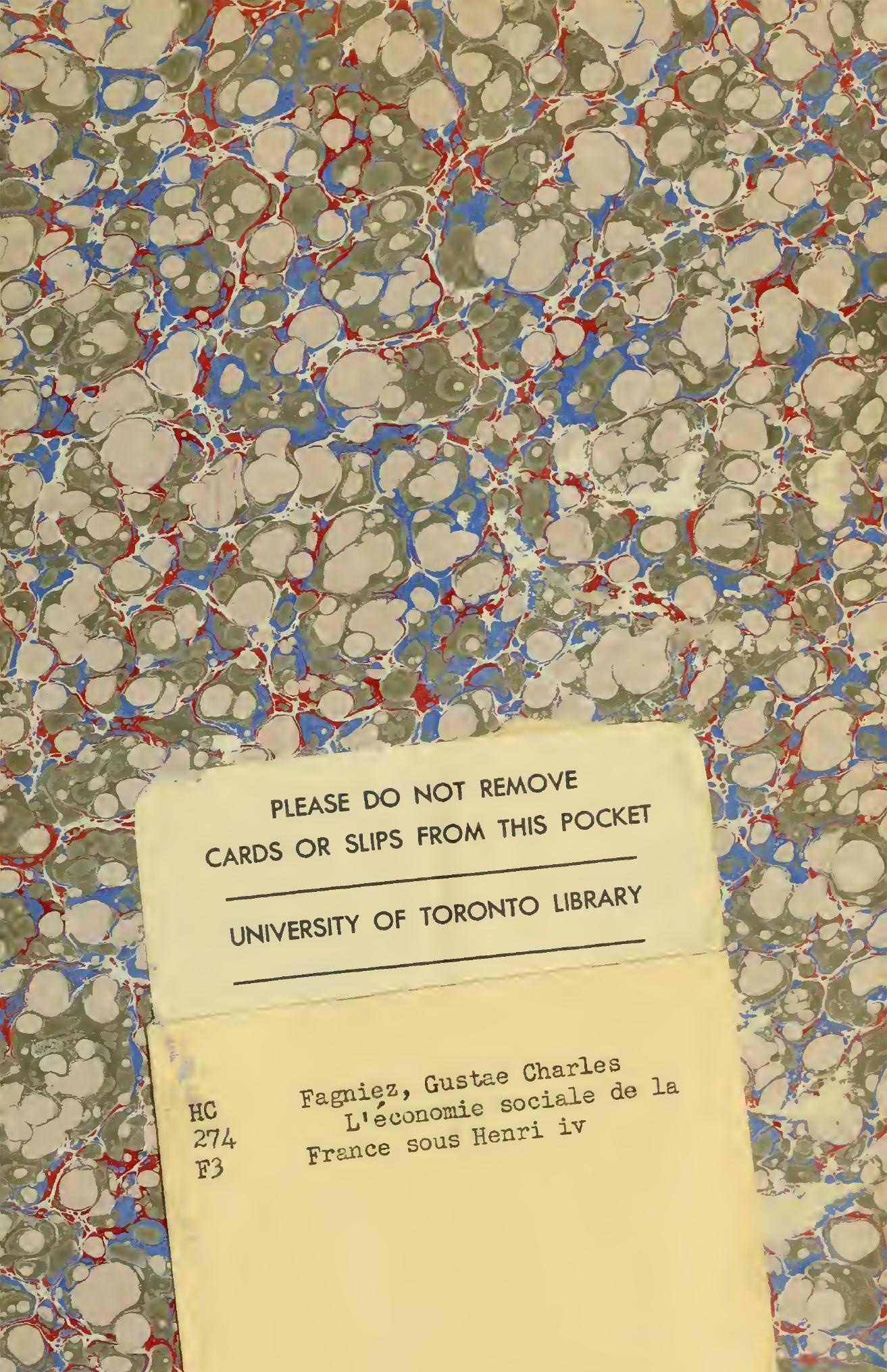


